NUREG/CR-3642

PNL-4971

\title{
A COBRA/TRAC, Best-Estimate Analysis of a Large-Break Accident in a PWR Equipped with Upper Head Injection
}

Prepared by T. E. Guidotti, M. J. Thurgood

Pacific Northwest Laboratory

Operated by

Battelle Memorial Institute

Prepared for

U.S. Nuclear Regulatory

Commission 


\section{NOTICE}

This report was prepared as an account of work sponsored by an agency of the United States Government. Neither the United States Government nor any agency thereof, or any of their employees, makes any warranty, expressed or implied, or assumes any legal liability of responsibility for any third party's use, or the results of such use, of any information, apparatus, product or process disclosed in this report, or represents that its use by such third party would not infringe privately owned rights.

\section{NOTICE}

\section{Availability of Reference Materials Cited in NRC Publications}

Most documents cited in NRC publications will be available from one of the following sources:

1. The NRC Public Document Room, 1717 H Street, N.W. Washington, DC 20555

2. The NRC/GPO Sales Program, U.S. Nuclear Regulatory Commission, Washington, DC 20555

3. The National Technical Information Service, Springfield, VA 22161

Although the listing that follows represents the majority of documents cited in NRC publications, it is not intended to be exhaustive.

Referenced documents available for inspection and copying for a fee from the NRC Public Document Room include NRC correspondence and internal NRC memoranda; NRC Office of Inspection and Enforcement bulletins, circulars, information notices, inspection and investigation notices; Licensee Event Reports; vendor reports and correspondence; Commission papers; and applicant and licensee documents and correspondence.

The following documents in the NUREG series are available for purchase from the NRC/GPO Sales Program: formal NRC staff and contractor reports, NRC-sponsored conference proceedings, and NRC booklets and brochures. Also available are Regulatory Guides, NRC regulations in the Code of Federal Regulations, and Nuclear Regulatory Commission Issuances.

Documents available from the National Technical Information Service include NUREG series reports and technical reports prepared by other federal agencies and reports prepared by the Atomic Energy Commission, forerunner agency to the Nuclear Regulatory Commission.

Documents available from public and special technical libraries include all open literature items, such as books, journal and periodical articles, and transactions. Federal Register notices, federal and state legislation, and congressional reports can usually be obtained from these libraries.

Documents such as theses, dissertations, foreign reports and translations, and non-NRC conference proceedings are available for purchase from the organization sponsoring the publication cited.

Single copies of NRC draft reports are available free, to the extent of supply, upon written request to the Division of Technical Information and Document Control, U.S. Nuclear Regulatory Com. mission, Washington, DC 20555.

Copies of industry codes and standards used in a substantive manner in the NRC regulatory process are maintained at the NRC Library, 7920 Norfolk Avenue, Bethesda, Maryland, and are available there for reference use by the public. Codes and standards are usually copyrighted and may be purchased from the originating organization or, if they are American National Standards, from the American National Standards Institute, 1430 Broadway, New York, NY 10018. 
NUREG/CR-3642

PNL-4971

R4

\section{A COBRA/TRAC, Best-Estimate Analysis of a Large-Break Accident in a PWR Equipped with Upper Head Injection}

Manuscript Completed: February 1984

Date Published: March 1984

Prepared by

T. E. Guidotti, M. J. Thurgood

Pacific Northwest Laboratory

Richland, WA 99352

Prepared for

Division of Accident Evaluation

Office of Nuclear Regulatory Research

U.S. Nuclear Regulatory Commission

Washington, D.C. 20555

NRC FIN B2391 

ABSTRACT

This report documents the simulation of a double-ended (200 percent), cold leg break, loss-of-coolant accident in a PWR equipped with an upper head injection system. The simulation was performed using the COBRA/TRAC thermal-hydraulic computer program developed at the Pacific Northwest Laboratories for the Nuclear Regulatory Commission to analyze PWR's with the upper head injection system. This analysis used best-estimate assumptions and a 556 cell multidimensional mesh in the vessel. Each of the four primary loops were modeled. Four cooling periods were predicted prior to the beginning of bottom reflood. The first cooling period was caused by the flashing of liquid in the lower plenum while the other three cooling periods were related to the hydrodynamic behavior in the upper head and the delivery of upper head cooling water to the core. The entire core was quenched during the first period of upper head water delivery to the core.

The peak clad temperature during the transient was $1155^{\circ} \mathrm{F}$ and occurred $8 \mathrm{sec}$ after the initiation blowdown. The peak temperature remained below $600^{\circ} \mathrm{F}$ for the remainder of the transient. The transient behavior of the reactor coolant system is presented in the form of plots of the key thermal-hydraulic variables as a function of time. Major phenomenon calculated during the transient (e.g., multidimensional effects, counter-current flow limiting, ECC bypass, etc.) are discussed in detail. These results are compared with a Westinghouse SATAN calculation. 
CONTENTS

Page

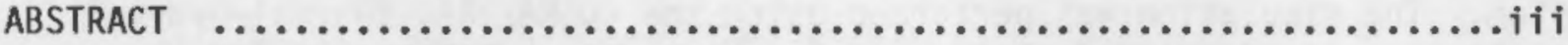

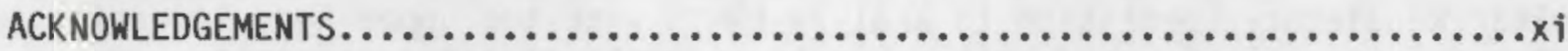

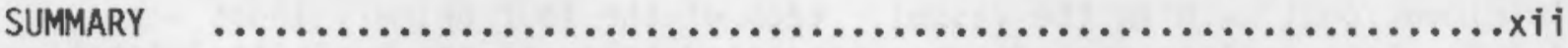

1.0 InTRODUCTION..............................................

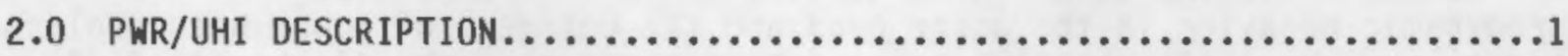

3.0 COBRA/TRAC DESCRIPTION.................................

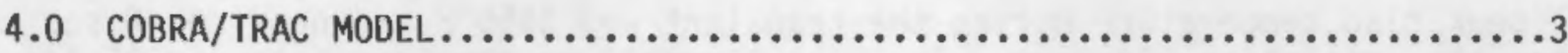

4.1 Loop Components.................................

4.2 Vessel Component....................................

4.2.1 Lower Plenum....................................

4.2 .2 Core Inlet...................................

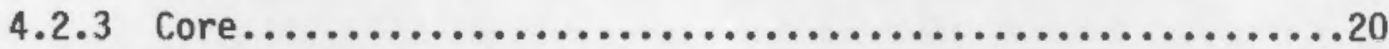

4.2.4 Core Bypass................................20

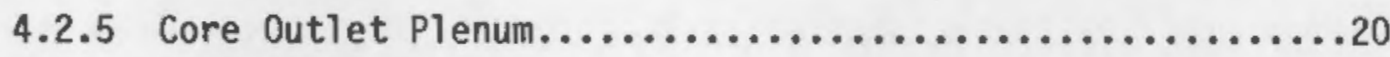

4.2.6 Upper Plenum...............................22

4.2 .7 Upper Head...................................23

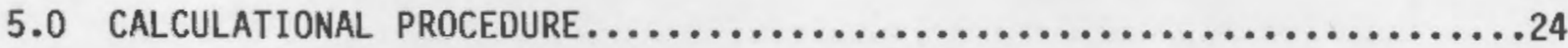

5.1 Steady-State Calculation..................................

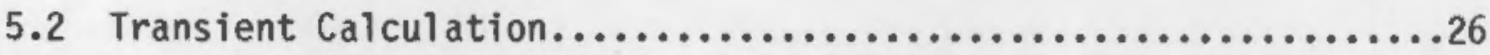

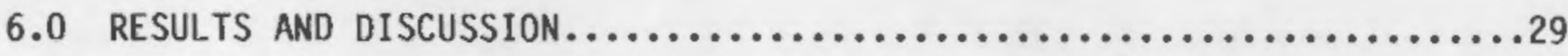

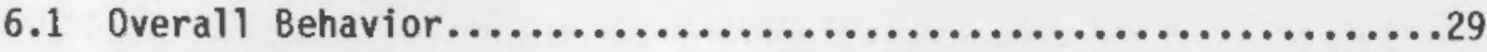

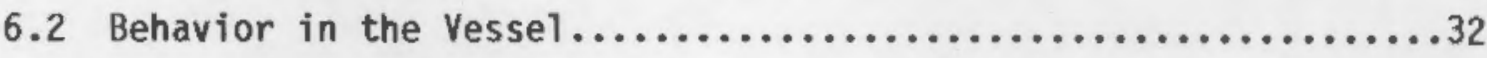

6.2 .1 Upper Head....................................32

6.2 .2 Downcomer and Lower Plenum..................... 40 
6.2 .3 Core........................................48

6.3 Behavior in the Loop Components..........................60

6.3 .1 Intact Loops................................60

6.3.2 Broken Loop.................................65

6.3 .3 UHI Components................................ 70

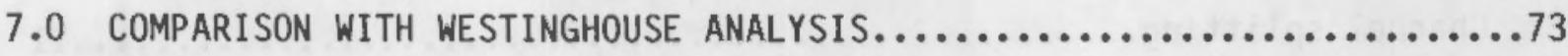

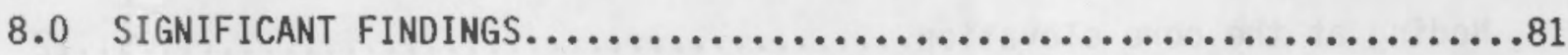

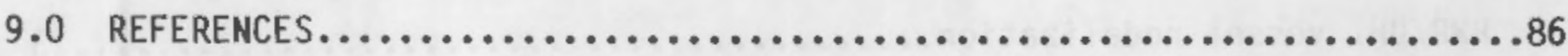

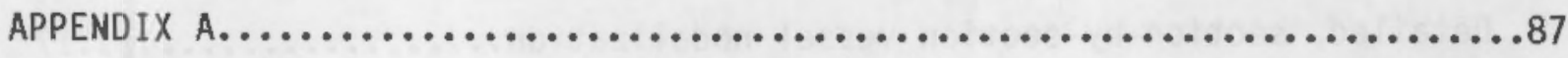

APPENDIX B................................................... 193

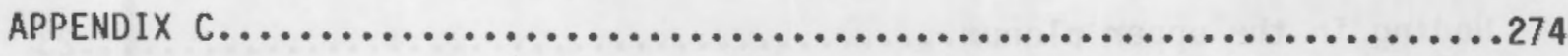

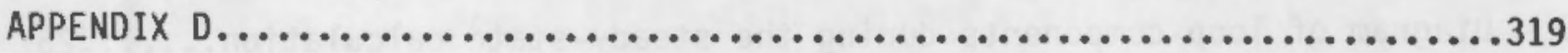




\section{ILLUSTRATIONS}

1 Sketch of PWR/UHI vesse1 $\ldots \ldots \ldots \ldots \ldots \ldots \ldots \ldots \ldots \ldots \ldots \ldots \ldots \ldots \ldots \ldots \ldots$

2 Diagram of loop components at initiation of blowdown.............

3 Steam generator noding...................................

4 Channel splitting........................................

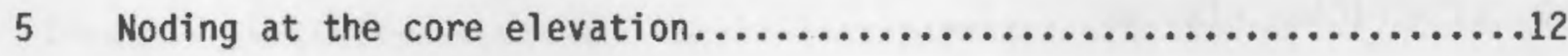

6 PWR/UHI vessel nodalization....................................

7 Detailed, section-by-section vessel nodalization..................

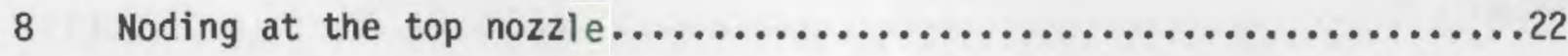

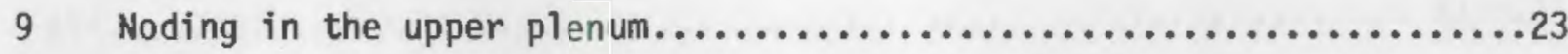

10 Diagram of loop components during the steady-state calculation......25

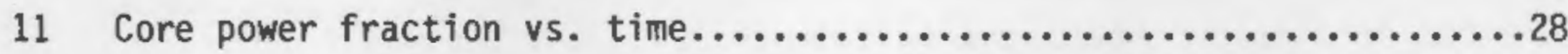

12 Core pressure vs. time......................................

13 Hot rod peak clad surface temperature vs. time..................31

14 Upper head behavior (contours are lines of constant enthalpy

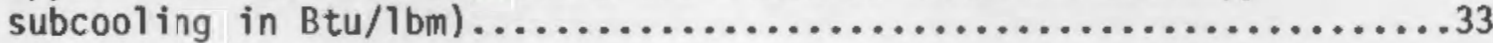

15 Pressure difference between the upper head and upper

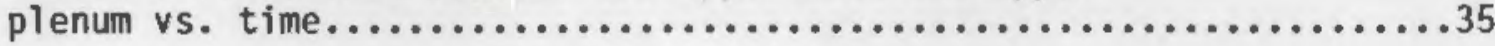

16 Upper head liquid level vs. time..............................

17 Upper head enthalpies vs. time....................................

18 Liquid and drop flow rates through all support columns vs. time.....37

19 Vapor flow rate through all support columns vs. time..............38

20 Liquid and drop flow rates through all guide tubes vs. time.........38

21 Vapor flow rate through all guide tubes vs. time................39

22. Guide tube liquid level vs. time............................... 
23 Liquid and drop flow rate through the upper head cooling jets vs. time............................................41

24 Vapor flow rate through the upper head cooling jets vs. time........41

25 Pressure difference between the core inlet and broken hot

leg vs. time............................................42

26 Core inlet liquid level vs. time............................42

27 Lower plenum liquid level vs. time...........................43

28 Downcomer liquid levels vs. time............................

29 Downcomer level averaged void fractions vs. time...............45

30 Total vapor flow rate at the bottom of the downcomer vs.

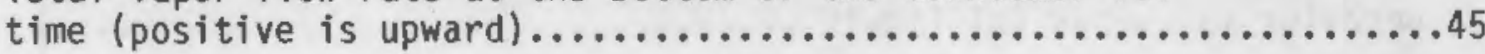

31 Total liquid flow rate at the bottom of the downcomer vs. time.......46

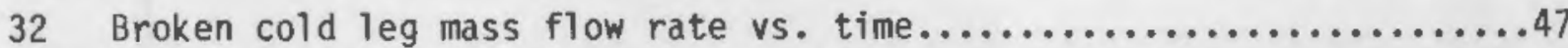

33 Void fraction contour in the downcomer at $22.0 \mathrm{~s} \ldots \ldots \ldots \ldots \ldots \ldots \ldots . . .67$

34 Void fraction contour in the downcomer at 26.4 s...................48

35 Void fraction contour in the downcomer at 45.3 s.................49

36 Void fraction contour in the downcomer at 48.8 s..................49

37 Void fraction contour in the downcomer at 69.9 s................. 50

38 Peak clad surface temperatures of the hot and average rods

vs. time.................................................

39 Peak clad surface temperatures of rods in the side core

channels................................................. 51

40 Peak clad surface temperatures of rods in the corner core

channels.................................................

41 Hot rod clad surface temperatures at the 1,3 , and 5 foot

levels...................................................53

42 Hot rod clad surface temperatures at the 7,9 , and 11 foot

levels....................................................53

43 Core vapor flow rates vs. time................................. 54

44 Core inlet liquid and drop flow rates vs. time..................54 
45 Core midplane liquid and drop flow rates vs. time................55

46 Core void fractions in channel 48 vs. time......................55

47 Core void fractions in channel 66 vs. time..................... 56

48 Core exit flow rates at the top of channel 66 vs. time (counter-current flow limiting) .................................

49 CCFL breakdown (a) times by channel (in seconds)

(b) void fraction in the top cell of channels 62,68 , and $70 \ldots \ldots \ldots .57$

50 Hot rod quench envelopes....................................

51 Core liquid level vs. time................................... 59

52 Cell centered velocities in the core during the venting behavior (a) vapor (b) liquid.................................61

53 Core void fractions at the top of channels 69 and 70 vs.

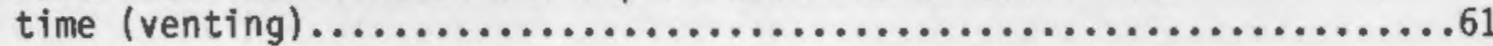

54 Mass flow rate from an intact cold leg accumulator vs. time.........62

55 Liquid volume discharged from an intact cold leg accumulator

vs. time................................................

56 Mass flow rate from one HPIS-LPIS FILL vs. time................63

57 Intact cold leg void fraction vs. time........................64

58 Intact cold leg mass flow rate vs. time (positive flow

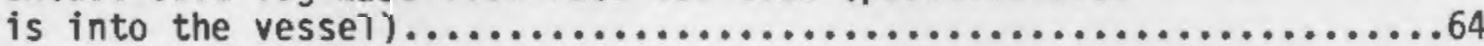

59 Intact hot leg void fraction vs. time.........................66

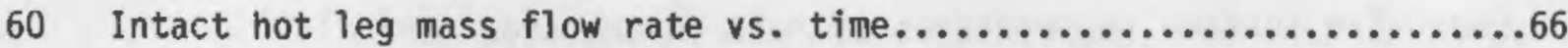

61 Hot leg void fraction in the pressurizer loop vs. time...........67

62 Hot leg mass flow rate in the pressurizer loop vs. time...........67

63 Surge line mass flow rate vs. time (positive flow is into

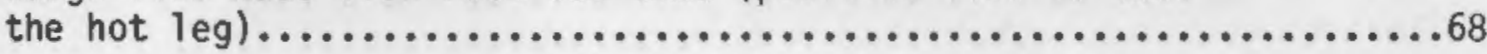

64 Total liquid volume discharged from the pressurizer vs. time.......68

65 Cold leg void fraction on the vessel side of the break

vs. time................................................69 
66 Cold leg mass flow rate on the vessel side of the break

vs. time..................................................69

67 Hot leg void fraction for the broken loop vs. time.................71

68 Hot leg mass flow rate for the broken loop vs. time...............71

69 Mass flow rate from the UHI accumulator vs. time..................72

70 Liquid volume discharged from the UHI accumulator vs. time..........72

71 Core pressure for COBRA/TRAC and SATAN (imperfect mixing) $\ldots \ldots \ldots \ldots \ldots 74$

72 Clad surface temperature for COBRA/TRAC and SATAN

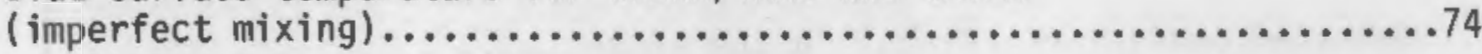

73 Clad surface temperature for COBRA/TRAC and SATAN

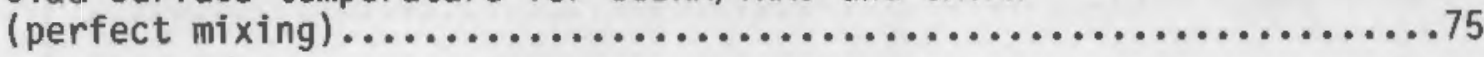

74 Support columm flow rate for COBRA/TRAC and SATAN

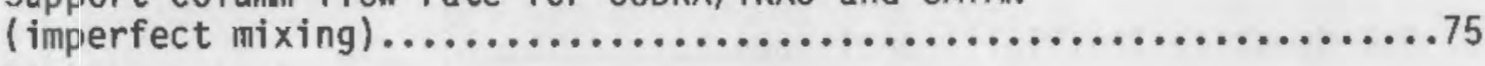

75 Support column flow rate for COBRA/TRAC and SATAN

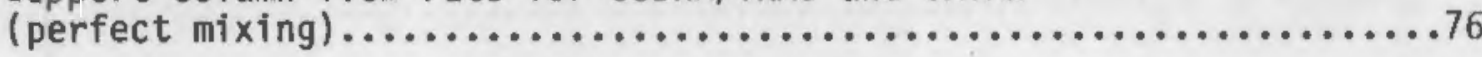

76 Guide tube flow rate for COBRA/TRAC and SATAN

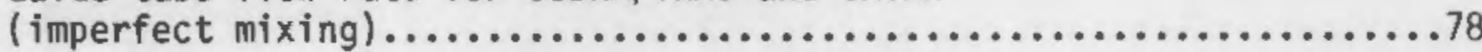

77 Guide tube flow rate for COBRA/TRAC and SATAN

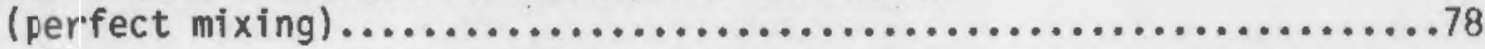

78 Core inlet flow rate for COBRA/TRAC and SATAN

(imperfect mixing)........................................... 79

79 Core inlet flow rate for COBRA/TRAC and SATAN

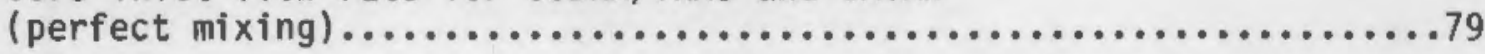

80 UHI accumulator flow rate for COBRA/TRAC and SATAN

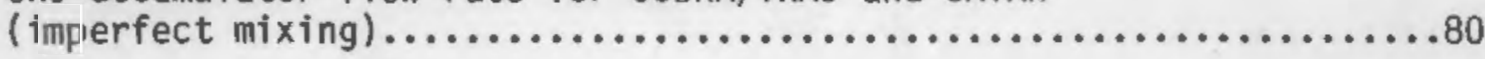

81 Cold leg accumulator flow rate ( 3 loops) for COBRA/TRAC

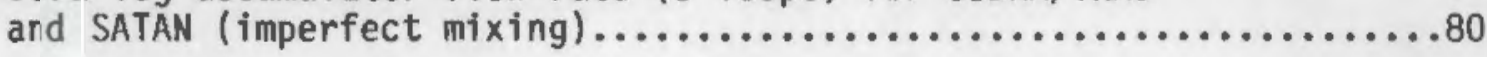

82 Quench temperature data vs. pressure..........................82

83 Quench temperature data with initial wall temperatures

greater than $1200^{\circ} \mathrm{F}$ vs. pressure............................. 


\section{TABLES}

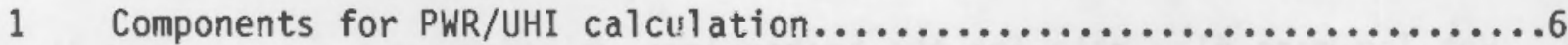

2 High pressure and low pressure injection system (HPIS-LPIS)

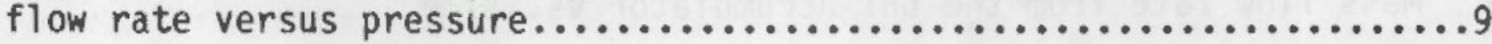

3 Boundary conditions in the loop components...................

4 Number of fluid cells and slab connections in the vessel by

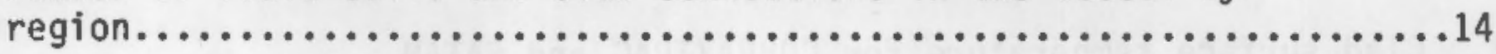

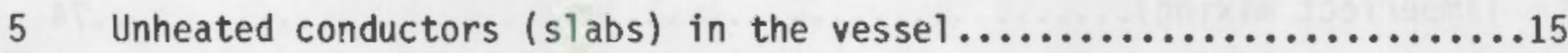

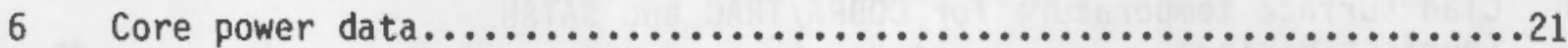

7 Steam generator operating data....................................

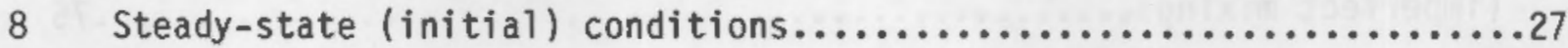

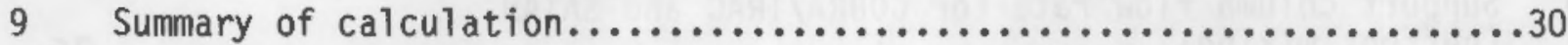




\section{ACKNOWLEDGEMENTS}

We would like to thank Brian McIntyre, Bob Kemper, Rick March, Mike Grigsby, and Don Weisensee, of Westinghouse, for their cooperation in providing information about the reactor system. 


\section{SUMMARY}

This report presents the COBRA/TRAC calculated results of a large-break lossof-coolant accident in a Westinghouse reactor equipped with upper head injection (UHI). The calculation was performed to assess the effectiveness of the UHI system in maintaining thermal-hydraulic safety margins during the accident.

COBRA/TRAC is a best-estimate systems code that was developed to model the complex internals of a reactor with UHI. The COBRA/TRAC mesh was threedimensional with 556 cells in the vessel. Each of the four primary coolant loops were modeled using the component models from TRAC-P02.

The simulated accident was a $200 \%$, double-ended, cold leg break that occurred while the reactor was operating at full-power. The code predicted that four periods of core cooling would occur prior to bottom reflood. The first was due to lower plenum flashing, while the others resulted from the behavior in the upper head.

The significant conclusions of this analysis are:

T A maximum clad temperature of $1155^{\circ} \mathrm{F}$ occurs during blowdown at $8 \mathrm{~s}$.

- The entire core quenches by water from the upper head at $14 \mathrm{~s}$.

- The early quenching occurs because water enters the core while the pressure is still high (>150 psia).

- The peak clad temperature remains below operating values once the core quenches.

- Delivery of UHI liquid to the core delays the beginning of bottom reflood. This delay does not effect the clad temperatures because the core remains quenched by the UHI liquid. Once this liquid is depleted, the reduced vapor generation allows liquid accumulated in the downcomer and lower plenum to enter the core.

- The core rapidly refills during bottom reflood. The rods are easily rewetted since the temperatures are below the minimum film boiling temperature.

- Multidimensional hydrodynamic behavior is predicted but does not have much effect on the clad temperature since the core was already quenched. 


\section{A COBRA/TRAC, BEST-ESTIMATE ANALYSIS OF A LARGE-BREAK \\ ACCIDENT IN A PWR WITH UPPER HEAD INJECTION}

\subsection{INTRODUCTION}

A large-break 10ss-of-coolant accident (LOCA) was analyzed for a pressurized water reactor (PWR) equipped with upper head injection (UHI). This 200 percent, double-ended, cold leg break was simulated using COBRA/TRAC, a bestestimate systems code that is capable of modeling the complex vessel internals of a UHI plant.

The U.S. Nuclear Regulatory Commission (NRC) sponsored the development, verification, and application of COBRA/TRAC. This work was performed for the NRC at the Pacific Northwest Laboratory (PNL) which is operated for the Department of Energy by Battelle Memorial Institute.

The purpose of this analysis was to assess the thermal-hydraulic phenomena and safety margins that exist during the accident, particularly the behavior in the core and upper head.

The PWR/UHI plant and the COBRA/TRAC code are described in Sections 2 and 3. The input model and the calculational procedure are discussed in Sections 4 and 5. Results are presented in Section 6. In Section 7, comparisons are made with a Westinghouse licensing analysis. Finally, the significant findings are discussed in Section 8.

\subsection{PWR/UHI DESCRIPTION}

The UHI system is an emergency core cooling system incorporated into four loop, Westinghouse designed, pressurized water reactors. It is a passive safety system that uses an accumulator to deliver liquid into the reactor vessel through four injection ports in the upper head when the reactor vessel fluid pressure drops below a preset value. Flow paths between the upper head and the core are provided by hollow guide tubes and support columns to allow flow of coolant from the upper head to the core (Figure 1).

There are other differences between conventional and UHI equipped PWR's. The pressure of the cold leg accumulators is reduced from 600 to 400 psia in the UHI design. In addition, all UHI plants have an ice condenser containment. It uses 2.5 million pounds of ice in about half the volume of a conventional containment to suppress the containment pressure during a loss-of-coolant accident. The rest of the system which includes the high and low pressure injection systems (HPIS-LPIS), pumps, steam generators and pressurizer is the same as for the non-UHI plant. 


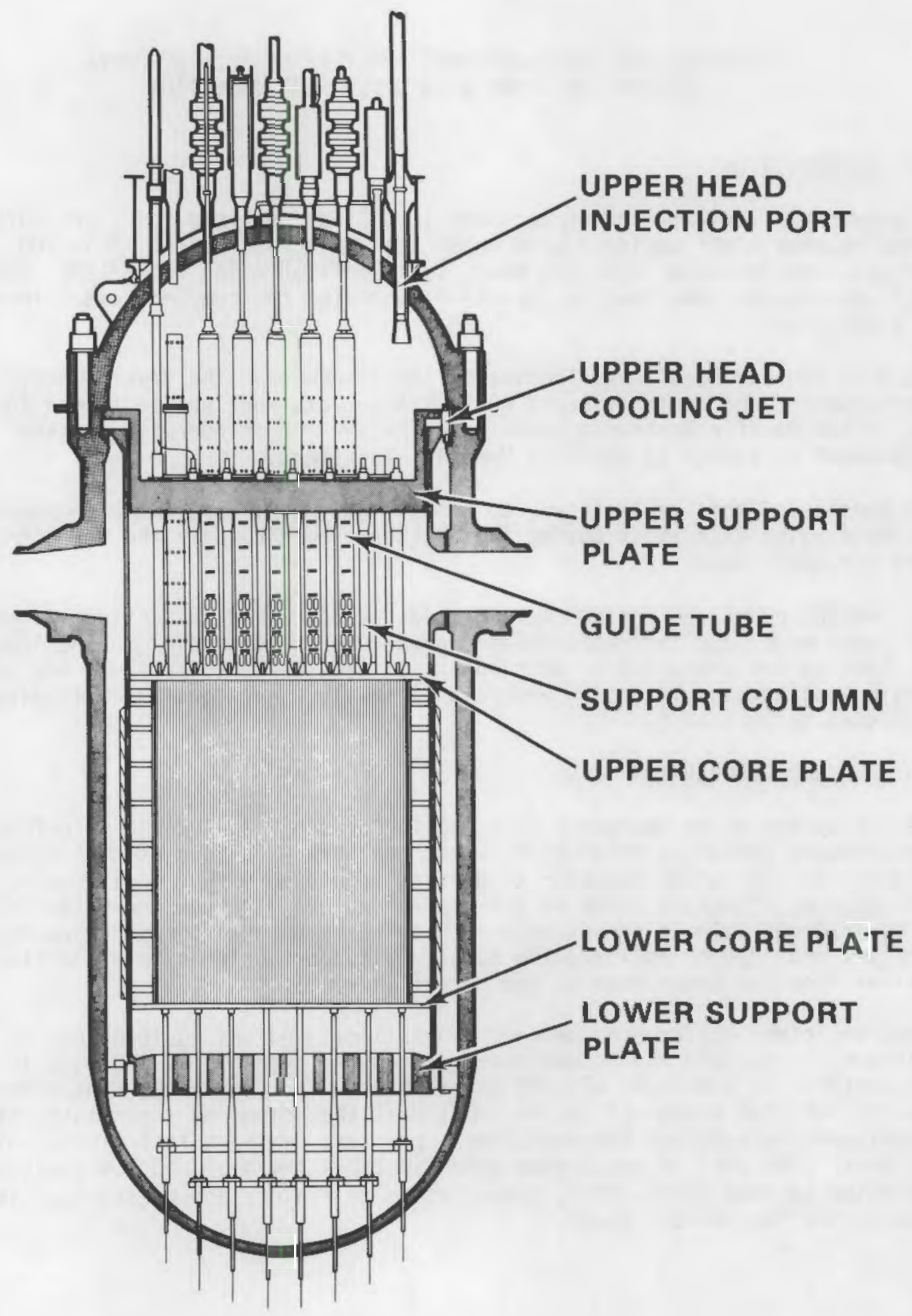

Figure 1. Sketch of PWR/UHI vessel 


\subsection{COBRA/TRAC DESCRIPTION}

The COBRA/TRAC computer program (Ref. 1) was developed to predict the thermalhydraulic response of the nuclear reactor primary coolant system to small- and large-break loss-of-coolant accidents and other anticipated transients. It was derived from the merging of COBRA-TF and TRAC-PD2 (Ref. 2).

COBRA-TF provides a two-fluid, three-field representation of two-phase flow. The three fields are vapor, drops, and continuous liquid. An eight-equation model is used to obtain three velocities, one for each field; and two temperatures, one for each phase. This approach allows the constituitive equations, describing the interaction between fields, to be based on mechanistic models that use actual velocities and temperatures rather than some type of average. It allows COBRA-TF to accurately predict nonhomogeneous, nonequilibrium effects.

The conservation equations for each field and for heat transfer from and within the solid structures in contact with the fluid are solved using a semiimplicit, finite-difference scheme on an Eulerian mesh. COBRA-TF features extremely flexible noding for both the hydrodynamic mesh and the heat transfer solution. This flexibility allows COBRA-TF to model the wide variety of geometries encountered in nuclear reactor systems.

TRAC-PD2 uses a six-equation, two-fluid model in the vessel component and a five-equation, drift flux hydrodynamic model in the one-dimensional 1oop components. Component modules are used to model the special features of the pump, steam generator, and pressurizer.

Both programs have limitations. TRAC-PD2 uses cylindrical coordinates to model the vessel in a three-dimensional calculation. This coordinate system is not amenable to modeling flow paths within the UHI vessel such as guide tubes and support columns. In addition, TRAC-PD2 does not model a droplet field which is important for accurate preditions of gravity reflood and counter-current flow limiting. COBRA-TF is limited because it cannot directly model the special features of loop components and the trip logic in the primary system.

To eliminate these shortcomings, the vessel module in TRAC-PO2 has been removed and COBRA-TF has been implemented as the new vessel component. The resulting code is called COBRA/TRAC. It has been assessed against a variety of two-phase flow data from experiments conducted to simulate important phenomena anticipated during postulated accidents and transients (Ref. 3 ).

\subsection{COBRA/TRAC MODEL}

The COBRA/TRAC input model for the PWR/UHI reactor is described in this section. It consists of two main parts--the input for the loop components and the input for the vessel. 


\subsection{Loop Components}

The loop components of the PWR/UHI reactor are modeled using the onedimensional component modules in TRAC-PD2. Figure 2 shows a diagram of the loop. Numbers inside squares identify each component and circled numbers identify junctions at the connection between two components. Each of the four loops is modeled independently and contains a steam generator and pump. The intact loops also include a cold leg emergency core cooling system, and a pressurizer connects to the hot leg of one intact loop. A description of each component is given in Table 1.

Steam generators are modeled using 10 cells on the primary side and 5 cells on the secondary side as shown in Figure 3. Only the tube region on the secondary side of the steam generators is modeled. Steam separators and dryers in the top of the steam generator are not modeled using the STGEN component nor is the downcomer. Two components are connected to the secondary. The first is a FILL, a mass flow rate boundary condition, that represents the inlet feedwater plus recirculated flow rate. The second is a BREAK, a constant pressure boundary condition that allows flow to exit the secondary side tube region of the steam generator.

The pumps use two fluid cells and have a heat source in the wall that conducts a total of $12 \mathrm{MW}$ of power into the fluid to model the heat dissipated by the pump. The pumps are Westinghouse type 93A-7000 hp pumps. Data for the pumps including the pump curves were taken from recent Westinghouse information. (a)

The cold leg emergency core cooling system (ECCS) consists of an accumulator, valve and HPIS-LPIS injection TEE. The accumulators deliver liquid to the reactor coolant system when the check valve opens as the pressure falls below 400 psia. The HPIS-LPIS is modeled using the pressure dependent mass flow rate listed in Table 2.

The pressurizer is connected to the hot leg of the intact loop that is adjacent to the broken loop. The surge line is connected to the pressurizer and modeled in TEE component No. 2 with an FL/D of 4.808. The volume of the pressurizer is $1800 \mathrm{ft}^{3}$, and it has an initial liquid volume of $1080 \mathrm{ft}^{3}$.

The UHI system is modeled by one accumulator, three tees, and four valves. The accumulator uses seven flujd cells to model the $3600-\mathrm{ft}^{3}$ volume. This volume is actually in two $1800-\mathrm{ft}^{3}$ accumulators, one filled with borated water and the other filled with nitrogen. They are separated from each other by a membrane that ruptures once the liquid filled accumulator begins delivery. As the pressure in the upper head of the vessel falls below 1250 psia, the check valves open allowing UHI coolant to enter the vessel through four injection ports in the upper head. The valves close on a low liquid level trip after $1000 \mathrm{ft}^{3}$ of liquid has been injected. Boundary conditions in these loop components are summarized in Table 3.

(a) Mike Grigsby, Westinghouse Monroeville Nuclear Center, personal communication to T. E. Guidotti, Battelle Pacific Northwest Laboratory, February 4, 1982. 


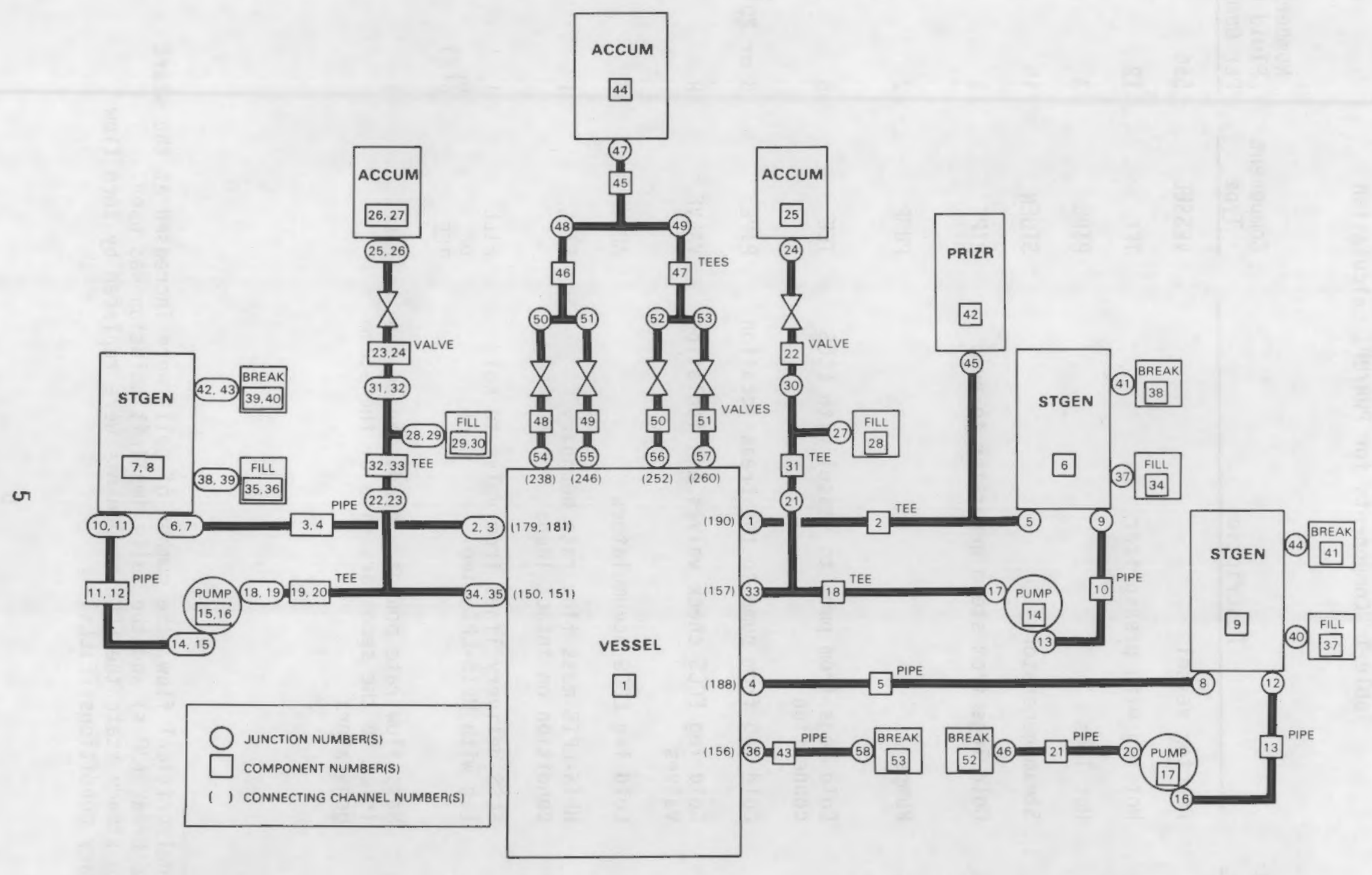

Figure 2. Diagram of loop components at initiation of blowdown 
Table 1 Components for PWR/UHI calculation

\begin{tabular}{|c|c|c|c|}
\hline $\begin{array}{l}\text { Component } \\
\text { Number }\end{array}$ & Description & $\begin{array}{l}\text { Component } \\
\text { Type } \\
\end{array}$ & $\begin{array}{l}\text { Number of } \\
\text { Fluid Cells } \\
\text { Per Component } \\
\end{array}$ \\
\hline 1 & Reactor vessel & VESSEL & 556 \\
\hline 2 & Hot leg with pressurizer & TEE & 12 \\
\hline $3,4,5$ & Hot legs & PIPE & 3 \\
\hline $6,7,8,9$ & Steam generators & STGEN & 15 \\
\hline $\begin{array}{l}10,11,12, \\
13\end{array}$ & Cold legs from steam generator to pump & PIPE & 5 \\
\hline $\begin{array}{l}14,15,16, \\
17\end{array}$ & Pumps & PUMP & 2 \\
\hline $18,19,20$ & $\begin{array}{l}\text { Cold legs from pump to vessel with ECCS } \\
\text { connection }\end{array}$ & TEE & 5 \\
\hline 21 & Cold leg from pump to the break location & PIPE & 3 or $20(1)$ \\
\hline $22,23,24$ & $\begin{array}{l}\text { Cold leg ECCS check valves and isolation } \\
\text { valves }\end{array}$ & VALVE & 8 \\
\hline $25,26,27$ & Cold leg ECCS accumulators & ACCUM & 6 \\
\hline $28,29,30$ & $\begin{array}{l}\text { HPIS-LPIS mass flow rate boundary } \\
\text { condition on intact loops }\end{array}$ & FILL & 1 \\
\hline $31,32,33$ & $\begin{array}{l}\text { ECCS delivery lines from valve to cold } \\
\text { leg with HPIS-LPIS tee }\end{array}$ & $\begin{array}{l}\text { FILL } \\
\text { or } \\
\text { TEE }\end{array}$ & $\begin{array}{l}1 \\
\text { or } \\
8\end{array}$ \\
\hline $\begin{array}{l}34,35,36, \\
37\end{array}$ & $\begin{array}{l}\text { Mass flow rate boundary condition on the } \\
\text { inlet to the secondary side of the steam } \\
\text { generators }\end{array}$ & FILL & 1 \\
\hline
\end{tabular}

(1) To model critical flow, the number of cells were increased at the start of the break $(30 \mathrm{~s})$ and the fully implicit solution was used.

(2) During steady state the. ECCS components were replaced by zero flow boundary conditions (FILLs) 
Table 1 (continued)

\begin{tabular}{|c|c|c|c|}
\hline $\begin{array}{l}\text { Component } \\
\text { Number } \\
\end{array}$ & Description & $\begin{array}{c}\text { Component } \\
\text { Type } \\
\end{array}$ & $\begin{array}{l}\text { Number of } \\
\text { Fluid Cells } \\
\text { Per Component }\end{array}$ \\
\hline $\begin{array}{l}38,39,40, \\
41\end{array}$ & $\begin{array}{l}\text { Pressure boundary condition on the outlet } \\
\text { of the secondary side of the steam } \\
\text { generators }\end{array}$ & BREAK & 1 \\
\hline 42 & $\begin{array}{l}\text { Pressure boundary condition } \\
\text { or } \\
\text { Pressurizer }\end{array}$ & $\begin{array}{l}\text { BREAK } \\
\text { or } \\
\text { PRIZER }\end{array}$ & $\begin{array}{l}1(3) \\
\text { or } \\
5\end{array}$ \\
\hline 43 & Cold leg from the vessel to the break & PIPE & 1 or $20^{(1)}$ \\
\hline 44 & UHI accumulator & ACCUM & 7 \\
\hline $45,46,47$, & UHI delivery lines & TEE & 4 \\
\hline $\begin{array}{l}48,49,50, \\
51\end{array}$ & UHI check valves and isolation valves & VALVE & 2 \\
\hline 52,53 & Containment pressure boundary conditions & BREAK & 1 \\
\hline
\end{tabular}

(3) During the first $20 \mathrm{~s}$ of the steady-state calculation the pressurizer was replaced by a pressure boundary condition (BREAK). 


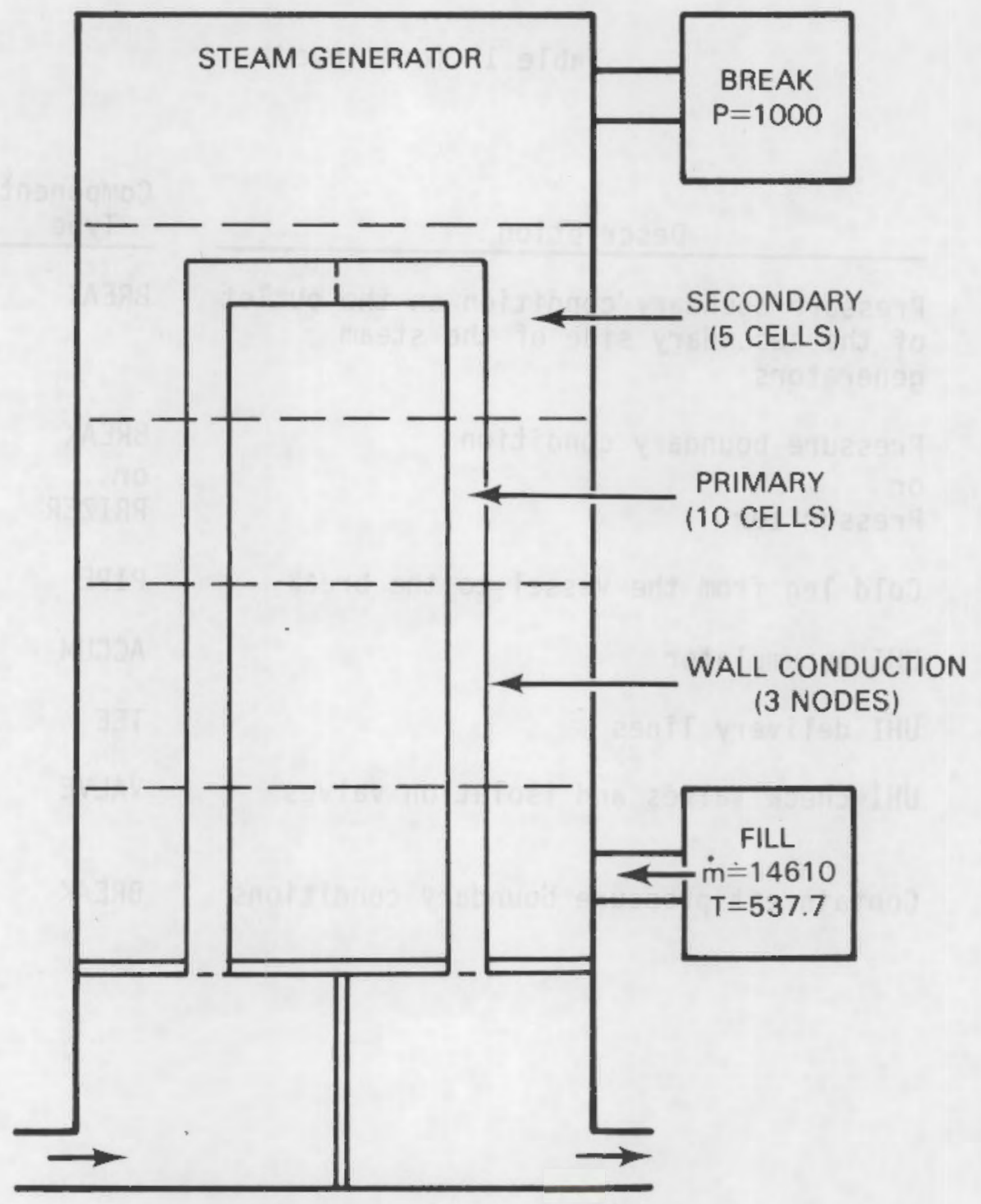

Figure 3. Steam generator noding 
Table 2 High pressure and low pressure injection system (HPIS-LPIS) flow rate versus pressure

\begin{tabular}{ccccc}
$\begin{array}{c}\text { Pressure } \\
\text { (psia) }\end{array}$ & $\begin{array}{c}\text { Flow Rate } \\
\text { (1bm/s) }\end{array}$ & $\begin{array}{c}\text { Pressure } \\
\text { (psia) }\end{array}$ & $\begin{array}{c}\text { Flow Rate } \\
\text { (1bm/s) }\end{array}$ \\
\cline { 1 - 2 } \cline { 5 - 5 } 1 & 845 & 1170 & 117 \\
16 & 845 & 1300 & 104 \\
28 & 820 & 1320 & 92 \\
79 & 695 & 1430 & 79 \\
119 & 570 & 1475 & 67 \\
150 & 445 & 1950 & 53 \\
167 & 319 & 2310 & 31 \\
171 & 257 & 2510 & 16 \\
580 & 169 & 2640 & 6 \\
960 & 135 & 2650 & 0
\end{tabular}

Table 3 Boundary conditions in the loop components

\begin{tabular}{|c|c|}
\hline $\begin{array}{l}\text { Pressure } \\
\text { Liquid Temperature } \\
\text { Injectable Liquid Volume } \\
\text { Delivery line FL/D ( } D=10.5 \text { in.) }\end{array}$ & $\begin{array}{l}1250 \text { psia } \\
80 \mathrm{~F}^{3} \\
1000 \mathrm{ft}^{3} \\
23.0\end{array}$ \\
\hline $\begin{array}{l}\text { Cold leg accumulator: } \\
\text { Pressure } \\
\text { Liquid Temperature } \\
\text { Injectable Liquid Volume } \\
\text { Delivery line } \mathrm{FL} / \mathrm{D}(\mathrm{D}=8.74 \text { in.) }\end{array}$ & $\begin{array}{l}400 \text { psia } \\
125 \mathrm{~F}^{3} \\
1120 \mathrm{ft}^{3} \\
23.0\end{array}$ \\
\hline $\begin{array}{l}\text { Pressurizer: } \\
\text { Pressure } \\
\text { Temperature (Tsat) } \\
\text { Initial Liquid }{ }^{\prime} \text { olume } \\
\text { Surge line } F L / D(D=11.15 \text { in.) }\end{array}$ & $\begin{array}{l}2280 \mathrm{psia} \\
654.6 \mathrm{~F} \\
1080 \mathrm{ft}^{3} \\
4.808\end{array}$ \\
\hline $\begin{array}{l}\text { Containment: } \\
\text { Pressure } \\
\text { Temperature }\end{array}$ & $\begin{array}{l}20 \text { psia } \\
125 \mathrm{~F}\end{array}$ \\
\hline
\end{tabular}




\subsection{Vessel Component}

The second part of the input specifies the model used by COBRA-TF in the vessel. The vessel mesh consists of 556 hydrodynamic cells. Fluid properties such as pressure, enthalpy, and void fraction are defined at the cell center. Flow rates and velocities are defined at the cell boundaries. In COBRA-TF, single mesh cells are stacked upon one another to form a channel. Channels can be grouped side-by-side to form a horizontal section of the reactor. Where lateral flow exists, "gaps" are used to model the flow path between adjacent channels. These groups of channels, referred to as "sections", are stacked upon each other to form the complete vessel mesh. Zero-flow boundary conditions are specified to close the top and bottom of the vessel or to represent any other flow blockage within the vessel.

The user specifies which channels connect to each other at section boundaries. A variable mesh in the vertical direction may be obtained by connecting one channel to two or more channels in the adjacent section. For example, Figure 4 shows one channel split into two channels above it. This allows a great deal of flexibility in modeling vessel internals. Detail can be added where it is needed.

Figure 5 illustrates this noding method as it is applied to the core elevation of the reactor vessel. Figure 5a shows nine channels that have been combined to model the core region and form a three-dimensional mesh. The core bypass region is modeled as a single channel using the one-dimensional configuration shown in Figure 5b. The downcomer is represented using eight channels in a two-dimensional mesh as shown in Figure 5c. These regions are combined to form a single section within the vessel (Figure 5d). A similar method is used in the other sections of the vessel. The sections are stacked upon each other to form the complete vessel mesh as illustrated in Figure 6 . Table 4 gives the number of fluid cells in each region.

Besides modeling the fluid, COBRA-TF uses "rods" and "slabs" to model the heat generation within the core and the stored heat within the vessel internals. slabs are unheated and serve only to conduct the stored thermal energy in a structure. They are contained within a section, that is, they do not cross section boundaries.

COBRA-TF uses different types of slab models for representing the various geometries in the vessel. Two slab types were used in this calculation-- "wa11" and "tube". Walls have two surfaces and are used to model flat, solid geometries in the vessel. Tubes also have two surfaces, an inside and outside surface, and are useful for modeling cylindrical shapes such as support columns or the core barrel. To transfer energy into the fluid each surface is connected to a channel. Table 4 shows the number of connections between slab surfaces and channel cells in each region of the vessel and Table 5 lists the vessel internals modeled by slabs.

Slabs are useful for modeling the release of stored thermal energy, however, rods are used when dryout or quenching is expected or when an internal heat source is present. Rods model the dryout and quenching process more accurately 


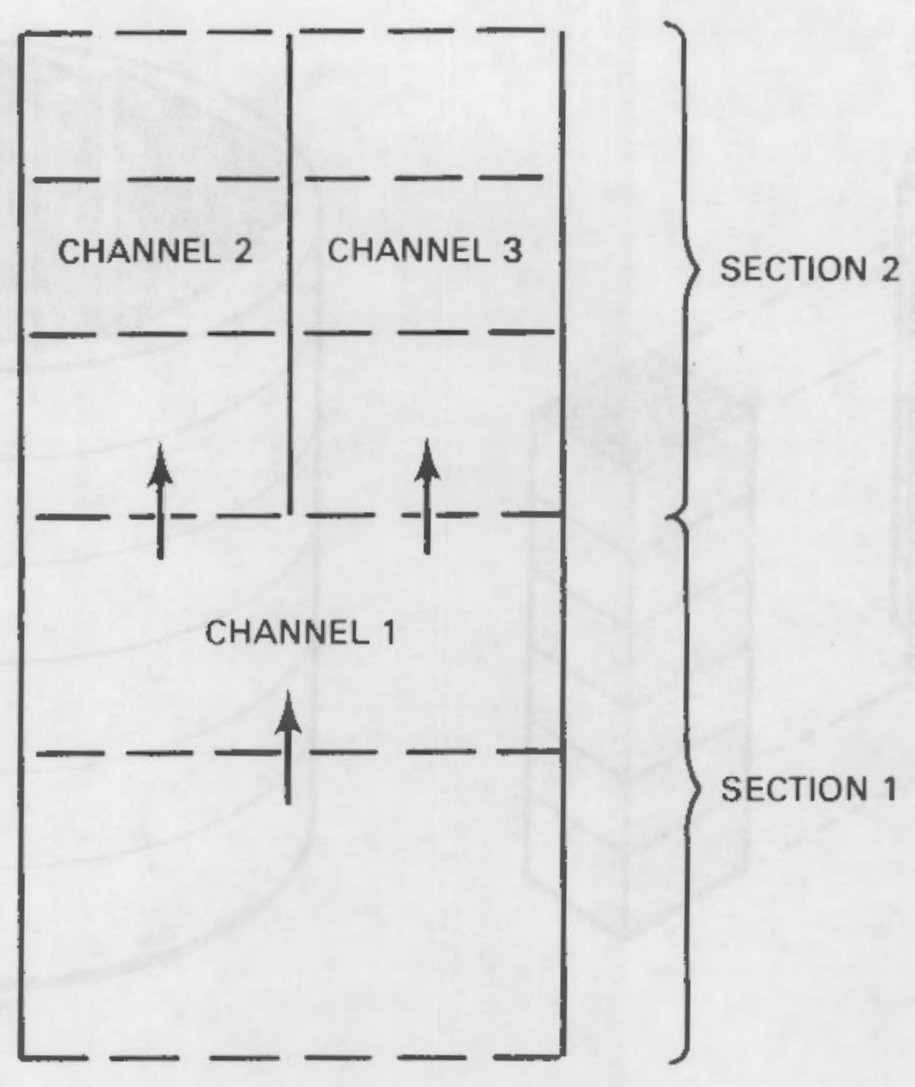

Figure 4. Channel splitting 

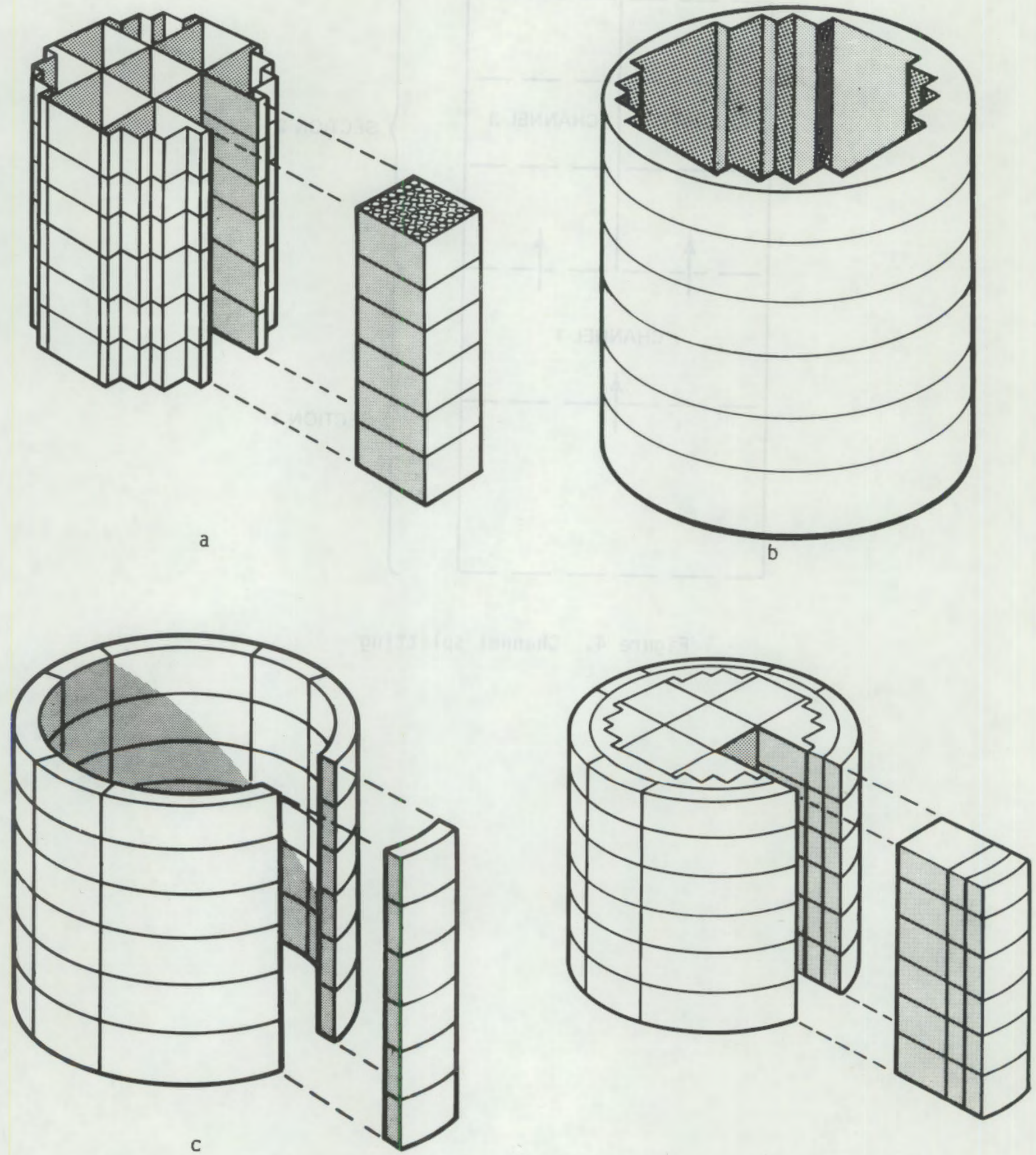

Figure 5. Noding at the core elevation 


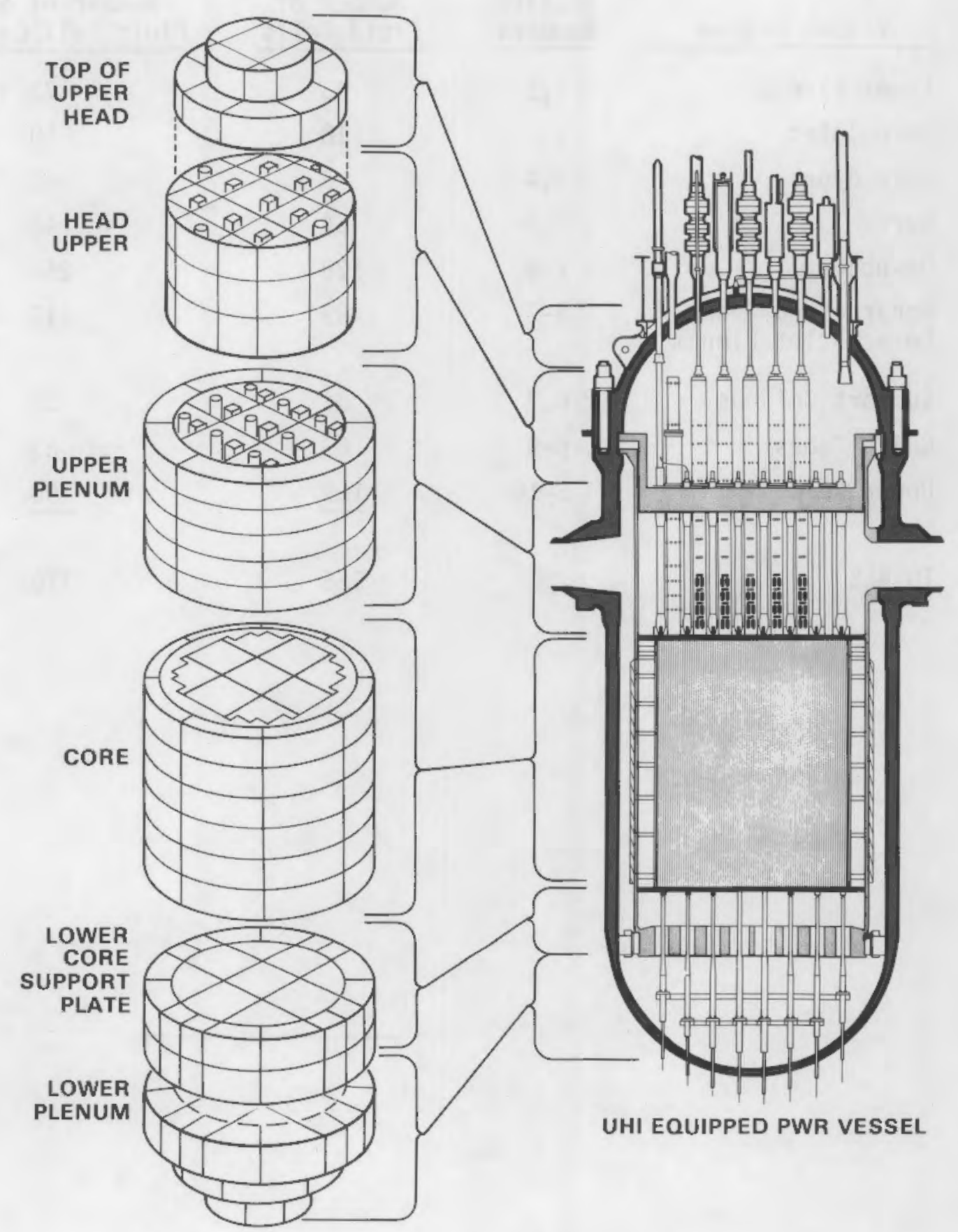

Figure 6. PWR/UHI vessel nodalization 
Table 4 Number of fluid cells and slab connections in the vessel by region

\begin{tabular}{|c|c|c|c|}
\hline Vessel Region & $\begin{array}{l}\text { Section } \\
\text { Numbers } \\
\end{array}$ & $\begin{array}{l}\text { Number of } \\
\text { Fluid Cells } \\
\end{array}$ & $\begin{array}{l}\text { Number of } \mathrm{Slab} \text { to } \\
\text { Fluid Cell Connections }\end{array}$ \\
\hline Lower Plenum & 1,2 & 43 & 73 \\
\hline Core Inlet & 2 & 18 & 50 \\
\hline Core Bypass & 3,4 & 6 & 48 \\
\hline Core & 3,4 & 54 & 48 \\
\hline Downcomer & $2-8$ & 128 & 256 \\
\hline $\begin{array}{l}\text { Upper Plenum and } \\
\text { Core Outlet Plenum }\end{array}$ & $5-7$ & 99 & 112 \\
\hline Support Columns & 6,7 & 36 & 36 \\
\hline Guide Tubes & $6-9$ & 63 & 63 \\
\hline Upper Head & $8-10$ & $\underline{109}$ & 90 \\
\hline TOTALS & & 556 & 776 \\
\hline
\end{tabular}


Table 5 Unheated conductors (slabs) in the vessel

\begin{tabular}{|c|c|c|c|c|c|}
\hline Vessel Part & $\begin{array}{c}\text { Number } \\
\text { of S1abs } \\
\end{array}$ & $\begin{array}{l}\text { STab } \\
\text { Type } \\
\end{array}$ & $\begin{array}{l}\text { Total Number } \\
\text { of Conduction } \\
\text { Nodes (1) }\end{array}$ & $\begin{array}{l}\text { Region Inside } \\
\text { of Slab }\end{array}$ & $\begin{array}{l}\text { Region Outside } \\
\text { of Slab }\end{array}$ \\
\hline Vessel Wall & 8 & Wall & 96 & Lower Plenum & - \\
\hline Vessel Wall & 64 & Wal1 & 864 & Downcomer & - \\
\hline Vessel Wall & 21 & Wall & 252 & Upper Head & - \\
\hline Core Barrel & 16 & Tube & 288 & Core Inlet & - \\
\hline Core Barrel & 16 & Tube & 288 & & Downcomer \\
\hline Core Barrel & 24 & Tube & 240 & Upper Plenum & Downcomer \\
\hline Core Barrel & 8 & Tube & 48 & Upper Head & Downcomer \\
\hline $\begin{array}{l}\text { Lower Support } \\
\text { Plate }\end{array}$ & 9 & Wall & 162 & Core Inlet & - \\
\hline $\begin{array}{l}\text { Former and } \\
\text { Baffle Plates }\end{array}$ & 16 & Wall & 288 & Core & Core Bypass \\
\hline Support Columns & 18 & Tube & 216 & $\begin{array}{l}\text { Support } \\
\text { Columns }\end{array}$ & Upper Plenum \\
\hline $\begin{array}{l}\text { Guide Tubes } \\
\text { Guide Tubes }\end{array}$ & $\begin{array}{l}18 \\
18\end{array}$ & $\begin{array}{l}\text { Wall } \\
\text { Wall }\end{array}$ & $\begin{array}{l}216 \\
162\end{array}$ & $\begin{array}{l}\text { Guide Tube } \\
\text { Guide Tube }\end{array}$ & $\begin{array}{l}\text { Upper Plenum } \\
\text { Upper Head }\end{array}$ \\
\hline $\begin{array}{l}\text { Upper Support } \\
\text { Plate }\end{array}$ & 13 & Wall & 78 & Upper Head & - \\
\hline
\end{tabular}

(1) Includes all radial conduction nodes at all axial levels. There are 6 radial nodes in every slab. 
than slabs by using a "fine-mesh renoding" scheme. This method adds a row of heat conduction nodes between two axial locations when the temperature gradient is large. Conversely, when the temperature gradient is small the method removes a row of fine mesh nodes. It is capable of resolving the sharp axial heat flux profiles at a quench front, and has proven itself by accurate predictions of many reflood tests (Ref. 3 ).

COBRA-TF allows several types of renoding heater rods to be used depending on the geometry. In this calculation only the "nuclear" rod type was used. The nuclear rod uses routines in COBRA-TF to calculate the properties of the uranium dioxide fuel and the zircaloy cladding as well as values for gap conductance. Unlike slabs, these rods can extend beyond section boundaries.

Details of the PWR/UHI vessel nodalization are shown by the drawings of each section in Figure 7. Section 1 models the lower plenum. Section 2 represents the core inlet and downcomer. The core and core bypass regions are modeled in Sections 3 and 4 . Section 5 models the region between the top nozzle plate and the upper core plate and is referred to as the "top nozzle section". The upper plenum is modeled in Sections 6 and 7. This is where the loop components connect to the vessel. Finally, Sections 8, 9, and 10 model the upper head.

\subsubsection{Lower Plenum}

The lower plenum is modeled in Section 1 and in the lowest level of Section 2. There are nine channels in Section 1. The nominal area and perimeter are changed axially using variation tables to represent the dome shape of the lower plenum. The continuity area is defjned at the center of the cell and is used to conserve the actual fluid volume(a). The momentum area is defined at the cell boundaries and was calculated from the total flow area of a horizontal slice through the lower plenum. Channels 1 through 9 connect to channels 15, $16,17,21,22,23,27,28$, and 29 , respectively in Section 2 (Figure $7 \mathrm{~b}$ ). The other channels in Section 2 do not connect to any fluid cells below. These downcomer channels are connected to the lower plenum channels by gaps in the lowest level of Section 2, between, for example, channel 10 and channel 15 . These gaps have been blocked off in the upper two levels of the section to represent the solid boundary of the core barrel.

\subsubsection{Core Inlet}

The area and volume of the lower core support plate is modeled in level 2 of Section 2 by a reduction in both the flow area (momentum area) and the continuity area. In addition, the stored energy of this metal volume is accounted for in a "slab" heat conduction model.

(a) In COBRA-TF, volume equals the continuity area times the cell height. 

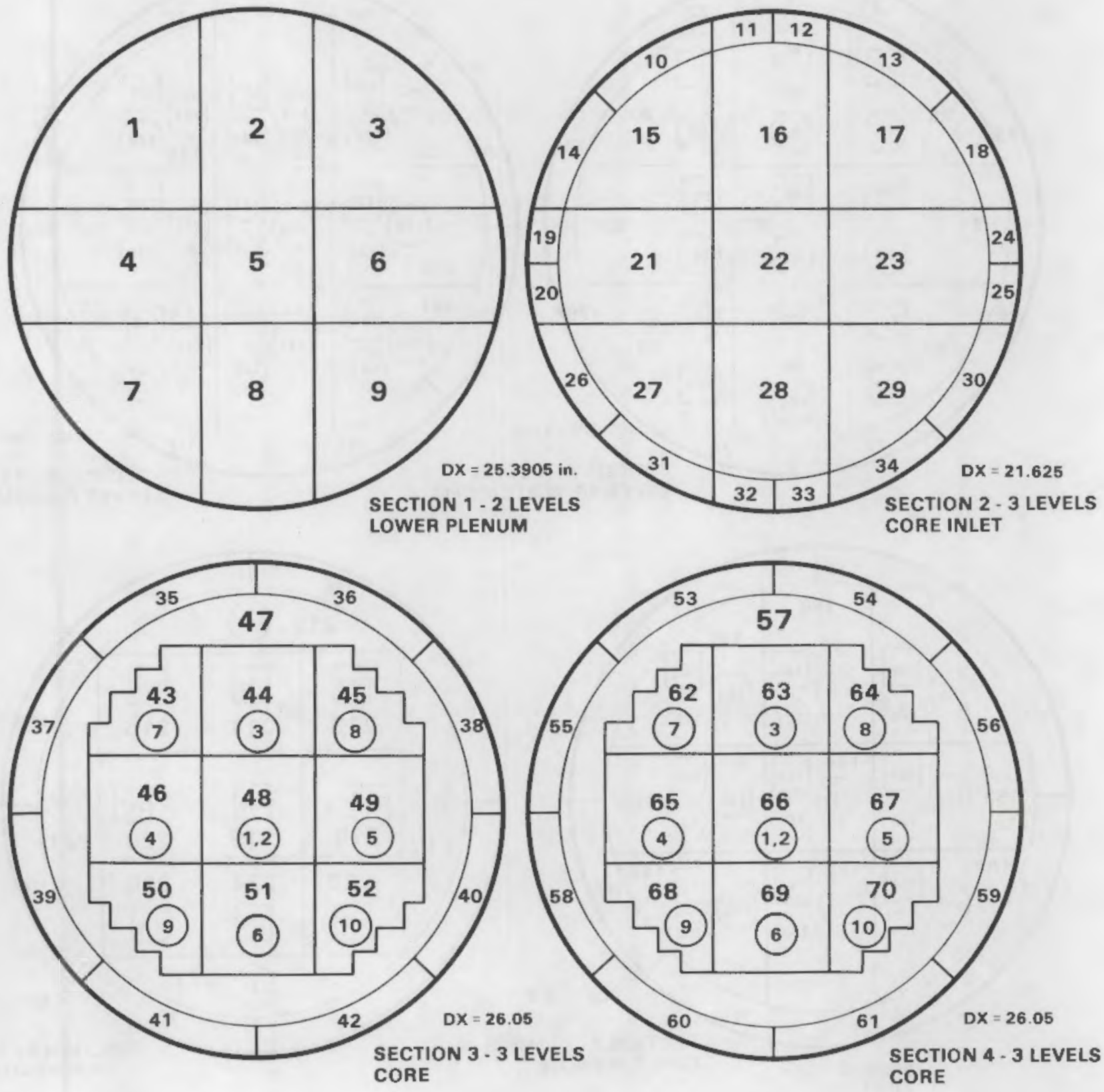

Figure 7. Detailed, section-by-section vessel nodalization (a thru d) 

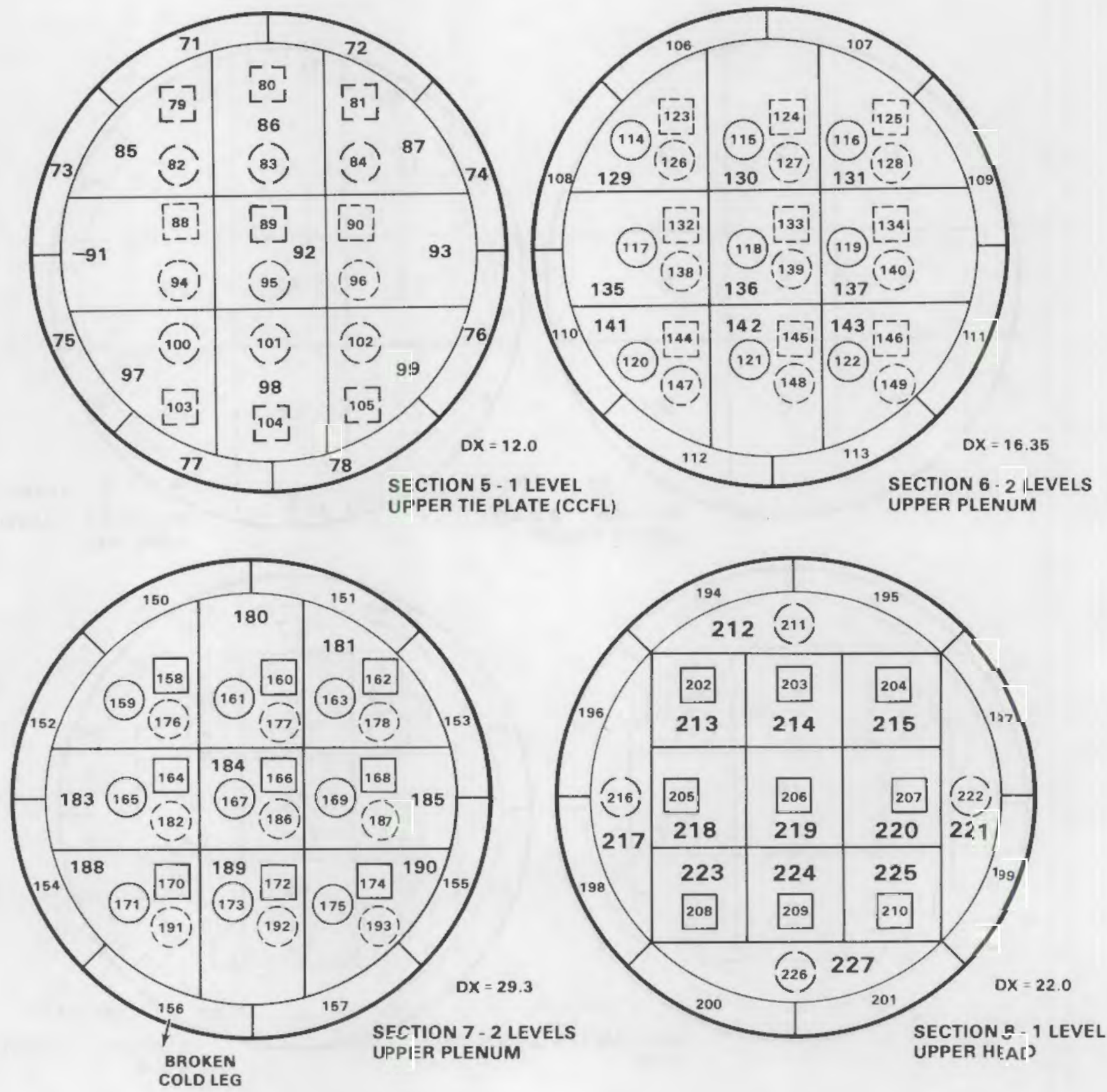

Figure 7. Detailed, section-by-section vessel nodalization (e thru $h$ ) 

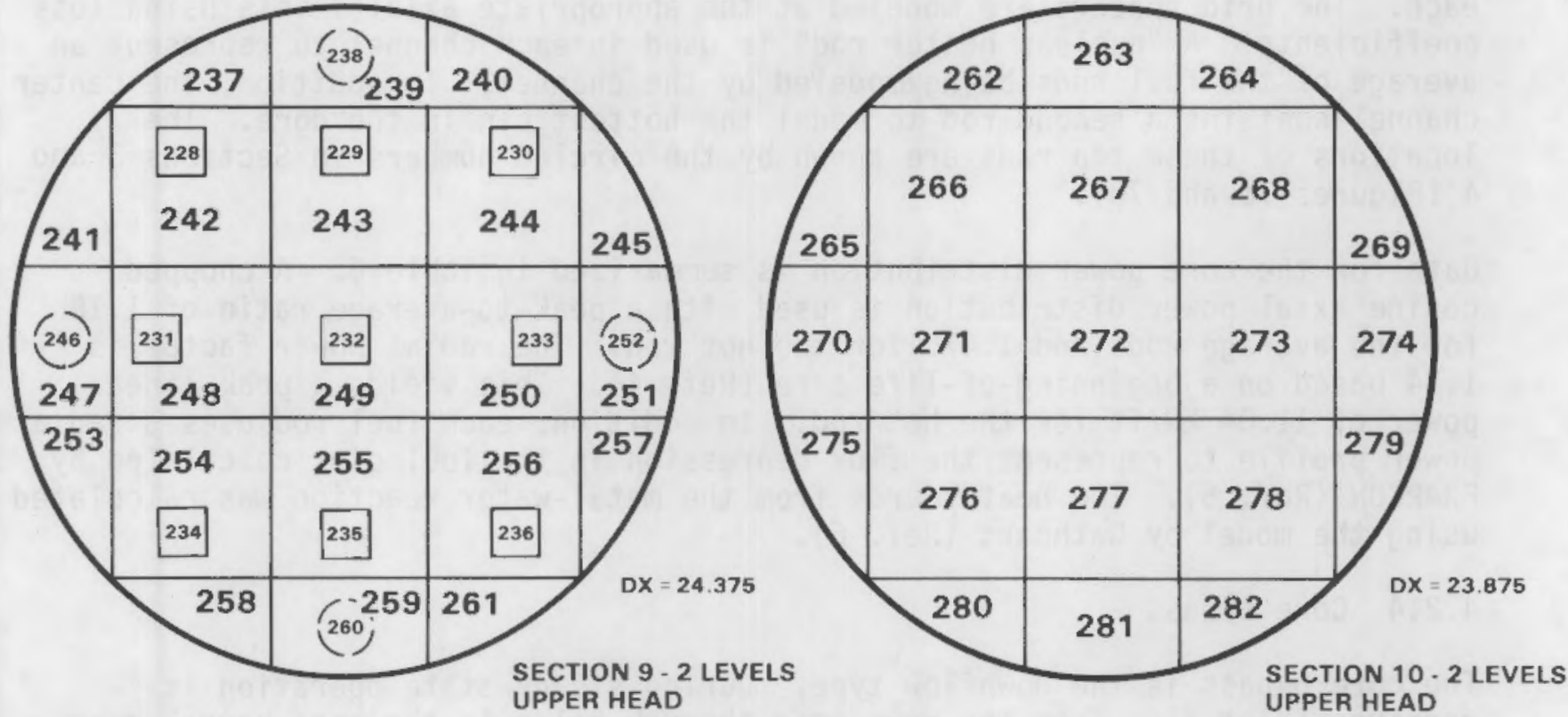

Figure 7. Detailed, section-by-section vessel nodalization ( $i$ and $j$ ) 


\section{2 .3 Core}

The core region is modeled in Sections 3 and 4. Nine channels model the flow area and volume within the 193 fuel assemblies. Each of the corner channels model 17 assemblies while the center and side channels model 25 assemblies each. The grid spacers are modeled at the appropriate axial levels using loss coefficients. A "nuclear heater rod" is used in each channel to represent an average of the fuel rods being modeled by the channel. In addition, the center channel contains a second rod to model the hottest pin in the core. The locations of these ten rods are shown by the circled numbers in Sections 3 and 4 (Figures $7 c$ and $7 d$ ).

Data for the core power distribution is summarized in Table 6 . A chopped cosine axial power distribution is used with a peak-to-average ratio of 1.18 for the average rods and 1.476 for the hot rod. The radial power factor is 1.34 based on a beginning-of-life core (Ref. 4). This yields a peak linear power of $11.04 \mathrm{~kW} / \mathrm{ft}$ for the hot rod. In addition, each fuel rod uses a radial power profile to represent the flux depression in the fuel pins calculated by FRAPCON (Ref. 5). The heat source from the metal-water reaction was calculated using the model by Cathcart (Ref. 6).

\subsubsection{Core Bypass}

The core bypass is the downflow type. During steady-state operation it receives inlet flow from the downcomer through holes in the core barrel near the top of the core bypass region. Then liquid flows down through the core bypass to exit into the core inlet. Pressure losses through the former plates are modeled using loss coefficients to obtain the correct flow rate in this region. The stored heat in the baffle plates and former plates was modeled using slabs.

\subsubsection{Core Outlet Plenum}

Section 5 models the top nozzle elevation of the vessel between the top of the fuel bundle and the upper core plate. There are nine "global" channels in this section. Each of these channels contain two "local" channels to model flow through the top nozzles. One channel is for the nozzles beneath guide tubes (e.g., channel 79, Figure 7e) and the other for nozzles beneath support columns (e.g., channel 82). Local channels use the flow area through top nozzle plates in the region defined by the global channel. The global channel (e.g, channel 85) uses the area surrounding the holes in the nozzle plates and a wetted perimeter of all the nozzle plate holes within that global region.

A sketch of this noding method is shown in Figure 8 . Figure $8 a$ is a drawing of two top nozzles just above the core; one below a guide tube and the other below a support column. Part b of the figure shows the mesh used. Channel 1 is the area surrounding the holes in both nozzle plates (the global channel). It uses the solid area of both plates and the wetted perimeter of the holes in these plates. Channel 2 uses the area and wetted perimeter of the holes in the nozzle plate beneath the guide tube. Channel 3 uses the area and wetted perimeter of the holes in the nozzle plate beneath the support column. 
Table 6 Core power data

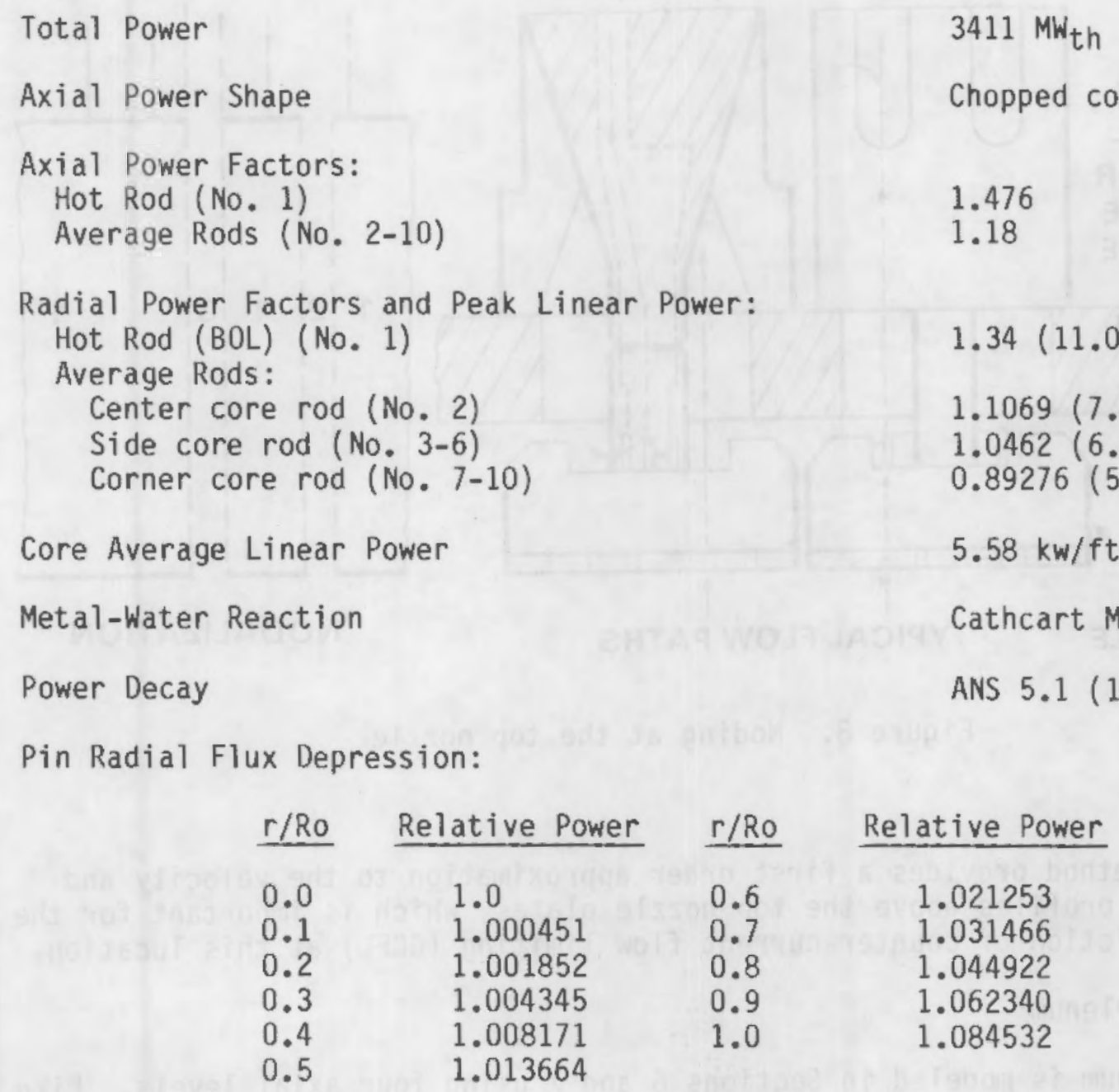




\section{GUIDE TUBE SUPPORT COLUMN}

\section{GUIDE SUPPORT TUBE COLUMN}
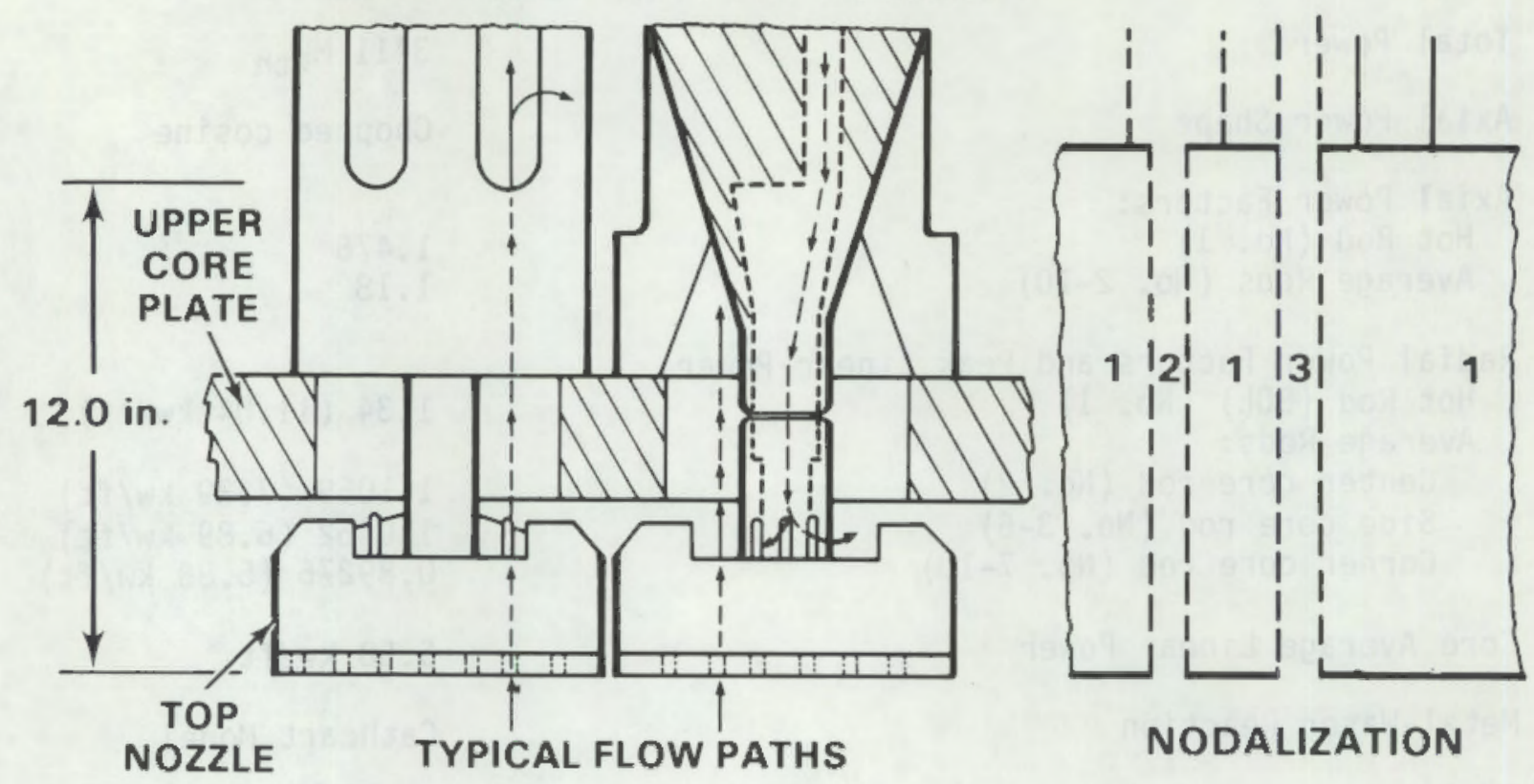

NODALIZATION

Figure 8. Noding at the top nozzle

This noding method provides a first order approximation to the velocity and void fraction profiles above the top nozzle plates, which is important for the accurate prediction of counter-current flow limiting (CCFL) at this location.

\subsubsection{Upper Plenum}

The upper plenum is modeled in Sections 6 and 7 using four axial levels. Like the previous section, Section 6 has nine global channels (e.g., channel 129, 130, etc., Figure 7f). Within each global channel there are three local channels that model the guide tube flow (e.g., channel 123), the flow through the upper core plate (e.g., channel 126), and the support column flow (e.g., channel 114). This is illustrated in Figure 9. Channel 1 represents the flow inside the guide tubes. It is connected to a gap that models the transverse flow out the guide tube slots. Channel 2 uses the area and wetted perimeter of the holes in the upper core plate to model the flow between the core outlet and the upper plenum. It is similar to the "CCFL" channels in the previous section, but is used to predict CCFL at the upper core plate instead of the top nozzle plate. The third local channel, channel 3, models the flow inside the support columns. Each of these areas and volumes are summed for the number of guide tubes and support columns located within the region defined by the global channel, channel 4. Global channels are connected by gaps to allow for crossflow within the upper plenum. 

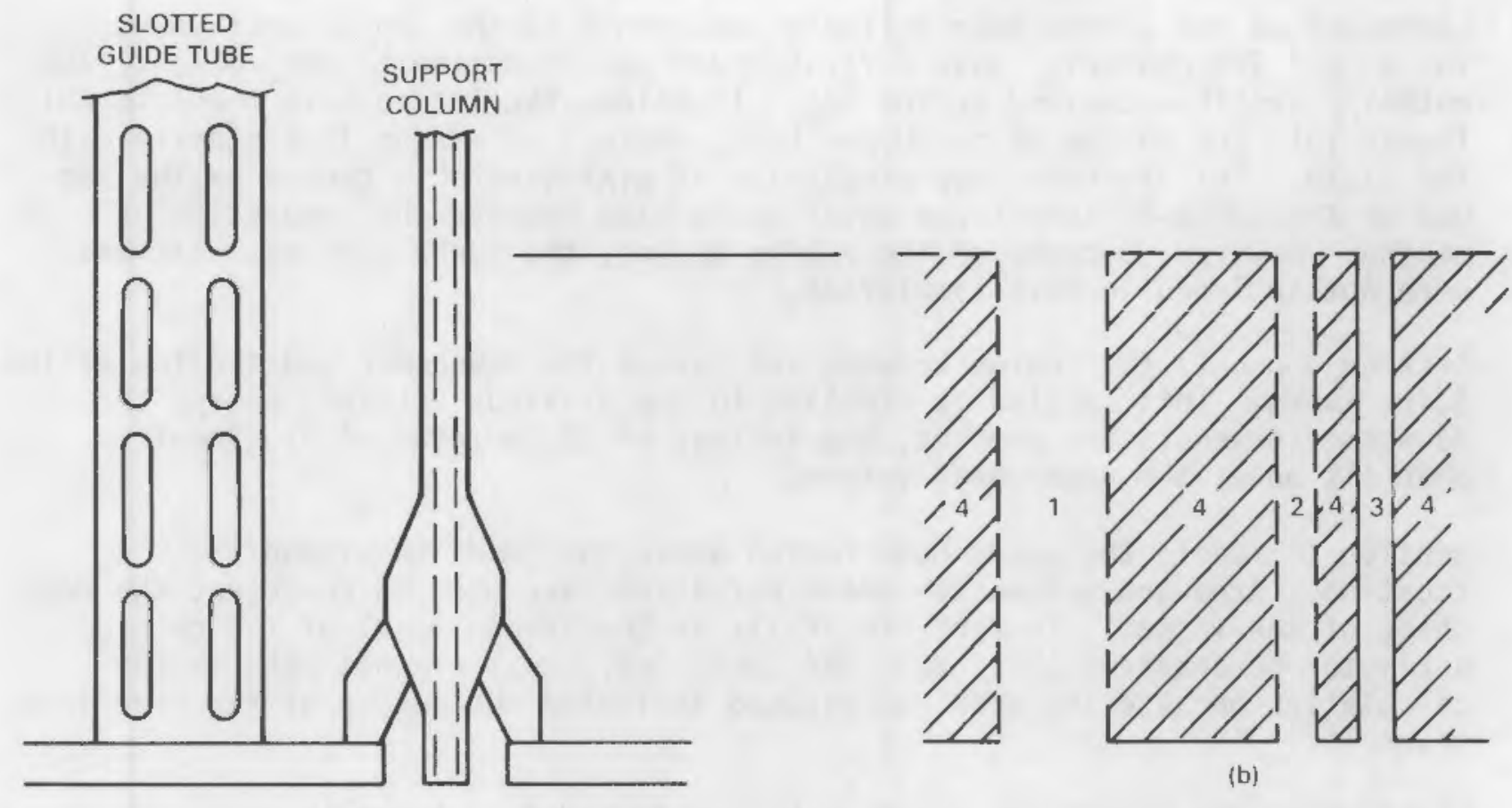

(a)

Figure 9. Noding in the upper plenum

Section 7 is the second upper plenum section, and it models the region above the slots in the guide tubes. The noding in this section is the same as in Section 6; except, the guide tubes do not connect to the upper plenum as there are no slots in the guide tube walls at this elevation. The loop components connect to the corner global channels $(179,181,188$, and 190). The broken hot leg is connected to channel 188 . These component to channel connections are identified by numbers given inside the parenthesis of Figure 2.

\subsubsection{Upper Head}

The upper head is modeled in Sections 8,9 , and 10 . Section 8 models the region between the bottom of the upper head and the top of the downcomer. Thirteen global channels model the upper head volume; nine that match with the boundaries of the global channels in the section below and an additional four around the perimeter of the upper support plate.

Within each of the inner global channels $(213,214$, etc.) there is a single local channel to represent the flow inside the guide tubes of that region. The support columns connect to the bottom of the global channels. For example, the bottom of channel 213 connects to the top of channel 159.

The outer global channels also contain a local channel to represent the UHI jet. It uses the flow area and wetted perimeter of the UHI nozzle and is 
connected to the accumulator delivery components at the top of section 9 . These "UHI jet channels" give a first order approximation to the velocity and enthalpy profiles created by the jet. It allows the jet to move the cold UHI liquid into the bottom of the upper head, instead of mixing it instantly with the fluid. This improves the prediction of mixing effects caused by the jet. Use of the COBRA-TF turbulence model would also improve the prediction of mixing. However, because of the coarse noding, the turbulence calculations were not included in this simulation.

Section 9 models the region between the top of the downcomer and the top of the guide tubes. This section is similiar to the previous section, except the downcomer channels are removed, and instead of 12, a total of 21 global channels model the upper head volume.

Section 10 models the upper head region above the guide tubes and UHI location. Area and wetted perimeter variations are used to represent the dome shape of the vessel. In fact, the cells in the second level of the outside perimeter of channels $(262,263,264,265,269$, etc.) are not used in the calculation because the area was reduced to inside the region of the nine inner channels.

Listings of the COBRA/TRAC input decks are included in Appendix A.

\subsection{CALCULATIONAL PROCEDURE}

Two steps are required to simulate a LOCA using COBRA/TRAC. First, a "steadystate" calculation is performed to initialize the flow rates and temperatures in the system. Boundary conditions, such as pressurizer pressure, core power, and pump performance are held constant to allow the system variables to come to equilibrium. Once the primary variables are steady and near the desired values, the transient calculation is begun by adding the break to the cold leg and changing appropriate boundary conditions in the system. The procedure to calculate the steady state and transient are described in the next two sections.

\subsection{Steady-State Calculation}

A diagram of the loop components used in the steady-state calculation is shown in Figure 1D. During steady state, the UHI components were removed and the ECCS components were replaced by zero velocity FILLs. In addition, the pressurizer (PRIZER) was replaced by a constant pressure boundary condition (BREAK). This allowed the pressure to approach equilibrium sooner and removed liquid from the system as it expanded while being heated. The pressure came to equilibrium without changing the initial liquid inventory in the pressurizer.

The steady-state calculation lasted $30 \mathrm{~s}$. However, for the purposes of the heat conduction in the rods, slabs, and one-dimensjonal component conduction models, the steady-state calculation lasted $300 \mathrm{s.}$ (a)

(a) A factor of 10 was used for the ratio of heat transfer to fluid time steps during the steady-state calculation. 


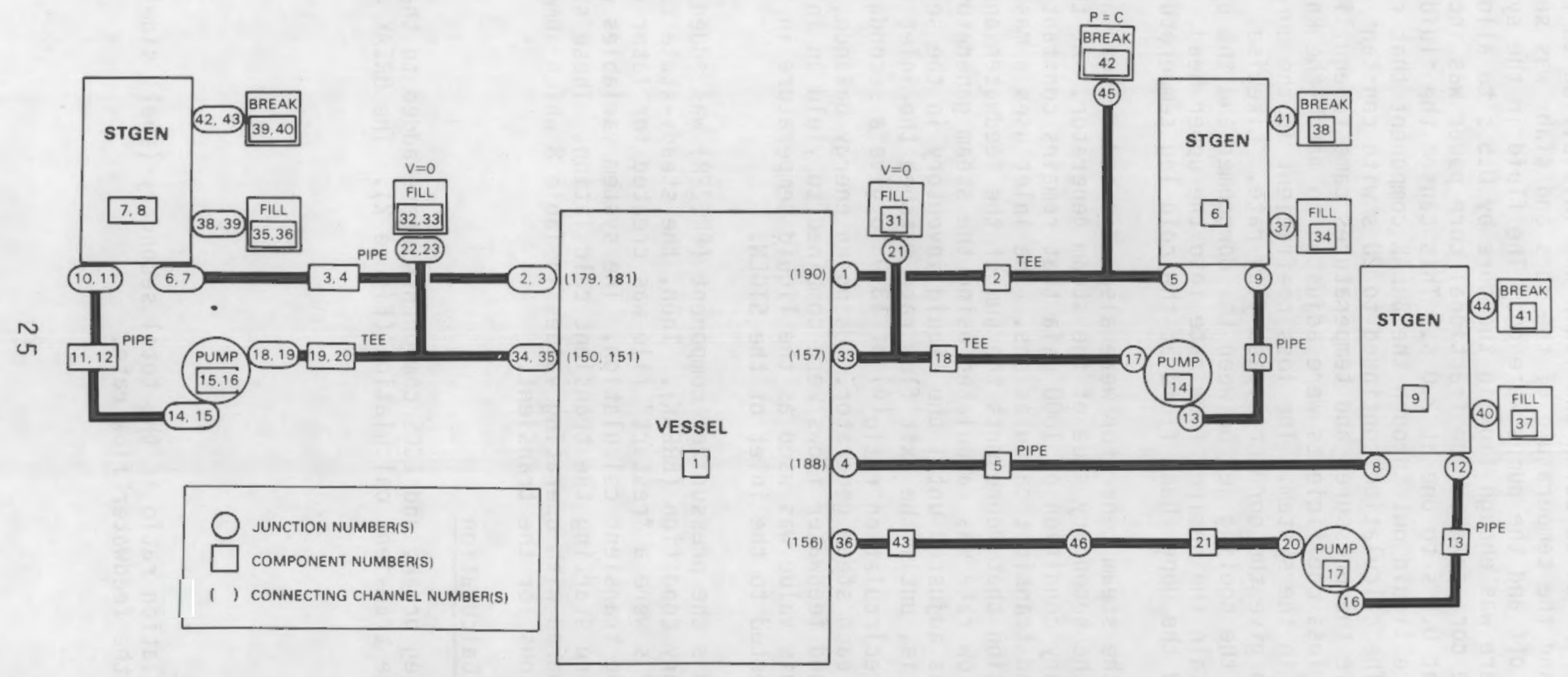

Figure 10. Diagram of loop components during the steady-state calculation 
At the start of the calculation the fluid was initialized to the enthalpy of the cold leg, and the temperature of the rods and slabs was set to $550 \mathrm{~F}$. The core power was off and the pumps were on. The fluid in the system began to circulate. There was enough flow in the core by $0.5 \mathrm{~s}$ to allow a gradual increase in the core power. The fractional core power was increased from a value of zero at $0.5 \mathrm{~s}$ to one at $2.0 \mathrm{5}$. This caused the fluid in the system to expand and force liquid out through the BREAK component that replaced the pressurizer. The calculation continued to $20 \mathrm{~s}$ with constant boundary conditions while the pressures and temperatures came to equilibrium. During this time, the loss coefficients were adjusted to match the known steady-state pressure drops in the system. The loss coefficient in the core bypass region was adjusted to give the correct bypass flow rate. Likewise, the loss coefficient in the cooling jet between the downcomer and the upper head was adjusted to obtain the desired flow rate into the upper head. This cooling jet flow maintained the upper head fluid at the cold leg temperature.

Conditions in the steam generator were also adjusted. There are two boundary conditions on the secondary side of the steam generator. At the exit is a pressure boundary condition of 1000 psia that remains constant throughout the steady-state and transient calculations. The inlet uses a mass flow rate joundary condition that represents the sum of the feedwater and recirculated tlows. This flow rate was calculated using the steam generator data shown in Table 7. It was adjusted until the liquid inventory in the secondary remained constant, that is, until the exit flow rate matched the inlet flow rate. This occurred at a recirculation ratio(a) of 13.9 to give a secondary flow rate of $14610 \mathrm{lbm} / \mathrm{s}$ in each steam generator. Using an energy balance, the recirculation and feedwater flows were combined to yield an inlet temperature of $537.7 \mathrm{~F}$. This value was used as the liquid temperature in the FILL component connected to the inlet of the STGEN.

Beginning at $20 \mathrm{~s}$ the pressurizer component (PRIZER) was added in place of the pressure boundary condition (BREAK). Then, the steady-state calculation was continued to $30 \mathrm{~s}$ were a "restart" file was created for later use at the beginning of the transient calculation. The system variables were checked a final time before starting the transient calculation. These steady-state values are compared with operating values in Table 8 which summarizes the initial conditions for the transient.

\subsection{Transient Calculation}

The UHI, cold leg break, and ECCS components where added to the model at the beginning of the transient calculation (Figure 2). The BREAK components that

(a) The recirculation ratio is the total secondary (shell side) flow rate divided by the feedwater flow rate. 
Table 7 Steam generator operating data

$\begin{array}{ll}\text { Secondary pressure } & 1000 \mathrm{psia} \\ \text { Feedwater temperature } & 440^{\circ} \mathrm{F} \\ \text { Steam temperature } & 544.6^{\circ} \mathrm{F} \\ \text { Steam flow rate } & 1051 \mathrm{lbm} / \mathrm{s} \\ \text { Recirculation ratio (1) } & 13.9 \\ \begin{array}{l}\text { Secondary flow rate } \\ \text { (FILL flow rate) }\end{array} & 14610 \mathrm{lbm} / \mathrm{s} \\ \begin{array}{l}\text { Secondary inlet temperature } \\ \text { (FILL liquid temperature) }\end{array} & 537.7^{\circ} \mathrm{F}\end{array}$

Table 8 Steady-state (initial) conditions

$\begin{array}{lll}\text { Cold leg temperature (F) } & 559.1 & 569.8 \\ \text { Hot leg temperature (F) } & 617.3 & 626.4 \\ \text { Primary flow rate (1bm/s-loop) } & 10055 & 9969 \\ \text { Pump speed (rad/s) } & 124.2 & 124.2 \\ \text { Pump pressure rise (psi) } & 93.8 & 91.6 \\ \text { Loop pressure drop (psi) } & - & 51.2 \\ \text { Vessel pressure drop (psi) } & - & 40.4 \\ \text { Upper plenum pressure (psia) } & 2280 & 2310\end{array}$

(1) Adjusted during the steady state to give a steady liquid inventory in the secondary side of the steam generator 
represent the containment used a fonstant pressure of 20 psia, a typical value for ice-condenser containments. (b) In addition, the pumps were turned off and their 12 MW heat source was removed.

The transient was initiated by the flow of coolant out the cold leg break. Once the UHI check values were open the valve type was changed from a check valve to an isolation valve with a trip on liquid level in the UHI accumulator. Once closed, the components it isolated were removed from the calculation.

The ANS 5.1 power decay (Ref. 10) was assumed to begin at the instant of the break. Figure 11 shows the power fraction used during the transient. The steady state and transient calculations were run using cycle 12 of COBRA/TRAC and took a total of 32 CPU hours on a CDC 7600 computer.

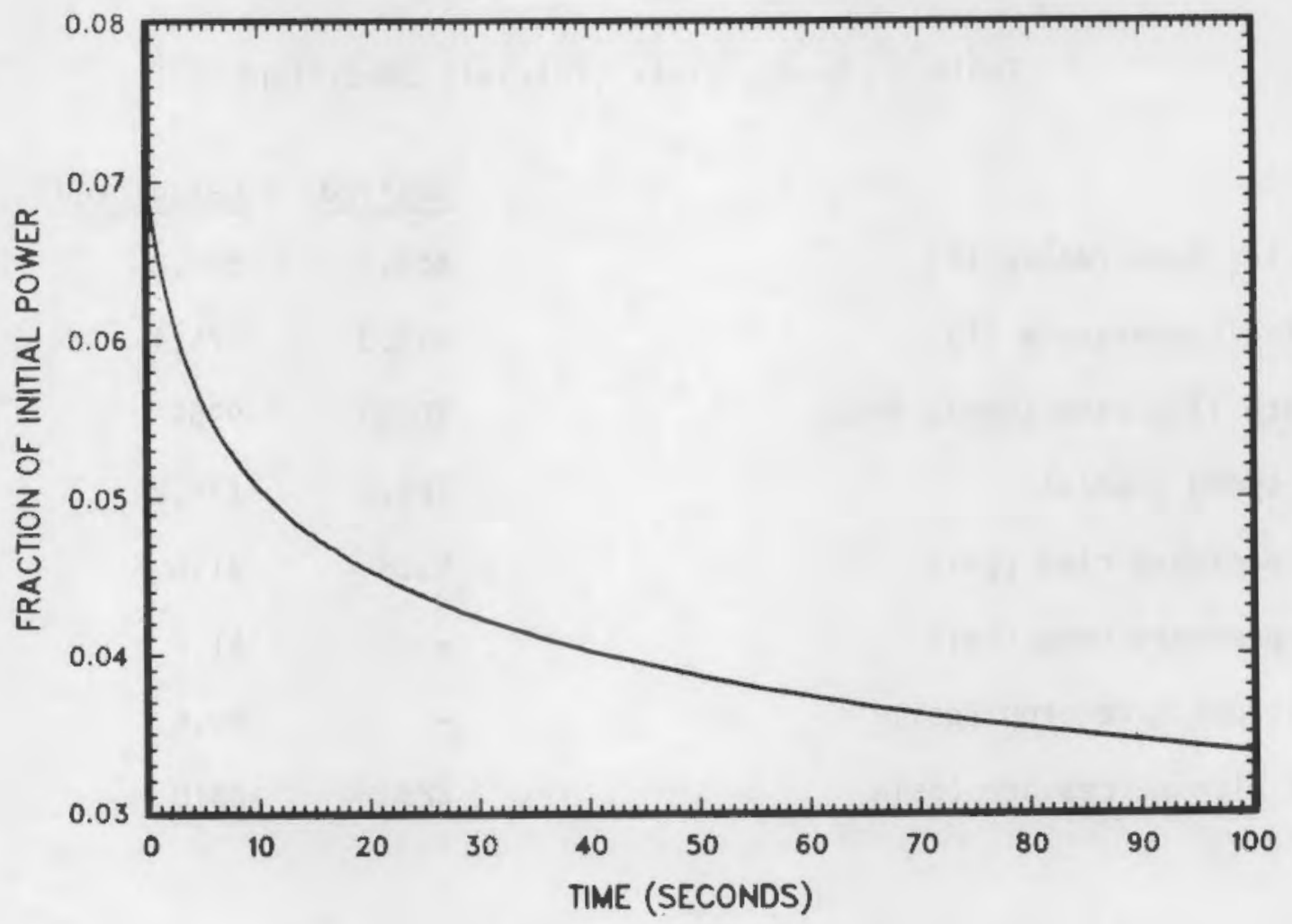

Figure 11. Core power fraction vs. time

(b) Bob Kemper, Westinghouse Monroeville Nuclear Center, personal communication to T. E. Guidotti, Battelle, Pacific Northwest Laboratory, August 26, 1982. 


\subsection{RESULTS AND DISCUSSION}

The results of the calculation are introduced in this section by describing the overall behavior of the transient. The discussion focuses on the behavior in specific regions of the system in later sections.

\subsection{Overall Behavior}

The key events after the initiation of blowdown are summarized in Table 9. The system underwent subcooled blowdown, rapidly depressurizing until bulk vapor generation began as the pressure approached saturation. The vapor generation slowed the rate of depressurization as shown in Figure 12, a plot of the pressure response in the core. By $2.4 \mathrm{~s}$ the pressure in the upper head was below 1250 psi allowing check valves to open and deliver coolant from the UHI accumulator.

Water in the upper head began to flash to steam at about $3 \mathrm{~s}$ as the pressure continued to decrease. The resulting formation of vapor raised the pressure difference between the upper head and upper plenum, forcing liquid down the support columns and guide tubes and into the core at $4 \mathrm{~s}$. This water eventually quenched the entire core by $14 \mathrm{~s}$ with a maximum clad surface temperature of $1155 \mathrm{~F}$ occurring at $8 \mathrm{~s}$. A plot of the peak clad temperature of the hot rod is shown in Figure 13 .

Cold liquid from the UHI accumulator condensed vapor in the upper head beginning at $14 \mathrm{~s}$. This caused the upper head pressure to decrease interrupting water delivery to the core.

The pressure in the cold legs dropped below the 400 psia accumulator pressure allowing the check valves to open at $14.8 \mathrm{~s}$. Although the check valves opened to deliver liquid from the cold leg accumulators, liquid did not enter the downcomer until $20 \mathrm{~s}$. Then the liquid was carried out the broken cold leg during a total bypass period that lasted until $26 \mathrm{~s}$. Some liquid penetrated the downcomer and entered the lower plenum at this time. This was the beginning of partial ECC bypass.

The core was drying out at $17 \mathrm{~s}$ since the low upper head pressure continued to prevent liquid from flowing down the support columns and into the core. Once again, the clad temperatures began to increase. Delivery to the core resumed at 19 s once the upper head refilled with liquid.

Accumulator injection into the upper head continued until 23.2 s when the UHI valves closed. However, liquid kept flowing down the support columns until a second round of condensation in the upper head interrupted flow to the core at $26 \mathrm{~s}$. At $32 \mathrm{~s}$ the gravity head of 1 iquid in the upper head was enough to overcome the pressure difference caused by condensation, so the liquid began draining down the support columns and into the core until the upper head was empty at $58 \mathrm{~s}$. A significant amount of liquid was delivered to the core which cooled the slight rise in the clad temperature at $38 \mathrm{~s}$ (Figure 13). 
Table 9 Summary of calculation

Event

Time(sec)

End of subcooled blowdown

$<0.5$

UHI accumulator on

2.4

Upper head liquid begins to flash

3.0

Liquid level swell in the lower plenum

3.0

Beginning of the first U.H. liquid delivery to the core

4.0

Maximum clad temperature of $1155 \mathrm{~F}$ occurs

8.0

Entire core is quenched

14.0

Condensation in the upper head begins

14.0

Delivery of U.H. liquid to the core ends

14.0

Pressurizer has discharged $1000 \mathrm{ft}^{3}$ of liquid

14.0

Cold leg accumulators on

14.8

Second U.H. liquid delivery to the core begins

19.0

Cold leg ECC water enters the downcomer

20.0

UHI accumulator off

23.2

Total ECC downcomer bypass ends

26.0

Second U.H. liquid delivery to the core ends

26.0

Third U.H. liquid delivery (drain) to the core begins

47.0

Upper head empties ending the third delivery

58.0

Bottom reflood begins

73.0

Core is rewetted

85.0

Calculation is stopped

93.0 


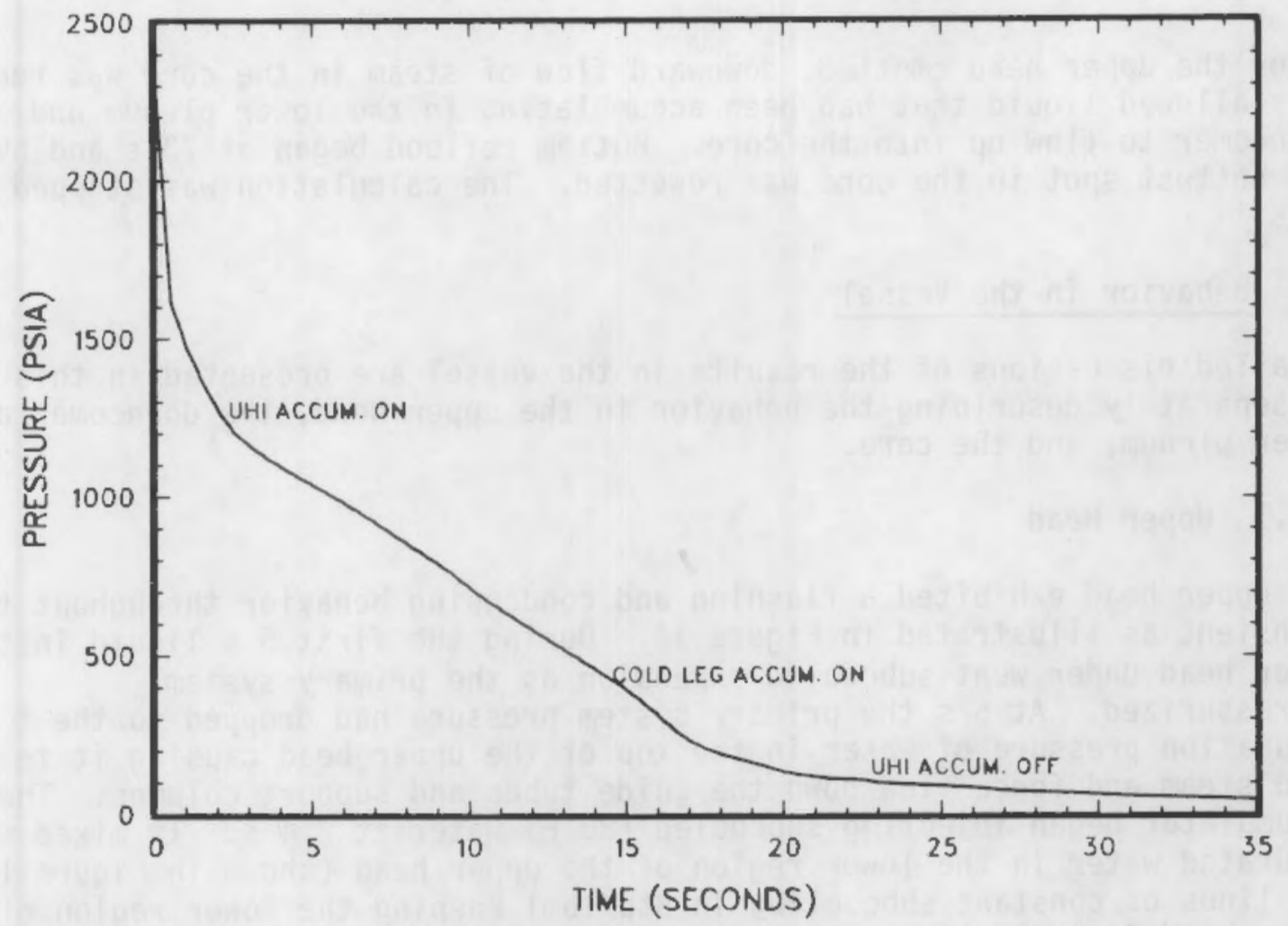

Figure 12. Core pressure vs. time

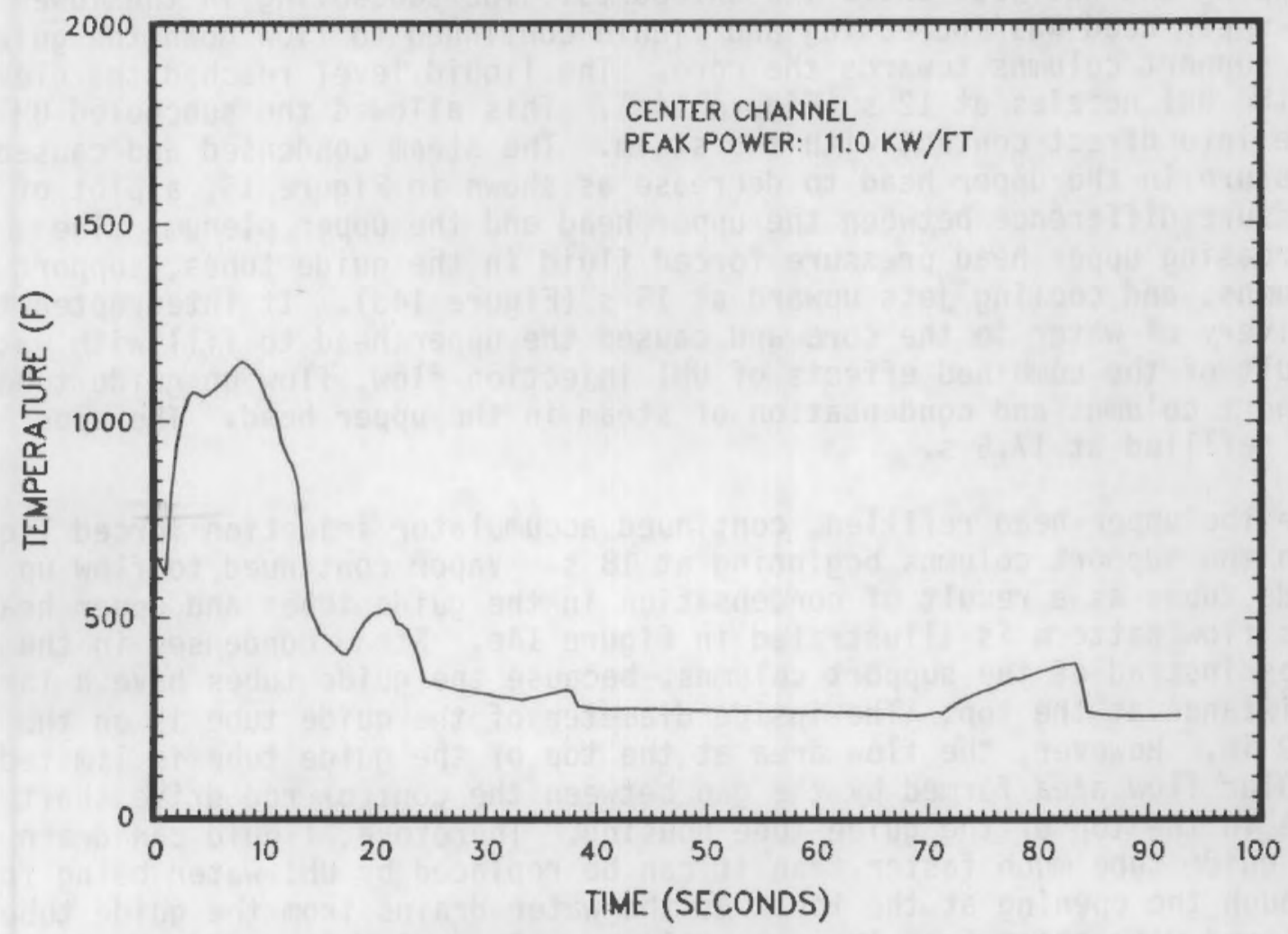

Figure 13. Hot rod peak clad surface temperature vs. time 
After the upper head emptied, downward flow of steam in the core was reduced. This allowed liquid that had been accumulating in the lower plenum and downcomer to flow up into the core. Bottom reflood began at $73 \mathrm{~s}$ and by $85 \mathrm{~s}$ the hottest spot in the core was rewetted. The calculation was stopped at. $93 \mathrm{~s}$.

\subsection{Behavior in the Vessel}

Detailed discussions of the results in the vessel are presented in this section by separately describing the behavior in the upper head, the downcomer and lower plenum, and the core.

\subsubsection{Upper Head}

The upper head exhibited a flashing and condensing behavior throughout the transient as illustrated in Figure 14. During the first 5 s liquid in the upper head under went subcooled expansion as the primary system depressurized. At $5 \mathrm{~s}$ the primary system pressure had dropped to the saturation pressure of water in the top of the upper head causing it to flash into steam and force flow down the guide tubes and support columns. The UHI accumulator began injecting subcooled $(80 \mathrm{~F})$ water at $2.4 \mathrm{~s}$. It mixed with saturated water in the lower region of the upper head (shown in Figure 14a by the lines of constant subcooling in Btu/lbm) keeping the lower region of the upper head from flashing. By $10 \mathrm{~s}$ (Figure 14b) the liquid level was still dropping and was just above the UHI ports. The subcooling in the lower part of the upper head was increasing and liquid continued to flow down the guide tubes and support columns towards the core. The liquid level reached the elevation of the UHI nozzles at $12 \mathrm{~s}$ (Figure 14c). This allowed the subcooled UHI jet to come into direct contact with the steam. The steam condensed and caused the pressure in the upper head to decrease as shown in Figure 15, a plot of the pressure difference between the upper head and the upper plenum. The decreasing upper head pressure forced fluid in the guide tubes, support columns, and cooling jets upward at $15 \mathrm{~s}$ (Figure 14d). It interrupted the delivery of water to the core and caused the upper head to fill with water as a result of the combined effects of UHI injection flow, flow up guide tubes and support columns and condensation of steam in the upper head. The upper head was refilled at $17.5 \mathrm{~s}$.

Once the upper head refilled, continued accumulator injection forced liquid down the support columns beginning at $18 \mathrm{~s}$. Vapor continued to flow up the guide tubes as a result of condensation in the guide tubes and upper head. This flow pattern is illustrated in Figure 14e. Steam condenses in the guide tubes instead of the support columns, because the guide tubes have a large flow resistance at the top. The inside diameter of the guide tube is on the order of $9 \mathrm{in}$. However, the flow area at the top of the guide tube is limited to the annular flow area formed by the gap between the control rod drive shaft and the hole in the top of the guide tube housing. Therefore, liquid can drain out of the guide tube much faster than it can be replaced by UHI water being forced through the opening at the top. As the water drains from the guide tube it is replaced with steam from the upper plenum. Some of this steam condenses on the water entering the guide tube from the upper head. This condensation produces 
FLASHING
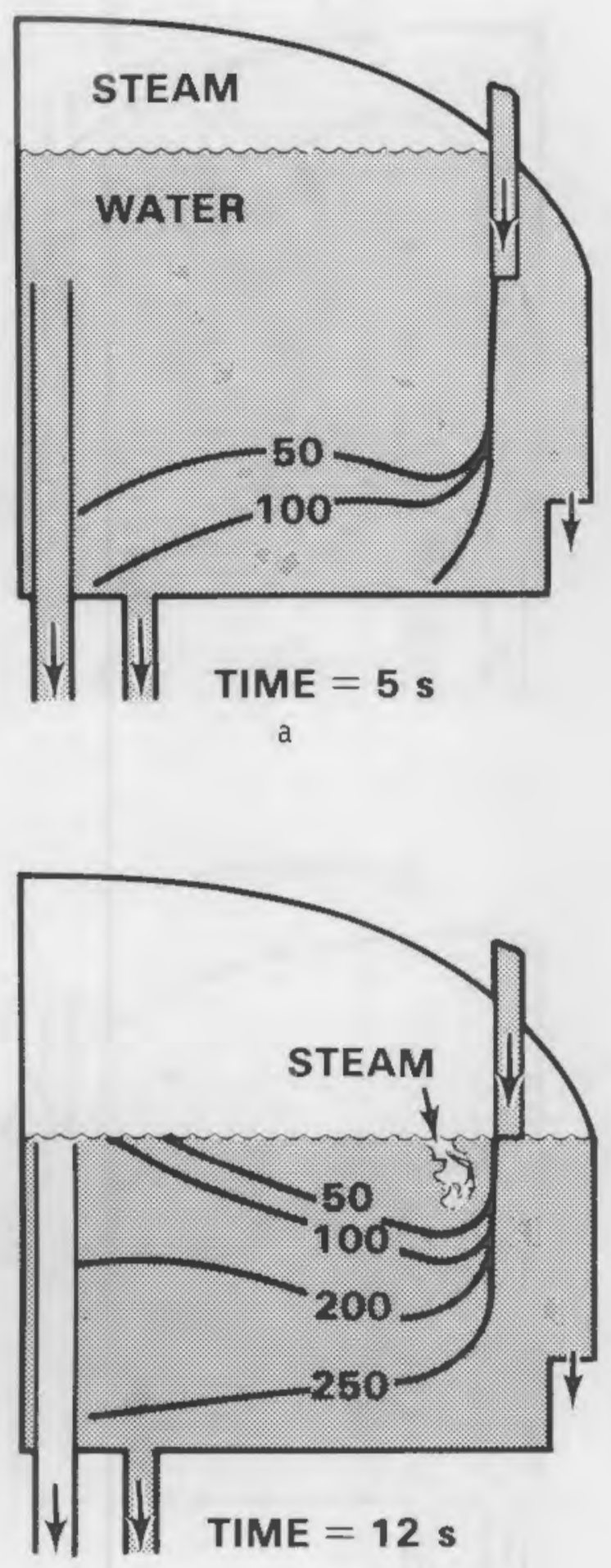

c
FLASHING

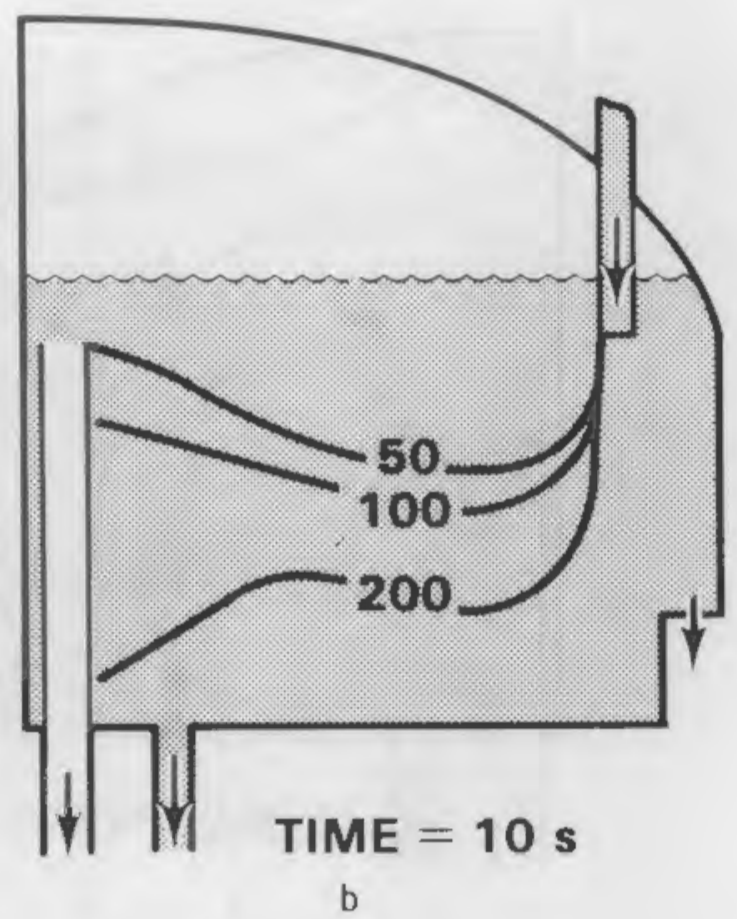

CONDENSING

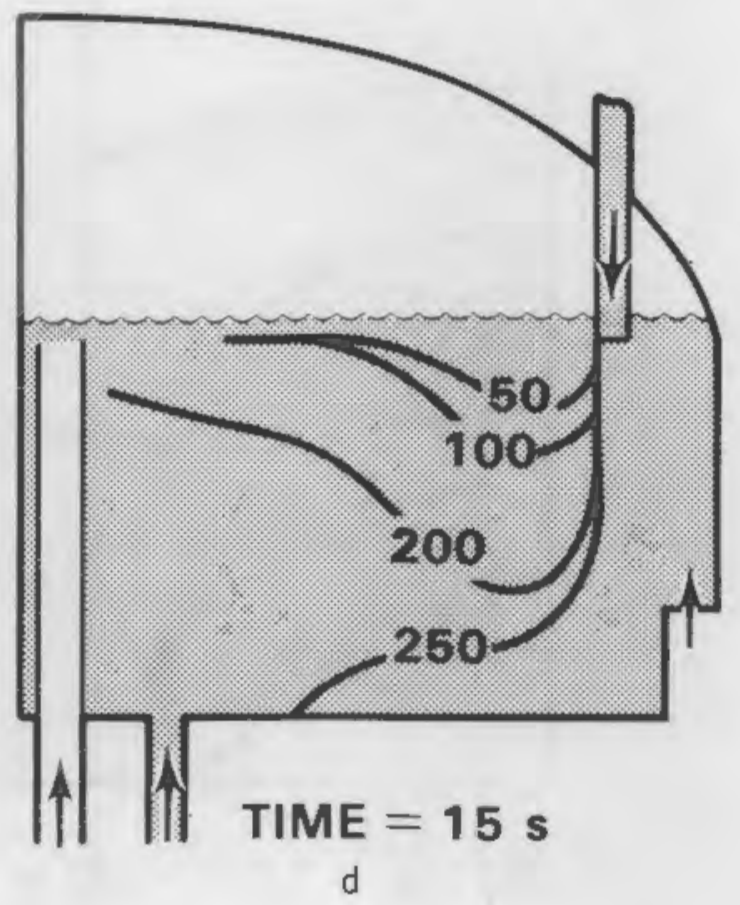

Figure 14. Upper head behavior (contours are lines of constant enthalpy subcooling in Btu/lbm) (a thru d) 


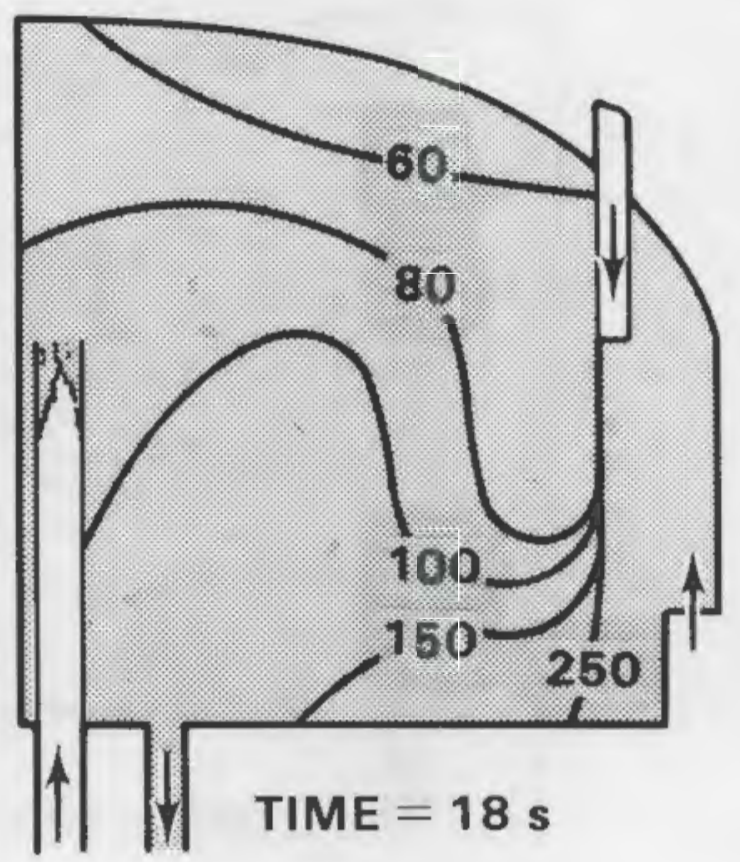

e

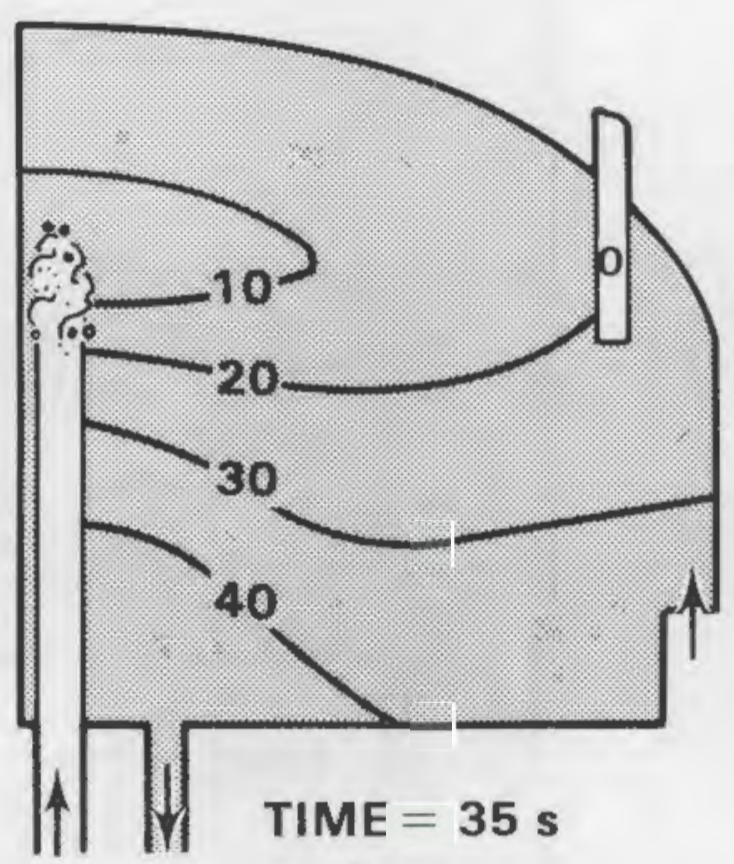

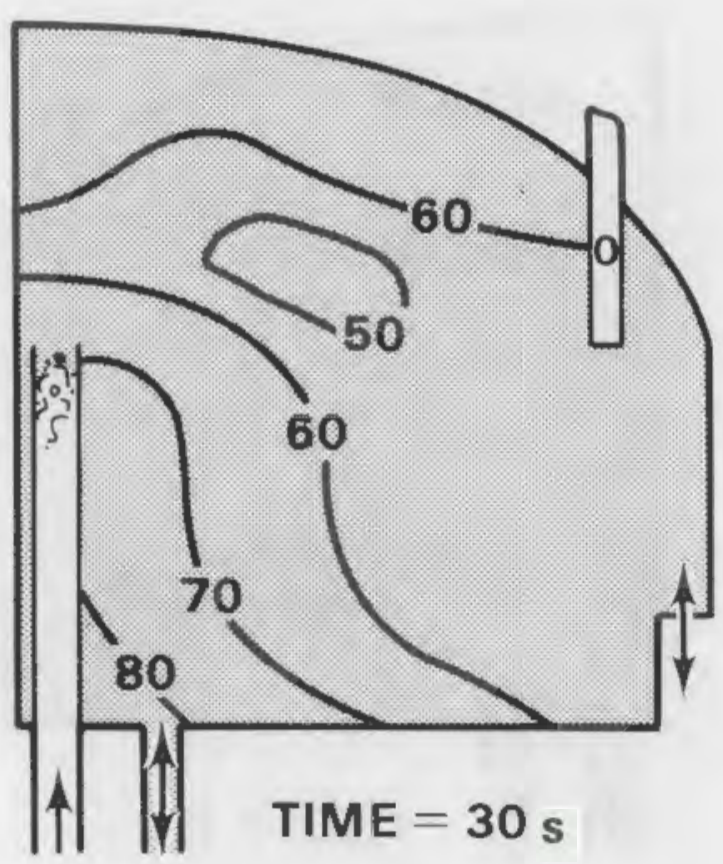

$f$

DRAINING

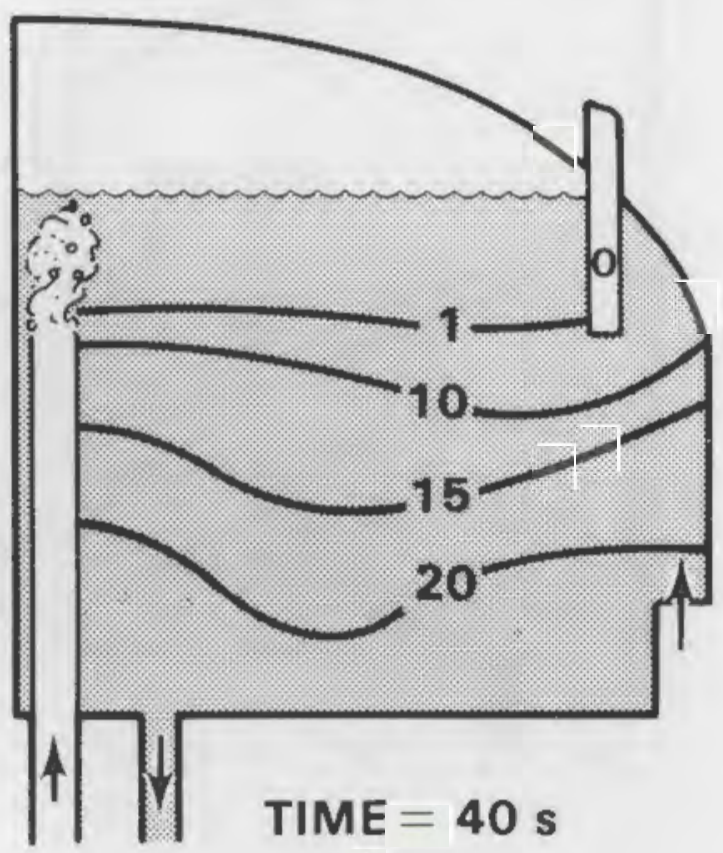

h

Figure 14. Upper head behavior (contours are lines of constant enthalpy subcooling in Btü/1bm) (e thru h) 


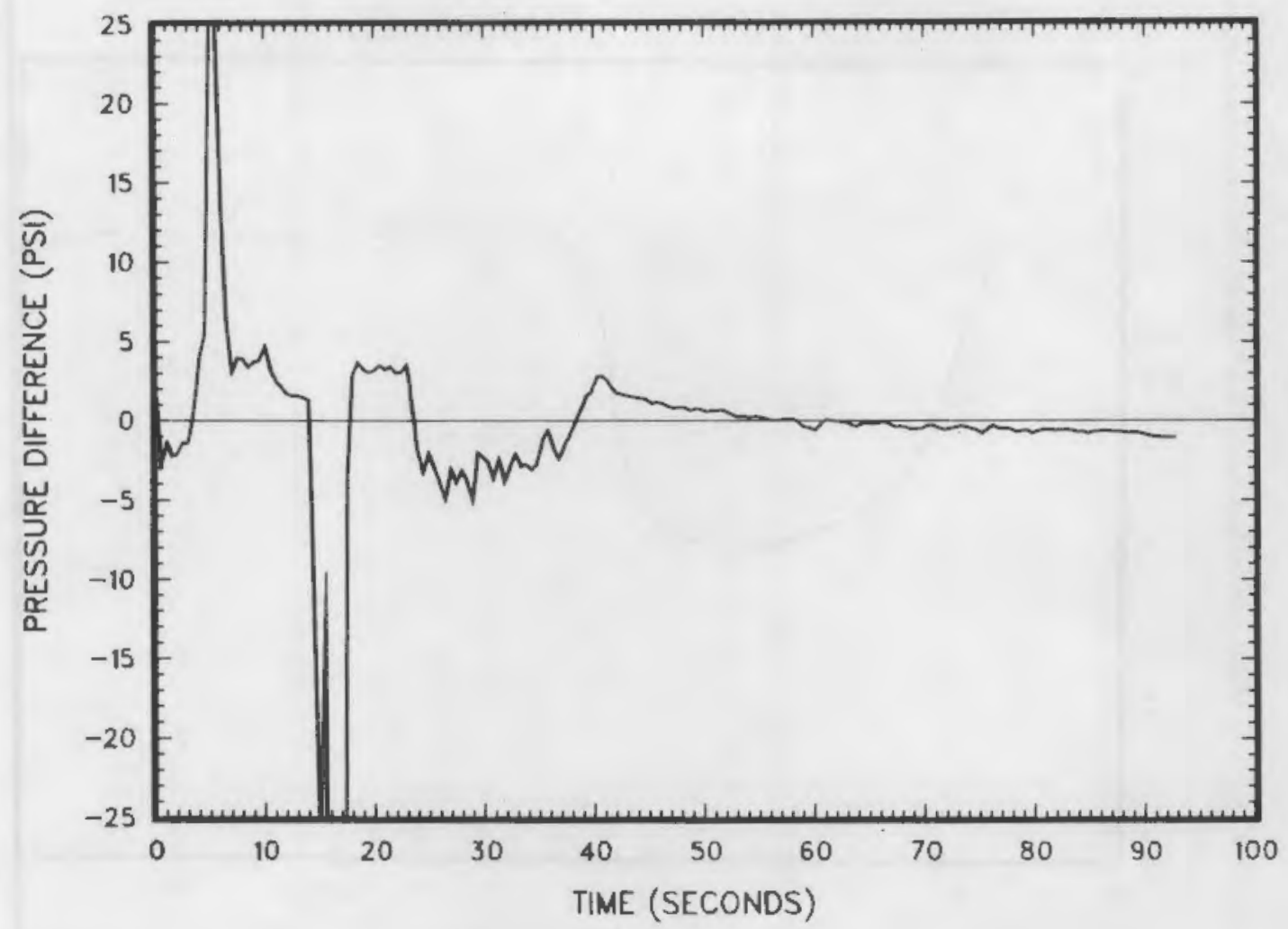

Figure 15. Pressure difference between the upper head and upper plenum vs. time

a pressure drop from the upper plenum to the top of the guide tube. This pressure drop maintains the flow of steam into the guide tube while condensate and UHI water continue to drain from the guide tube at a faster rate than water can enter from the top.

Liquid continued flowing down the support columns until the accumulator was isolated at $23.2 \mathrm{~s}$. Without forced injection, condensation on the cold water in the upper head lowered the pressure and prevented liquid from flowing down the support columns. The liquid flow rates in the support columns and upper head cooling jets oscillated while vapor flowed up to condense on liquid in the top of the guide tubes. This is illustrated in Figure $14 \mathrm{f}$ at $30 \mathrm{~s}$. Steam flowing up the guide tubes gradually heated the upper head liquid (Figure 14g) until the fluid above the guide tubes reached saturation (Figure 14h). This decreased the condensation rate causing an increase in the upper head pressure that allowed liquid to drain down the support columns as shown in Figure 14h. This was the third time the upper head delivered liquid to the core and is known as the upper head "drain" period. This process continued until the upper head emptied at $58 \mathrm{~s}$.

Figure 16 also indicates the flashing and condensing behavior. It is a plot of the collapsed liquid level in the upper head. The liquid level decreased during upper head flashing from 3 to $12 \mathrm{~s}$ and increased again during the condensation period from 12 to $17.5 \mathrm{~s}$. 


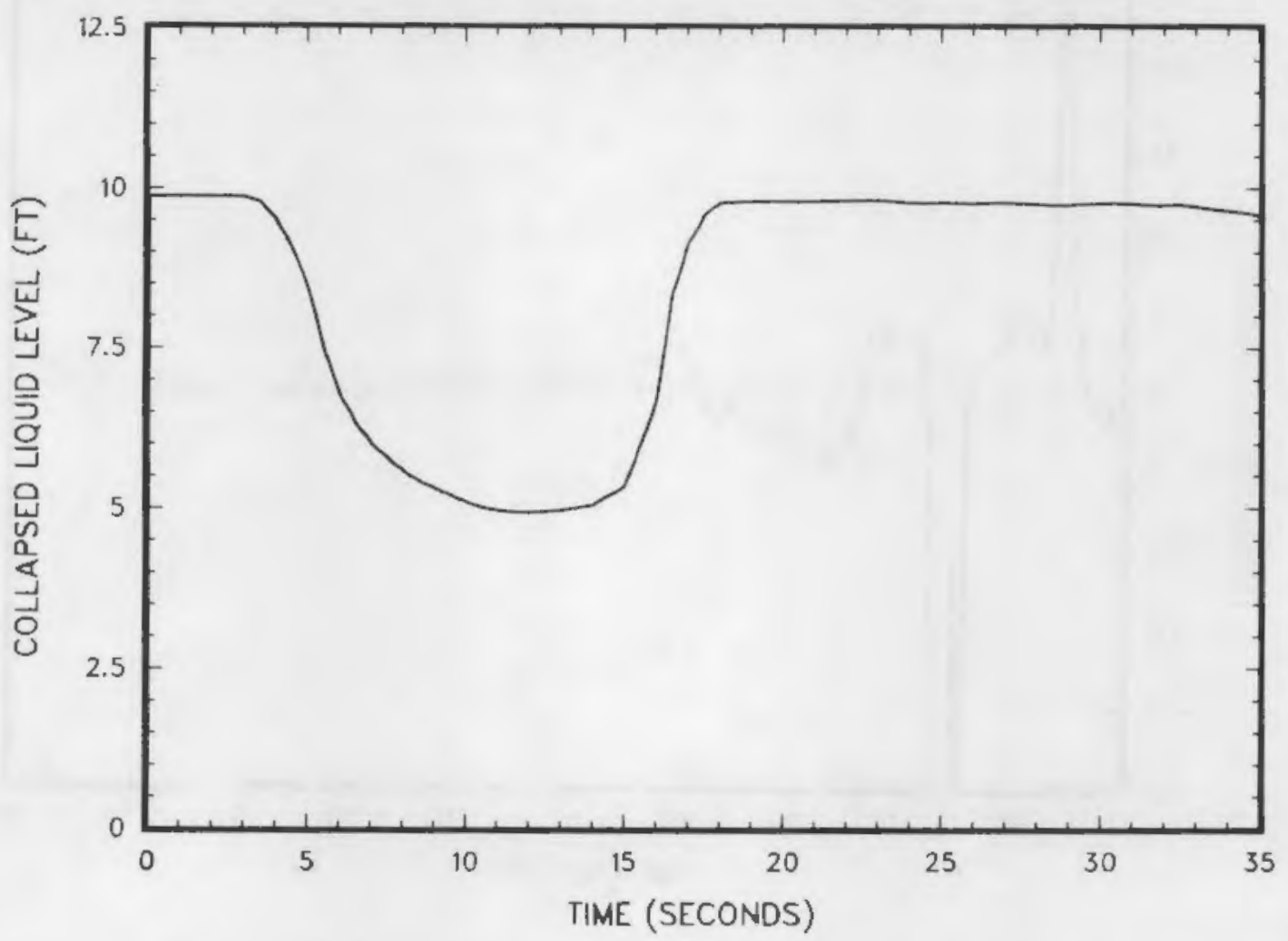

Figure 16. Upper head liquid level vs. time

The vertical enthalpy distribution in the center channel of the upper head is shown in Figure 17. The enthalpy in the bottom two cells remained subcooled until the end of UHI injection. The enthalpy in the center cell followed saturation until about $8.5 \mathrm{~s}$ when it also became subcooled. The enthalpy in the top two cells followed saturation until $16 \mathrm{~s}$ when the upper head refilled with water as a result of the condensation in the upper head. Fluid in the bottom three cells was heated by steam flowing up the support columns and condensing in the lower part of the upper head. The enthalpy in the upper head reached a minimum at $23.5 \mathrm{~s}--$ just after UHI injection was terminated.

The liquid and drop mass flow rates for all of the support columns are plotted in Figure 18. The three periods when liquid was delivered to the core during the flashing, forced injection, and drain periods are clearly shown (negative flow is towards the core). The large liquid flow up into the upper head during the first condensation phase is also shown. The vapor flow rate through the support columns is shown in Figure 19. The only time vapor entered the support columns was when steam flowed upward to condense in the upper head at $15 \mathrm{~s}$.

The liquid and drop flow rates in the guide tubes are shown in Figure 20 and the vapor flow rate is shown in Figure 21. A large amount of liquid flowed down the guide tubes while the upper head was flashing (3-10 s). During this time the guide tubes emptied as shown by the liquid level plotted in

Figure 22. The vapor flow rate up the guide tubes increased during the upper 


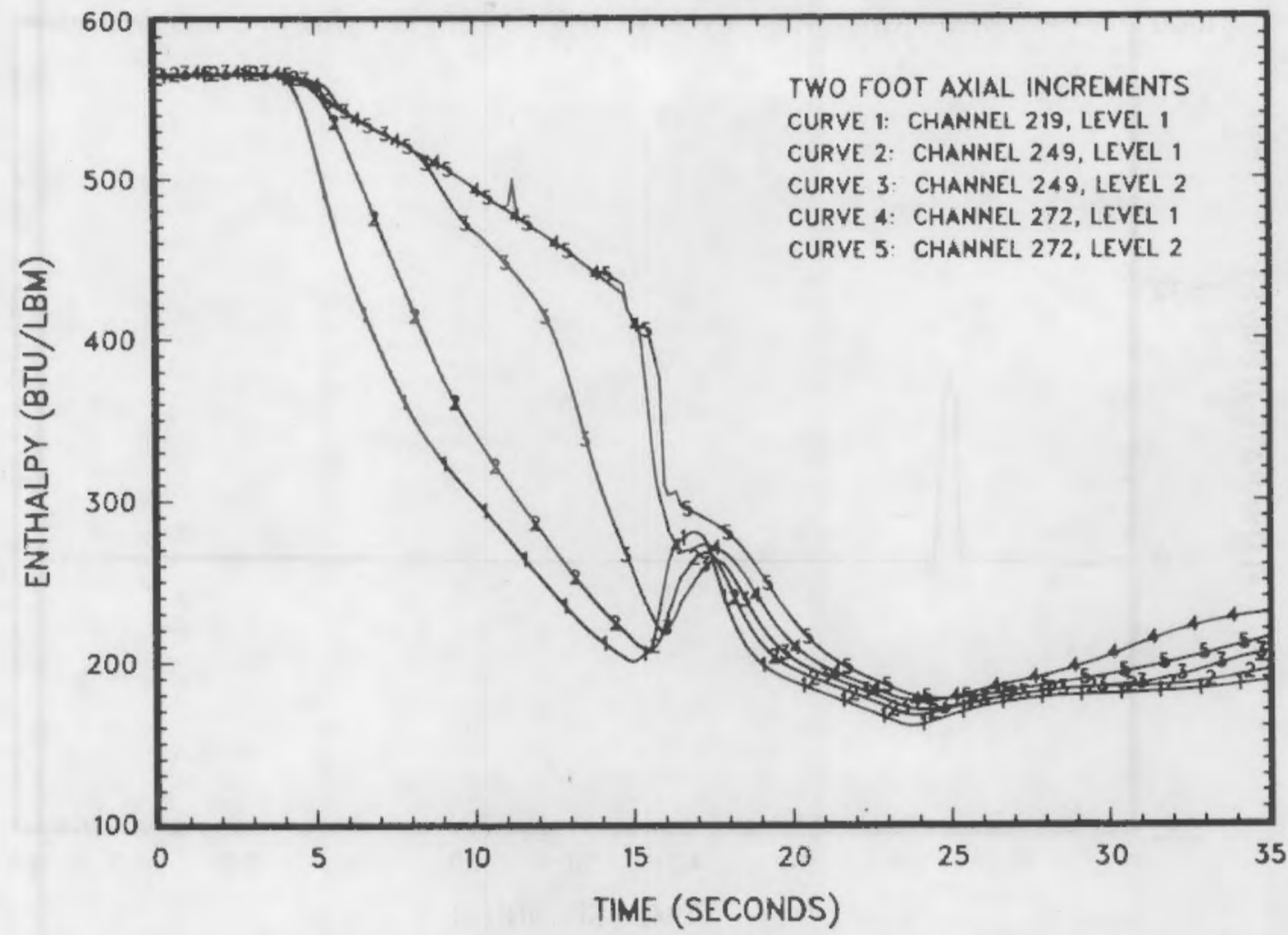

Figure 17. Upper head enthalpies vs. time

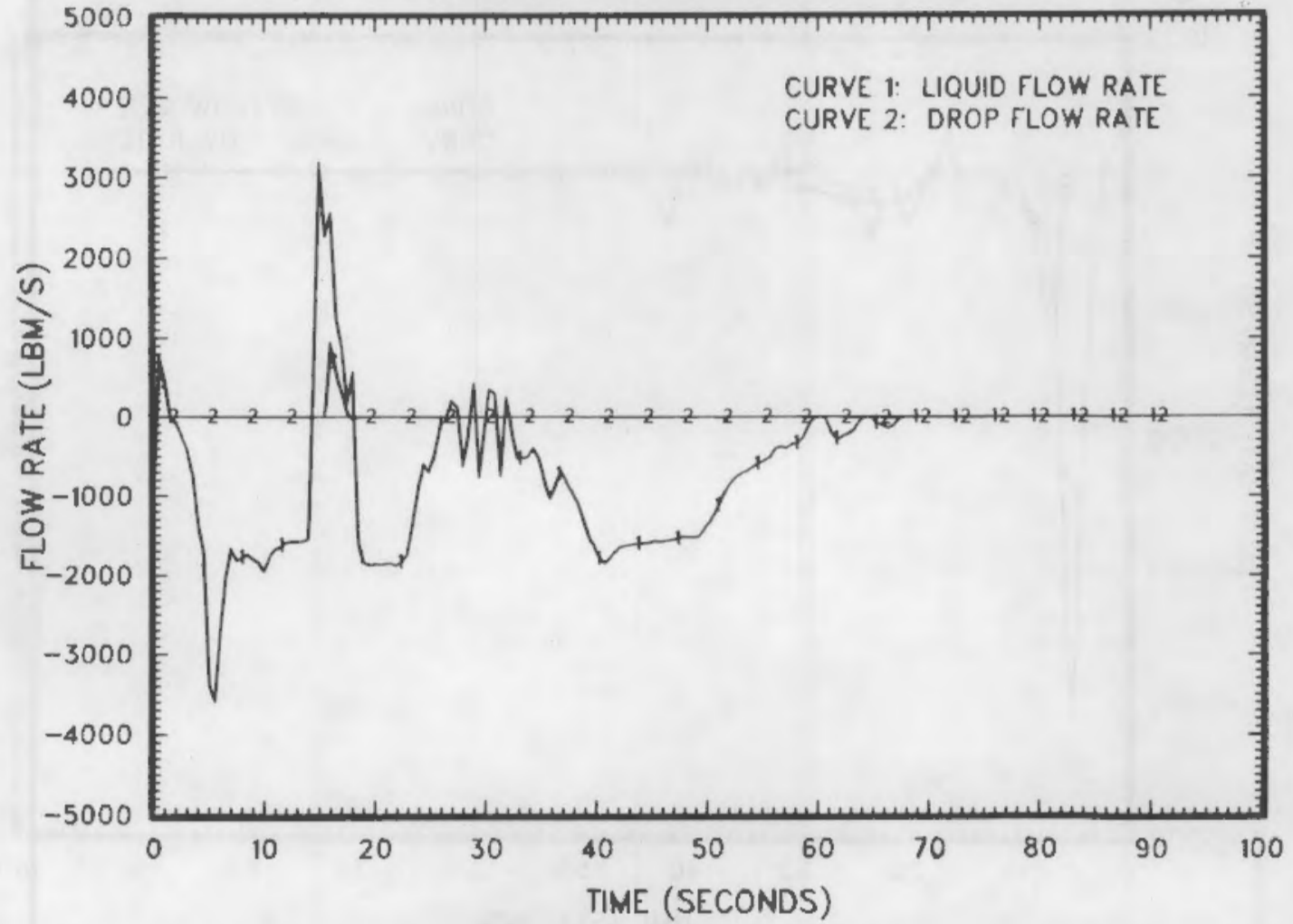

Figure 18. Liquid and drop flow rates through all support columns vs. time 


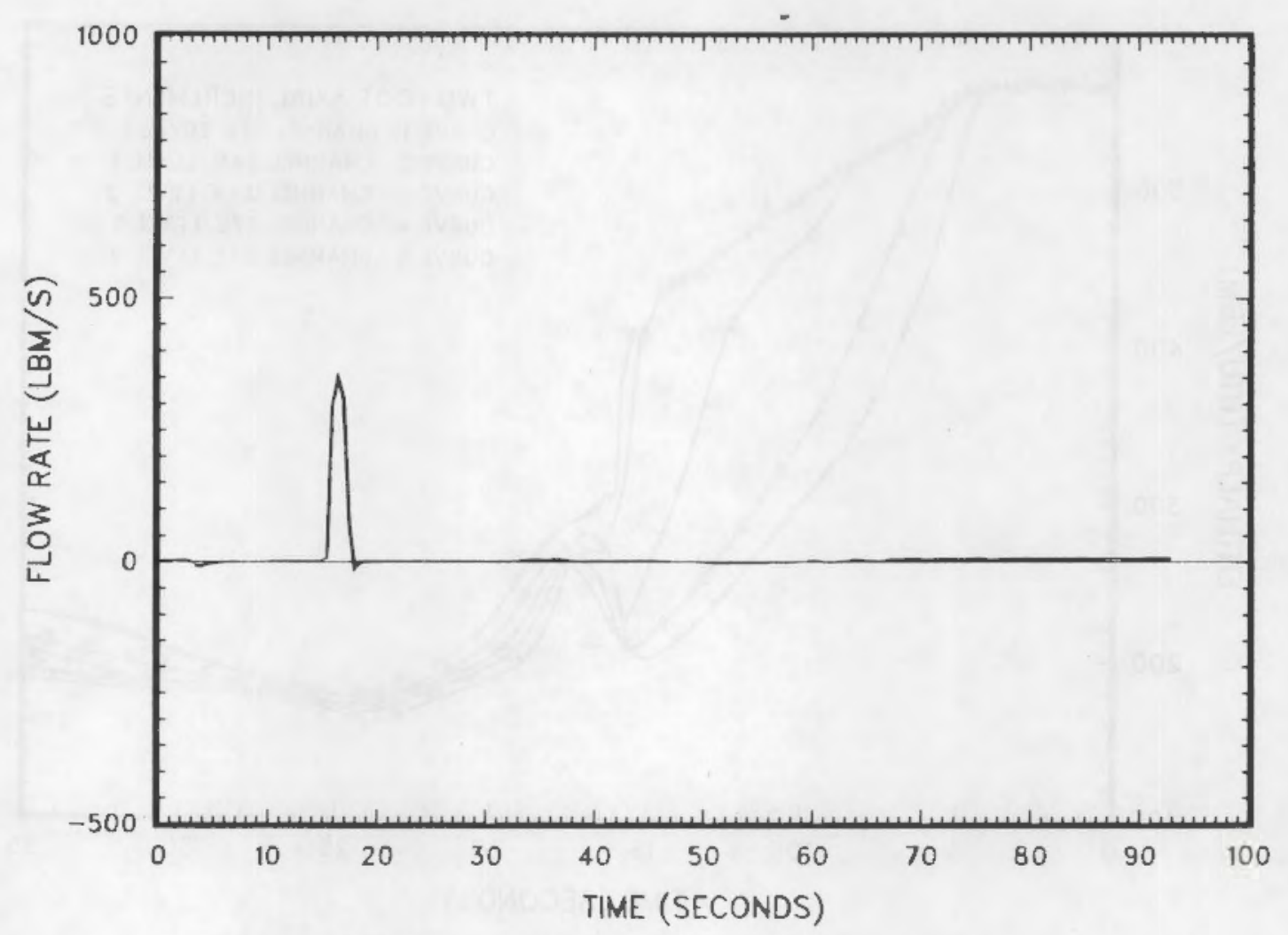

Figure 19. Vapor flow rate through all support columns vs. time

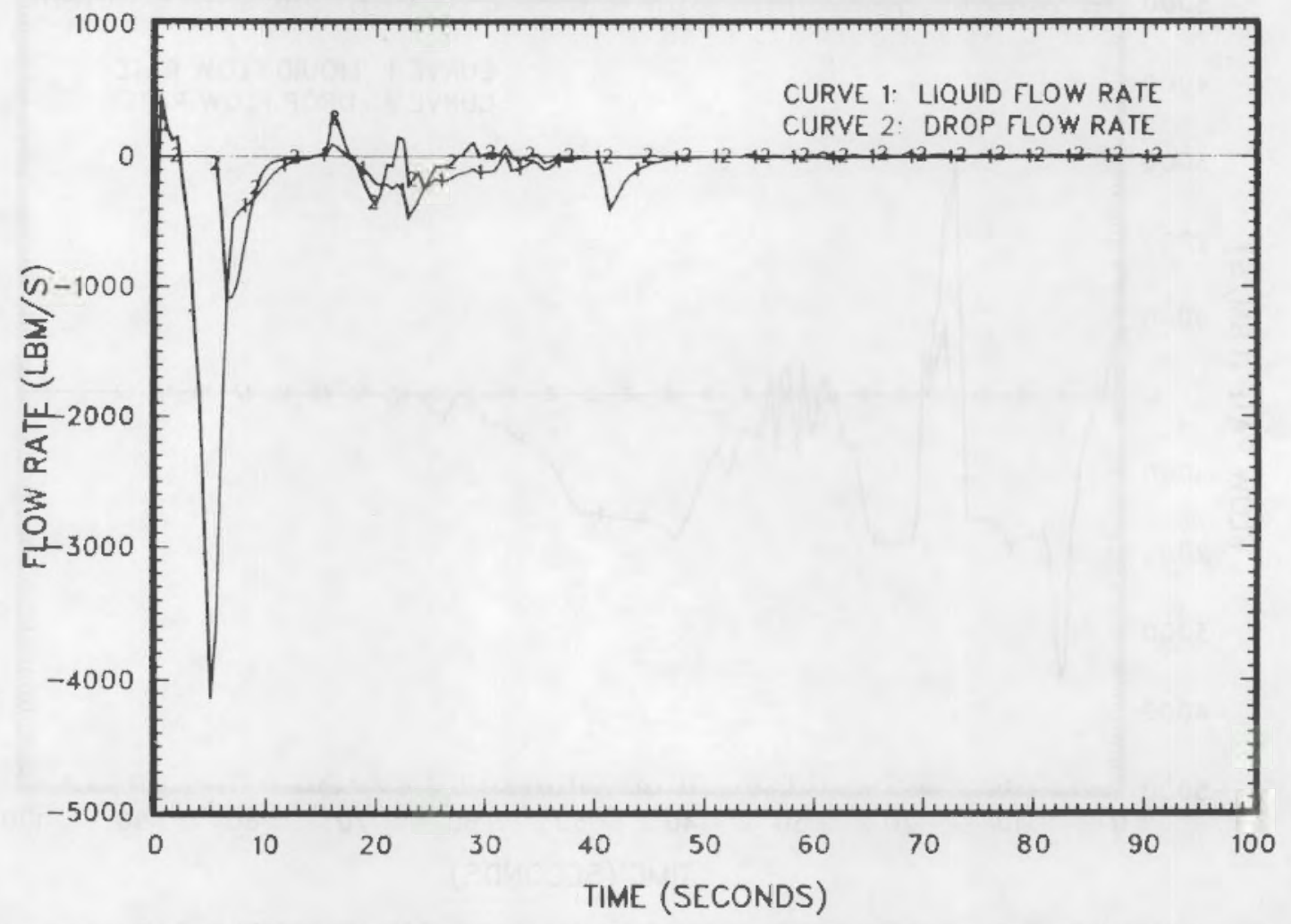

Figure 20. Liquid and drop flow rates through all guide tubes vs. time 


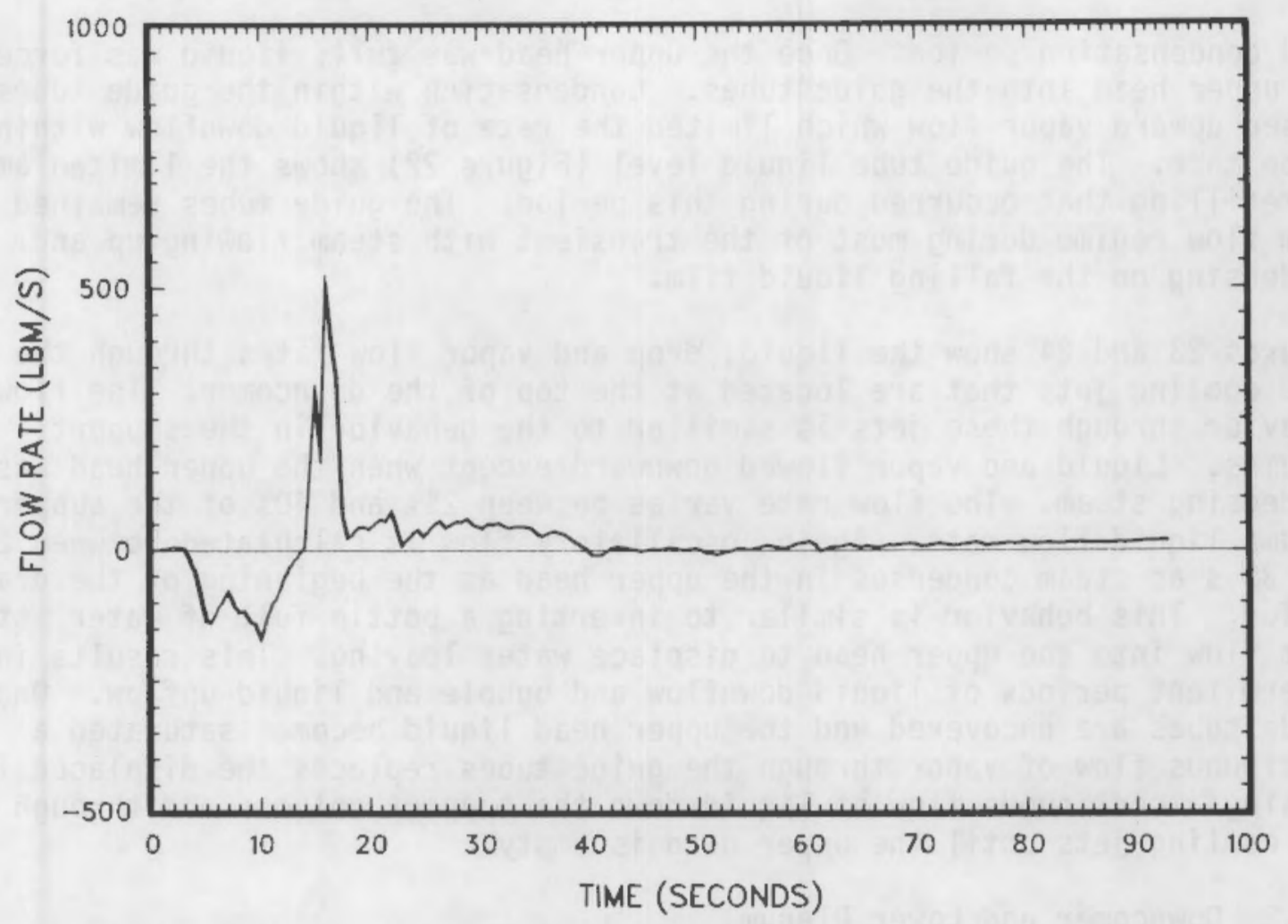

Figure 21. Vapor flow rate through all guide tubes vs. time

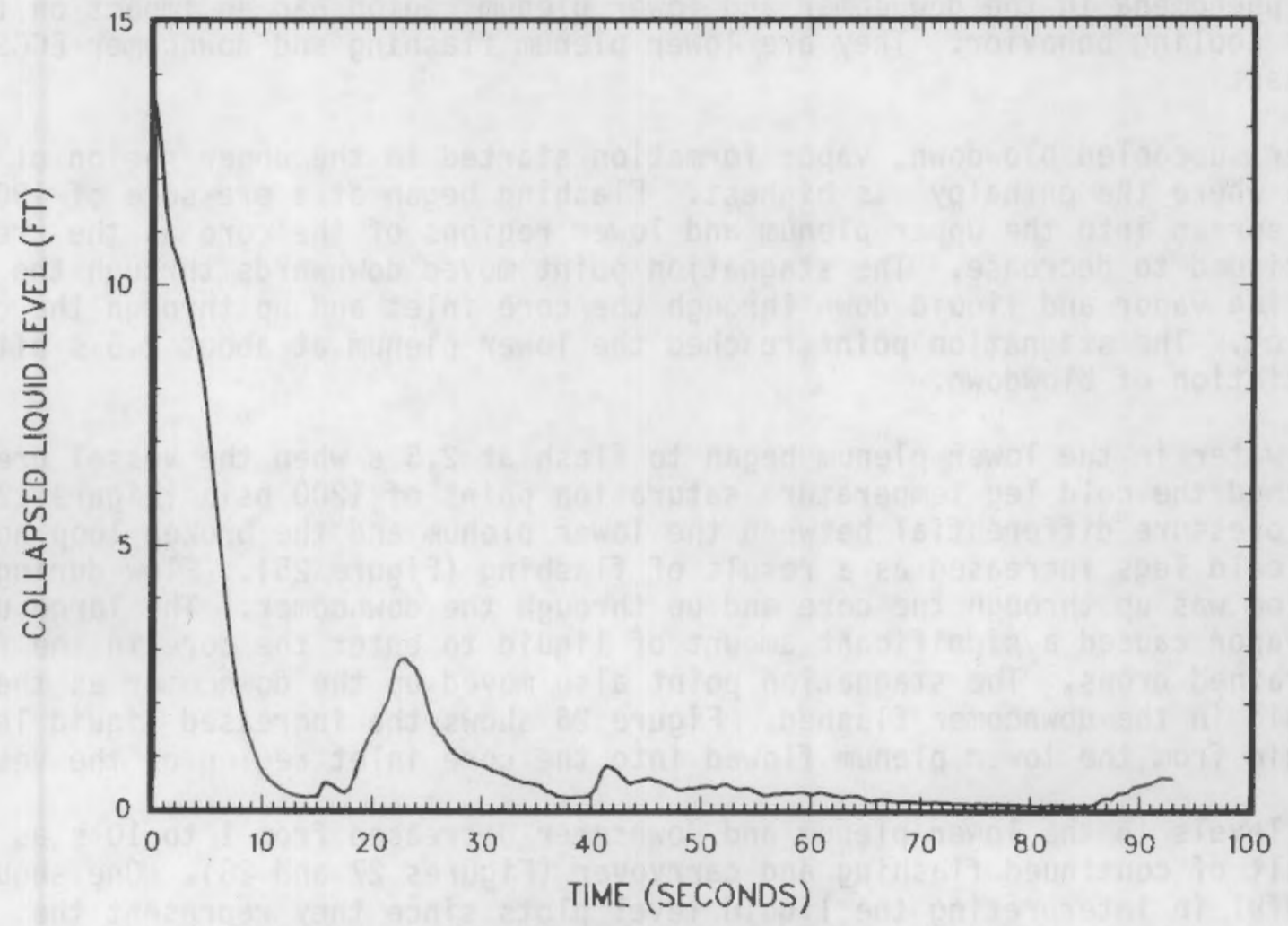

Figure 22. Guide tube liquid level vs. time 
head condensation period. Once the upper head was full, liquid was forced from the upper head into the guide tubes. Condensation within the guide tubes caused upward vapor flow which limited the rate of liquid downflow within the guide tube. The guide tube liquid level (Figure 22) shows the limited amount of refilling that occurred during this period. The guide tubes remained in a film flow regime during most of the transient with steam flowing up and condensing on the falling liquid film.

Figures 23 and 24 show the liquid, drop and vapor flow rates through the upper head cooling jets that are located at the top of the downcomer. The flow behavior through these jets is similiar to the behavior in the support columns. Liquid and vapor flowed downward except when the upper head was condensing steam. The flow rate varies between $25 \%$ and $40 \%$ of the support column liquid flow rate. Again, oscillatory flow is calculated between 23.5 and $38 \mathrm{~s}$ as steam condenses in the upper head at the beginning of the drain period. This behavior is similar to inverting a bottle full of water, steam must flow into the upper head to displace water leaving. This results in intermitent periods of liquid downflow and bubble and liquid upflow. Once the guide tubes are uncovered and the upper head liquid becomes saturated a continuous flow of vapor through the guide tubes replaces the displaced liquid causing a continuous flow of liquid down the support columns and through the UHI cooling jets until the upper head is empty.

\subsubsection{Downcomer and Lower Plenum}

Two phenomena in the downcomer and lower plenum region had an impact on the core cooling behavior. They are lower plenum flashing and downcomer ECCS bypass.

After subcooled blowdown, vapor formation started in the upper region of the core where the enthalpy was highest. Flashing began at a pressure of 1900 psia and spread into the upper plenum and lower regions of the core as the pressure continued to decrease. The stagnation point moved downwards through the core forcing vapor and liquid down through the core inlet and up through the core outlet. The stagnation point reached the lower plenum at about $2.5 \mathrm{~s}$ after initiation of blowdown.

The water in the lower plenum began to flash at $2.5 \mathrm{~s}$ when the vessel pressure reached the cold leg temperature saturation point of 1200 psia (Figure 12). The pressure differential between the lower plenum and the broken loop hot leg and cold legs increased as a result of flashing (Figure 25). Flow during this period was up through the core and up through the downcomer. The large upflow of vapor caused a significant amount of liquid to enter the core in the form of entrained drops. The stagnation point also moved up the downcomer as the liquid in the downcomer flashed. Figure 26 shows the increased liquid level as liquid from the lower plenum flowed into the core inlet region of the vessel.

The levels in the lower plenum and downcomer decreased from 1 to $10 \mathrm{~s}$ as a result of continued flashing and carryover (Figures 27 and 28 ). One should be careful in interpreting the liquid level plots since they represent the collapsed liquid level. The downcomer liquid level decreased from 1 to $10 \mathrm{~s}$ as 


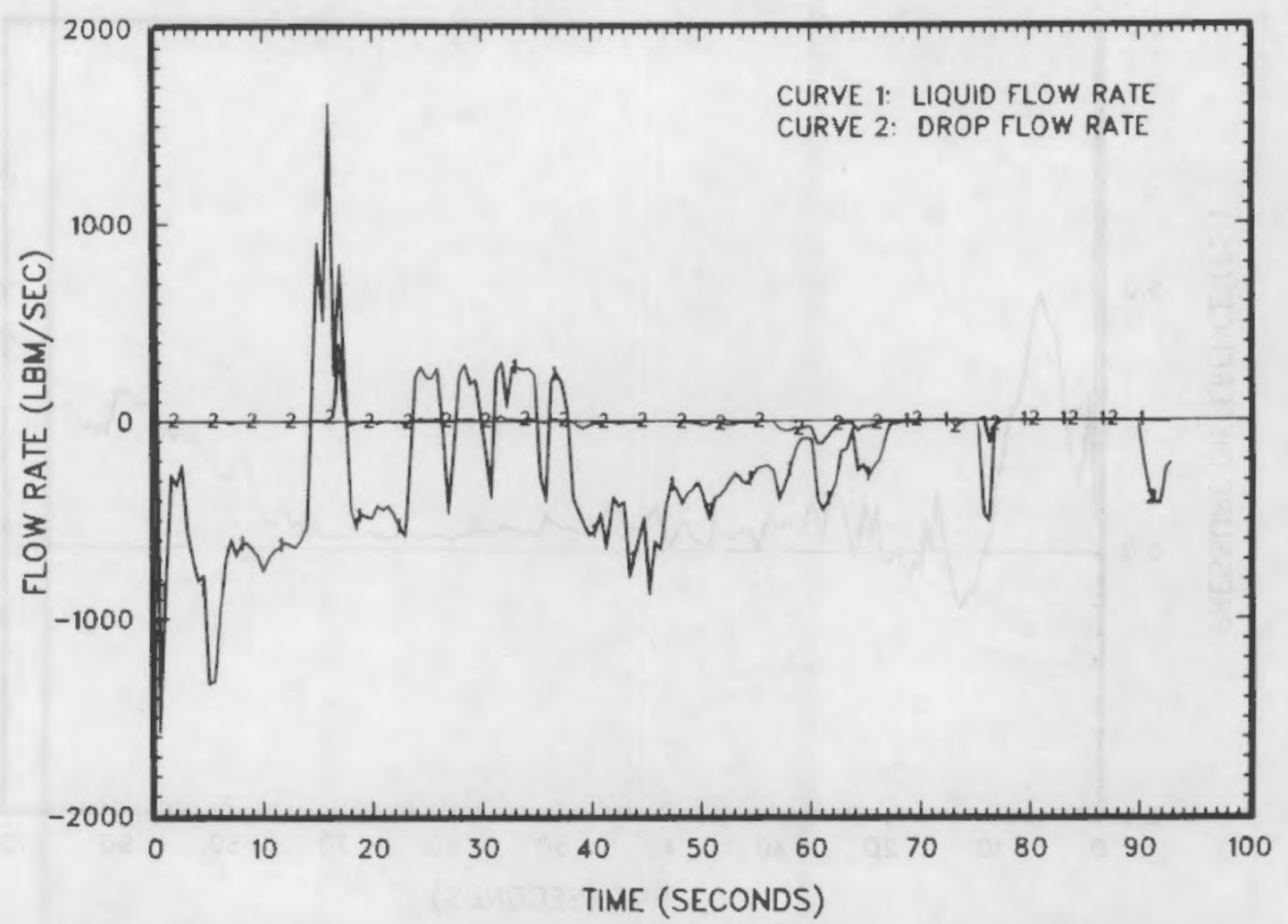

Figure 23. Liquid and drop flow rate through the upper head cooling jets

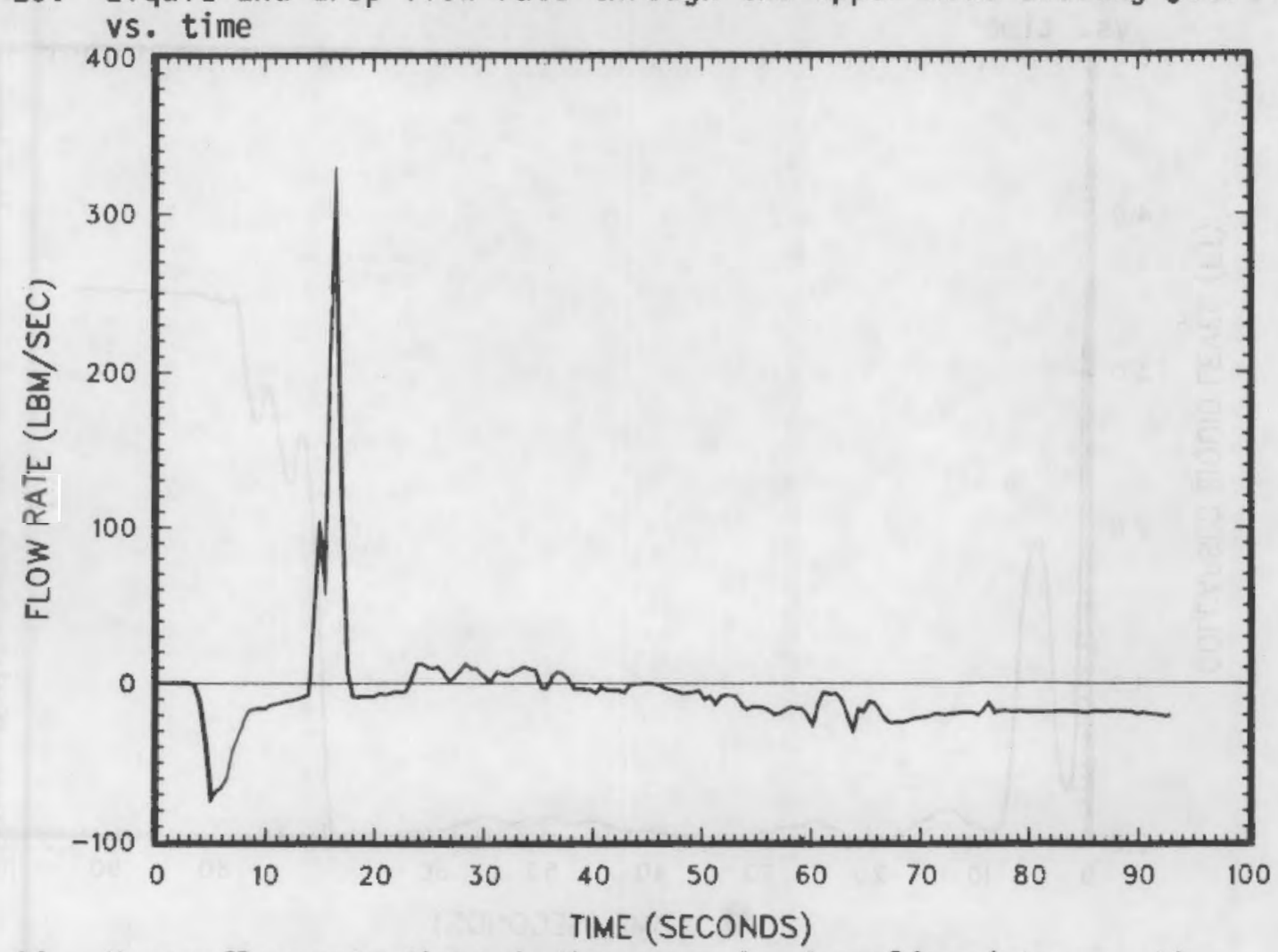

Figure 24. Vapor flow rate through the upper head cooling jets vs. time 


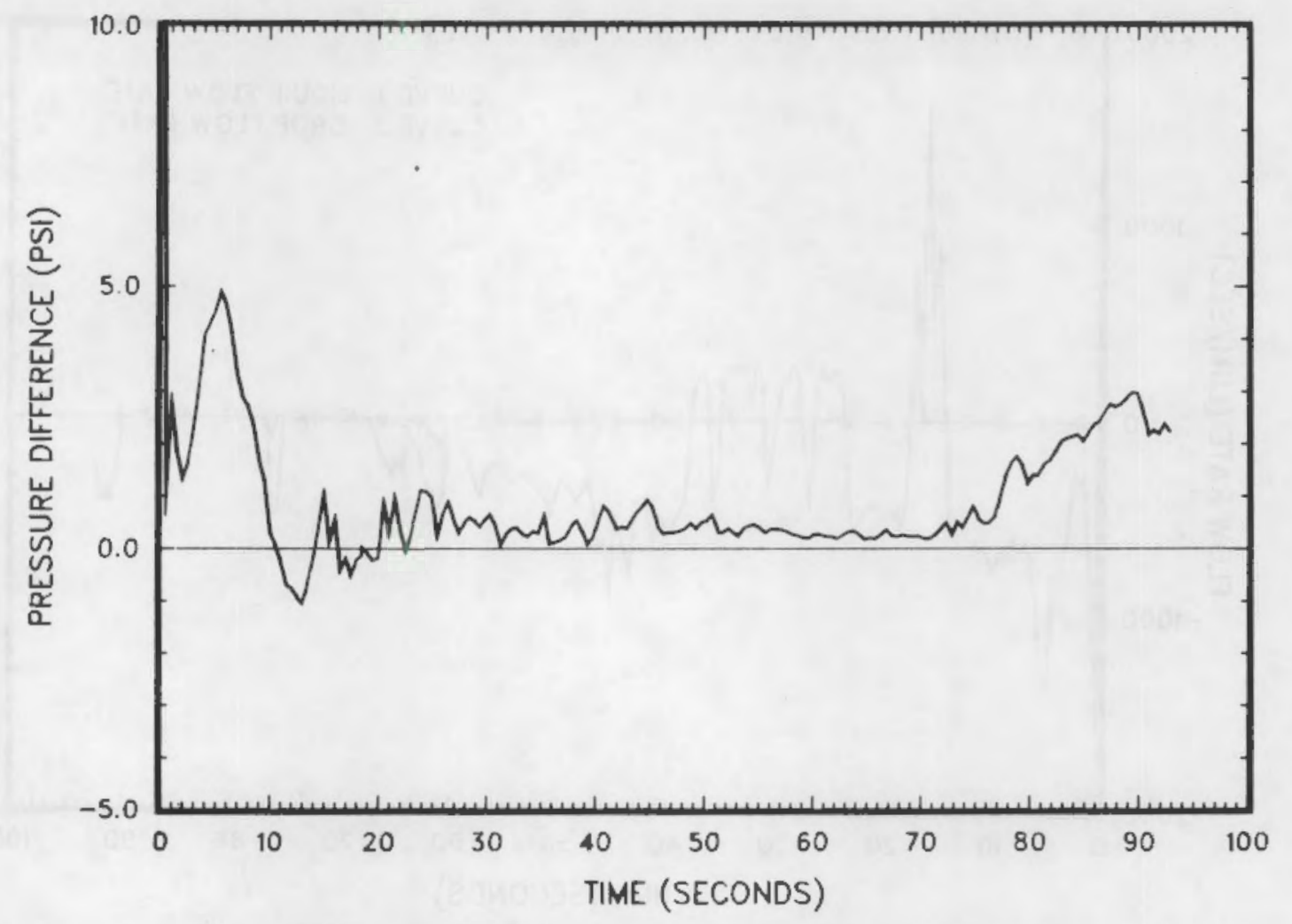

Figure 25. Pressure difference between the core inlet and broken hot leg vs. time

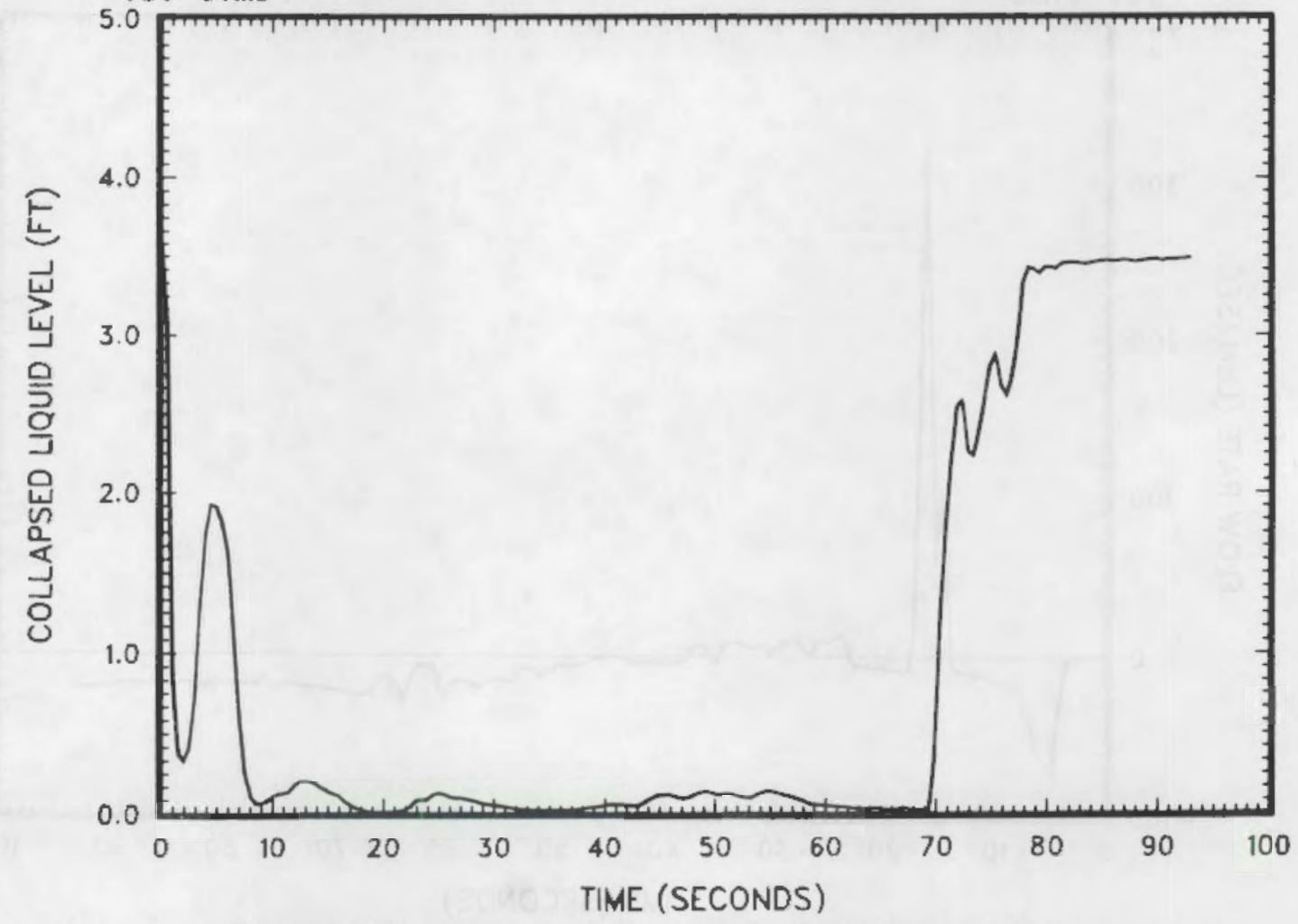

Figure 26. Core inlet liquid level vs. time 


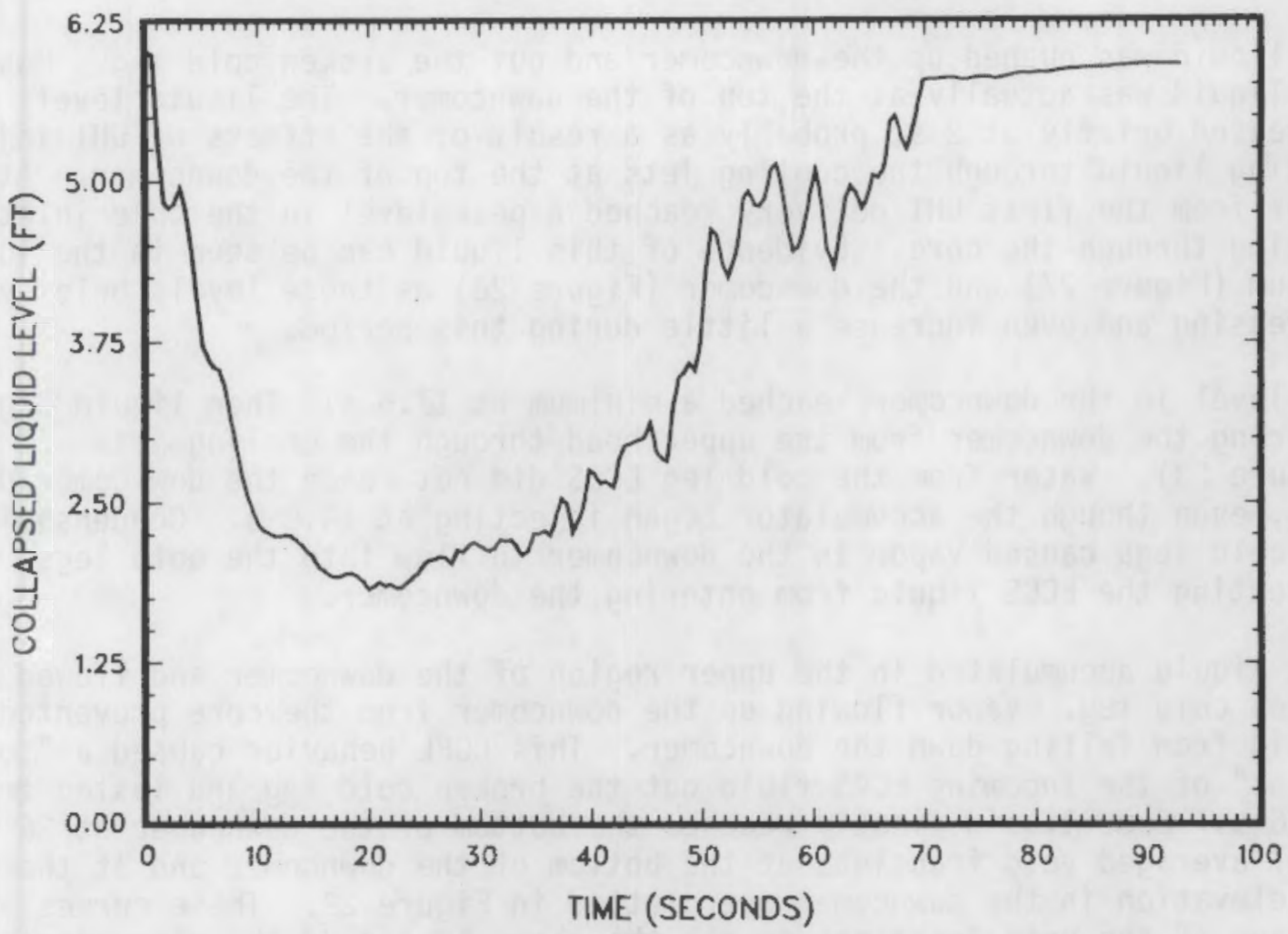

Figure 27. Lower plenum liquid level vs. time

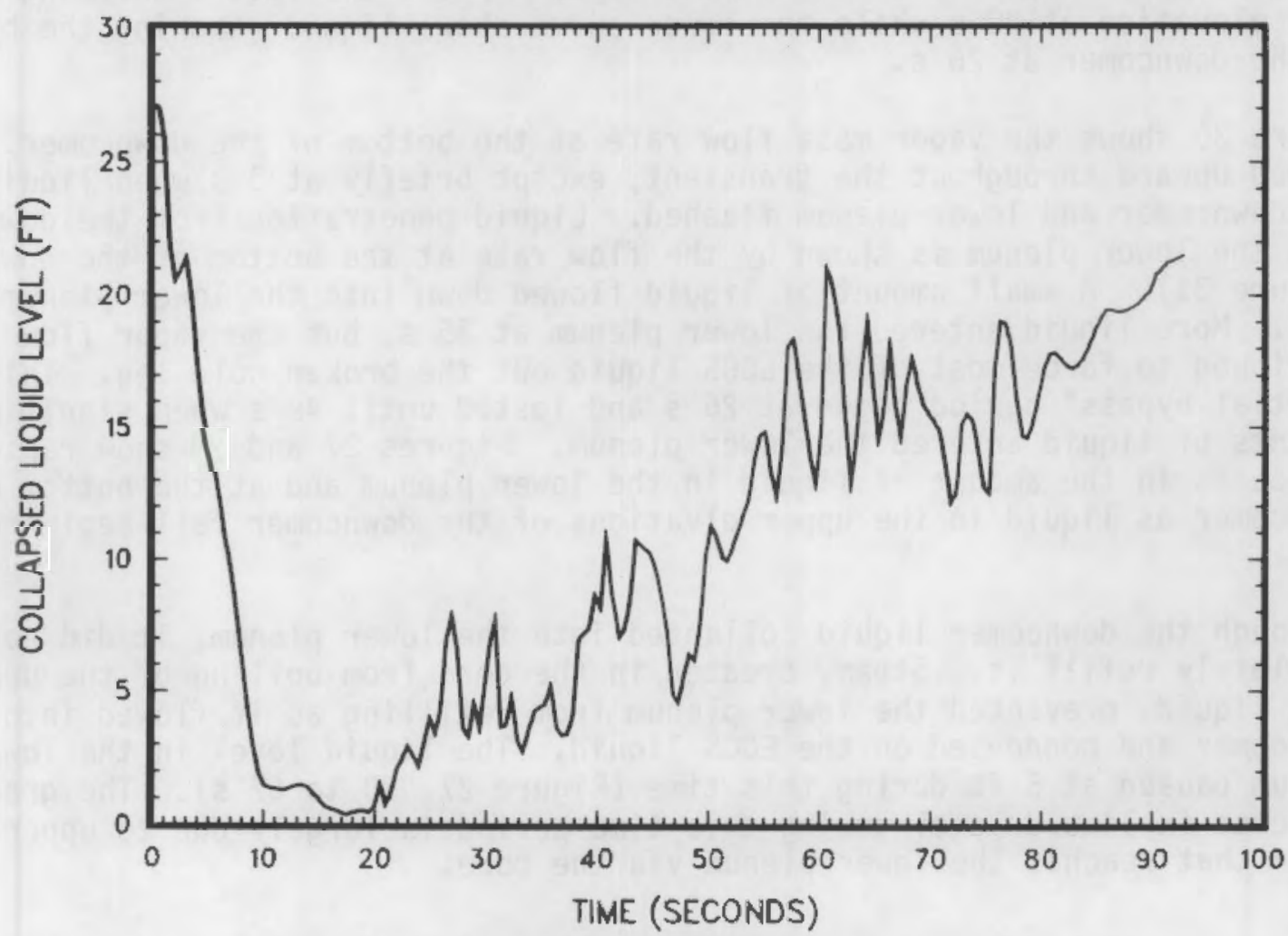

Figure 28. Downcomer liquid level vs, time 
the liquid was pushed up the downcomer and out the broken cold leg. Most of the liquid was actually at the top of the downcomer. The liquid level increased briefly at $2 \mathrm{~s}$, probably as a result of the effects of UHI injection forcing liquid through the cooling jets at the top of the downcomer. At $13 \mathrm{~s}$, water from the first UHI delivery reached a peak level in the core inlet after flowing through the core. Evidence of this liquid can be seen in the lower plenum (Figure 27) and the downcomer (Figure 28) as these levels briefly stop decreasing and even increase a little during this period.

The level in the downcomer reached a minimum at $17.5 \mathrm{~s}$. Then liquid began entering the downcomer from the upper head through the cooling jets (Figure 23). Water from the cold leg ECCS did not reach the downcomer until $20 \mathrm{5}$, even though the accumulator began injecting at $14.8 \mathrm{~s}$. Condensation in the cold legs caused vapor in the downcomer to flow into the cold legs preventing the ECCS liquid from entering the downcomer.

ECCS liquid accumulated in the upper region of the downcomer and f1owed out the broken cold leg. Vapor flowing up the downcomer from the core prevented the liquid from falling down the downcomer. This CCFL behavior caused a "total bypass" of the incoming ECCS fluid out the broken cold leg and lasted from 20 to $26 \mathrm{~s}$. Some liquid finally reached the bottom of the downcomer at $26 \mathrm{~s}$. Level averaged void fractions at the bottom of the downcomer and at the cold leg elevation in the downcomer are plotted in Figure 29. These curves are an average of the void fractions in all the channels around the circumference of the downcomer at each elevation. The upper curve shows liquid entering the loop elevation at $20 \mathrm{~s}$ while the lower curve shows liquid reaching the bottom of the downcomer at $26 \mathrm{~s}$.

Figure 30 shows the vapor mass flow rate at the bottom of the downcomer. It flowed upward throughout the transient, except briefly at $3 \mathrm{~s}$ when liquid in the downcomer and lower plenum flashed. Liquid penetration from the downcomer into the lower plenum is shown by the flow rate at the bottom of the downcomer (Figure 31). A small amount of liquid flowed down into the lower plenum at $26 \mathrm{~s}$. More liquid entered the lower plenum at $35 \mathrm{~s}$, but the vapor flow continued to force most of the ECCS liquid out the broken cold leg. This "partial bypass" period began at 26 s and lasted until 48 s when significant amounts of liquid entered the lower plenum. Figures 27 and 29 show rapid increases in the amount of liquid in the lower plenum and at the bottom of the downcomer as liquid in the upper elvations of the downcomer fell beginning at $48 \mathrm{~s}$.

Al though the downcomer liquid collapsed into the lower plenum, it did not completely refill it. Steam, created in the core from boiling of the upper head liquid, prevented the lower plenum from refilling as it flowed into the downcomer and condensed on the ECCS liquid. The liquid level in the lower plenum paused at $5 \mathrm{ft}$ during this time (Figure 27,50 to $67 \mathrm{~s}$ ). The gradual increase in liquid level during this time period is largely due to upper head water that reaches the lower plenum via the core. 


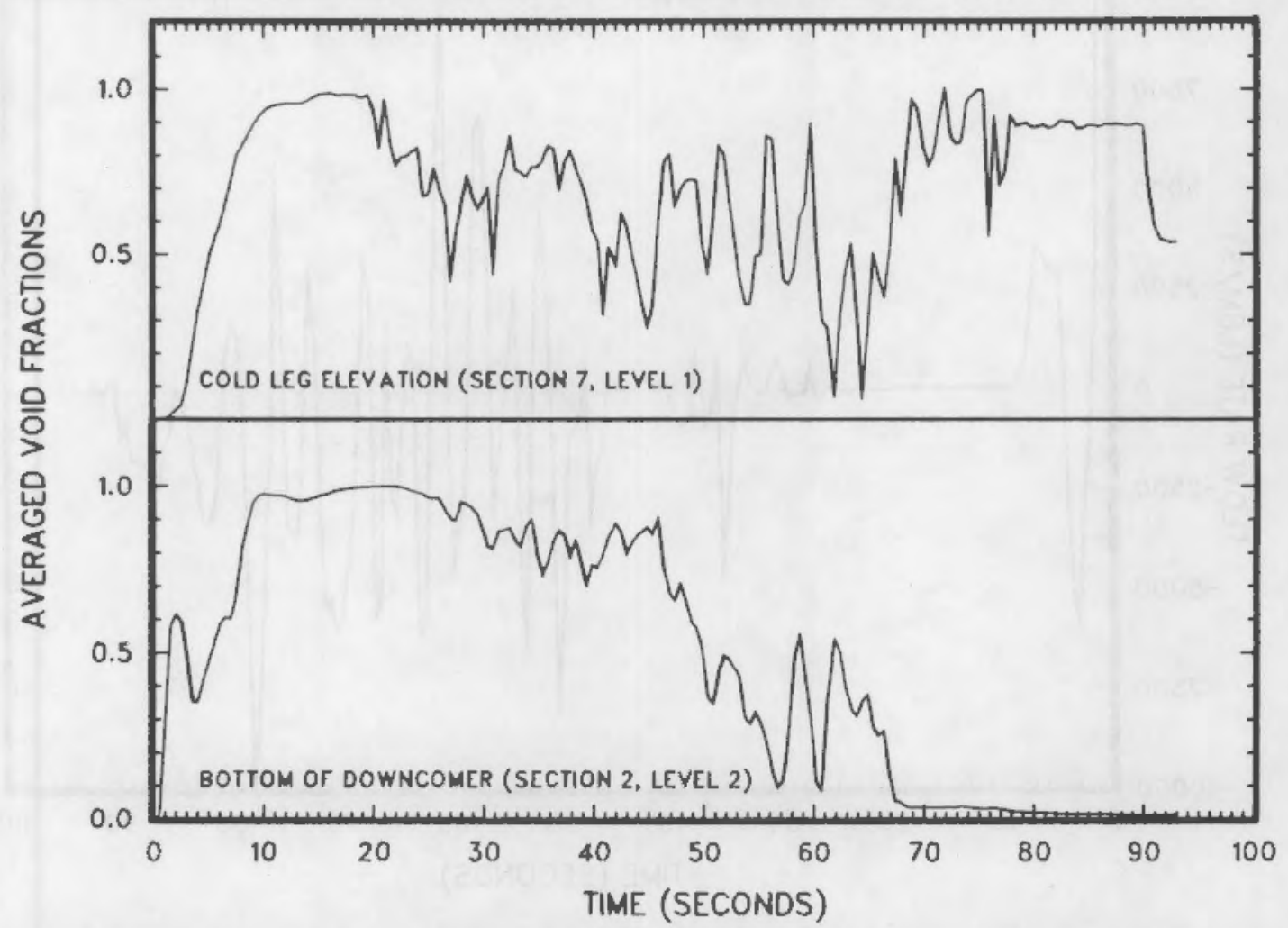

Figure 29. Downcomer level averaged void fractions vs. time

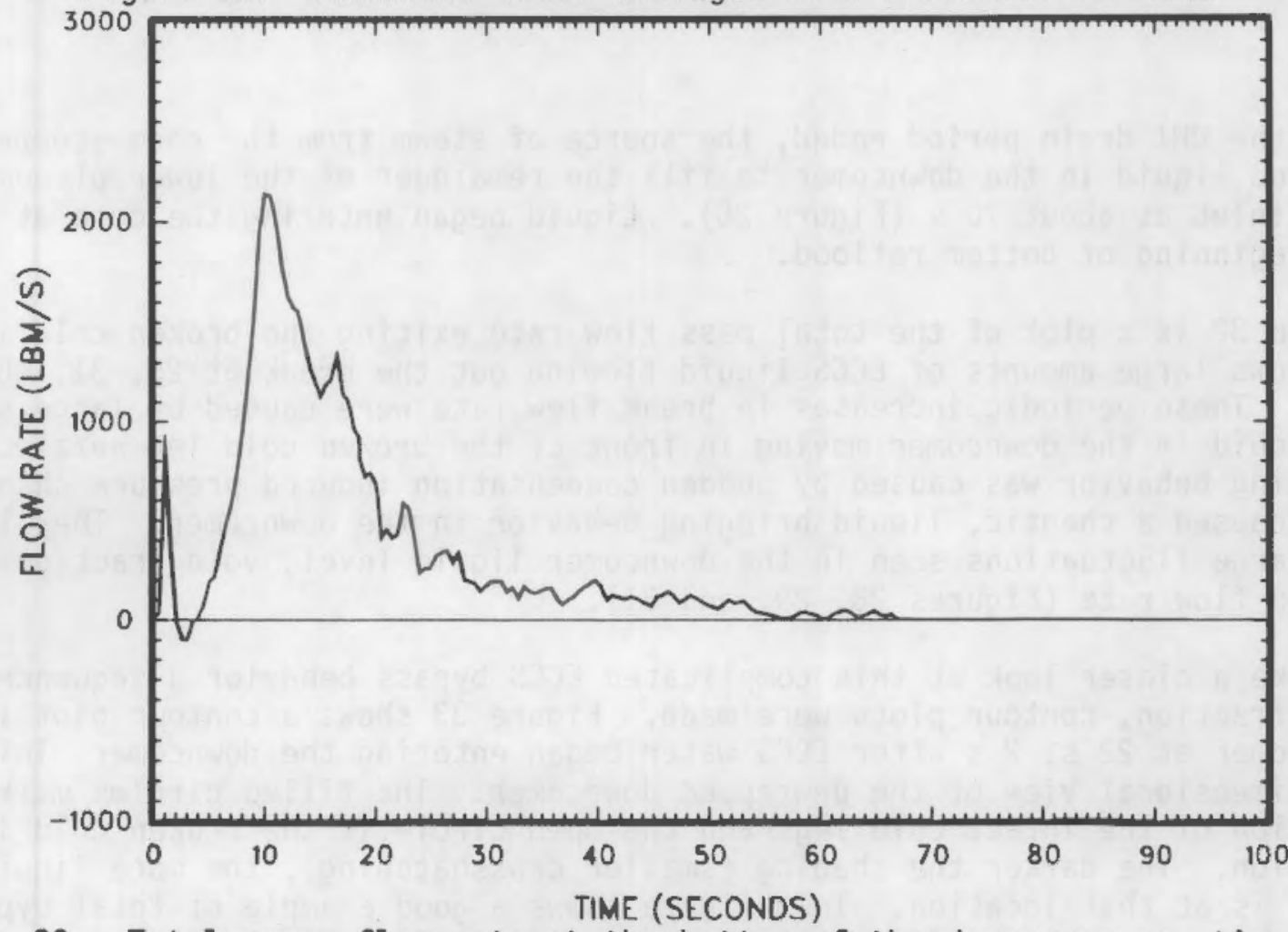

Figure 30. Total vapor flow rate at the bottom of the downcomer vs. time (positive vs. upward) 


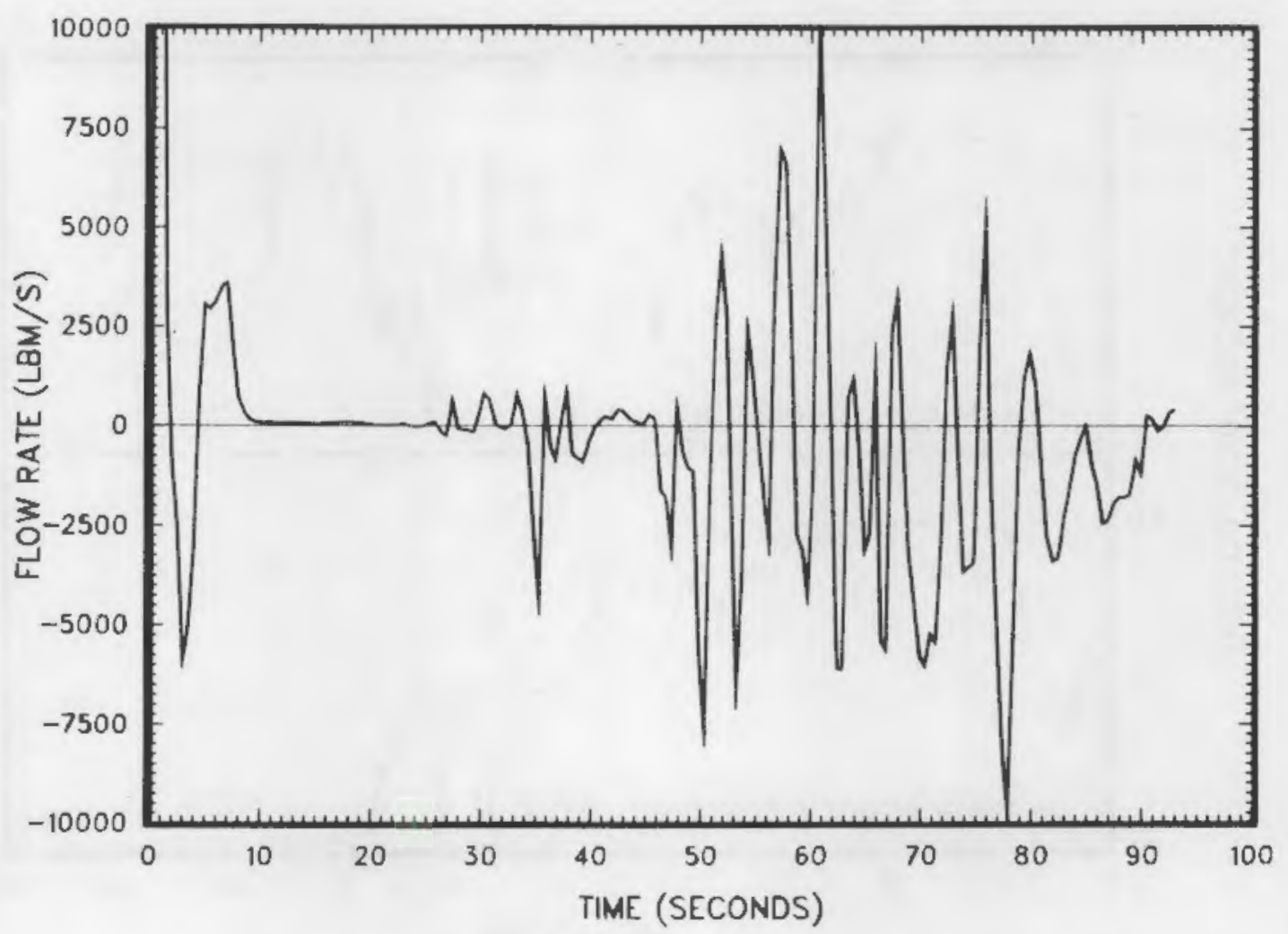

Figure 31. Total liquid flow rate at the bottom of the downcomer vs. time

Once the UHI drain period ended, the source of steam from the core stopped and allowed liquid in the downcomer to fill the remainder of the lower plenum and core inlet at about $70 \mathrm{~s}$ (Figure 26). Liquid began entering the core at $73 \mathrm{~s}--$ the beginning of bottom reflood.

Figure 32 is a plot of the total mass flow rate exiting the broken cold leg. It shows large amounts of ECCS liquid flowing out the break at $28,31,40$, and $45 \mathrm{~s}$. These periodic increases in break flow rate were caused by large slugs of liquid in the downcomer moving in front of the broken cold leg nozzle. This slugging behavior was caused by sudden condensation induced pressure changes that caused a chaotic, liquid bridging behavior in the downcomer. They led to the large fluctuations seen in the downcomer liquid level, void fractions and liquid flow rate (Figures 28, 29, and 31 ).

To take a closer look at this complicated ECCS bypass behavior a sequence of void fraction, contour plots were made. Figure 33 shows a contour plot in the downcomer at $22 \mathrm{~s}, 2 \mathrm{~s}$ after ECCS water began entering the downcomer. This is a two-dimensional view of the unwrapped downcomer. The filled circles mark the location of the intact cold legs and the open circle is the broken cold leg location. The darker the shading (smaller crosshatching), the more liquid there is at that location. This figure shows a good example of total bypass. Figure 34 shows the void fractions when the first ECCS liquid is being delivered to the lower plenum at $26 \mathrm{~s}$. 


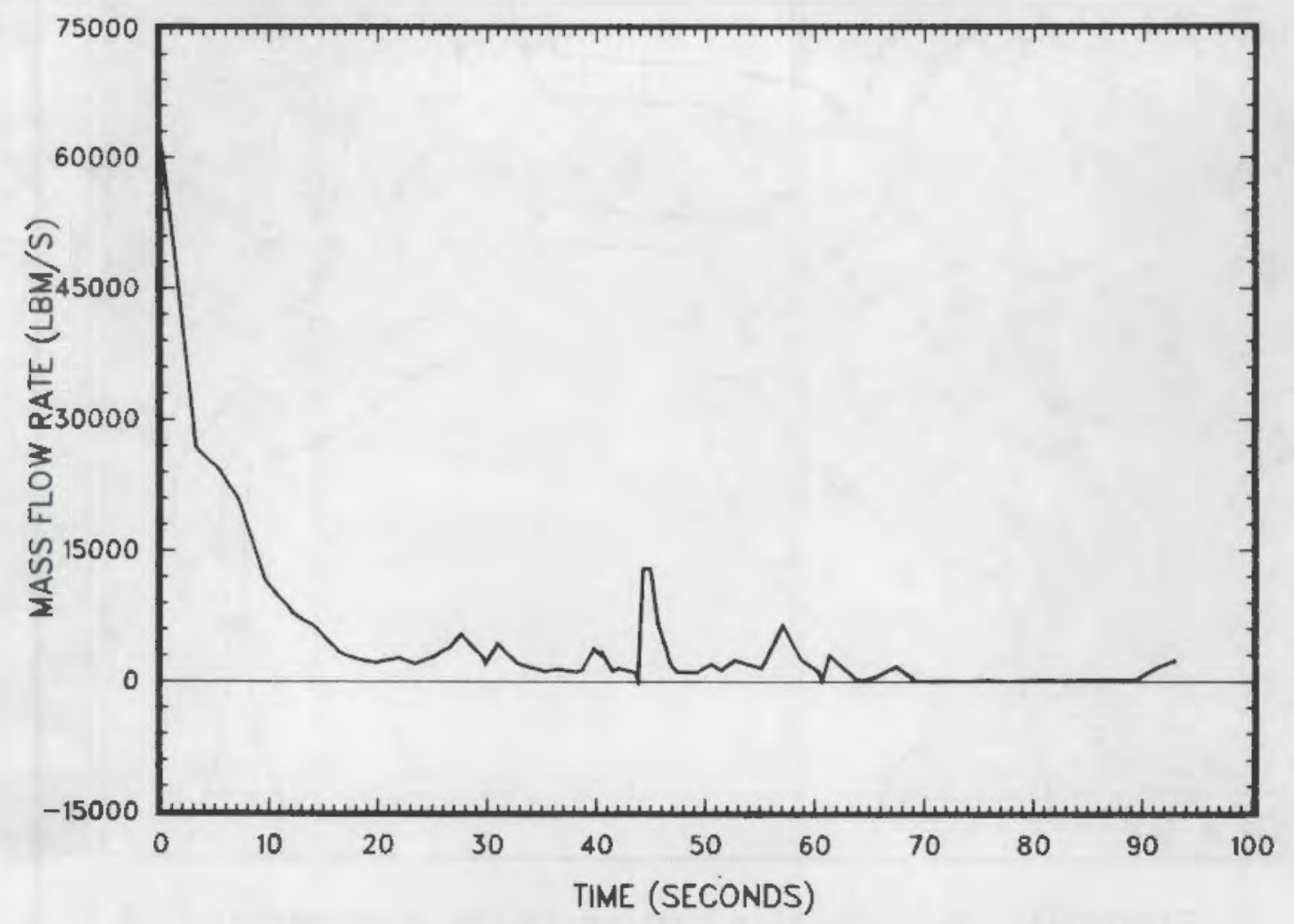

Figure 32. Broken cold leg mass flow rate vs. time

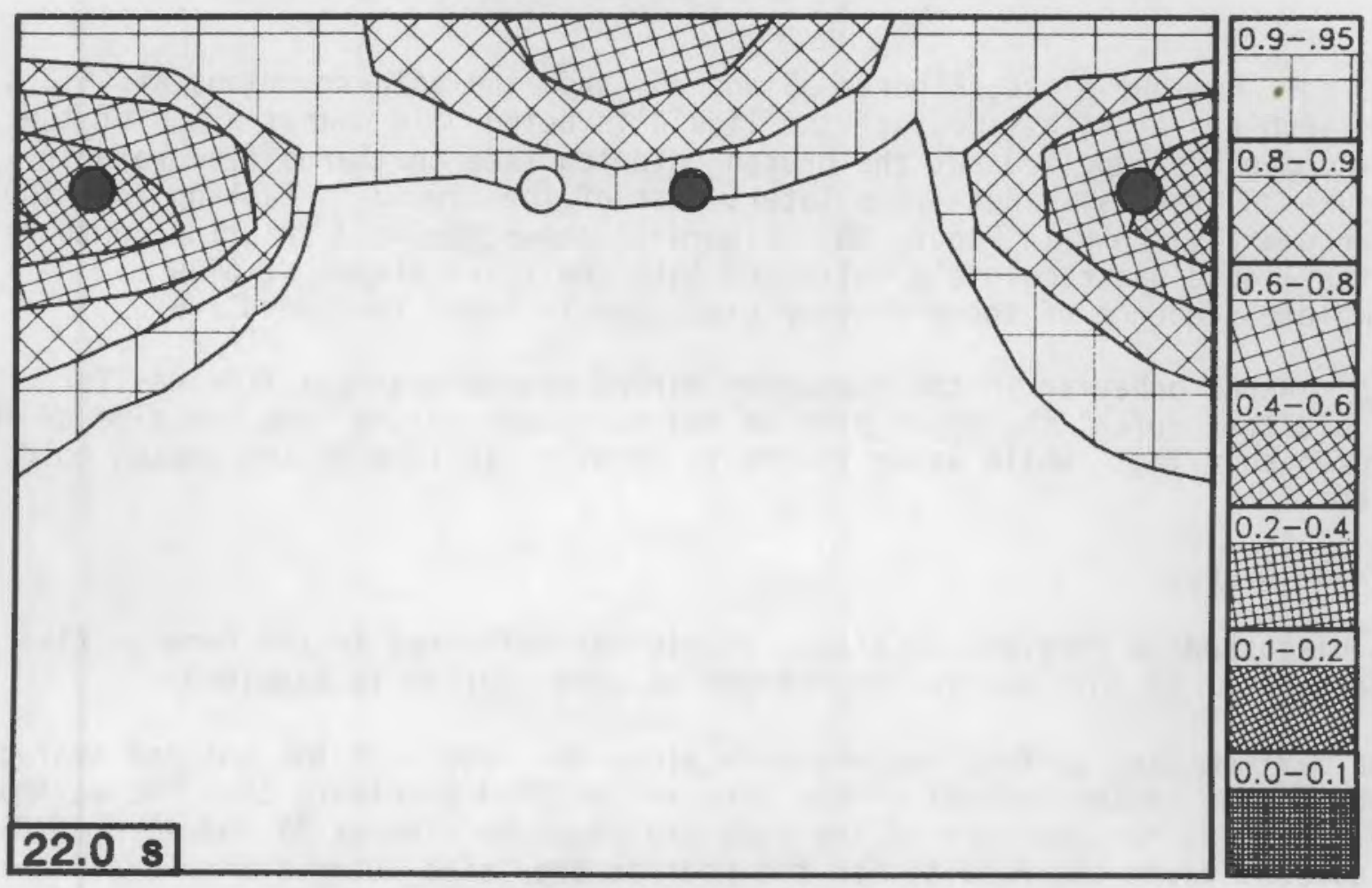

Figure 33. Void fraction contour in the downcomer at $22.0 \mathrm{~s}$ 


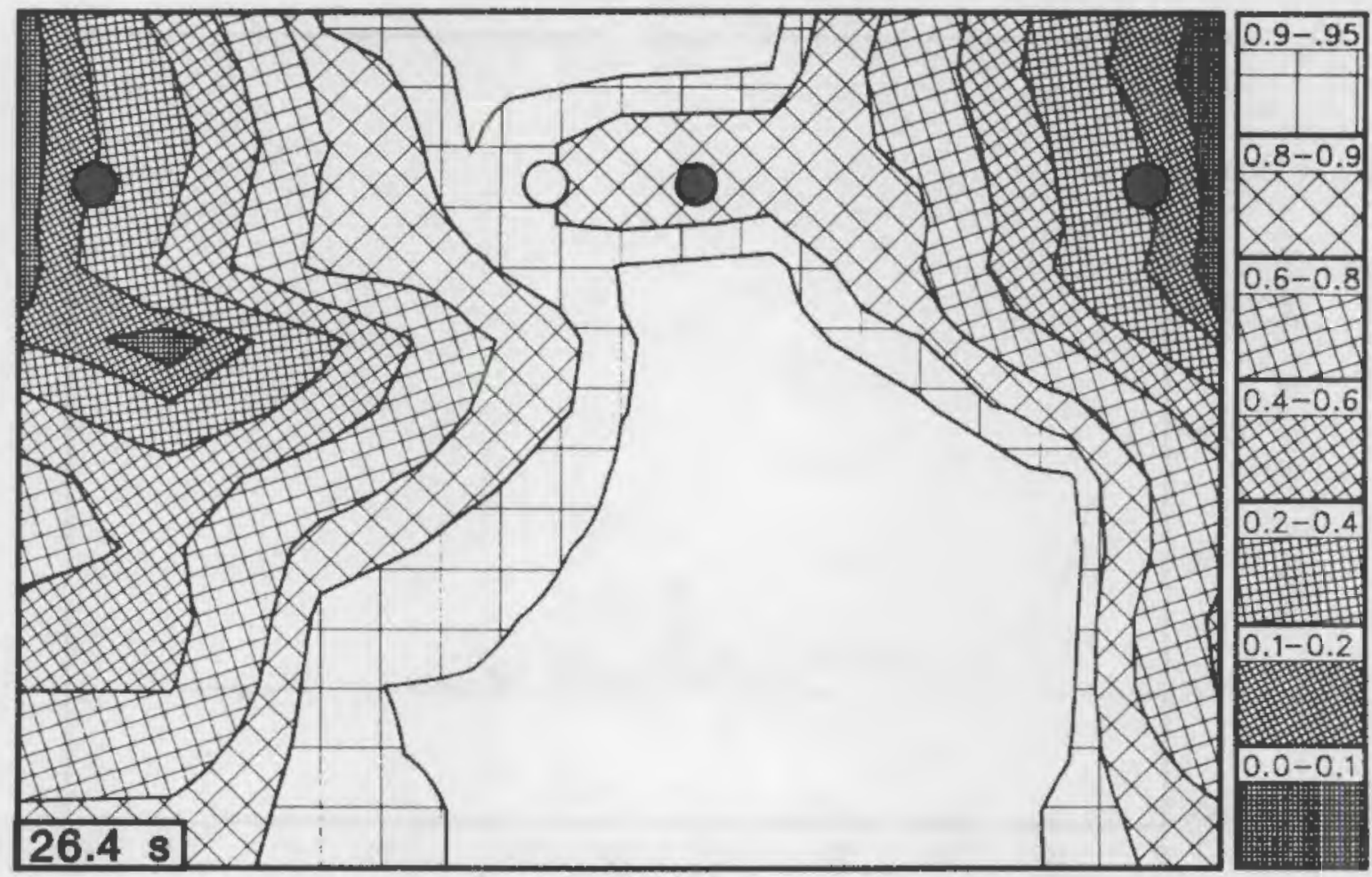

Figure 34. Void fraction contour in the downcomer at $26.4 \mathrm{~s}$

Two more contour plots, Figures 35 and 36 , show the void fractions at $45.3 \mathrm{~s}$ and $48.8 \mathrm{~s}$. At $45.3 \mathrm{~s}$ most of the liquid is being held near the top of the downcomer and expelled out the broken cold leg (see the large flow rate in Figure 32 at $45 \mathrm{~s}$ ). But $4.5 \mathrm{~s}$ later, most of the liquid is falling into the downcomer as shown in Figure 36. Figure 37 shows the void fraction contours after liquid has completely collapsed into the lower plenum at $69.9 \mathrm{~s}$. A complete sequence of these contour plots are included in Appendix B.

The general behavior in the downcomer during counter-current flow was for liquid to "prefer" the upper part of the downcomer on the opposite side of the broken cold leg. While vapor tended to "prefer" to flow up the broken cold leg side.

\section{2 .3 Core}

As discussed in previous sections, liquid was delivered to the core on five occasions. In this section the effect on core cooling is examined.

The maximum clad surface temperatures along the length of the hot and average rods in the center channel of the core are plotted in Figure 38. The maximum temperatures for the rest of the rods are shown in Figures 39 and 40 . Figure 39 gives the results for the rods in the "side" core channels and Figure 40 shows rod temperatures in the "corner" channels of the core. The clad surface temperature at fixed elevations along the hot rod are plotted in 


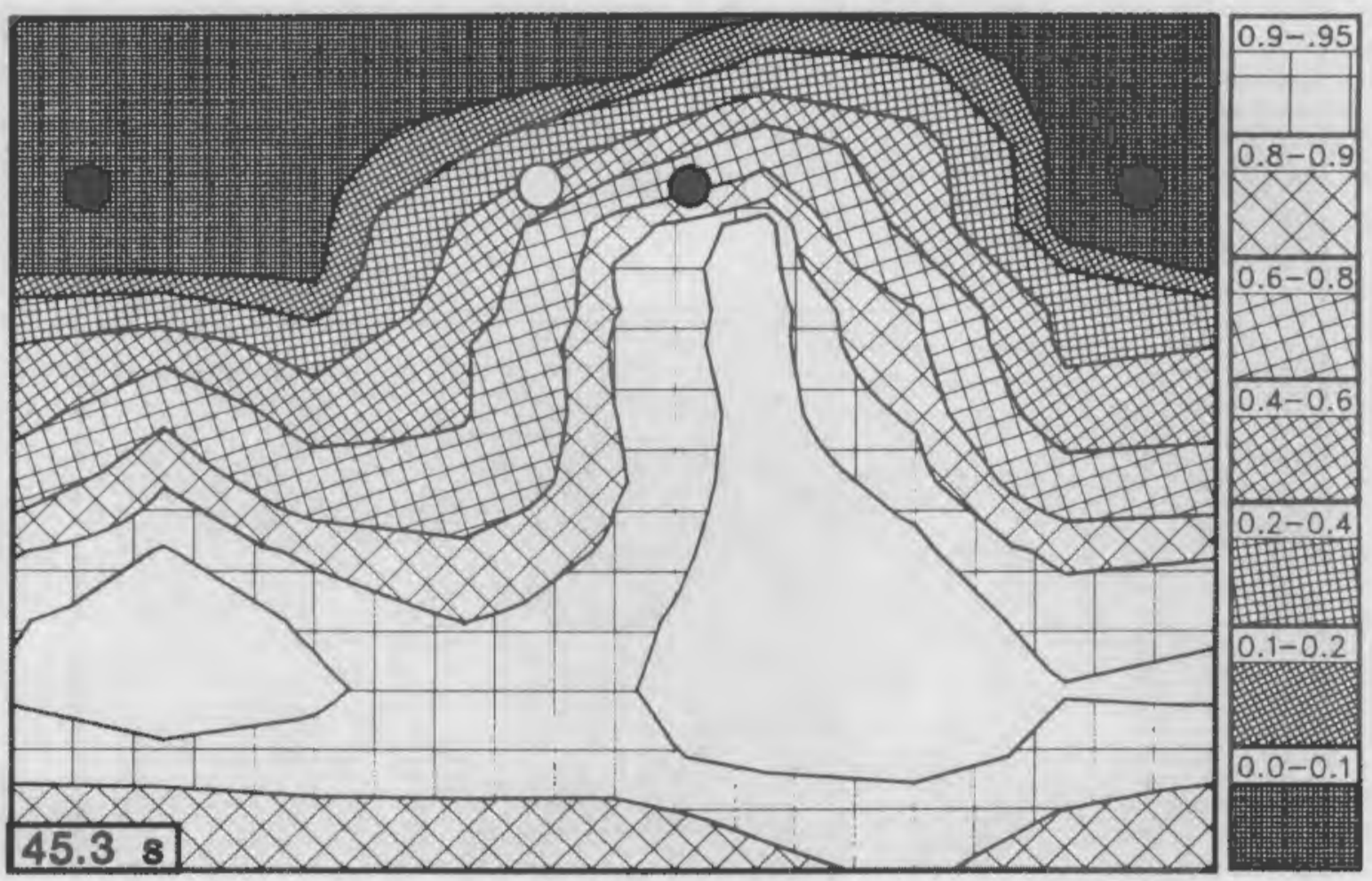

Figure 35. Void fraction contour in the downcomer at $45.3 \mathrm{~s}$

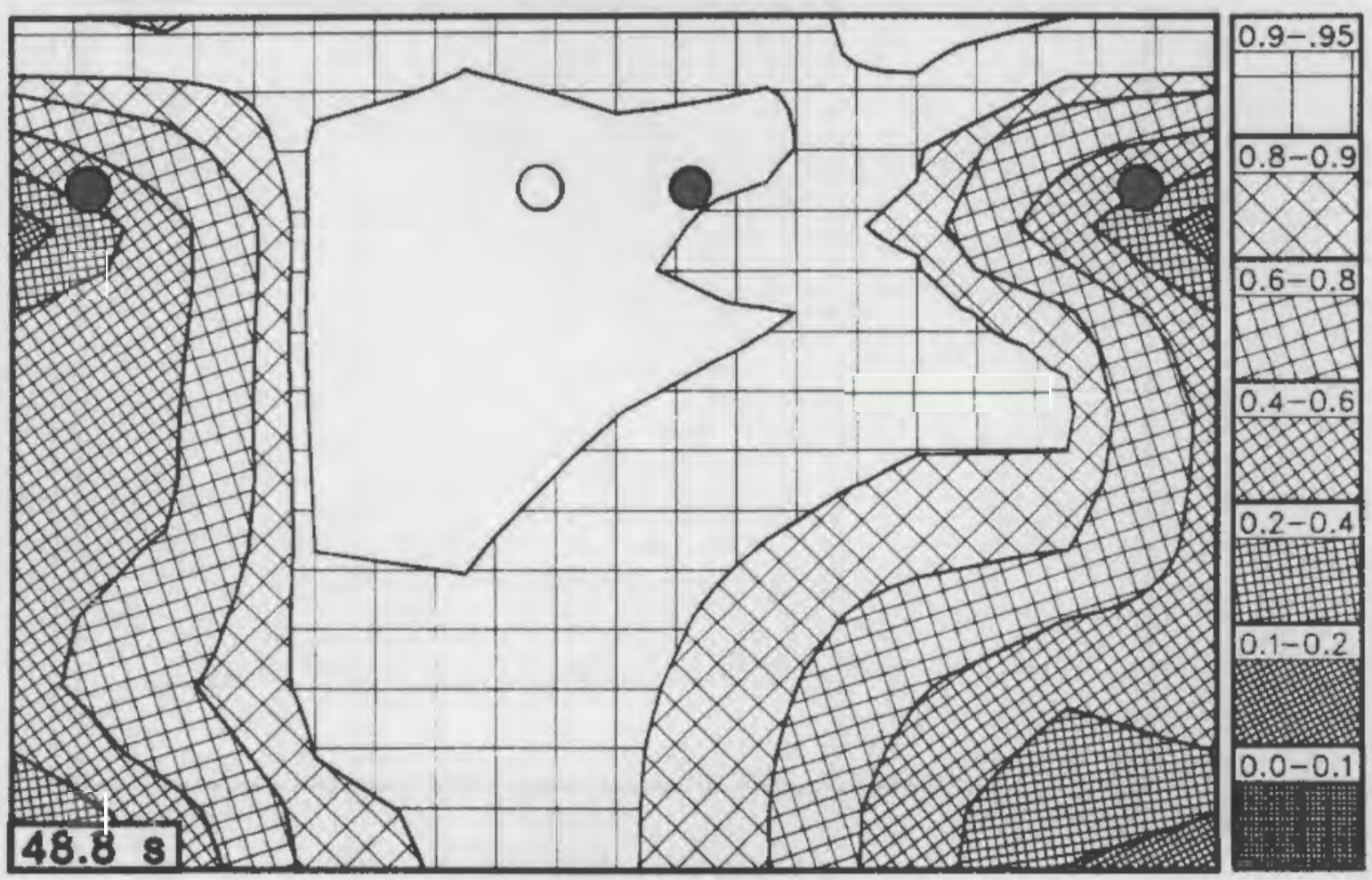

Figure 36. Void fraction contour in the downcomer at $48.8 \mathrm{~s}$ 


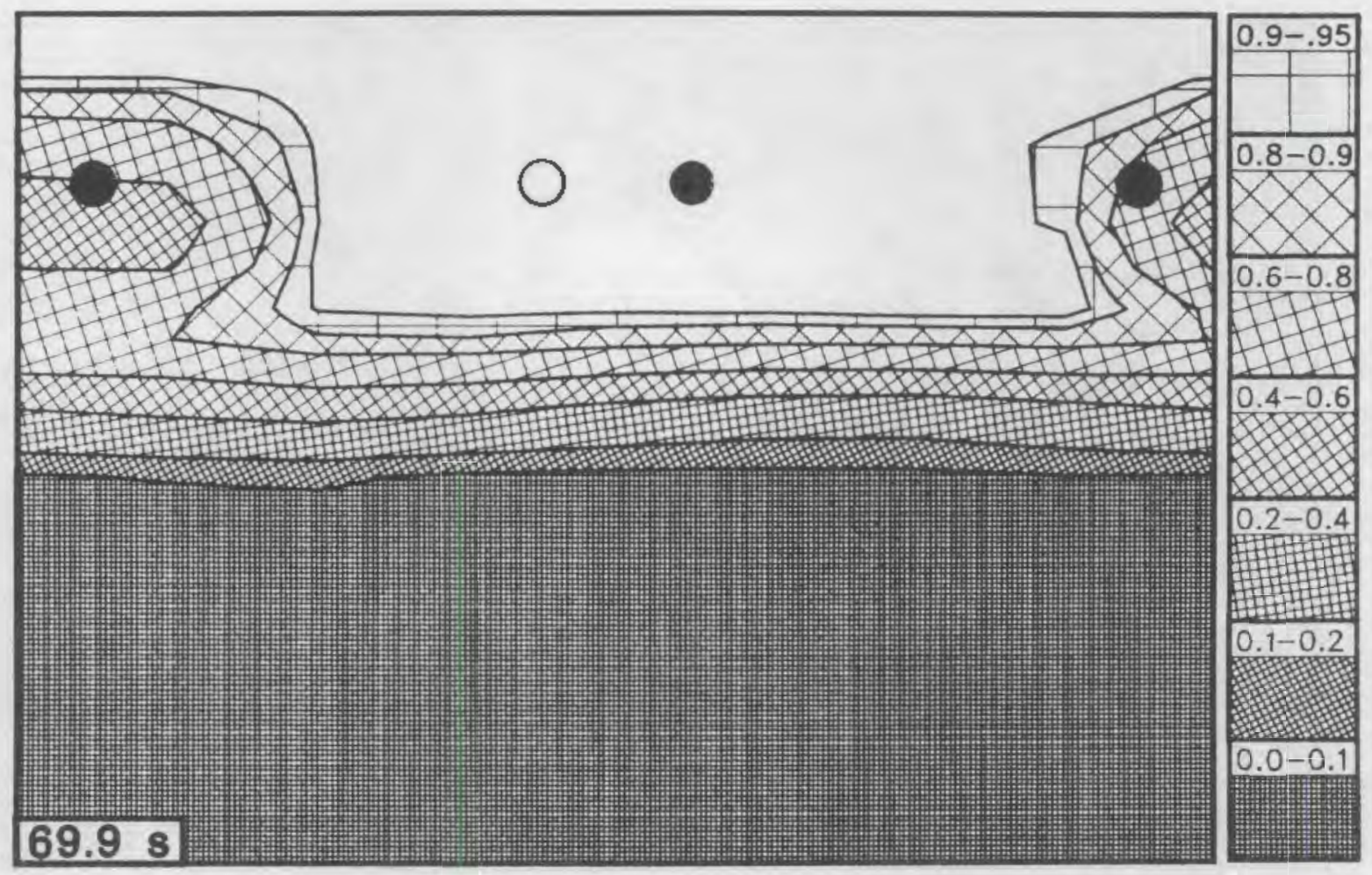

Figure 37. Void fraction contour in the downcomer at $69.9 \mathrm{~s}$

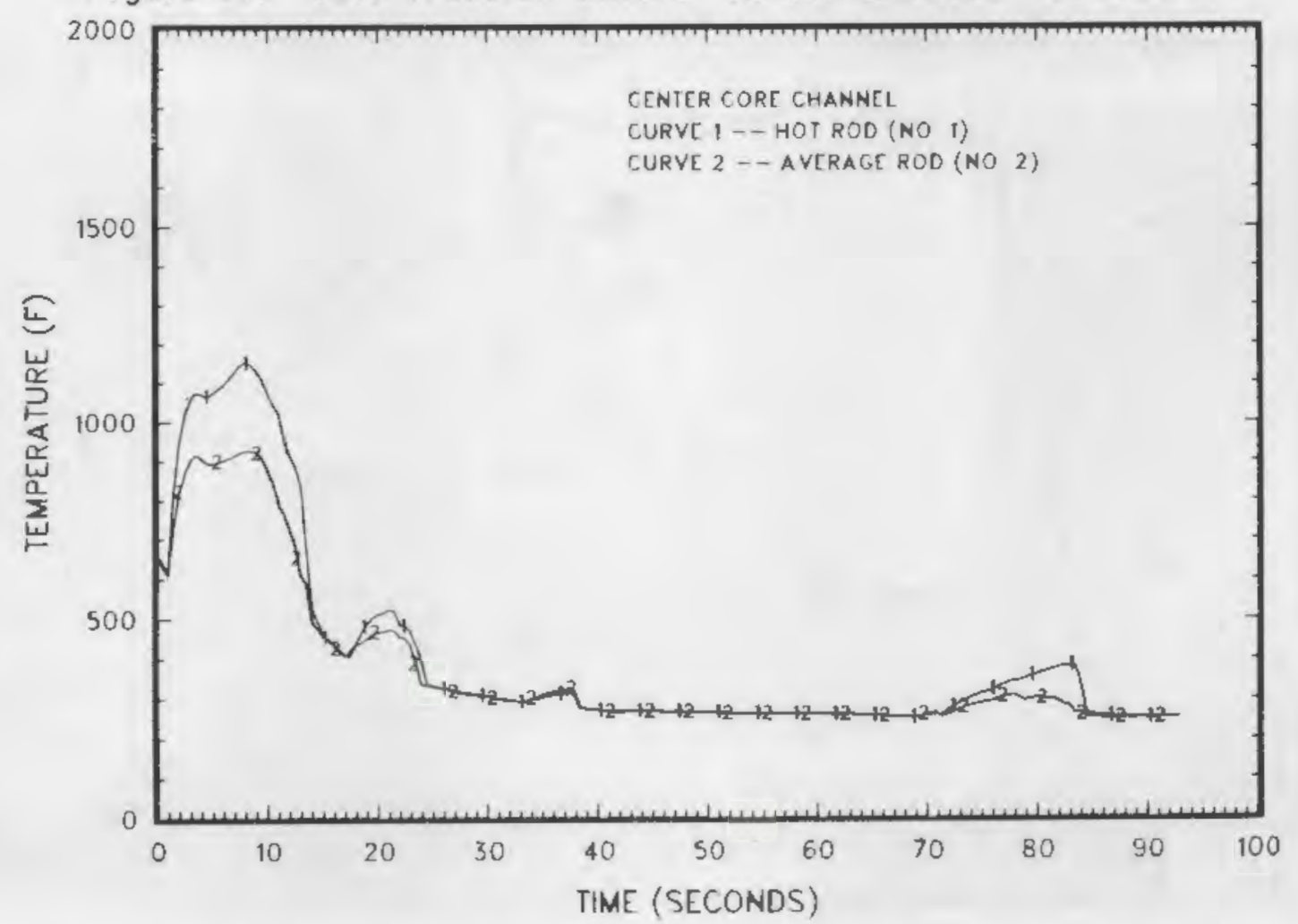

Figure 38. Peak clad surface temperatures of the hot and average rods vs. time 


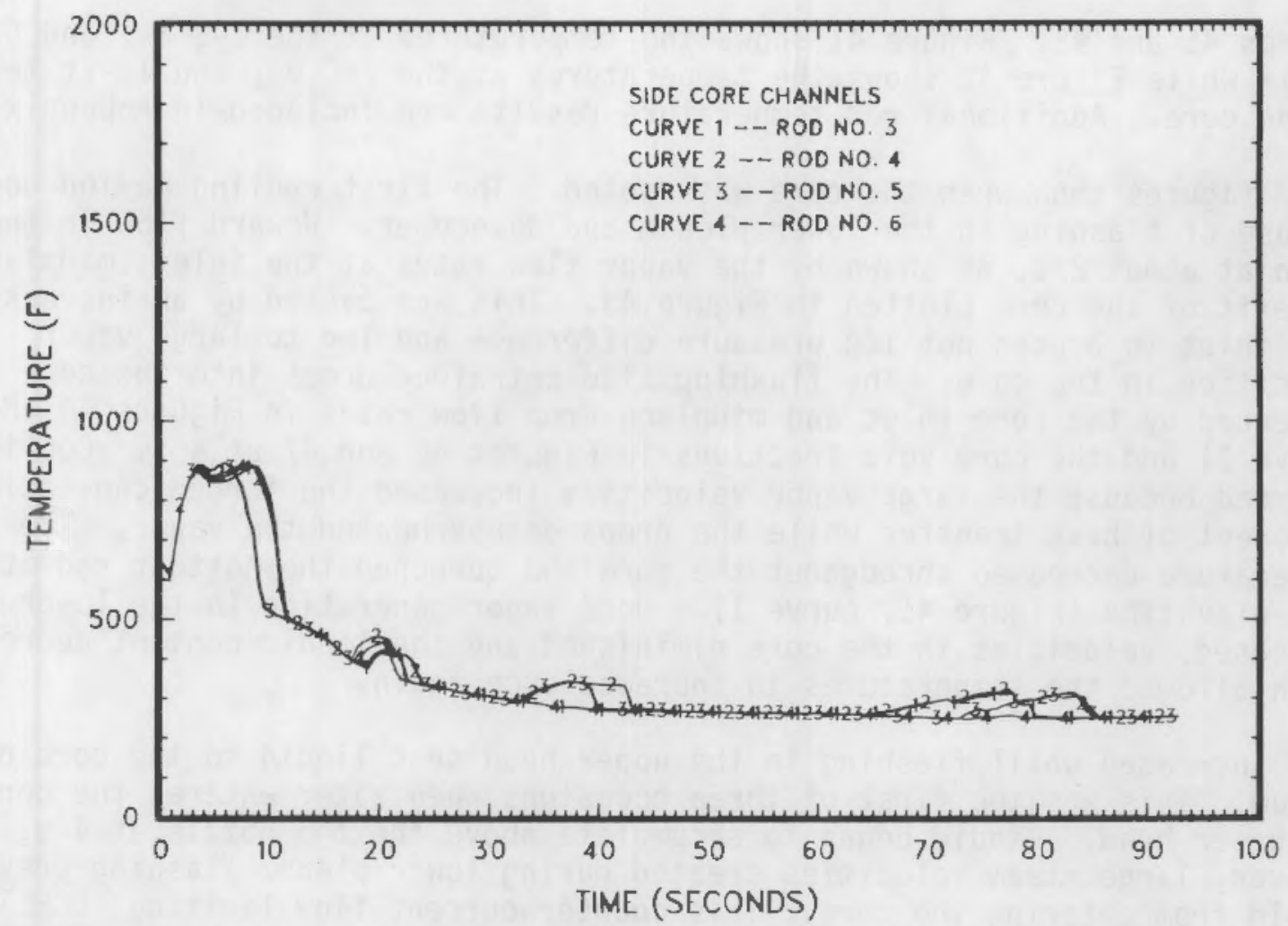

Figure 39. Peak clad surface temperatures of rods in the side core channels

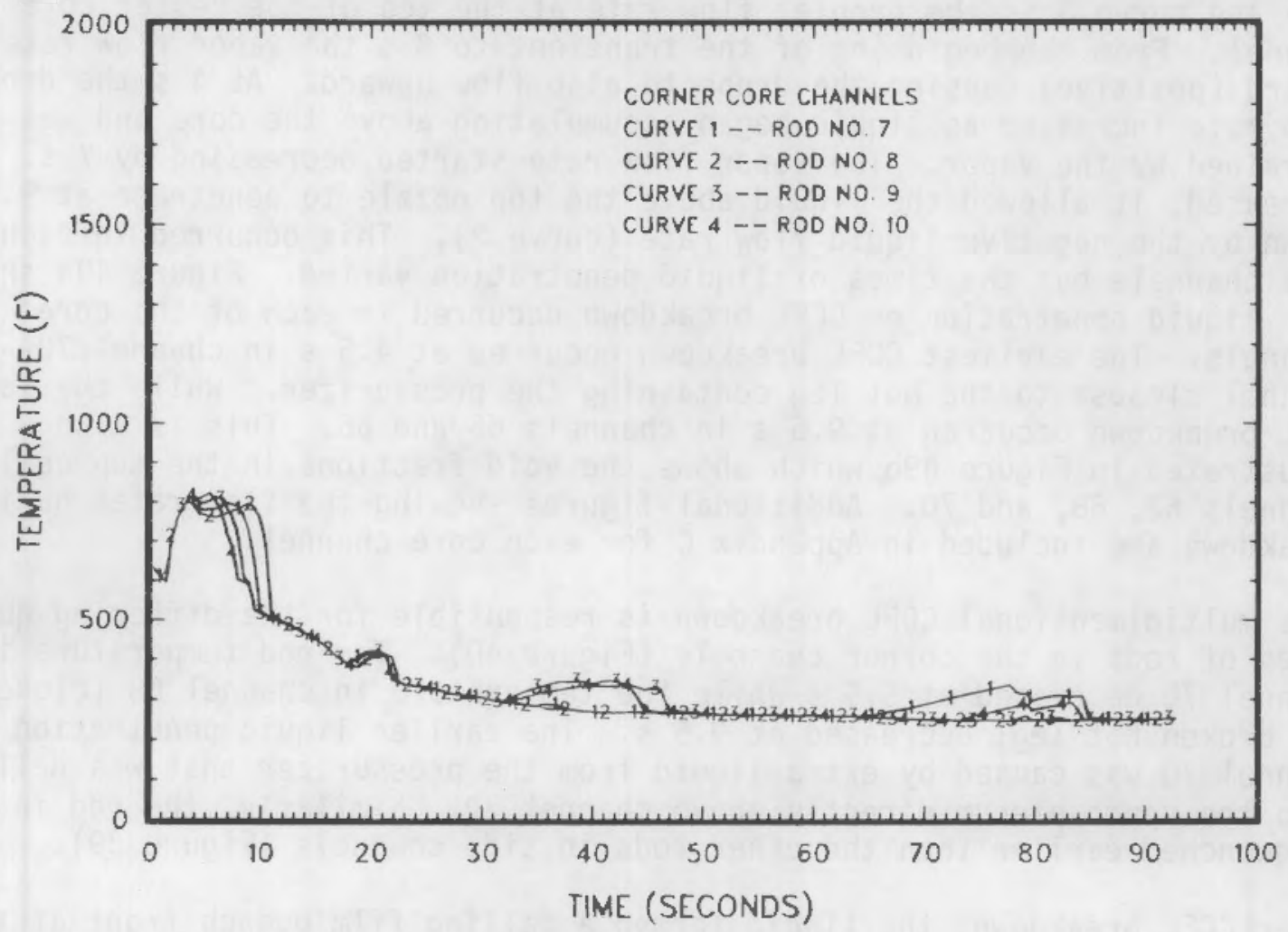

Figure 40. Peak clad surface temperatures of rods in the corner core channels 
Figures 41 and 42. Figure 41 shows the temperatures at the 1-, 3-, and 5-ft levels while Figure 42 shows the temperatures at the $7-, 9-$, and $11-\mathrm{ft}$ levels in the core. Additional rod temperature results are included in Appendix $C$.

These figures show when the core was cooled. The first cooling period occurred because of flashing in the lower plenum and downcomer. Upward flow in the core began at about $2 \mathrm{~s}$, as shown by the vapor flow rates at the inlet, midplane, and exit of the core plotted in Figure 43. This was caused by an increased core inlet to broken hot leg pressure difference and led to large vapor velocities in the core. The flashing also entrained drops into the core as evidenced by the core inlet and midplane drop flow rates in Figures 44 and 45 (curve 2) and the core void fractions in Figures 46 and 47 at $4 \mathrm{~s}$. Cooling occurred because the large vapor velocities increased the forced convection component of heat transfer while the drops desuperheated the vapor. The temperature decreased throughout the core and quenched the hottest rod at the 1-ft elevation (Figure 41, curve 1). Once vapor generation in the lower plenum decreased, velocities in the core diminished and the liquid content decreased which allowed the temperatures to increase once again.

They increased until flashing in the upper head sent liquid to the core outlet plenum. This was the first of three occasions when water entered the core from the upper head. Liquid began to accumulate above the top nozzle at $4 \mathrm{~s}$; however, large steam velocities created during lower plenum flashing prevented liquid from entering the core. This counter-current flow limiting (CCFL) is shown in Figure 48. Curve 1 is the vapor flow rate, curve 2 is the liquid flow rate and curve 3 is the droplet flow rate at the top of the center core channel. From the beginning of the transient to $9 \mathrm{~s}$ the vapor flow rate is upward (positive) causing the drops to also flow upward. At $4 \mathrm{~s}$ the droplet flow rate increased as liquid began accumulating above the core and was entrained by the vapor. The vapor flow rate started decreasing by $7 \mathrm{~s}$. As it decreased, it allowed the liquid above the top nozzle to penetrate at $9.5 \mathrm{~s}$ as shown by the negative liquid flow rate (curve 2 ). This occurred in each of the nine channels but the times of liquid penetration varied. Figure 49a shows when liquid penetration or CCFL breakdown occurred in each of the core channels. The earliest CCFL breakdown occurred at $4.5 \mathrm{~s}$ in channel $70--$ the channel closest to the hot leg containing the pressurizer. While the latest CCFL breakdown occurred at $9.5 \mathrm{~s}$ in channels 65 and 66 . This is also illustrated in Figure 49b which shows the void fractions in the top cells of channels 62,68 , and 70 . Additional figures showing the flow rates during CCFL breakdown are included in Appendix $C$ for each core channel.

This multidimensional CCFL breakdown is responsible for the differing quench times of rods in the corner channels (Figure 40). The rod temperature in channel 70 decreased at $5.5 \mathrm{~s}$ while the temperature in channel 68 (closest to the broken hot leg) decreased at $9.5 \mathrm{~s}$. The earlier liquid penetration in channel 70 was caused by extra liquid from the pressurizer that was delivered into the upper plenum directly above channel 70. Similarly, the rod in channel 67 quenched earlier than the other rods in side channels (Figure 39).

After CCFL breakdown, the liquid formed a falling film quench front at the top of the core. Some of the liquid evaporated as it flowed through the core 


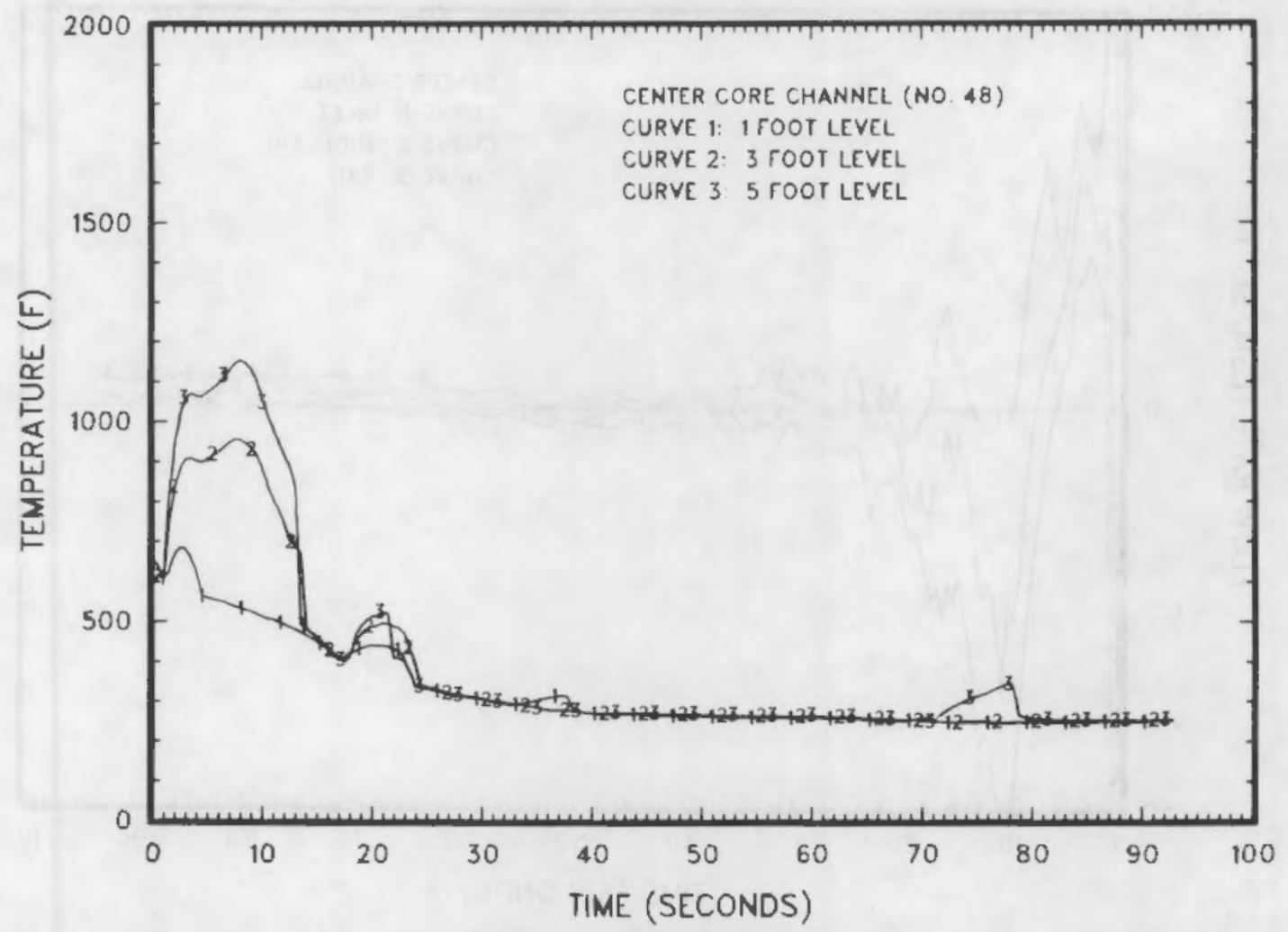

Figure 41. Hot rod clad surface temperatures at the 1,3 , and $5 \mathrm{ft}$ levels

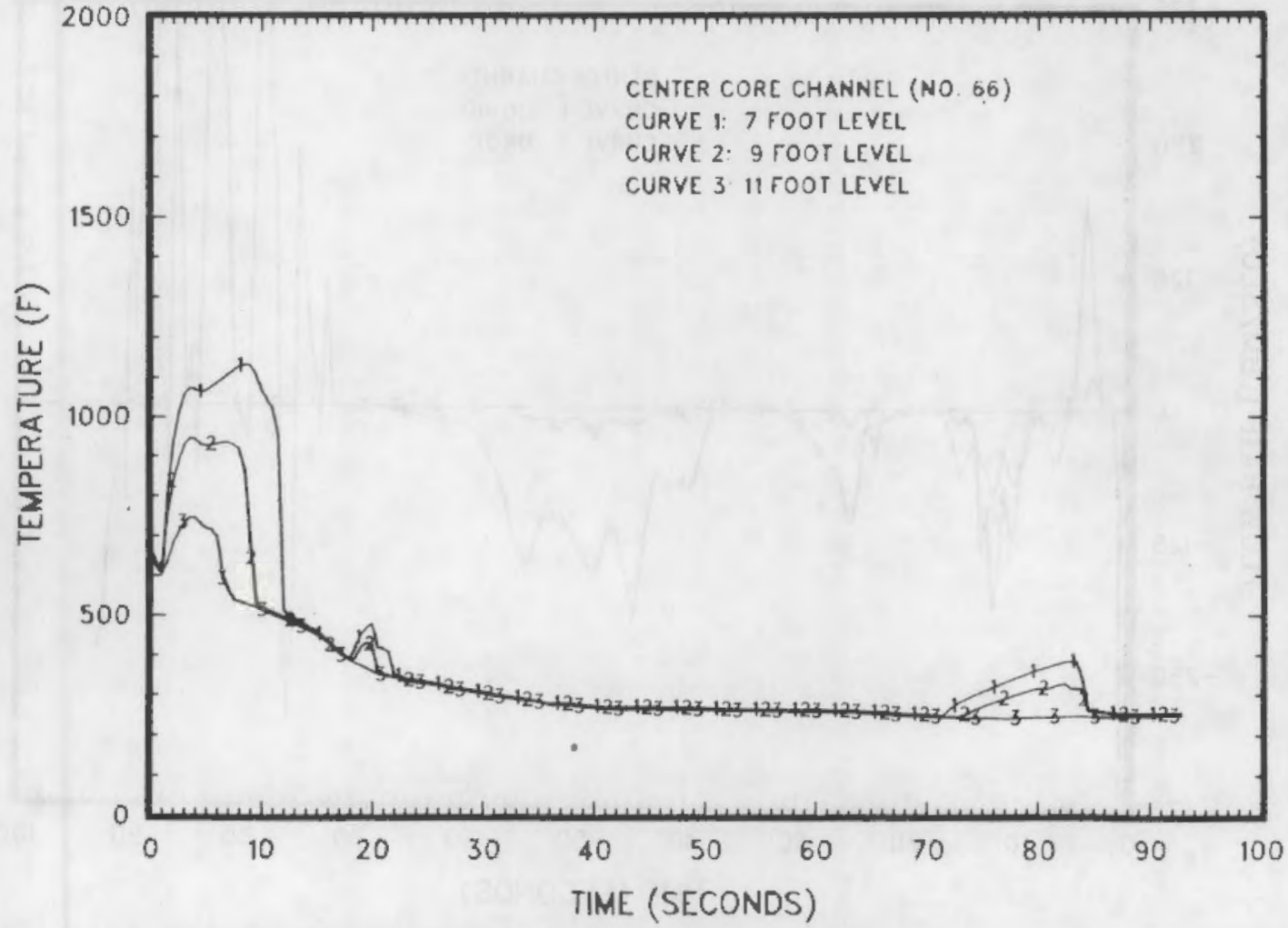

Figure 42. Hot rod clad surface temperatures at the 7,9 , and $11 \mathrm{ft}$ levels 


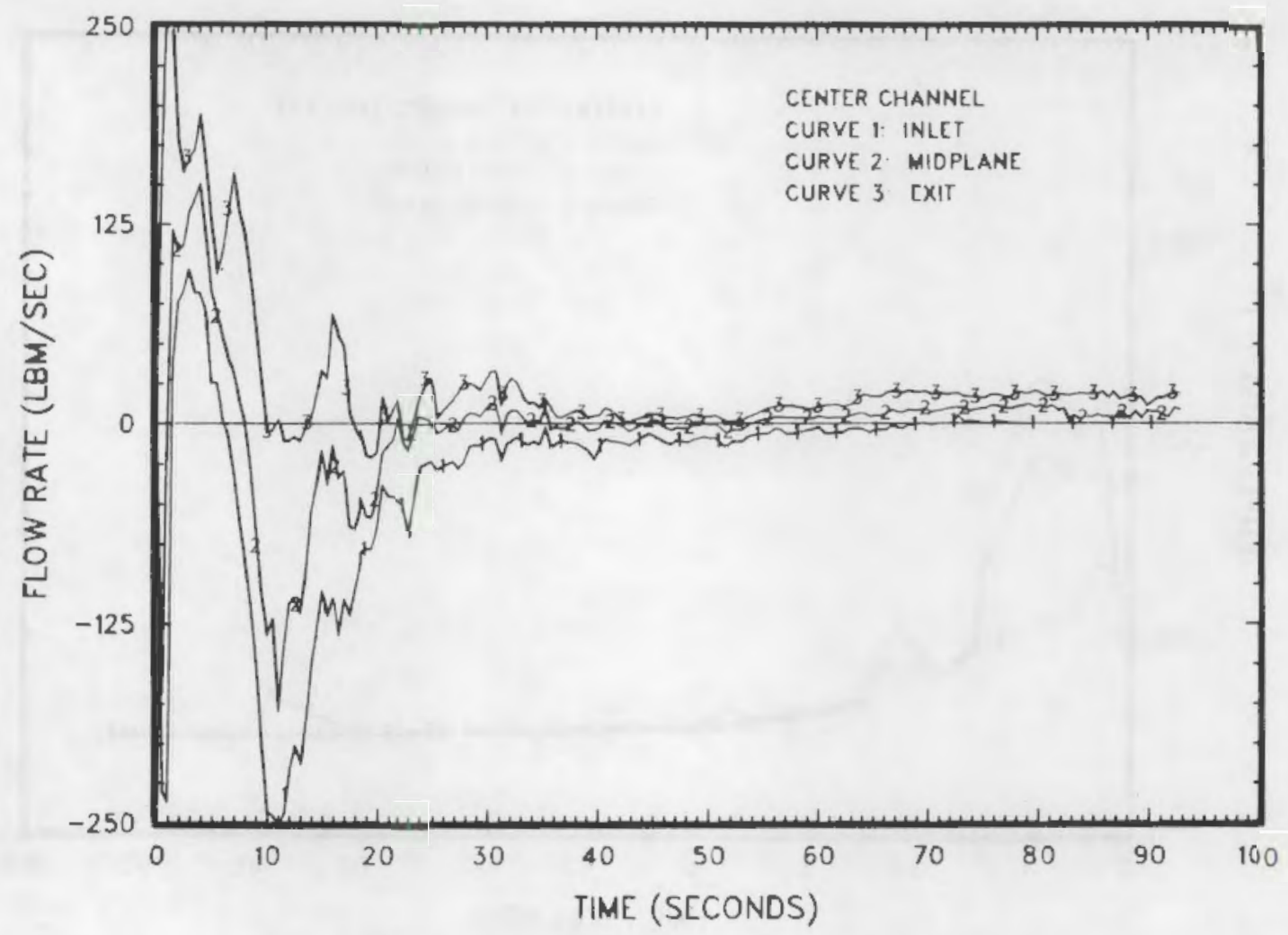

Figure 43. Core vapor flow rates vs. time

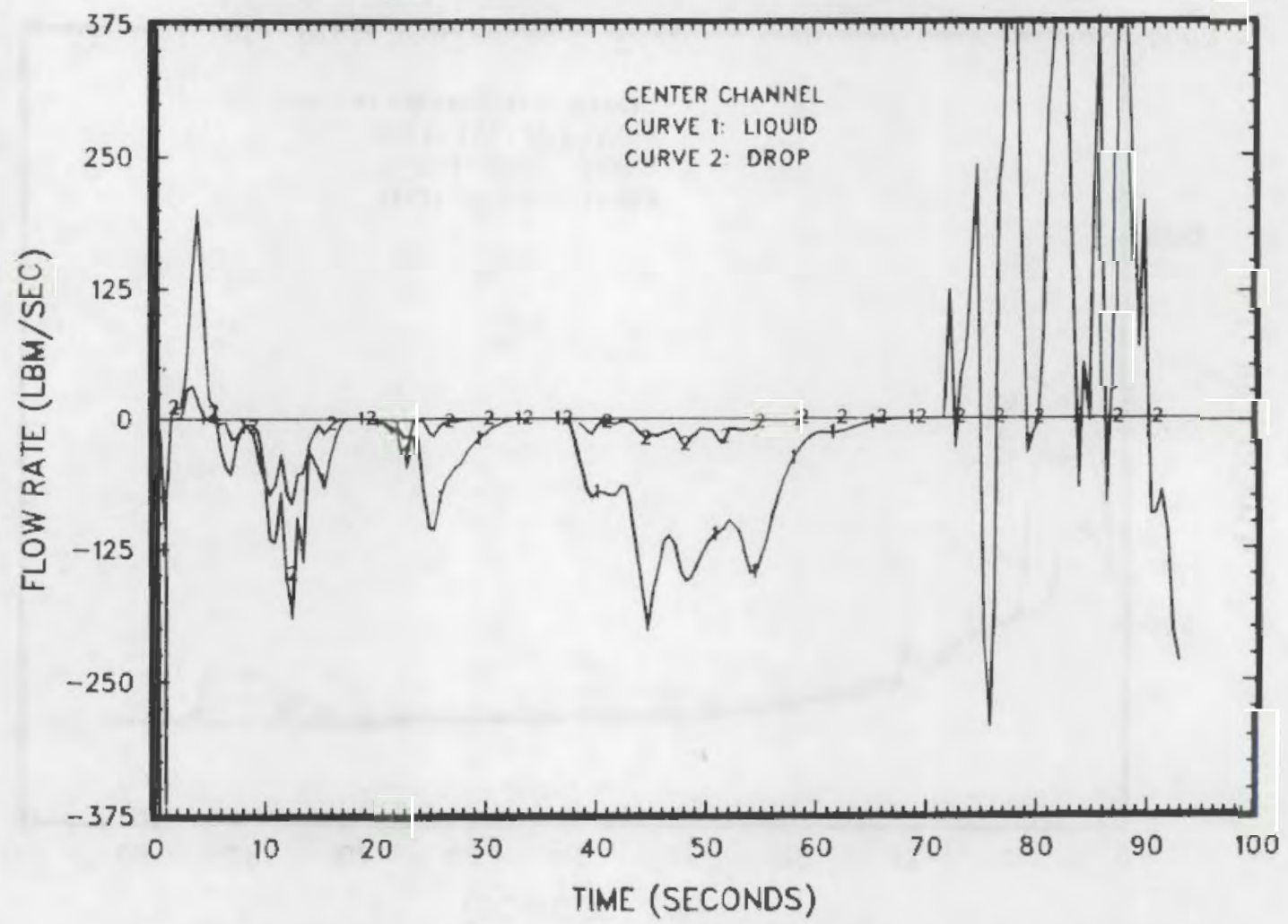

Figure 44. Core inlet liquid and drop flow rates vs. time 


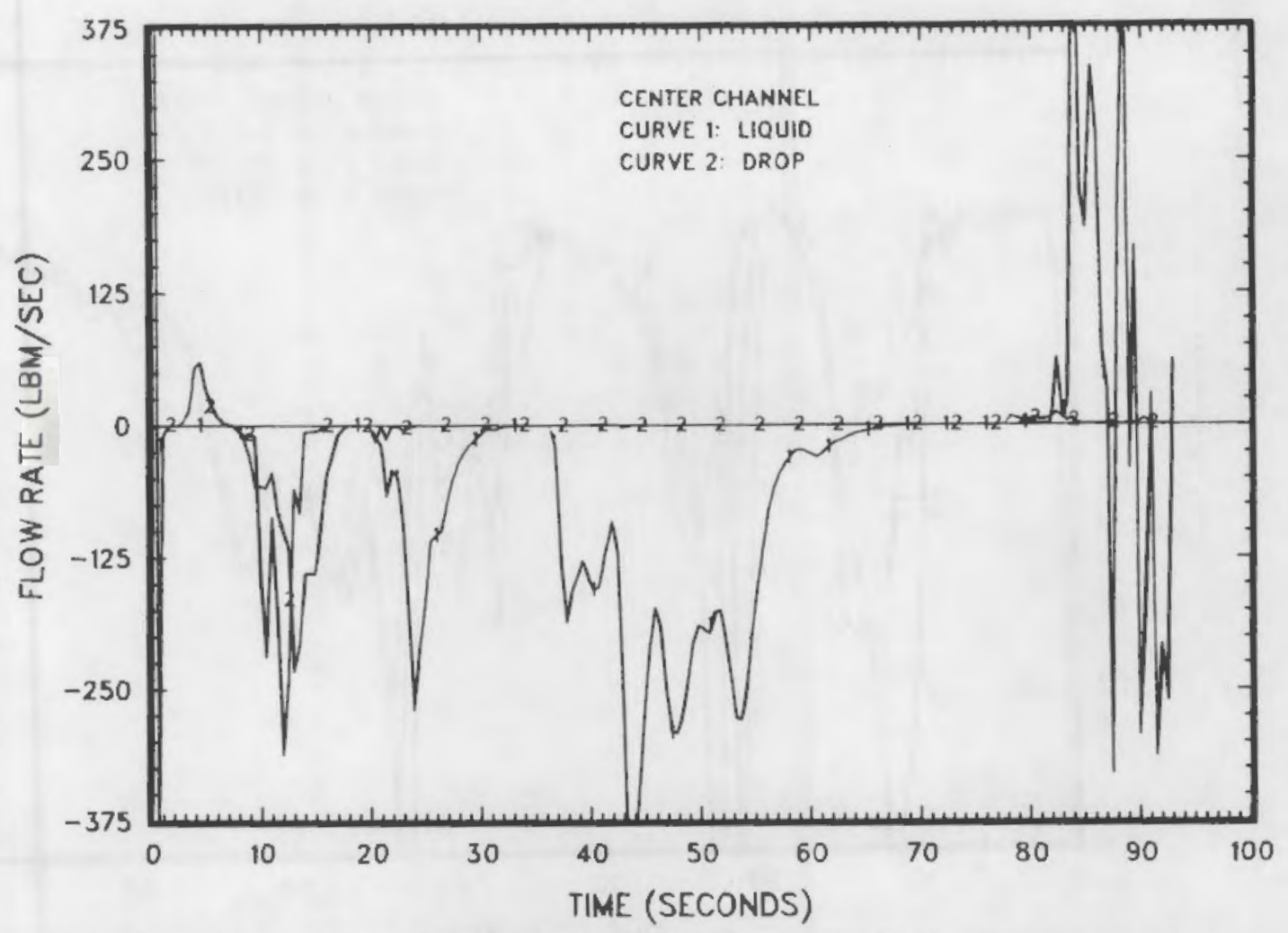

Figure 45. Core midplane liquid and drop flow rates vs. time

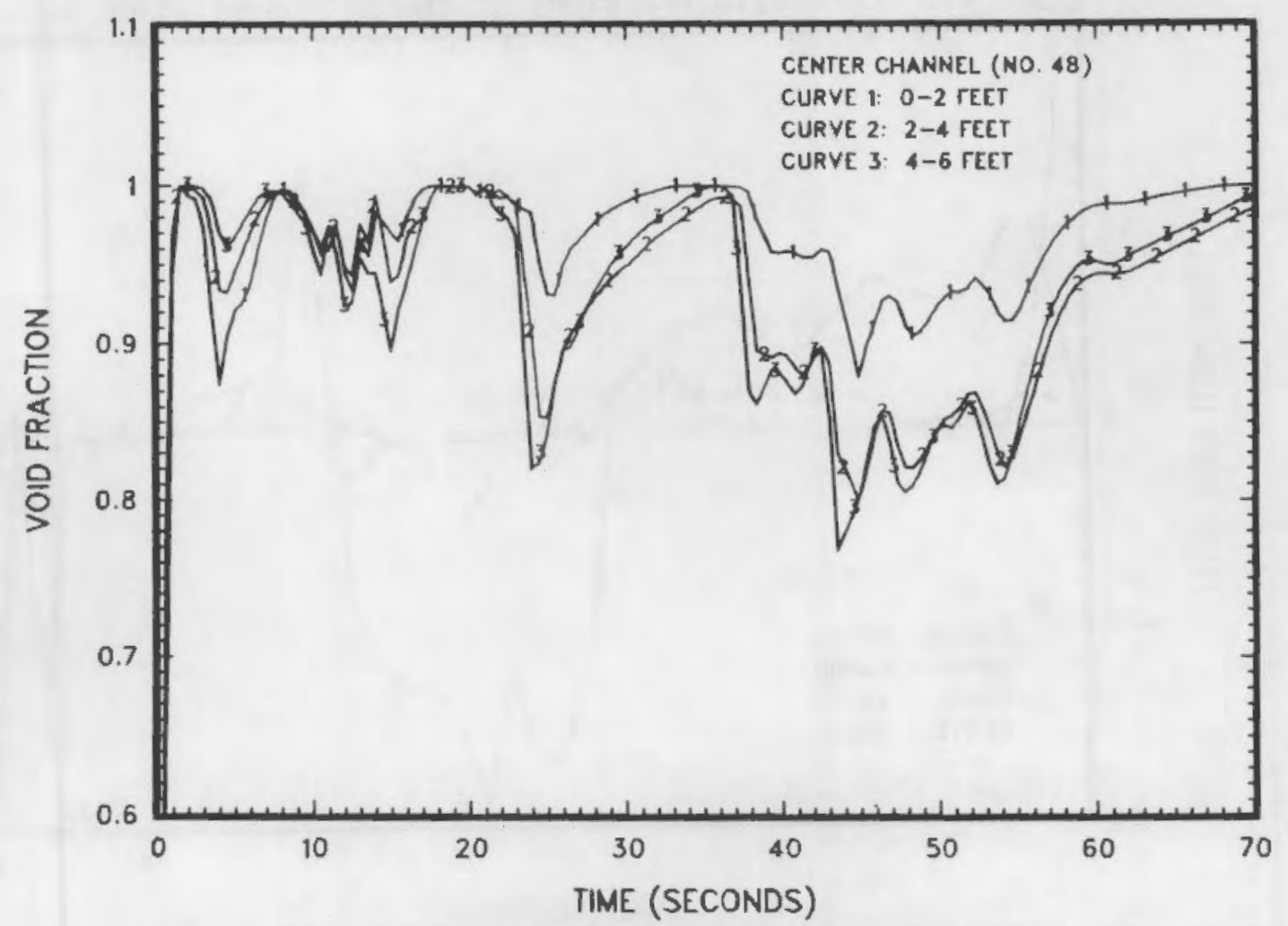

Figure 46 . Core void fractions in channel 48 vs. time 


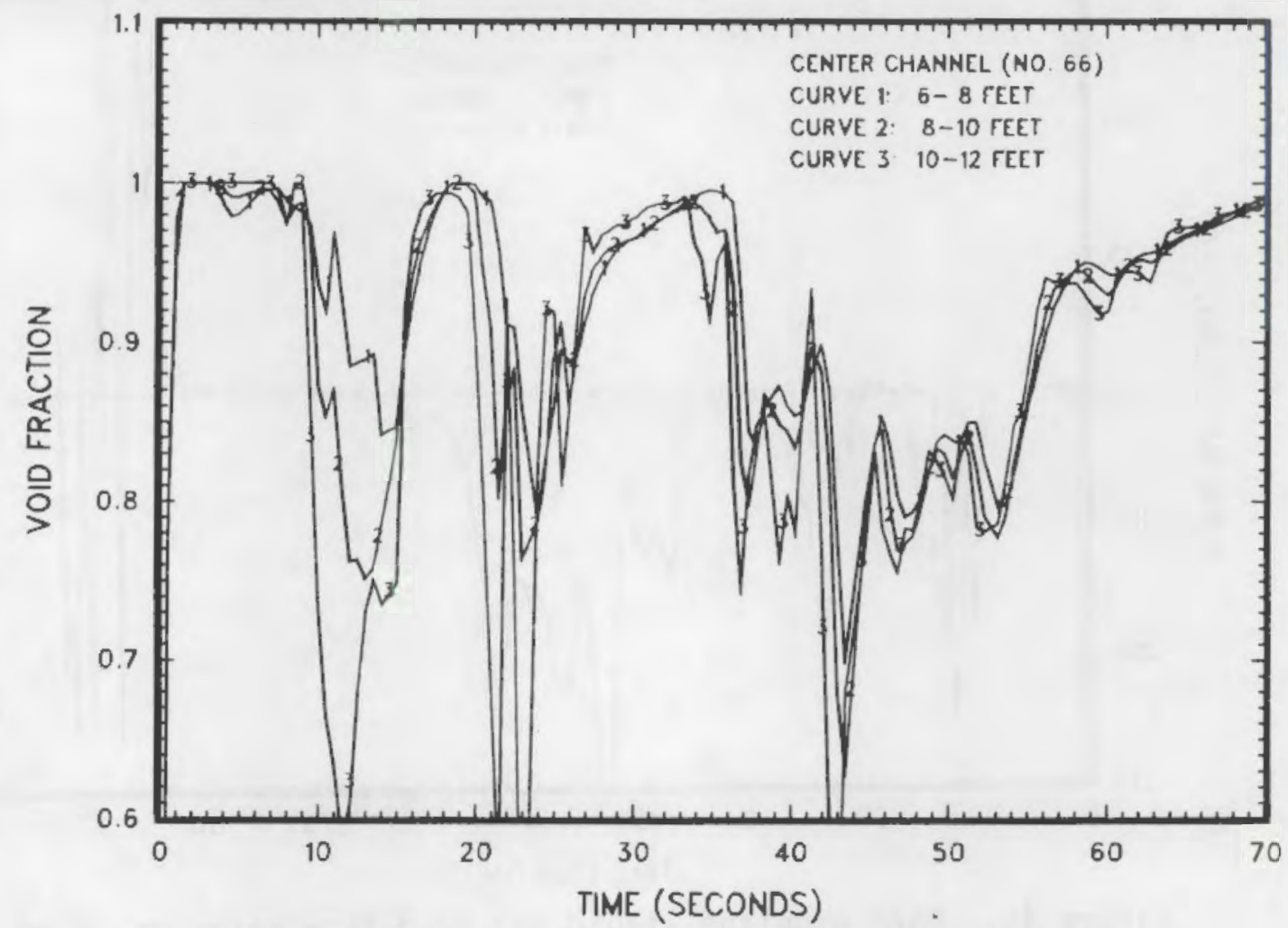

Figure 47 . Core void fractions in channel 66 vs. time

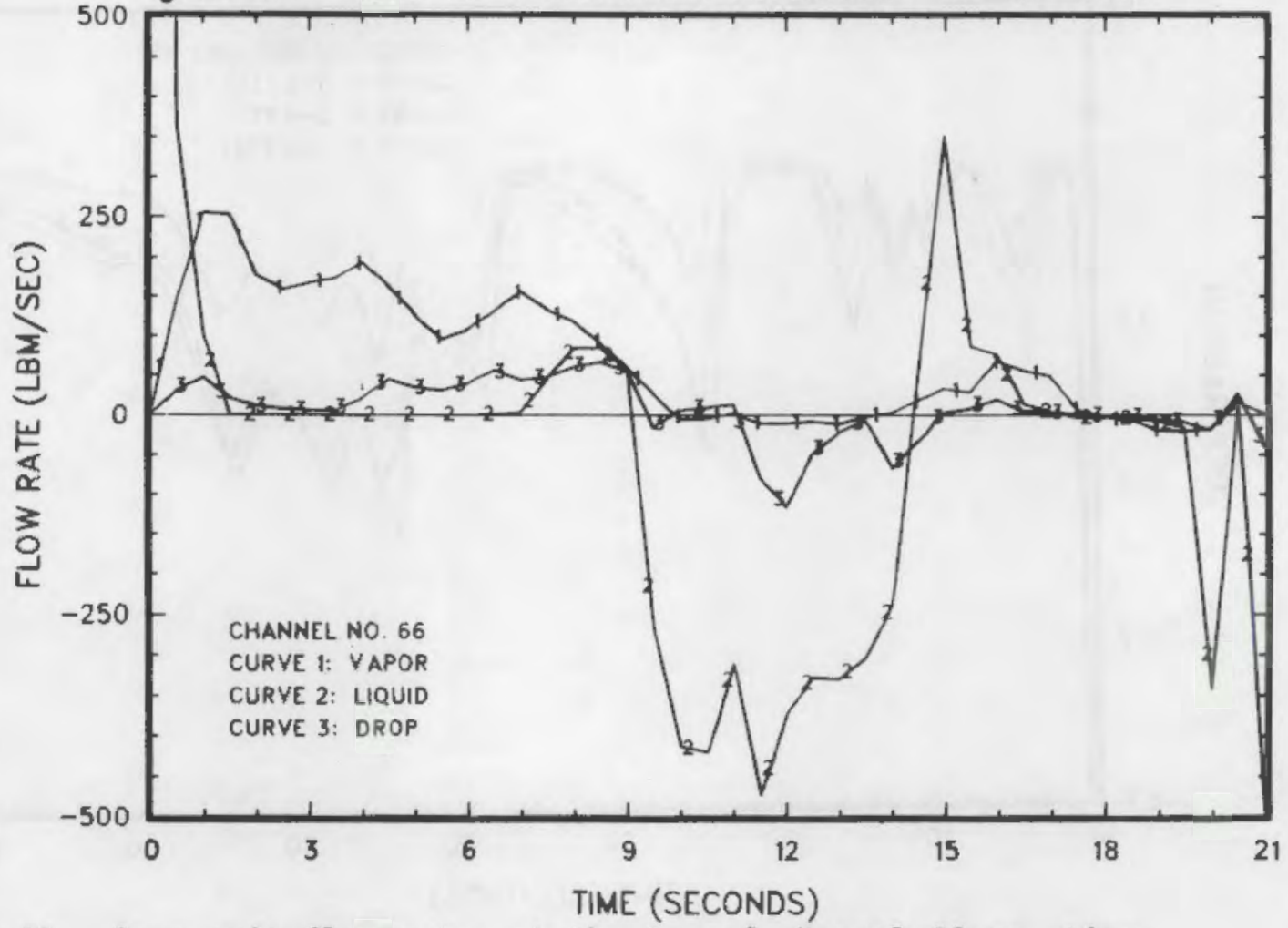

Figure 48. Core exit flow rates at the top of channel 66 vs. time (counter-current flow limiting) 

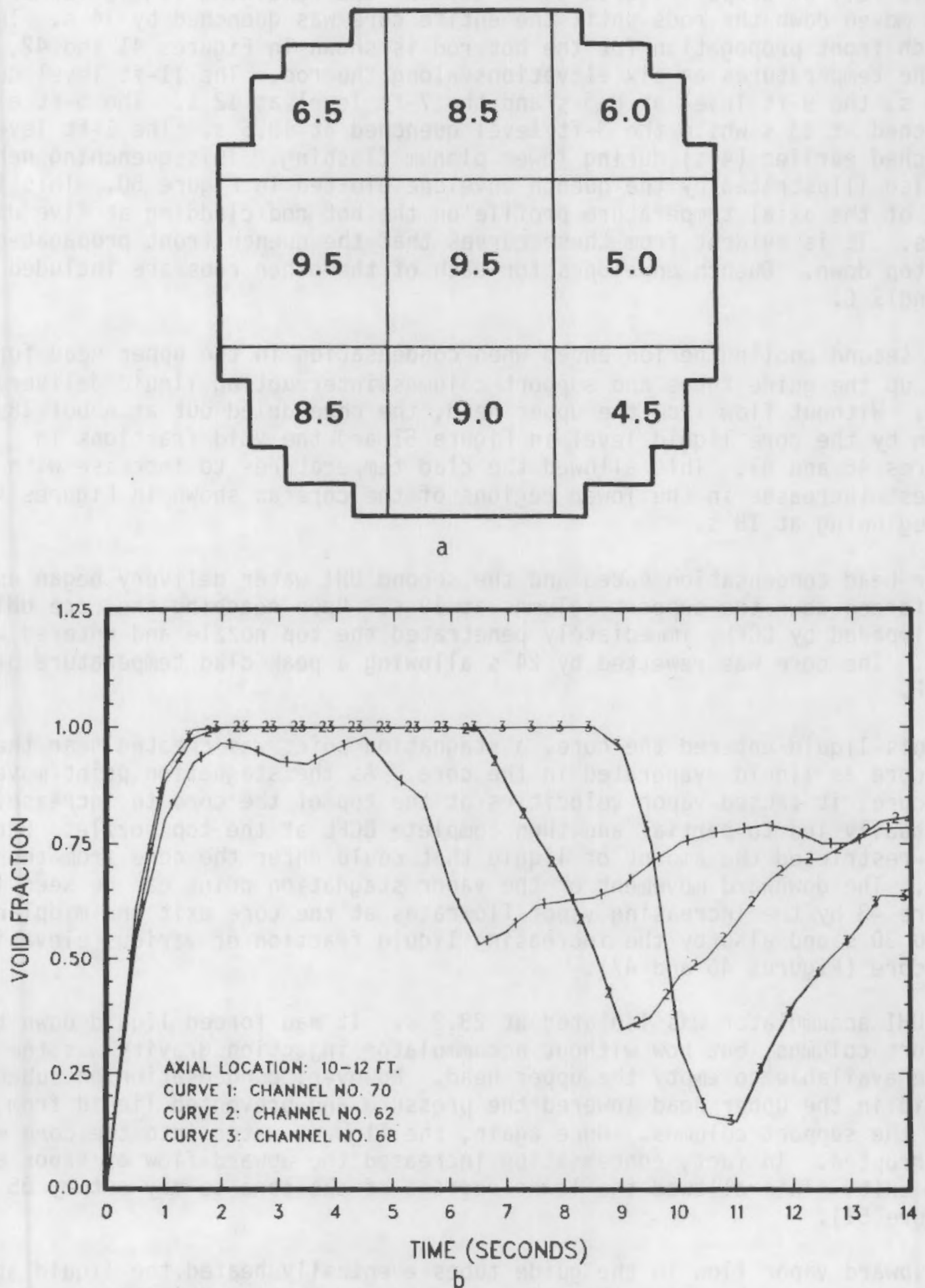

Figure 49. CCFL breakdown

(a) times by channel (in seconds)

(b) void fraction in the top cell of channels 62,68 , and 70 
creating large vapor velocities (Figure 43 at $11 \mathrm{~s}$ ). Another portion of the liquid fell as drops (Figures 44 to 46) but the remaining liquid formed a film that moved down the rods until the entire core was quenched by $14 \mathrm{~s}$. The quench front propogation for the hot rod is shown in Figures 41 and 42 , plots of the temperatures at six elevations along the rod. The $11-\mathrm{ft}$ level quenched at $6 \mathrm{~s}$, the $9-\mathrm{ft}$ level at $8.5 \mathrm{~s}$ and the $7-\mathrm{ft}$ level at $12 \mathrm{~s}$. The $5-\mathrm{ft}$ elevation quenched at $13 \mathrm{~s}$ while the $3-\mathrm{ft}$ level quenched at $13.5 \mathrm{~s}$. The 1 -ft level had quenched earlier ( $4 \mathrm{~s}$ ) during lower plenum flashing. This quenching behavior is also illustrated by the quench envelope plotted in Figure 50. This is a plot of the axial temperature profile on the hot rod cladding at five different times. It is evident from these curves that the quench front propagated from the top down. Quench envelopes for each of the other rods are included in Appendix $C$.

This second cooling period ended when condensation in the upper head forced flow up the guide tubes and support columns interrupting liquid delivery to the core. Without flow from the upper head, the core dried out at about $18 \mathrm{~s}$ as shown by the core liquid level in Figure 51 and the void fractions in Figures 46 and 47 . This allowed the clad temperatures to increase with the largest increases in the lower regions of the core as shown in Figures 41 and 42 beginning at $18 \mathrm{~s}$.

Upper head condensation ended and the second UHI water delivery began as liquid was forced down the support columns at $19 \mathrm{~s}$. Upon reaching the core UHI water, not impeded by CCFL, immediately penetrated the top nozzle and entered the core. The core was rewetted by $24 \mathrm{~s}$ allowing a peak clad temperature of only $520 \mathrm{~F}$.

As this liquid entered the core, a stagnation point was created near the top of the core as liquid evaporated in the core. As the stagnation point moved down the core, it caused vapor velocities at the top of the core to increase. This eventually led to partial and then complete CCFL at the top nozzle. Once again CCFL restricted the amount of liquid that could enter the core from the upper head. The downward movement of the vapor stagnation point can be seen in Figure 43 by the increasing vapor flowrates at the core exit and midplane from 19 to $30 \mathrm{~s}$ and also by the increasing liquid fraction of various elevations in the core (Figures 46 and 47 ).

The UHI accumulator was isolated at $23.2 \mathrm{~s}$. It had forced liquid down the support columns, but now without accummulator injection gravity was the only force available to empty the upper head. However, condensation on subcooled liquid in the upper head lowered the pressure and prevented liquid from flowing down the support columns. Once again, the flow of water into the core was interrupted. In fact, condensation increased the upward flow of vapor at the core exit. This allowed the lower regions of the core to dry out by $35 \mathrm{~s}$ (Figure 51).

The upward vapor flow in the guide tubes eventually heated the liquid at the top of the upper head to saturation causing the pressure to increase and allowing liquid to flow down the support columns. This drain period began at $33 \mathrm{~s}$ and delivered a large amount of liquid to the core (Figures 46, 47, and 51). It rewet the core by $47 \mathrm{~s}$ (Figure 40 ). 


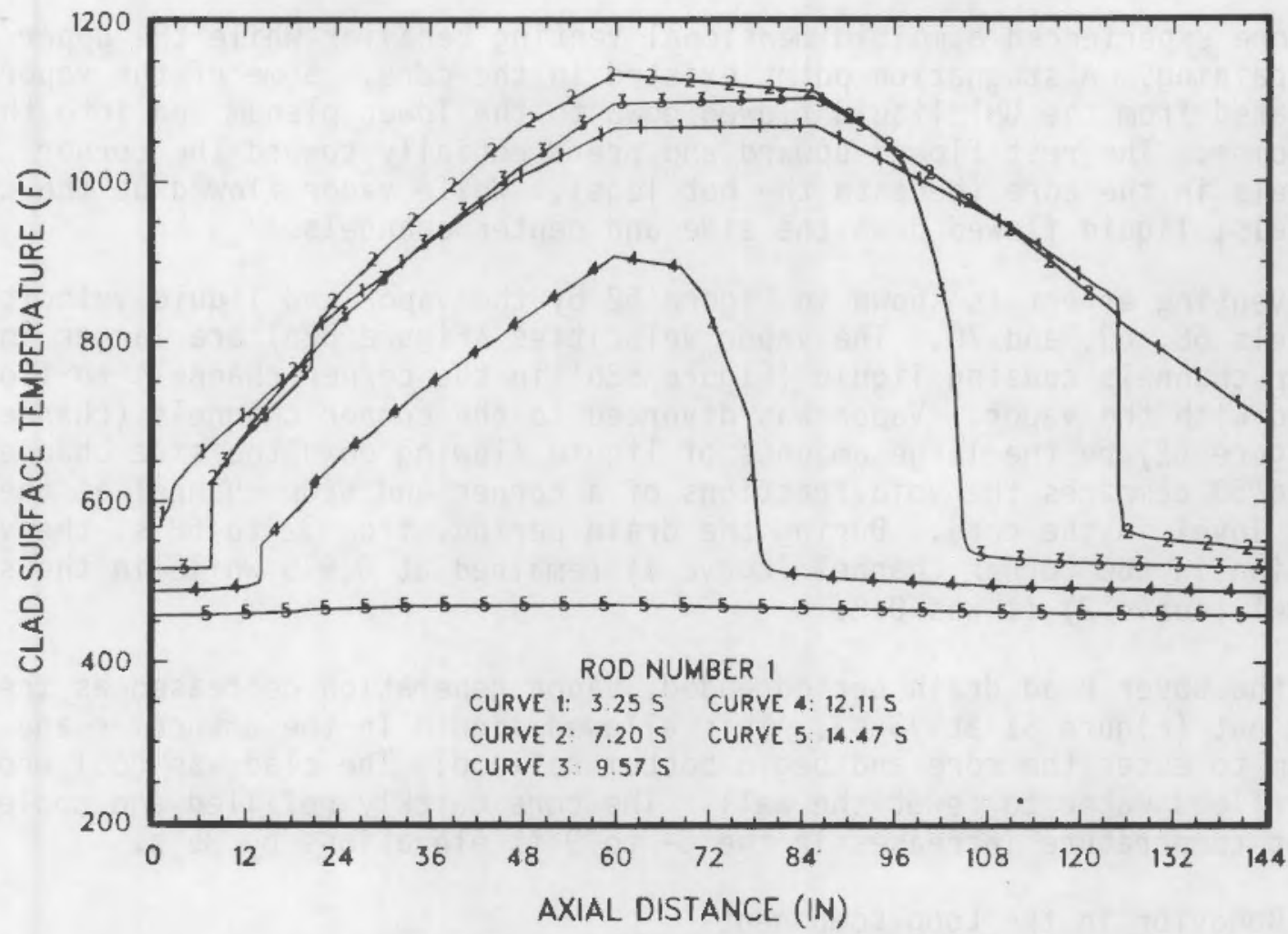

Figure 50. Hot rod quench enevelopes

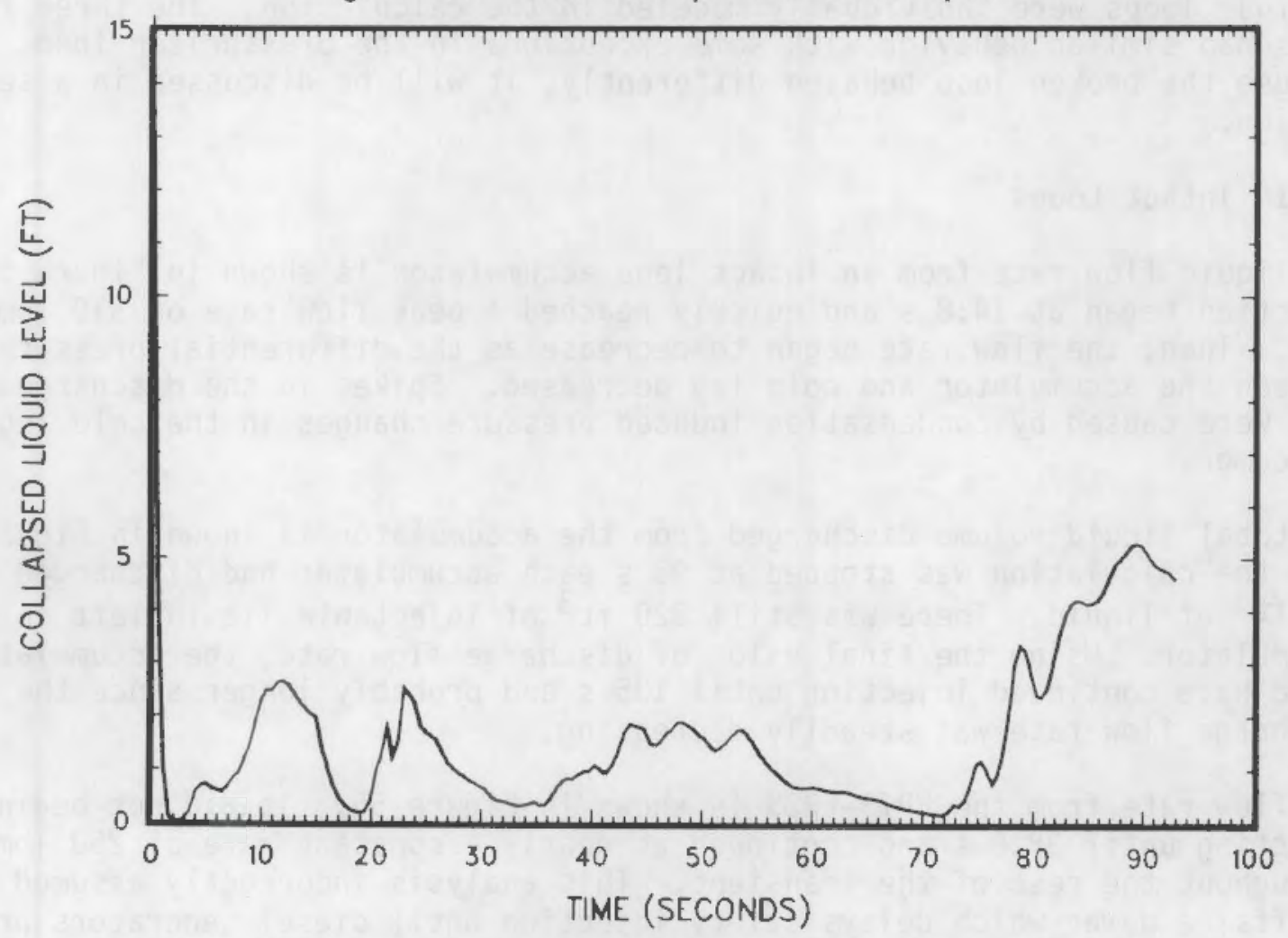

Figure 51. Core liquid level vs. time 
The core experienced a multidimensional venting behavior while the upper head was draining. A stagnation point existed in the core. Some of the vapor generated from the UHI liquid flowed down to the lower plenum and into the downcomer. The rest flowed upward and preferentially toward the corner channels in the core (beneath the hot legs). While vapor flowed up the corner channels, liquid flowed down the side and center channels.

This venting effect is shown in Figure 52 by the vapor and liquid velocities in channels 68,69, and 70. The vapor velocities (Figure 52a) are larger in the corner channels causing liquid (Figure 52b) in the corner channels to flow upward with the vapor. Vapor was diverted to the corner channels (channel 70 in Figure 52) by the large amounts of liquid flowing down the side channels. Figure 53 compares the void fractions of a corner and side channel at the 10 to $12-\mathrm{ft}$ level in the core. During the drain period, from 32 to $58 \mathrm{~s}$, the void fraction in the corner channel (curve 1) remained at 0.975 while in the side channel (curve 2) it was 0.8 .

Once the upper head drain period ended, vapor generation decreased as the core dried out (Figure 51 at $73 \mathrm{~s}$ ). This allowed liquid in the downcomer and lower plenum to enter the core and begin bottom reflood. The clad was cool enough for reflood water to rewet the wall. The core quickly refilled and cooled the slight temperature increases in the 5- to 9-ft elevations by $85 \mathrm{~s}$.

\subsection{Behavior in the Loop Components}

All four loops were individually modeled in the calculation. The three intact loops had similar behavior with some exceptions in the pressurizer loop. Because the broken loop behaved differently, it will be discussed in a seperate section.

\subsubsection{Intact Loops}

The liquid flow rate from an intact loop accumulator is shown in Figure 54 . Injection began at $14.8 \mathrm{~s}$ and quickly reached a peak flow rate of $9101 \mathrm{bm} / \mathrm{s}$ at $20 \mathrm{~s}$. Then, the flow rate began to decrease as the differential pressure between the accumulator and cold leg decreased. Spikes in the discharge flow rate were caused by condensation induced pressure changes in the cold leg and downcomer.

The total liquid volume discharged from the accumulator is shown in Figure 55. When the calculation was stopped at $93 \mathrm{~s}$ each accumulator had discharged nearly $800 \mathrm{ft}^{3}$ of liquid. There was still $320 \mathrm{ft}^{3}$ of injectable liquid left in the accumulator. Using the final value of discharge flow rate, the accumulators could have continued injecting until $135 \mathrm{~s}$ and probably longer since the discharge flow rate was steadily decreasing.

The flow rate from the HPIS-LPIS is shown in Figure 56. It did not begin injecting until $38.8 \mathrm{~s}$ and continued at nearly a constant rate of $250 \mathrm{lbm} / \mathrm{s}$ throughout the rest of the transient. This analysis incorrectly assumed loss of offsite power which delays safety injection until diesel generators provide power to the HPIS-LPIS pumps. In a best-estimate analysis, offsite power is 


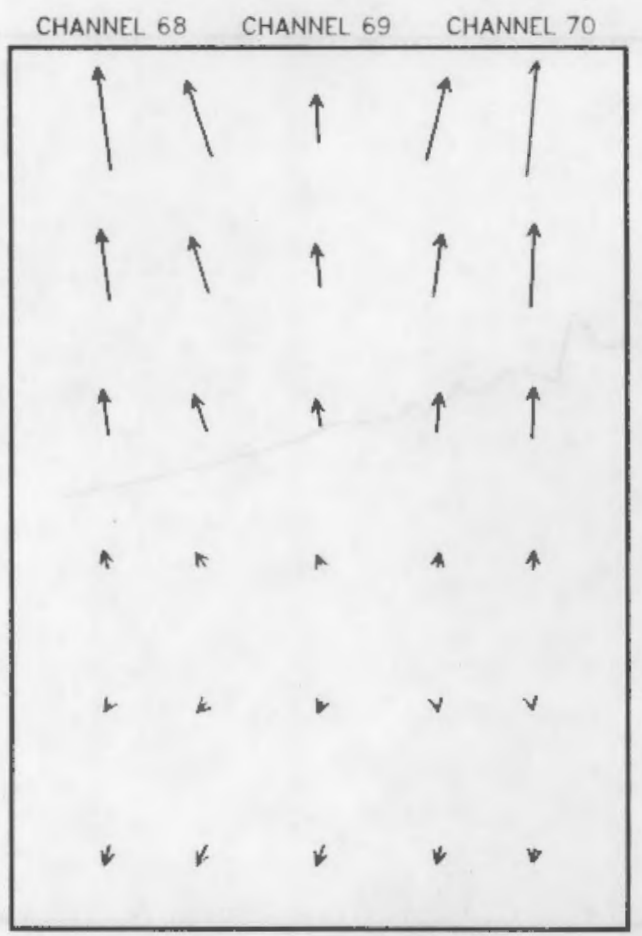

EQUALS $500 \mathrm{FT} / \mathrm{S}$

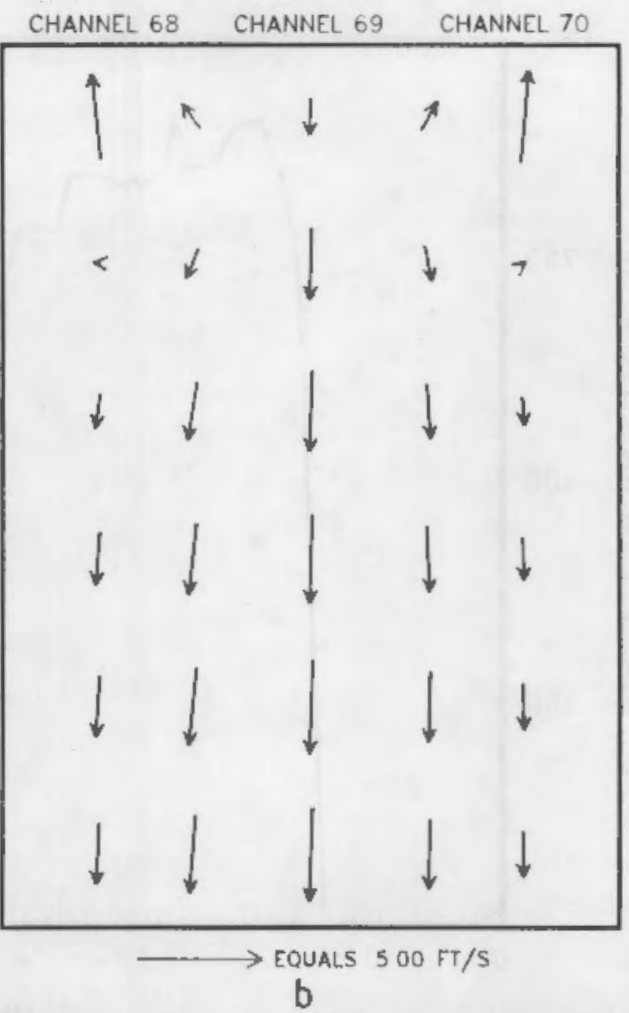

$b$

Figure 52. Cell centered velocities in the core during the venting behavior

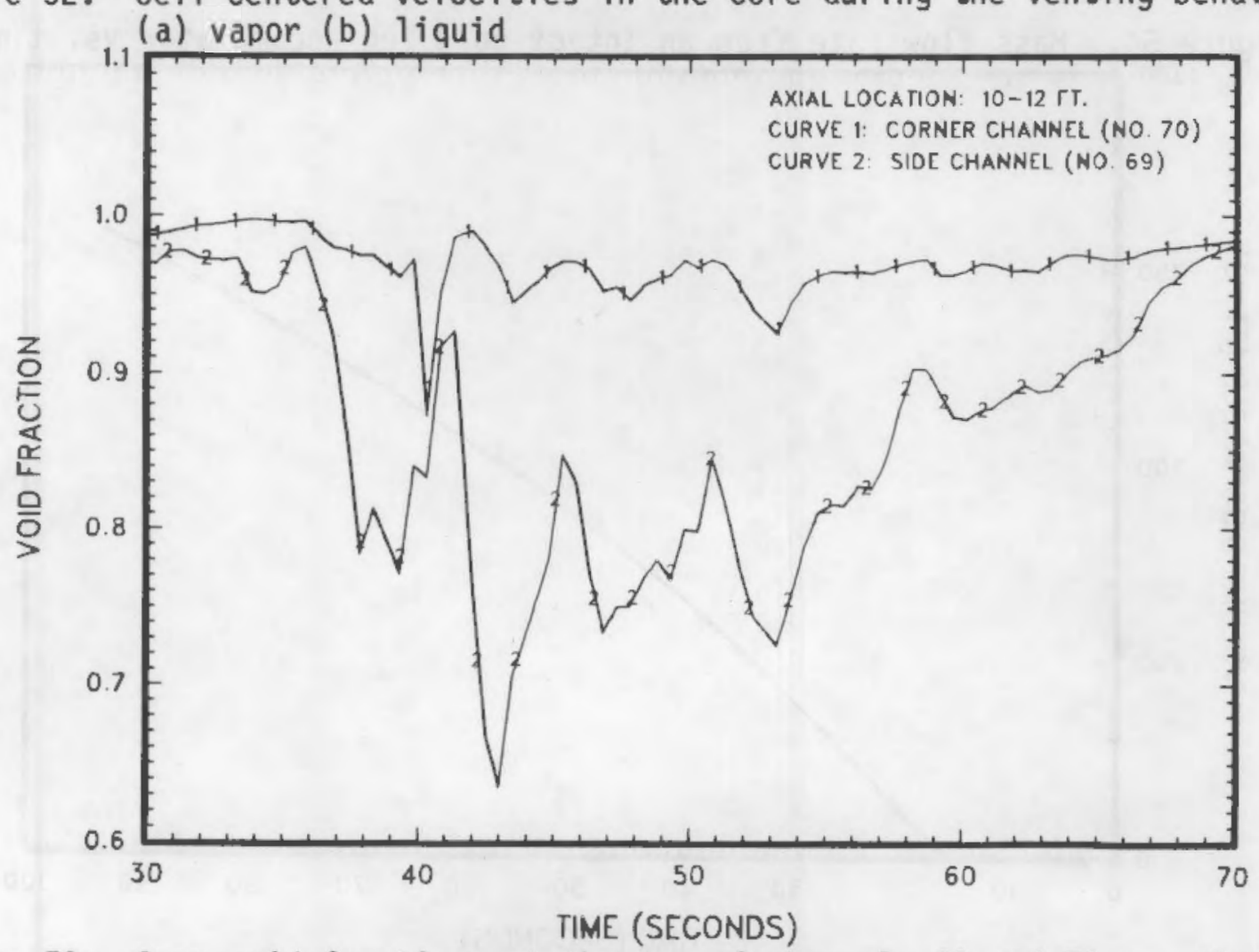

Figure 53. Core void fractions at the top of channels 69 and 70 vs. time (venting) 


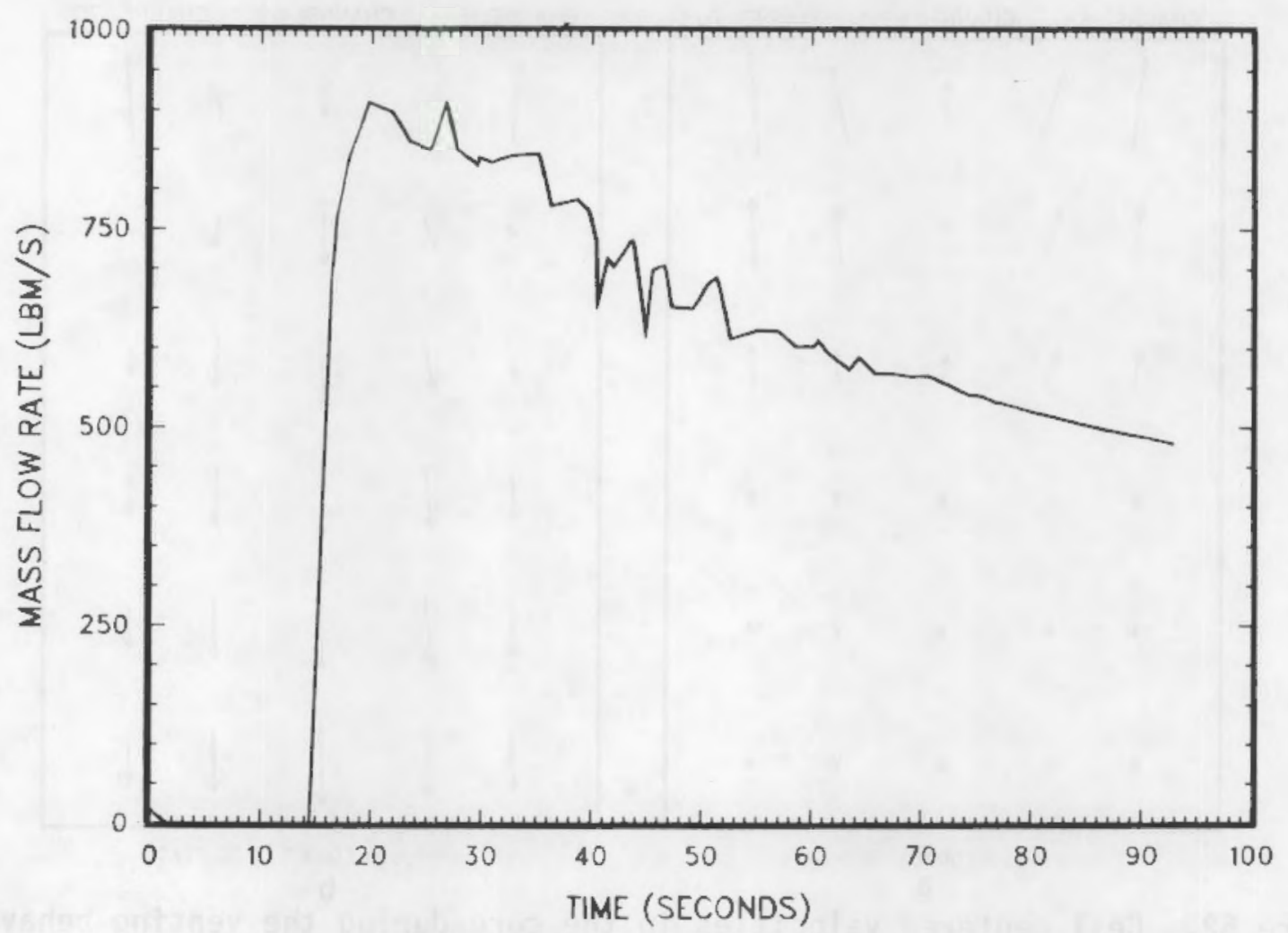

Figure 54. Mass flow rate from an intact cold leg accumulator vs. time

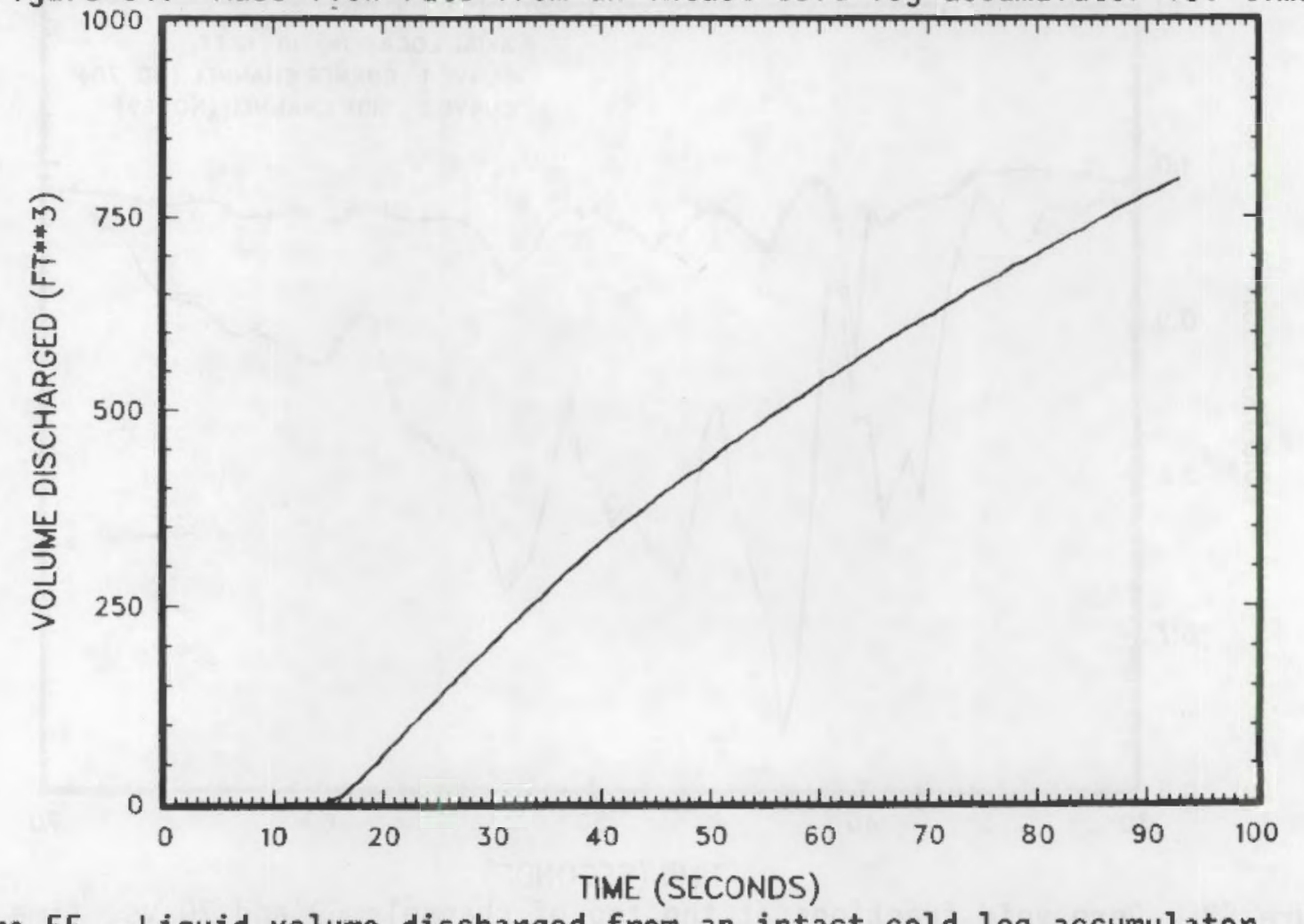

Figure 55. Liquid volume discharged from an intact cold leg accumulator vs. time 


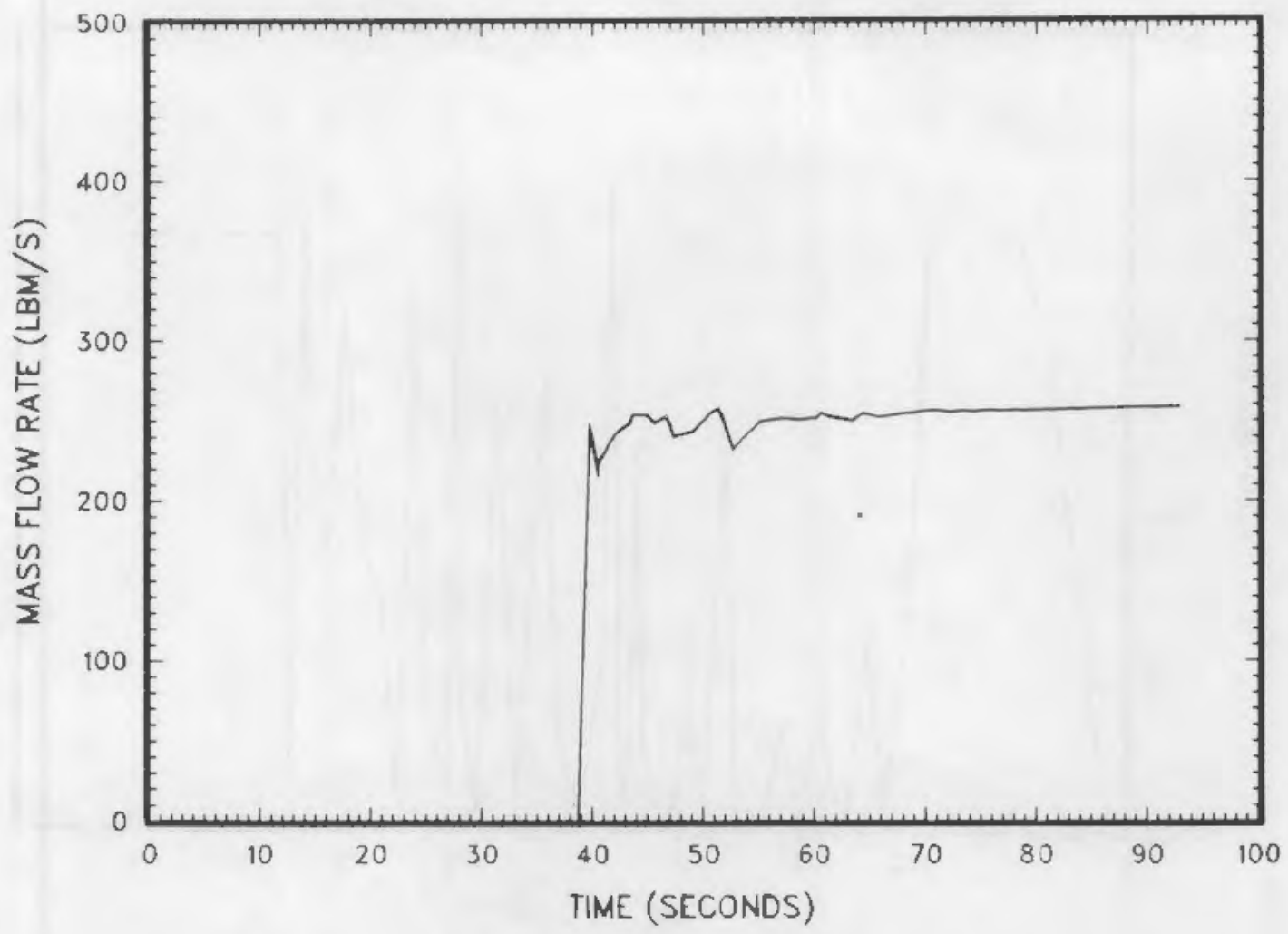

Figure 56. Mass flow rate from one HPIS-LPIS FILL vs. time

available so the pumps would start almost immediately after the break. However, this mistake had only a small effect on the results, since most of the ECCS liquid was being bypassed before $38 \mathrm{~s}$.

The void fraction and mass flow rate in the intact cold leg are shown in Figures 57 and $58(\mathrm{a})$. The cold leg void fraction increased after the pressure reached saturation. It reached a maximum void fraction just before the accumulators began injecting at $14.8 \mathrm{~s}$. By $20 \mathrm{~s}$ the cold leg was mostly full of liquid with occasional increases in the void fraction caused by slugging in the downcomer and cold leg.

Ouring subcooled blowdown, the mass flow rate increased beyond the steady state flow of $10,0001 \mathrm{bm} / \mathrm{s}$. It decreased as the pressure decreased and the loop was emptied into the downcomer reaching a minimum flow rate at $18 \mathrm{~s}$. Then, the flow rate increased as ECCS liquid entered the downcomer. The effect of condensation on the mass flow rate is also apparent. It caused periodic flow reversals back into the cold leg until bottom reflood began. Then, the flow rate leveled out to about $750 \mathrm{1bm} / \mathrm{s}$ into the vessel.

(a) The sign convention of flow inside the loops is defined as positive in the direction of flow during steady state. That is, cold leg flow into the vessel is positive as is hot leg flow out of the vessel. 


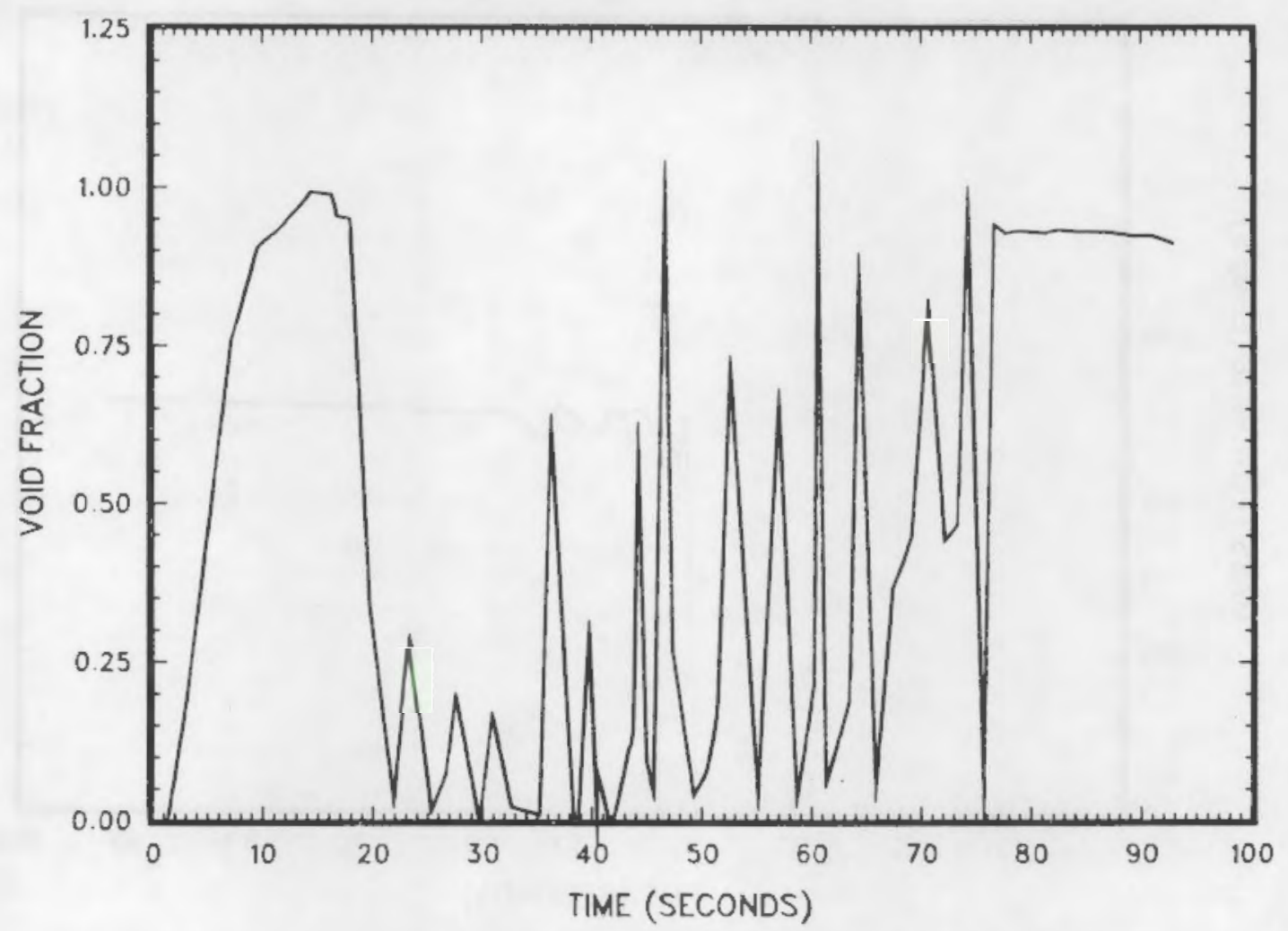

Figure 57. Intact cold leg void fraction vs. time

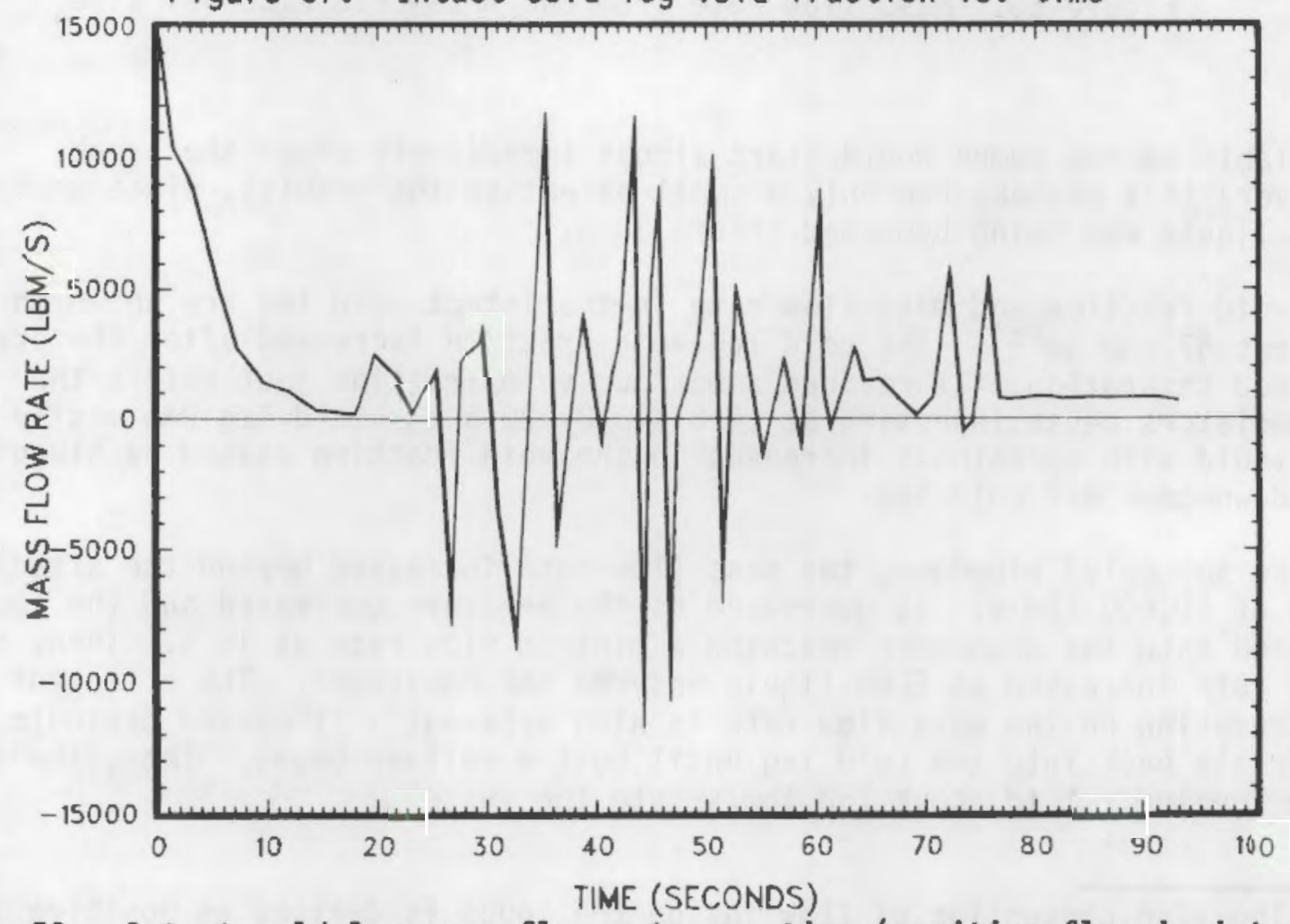

Figure 58. Intact cold leg mass flow rate vs. time (positive flow is into the vessel) 
The void fraction and mass flow rate for an intact hot leg are shown in Figures 59 and 60 . The hot leg voided more rapidly than the cold leg because it was hotter. Liquid present in the hot leg from 3 to $20 \mathrm{~s}$ came from two sources-the upper head and the pressurizer. As already discussed, flashing in the upper head forced liquid down the support columns at the same time the lower plenum was flashing. Vapor created in the lower plenum caused upward flow in the core and led to CCFL at the top the core. This prevented upper head liquid from flowing down into the core. Liquid accumulated in the upper plenum where some of it was carried out the intact and broken hot legs.

The pressurizer also added liquid to the upper plenum during this time. Figure 61 shows the hot leg void fraction in the loop with the pressurizer. Liquid in the hot leg during the first $15 \mathrm{~s}$ is leaving the pressurizer and flowing into the vessel at the flow rates shown in Figure 62 (negative flow is into the vessel). Figure 63 shows the flow rate into the hot leg from the surge line and Figure 64 is the total liquid volume discharged from the pressurizer. After entering the upper plenum, some of the liquid flowed out the other hot legs with the remainder falling into the core once CCFL breakdown occurred. This liquid was responsible for the earlier CCFL breakdown in channel 70 which is closest to the pressurizer.

After the upper plenum emptied, near $20 \mathrm{~s}$, the hot legs remained dry. Steam binding caused by the entrainment of drops into the steam generator did not occur. During liquid delivery from the upper head, most of the generated vapor flowed down the core instead of up into the hot legs. Steam binding usually occurs during bottom reflood when large vapor generation rates entrain drops into the loops. But, in this calculation the core was quenched before bottom reflood, so vapor generation during reflood was much lower. The vapor did not entrain enough liquid to cause steam binding.

\subsubsection{Broken Loop}

The void fraction on the vessel side of the broken cold leg is shown in Figure 65. It remained below 0.25 until cold leg liquid began to evaporate around $3 \mathrm{~s}$. Then, the void fraction rapidly increased as the liquid was pushed out the break reaching a maximum at $16 \mathrm{~s}$. Beginning at $20 \mathrm{~s}$ ECCS liquid was bypassing the downcomer and was exiting the break. An oscillatory flow was calculated out of the break cycling between vapor and liquid flow as shown in this figure.

The flow rate out the broken cold leg from the vessel is shown in Figure 66 . A peak flow rate of $60,0001 \mathrm{bm} / \mathrm{s}$ occurred during subcooled blowdown, decreasing to $27,000 \mathrm{lbm} / \mathrm{s}$ once flashing began in the downcomer and lower plenum. The flow rate of ECCS liquid out the break is shown from 20 to $69 \mathrm{~s}$. Starting at $69 \mathrm{~s}$ no flow exited the break while the downcomer filled since all of the steam was condensed in the downcomer. Reverse break flow did not occur since condensation was stopped when the vessel pressure dropped below the containment pressure as one would expect to occur as a result of noncondensable gases entering the break. 


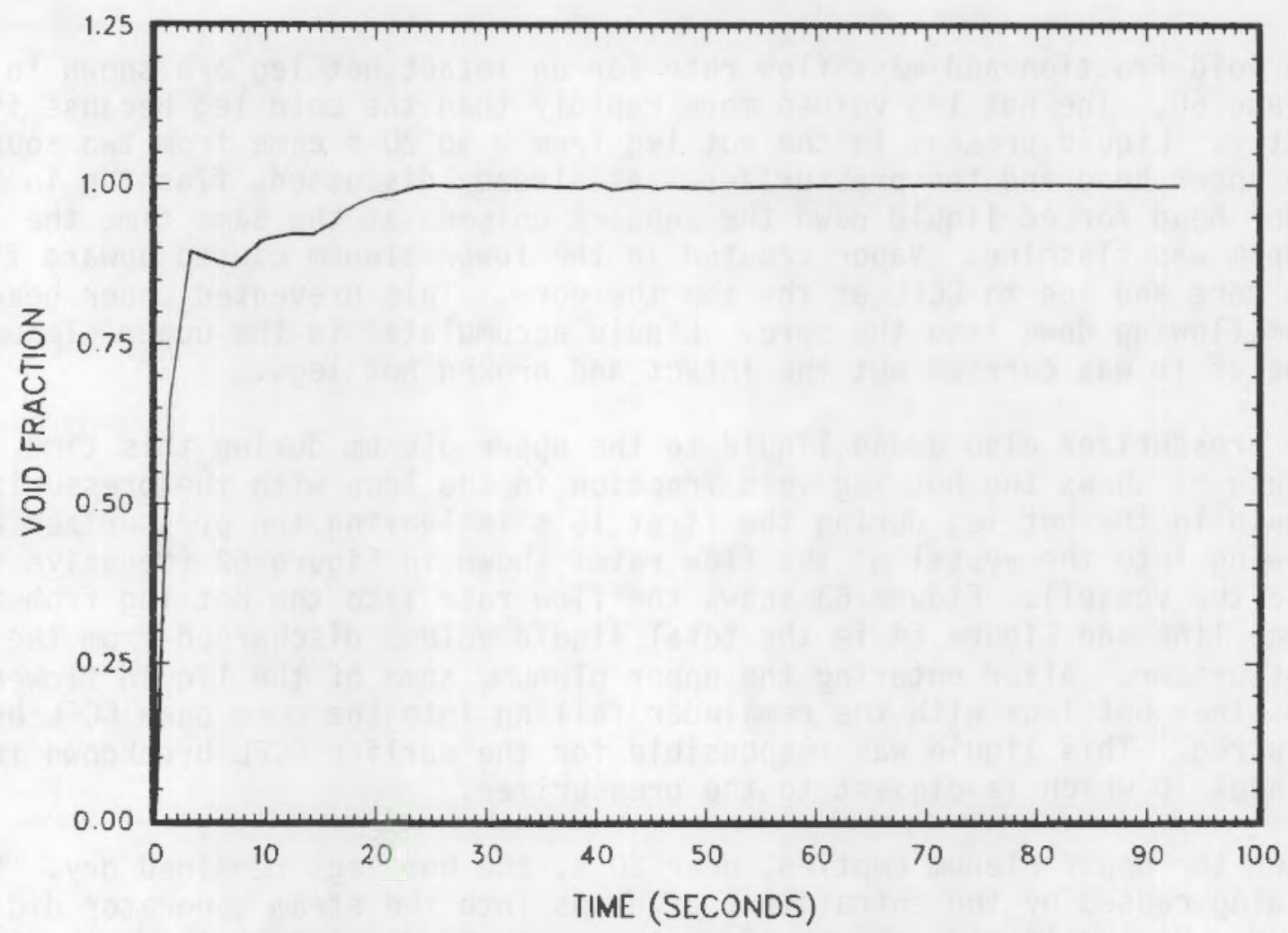

Figure 59. Intact hot leg void fraction vs. time

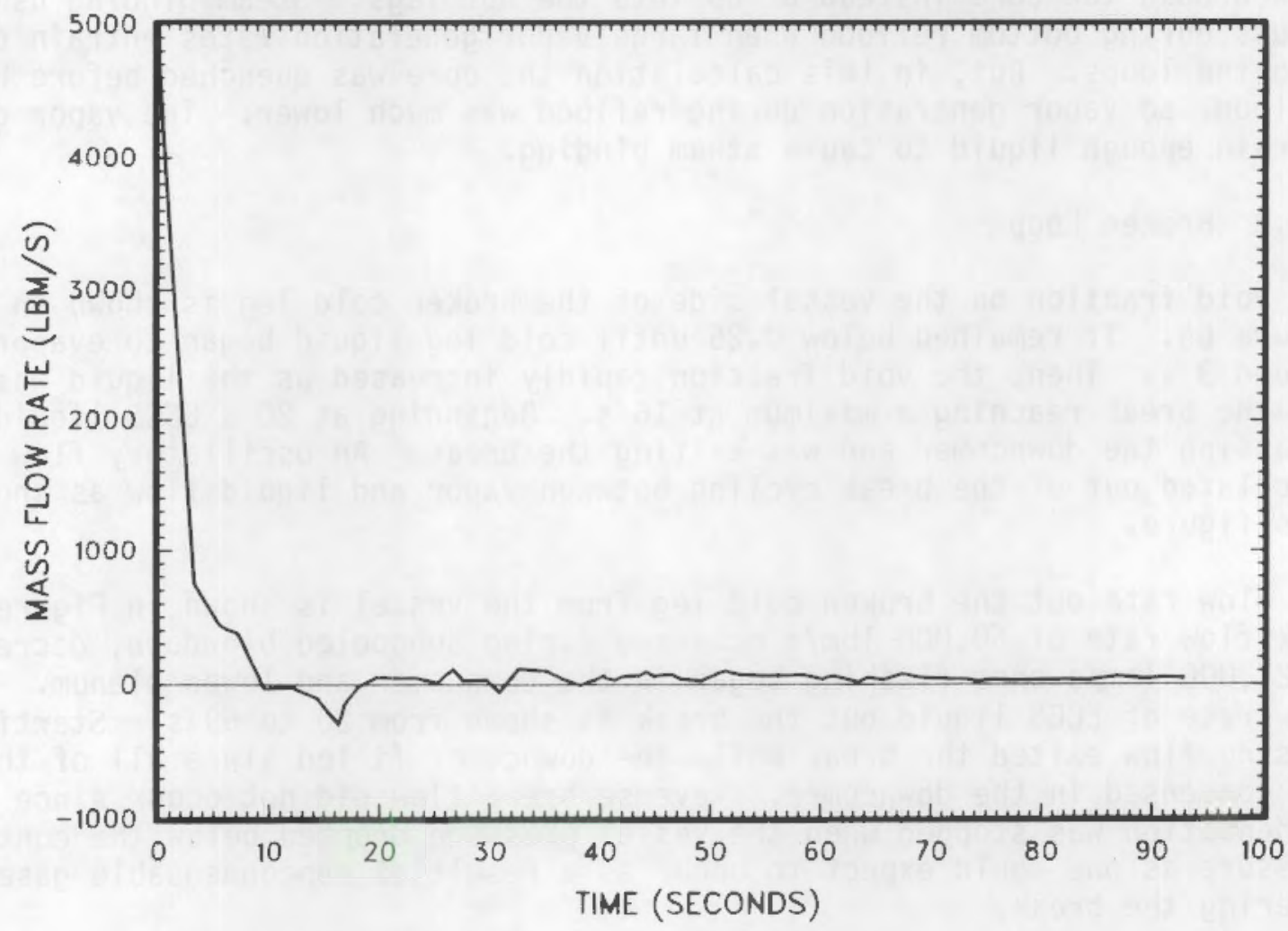

Figure 60 . Intact hot leg mass flow rate vs. time 


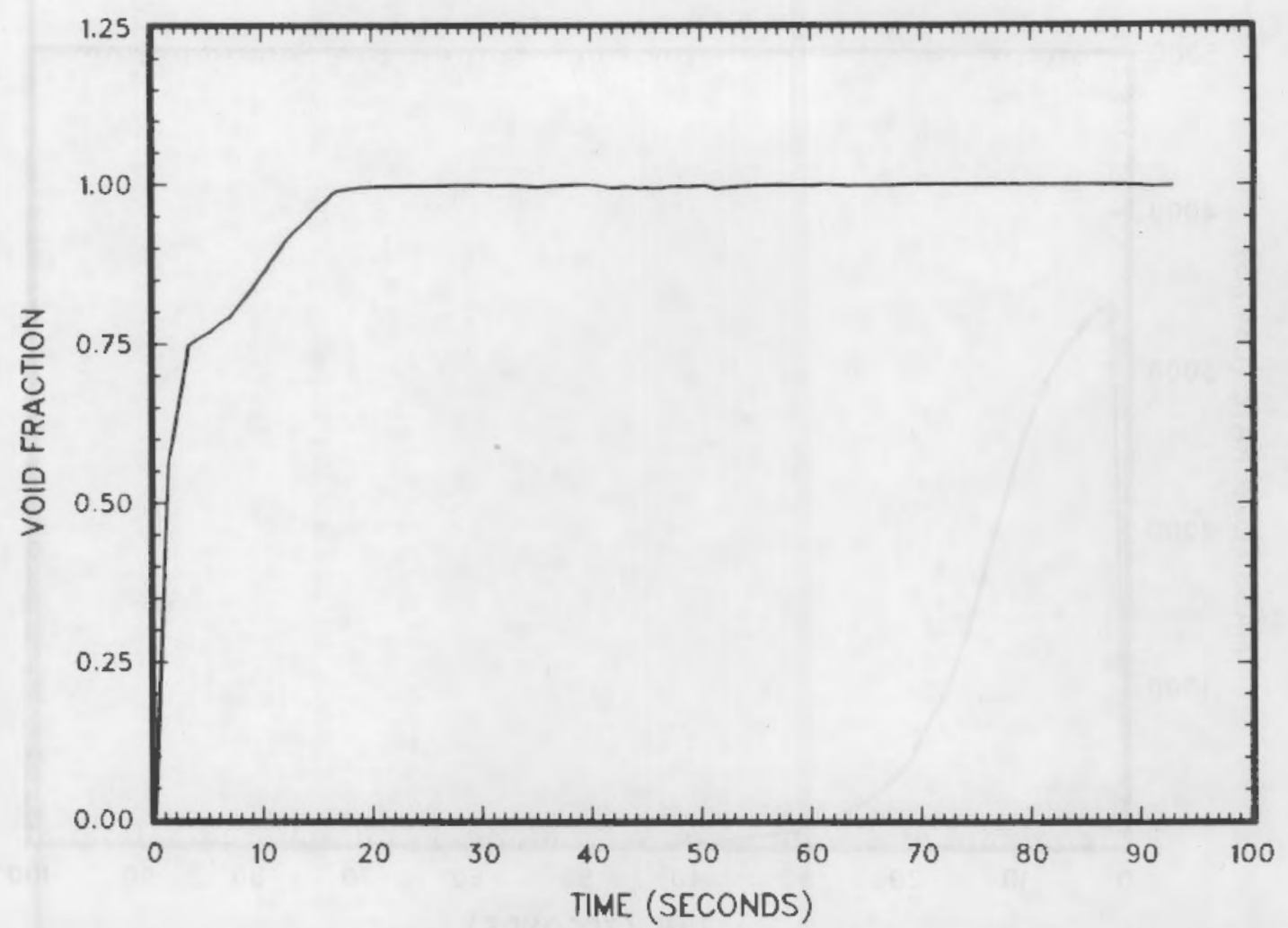

Figure 61 . Hot leg void fraction in the pressurizer loop vs. time

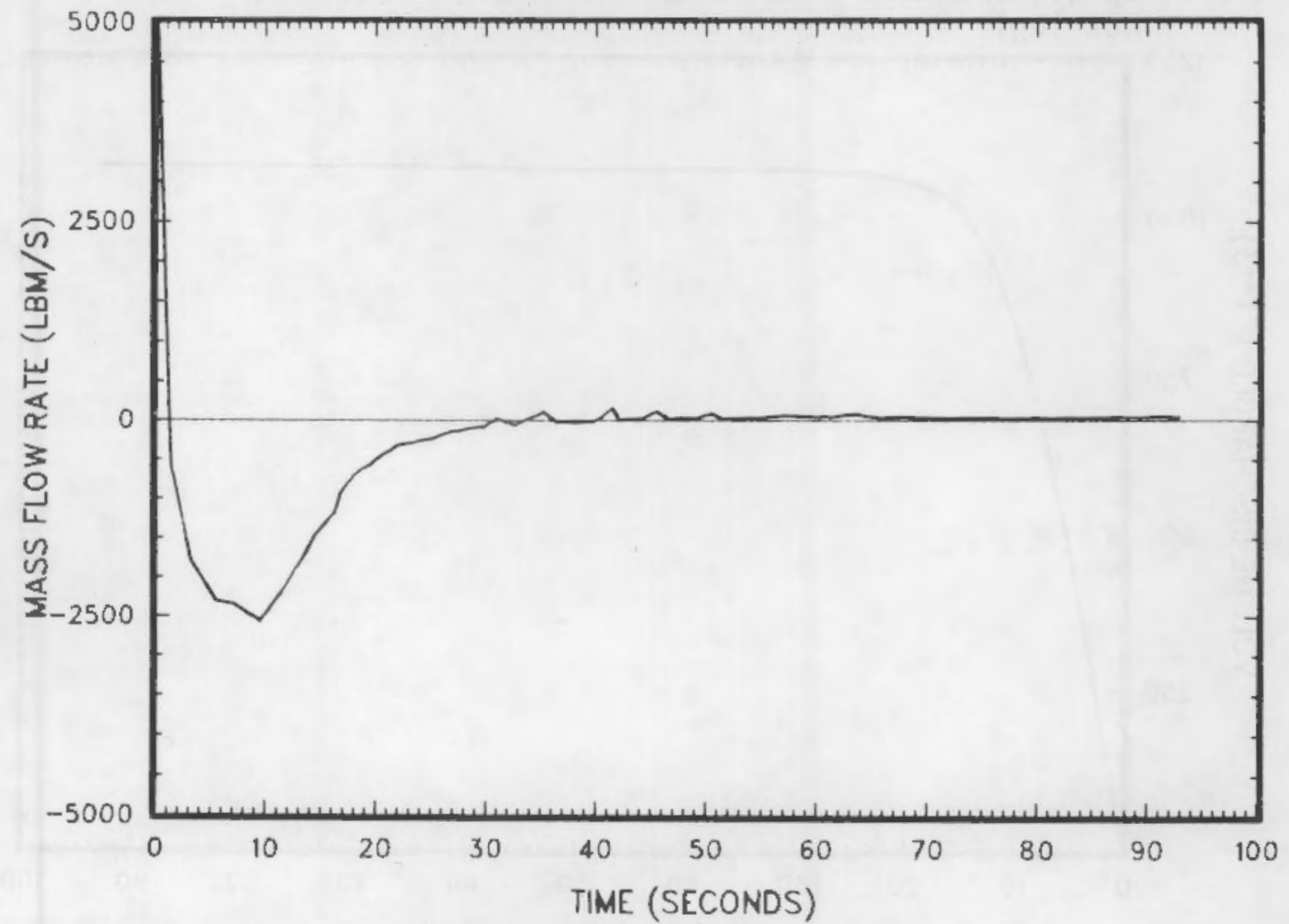

Figure 62. Hot leg mass flow rate in the pressurizer loop vs. time 


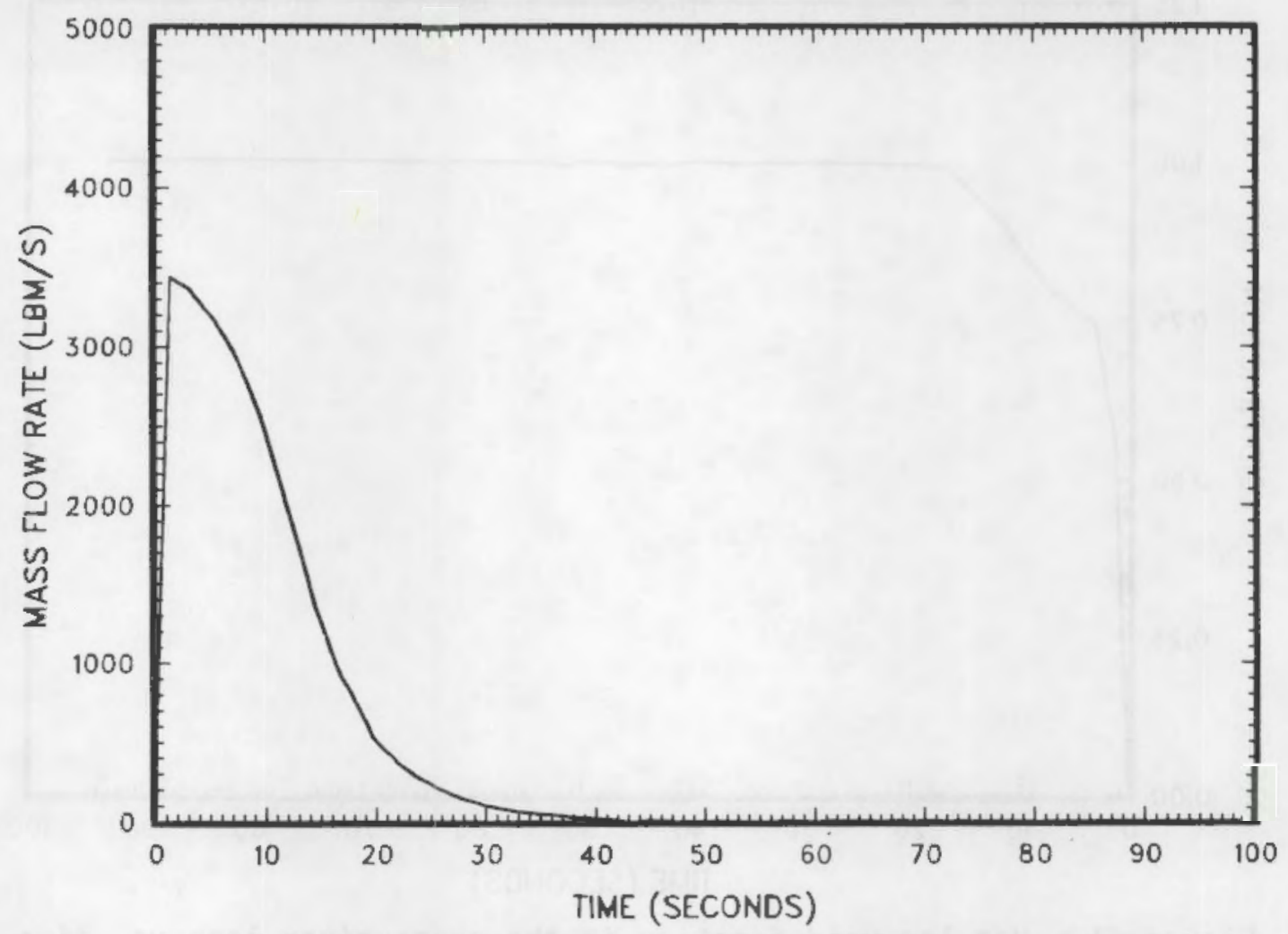

Figure 63. Surge line mass flow rate vs. time (positive flow is into the hot 1 eg)

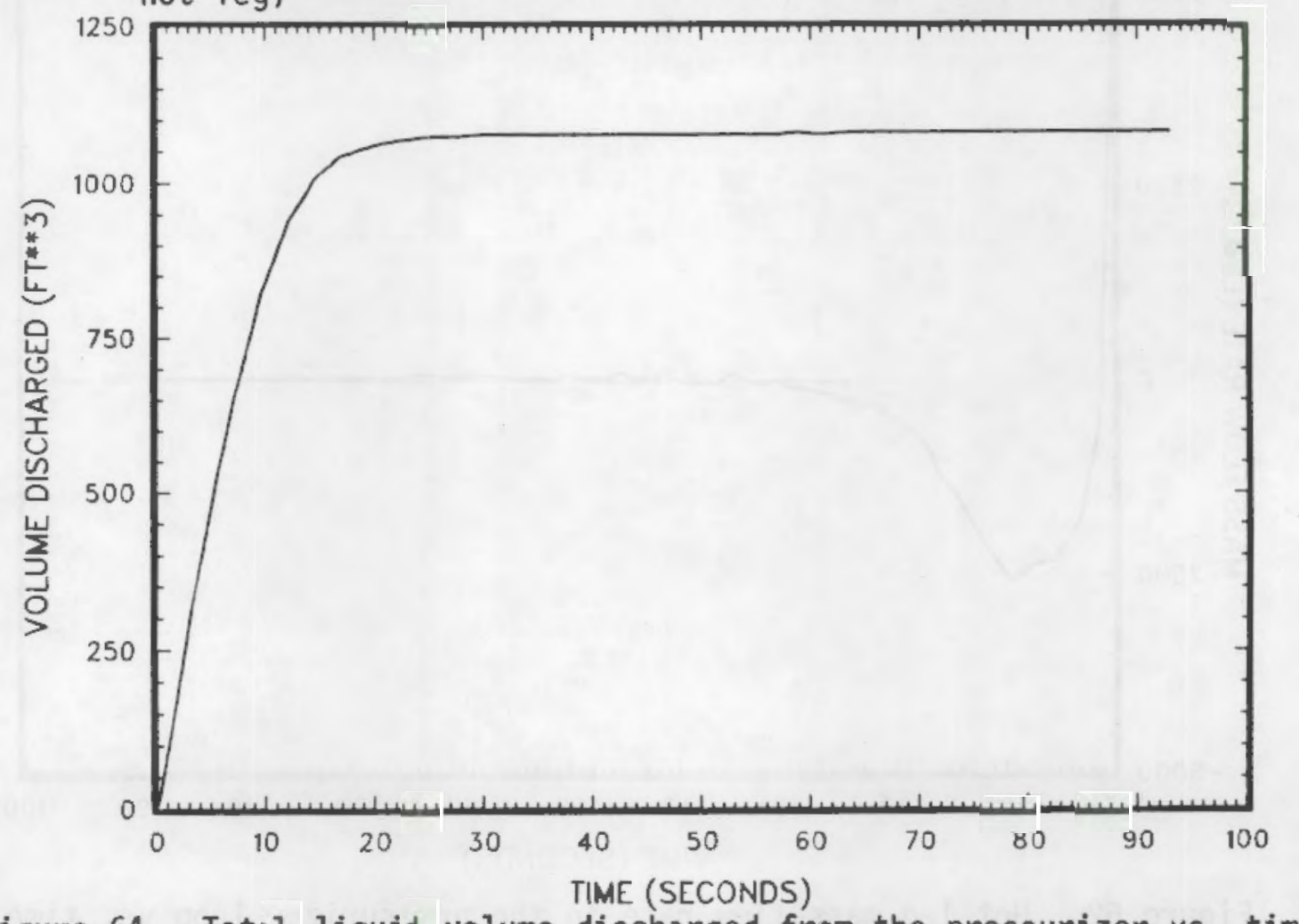

Figure 64. Total liquid volume discharged from the pressurizer vs. time 


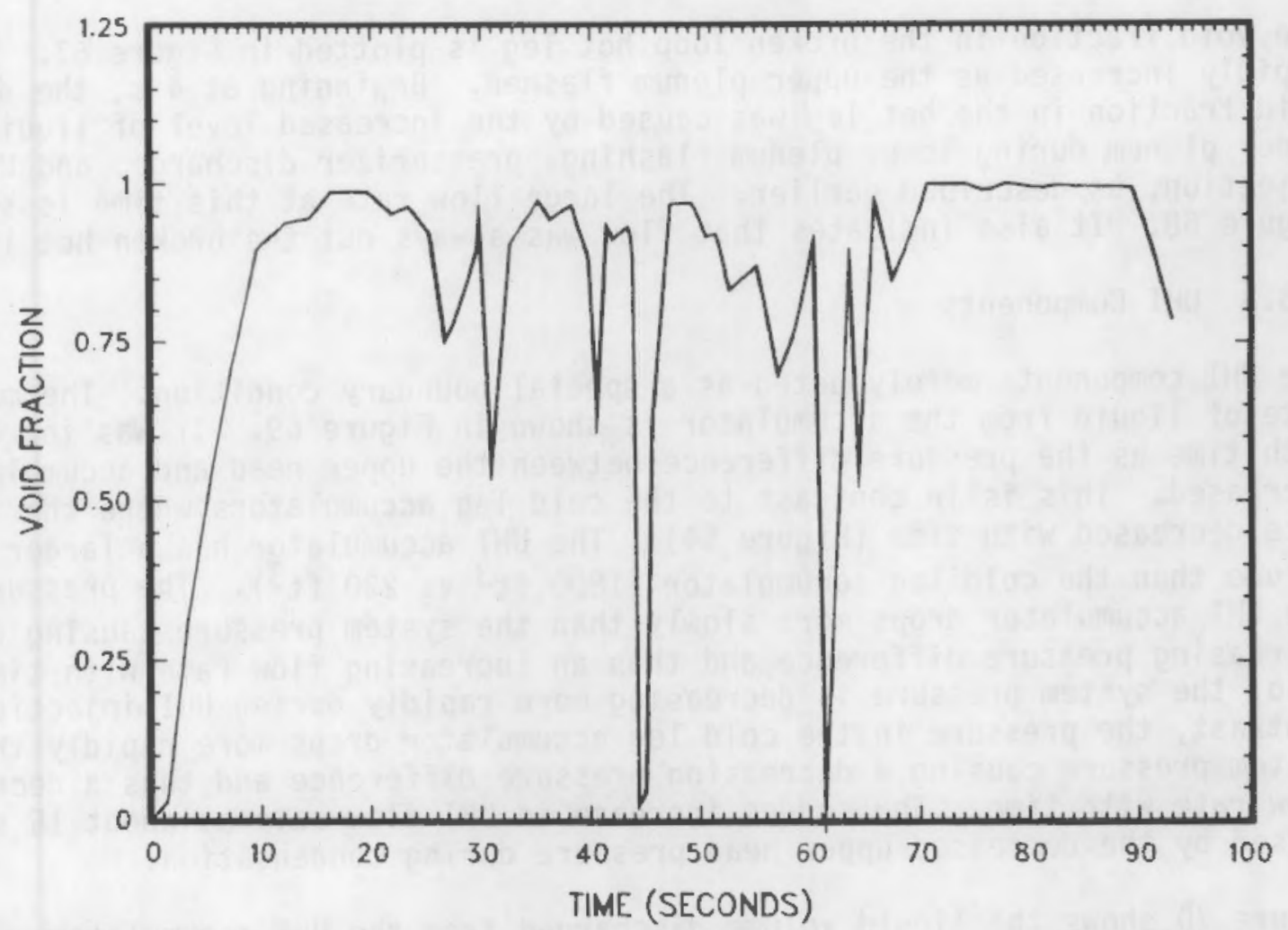

Figure 65. Cold leg void fraction on the vessel side of the break vs. time

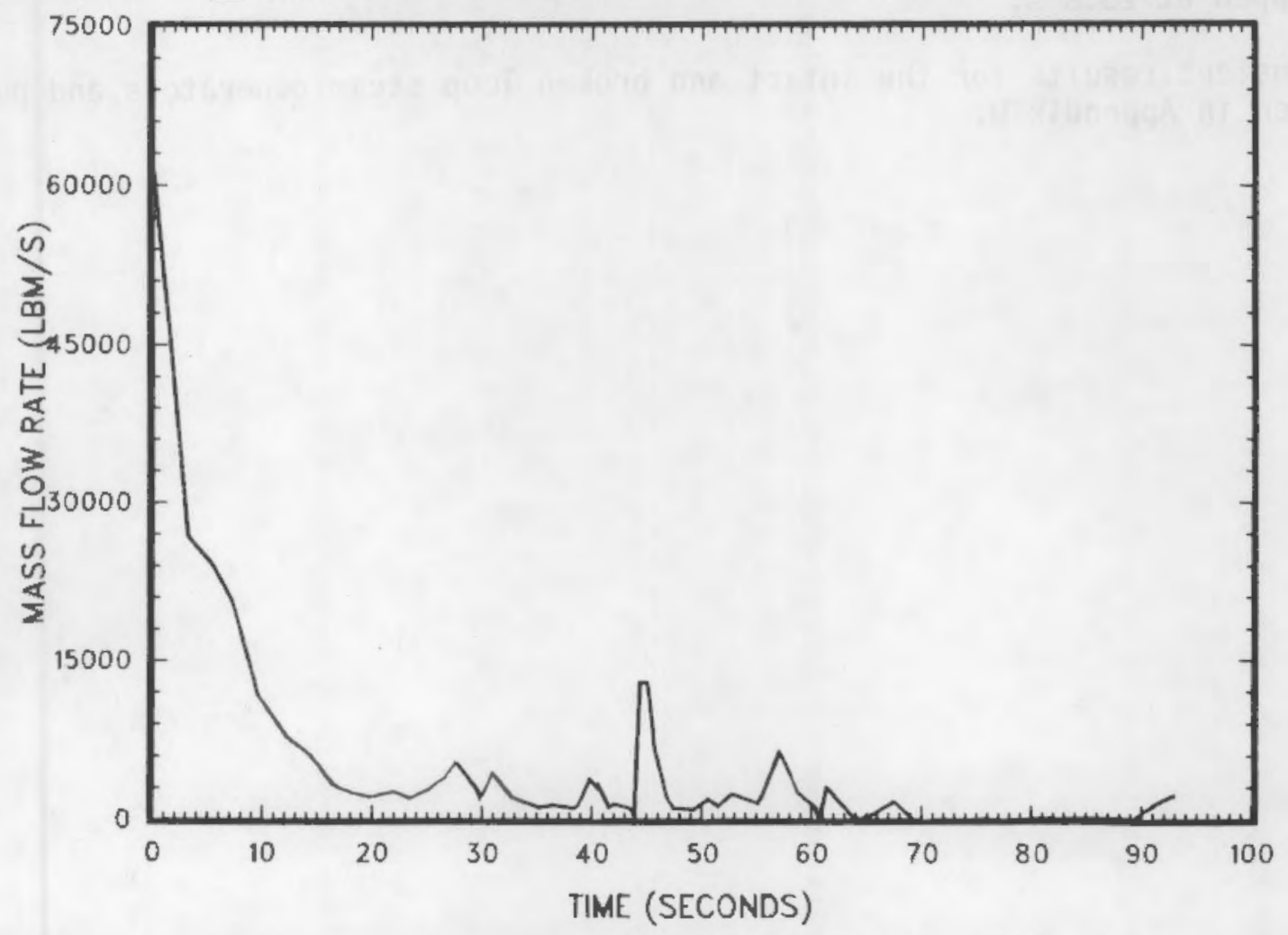

Figure 66. Cold leg mass flow rate on the vessel side of the break vs. time 
The void fraction in the broken loop hot leg is plotted in Figure 67. It rapidly increased as the upper plenum flashed. Beginning at $4 \mathrm{~s}$, the decreased void fraction in the hot leg was caused by the increased level of liquid in the upper plenum during lower plenum flashing, pressurizer discharge, and UHI injection, as described earlier. The large flow rate at this time is shown in Figure 68. It also indicates that flow was always out the broken hot leg.

\subsubsection{UHI Components}

The UHI components merely acted as a special boundary condition. The mass flow rate of liquid from the accumulator is shown in Figure 69. It was increasing with time as the pressure difference between the upper head and accumulator increased. This is in contrast to the cold leg accumulators where the flow rate decreased with time (Figure 54). The UHI accumulator has a larger gas volume than the cold leg accumulator $\left(1800 \mathrm{ft}^{3}\right.$ vs $\left.230 \mathrm{ft}^{3}\right)$. The pressure in the UHI accumulator drops more slowly than the system pressure causing an increasing pressure difference and thus an increasing flow rate with time. Also, the system pressure is decreasing more rapidly during UHI injection. In contrast, the pressure in the cold leg accumulator drops more rapidly than the system pressure causing a decreasing pressure difference and thus a decreasing flow rate with time. The sudden increase in UHI flow rate at about $15 \mathrm{~s}$ was caused by the decreased upper head pressure during condensation.

Figure 70 shows the liquid volume discharged from the UHI accumulator. The accumulator had discharged $1000 \mathrm{ft}^{3}$ into the upper head when injection was stopped at $23.8 \mathrm{~s}$.

Transient results for the intact and broken loop steam generators and pumps are given in Appendix $D$. 


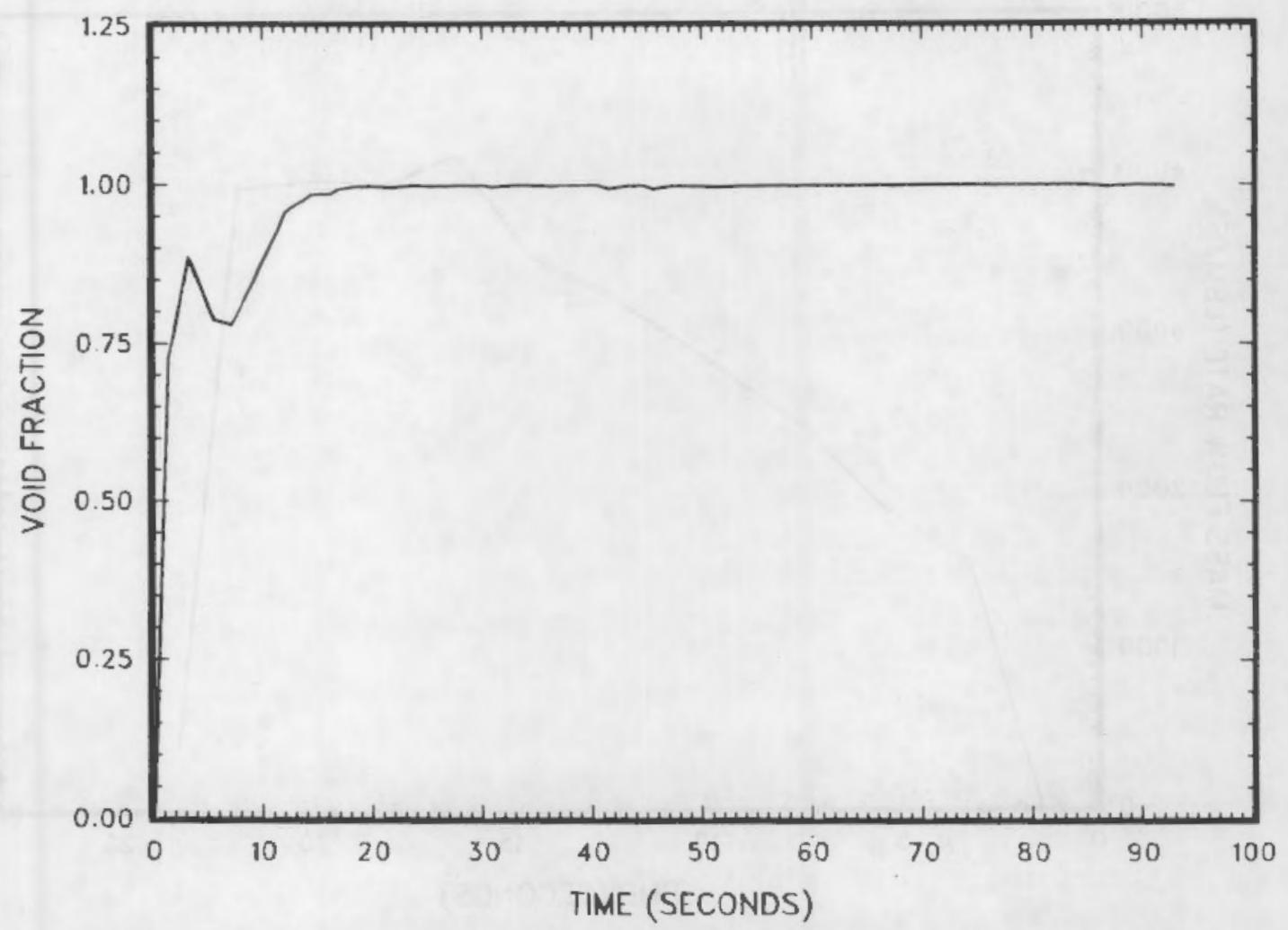

Figure 67. Hot leg void fraction for the broken loop vs. time

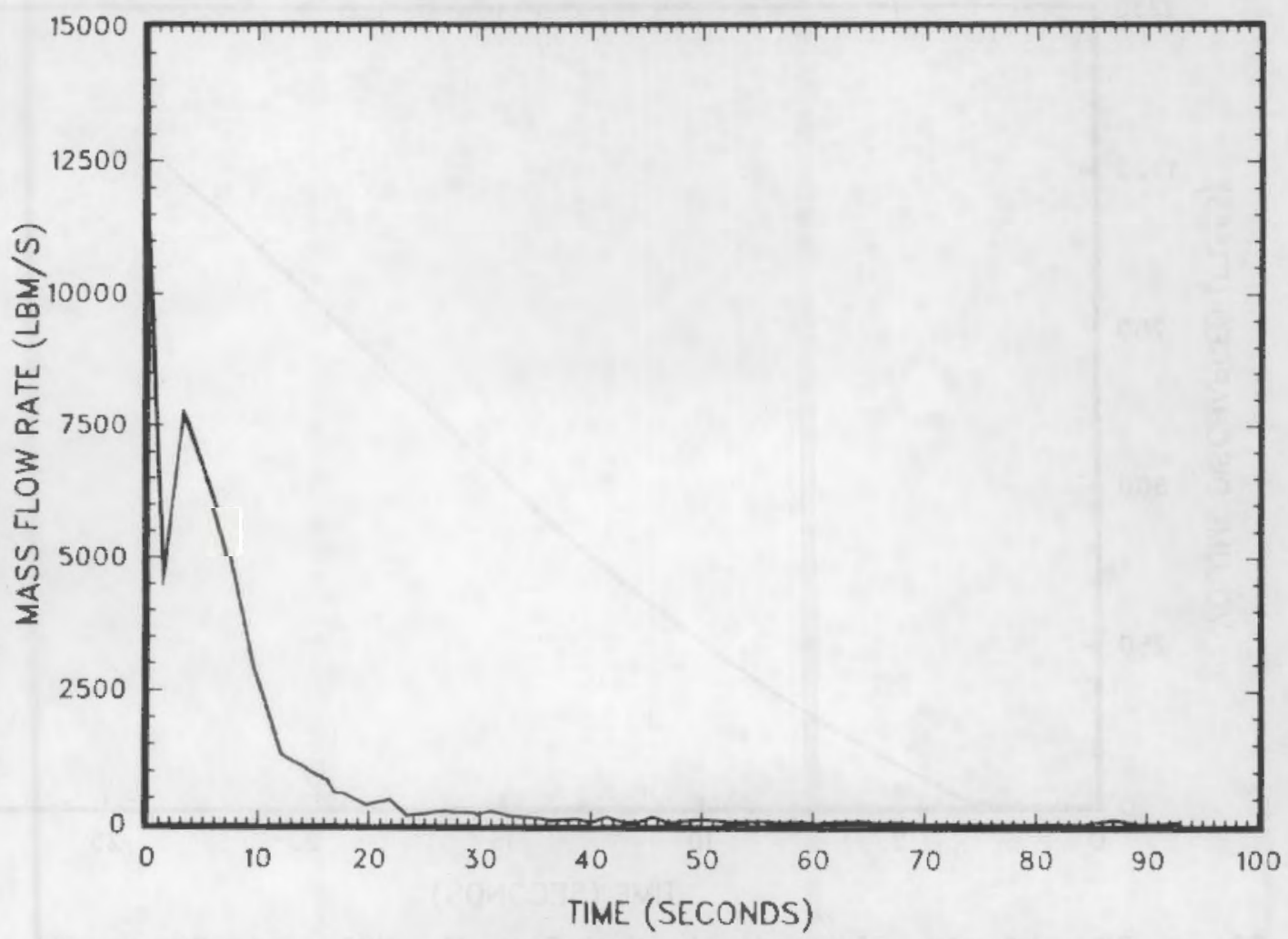

Figure 68. Hot leg mass flow rate for the broken loop vs. time 


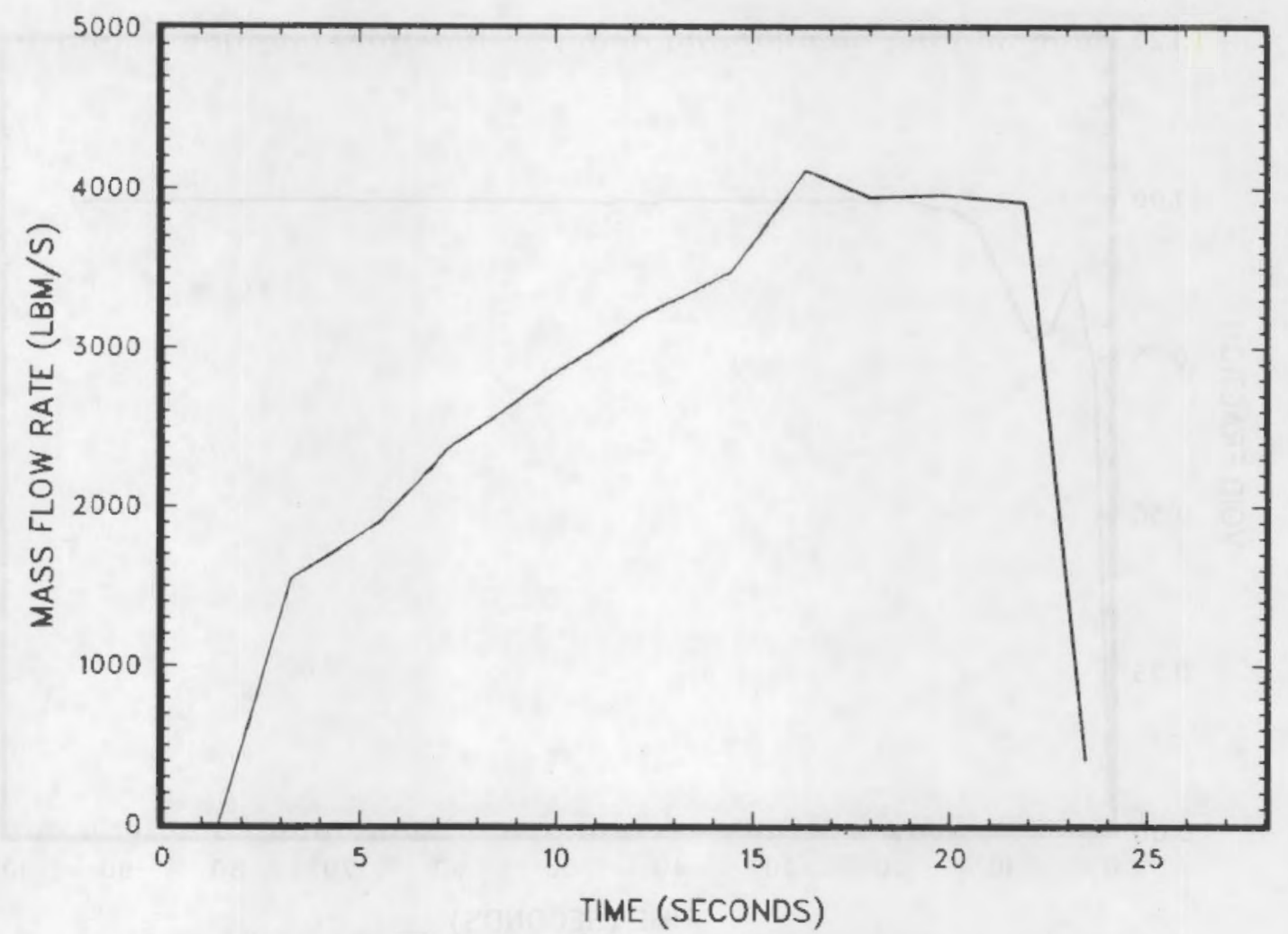

Figure 69. Mass flow rate from the UHI accumulator vs. time

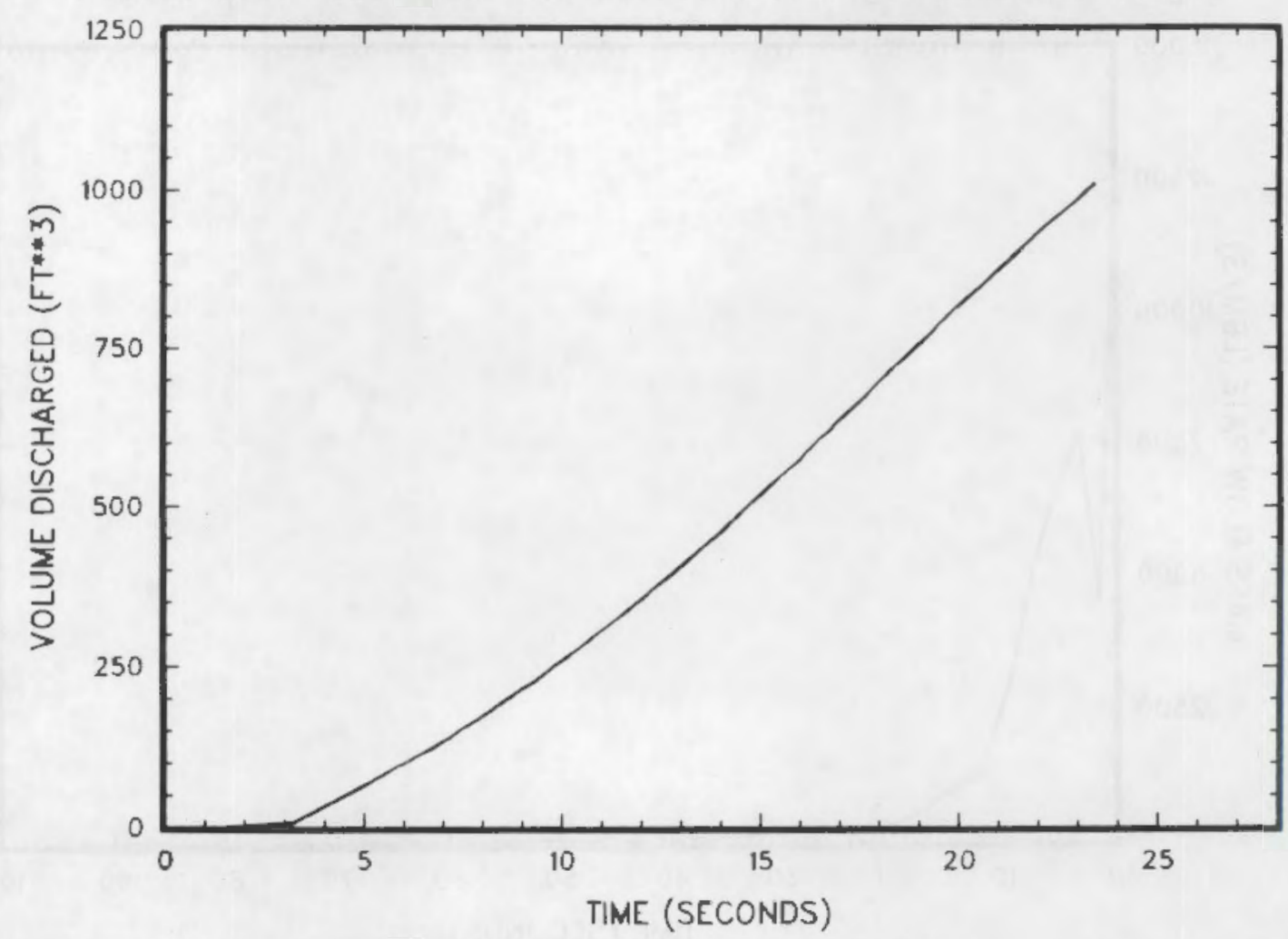

Figure 70. Liquid volume discharged from the UHI accumulator vs. time 


\subsection{COMPARISON WITH WESTINGHOUSE ANALYSIS}

Westinghouse analyzed the emergency core cooling system of the UHI plant using the SATAN-VI computer code. SATAN was developed by Westinghouse and licensed by the NRC to perform thermal-hydraulic calculations using a drift flux model. It satisfies the requirements in 10CFR50.46, "Acceptance Criteria for Emergency Core Cooling Systems for Light Water-Cooled Nuclear Power Reactors." This section shows a comparison between the SATAN and COBRA/TRAC results.

SATAN uses a control volume approach to predict the blowdown and refill behavior following a loss-of-coolant accident. The SATAN mesh consisted of 52 control volumes in the vessel and loops. Two control volumes were used in the upper head, one in the guide tubes, and another in the support columns. For comparison, the COBRA/TRAC noding used 196 mesh cells in the upper head, guide tubes, and support columns. This detailed mesh better approximated the vertical and horizontal enthalpy profiles in the upper head which is important for adequate predictions of the flashing and condensing behavior.

Because of the coarse SATAN noding, Westinghouse ran two calculations that used bounding assumptions for the degree of mixing in the upper head. The first calculation assumed no energy transfer between the two SATAN control volumes in the upper head. It was called the imperfect mixing calculation. In this case the cold liquid injected into the lower volume would not mix with the fluid above the guide tubes in the upper volume. This allowed liquid in the upper volume to saturate, flash to steam, and force liquid out of the lower control volume, down the support columns and into the core.

The second calculation assumed the temperature was the same in both of the upper head control volumes. In this "perfect mixing" calculation the injection of cold water prevented both volumes from flashing during blowdown. Less liquid was forced down the support columns for this case.

Figure 71 shows the core pressure as predicted by SATAN and COBRA/TRAC. The SATAN calculation predicted a higher pressure because Westinghouse used a lower break discharge coefficient of 0.6 (COBRA/TRAC used 1.0). The shape of the pressure transients are similar.

Figures 72 and 73 compare the SATAN clad temperatures to COBRA/TRAC. Figure 72 shows the SATAN results for the imperfect mixing assumption. Both calculations predicted that water from the upper head would quench the core during blowdown at about $15 \mathrm{~s}$. Then after $20 \mathrm{~s}$ the evaluation model required the core to be unquenched causing the SATAN temperature to increase. The best-estimate COBRA/TRAC calculation predicted that the core would remain cool as water continued to flow down through the core from the upper head. The core did not quench during blowdown in the perfect mixing SATAN calculation as shown in Figure 73 because less water flowed through the core.

The effect of mixing assumption on the delivery rate from the upper head to the core is seen by comparing the support column flow rates in Figures 74 and 75 . 


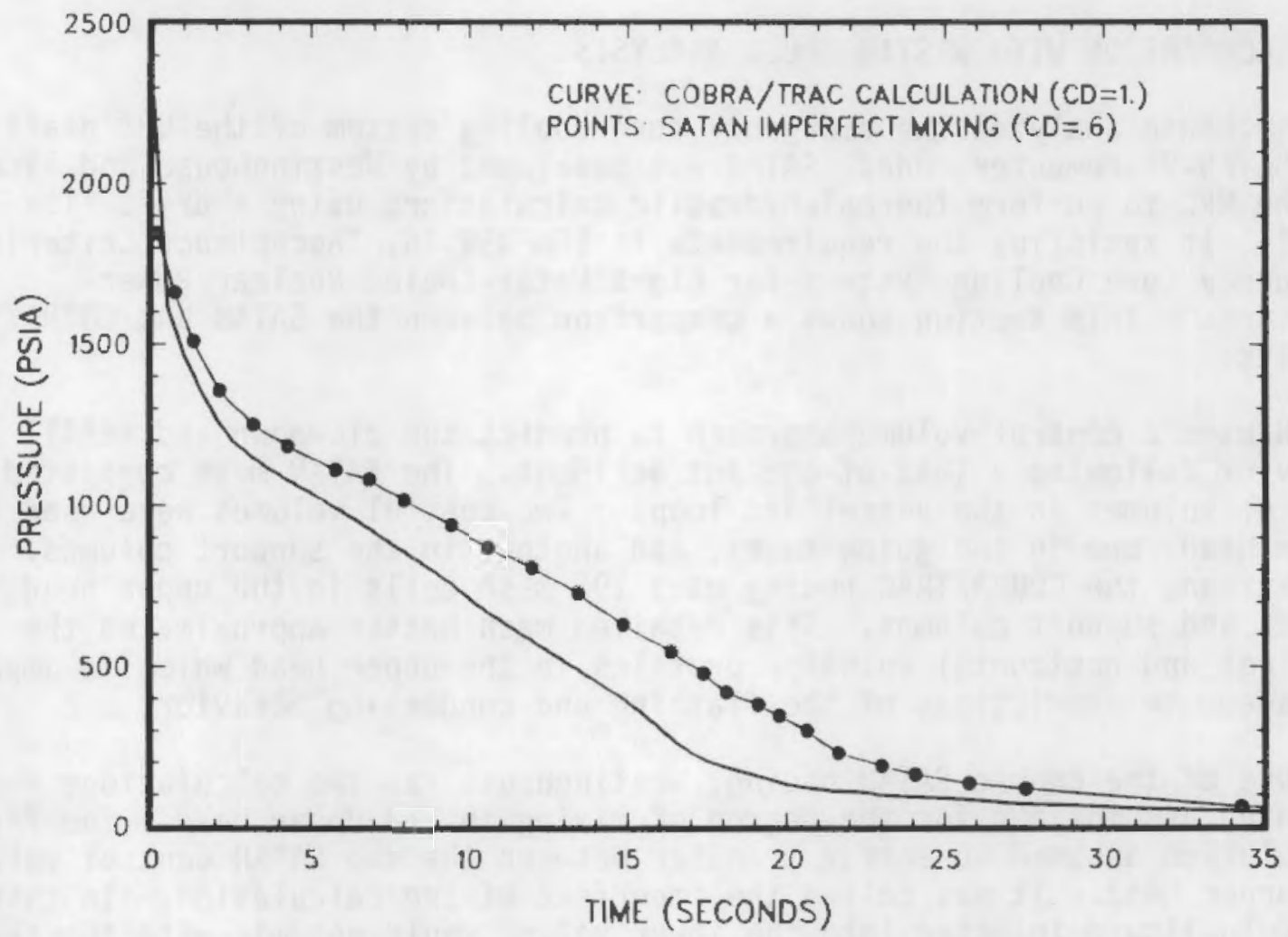

Figure 71. Core pressure for COBRA/TRAC and SATAN (imperfect mixing)

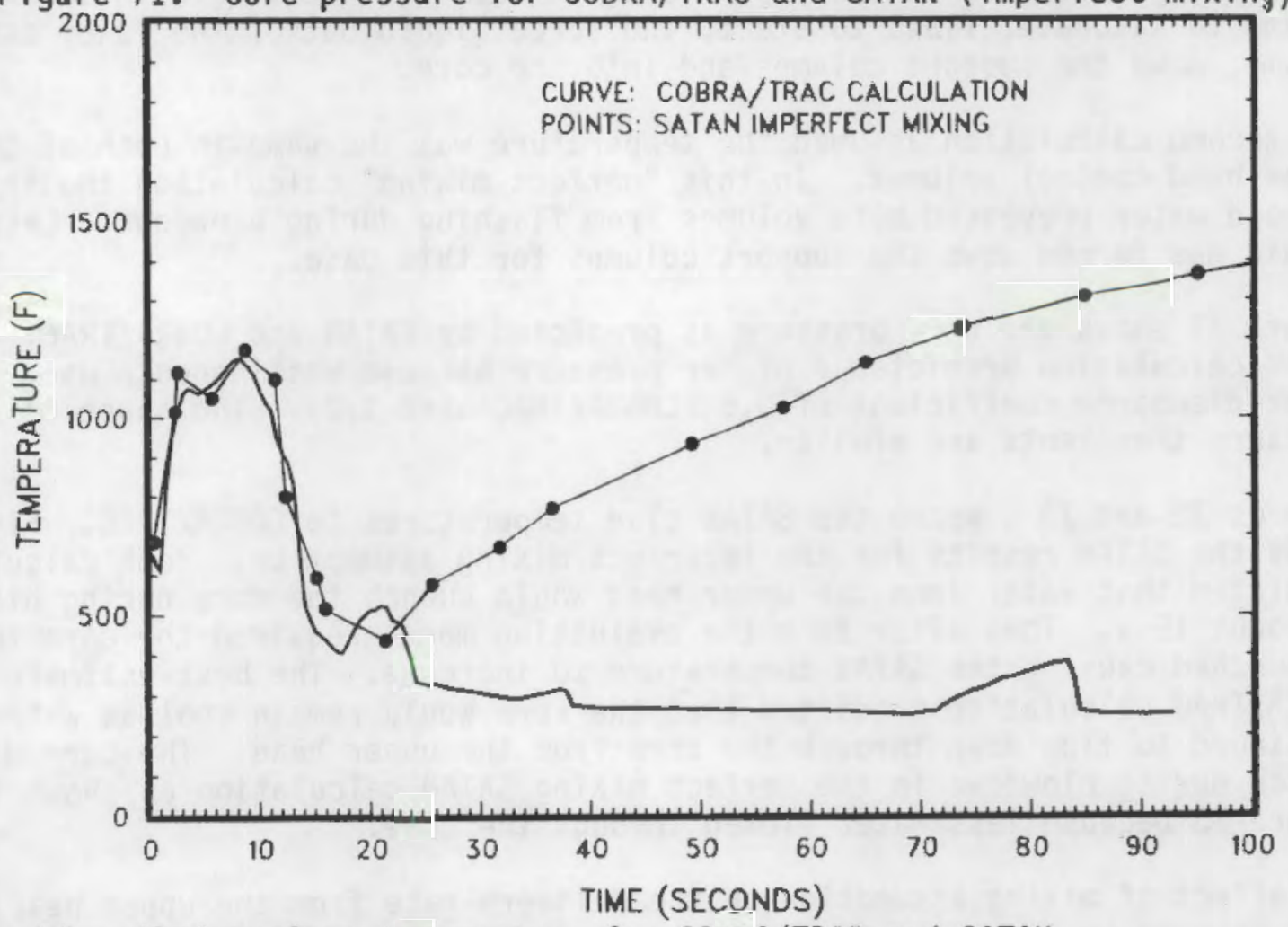

Figure 72. Clad surface temperature for COBRA/TRAC and SATAN (imperfect mixing) 


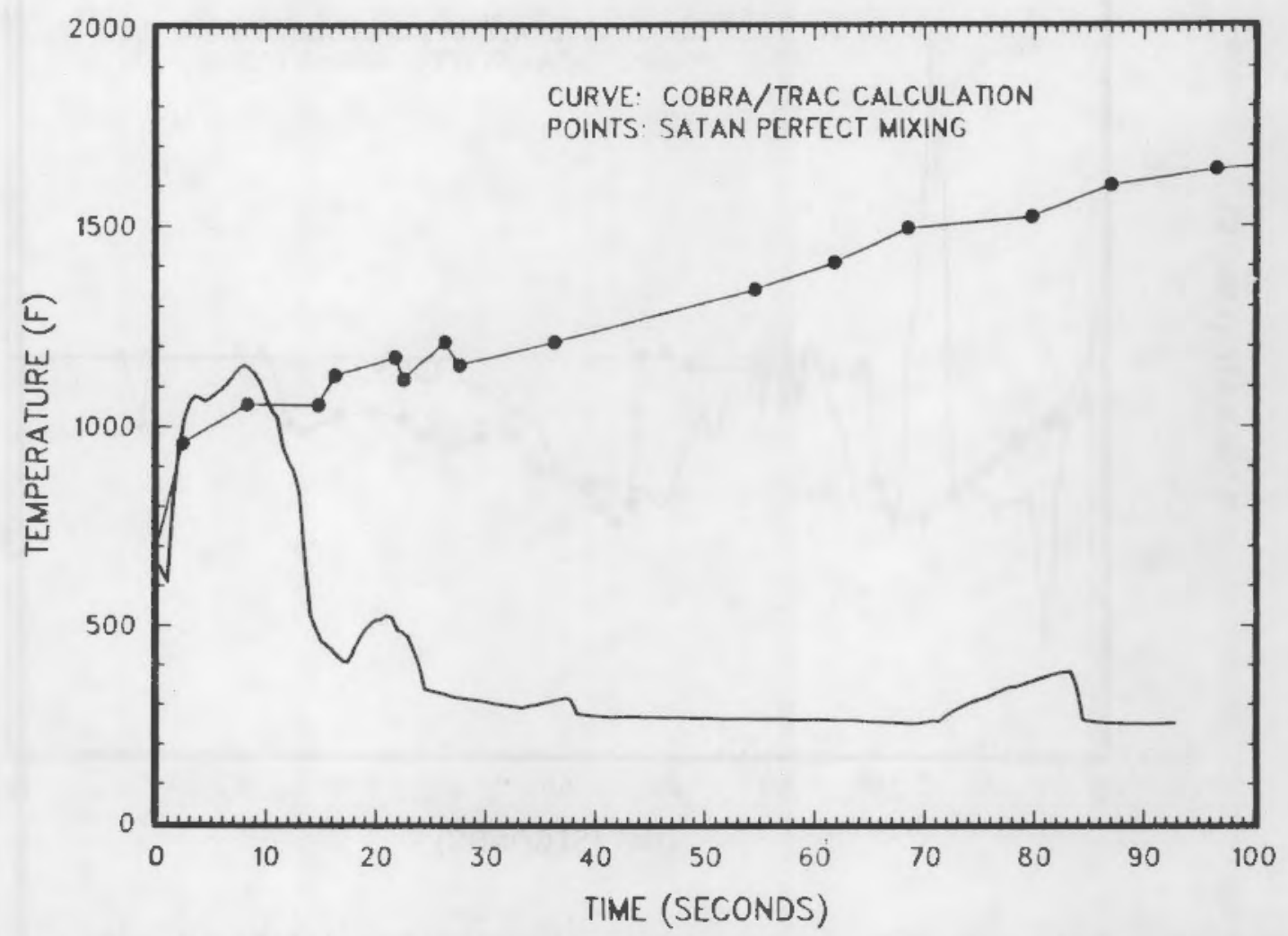

Figure 73. Clad surface temperature for COBRA/TRAC and SATAN (perfect mixing)

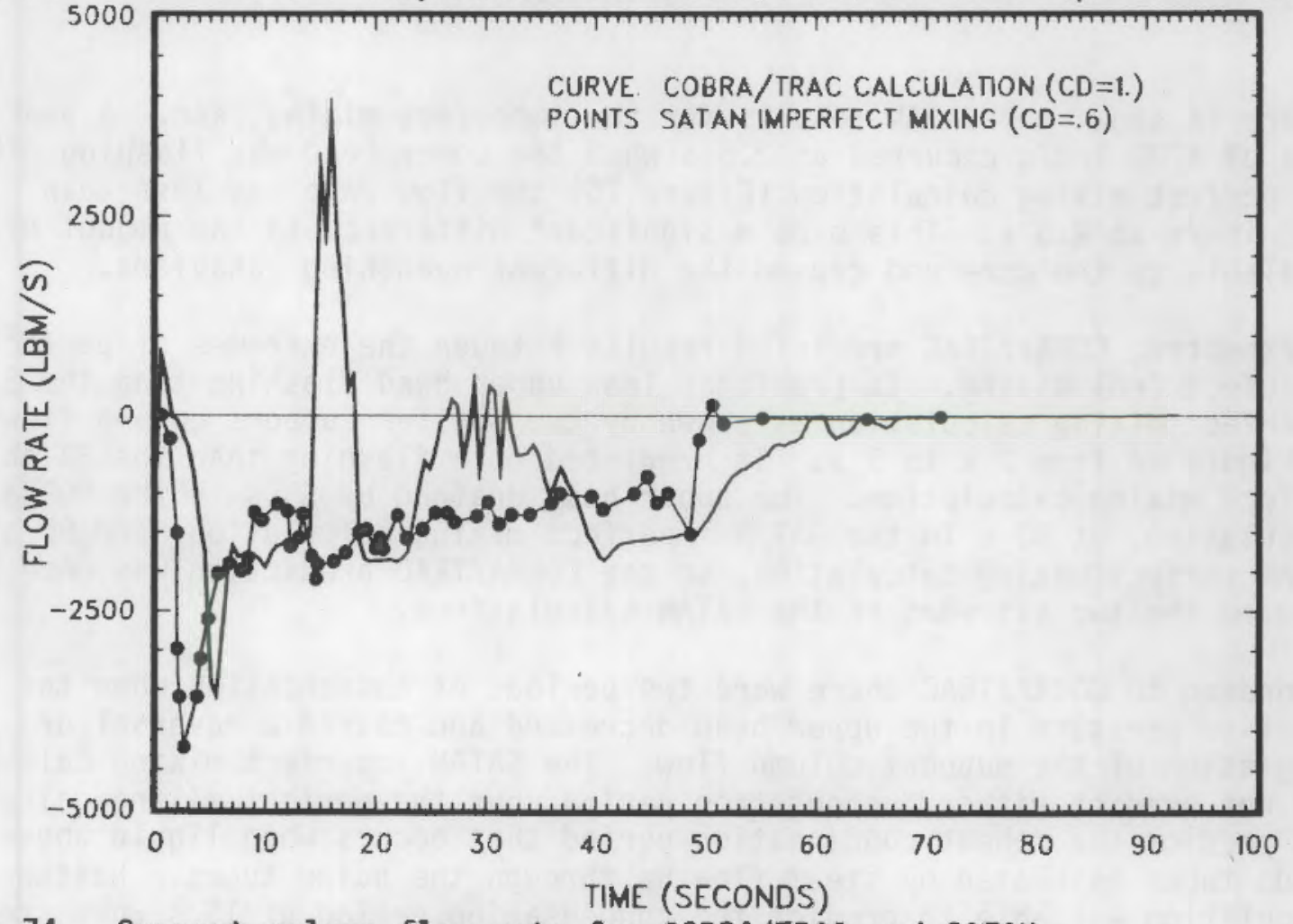

Figure 74. Support column flow rate for COBRA/TRAC and SATAN (imperfect mixing) 


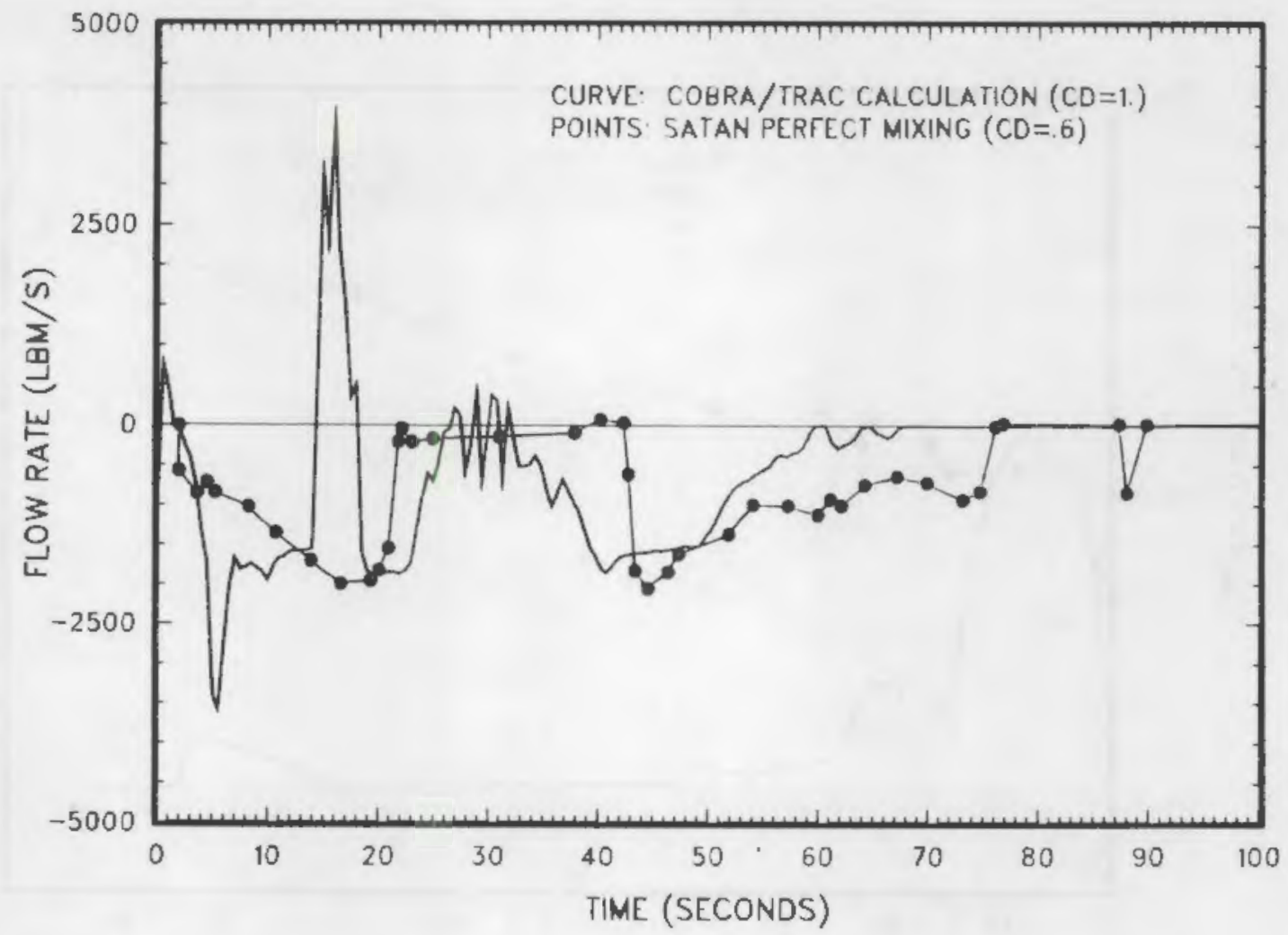

Figure 75. Support column flow rate for COBRA/TRAC and SATAN (perfect mixing)

Figure 74 shows the SATAN results for the imperfect mixing case. A peak flow rate of $4200 \mathrm{lbm} / \mathrm{s}$ occurred at $2.5 \mathrm{~s}$ when the upper head was flashing. But, in the perfect mixing calculation (Figure 75 ) the flow rate was less than $1000 \mathrm{lbm} / \mathrm{s}$ at $2.5 \mathrm{~s}$. This made a signficant difference in the amount of liquid available to the core and caused the different quenching behaviors.

As expected, COBRA/TRAC predicted results between the extremes of perfect and imperfect (no) mixing. It predicted less upper head flashing than the SATAN imperfect mixing calculation as shown by the smaller support column flow rate in Figure 74 from $2 \mathrm{~s}$ to $\mathrm{B} \mathrm{s}$. It predicted more flashing than the SATAN perfect mixing calculation. The upper head drained by $58 \mathrm{~s}$ in the COBRA/TRAC calculation, at $50 \mathrm{~s}$ in the SATAN imperfect mixing calculation, and $90 \mathrm{~s}$ in the SATAN perfect mixing calculation, so the COBRA/TRAC prediction was once again between the two extremes of the SATAN calculations.

According to COBRA/TRAC there were two periods of condensation when the relative pressure in the upper head decreased and caused a reversal or stagnation of the support column flow. The SATAN imperfect mixing calculation did not predict either condensation period, but the perfect mixing calculation did predict the reheat condensation period that occurs when liquid above the guide tubes is heated by steam flow up through the guide tubes. Neither SATAN calculation was able to predict the condensation period at $15 \mathrm{~s}$ when steam in the upper part of the upper head condensed on the cold liquid in the lower part. 
Figures 76 and 77 show the flow rates in the guide tubes. The COBRA/TRAC result is closer to the SATAN imperfect mixing results because both calculations predicted the flashing behavior in the upper head.

The core inlet flow rates are plotted in Figures 78 and 79 . Liquid flowing down through the core reached a peak flow rate at $16 \mathrm{~s}$ in the SATAN imperfect mixing calculation (Figure 78 ), but did not reach a peak until $22 \mathrm{~s}$ in the perfect mixing calculation (Figure 79). This time delay partially accounts for the different quenching behaviors of the two calculations. The quench temperature decreases rapidly as the pressure decreases below 150 psia. At $16 \mathrm{~s}$ the quench temperature is higher than the clad temperatures so the clad quenched. In the perfect mixing calculation at $22 \mathrm{~s}$, the quench temperature has decreased below the clad temperature preventing quench. This pressure dependence of the quench temperature will be discussed in more detail in the next section.

The UHI accumulator flow rates are plotted in Figure 80 , The two programs predicted similar results with the SATAN calculation delivering more liquid early in the calculation. The flow rate from the cold leg accumulator is shown in Figure 81. Again the results are similar with the SATAN calculation beginning delivery about 3 s later. This was caused by the slower rate of depressurization in the SATAN calculations which used a smaller break discharge coefficient.

In general, there is good agreement between the COBRA/TRAC and SATAN analyses. The blowdown quench was predicted by both codes if flashing occurred in the upper head. COBRA/TRAC compares better with the SATAN imperfect mixing assumption during blowdown out to $15 \mathrm{~s}$ when COBRA/TRAC predicted the upper head would refill with liquid. After $15 \mathrm{~s}$ the SATAN perfect mixing calculation compares better with the COBRA/TRAC results. 


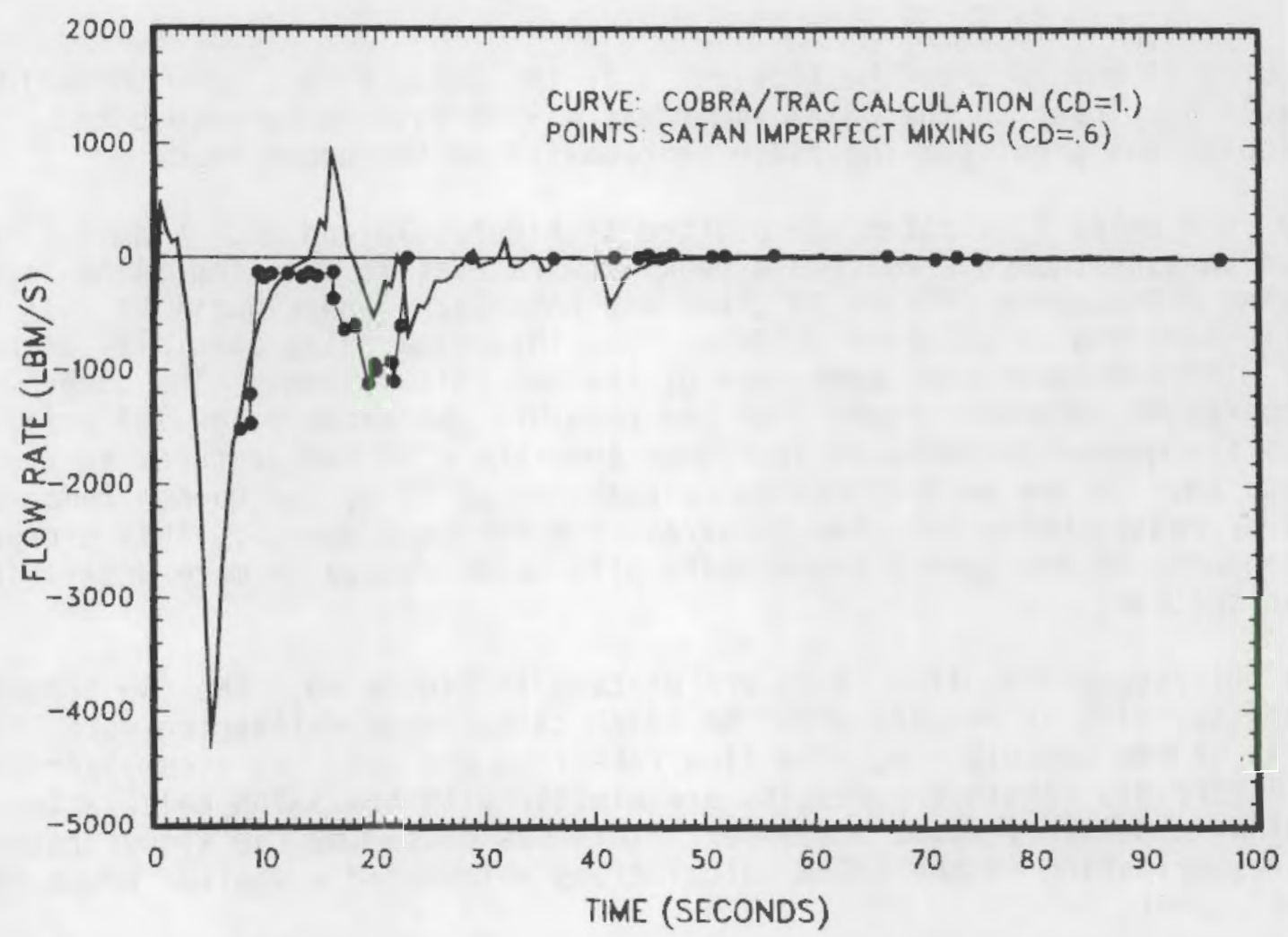

Figure 76. Guide tube flow rate for COBRA/TRAC and SATAN (imperfect mixing)

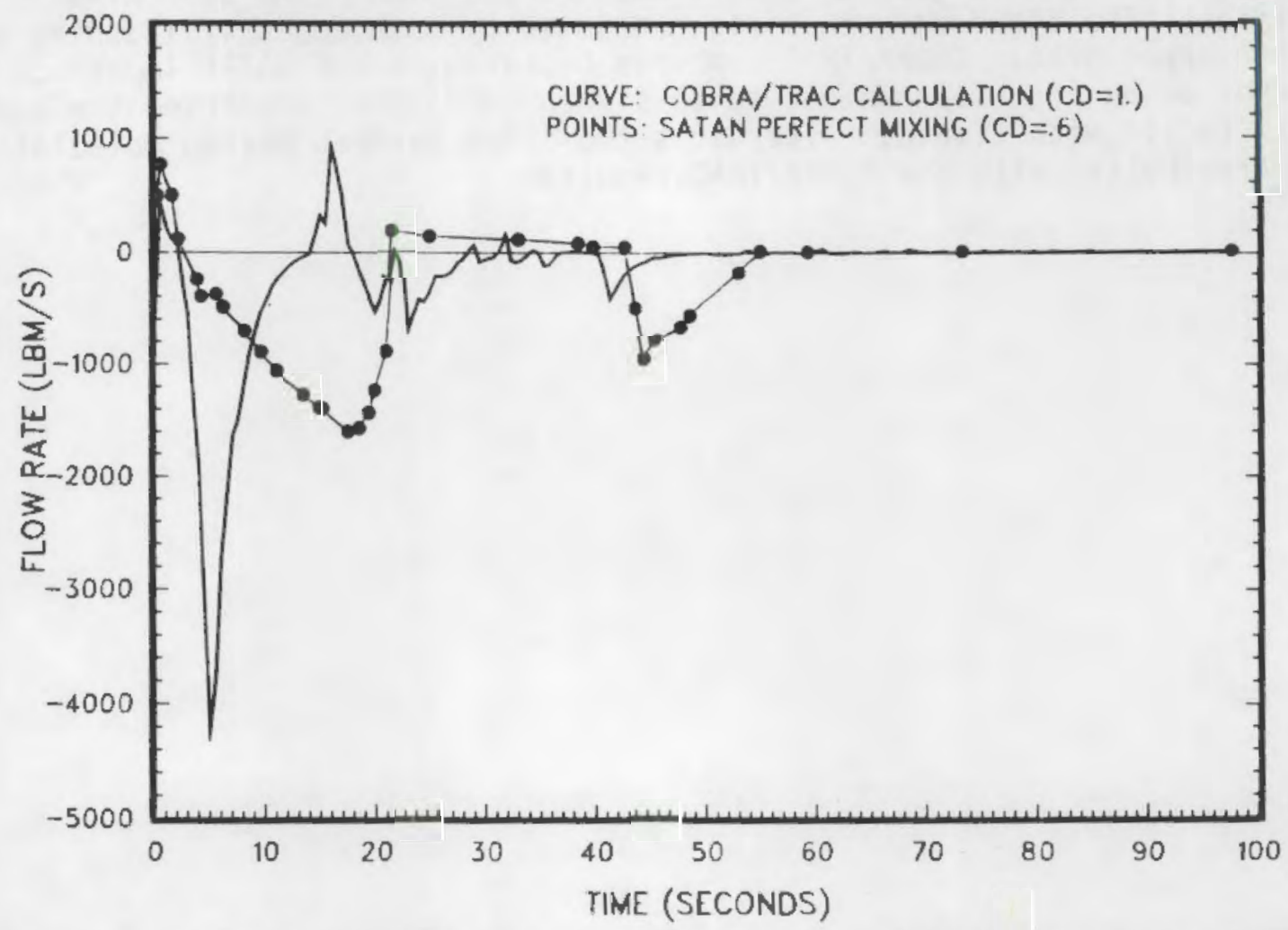

Figure 77. Guide tube flow rate for COBRA/TRAC and SATAN (perfect mixing) 


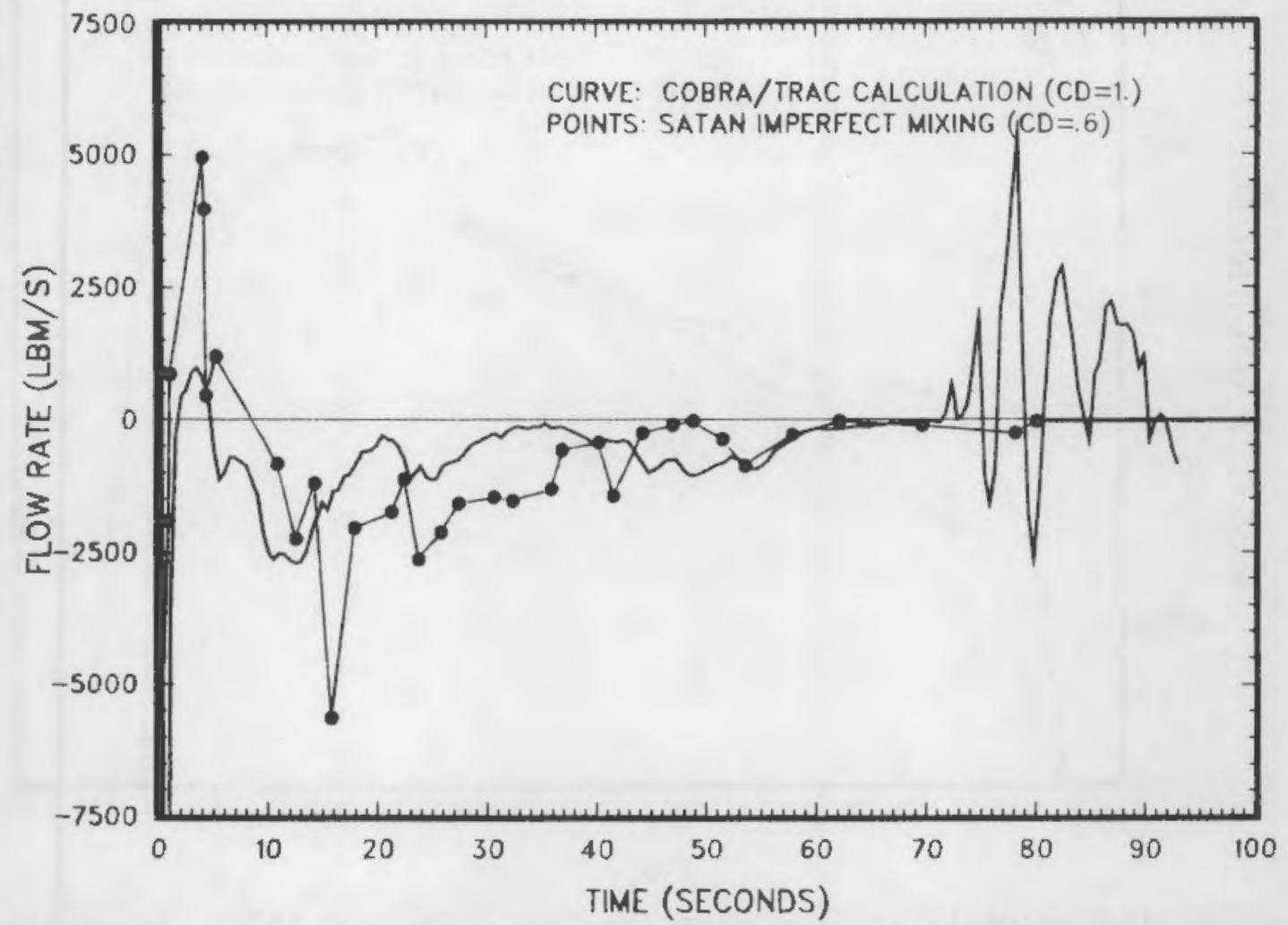

Figure 78. Core inlet flow rate for COBRA/TRAC and SATAN (imperfect mixing)

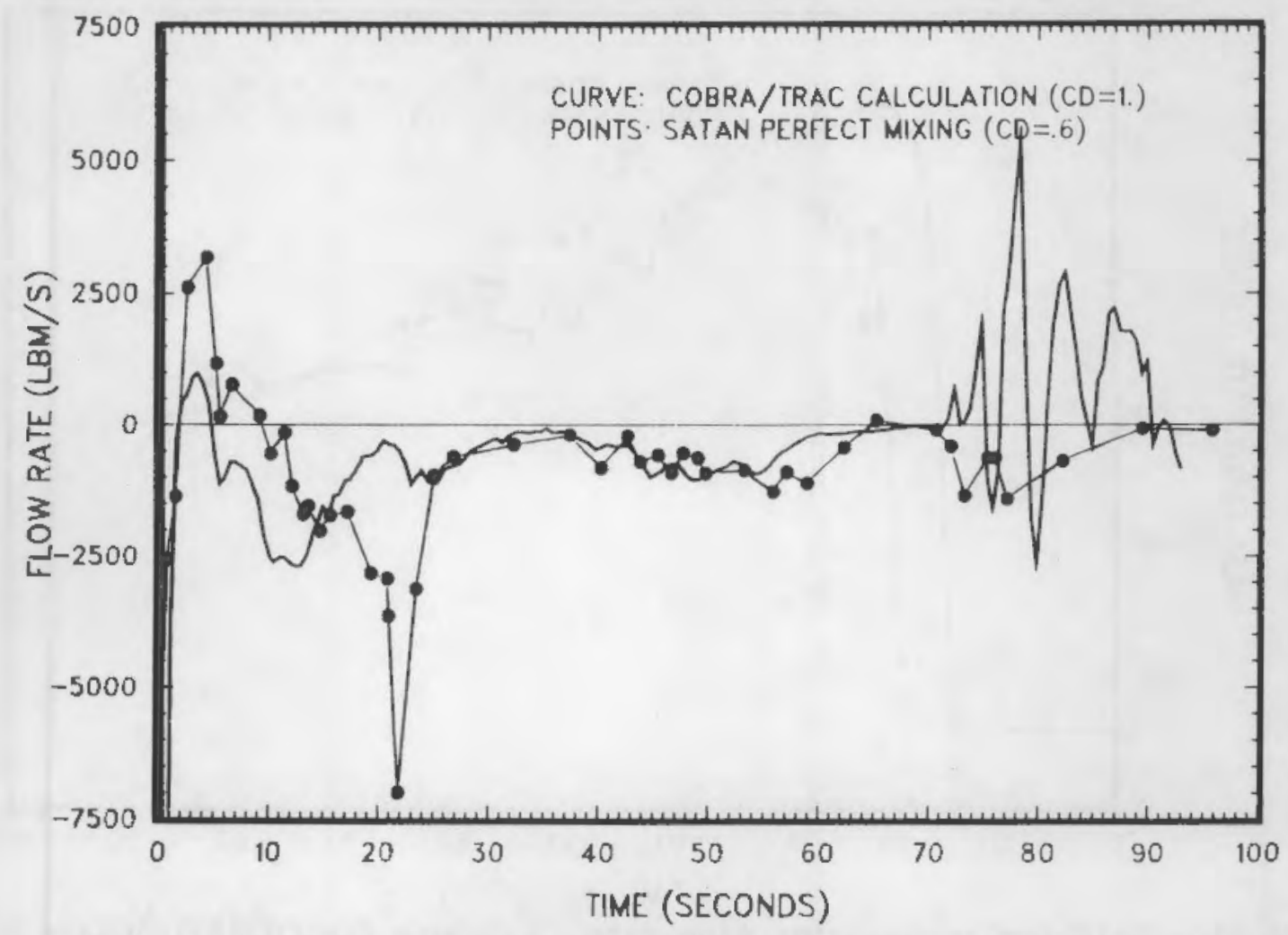

Figure 79. Core inlet flow rate for COBRA/TRAC and SATAN (perfect mixing) 


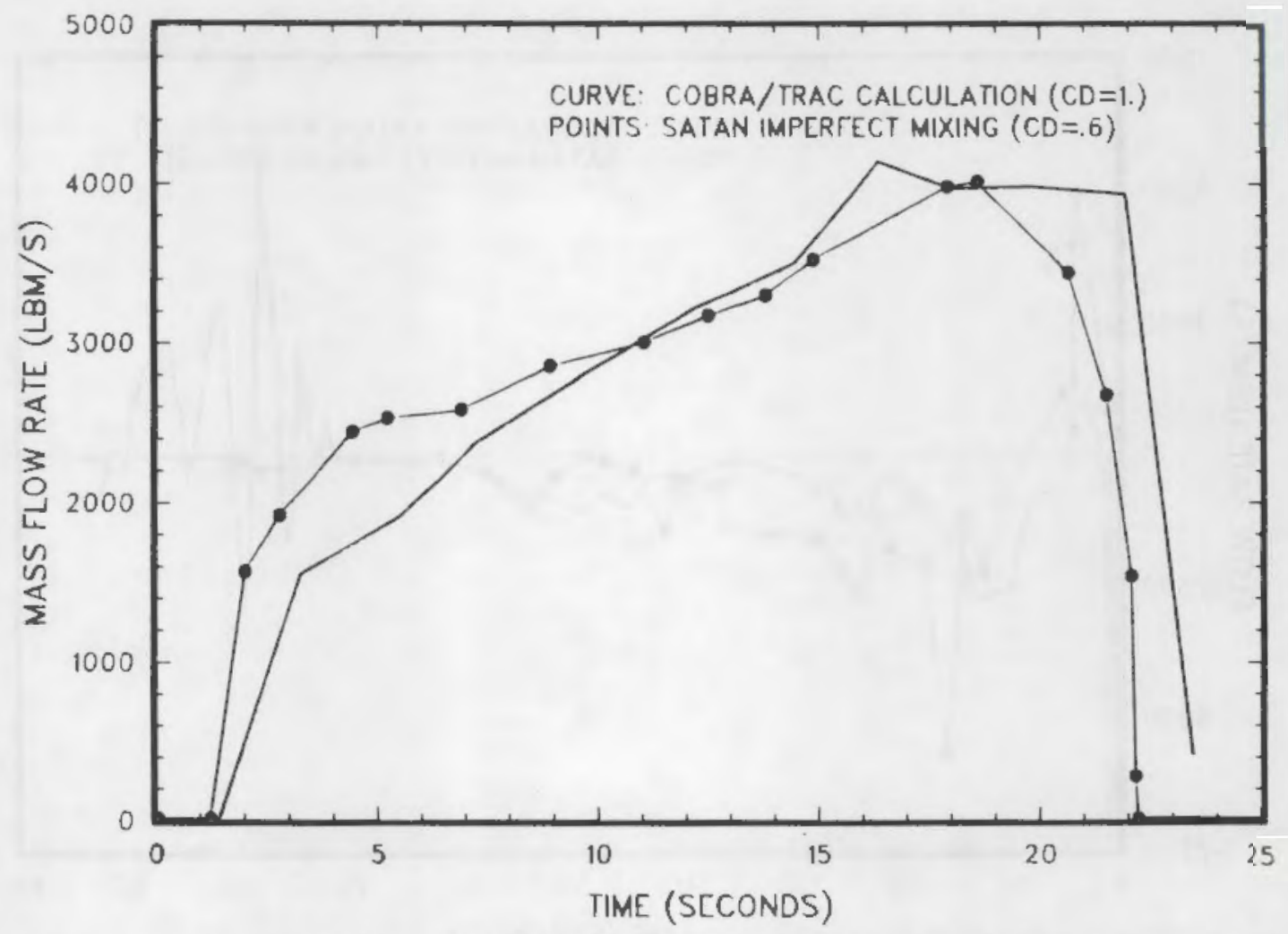

Figure 80. UHI accumulator flow rate for COBRA/TRAC and SATAN (imperfect mixing)

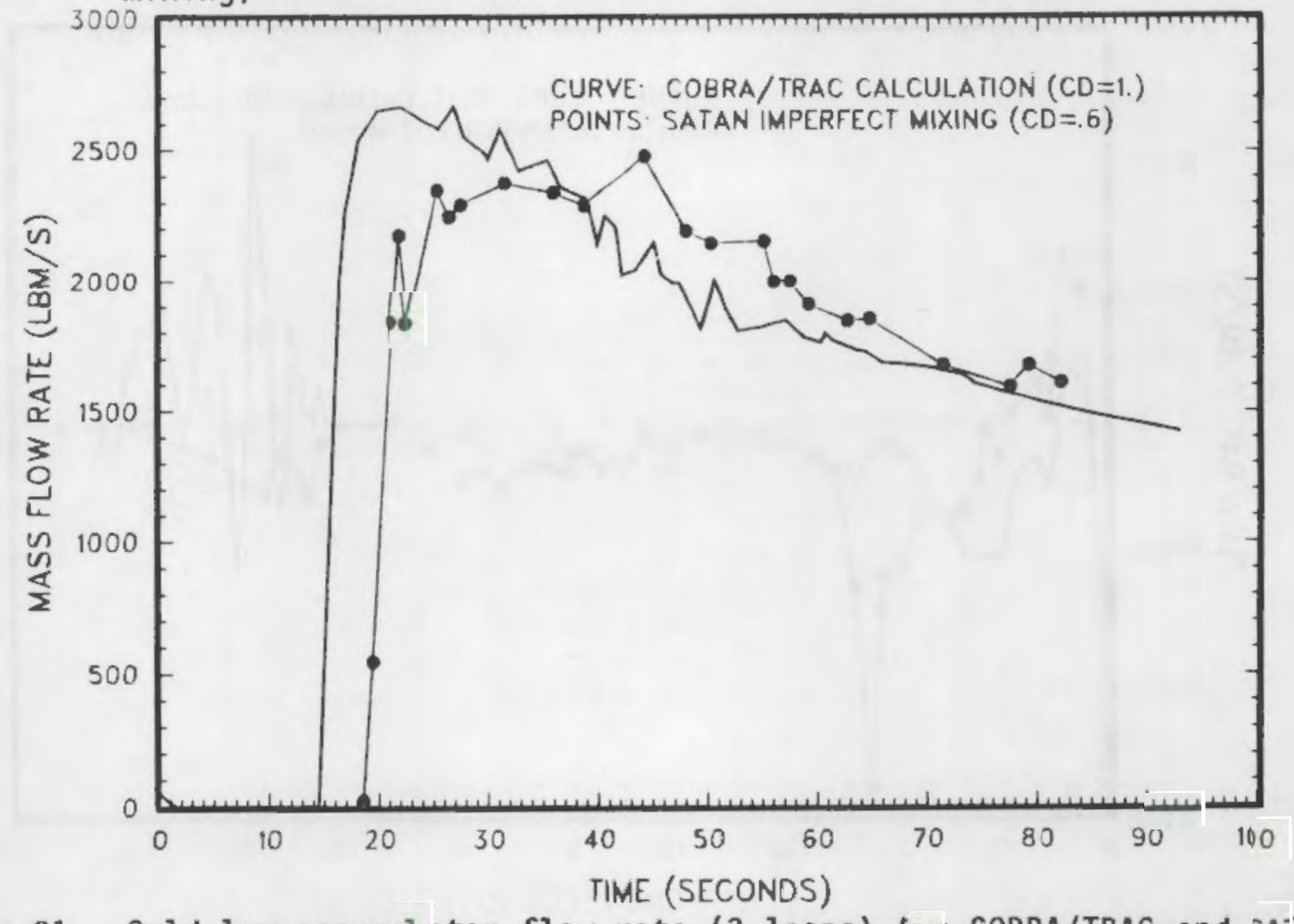

Figure 81. Cold leg accumulator flow rate (3 loops) for COBRA/TRAC and SATAN (imperfect mixing) 


\subsection{SIGNIFICANT FINDINGS}

COBRA/TRAC predicted an early quench of the core by water from the upper head. Quenching occurred because water was delivered to the core while the system pressure was still high (greater than 400 psia). Recent analysis of Westinghouse top reflood G-2 data $(a)$ and comparisions with quench temperature data from General Electric (Ref. 8) and LOFT L2-3 (Ref. 9) indicate a minimum film boiling temperature $\left(T_{\text {min }}\right.$ ) of $1200 \mathrm{~F}$ is appropriate at pressures above 150 psia. This is considerably higher than the $T_{\min }$ of $800 \mathrm{~F}$ used for all pressures in other codes such as TRAC and RELAP.

The quench temperature is the temperature at which liquid comes in contact with the rod and nucleate boiling is reestablished. It is interpreted from thermocouple data as the point where the temperature rapidly decreases. Tmin
also indicates wetting of a rod, but applies only to rods that were in the $\mathrm{f}_{1 \mathrm{~m}}$ boiling heat transfer regime prior to reflood. The stable vapor film isolating the liquid from the rod starts to break down at $\mathrm{T}_{\text {min }}$ allowing liquid to contact the rod.

Quench temperature data can be used to determine $T_{\min }$ if the data meets two conditions. First, liquid must be available to quench the rod. Second, the initial rod temperatures must be greater than $T_{\text {min. Figure }} 82$ shows quench data from General Electric and LOFT as a function of pressure (the G-2 data is not shown because it is proprietary) quenching occurs over a range of temperatures from 800 to $1200 \mathrm{~F}$. The curve shows $T_{\min }$ as predicted by COBRA/TRAC. As just mentioned, two conditions must be met to obtain a value of $T_{\text {min }}$ from quench temperature data. This data was measured at locations that had plenty of liquid available to quench the rod, so the first condition was met. The second condition requires that data with initial temperatures lower than $T_{\text {min }}$ not be used. Quench data with initial temperatures lower than $1200 \mathrm{~F}$ were removed from Figure 82 and are plotted in Figure 83 . Initial temperatures are indicated by a bar above each data point. This figure shows that quenchina occurs after the wall temperature falls below $1200 \mathrm{~F}$. Although the amount of data in this figure is limited, the $1200 \mathrm{~F}$ limit was actually developed using just G-2 data. Comparisions were made with the GE and LOFT data later, to justify this value of $T_{\text {min }}$ using publicly available data. The fact that independent comparisions of quench temperature yield the same upper limit on $T_{\text {min }}$ strengthens the argument of using $1200^{\circ} \mathrm{F}$ as an upper limit.

A higher $T_{\text {min }}$ allows earlier quenching of the core. Liquid must be delivered to the core before the pressure falls below 150 psi and before the clad temperature exceeds $1200 \mathrm{~F}$. Both conditions were met in this calculation. However, had the stored energy of the fuel been larger, the initial heatup may have raised the temperature above $1200 \mathrm{~F}$ which would delay the onset of transition boiling and increase the time to quench. Therefore, early quenching is sensitive to anything that effects the stored energy in the fuel rods such as gap conductance and local power densities.

(a) B. A. McIntrye, Westinghouse Monroeville Nuclear Center, personal communication to C. A. McMonagle, 1976. 


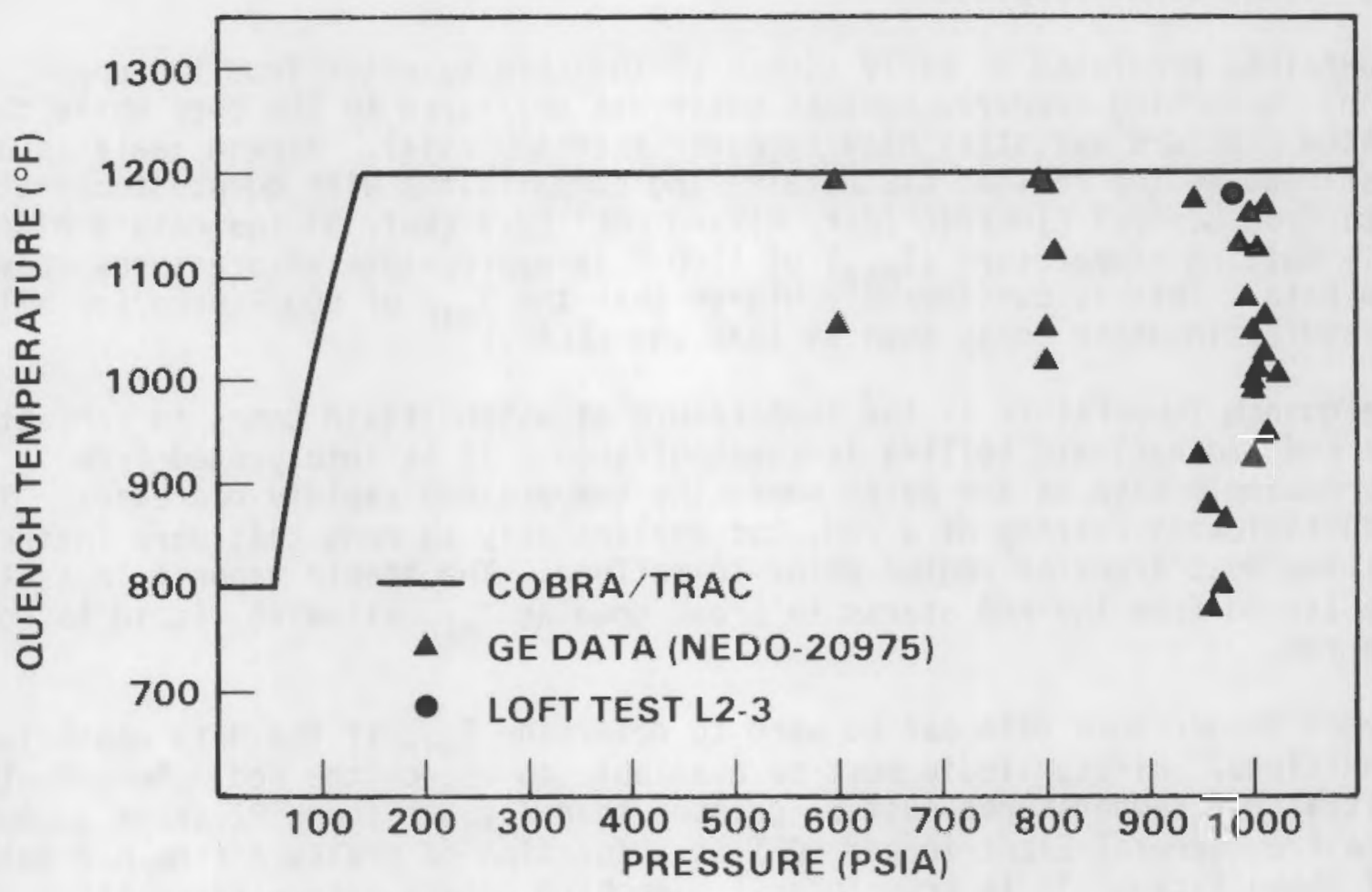

Figure 82. Quench temperature data vs. pressure

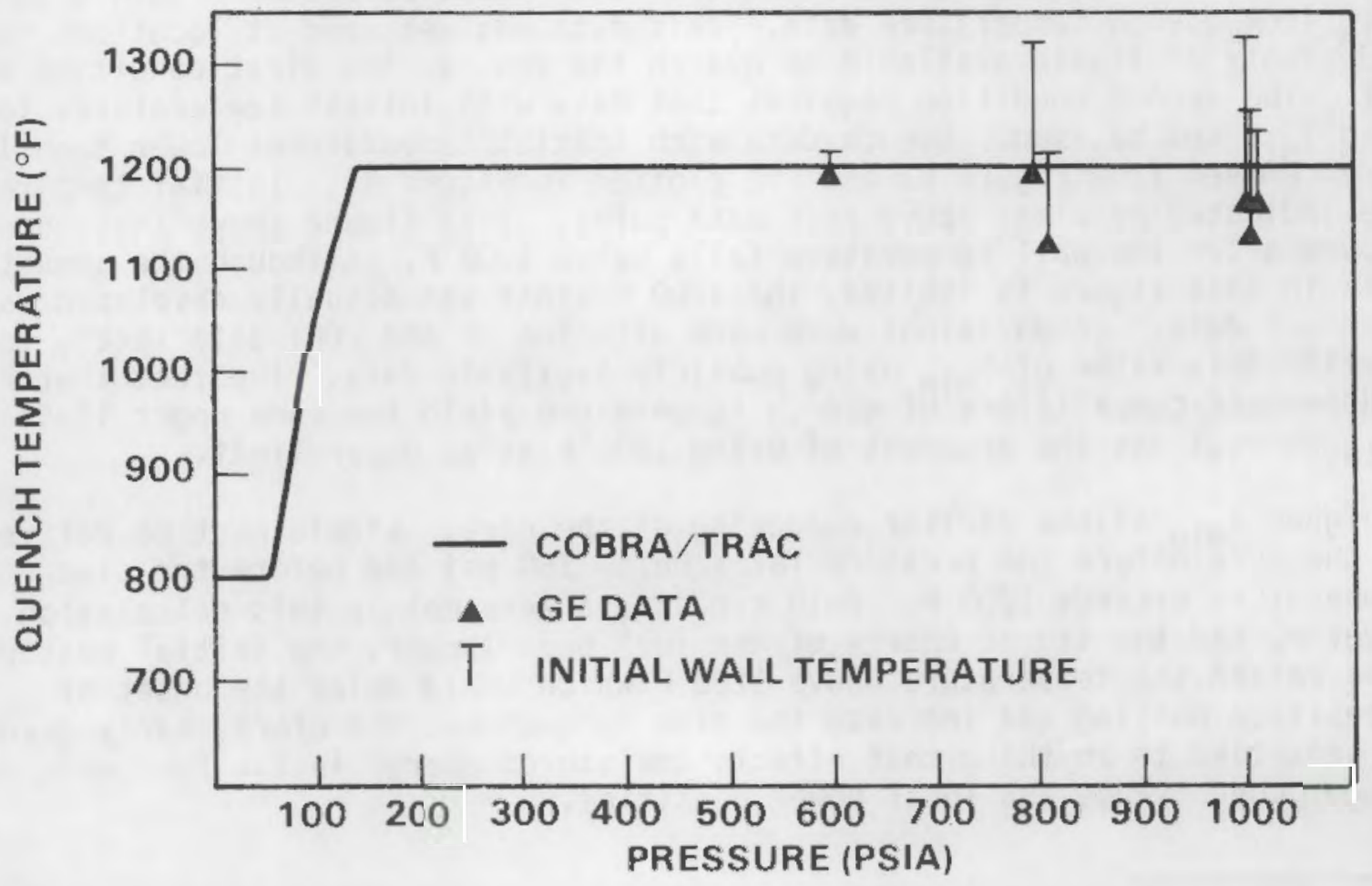

Figure 83. Quench temperature data with initial wall temperatures greater than $1200^{\circ} \mathrm{F}$ vs. pressure 
A great deal of care was used in specifying the gap conductance and power factors for this calculation. Values of gap conductance were verified using results from FRAPCON-2 (Ref 10), a best-estimate, steady-state fuel pin code. Power factors were obtained using information supplied by $\mathrm{NRC}^{(a)}$ and verified by Westinghouse. This provided assurance that the initial stored energy in the fuel was computed correctly.

A condition for early quench is delivery of liquid into the core while the pressure is high. This is possible in a UHI design, but not necessarily in a conventional PWR where significant water delivery may not occur until bottom reflood. The pressure is typically in the 20 to 30 psia range during bottom reflood, so quenching is delayed until the temperature decreases to the lower value of $T_{\min }(800 \mathrm{~F})$. However, some water is delivered to the core before bottom reflood because of lower plenum flashing. In this calculation that water quenched the lowest two feet in the core. The same behavior is expectedin a non-UHI PWR, since its lower plenum has nearly the same volume. During lower plenum flashing, the hot rod entered transition boiling, because its temperature was below $1200 \mathrm{~F}$. It was rapidly cooled but did not quench, because water was available for only a short time. Had the liquid delivery lasted longer the hot rod may have quenched.

This is what happened in LOFT experiment L2-3 where the core did quench during lower plenum flashing. It met both conditions for early quench with a pressure of 1000 psia and liquid delivery while the temperature was below $1200 \mathrm{~F}$.

Because the scaled lower plenum volume in the LOFT facility is much larger than in a PWR $(b)$, liquid delivery through the core lasted longer. This allowed additional time for transition boiling and led to quenching of the LOFT core during lower plenum flashing. The shortness of the 5.5-ft core also made quenching more likely since the froth level extended through the core. Water was also delivered to the core at high pressure as a result of upper head flashing. This can result in a total quench of the core even for a conventional PWR if the upper head volume is sufficiently large.

Because early quench depends on early and sustained delivery of liquid to the core, condensation in the upper head can also have a strong influence on the peak clad temperature. Had condensation occurred earlier, flow to the core would have been interrupted before the rods were quenched. When liquid delivery to the core resumed after condensation, the hot rod would enter transition boiling if the pressure was still above 150 psia (where $T_{\text {min }}$ is $1200 \mathrm{~F}$ ) and if the clad temperature were below $1200^{\circ} \mathrm{F}$. At lower pressures, $\mathrm{T}_{\text {min }}$ is lower. A lower $\mathrm{T}_{\text {min }}$ which might leave the rods in the film boiling regime where the reduced heat transfer could delay or prevent early quench.

The core cooling behavior is sensitive to any factors that effect the time and duration of condensation in the upper head because of the effect pressure has

(a) J. Han, Nuclear Regulatory Commission, personal communication to T. E. Guidotti, Battelle Pacific Northwest Laboratory, January 22, 1982.

(b) In LOFT the ratio of lower plenum plus core inlet volume to the core volume is 2.3 while in a PWR $(17 \times 17$ design) the ratio is 1.3 
on $T_{\min }$. These factors include the UHI accumulator setpoint pressure, the amount of mixing in the upper head and the initial temperature in the upper head. For example, had the UHI accumulator setpoint been raised to 1350 psia, instead of 1250 psia (the actual range of the setpoint is between 1200 and 1300 psia), injection would have begun at $1.6 \mathrm{~s}$ instead of $2.3 \mathrm{~s}$. Condensation would start earlier, since the cold UHI liquid began mixing with the upper head fluid sooner. With enough mixing the upper head may have remained full of subcooled liquid and never flashed. In this case, the upper head liquid would not condense, but would continue being injected into the core. However, this is not likely to occur since liquid in the upper head reaches saturation by $3.0 \mathrm{~s}$ and so there is little time for the UHI liquid to completely mix with the upper head fluid to keep it subcooled. Parametric calculations that vary upper head condensation behavior should be performed to access their effect on the peak clad temperatures.

Another significant phenomena that had an influence on clad temperature was counter-current flow limiting. It occurred at the top of the core, in the downcomer and in the guide tubes. The main influence of CCFL was to allow liquid to enter the core from one direction at a time. There were five periods of liquid delivery. Three from the top (upper head flashing, forced injection, and drain) and two from the bottom of the core (lower plenum flashing and bottom reflood). In all cases flow in one direction would inhibit flow from the other direction. Liquid from the upper head could not enter the top of the core during flashing in the lower plenum because of CCFL. Once lower plenum flashing subsided the upper head liquid entered the core. This generated vapor that prevented liquid in the downcomer and lower plenum from entering the core. Once the upper head was empty, liquid in the downcomer collapsed and rapidly filled the lower plenum and core inlet. The generation of vapor in the core as a result of UHI injection delayed the end of downcomer CCFL significantly longer than in non-UHI plants.

Multidimensional effects were predicted in the calculation. Breakdown of CCFL at the top of the core was a three-dimensional effect caused by the emptying of the pressurizer into the upper plenum. The increased pressure and liquid level above the core channel closest to the pressurizer, hindered the upward flow of vapor at the top of that channel. The vapor diverted to other channels where it exited the core and prolonged CCFL in those channels. The reduced vapor flow caused an early breakdown of CCFL that allowed liquid to enter the pressurizer side of the core $5 \mathrm{~s}$ earlier than on the opposite side of the core. This led to assymetric flows in the core and earlier quenching of the rods beneath the pressurizer's hot leg.

Another multidimensional phenomena was the venting effect that occurred in the core while the upper head was draining. Near the top of the core, corner channels were drier than the side and center channels because liquid flowed down these channels while vapor flowed up the corner channels. This had a small effect on the cooling behavior in the core allowing the dry rods in the side channels to rewet sooner than rods in the corner channels.

A multidimensional flow pattern also developed in the downcomer during ECCS delivery. In general, vapor preferred to flow up the broken cold leg side of 
the downcomer while liquid flowed down the opposite, intact side of the downcomer. However, the flow was very chaotic, because of condensation induced pressure changes in the downcomer that led to slugging in the intact cold leg.

To assess the impact of these multidimensional phenomena on the final peak clad temperature one-dimensional mesh was recently used to analyze the same transient. This model was created directly from the input for the threedimensional mesh by lumping the flow areas, volumes, wetted perimeters, and metal masses of the three-dimensional mesh into the one-dimensional mesh. Both calculations used the same version of the code. Although there were differences, the one-dimensional calculation predicted the same peak clad surface temperature as the three-dimensional version (within $1^{\circ} \mathrm{F}$ ). By comparing the one-dimensional and three-dimensional calculations it appears that multidimensional phenomena did not effect the peak temperature at least in this calculation where the entire core was quenched early during blowdown. Details of the one-dimensional calculation will be described in a separate report.

In summary, water from the upper head quenched the entire core $14 \mathrm{~s}$ after the break occurred allowing a maximum clad temperature of $1155^{\circ} \mathrm{F}$ at $8 \mathrm{~s}$. Once quenched the temperatures remained below operating values. This calculation demonstrates that the UHI system is effective in cooling the core during a large-break LOCA. 


\subsection{REFERENCES}

1. M. J. Thurgood, et al., "COBRA/TRAC - A Thermal-Hydraulic Code for Transient Analysis of Nuclear Reactor Vessels and Primary Coolant Systems", Volumes 1-5, NUREG/CR-3046, PNL-4385, March 1982.

2. D. R. Liles, et al., "TRAC-PD2 - An Advanced Best-Estimate Computer Program for Pressurized Water Reactor Loss-of-Coolant-Accident Analysis", NUREG/CR-2054, 1981. Available for purchase from the National Technical Information Service, Springfield, VA, 22161.

3. M. J. Thurgood, et al., "COBRA/TRAC - A Thermal-Hydraulic Code for Transient Analysis of Nuclear Reactor Vessels and Primary Coolant Systems, Developmental Assessment and Data Comparisons", Volume 4, NUREG/CR-3046, PNL-4385, March 1983. Available for purchase from the National Technical Information Service, Springfield, VA, 22161.

4. "Reference Core Report 17x17", WCAP-8185, September 1973, Westinghouse Electric Corporation, Pittsburg, Pennsylvania.

5. G. A. Berna and M. P. Bohn, "FRAPCON-1: A Computer Code for the SteadyState Analysis of 0xide Fuel Rods". NUREG/CR-1463, EGG-2039, February 1981. Available for purchase from the National Technical Information Service, Springfield, VA, 22161.

6. J. V. Cathcart, "Quarterly Progress Report on the Zirconium Metal-Water Oxidation Kinetics Program Sponsored by the NRC Division of Reactor Safety Research for April-June 1976," ORNL/NUREG/TM041, August 1976.

7. "Decay Heat Power in Light Water Reactors", American Nuclear Society/American National Standards Institute, Standard 5.1, 1979. ANS, 555 N. Kensington Ave., LaGrange Park, ILL, 60525.

8. E. Janssen and J. A. Kervinen, "Film Boiling and Rewetting", NDE0-20975, August 1975, General Electric Company, San Jose, CA, 95125.

9. P. G. Prassinos, B. M. Galusha, and D. B. Engleman, "Experimental Data Report for LOFT Power Ascension Experiment 12-3," NUREG/CR-1792, TREE1326, July 1979.

10. G. A. Berna, et al., "FRAPCON-2: A Computer Code for the Calculation of Steady-State thermal Mechanical Behavior of Oxide Fuel Rods", NUREG/CR1845, EGG Idaho, Inc., Idaho Falls, Idaho. 


\section{APPENDIX A}

\section{INPUT LISTINGS}

\section{INTRODUCTION}

This appendix gives the COBRA/TRAC input listings for the PWR/UHI reactor. Three input decks are listed. The first is the input at time zero and contains the vessel and primary loops. It does not include the pressurizer and ECCS components. This deck is used to start the steady-state calculation.

The second input deck is used at $20 \mathrm{~s}$ (beginning on page 163) to add the pressurizer to the calculation. Up to this time a pressure boundary condition was used to allow the liquid inventory in the system to come to equilibrium as it expanded while being heated by the core. By adding the pressurizer after equilibrium was achieved, the pressurizer contained the correct liquid volume at the beginning of the accident. It is called a "restart" input deck because it was used to continue a previous calculation. The steady-state calculation was continued to $30 \mathrm{~s}$.

The third input deck (page 170) started the transient at $30 \mathrm{~s}$. It added the cold leg ECCS components, the UHI components, and the cold leg break components to the calculation.

This simulation used cycle 12 of COBRA/TRAC. The input to cycle 12 is the same as the input to cycle 13 , the documented version, with two exceptions. In the documentation for cycle 13 three variables are input on card VESSEL2.3

(Ref. A.1, p. 2.55); they are INODE, KGAPB and KGAPA. A fourth variable, ALAT was also input on this card in cycle 12 and is reflected in the input decks listed here.

The other difference between the input decks and the documentation is in the number of blank cards at the end of vessel card group 15 . The documentation shows one blank card is used (card VESSEL14.6) but in these decks (cycle 12) two blank cards were used. 


\section{REFERENCES}

A.1 M. J. Thurgood, et al. "COBRA/TRAC - A Therma1-Hydraulic Code for Transient Analysis of Nuclear Reactor Vessels and Primary Coolant Systems, Volume 3: Users' Manua1," NUREG/CR-3046, PNL-4385, March 1983. Available from the National Technical Information Service, Springfield, VA, 22161. 
The input listings ( $p p .89-192$ ) have been removed at the request of Westinghouse. These listings contain proprietary information. 


\section{APPENDIX B}

\section{ADDITIONAL DOWNCOMER RESULTS}

This appendix gives additional plots of the results in the downcomer which show the behavior of the ECCS liquid during the transient. The first plot,

Figure B.1, shows the void fractions at each level in the downcomer. They were obtained by averaging the void fractions in the individual cells around the circumference of the downcomer at each level. The cold legs are connected to section 7 at level 1 . This figure indicates the amount of water that penetrates the length of the downcomer as a function of time. Figures B. 2 and $B .3$ are plots of the liquid and vapor volume flow rates at the bottom of the downcomer. Figures B.4 to B.158 are shaded contour plots of void fraction in a two-dimensional view of the unwrapped downcomer. They are plotted at about $0.5 \mathrm{~s}$ increments. In these figures darker shading indicates increased liquid fractions. The location of the intact cold legs is indicated by the three filled circles and the location of the broken cold leg is shown by the open circle. They show the chaotic nature of the flow in the downcomer during counter-current flow. 


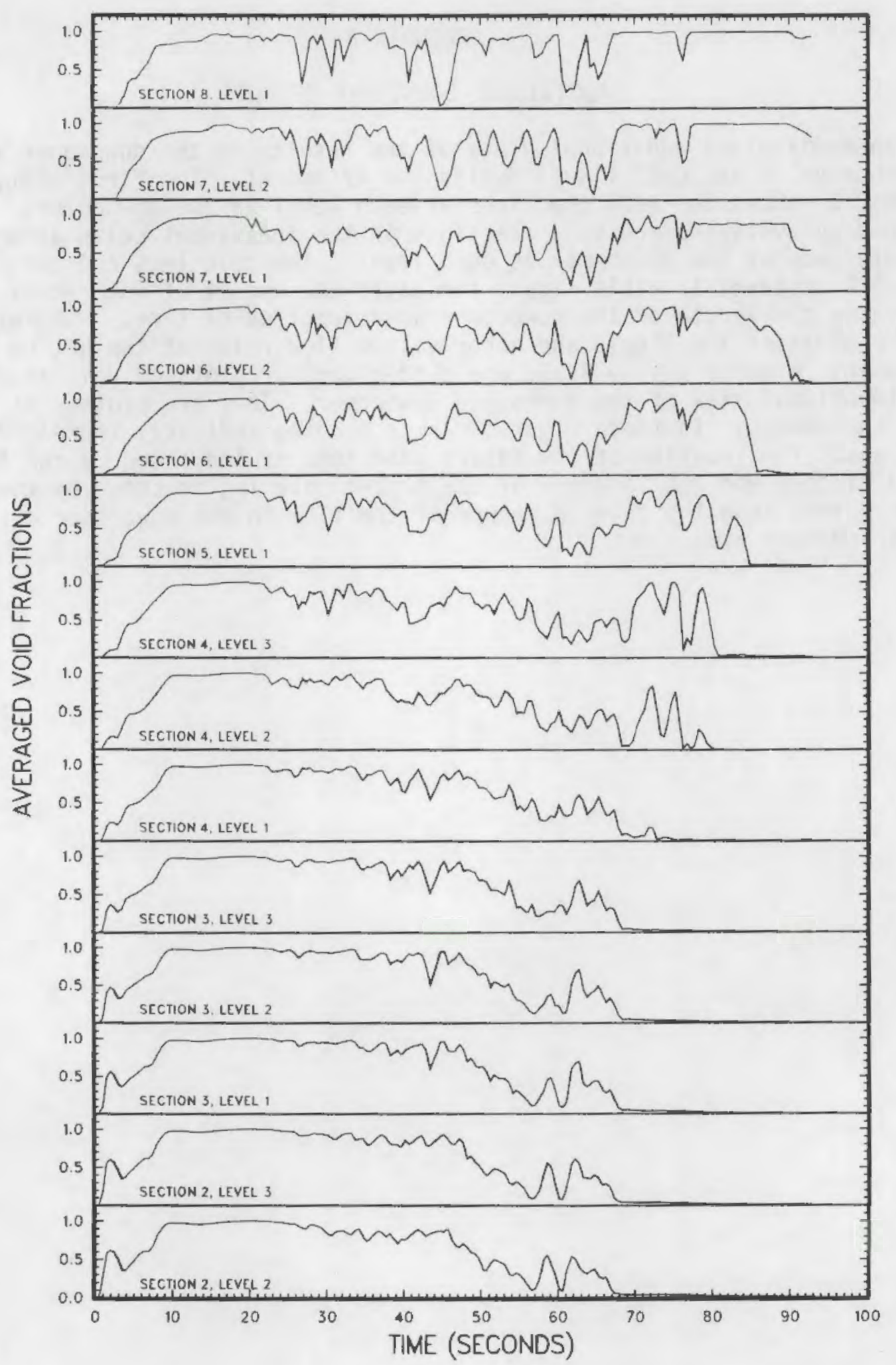

Figure B.1. Circumferentially averaged void fractions at 14 levels in the downcomer 


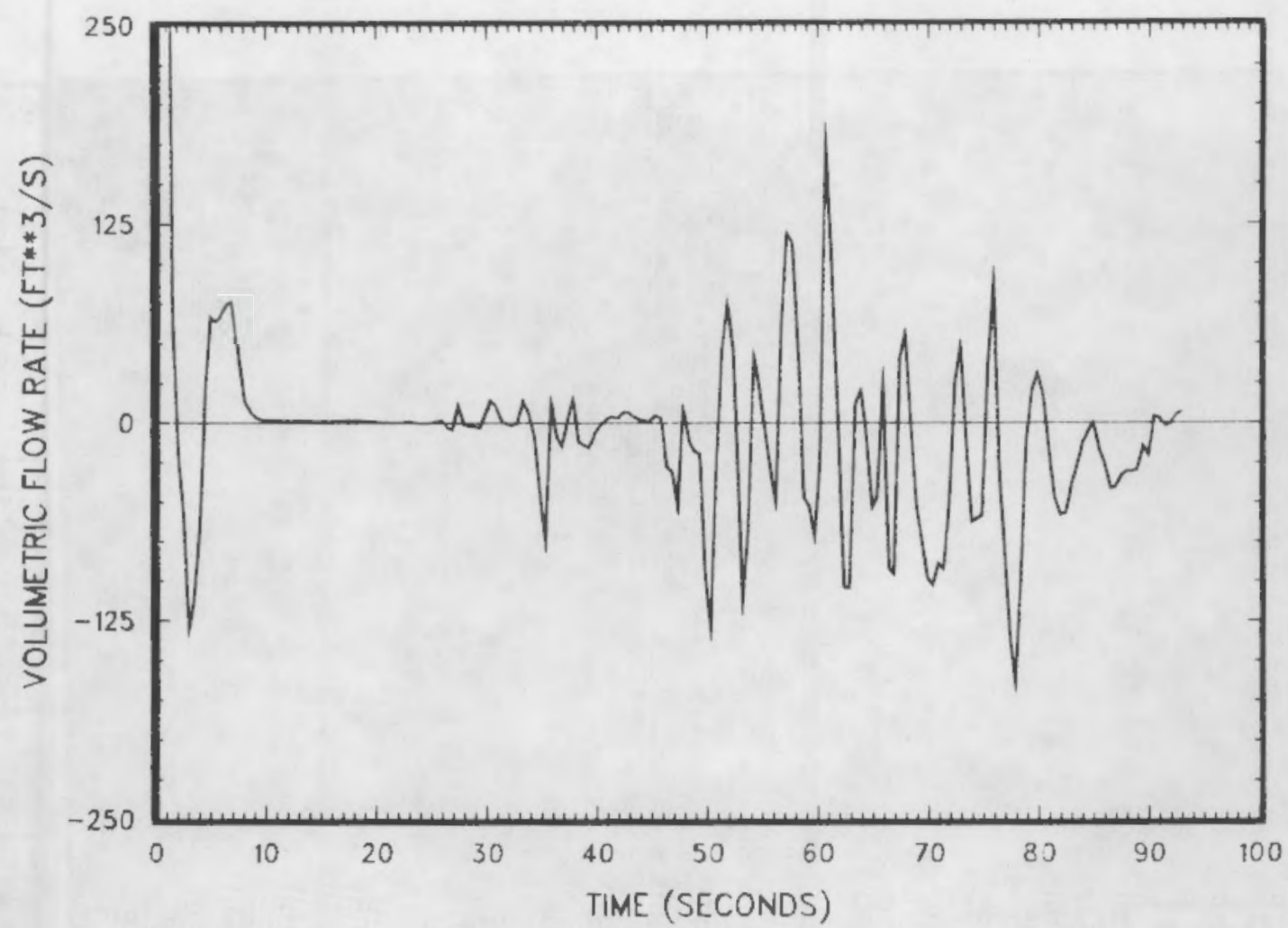

Figure B.2. Liquid volume flow rate at the bottom of the downcomer vs. time

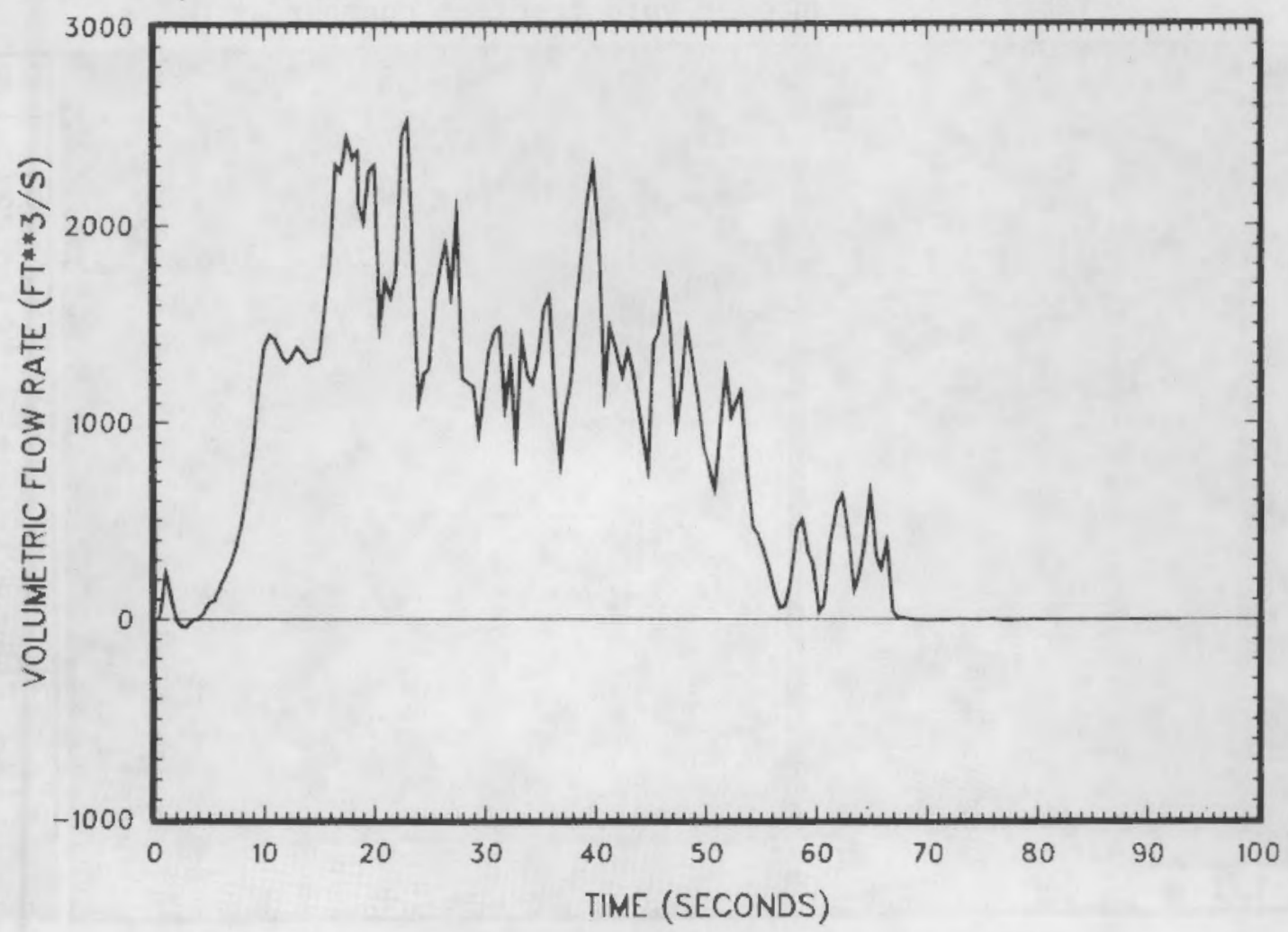

Figure B.3 Vapor volume flow rate at the bottom of the downcomer vs. time 


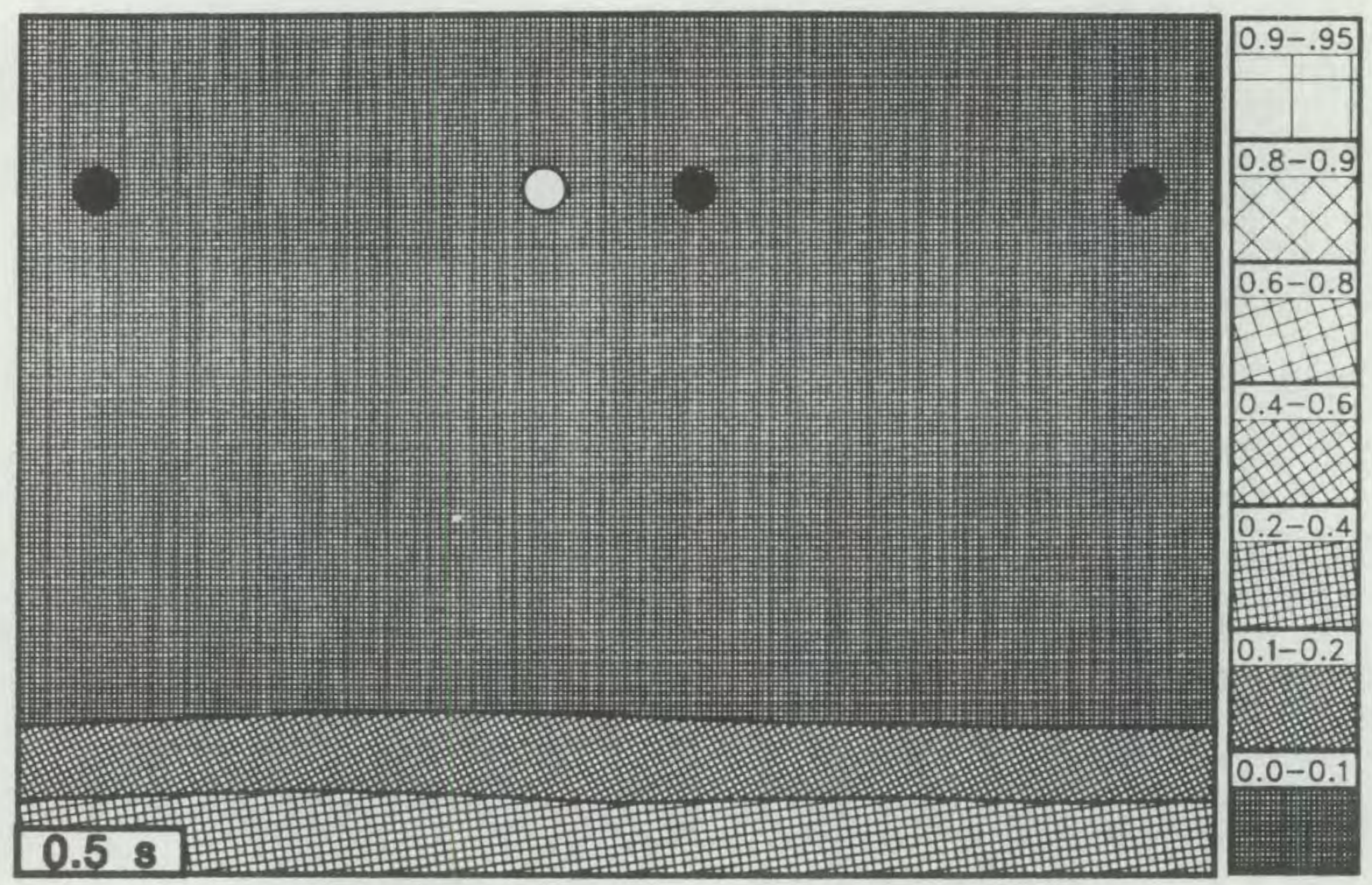

Figure B.4. Downcomer void fraction contour at $0.5 \mathrm{~s}$

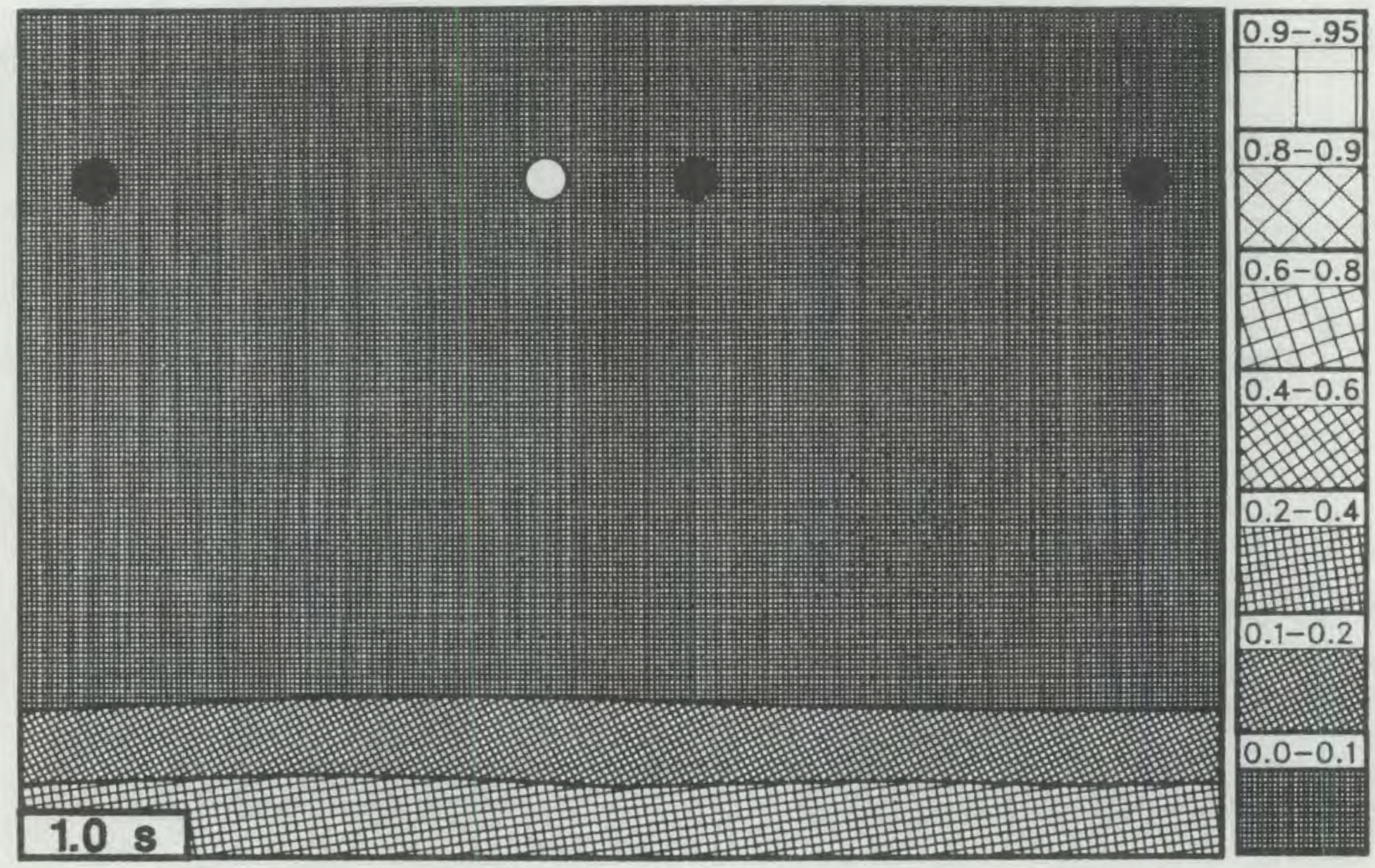

Figure B.5. Downcomer void fraction contour at $1.0 \mathrm{~s}$ 

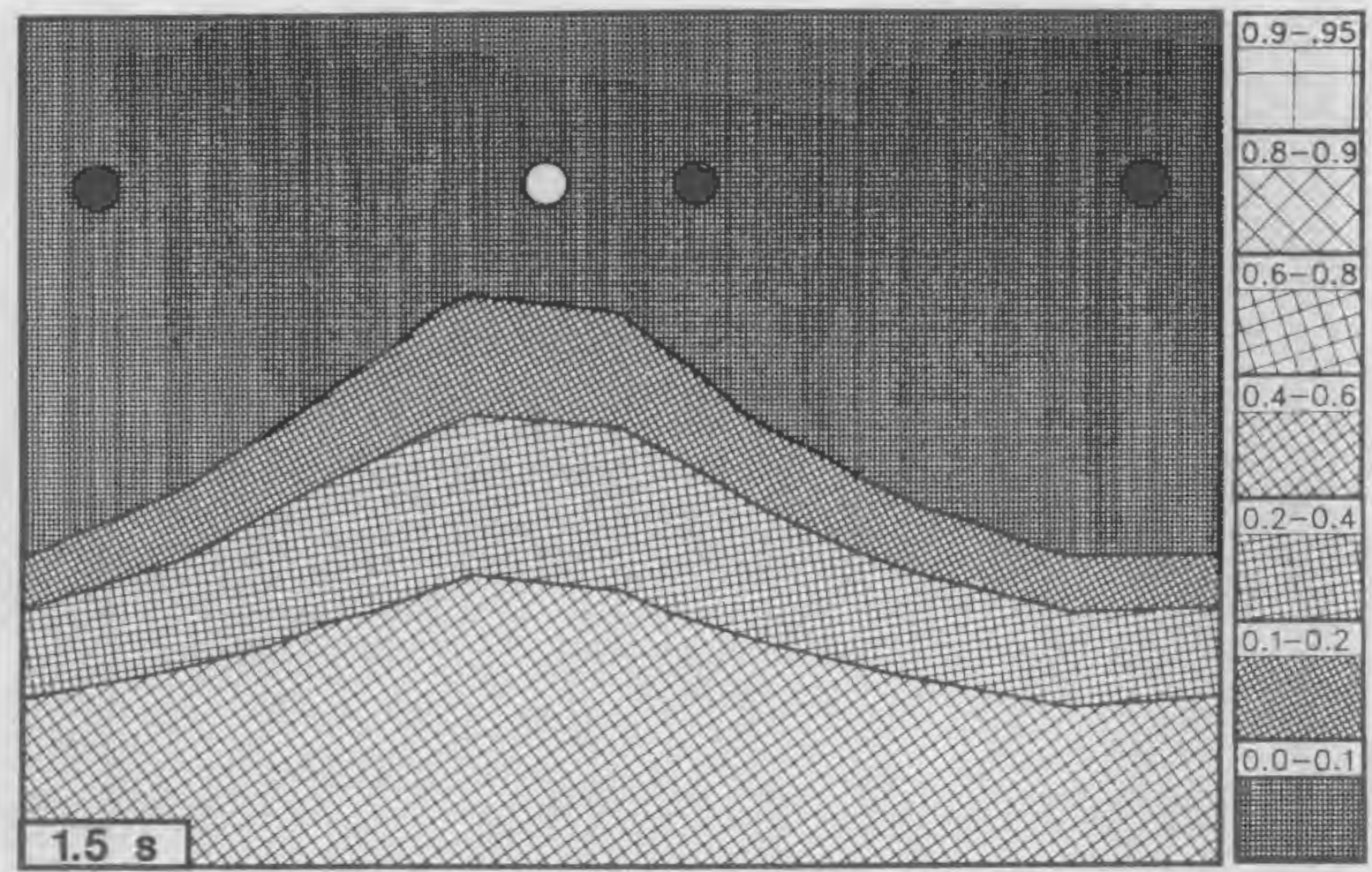

Figure B.6. Downcomer void fraction contour at $1.5 \mathrm{~s}$
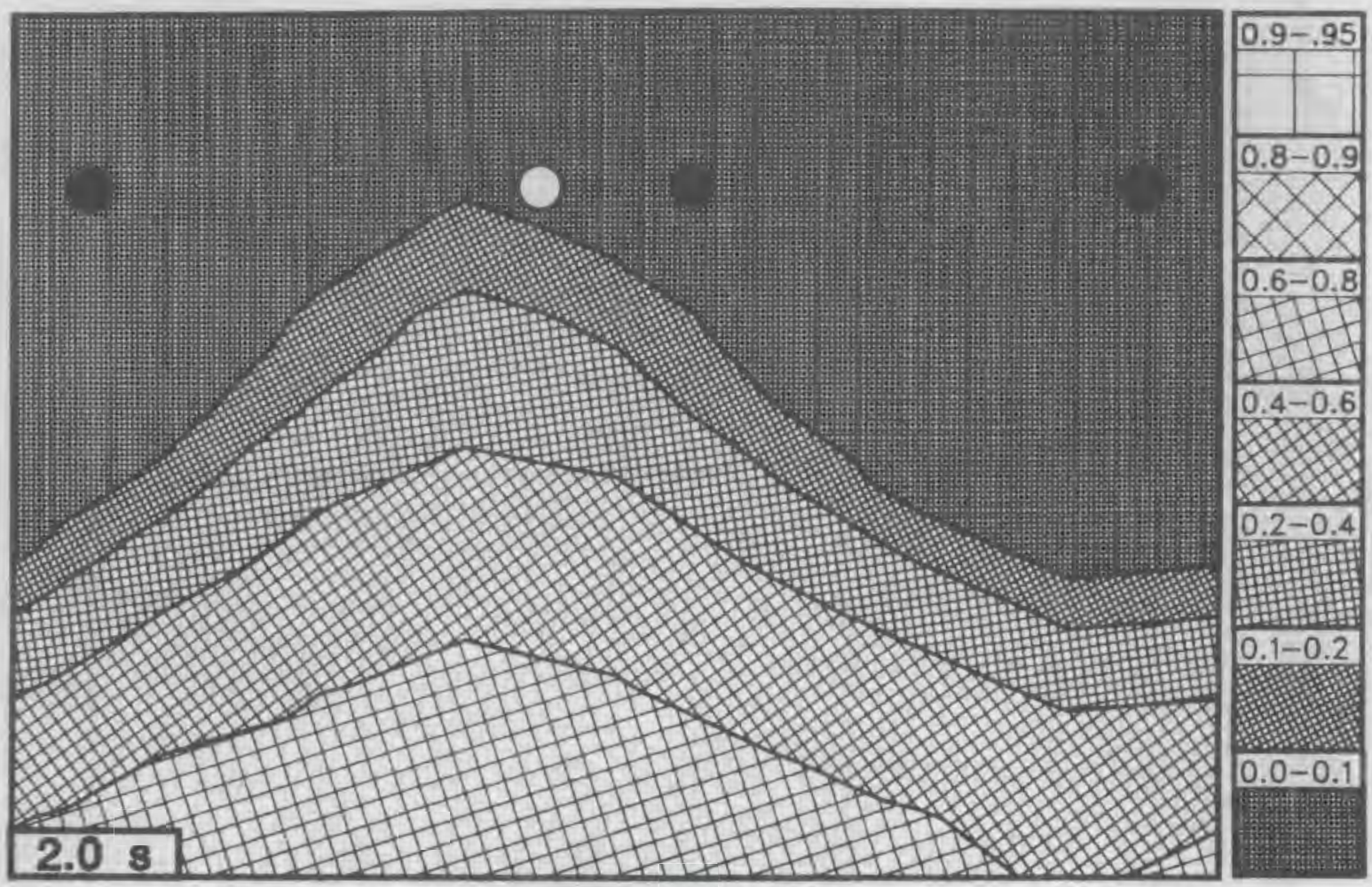

Figure B.7. Downcomer void fraction contour at $2.0 \mathrm{~s}$ 


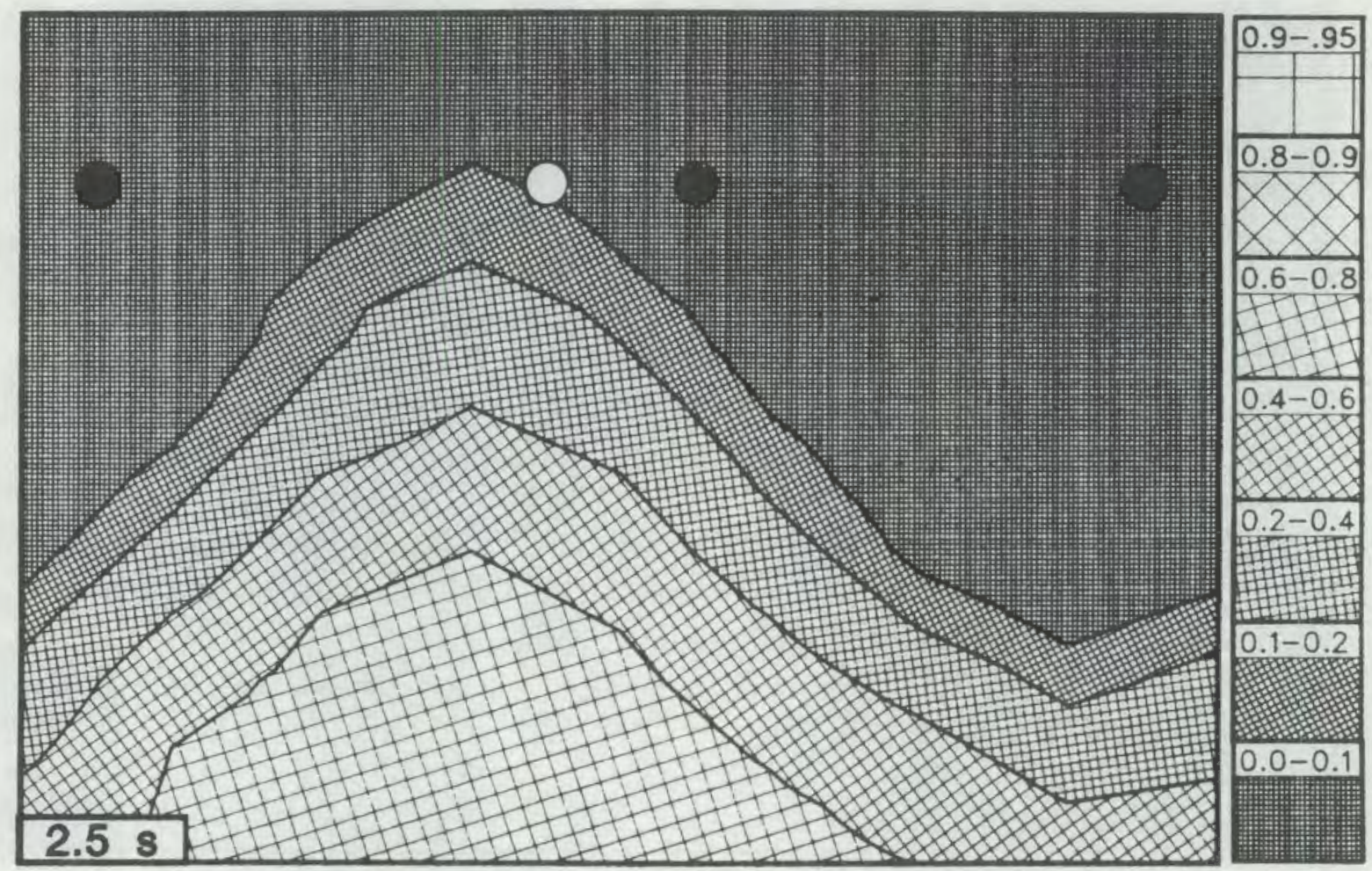

Figure B.8. Downcomer void fraction contour at $2.5 \mathrm{~s}$
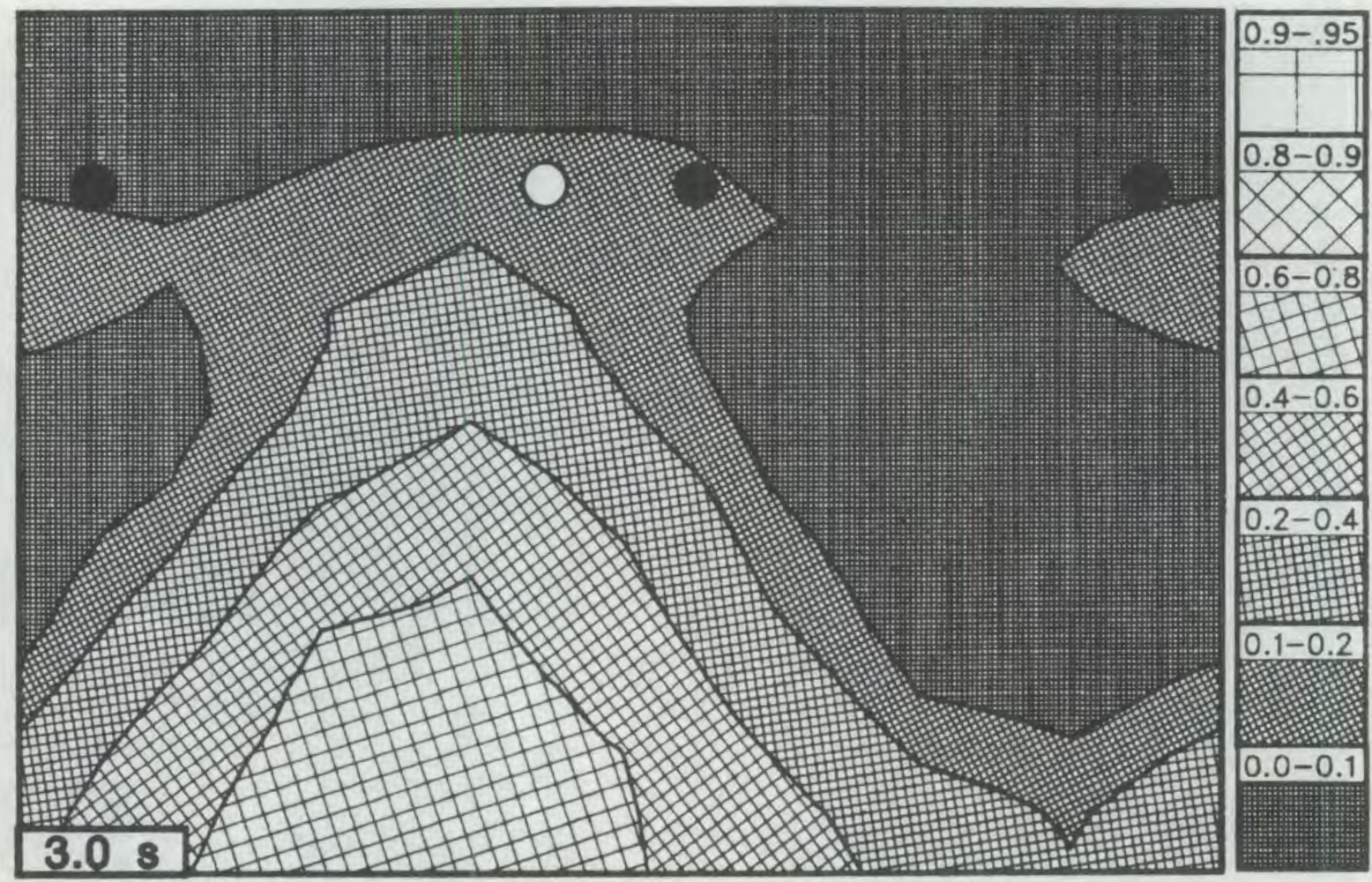

Figure B.9. Downcomer void fraction contour at $3.0 \mathrm{~s}$ 


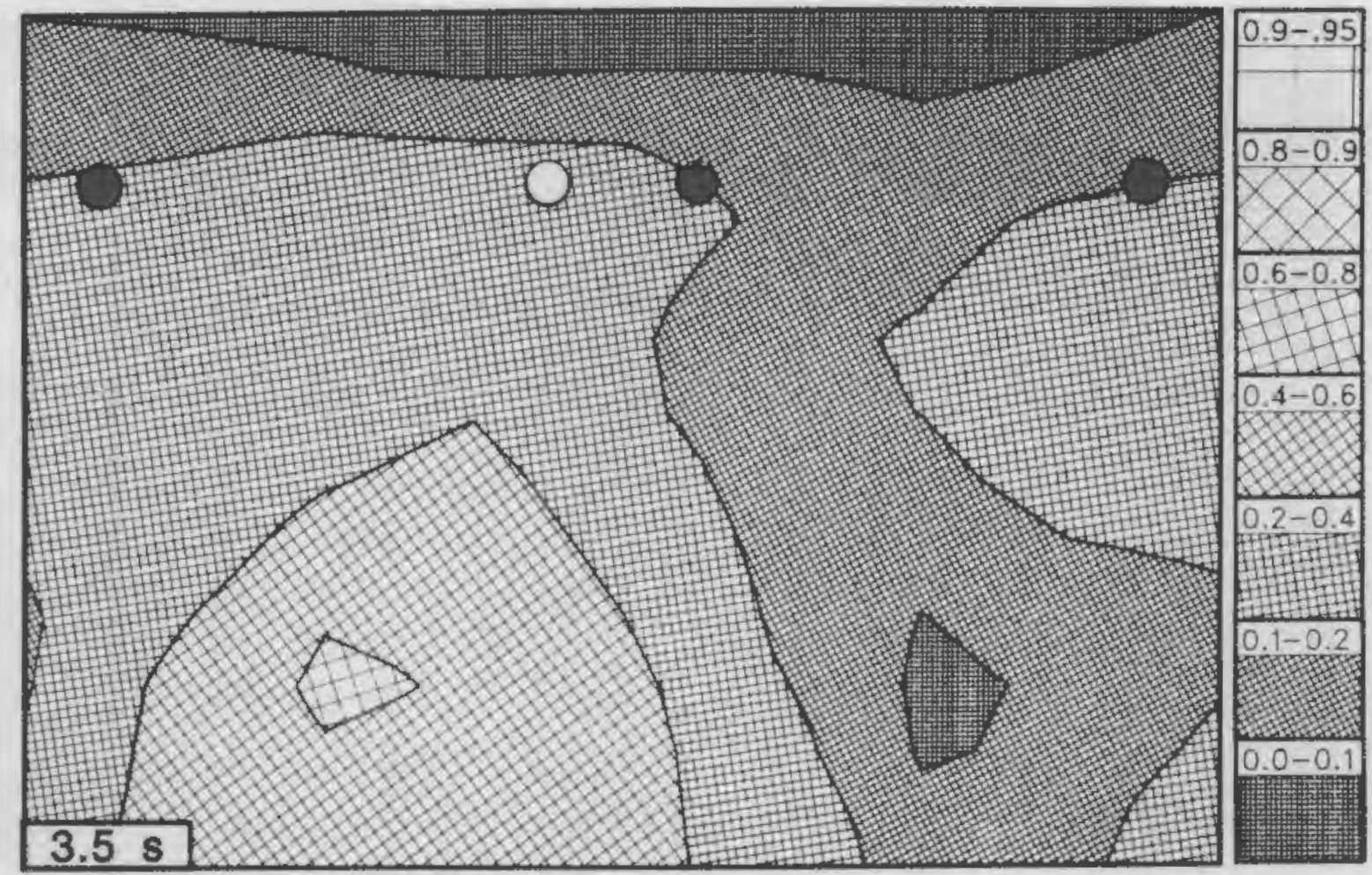

Figure 8.10 . Oowncomer void fraction contour at $3.5 \mathrm{~s}$

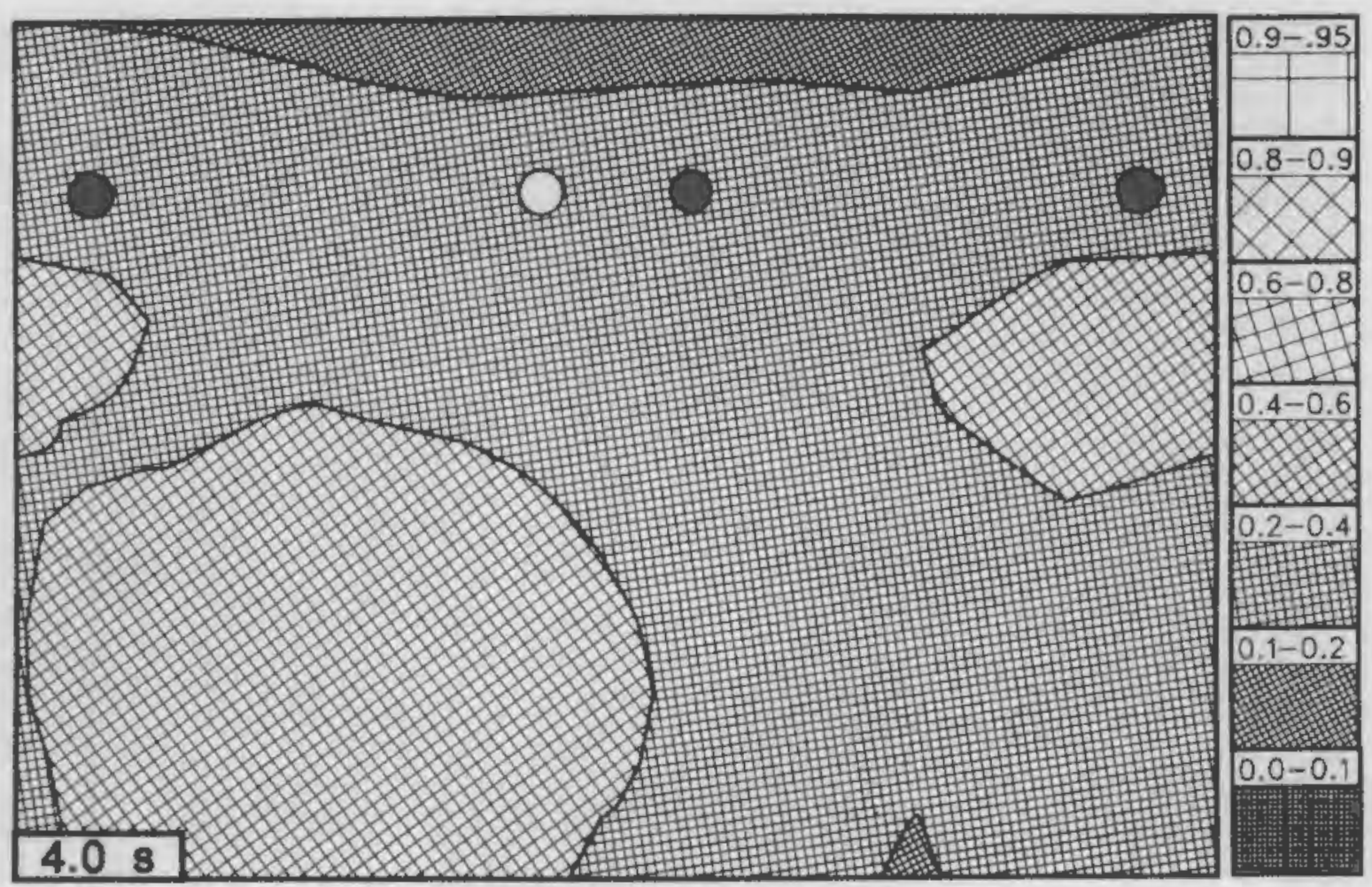

Figure B.11. Downcomer void fraction contour at $4.0 \mathrm{~s}$ 


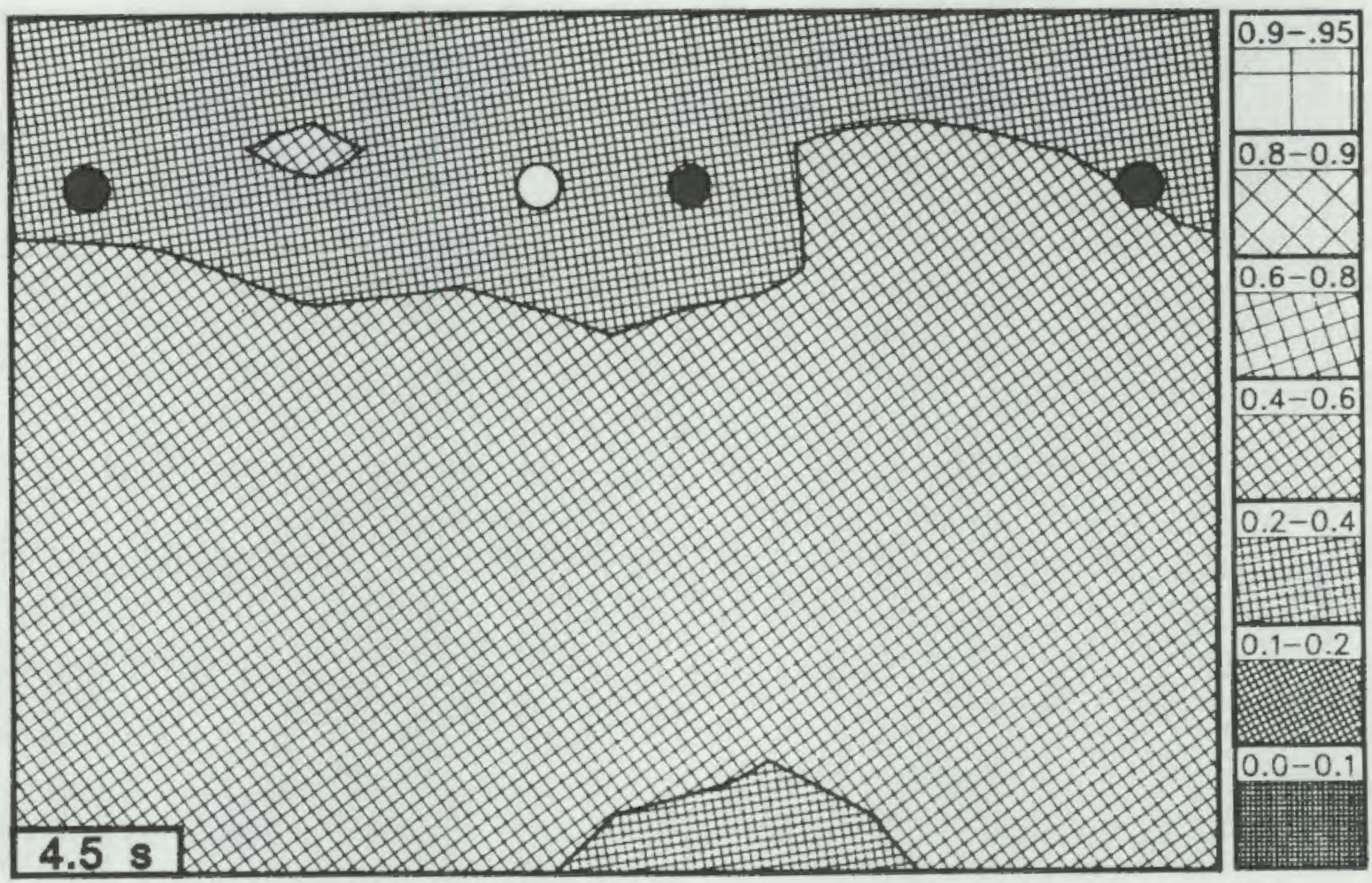

Figure B.12. Downcomer void fraction contour at $4.5 \mathrm{~s}$

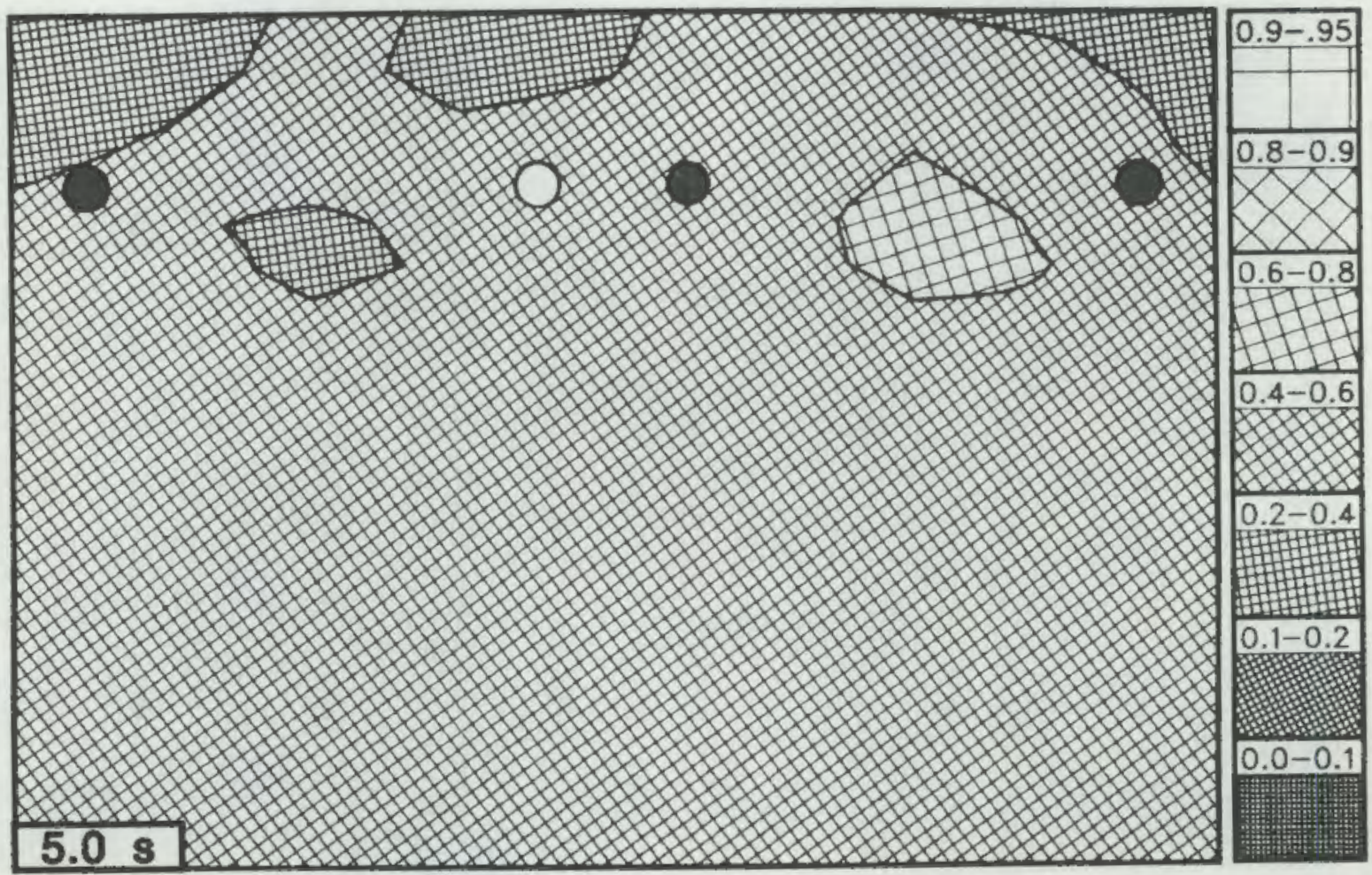

Figure B.13. Downcomer void fraction contour at $5.0 \mathrm{~s}$ 


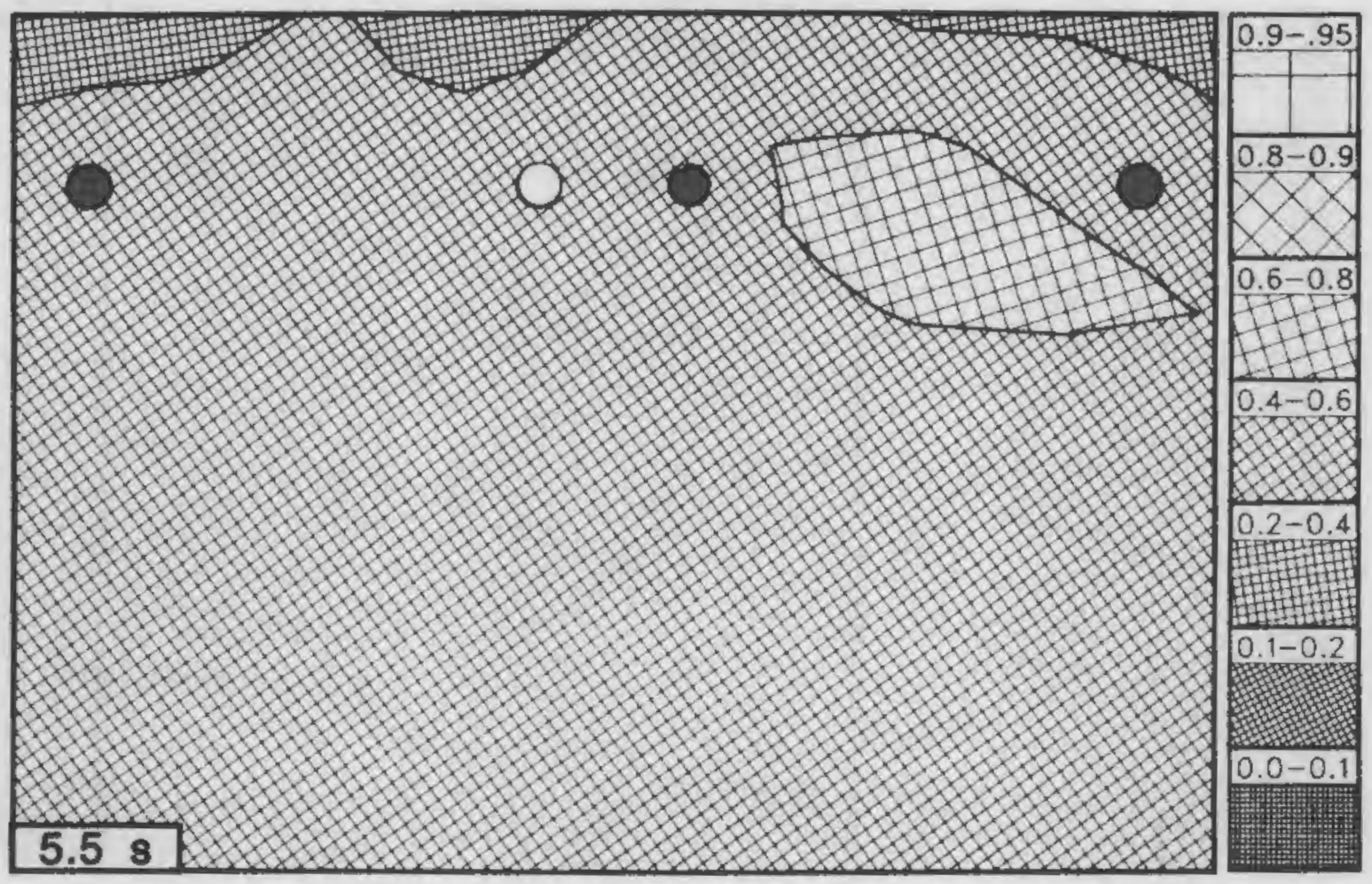

Figure B.14. Downcomer void fraction contour at $5.5 \mathrm{~s}$

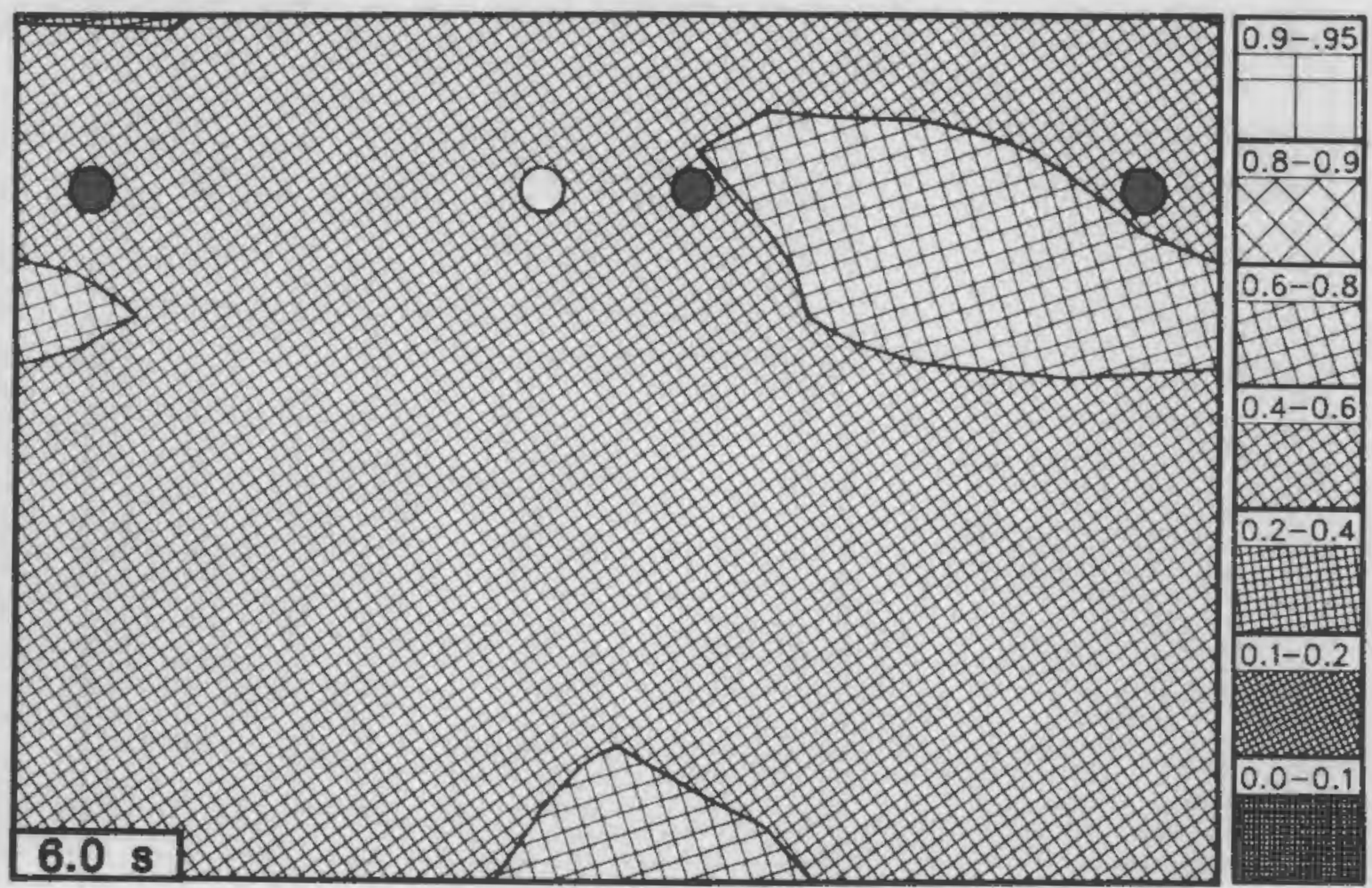

Figure B.15. Downcomer void fraction contour at $6.0 \mathrm{~s}$ 


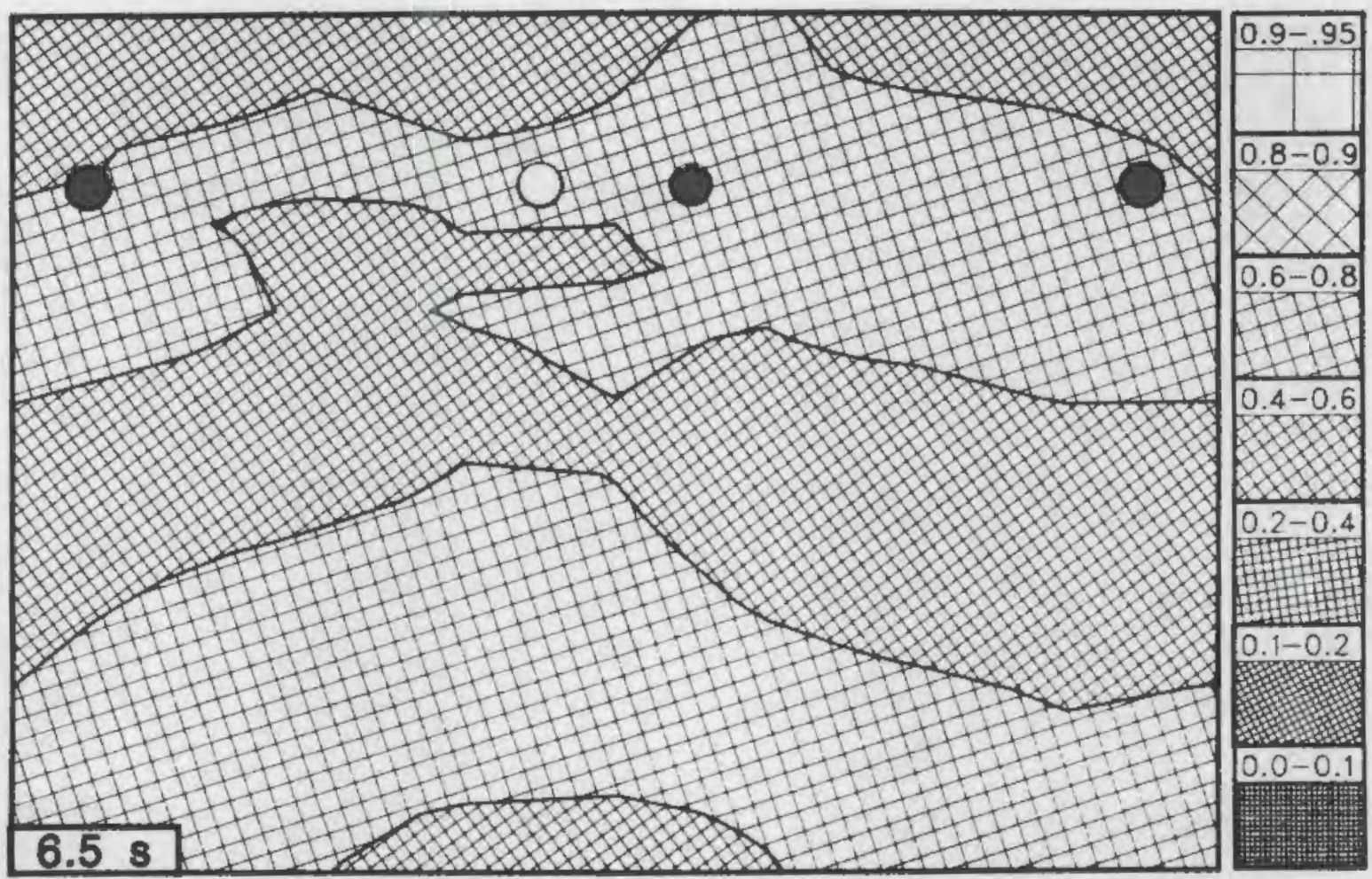

Figure B.16. Downcomer void fraction contour at 6.55

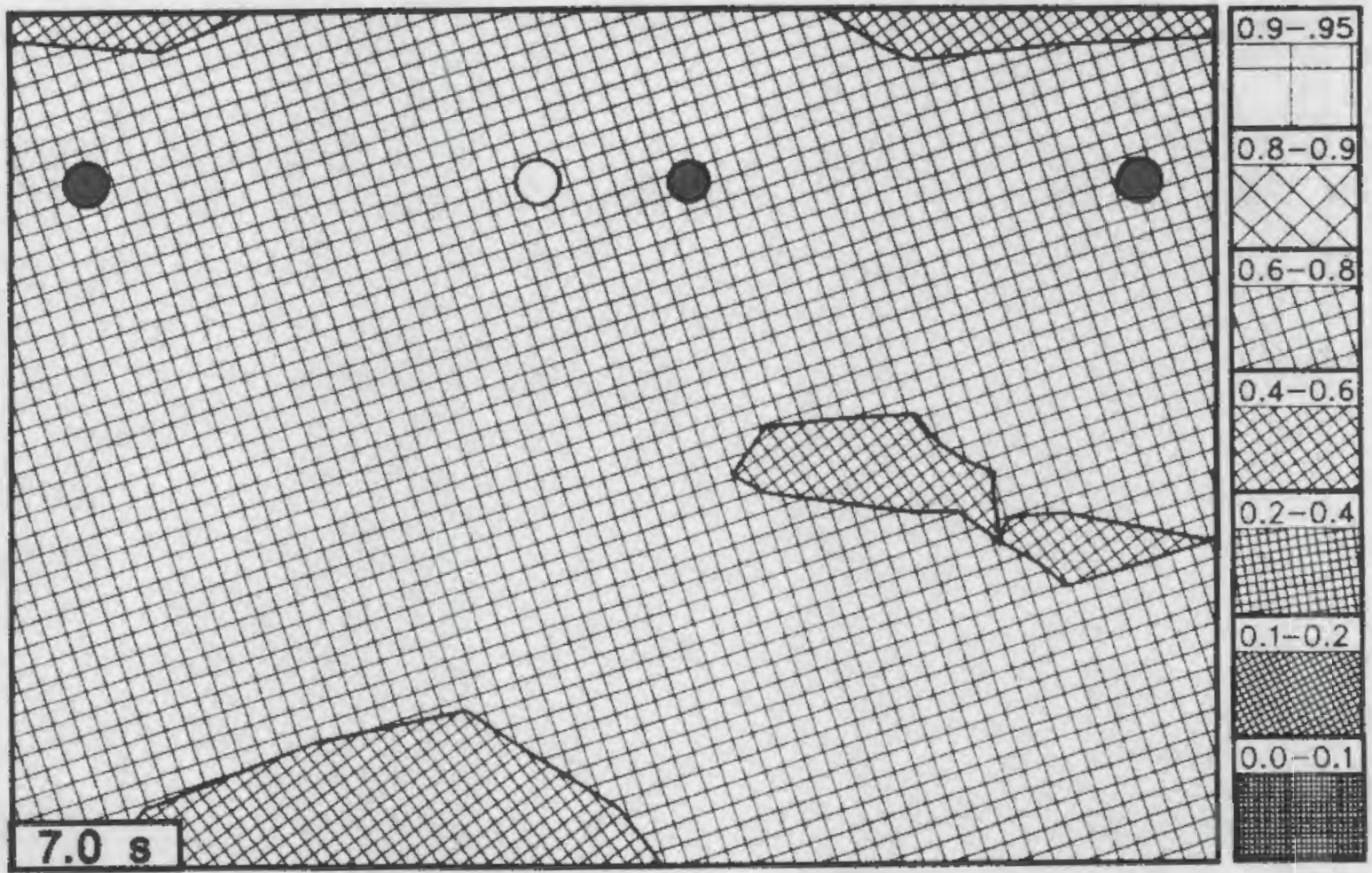

Figure B.17. Downcomer void fraction contour at $7.0 \mathrm{~s}$ 


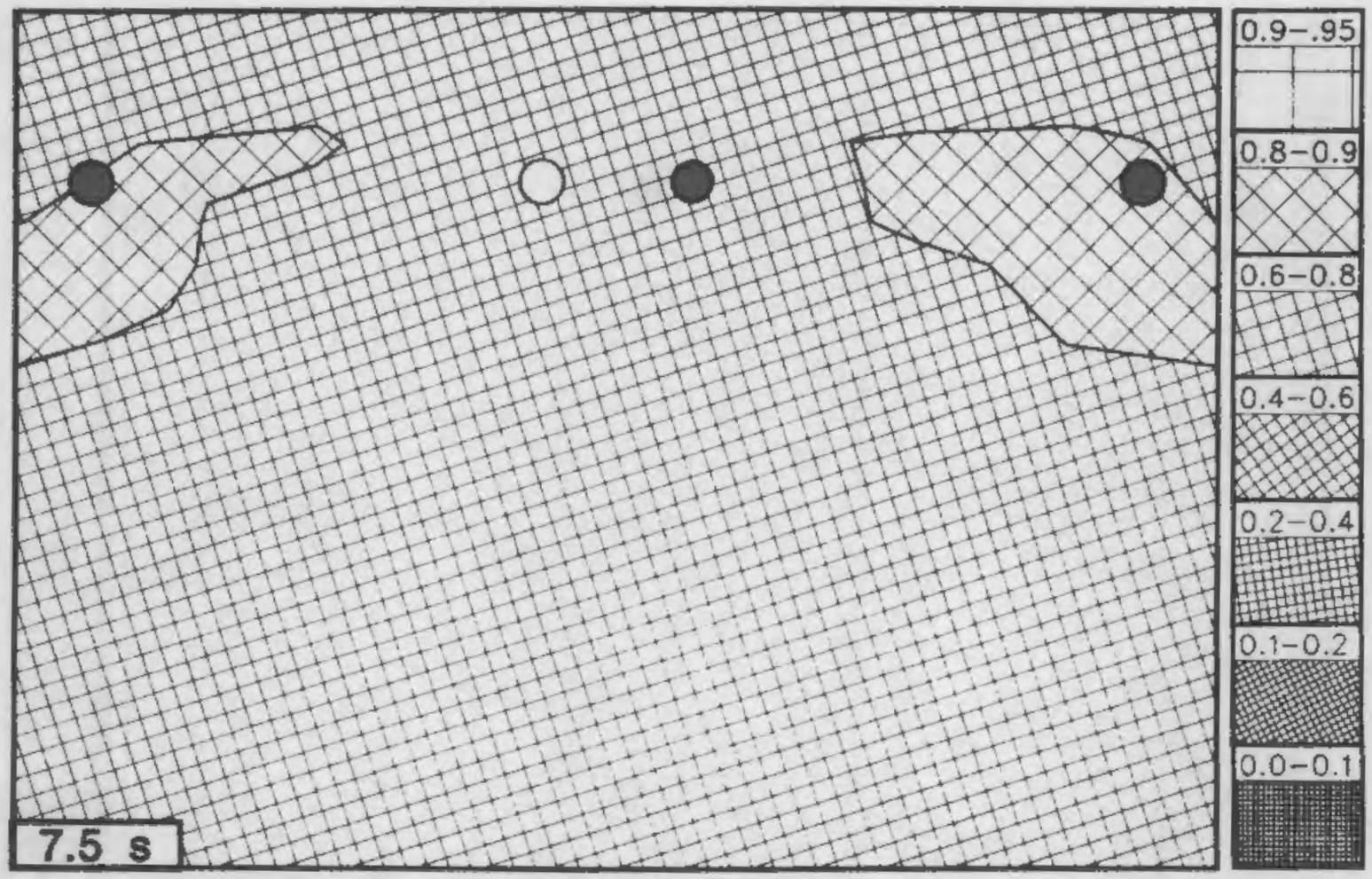

Figure B.18. Downcomer void fraction contour at $7.5 \mathrm{~s}$

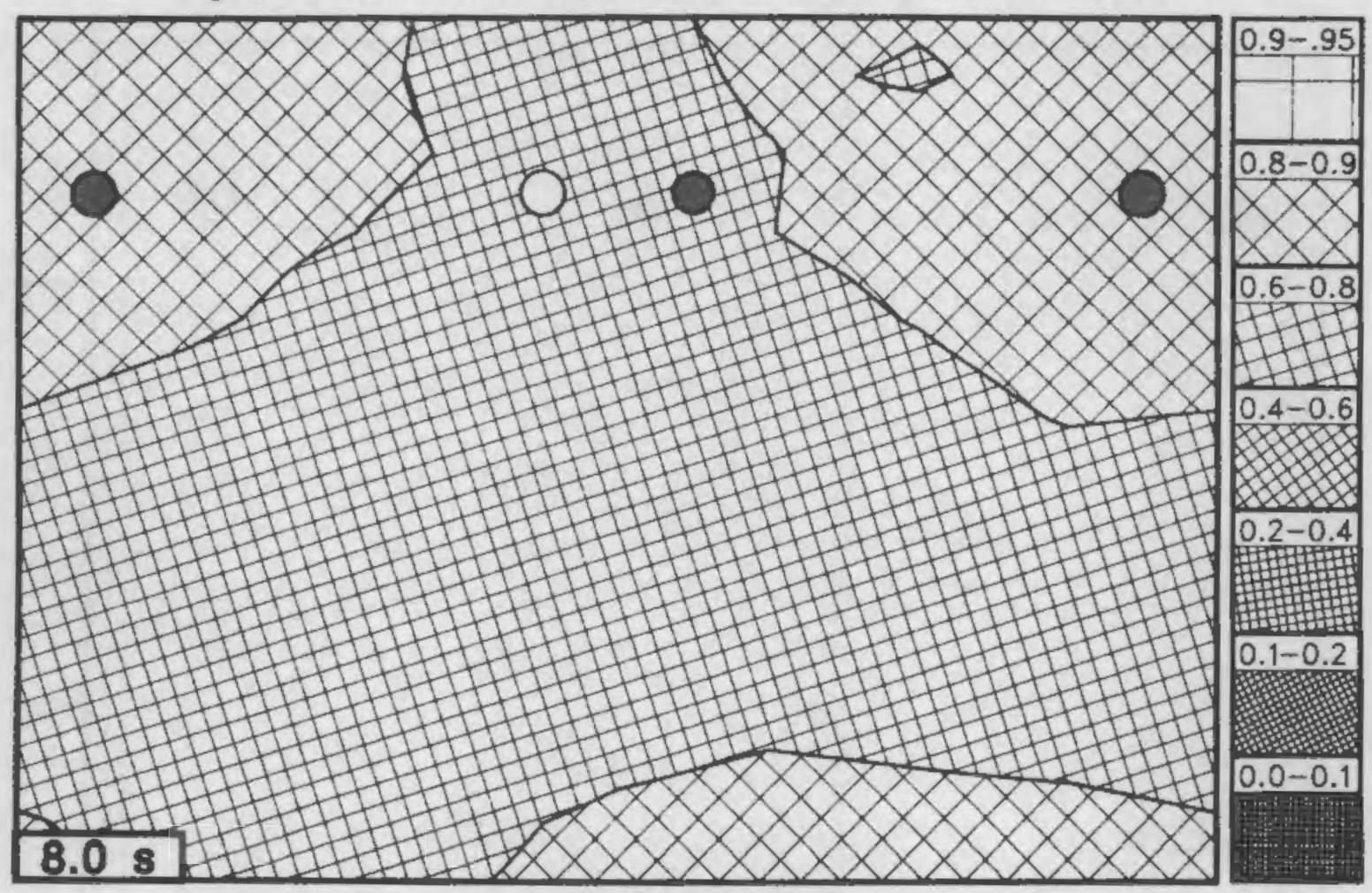

Figure B.19. Downcomer void fraction contour at $8.0 \mathrm{~s}$ 


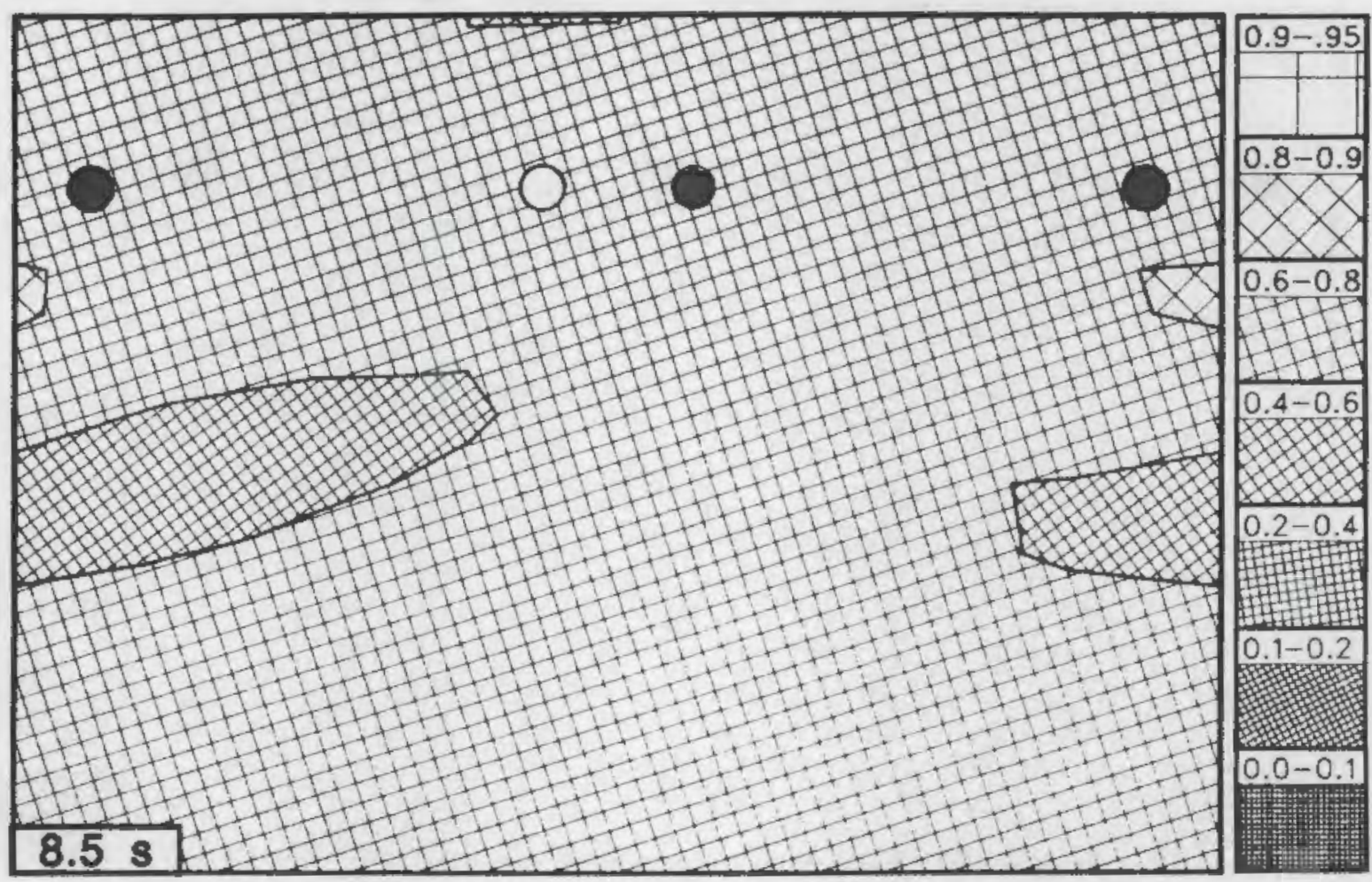

Figure B.20. Downcomer void fraction contour at $8.5 \mathrm{~s}$

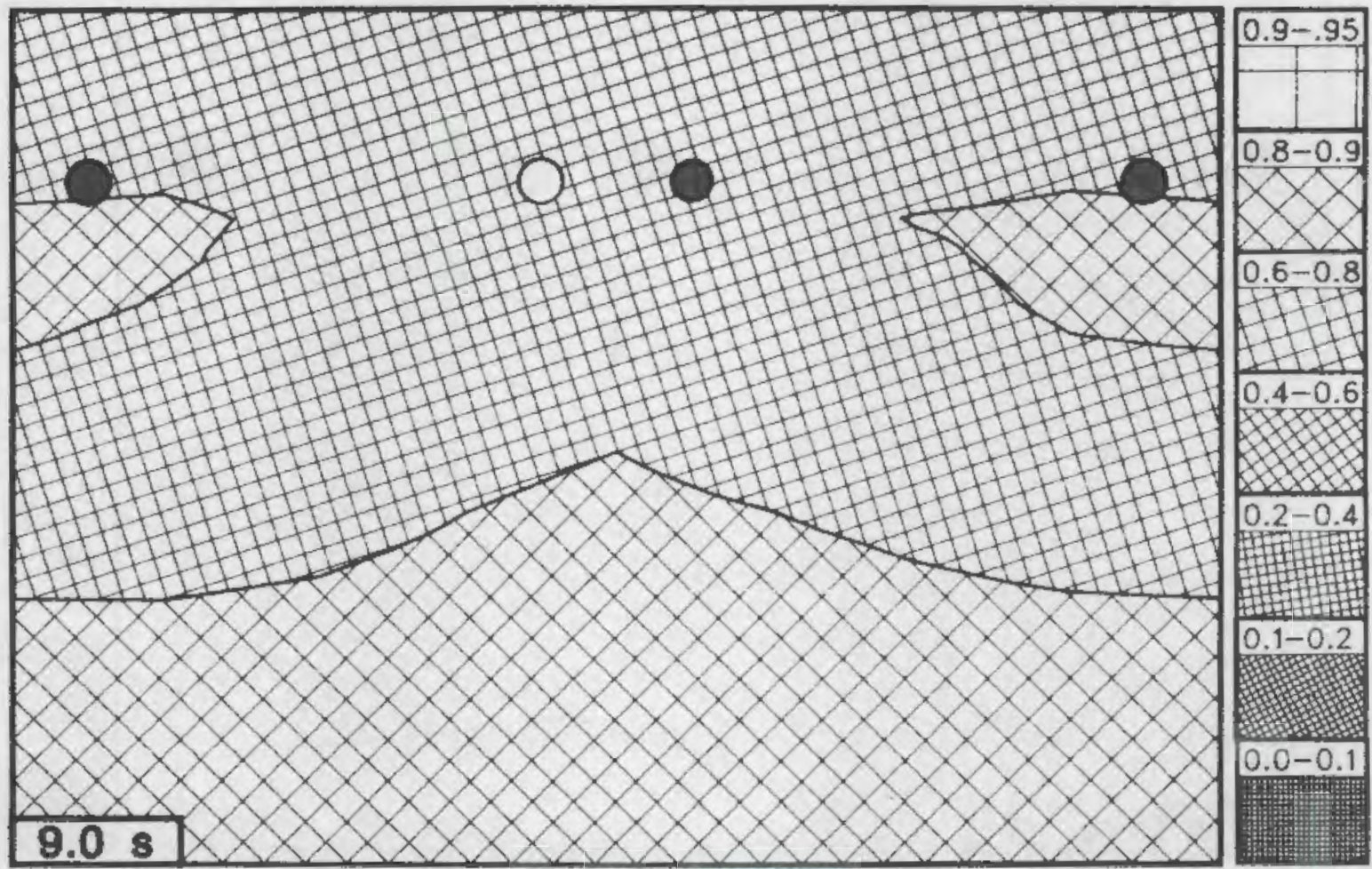

Figure B.21. Downcomer void fraction contour at $9.0 \mathrm{~s}$ 


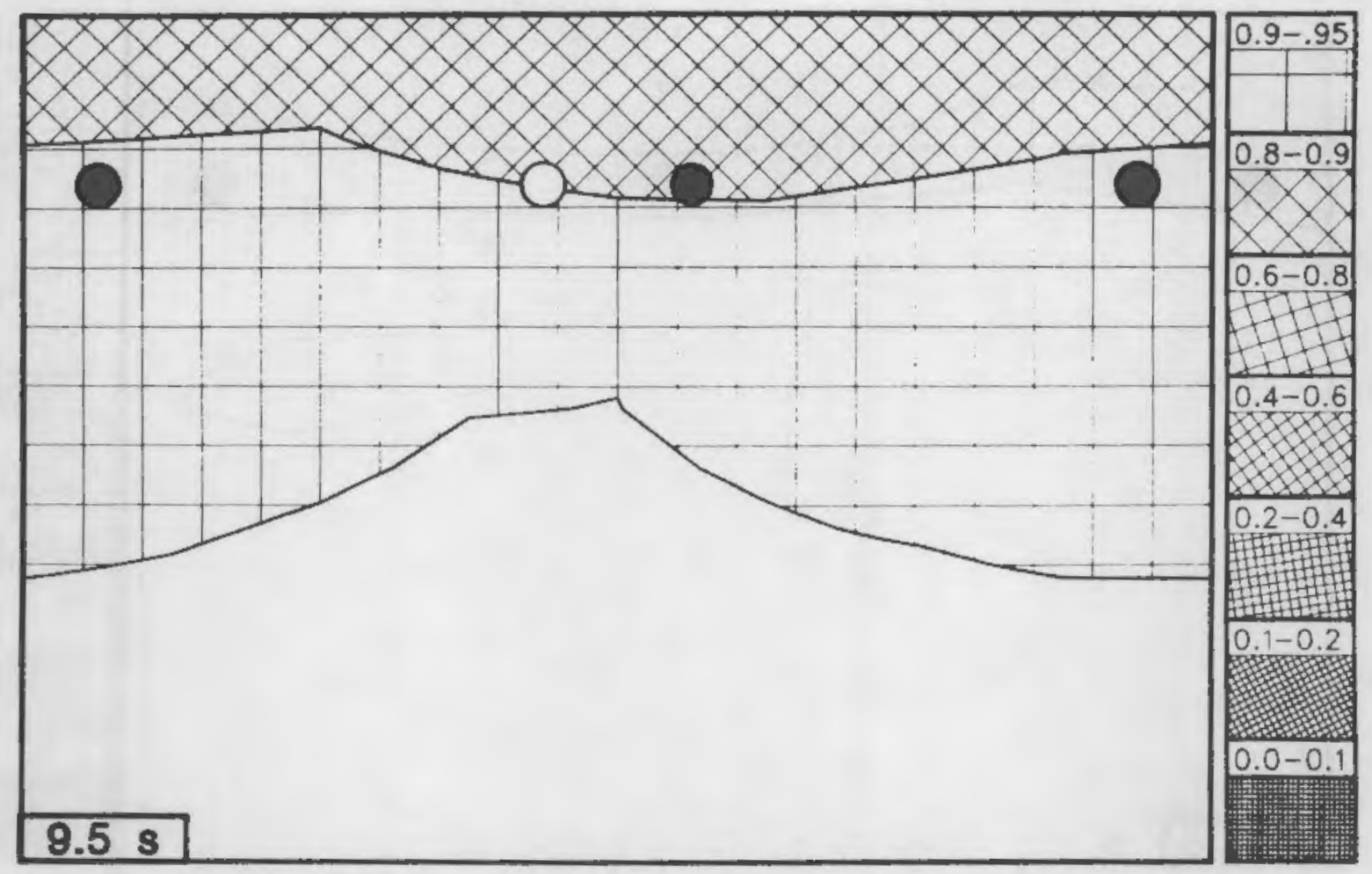

Figure B.22. Downcomer void fraction contour at $9.5 \mathrm{~s}$

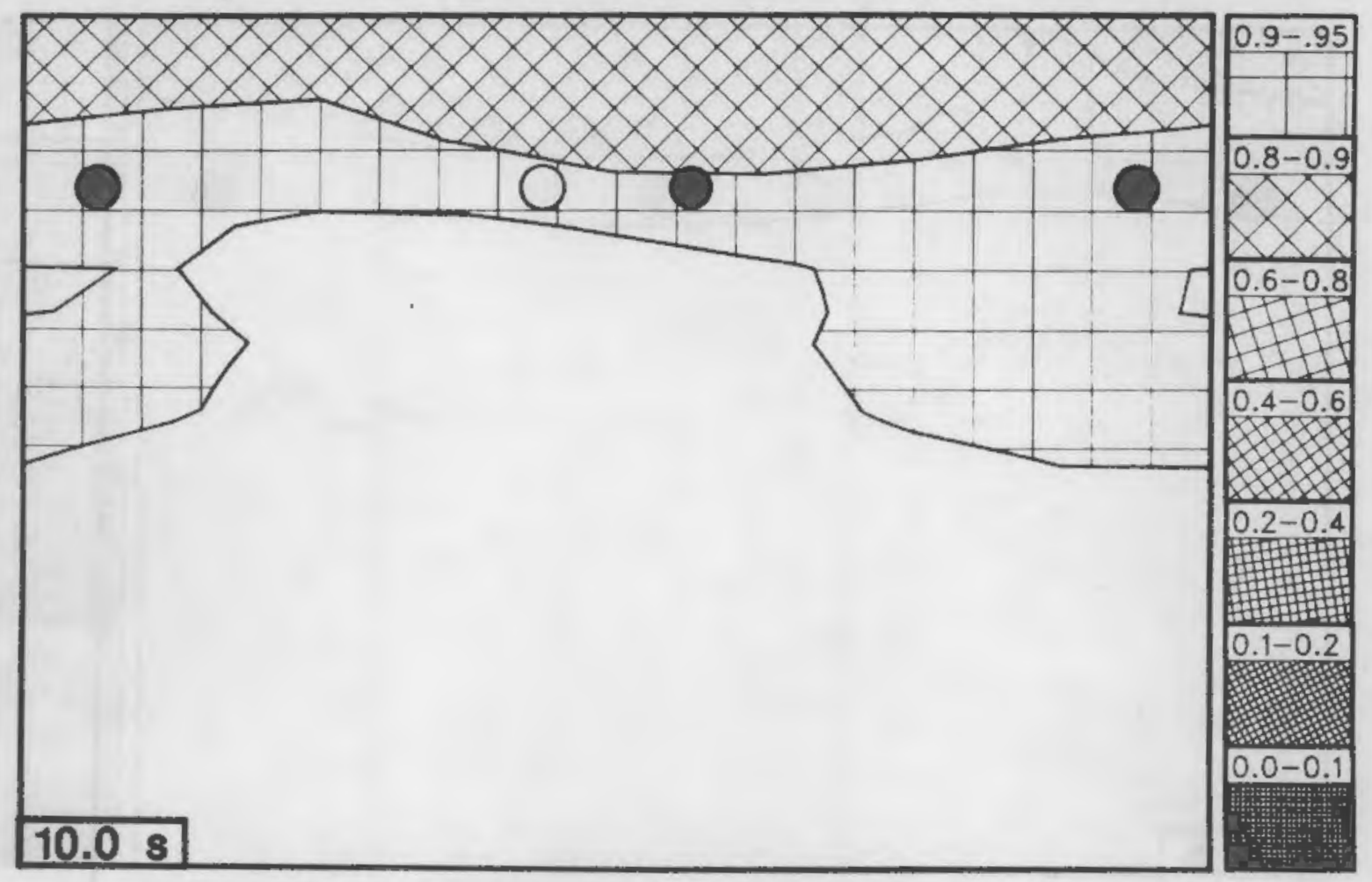

Figure B.23. Downcomer void fraction contour at $10.0 \mathrm{~s}$ 


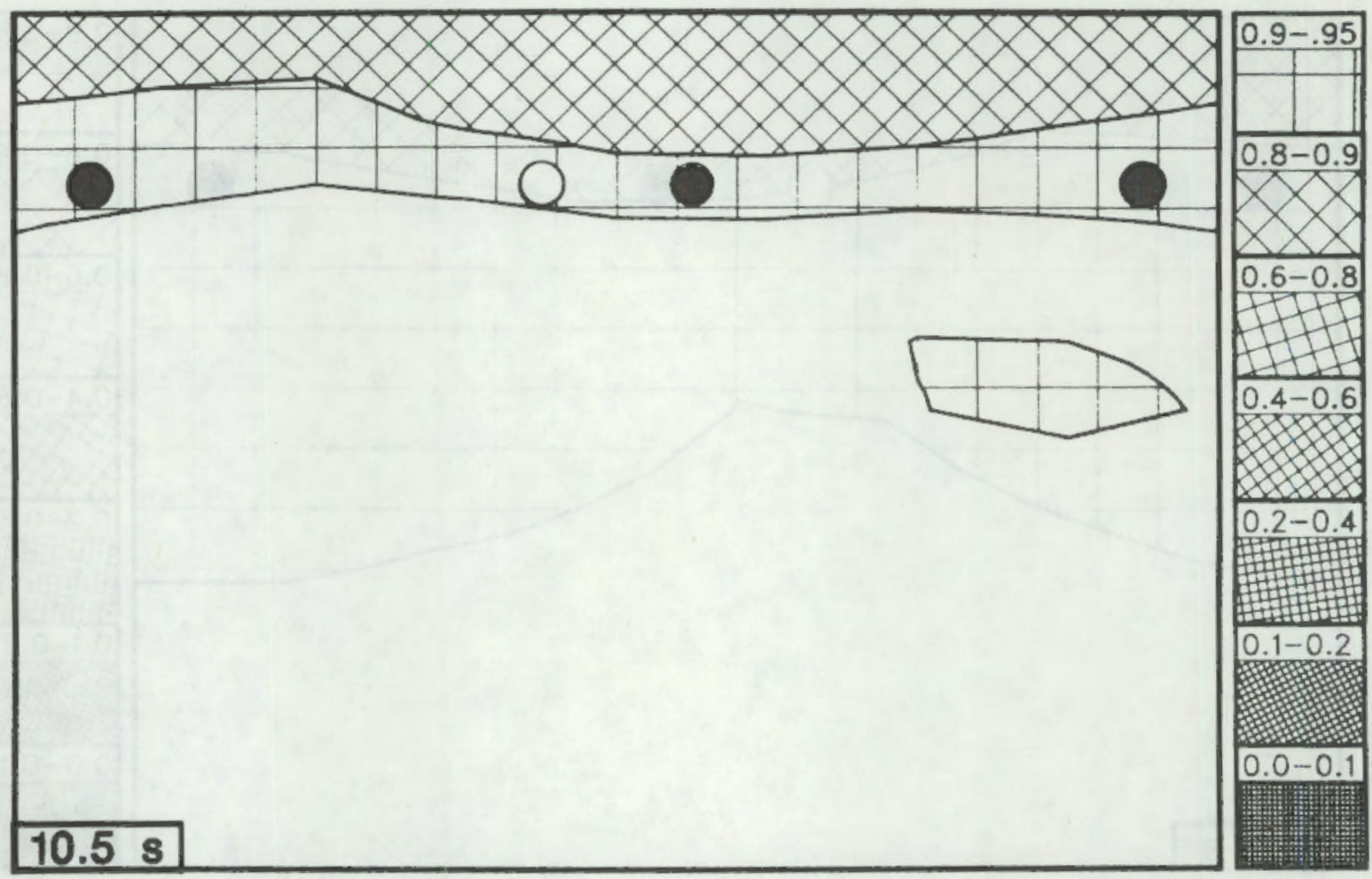

Figure B.24. Downcomer void fraction contour at $10.5 \mathrm{~s}$

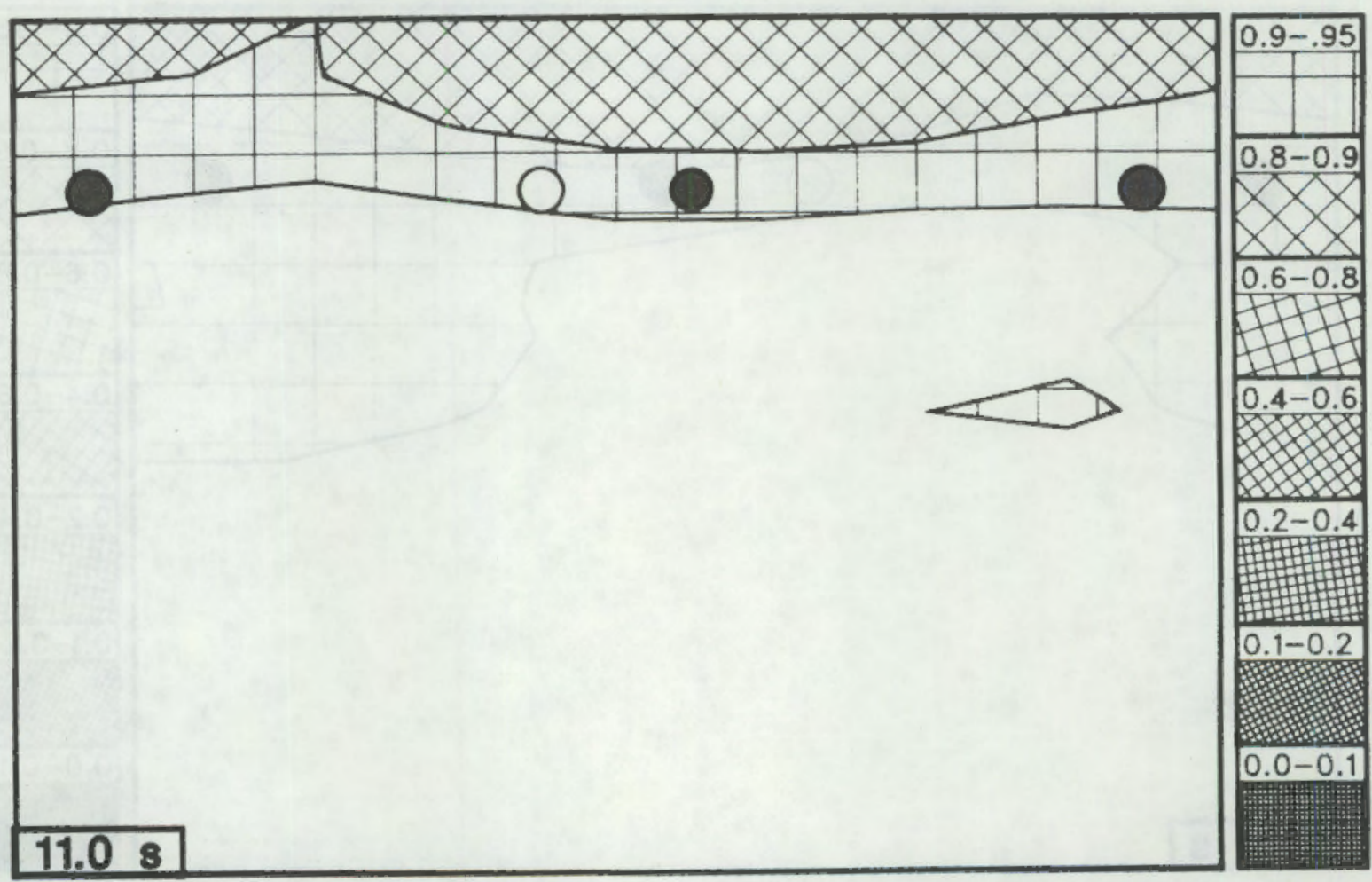

Figure B.25. Downcomer void fraction contour at $11.0 \mathrm{~s}$ 


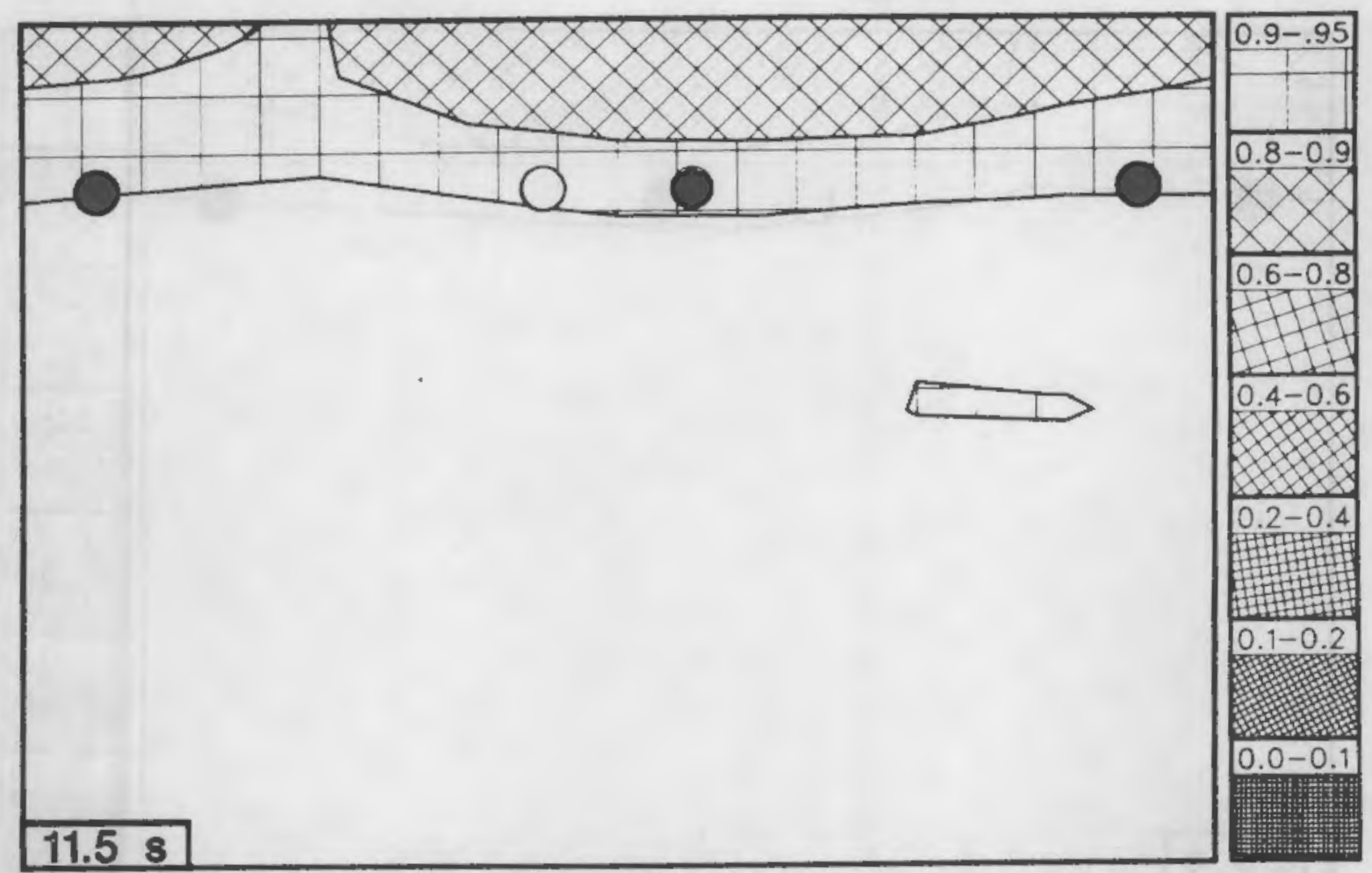

Figure B.26. Downcomer void fraction contour at $11.5 \mathrm{~s}$

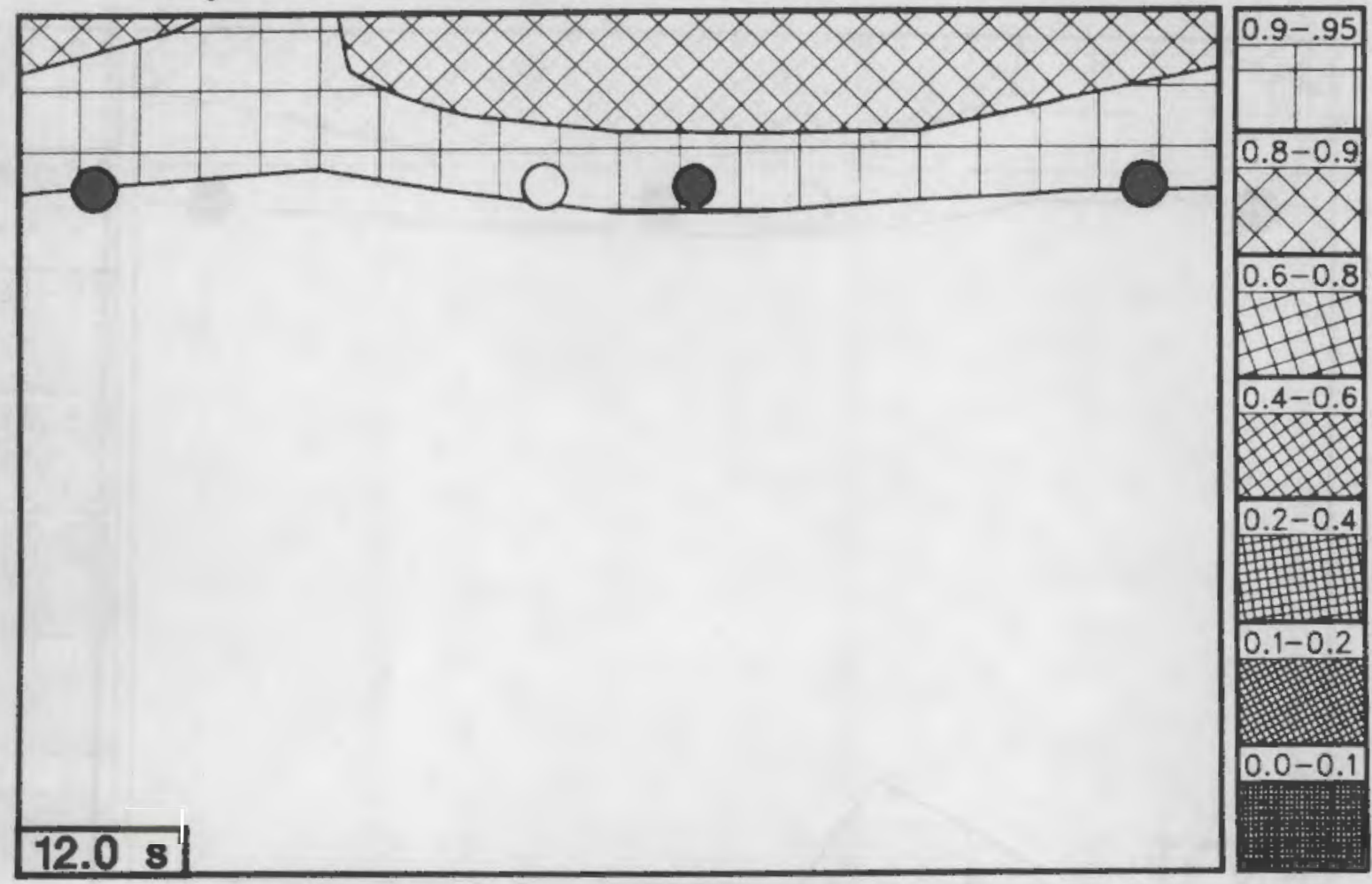

Figure B.27. Downcomer void fraction contour at $12.0 \mathrm{~s}$ 


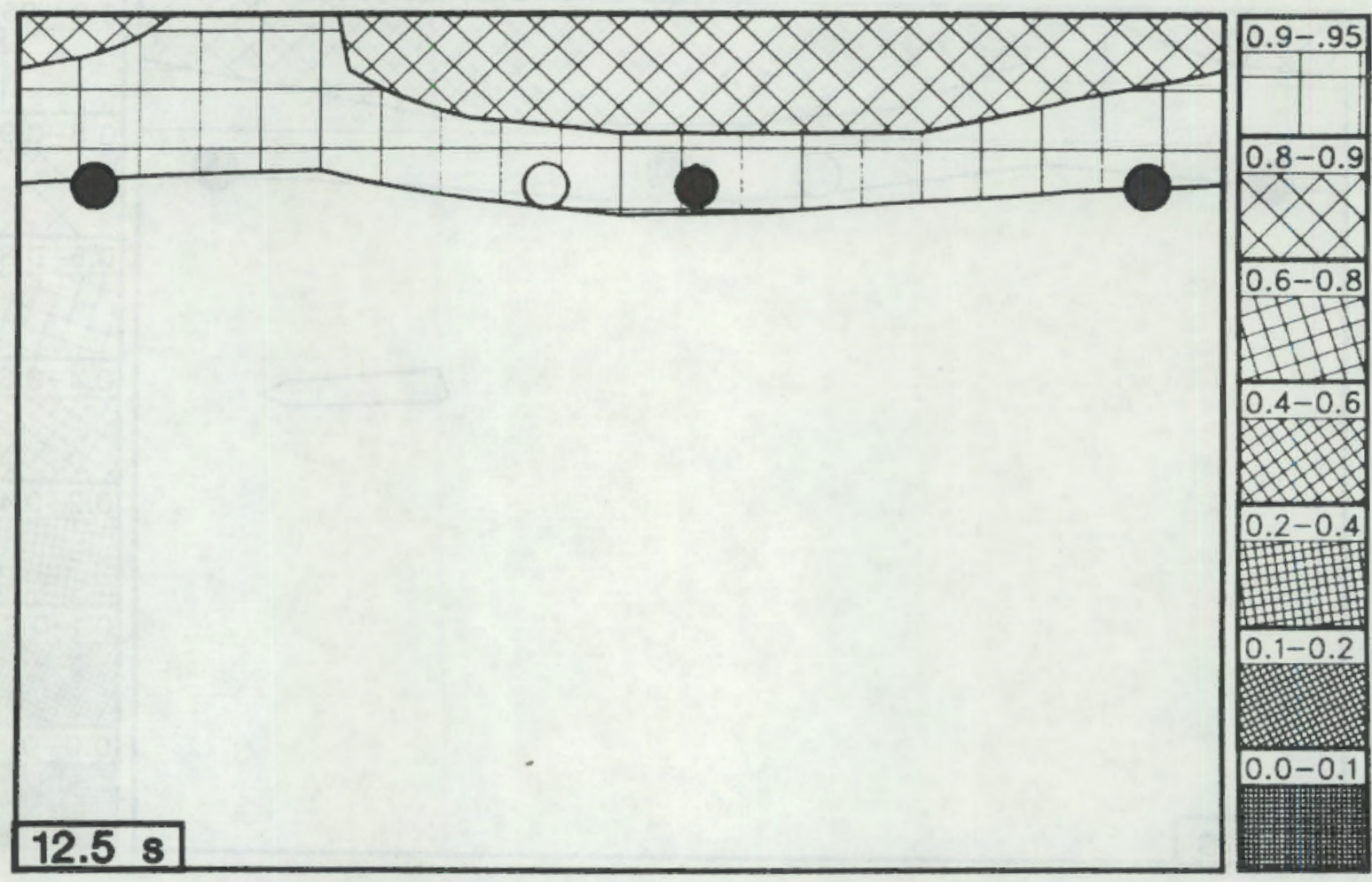

Figure B.28. Downcomer void fraction contour at $12.5 \mathrm{~s}$

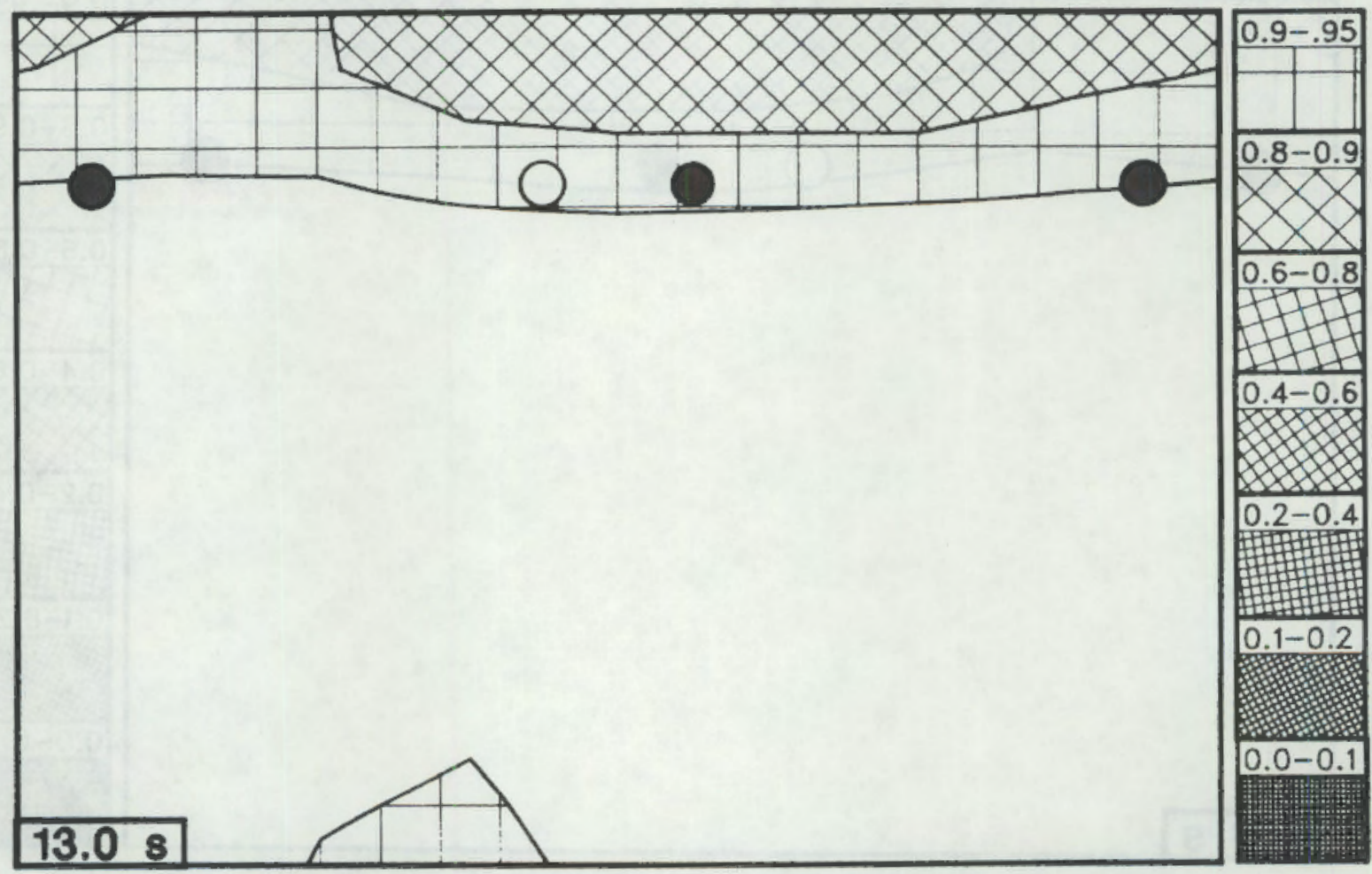

Figure B.29. Downcomer void fraction contour at $13.0 \mathrm{~s}$ 


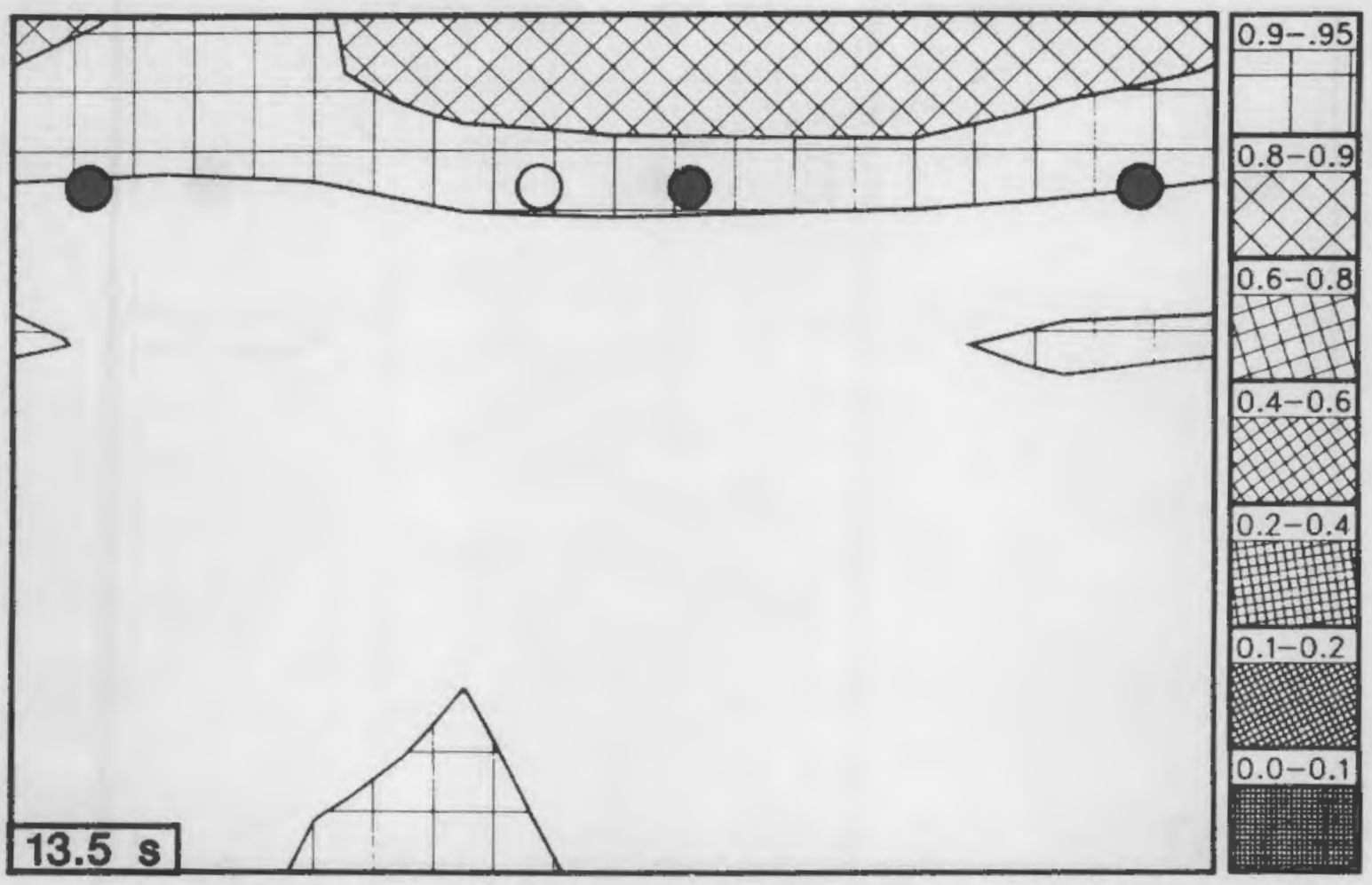

Figure B.30. Downcomer void fraction contour at $13.5 \mathrm{~s}$

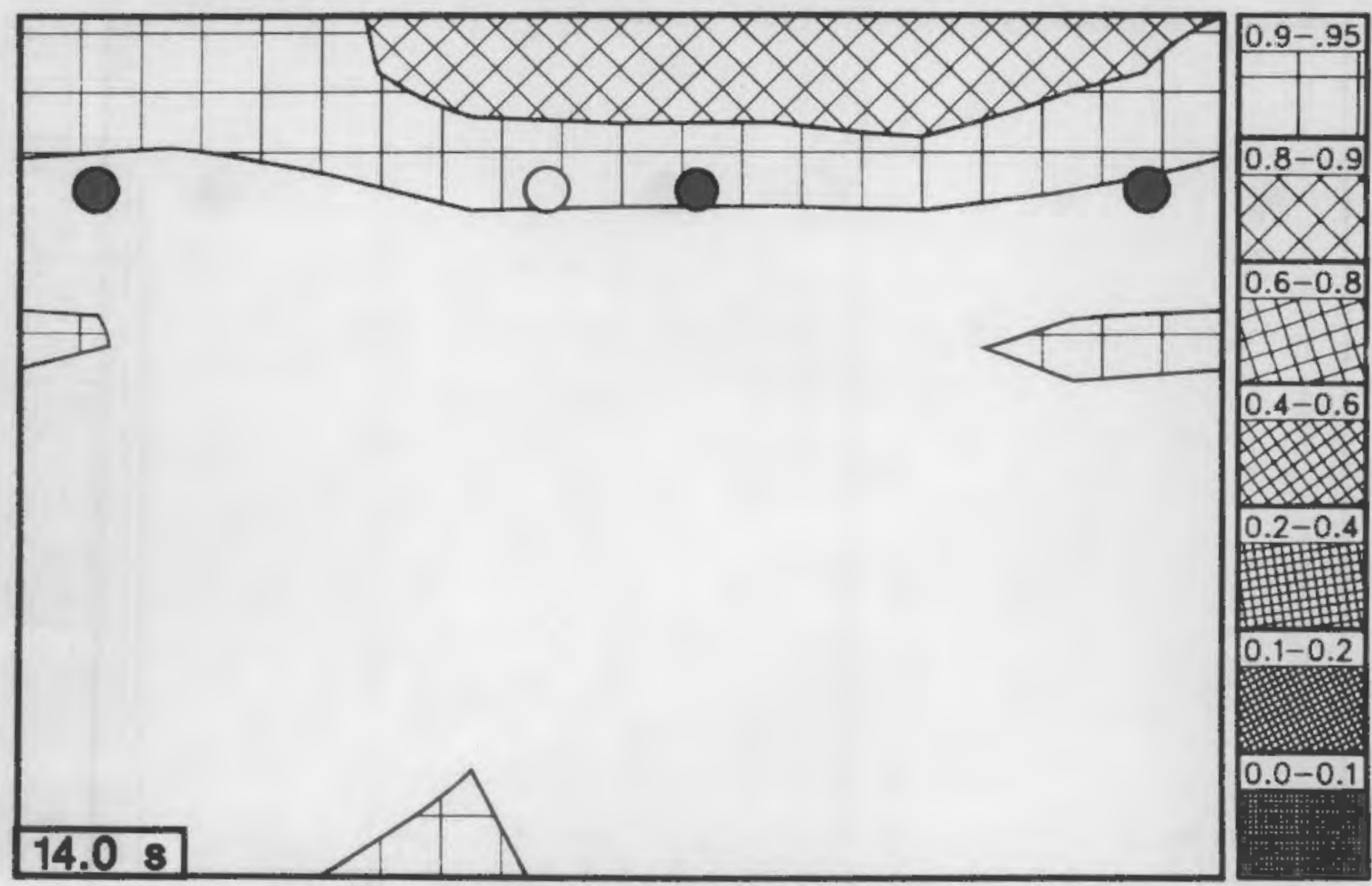

Figure B.31. Downcomer void fraction contour at $14.0 \mathrm{~s}$ 


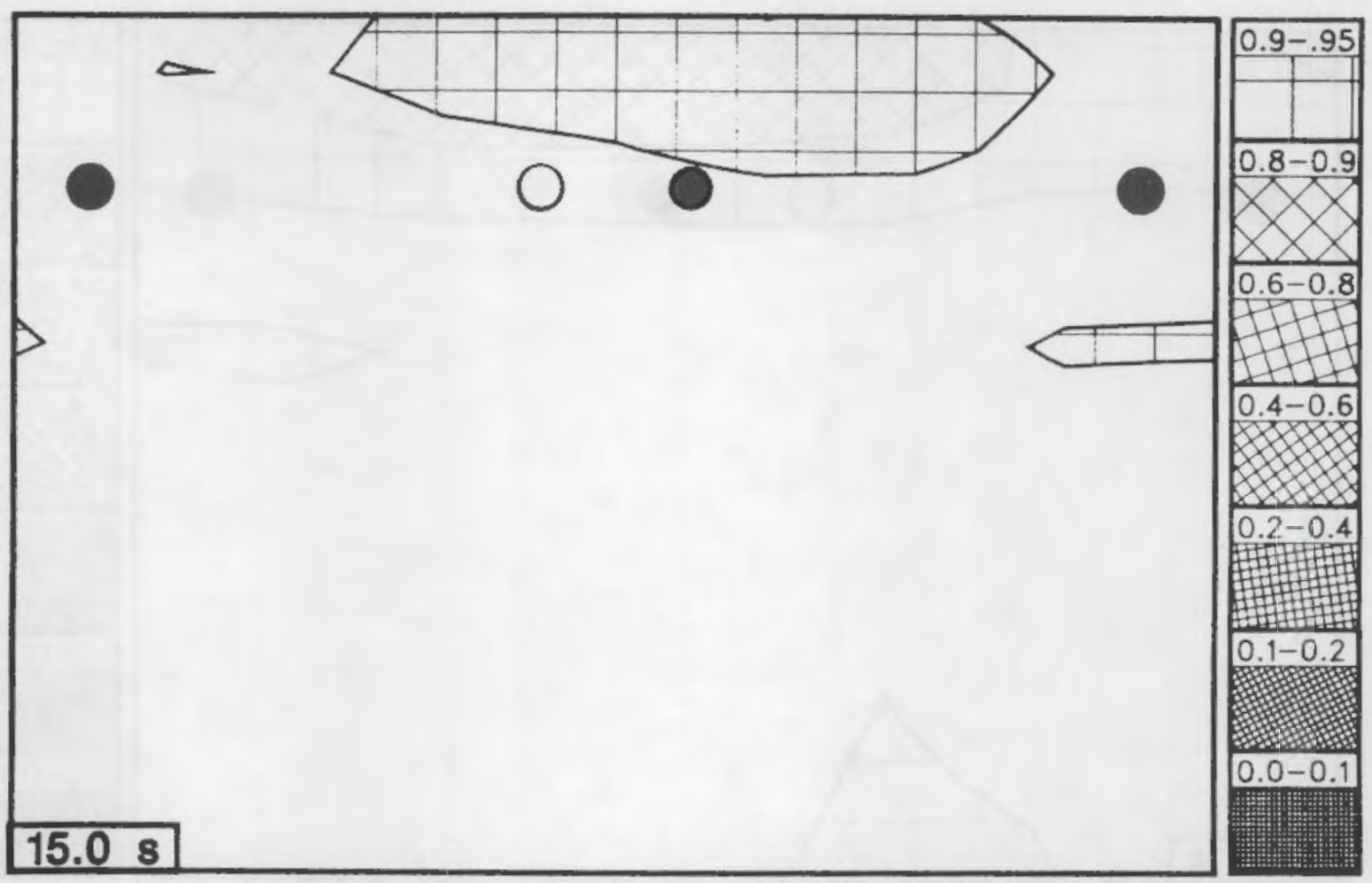

Figure B.32. Downcomer void fraction contour at $15.0 \mathrm{~s}$

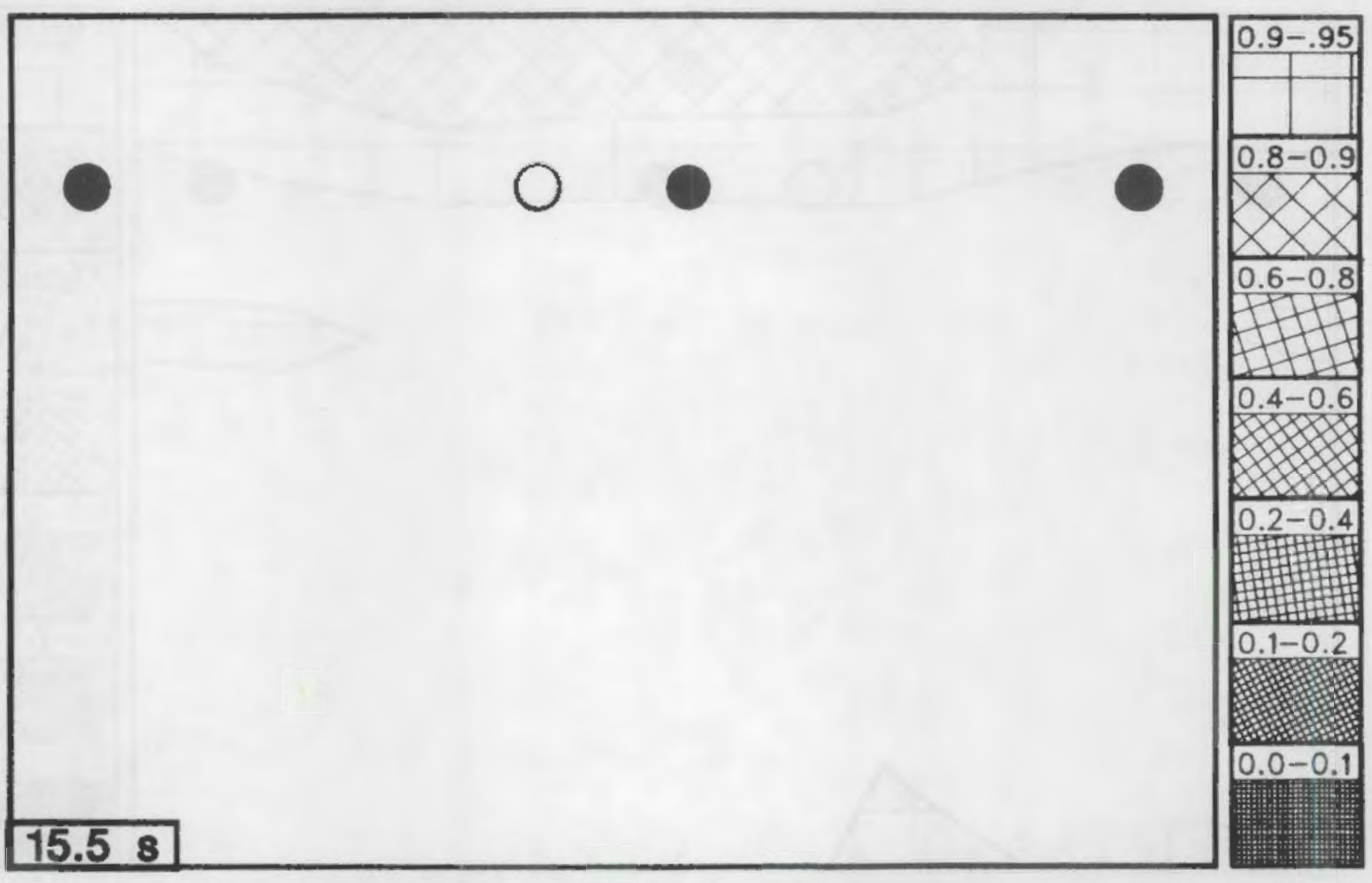

Figure 3.33 . Downcomer void fraction contour at $15.5 \mathrm{~s}$ 


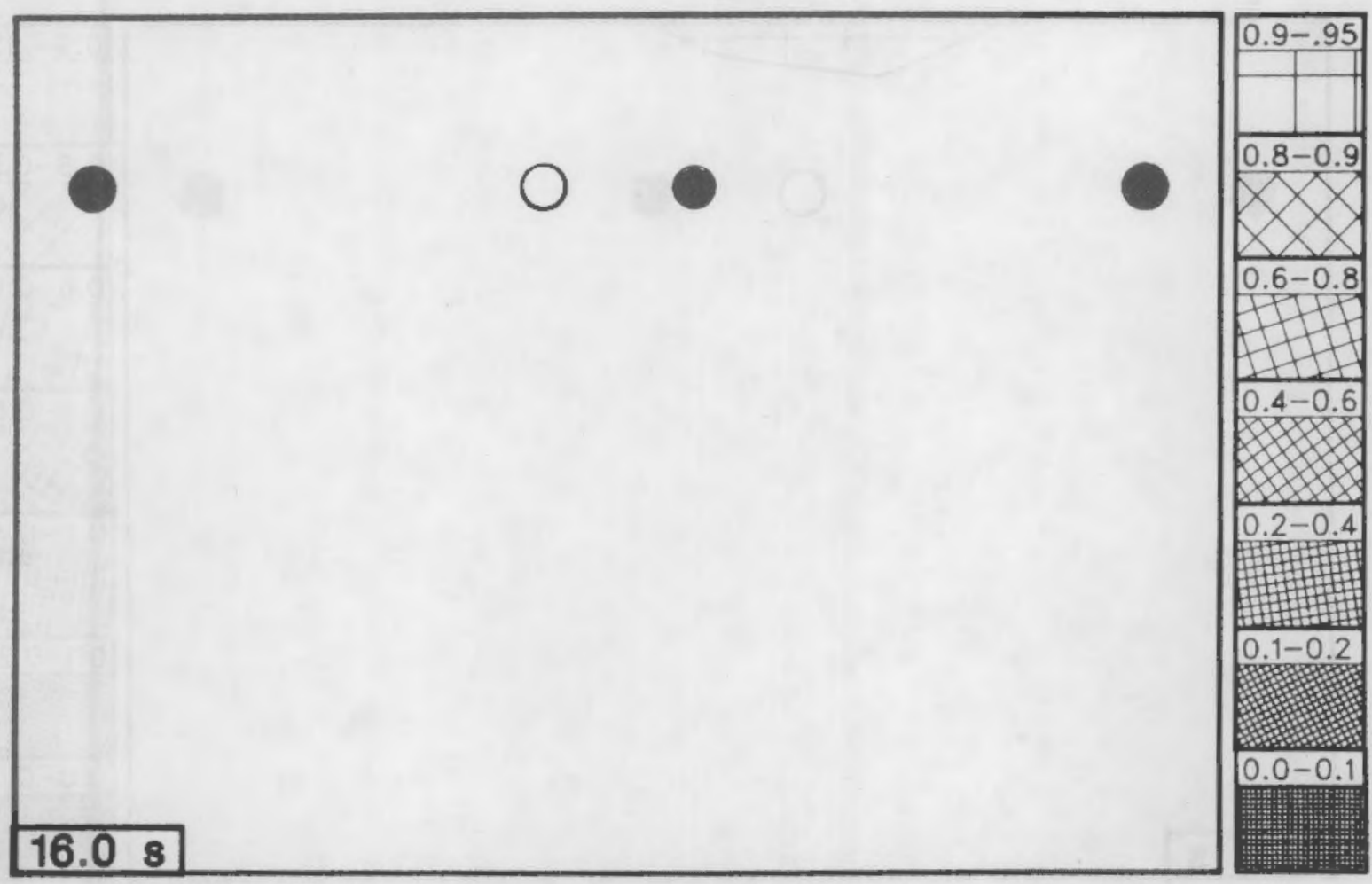

Figure B.34. Downcomer void fraction contour at $16.0 \mathrm{~s}$

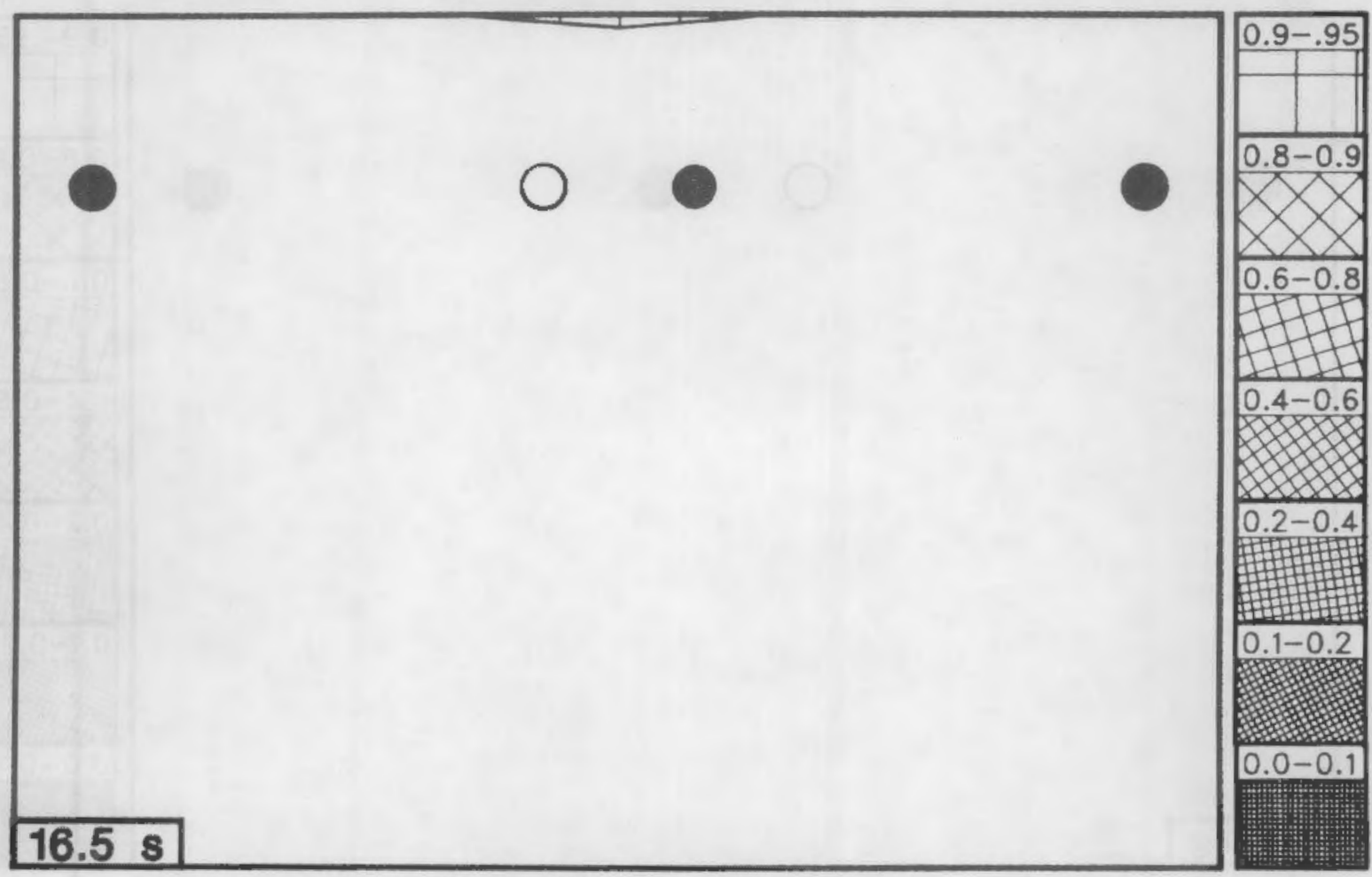

Figure B35. Downcomer void fraction contour at $16.5 \mathrm{~s}$ 


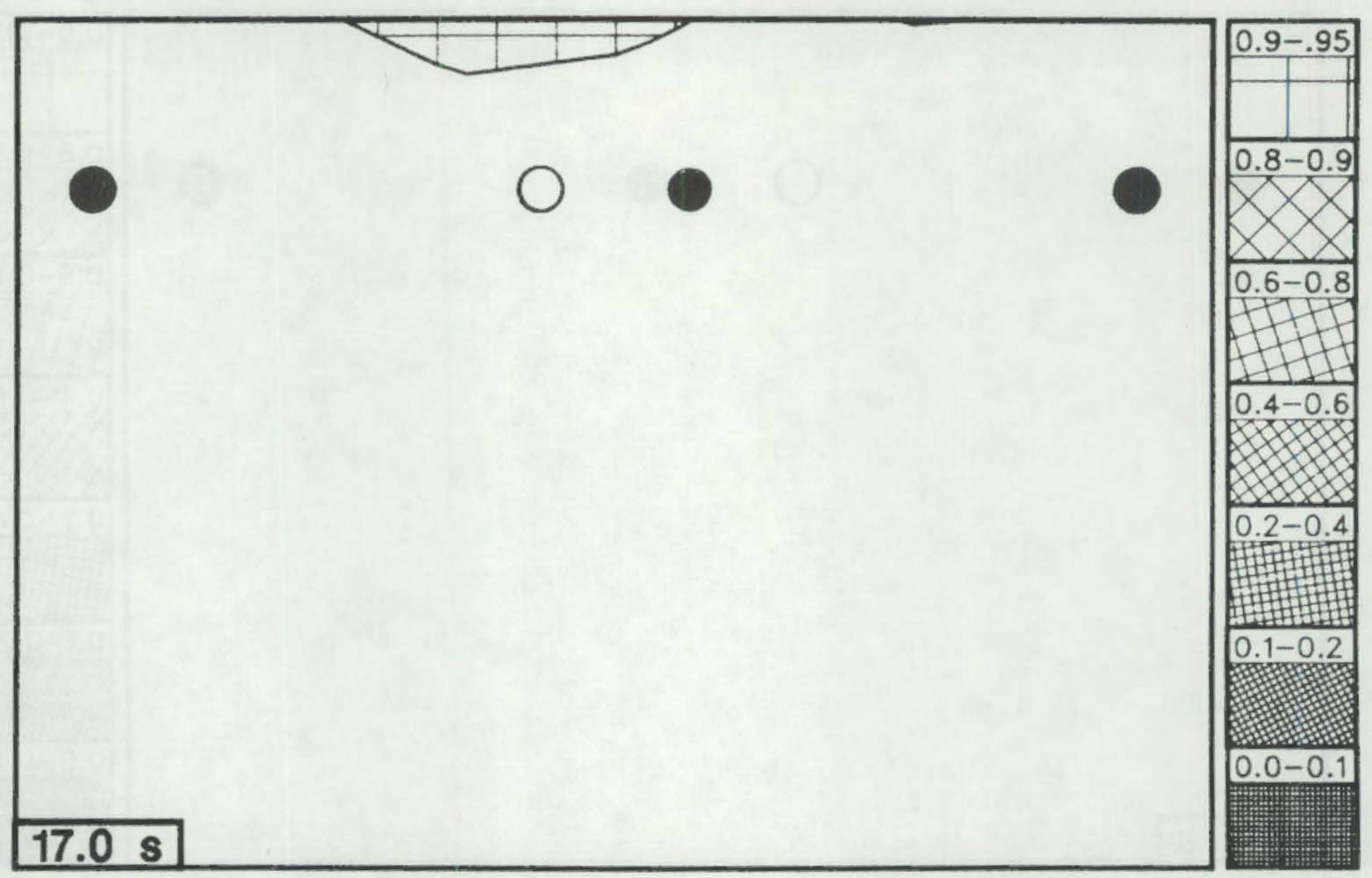

Figure B.36. Downcomer void fraction contour at $17.0 \mathrm{~s}$

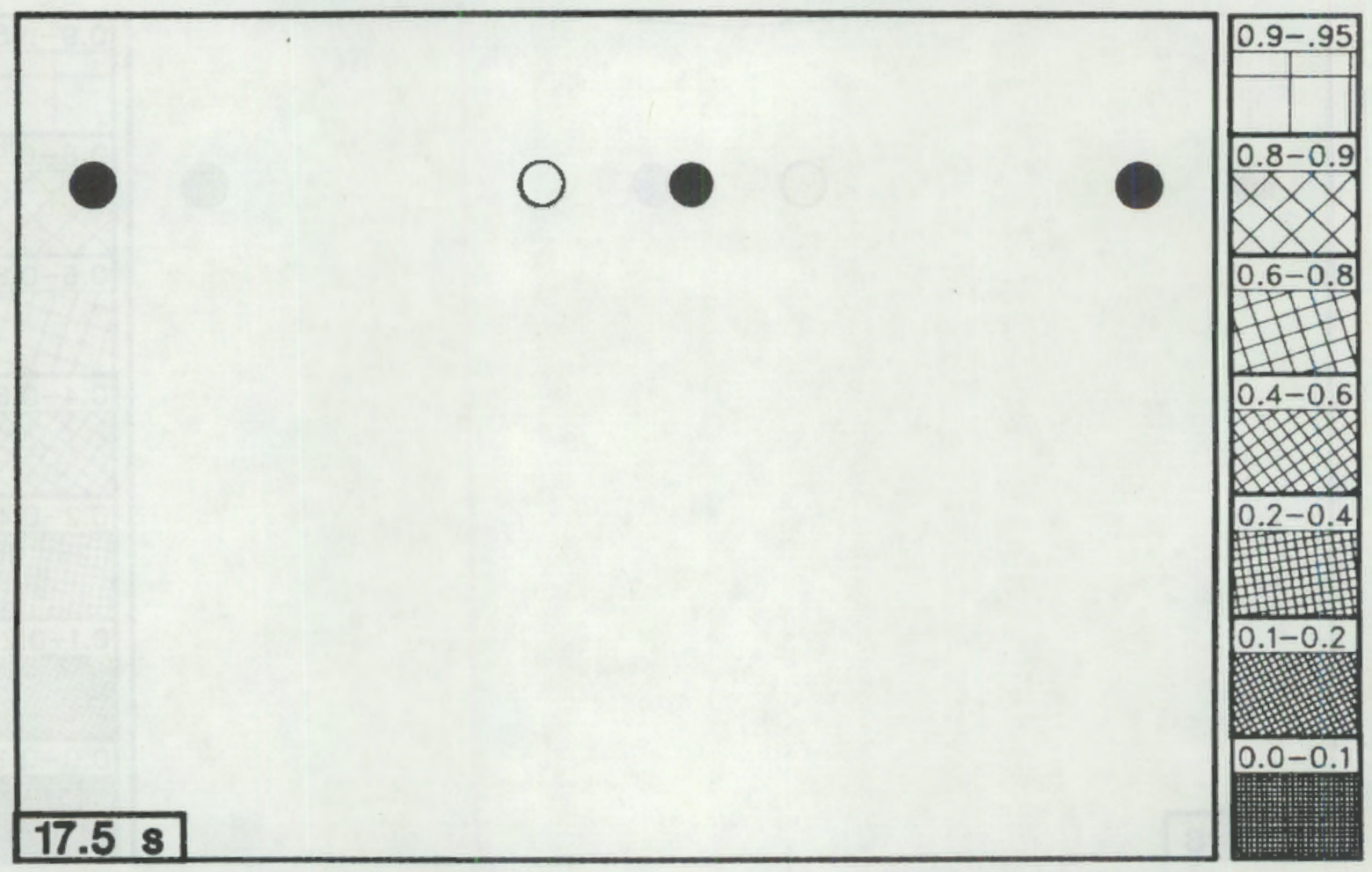

Figure B.37. Downcomer void fraction contour at $17.5 \mathrm{~s}$ 


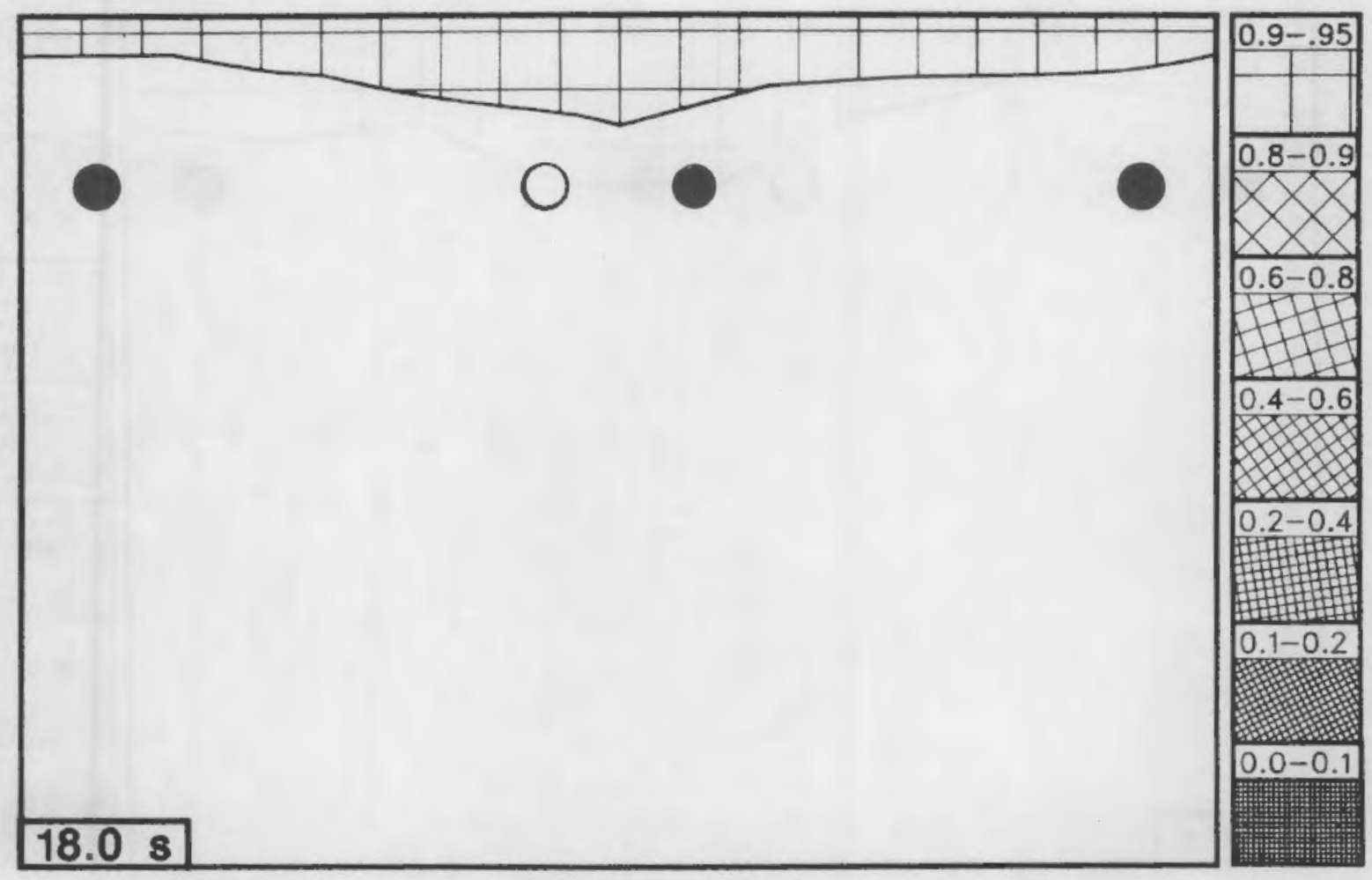

Figure B.38. Downcomer void fraction contour at $18.0 \mathrm{~s}$

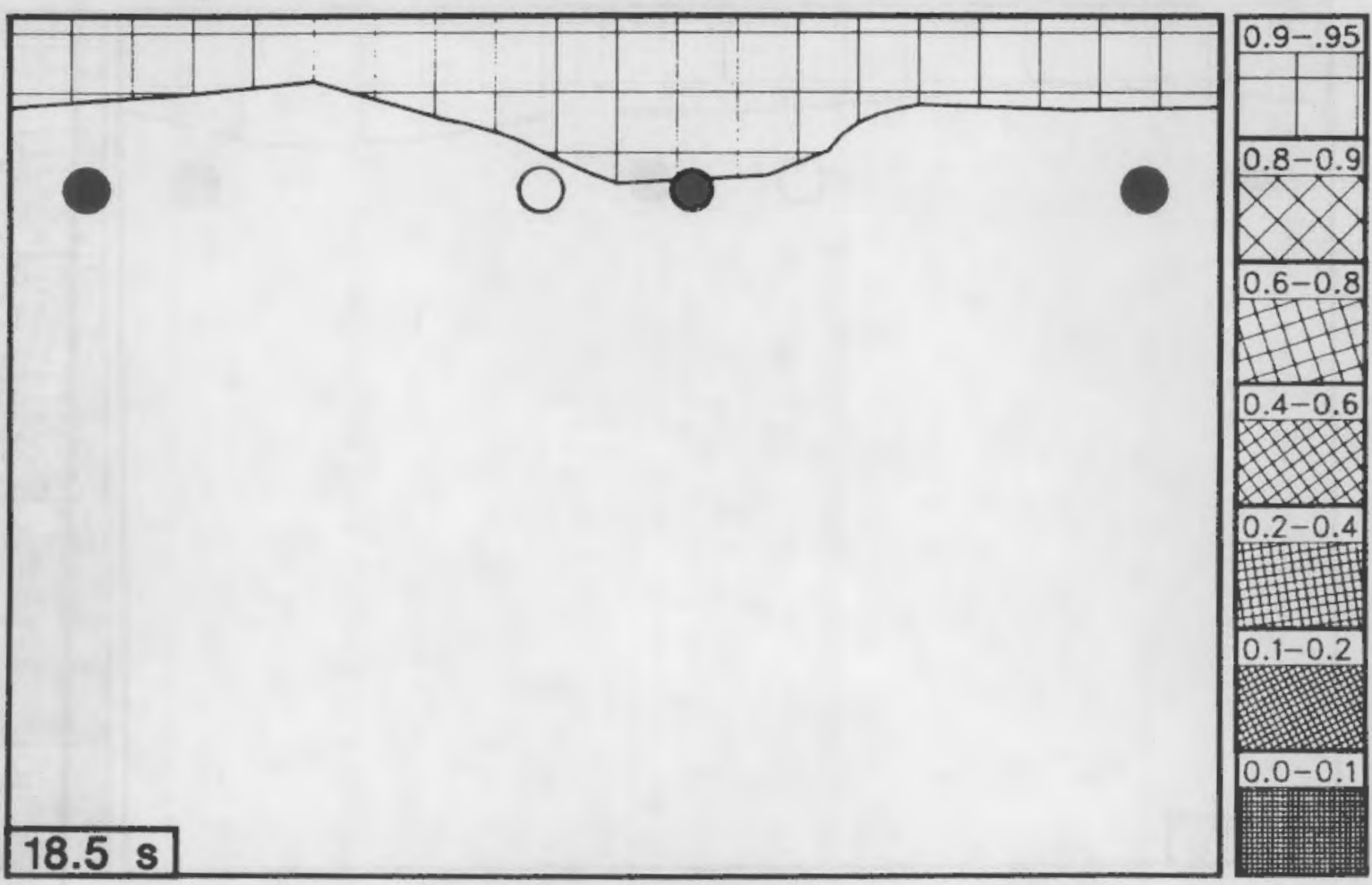

Figure B.39. Downcomer void fraction contour at $18.5 \mathrm{~s}$ 


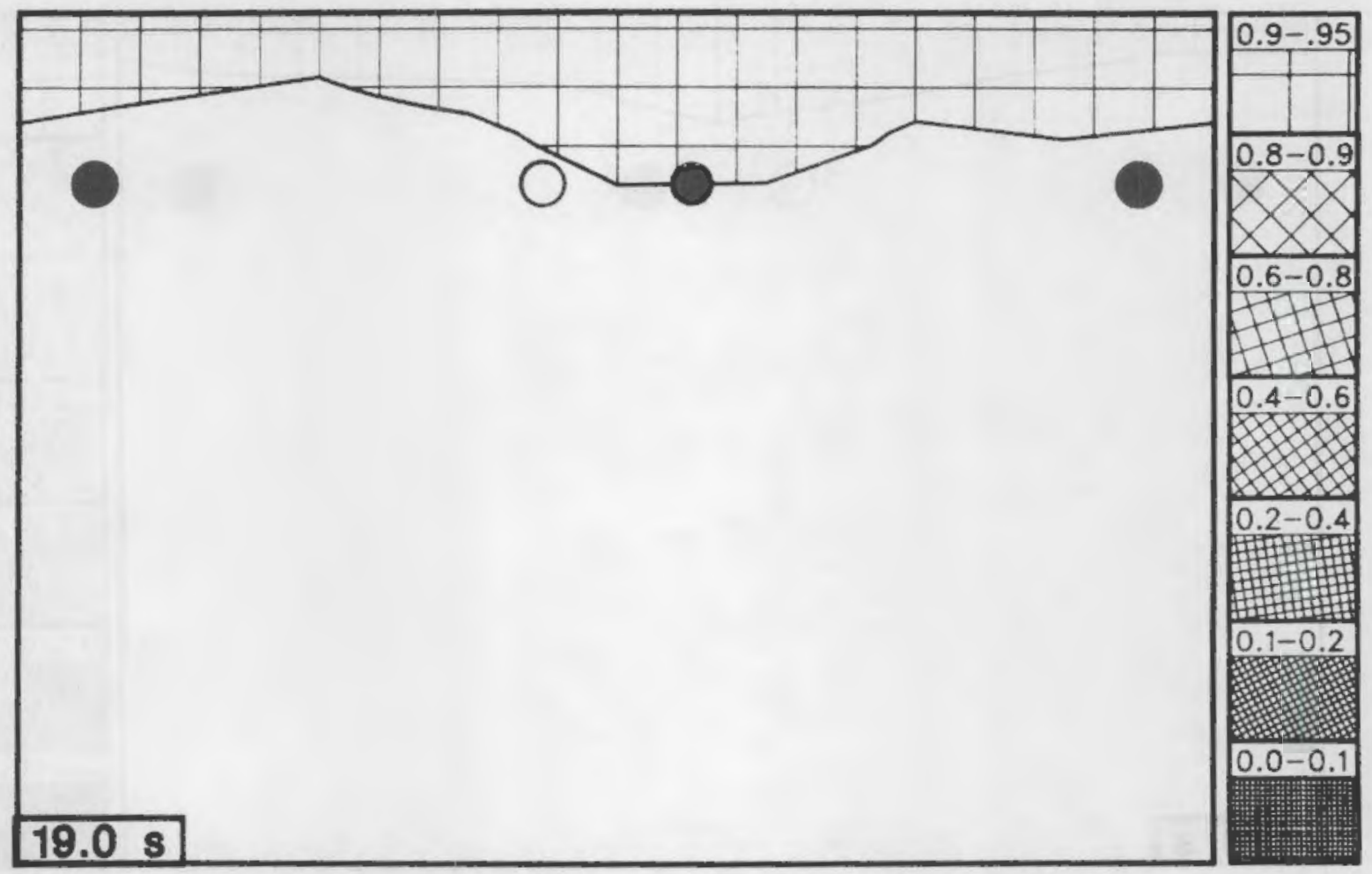

Figure B.40. Downcomer void fraction contour at $19.0 \mathrm{~s}$

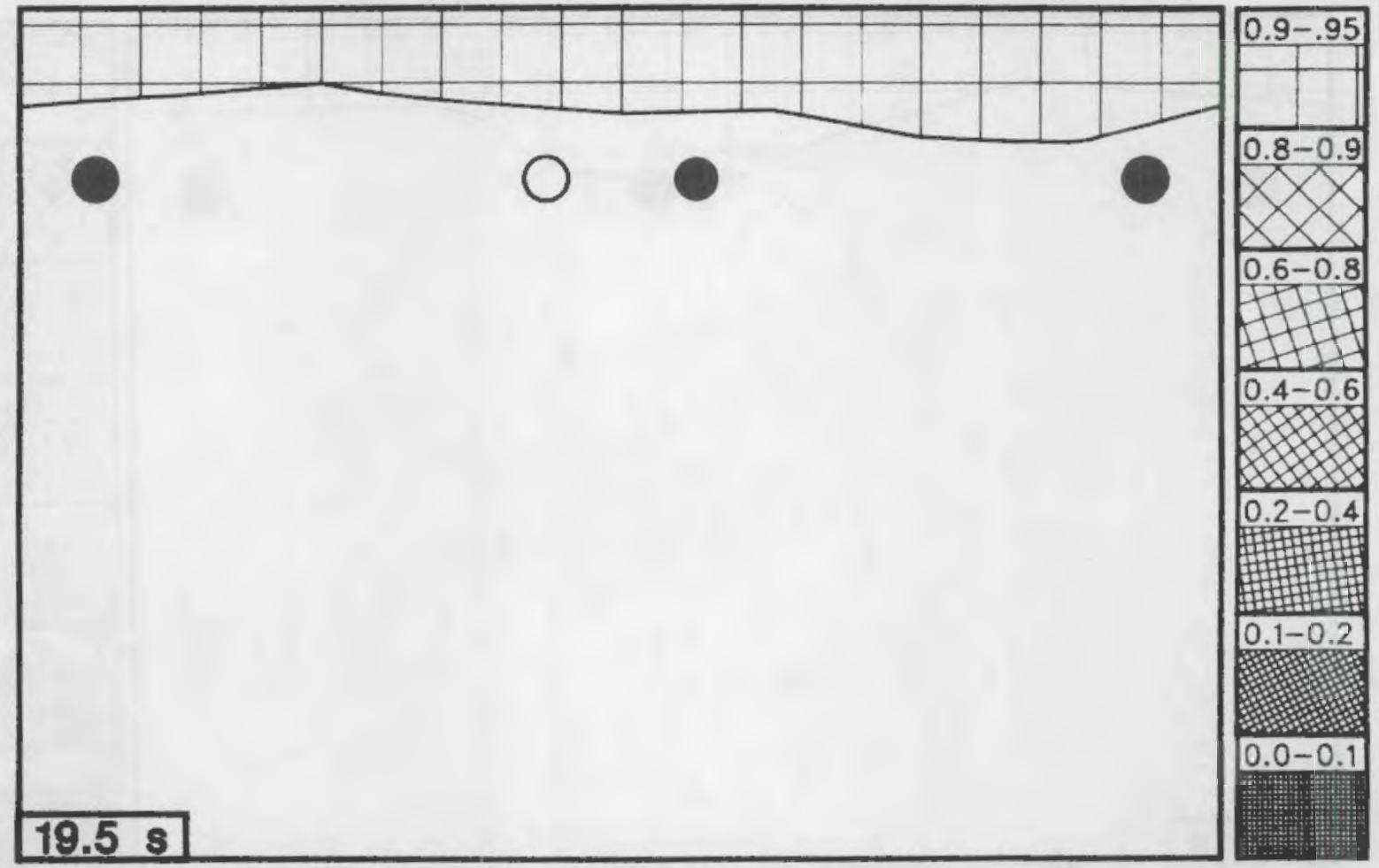

Figure B.41. Downcomer void fraction contour at $19.5 \mathrm{~s}$ 


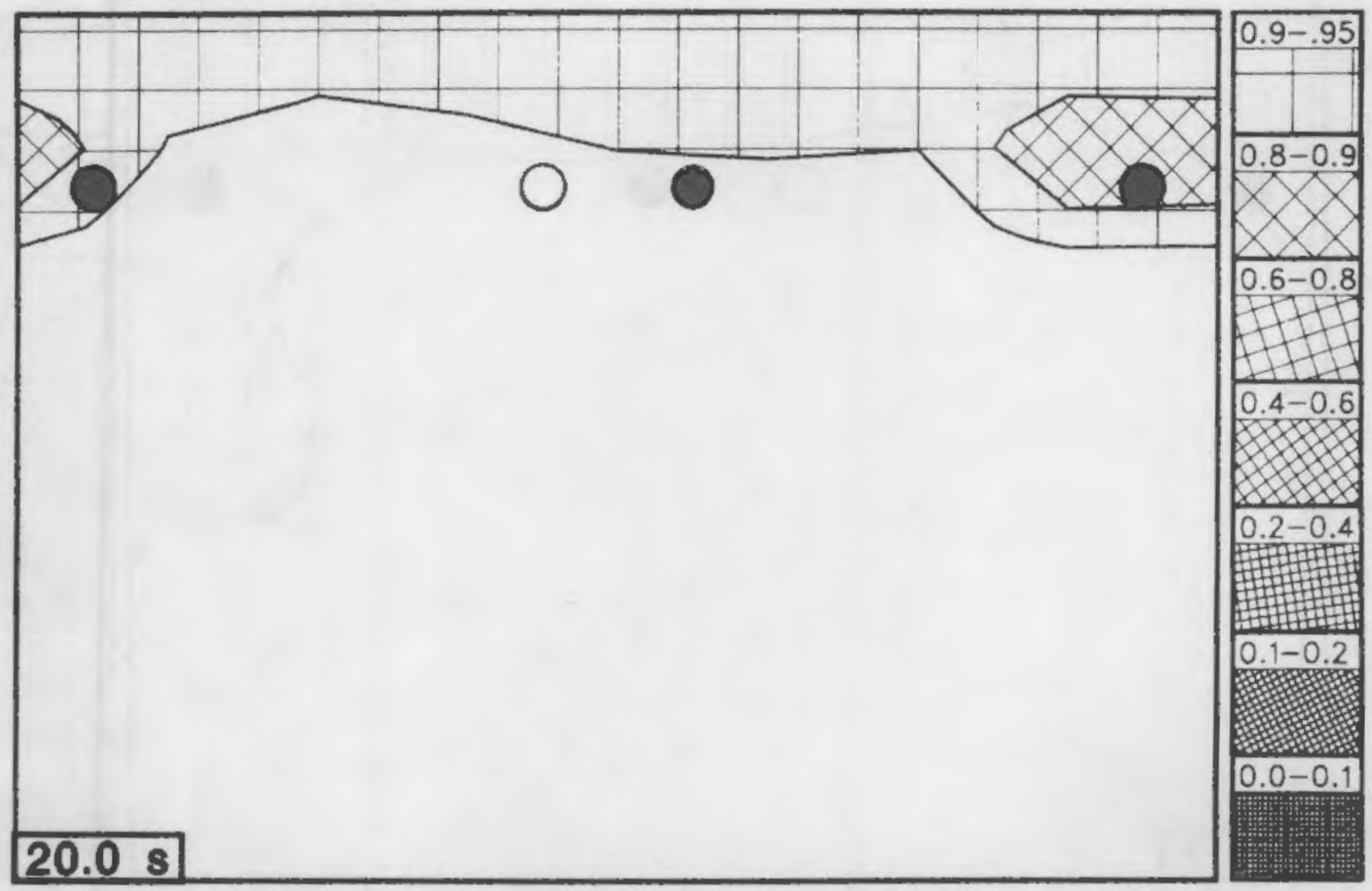

Figure B.42. Downcomer void fraction contour at $20.0 \mathrm{~s}$

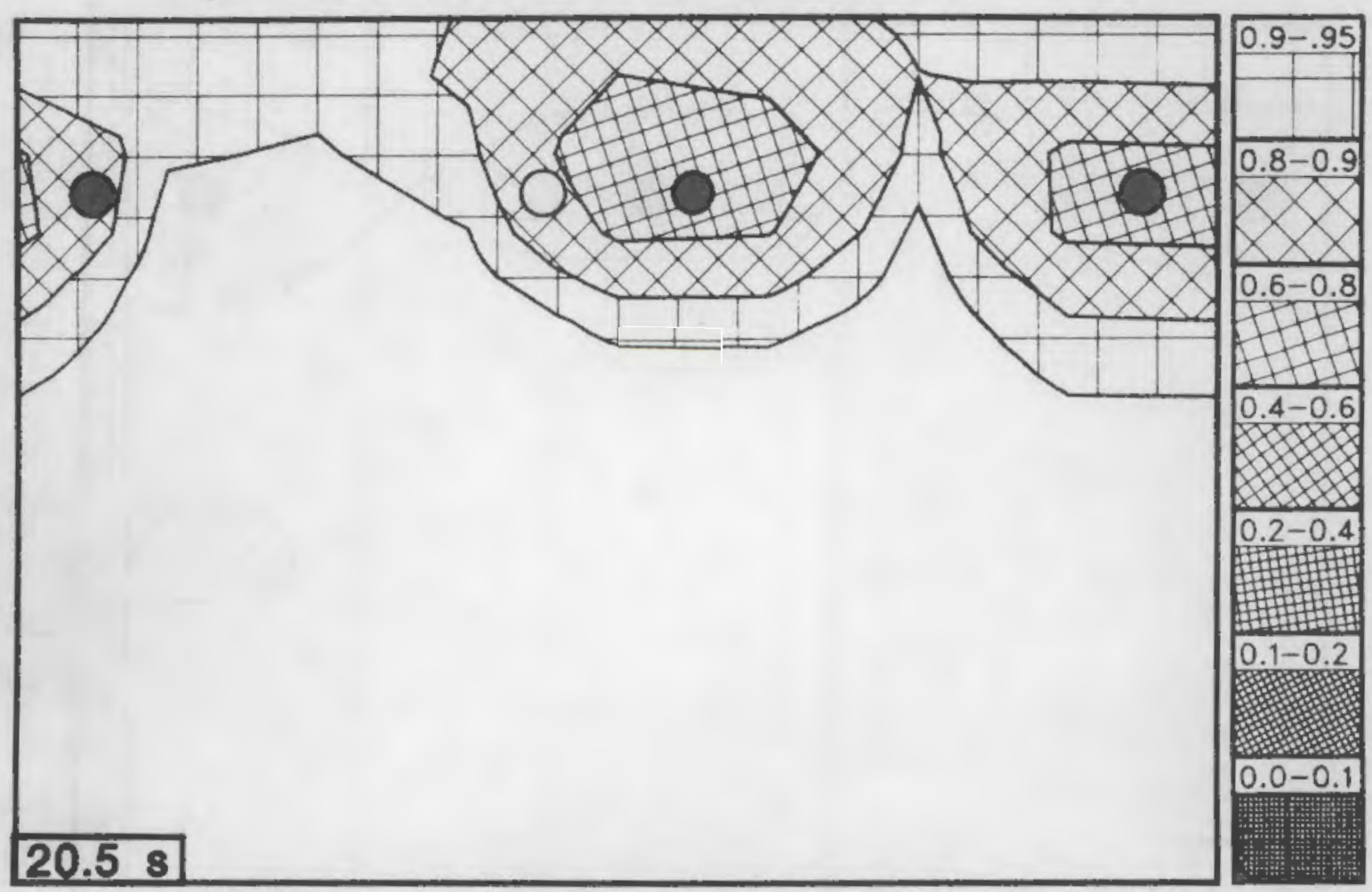

Figure B.43. Downcomer void fraction contour at $20.5 \mathrm{~s}$ 


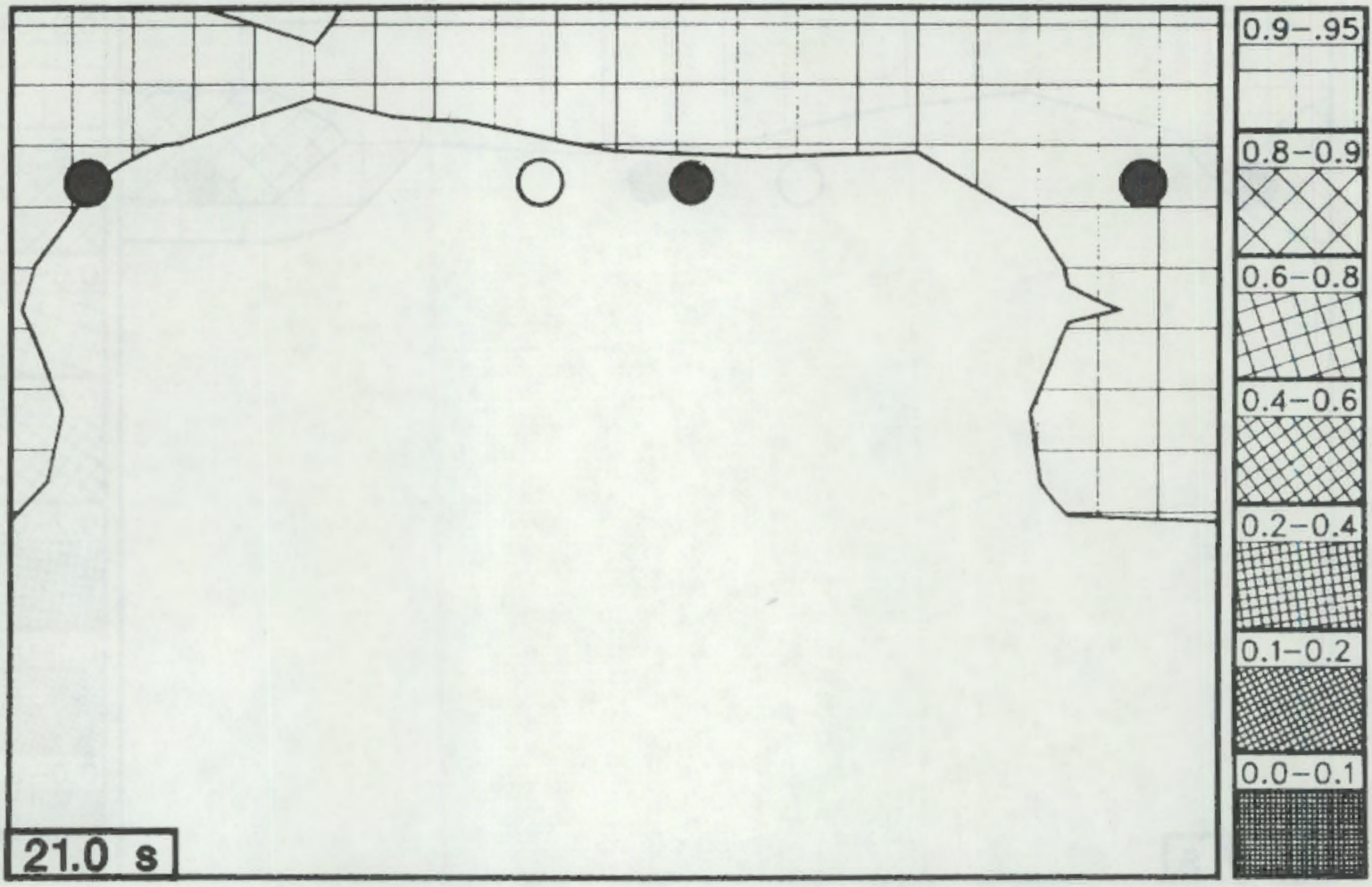

Figure B.44. Downcomer void fraction contour at $21.0 \mathrm{~s}$

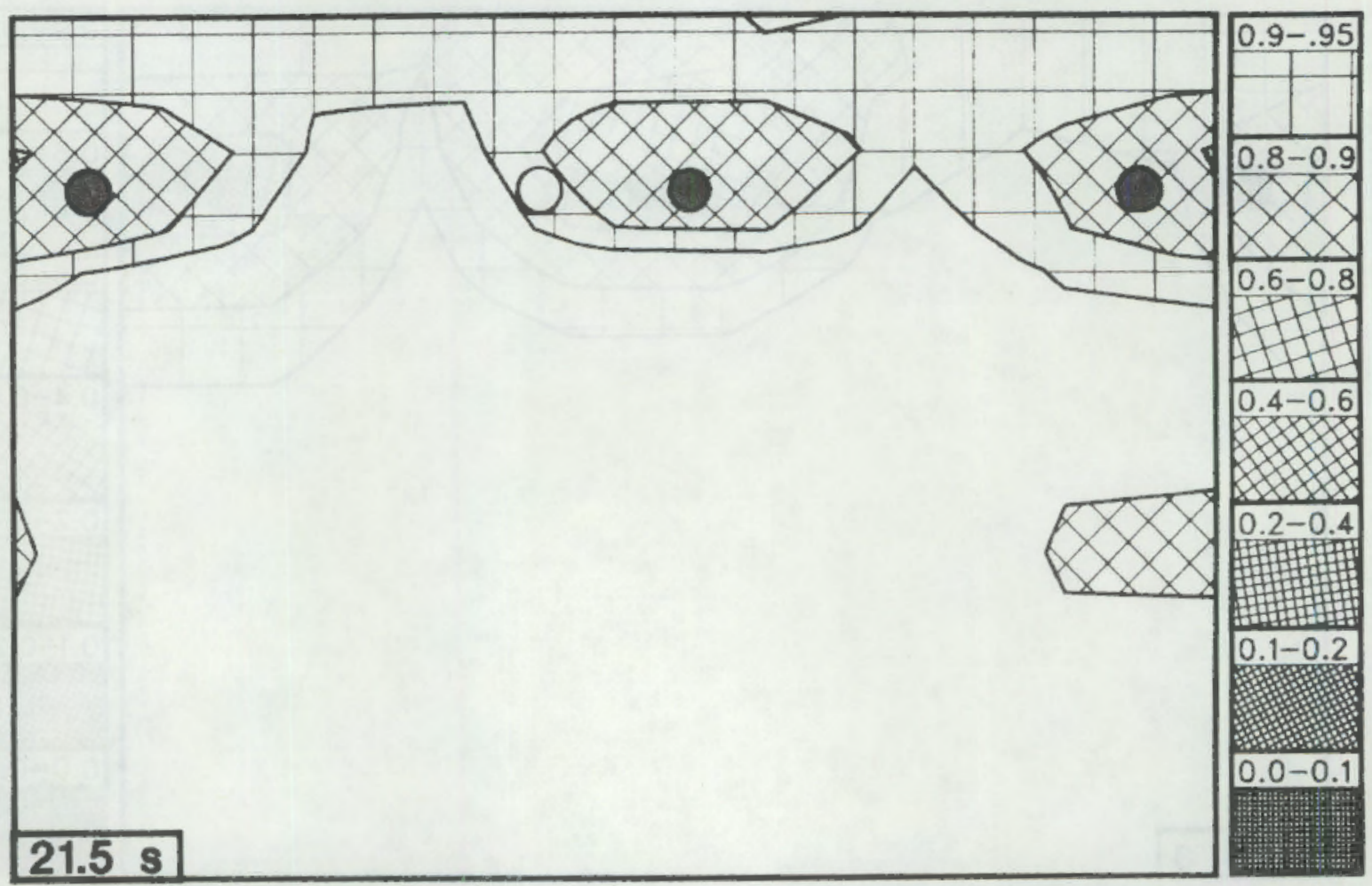

Figure B.45. Downcomer void fraction contour at $21.5 \mathrm{~s}$ 


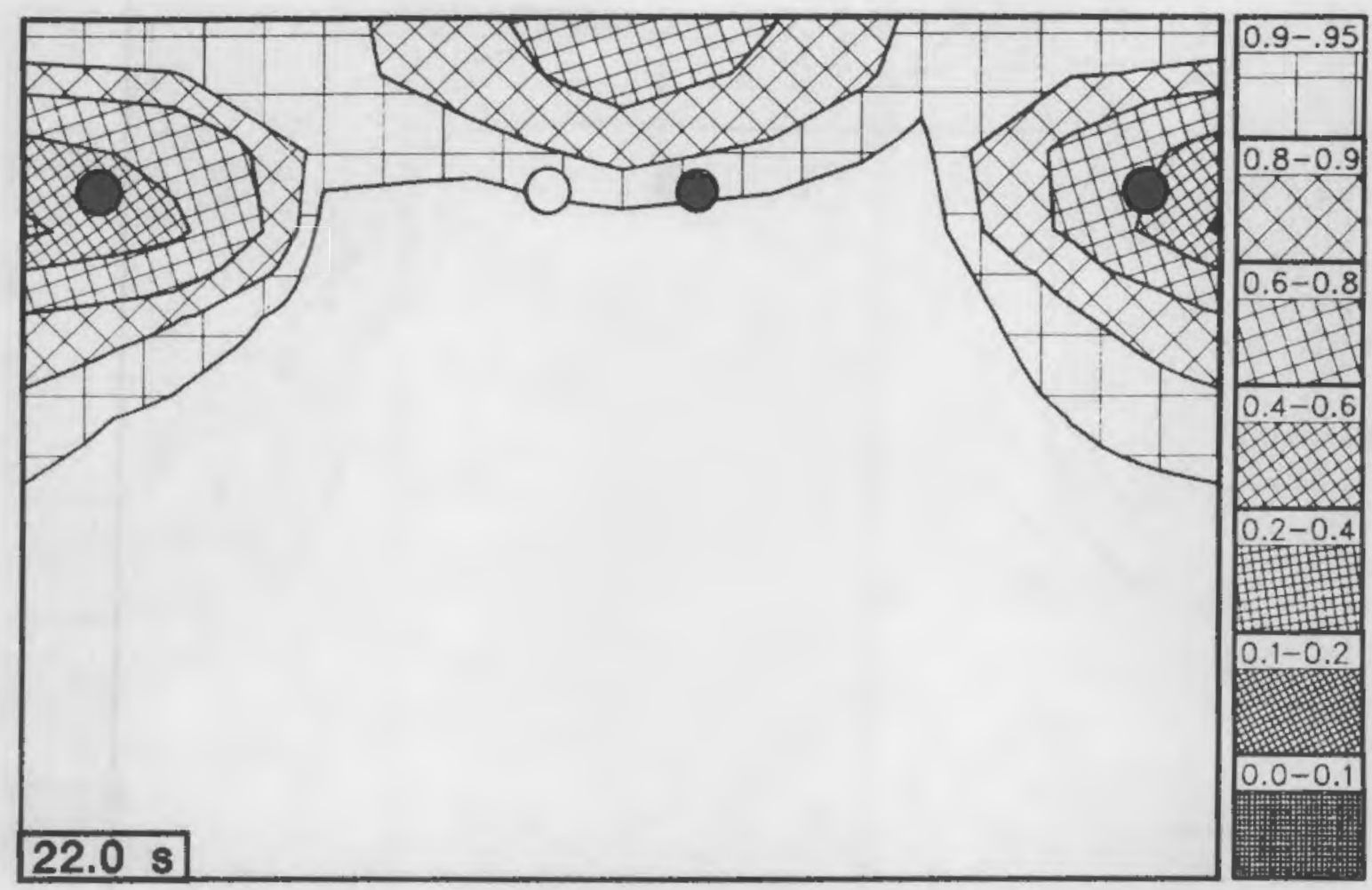

Figure B.46. Downcomer void fraction contour at $22.0 \mathrm{~s}$

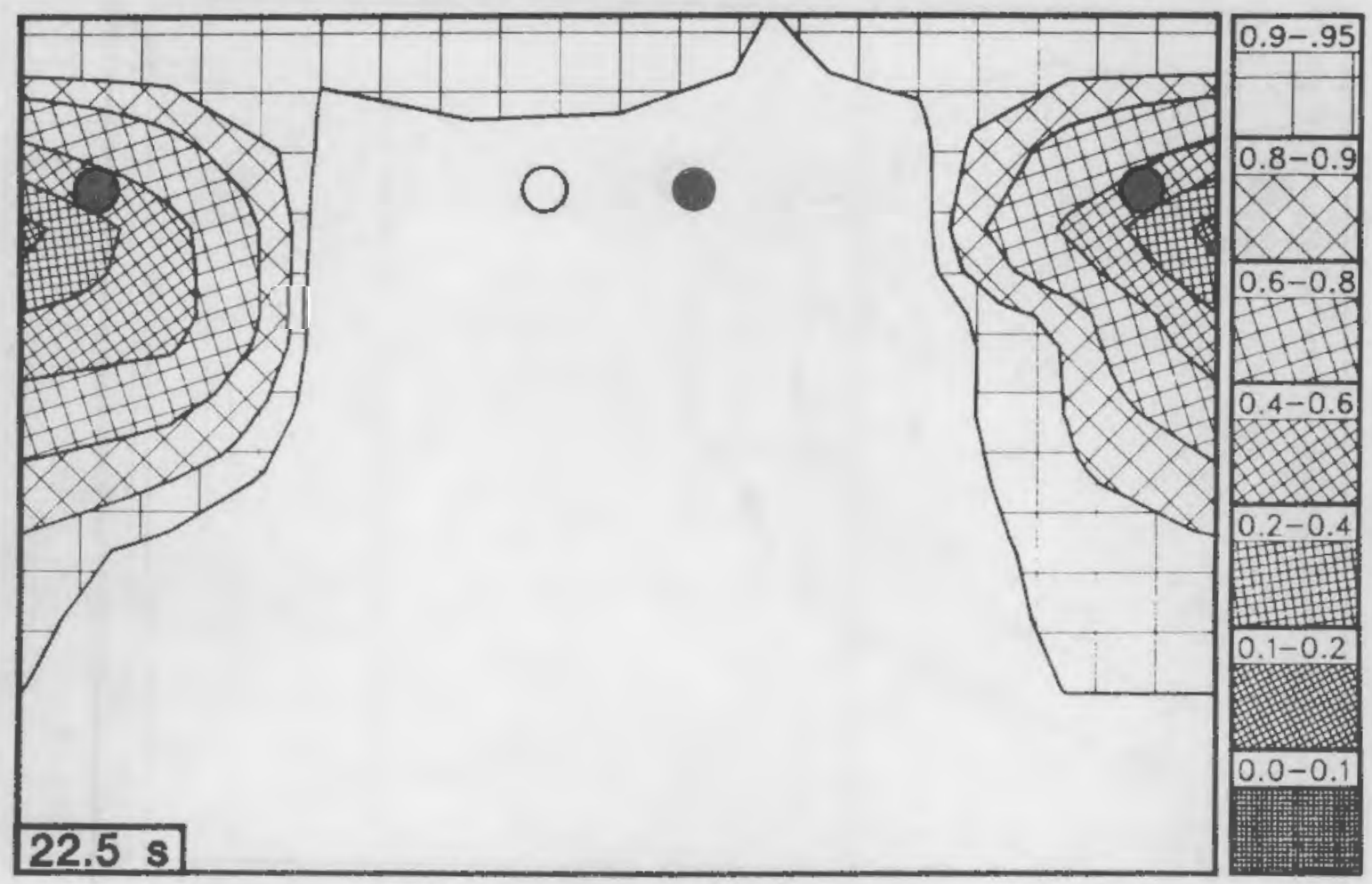

Figure B.47. Downcomer void fraction contour at $22.5 \mathrm{~s}$ 


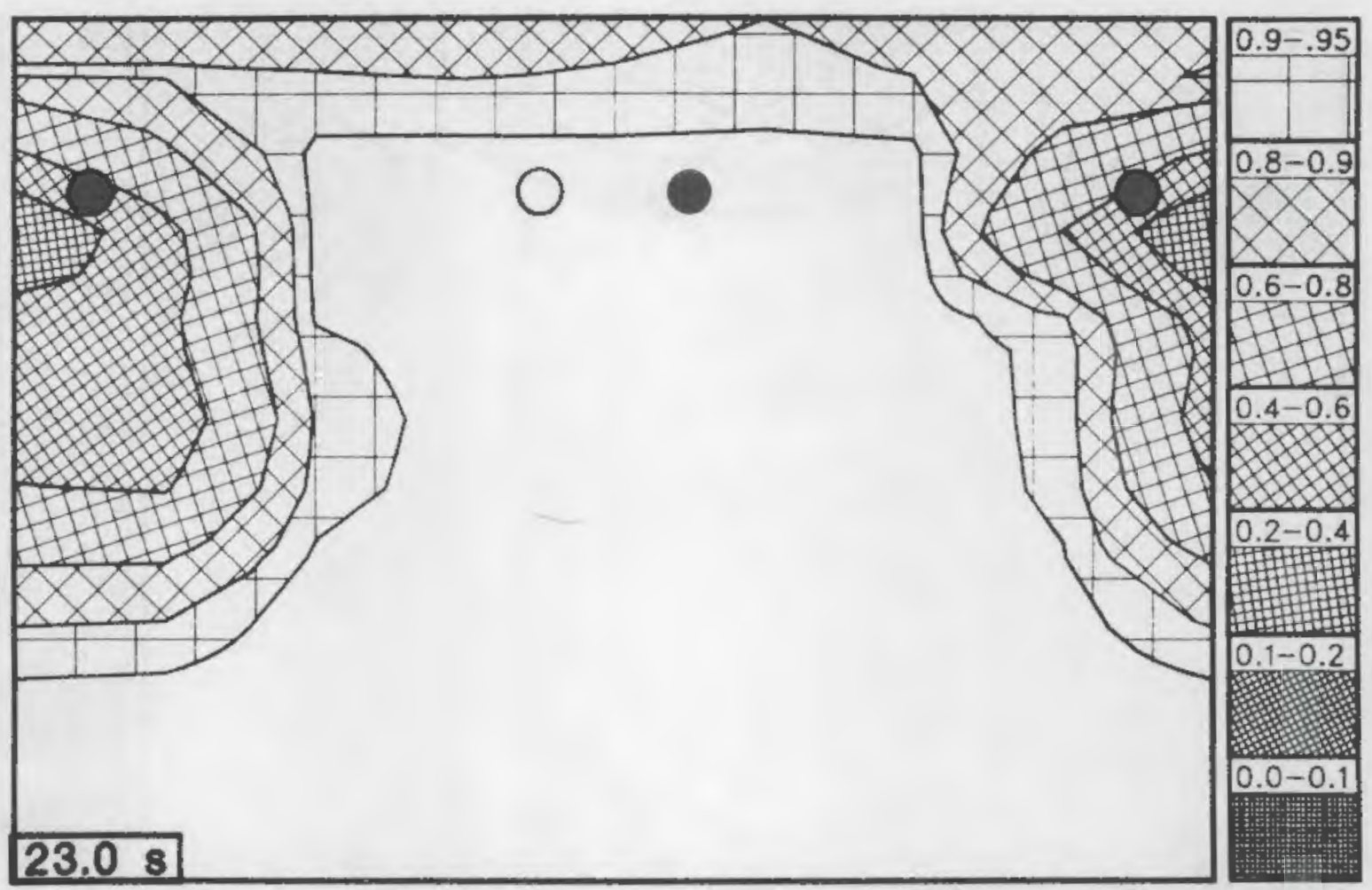

Figure B.48. Downcomer void fraction contour at $23.0 \mathrm{~s}$

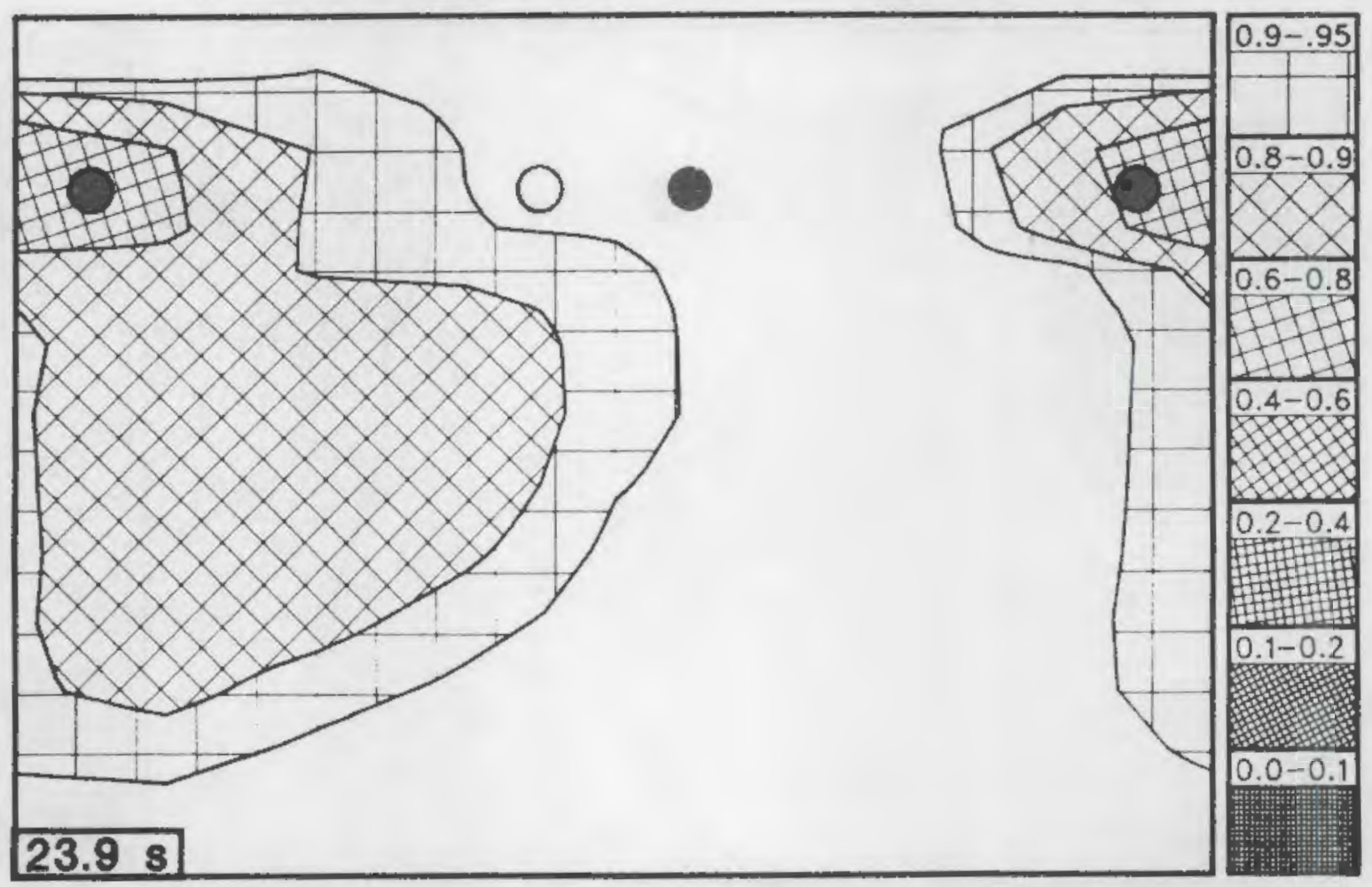

Figure B.49. Downcomer void fraction contour at $23.9 \mathrm{~s}$ 


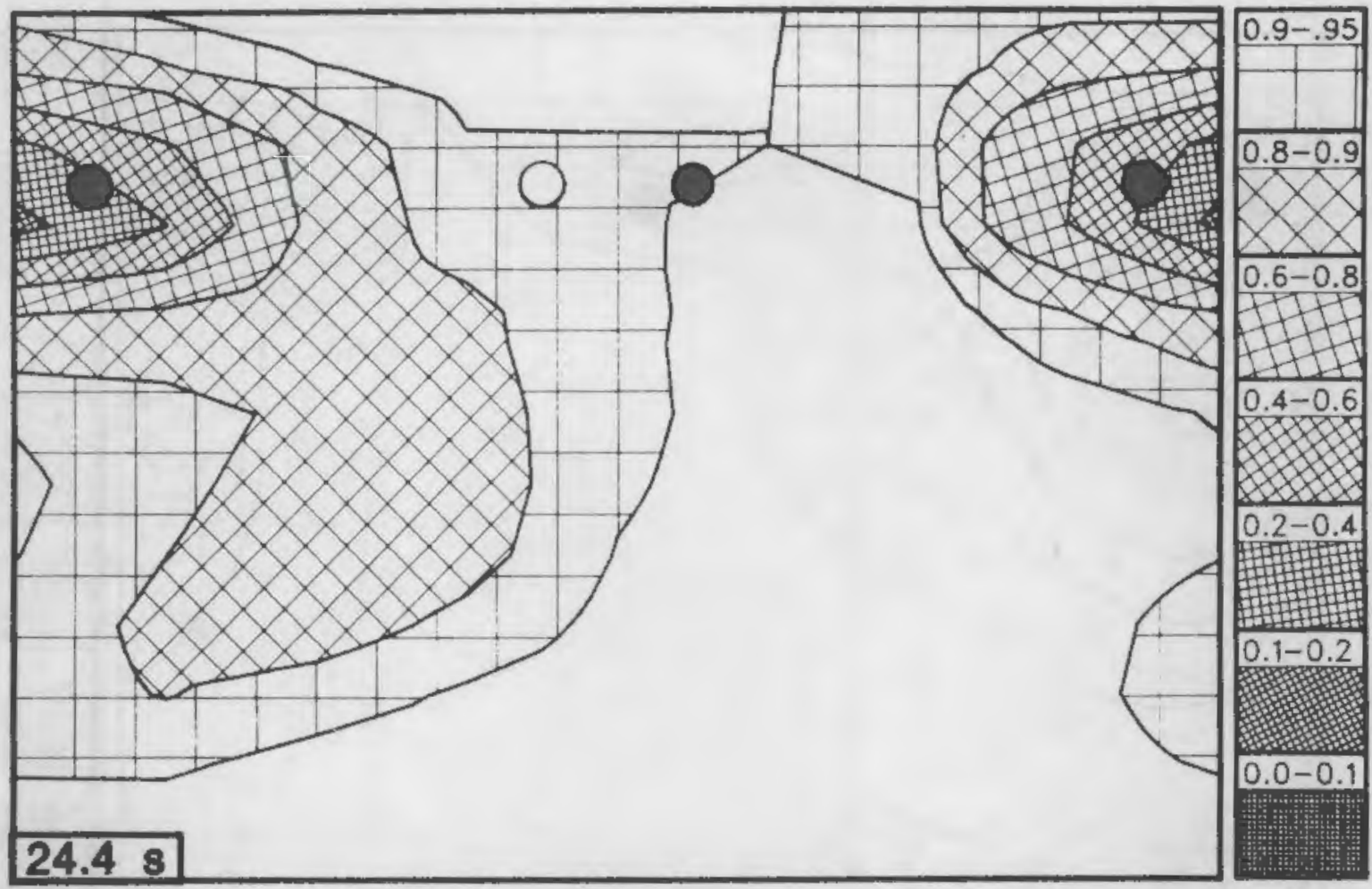

Figure B.50. Downcomer void fraction contour at $24.4 \mathrm{~s}$

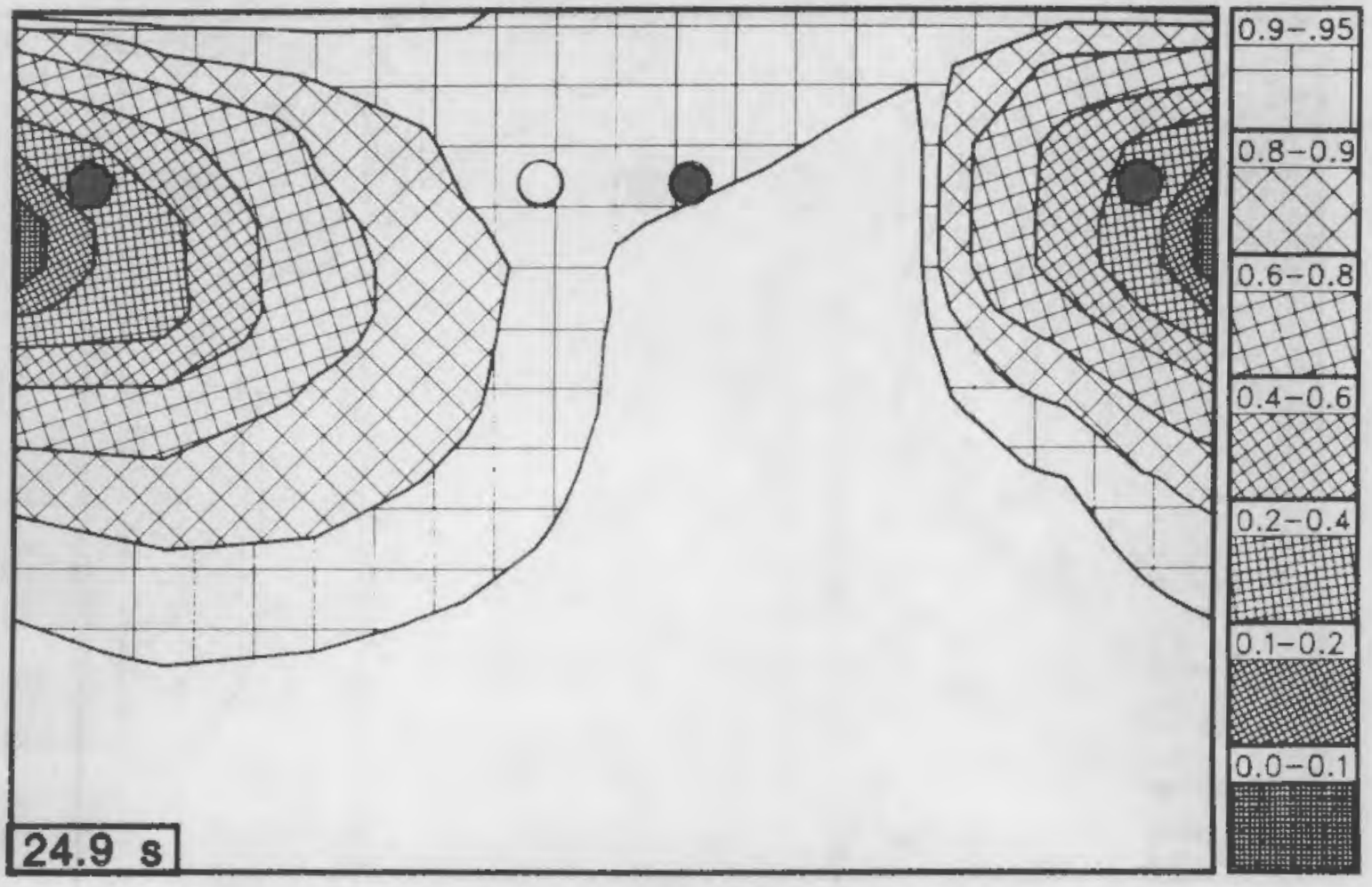

Figure B.51. Downcomer void fraction contour at $24.9 \mathrm{~s}$ 


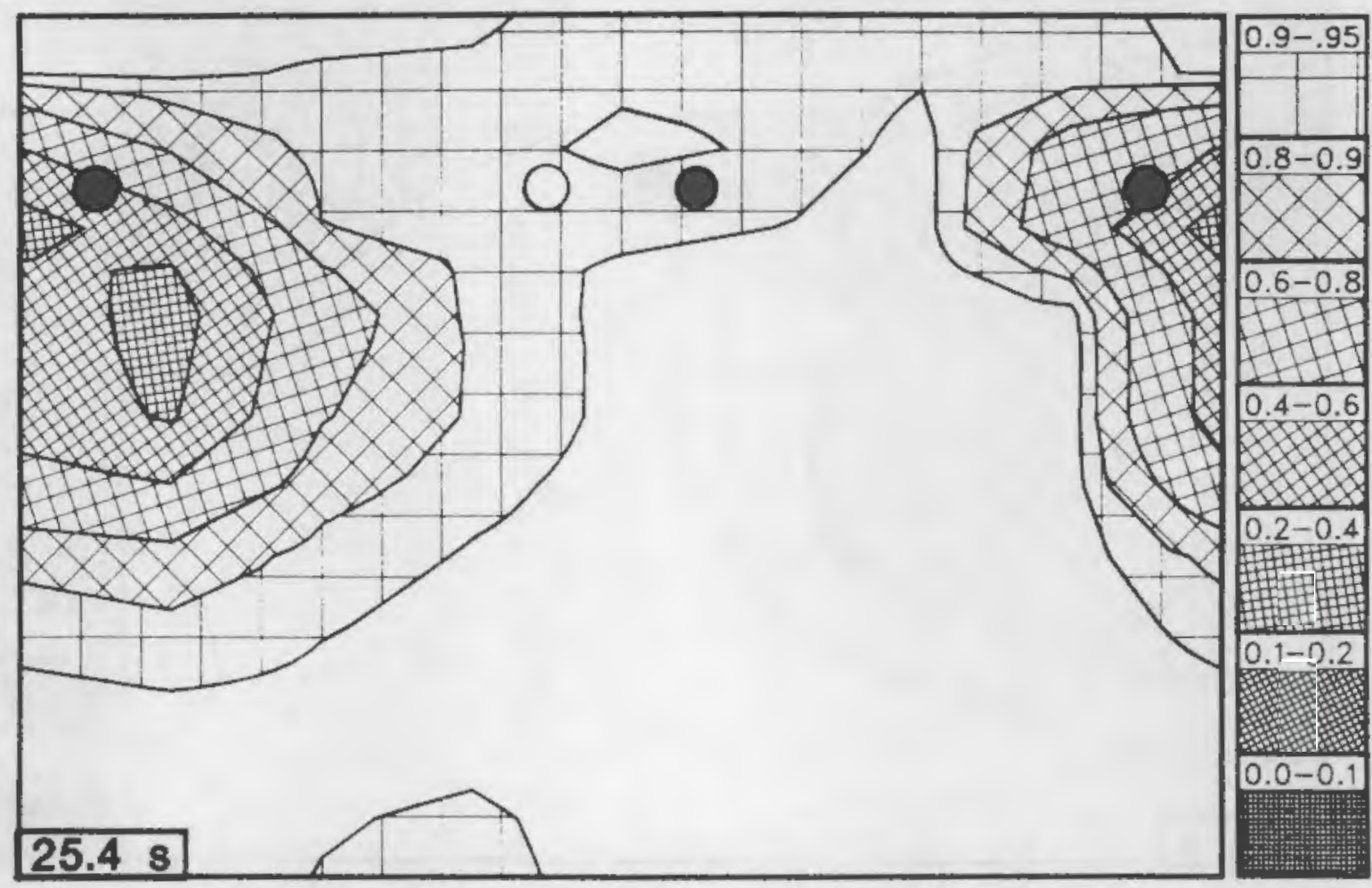

Figure B.52. Downcomer void fraction contour at $25.4 \mathrm{~s}$

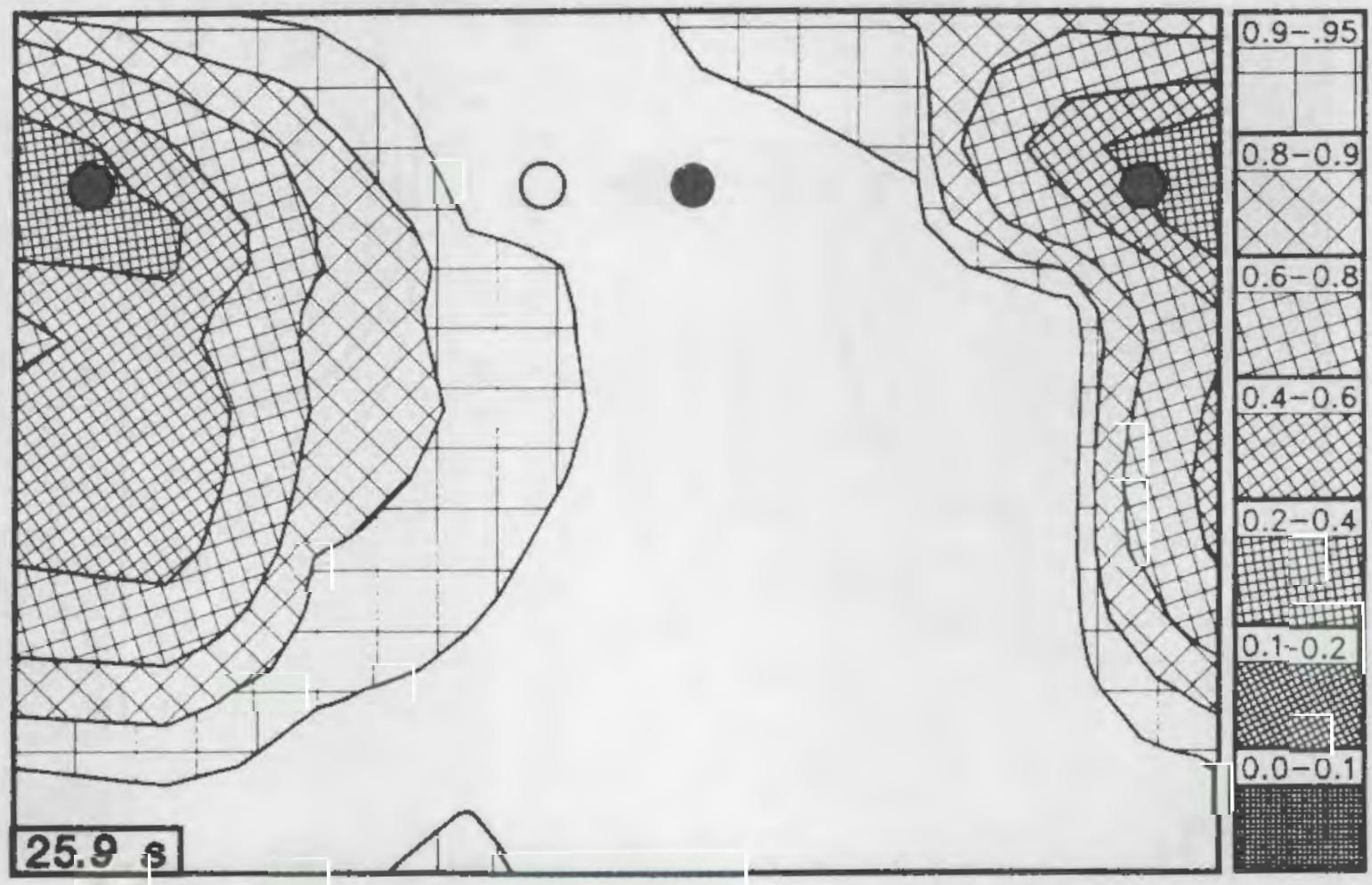

Figure B.53. Downcomer void fraction contour at $25.9 \mathrm{~s}$ 


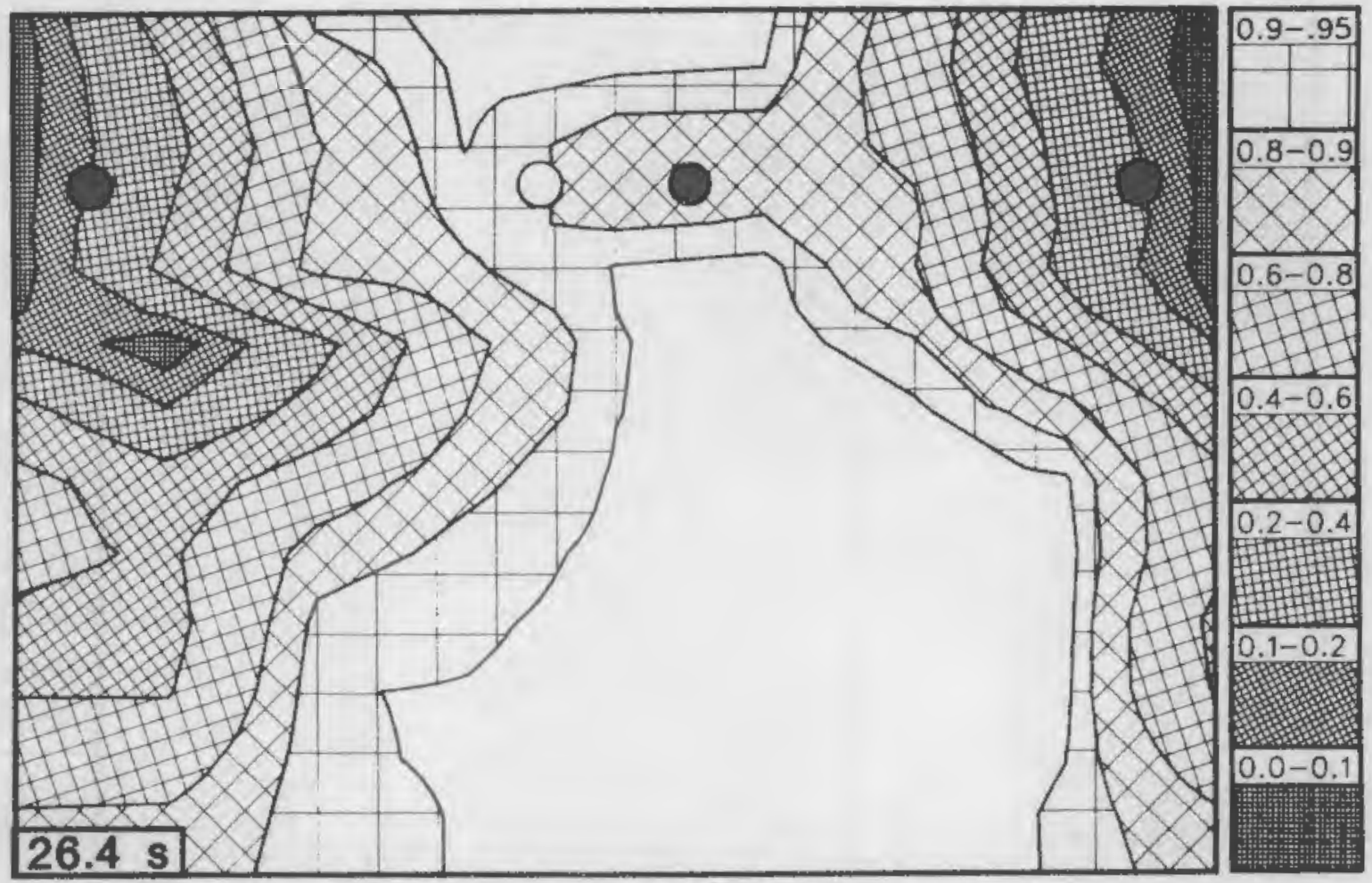

Figure B.54. Downcomer void fraction contour at $26.4 \mathrm{~s}$

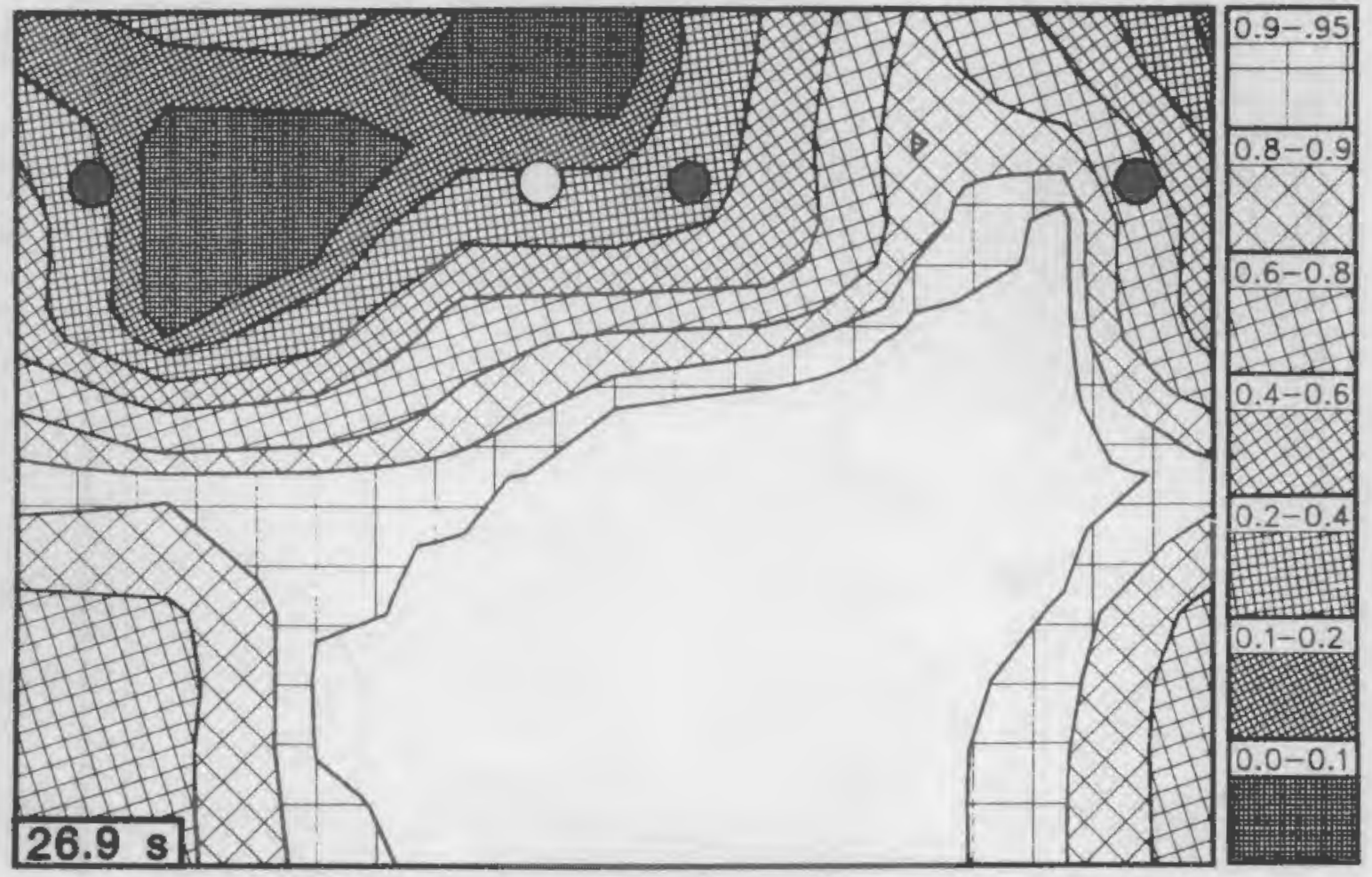

Figure B.55. Downcomer void fraction contour at $26.9 \mathrm{~s}$ 


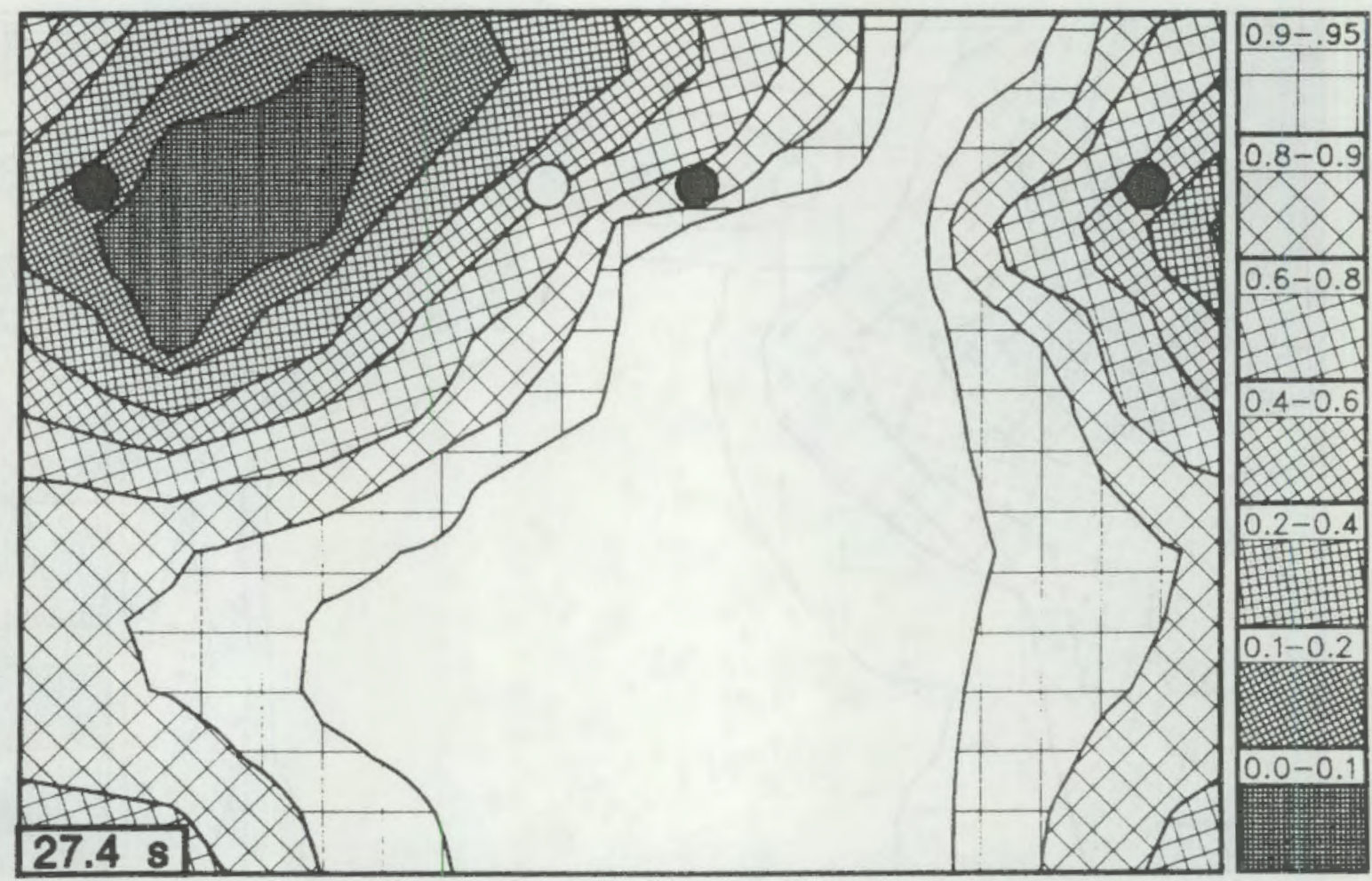

Figure B.56. Downcomer void fraction contour at $27.4 \mathrm{~s}$

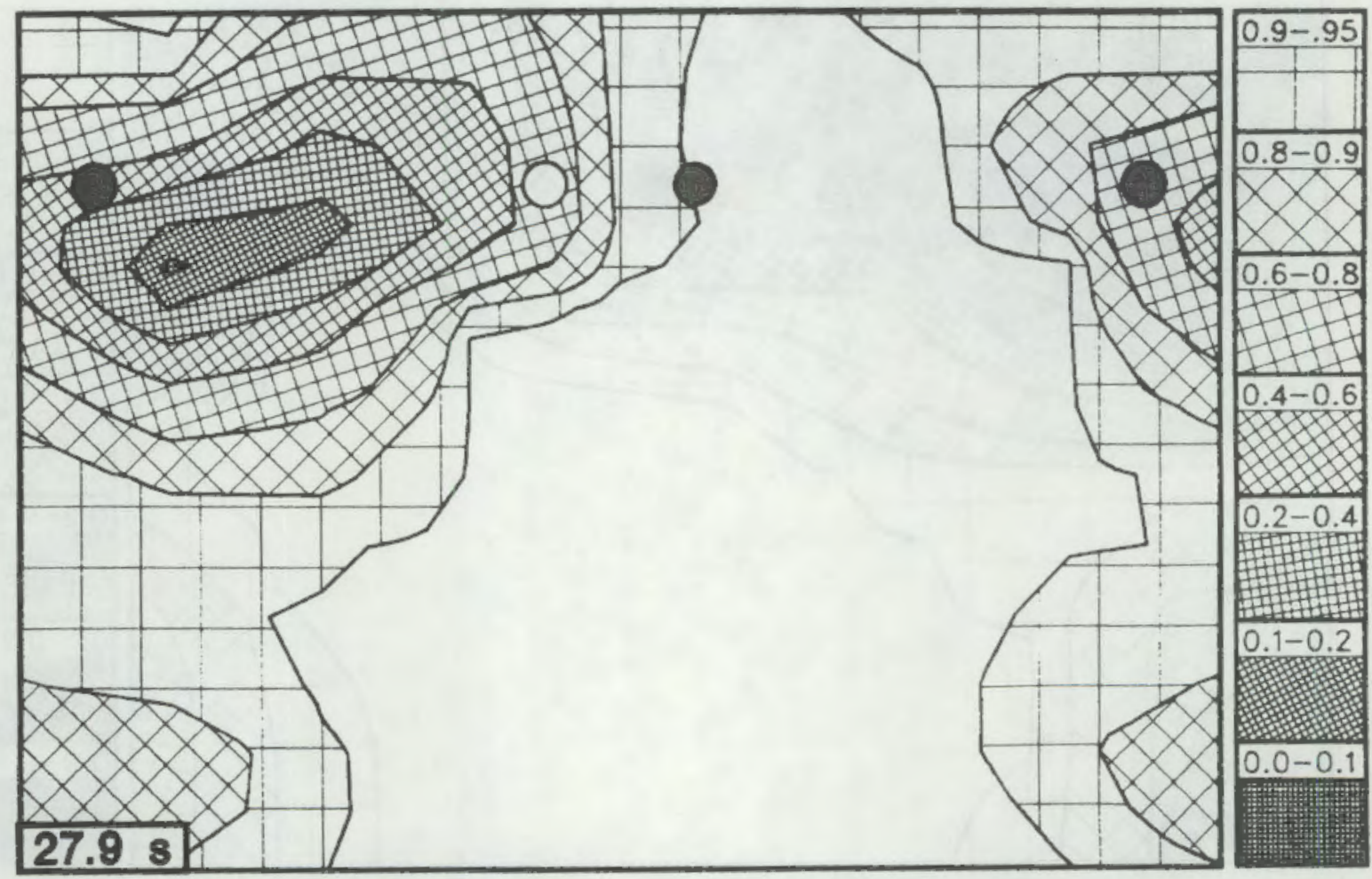

Figure B.57. Downcomer void fraction contour at $27.9 \mathrm{~s}$ 


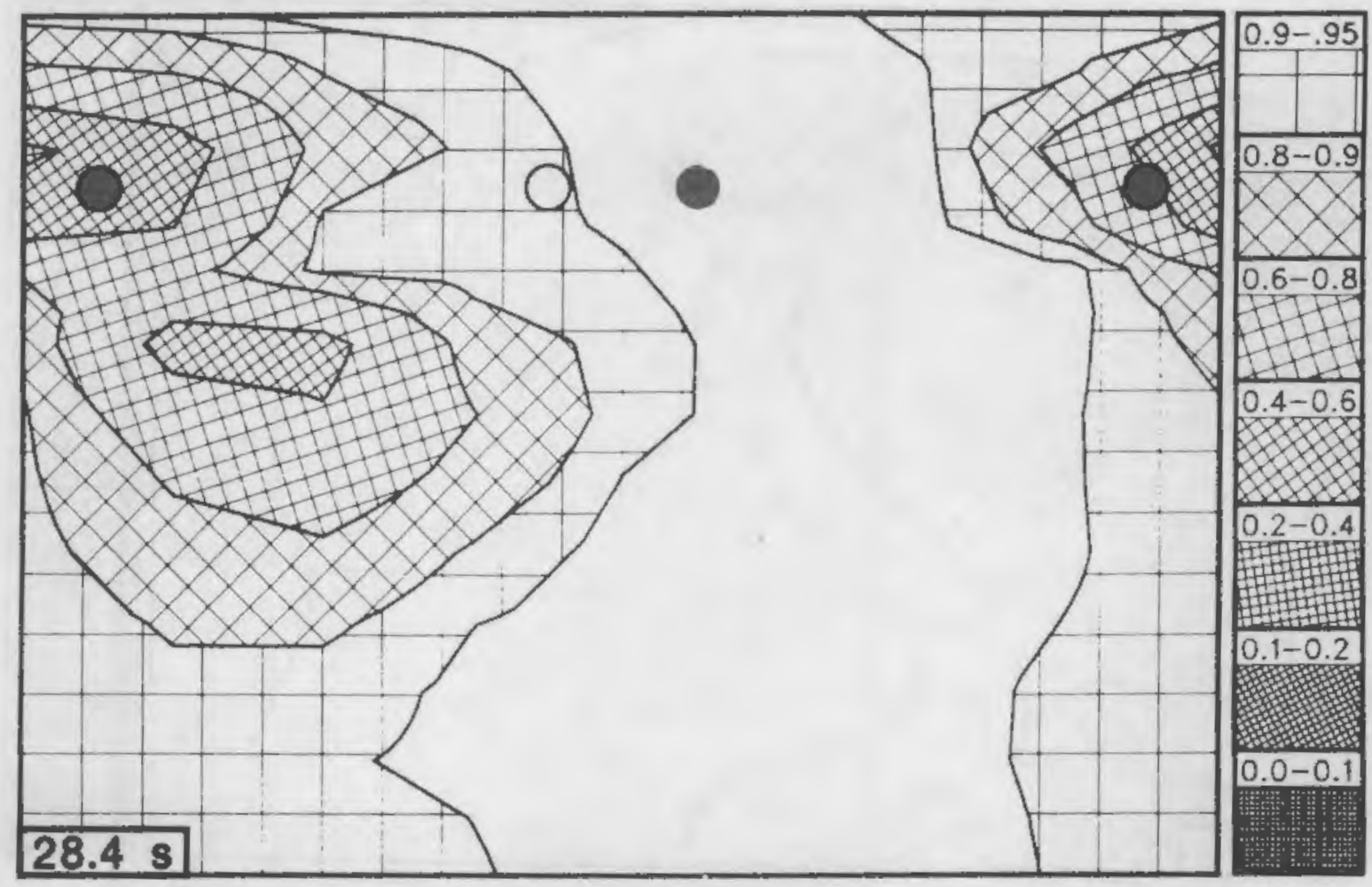

Figure B.58. Downcomer void fraction contour at $28.4 \mathrm{~s}$

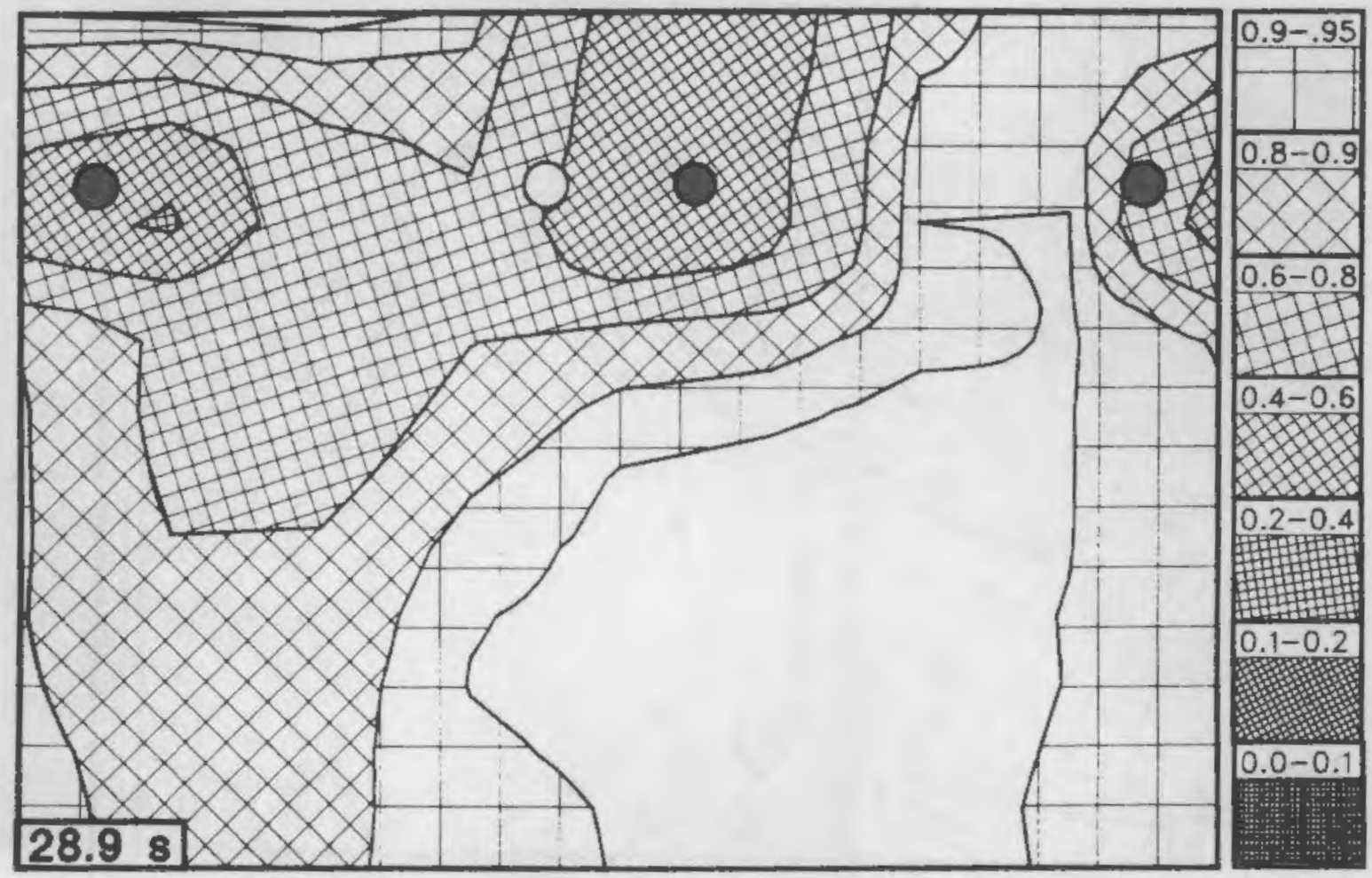

Figure B.59. Downcomer void fraction contour at $28.9 \mathrm{~s}$ 


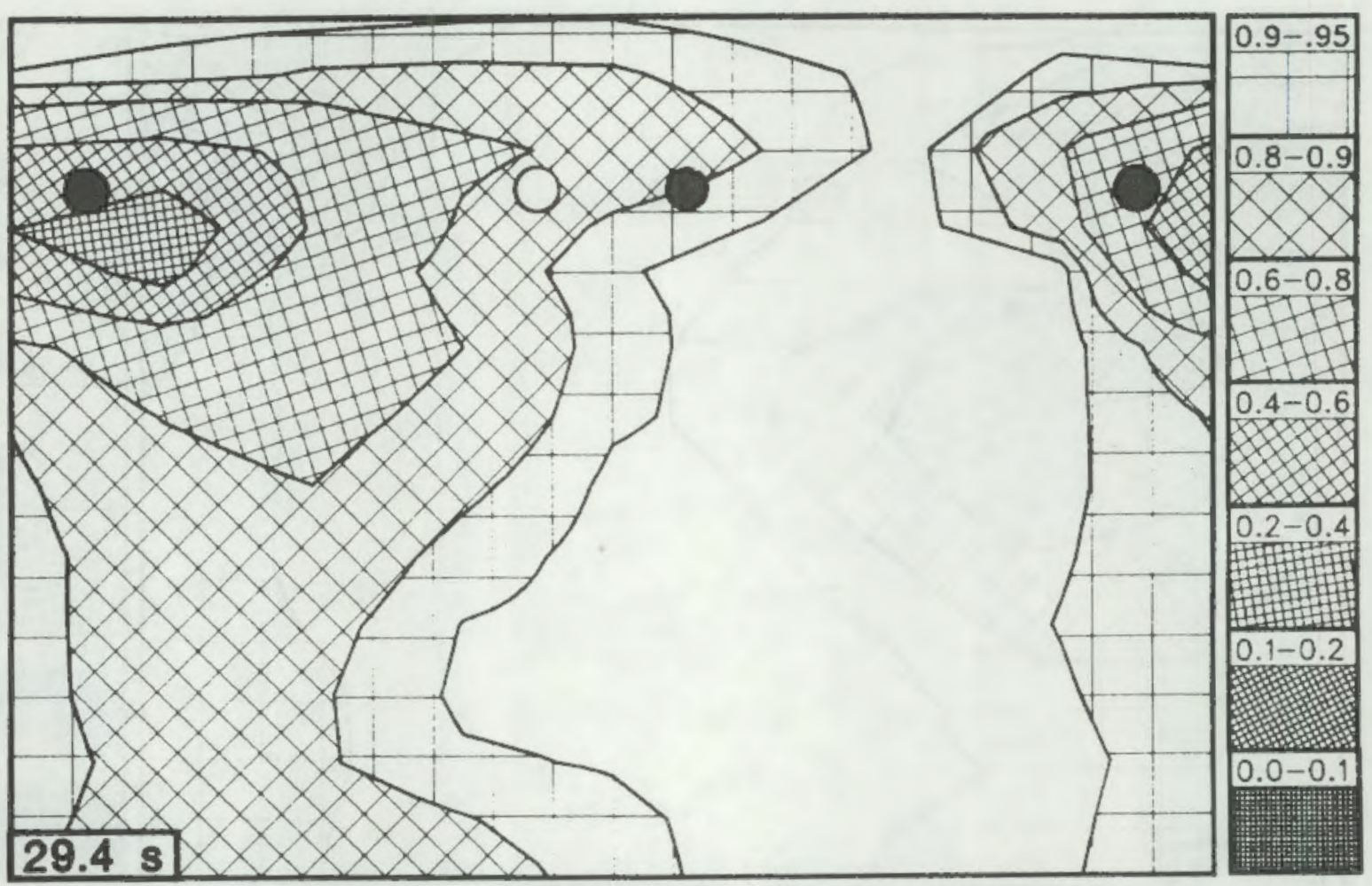

Figure B.60. Downcomer void fraction contour at $29.4 \mathrm{~s}$

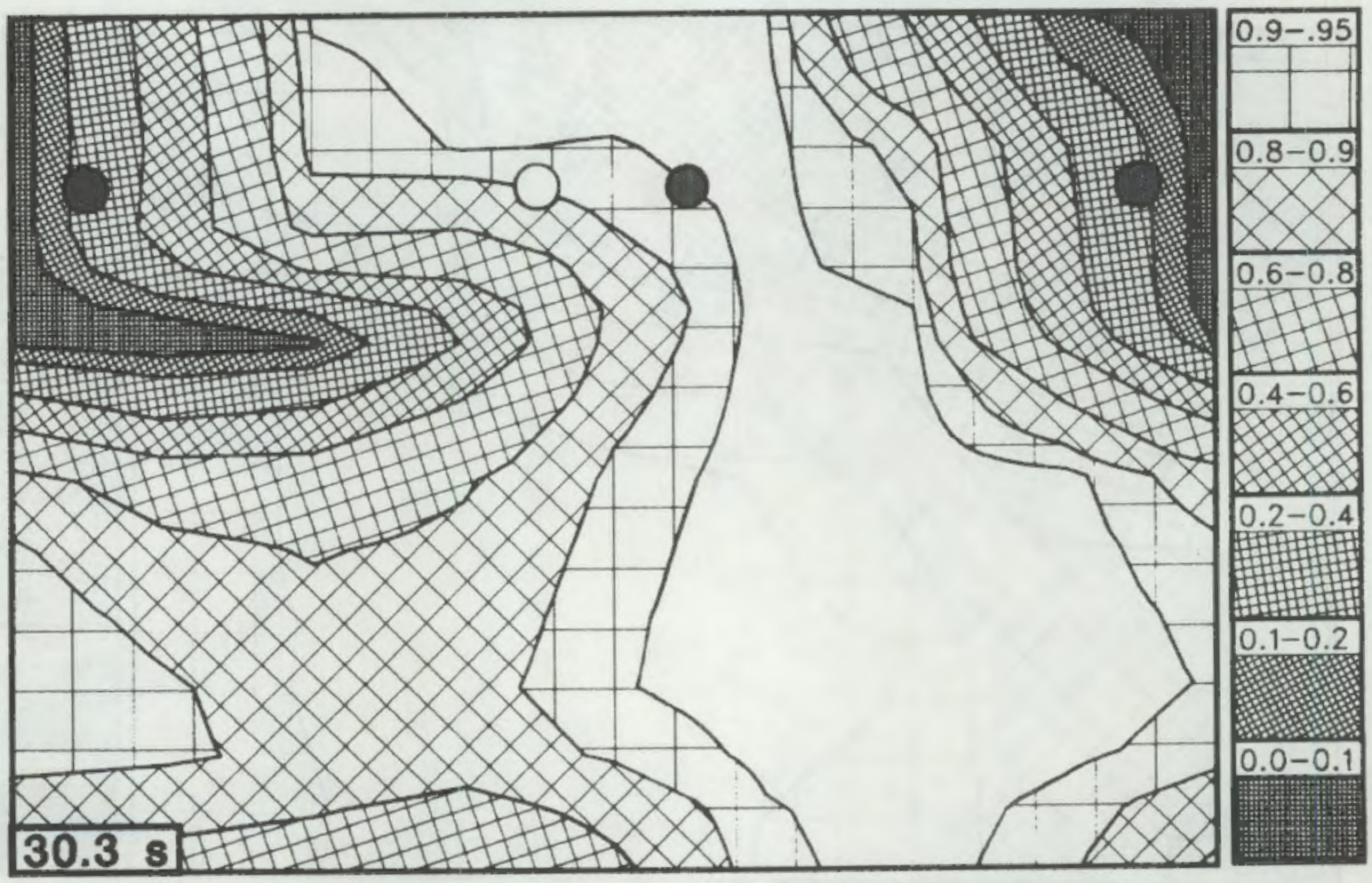

Figure B.61. Downcomer void fraction contour at $30.3 \mathrm{~s}$ 


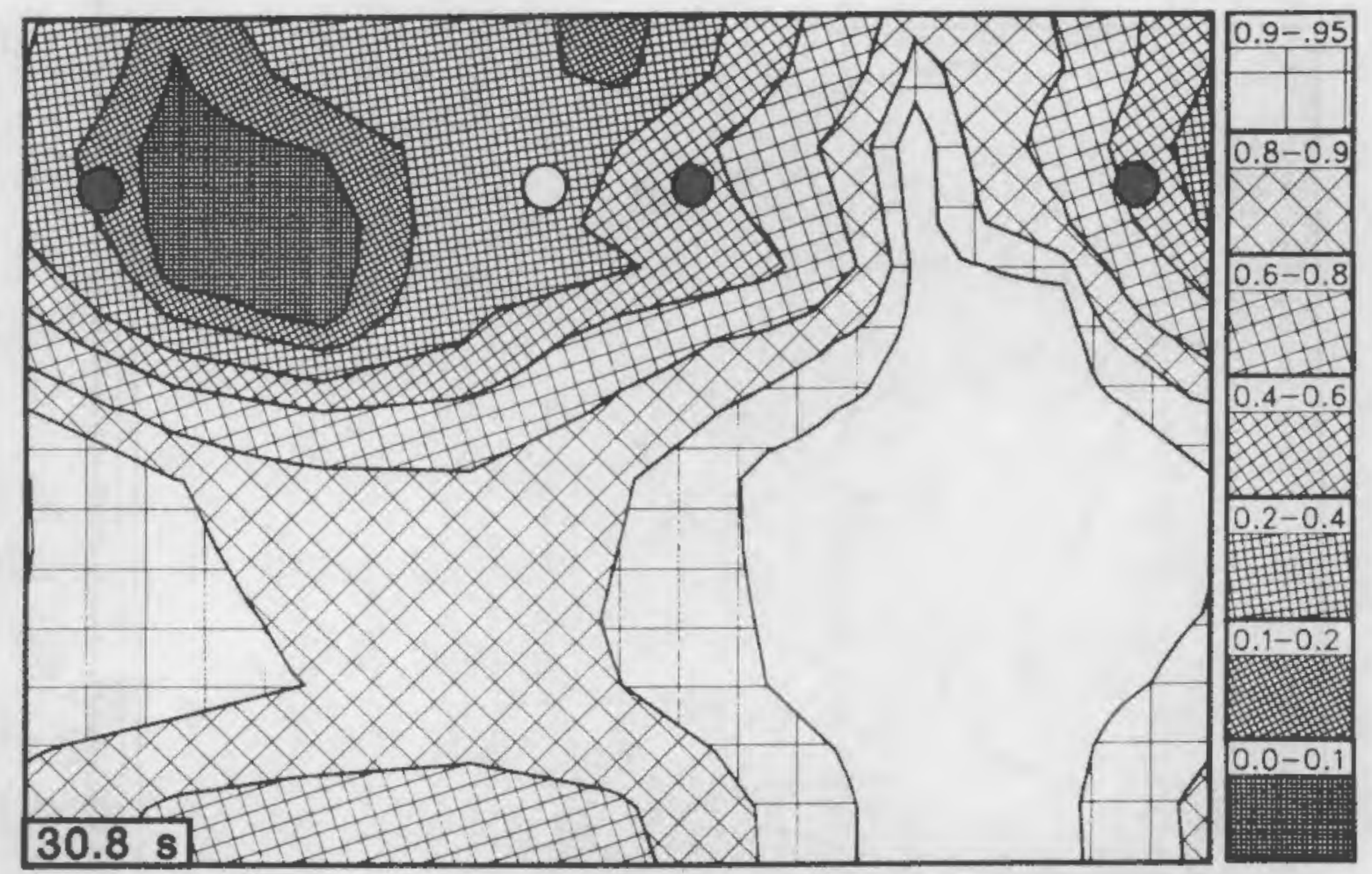

Figure B.62. Downcomer void fraction contour at $30.8 \mathrm{~s}$

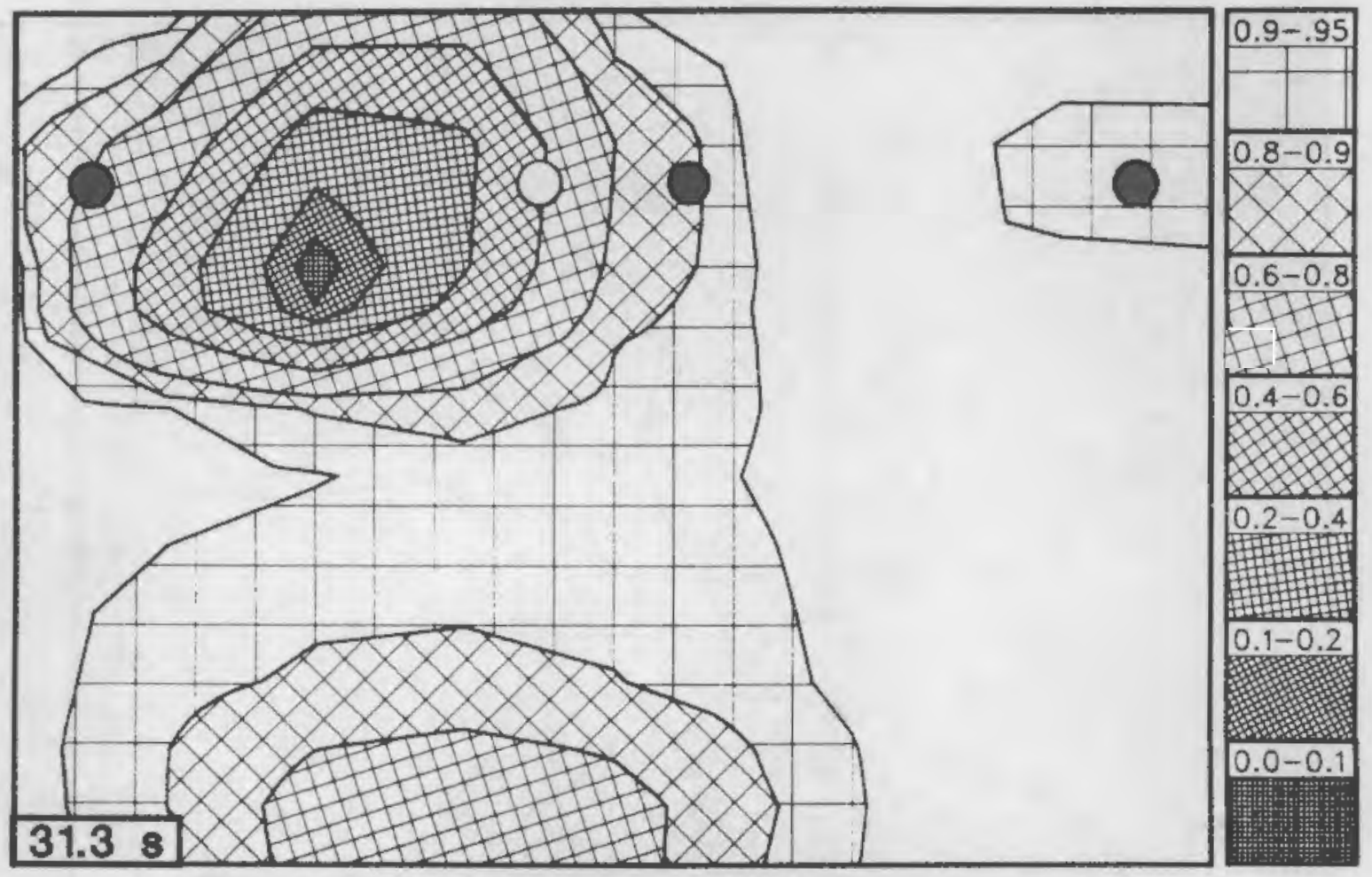

Figure B.63. Downcomer void fraction contour at $31.3 \mathrm{~s}$ 


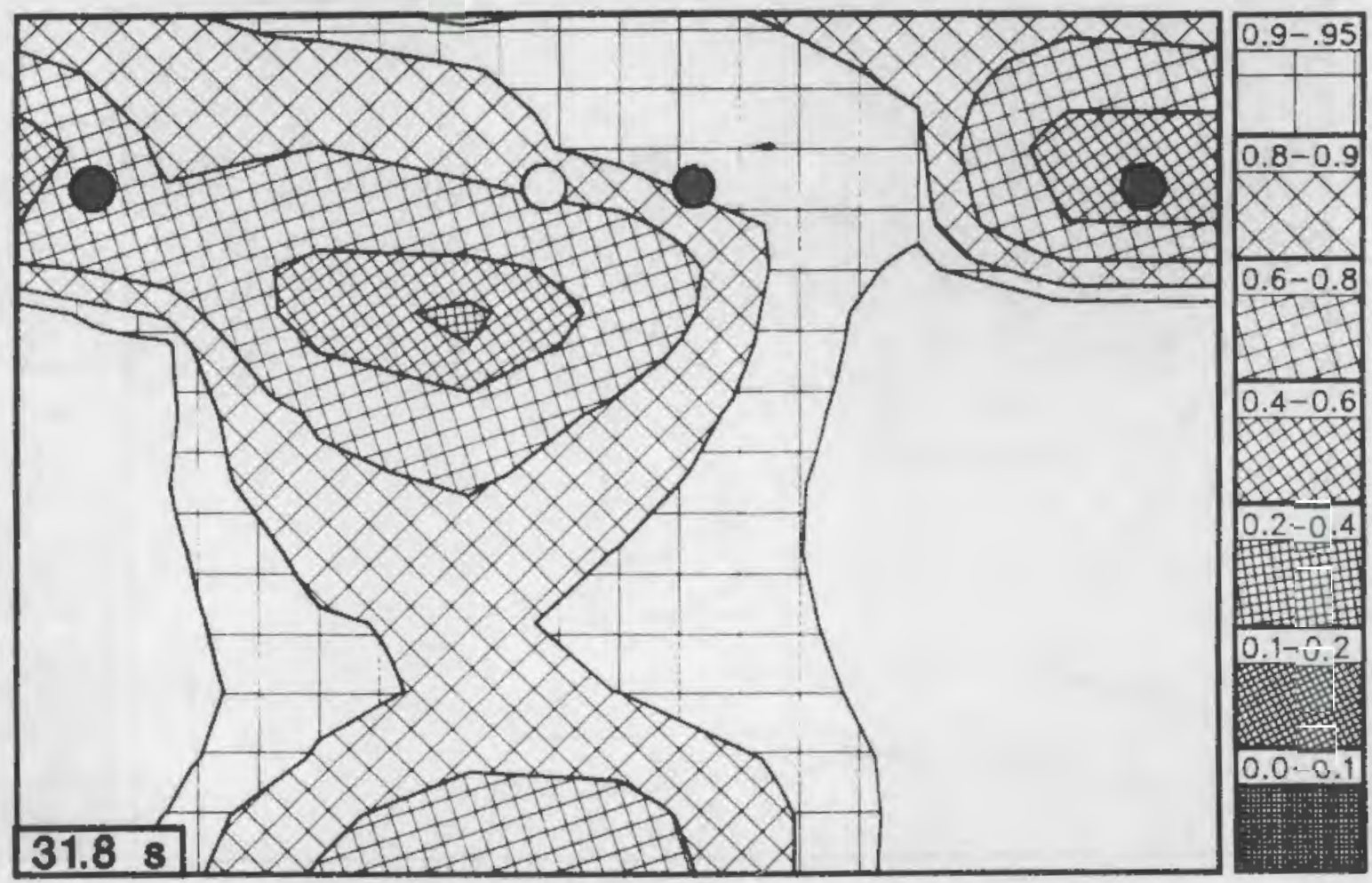

Figure B.64. Downcomer void fraction contour at 31.8
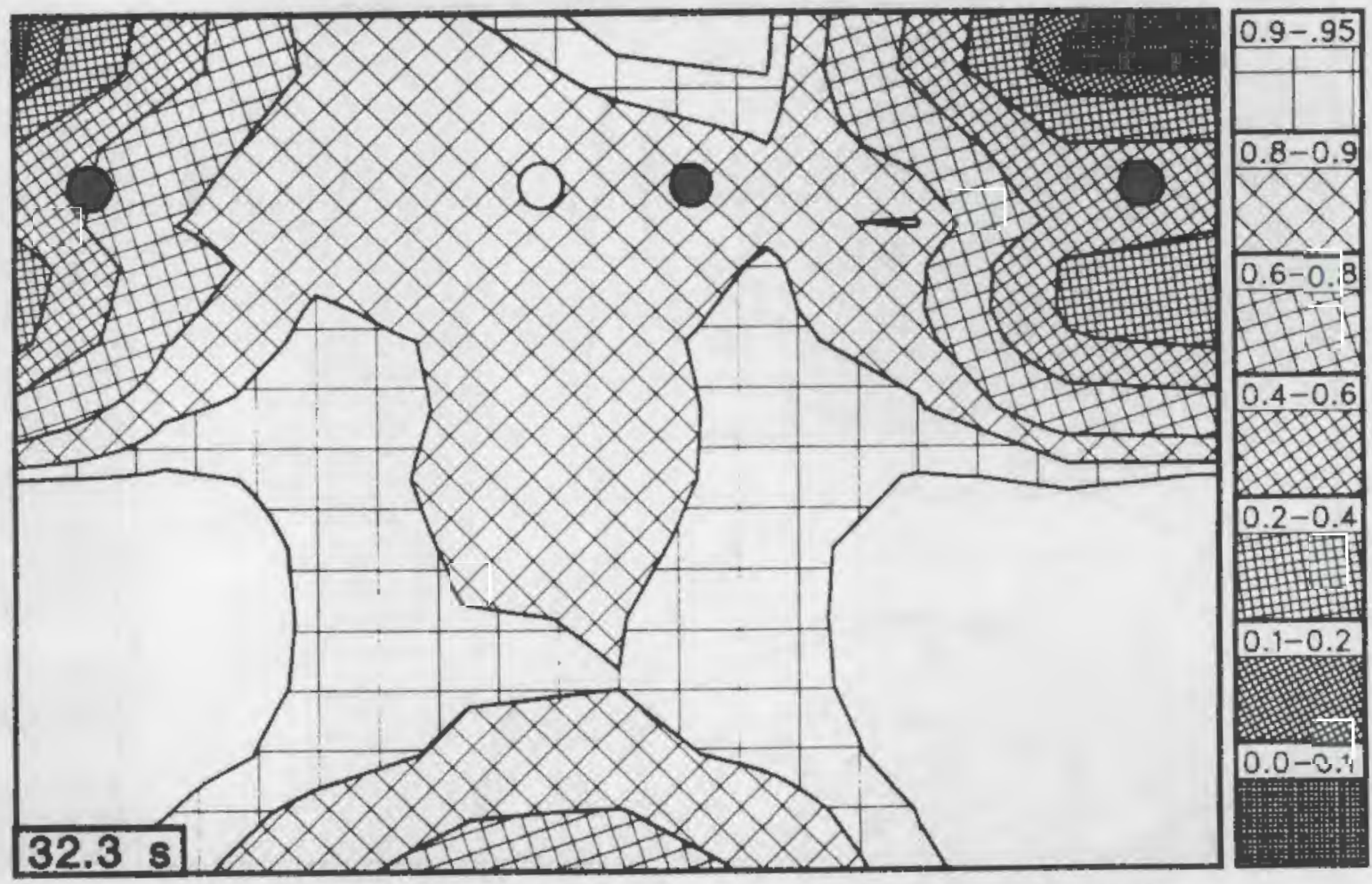

Figure 8.65 . Downcomer void fraction contour at $32.3 \mathrm{~s}$ 


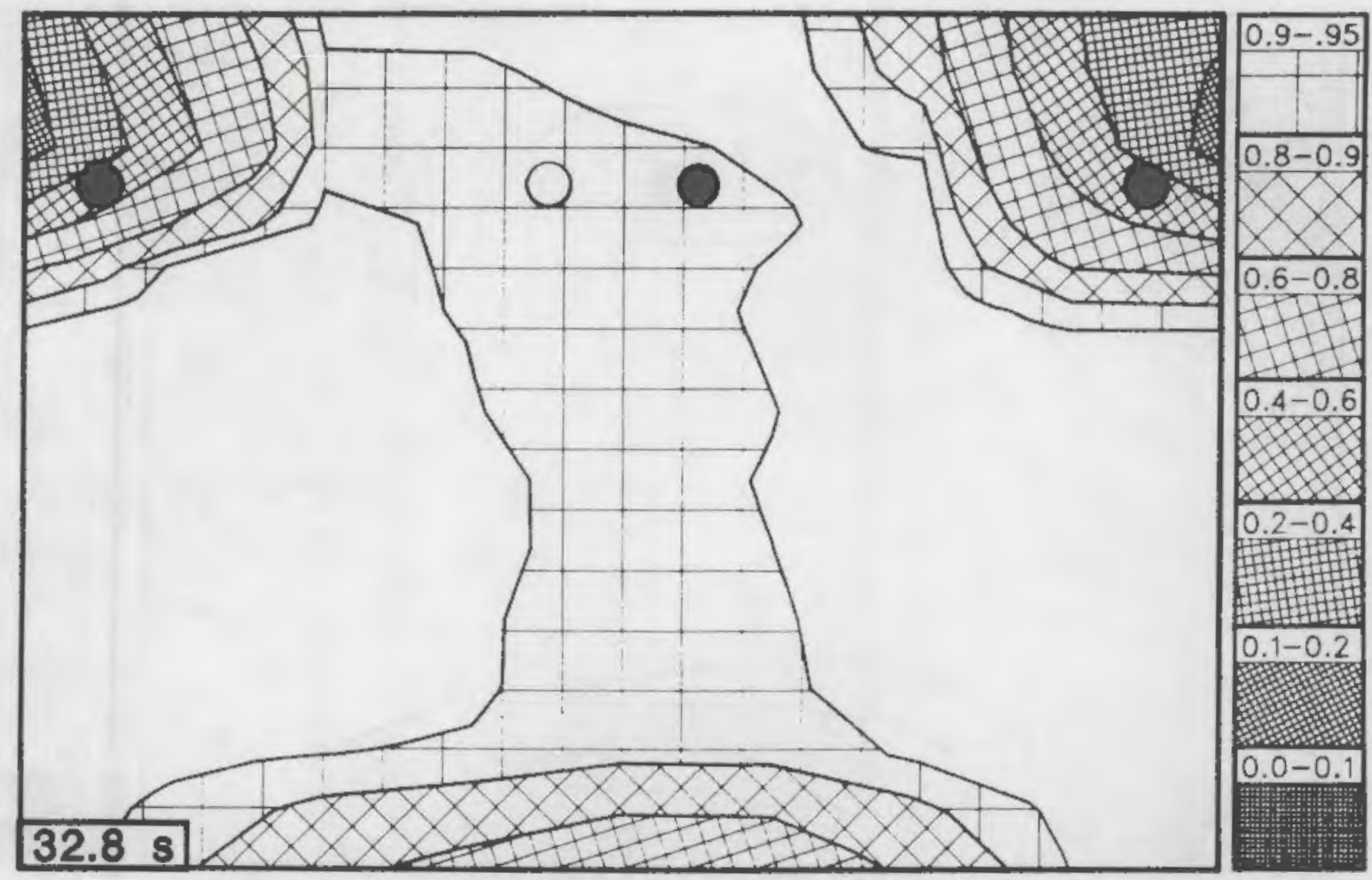

Figure B.66. Downcomer void fraction contour at $32.8 \mathrm{~s}$

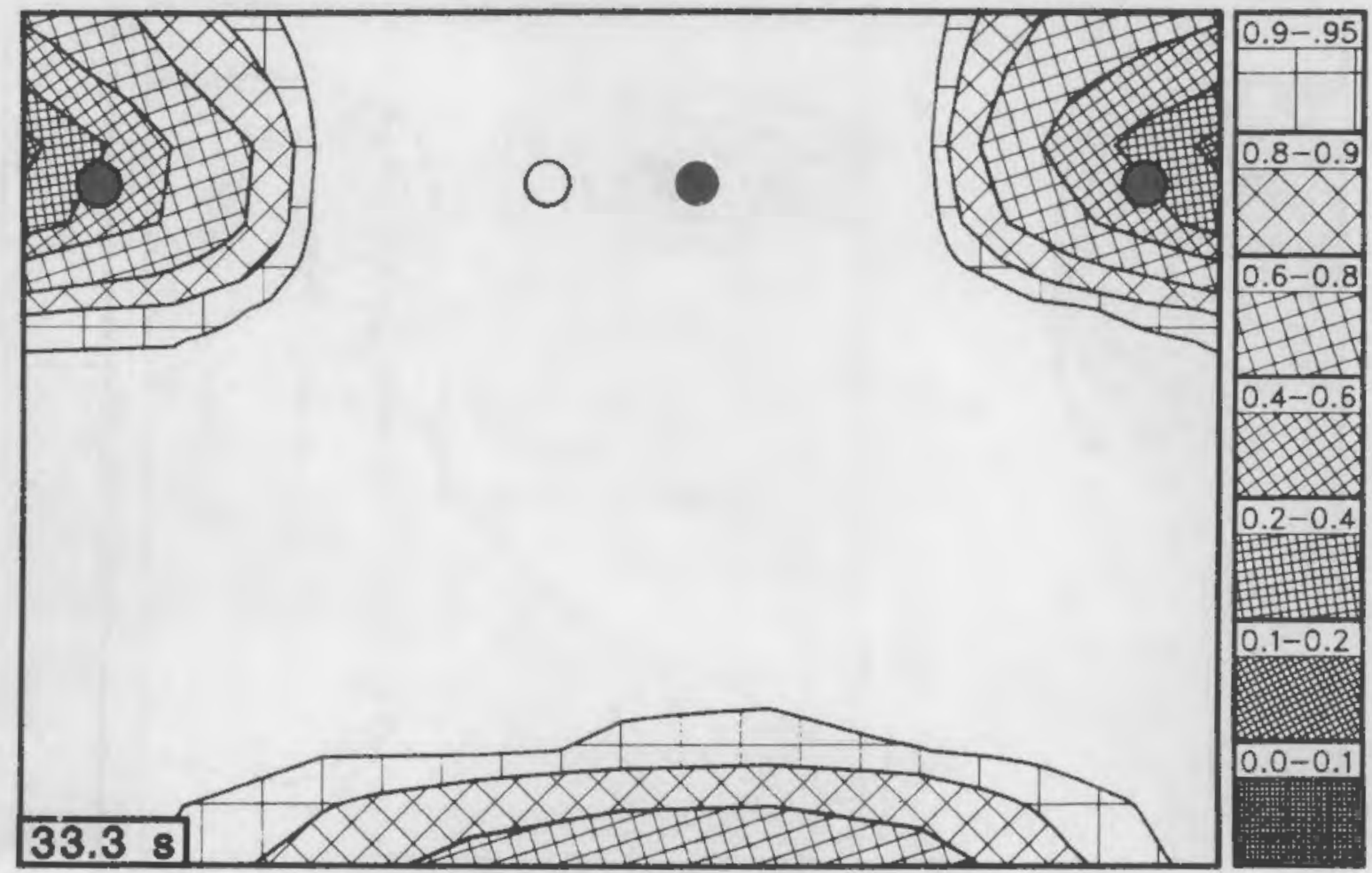

Figure B.67. Downcomer void fraction contour at $33.3 \mathrm{~s}$ 


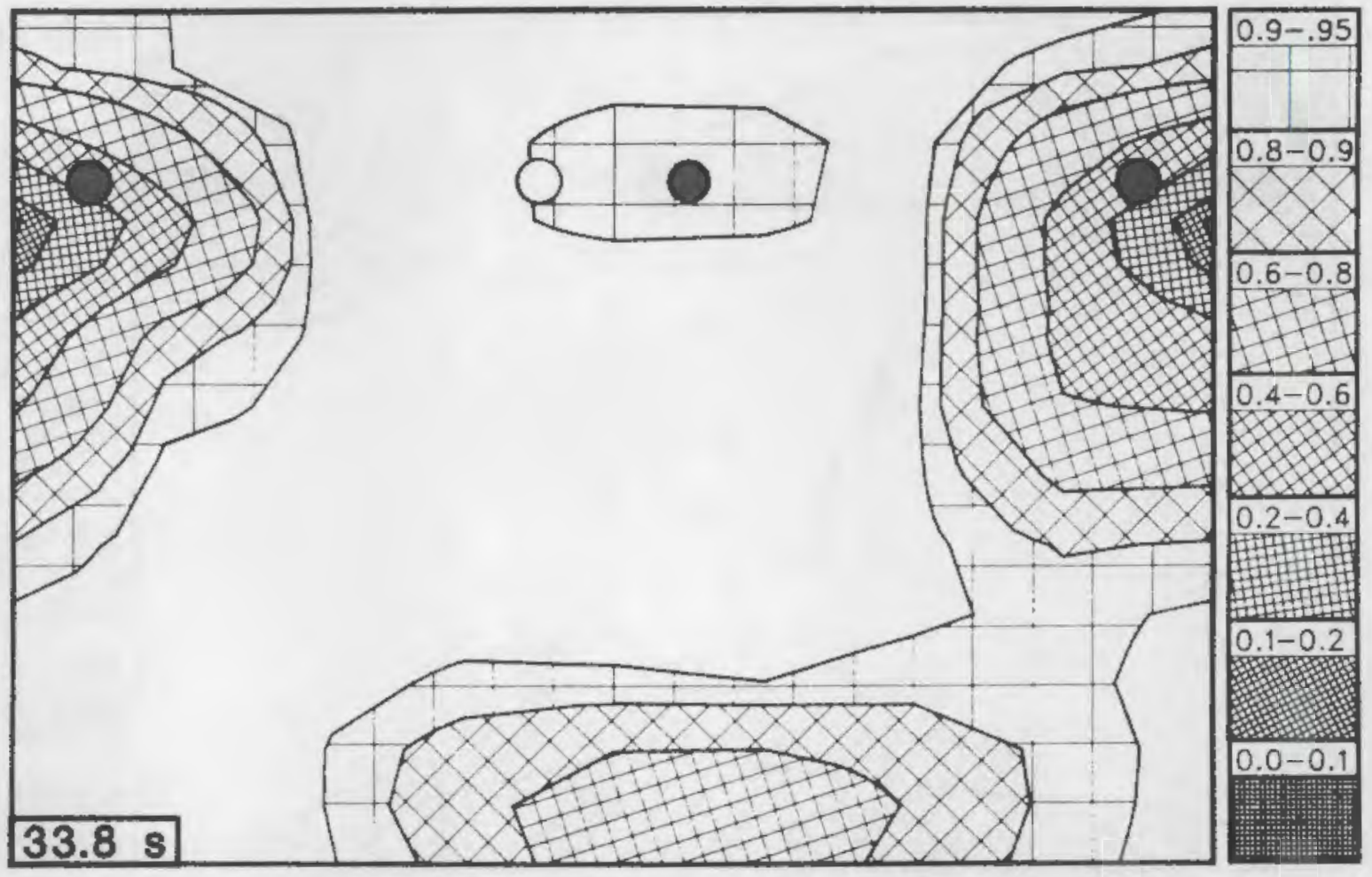

Figure B.68. Downcomer void fraction contour at $33.8 \mathrm{~s}$

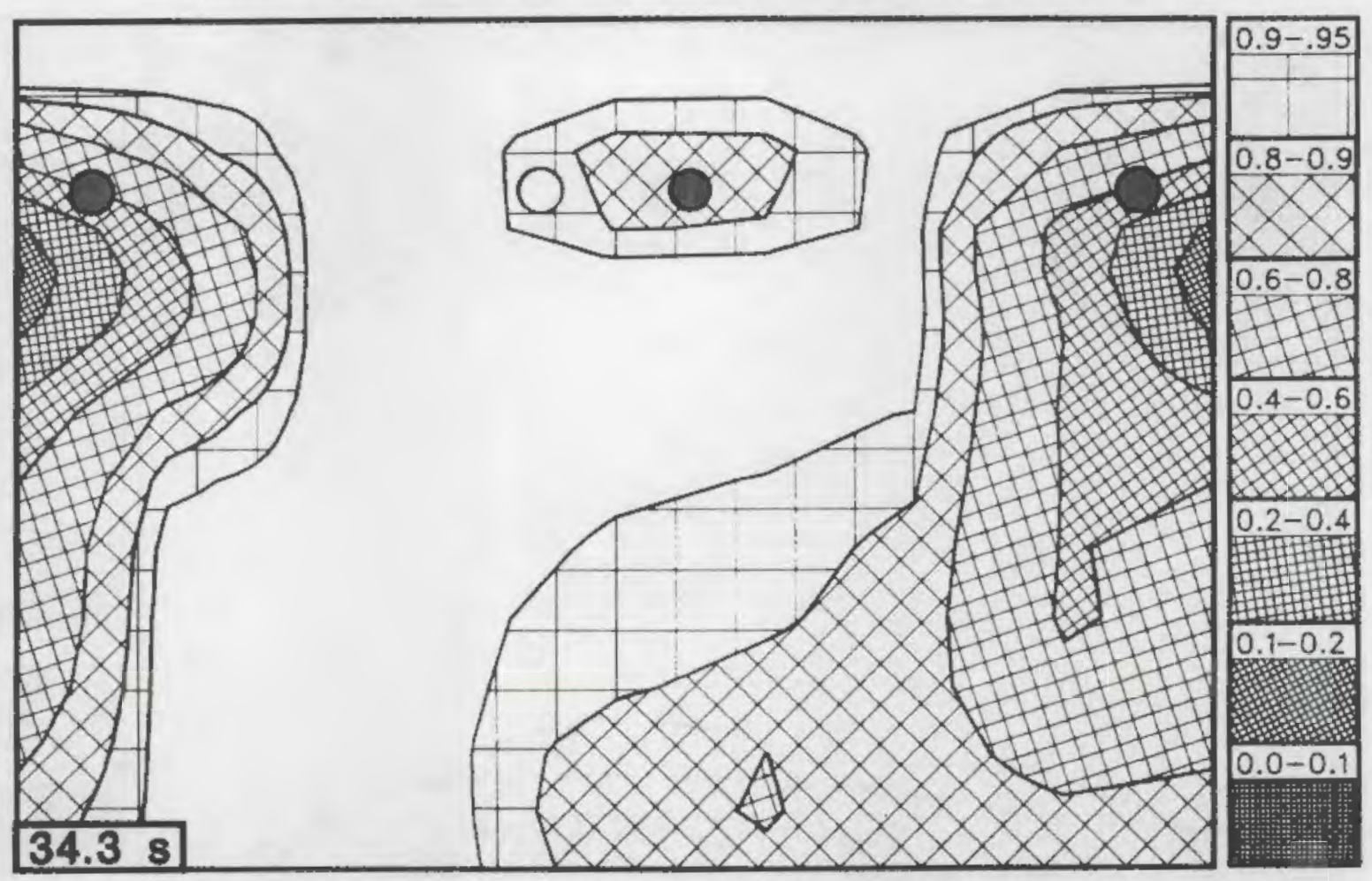

Figure 8.69. Downcomer void fraction contour at $34.3 \mathrm{~s}$ 


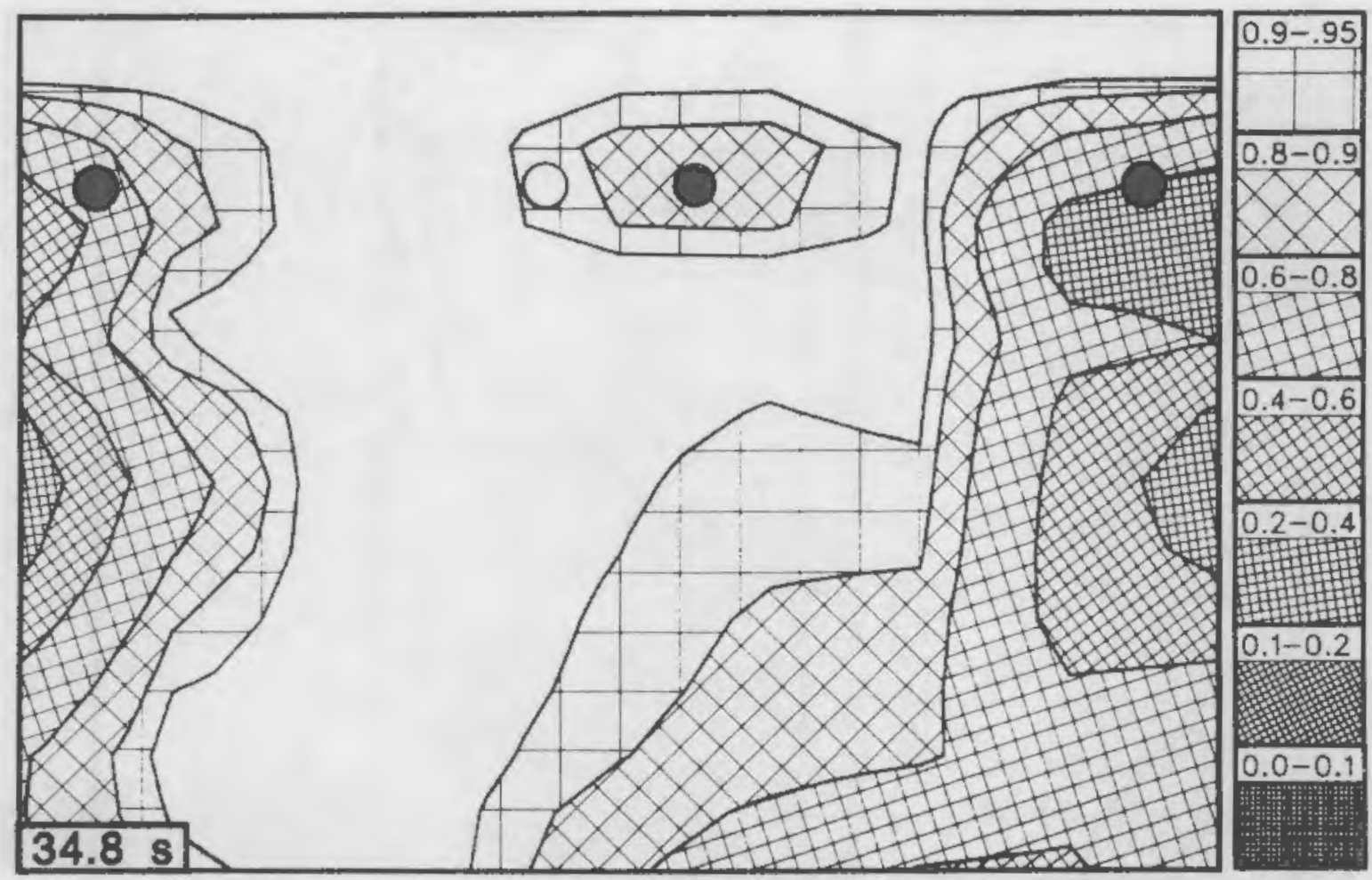

Figure B.70. Downcomer void fraction contour at $34.8 \mathrm{~s}$

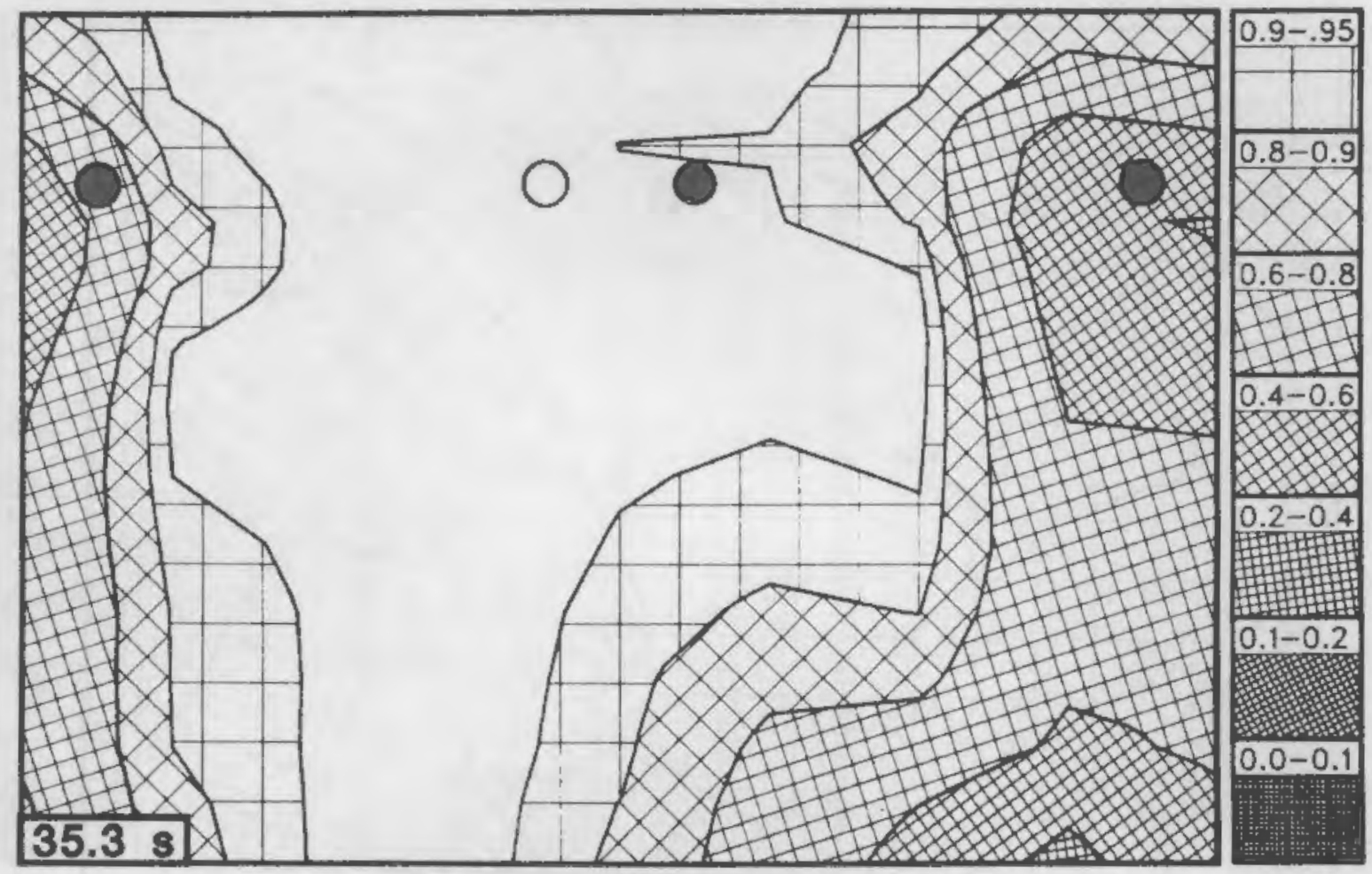

Figure B.71. Downcomer void fraction contour at $35.3 \mathrm{~s}$ 


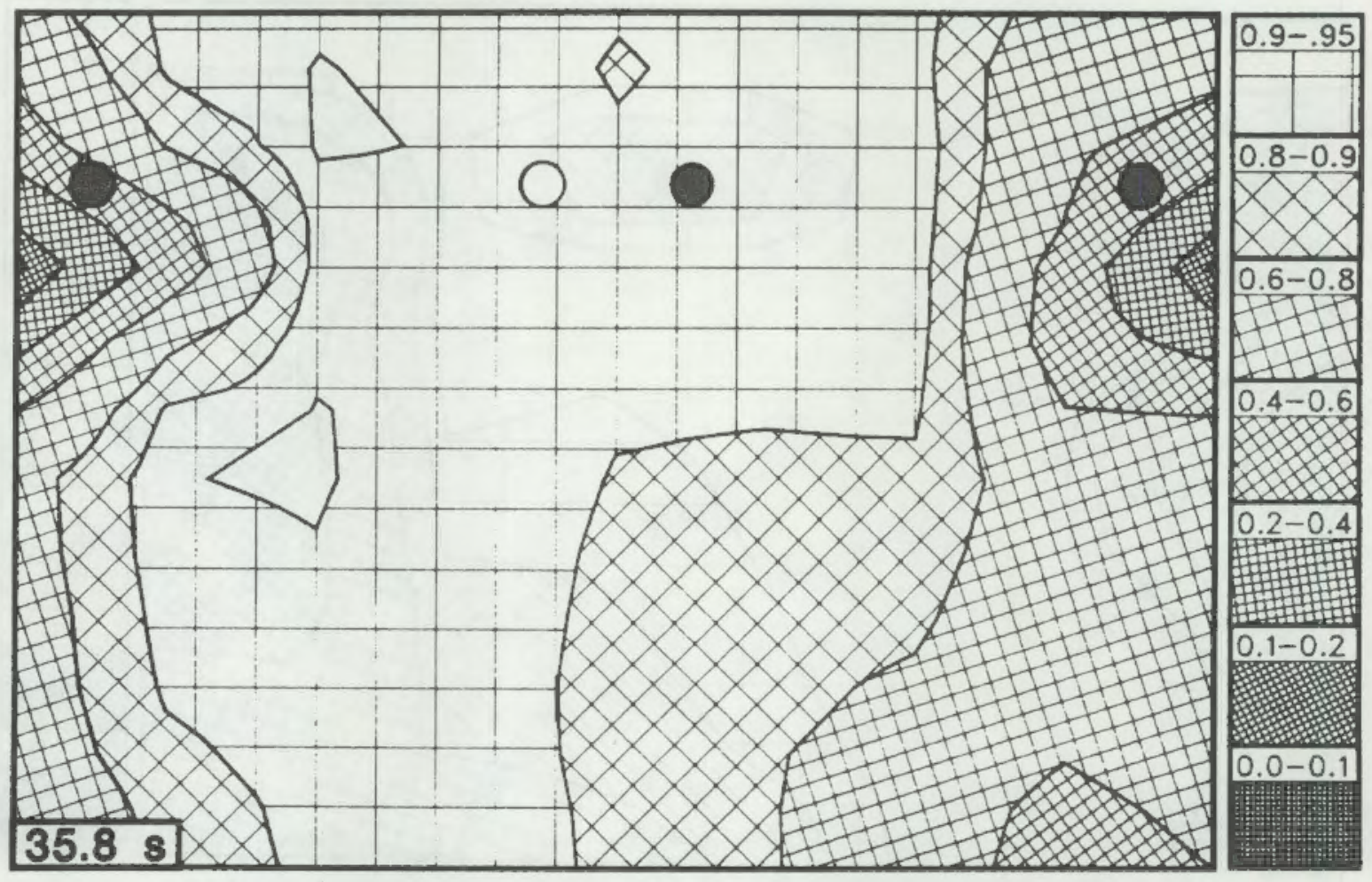

Figure B.72. Downcomer void fraction contour at $35.8 \mathrm{~s}$

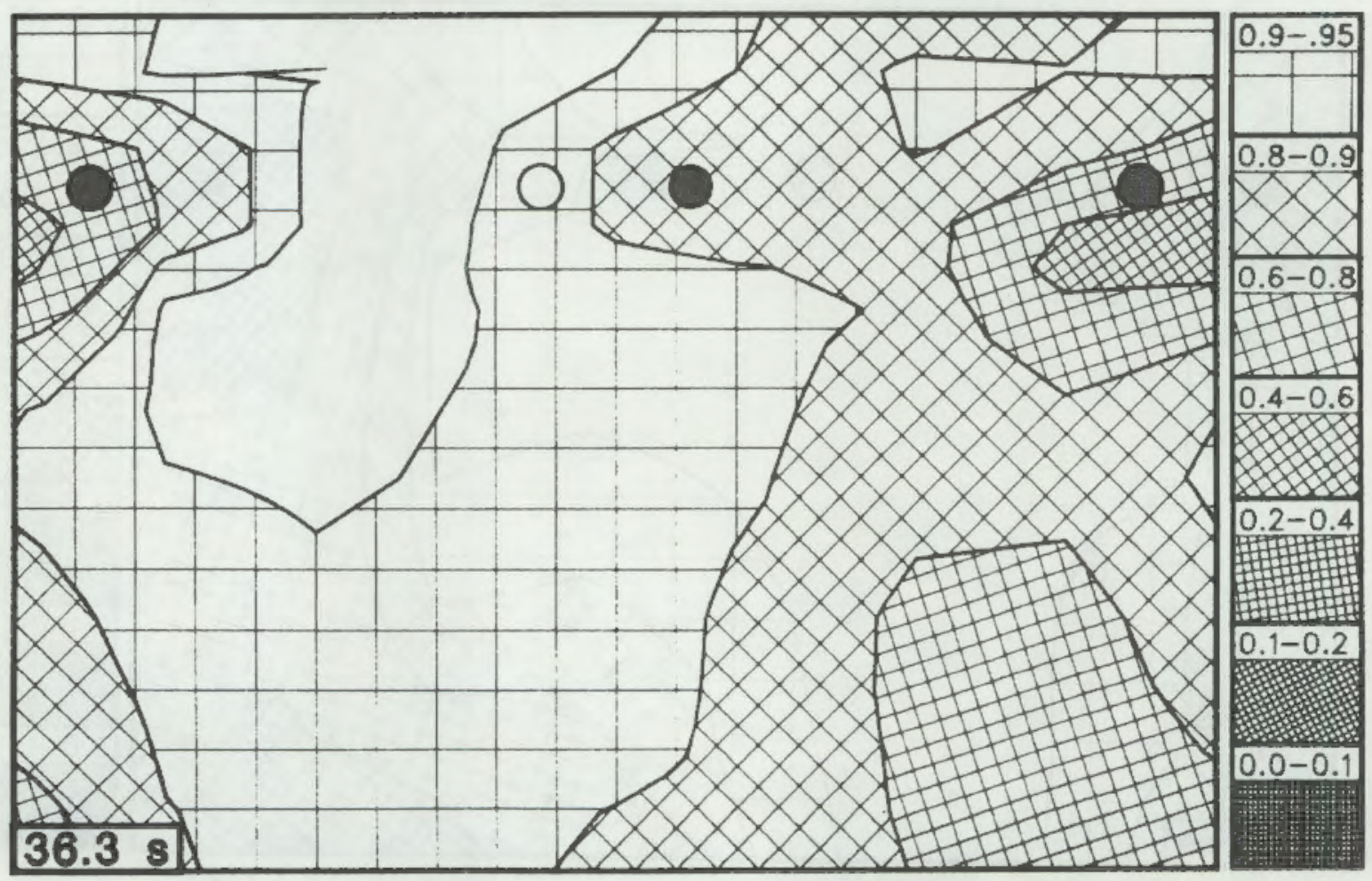

Figure B.73. Downcomer void fraction contour at $36.3 \mathrm{~s}$ 


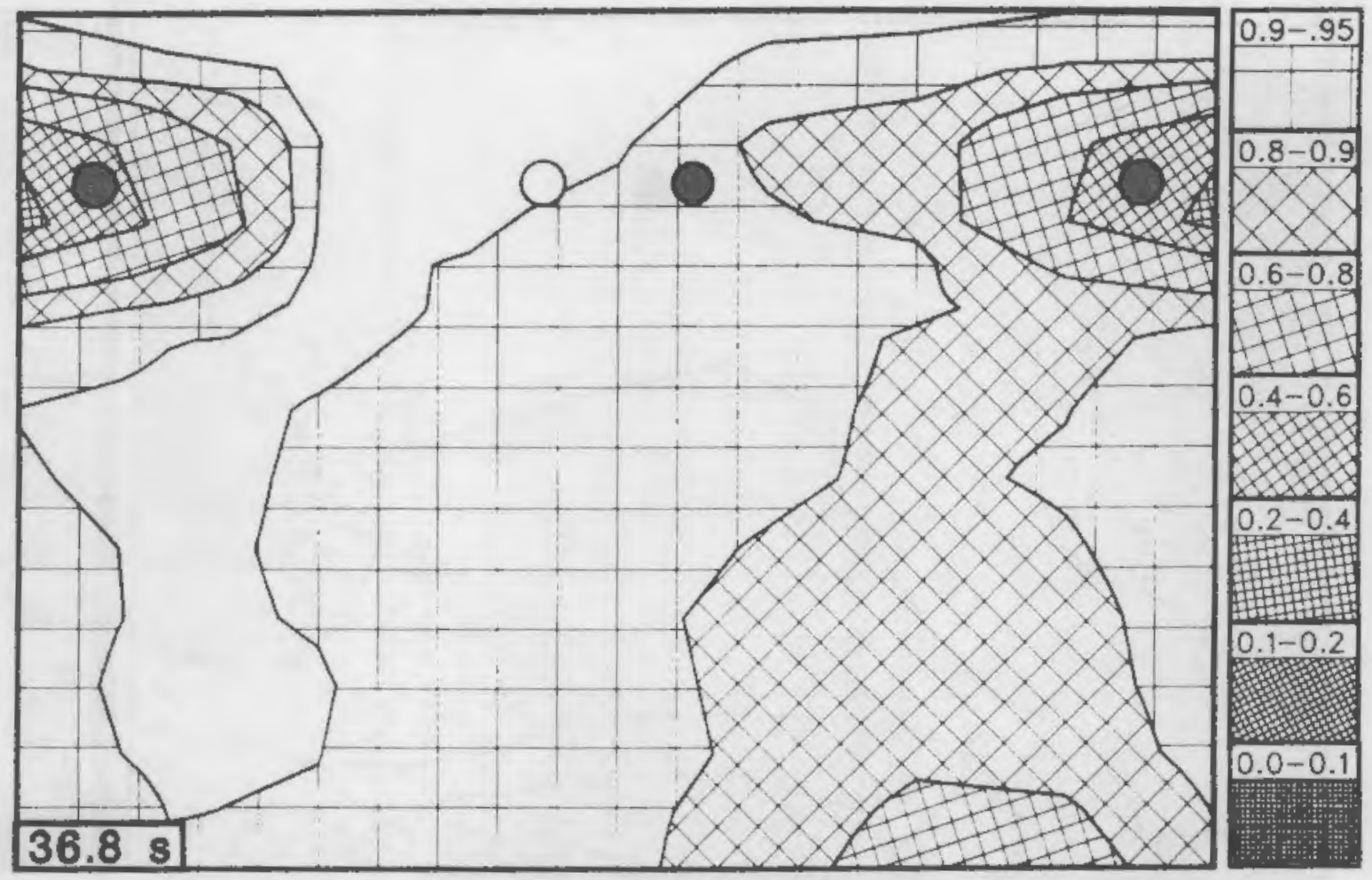

Figure B.74. Downcomer void fraction contour at $36.8 \mathrm{~s}$

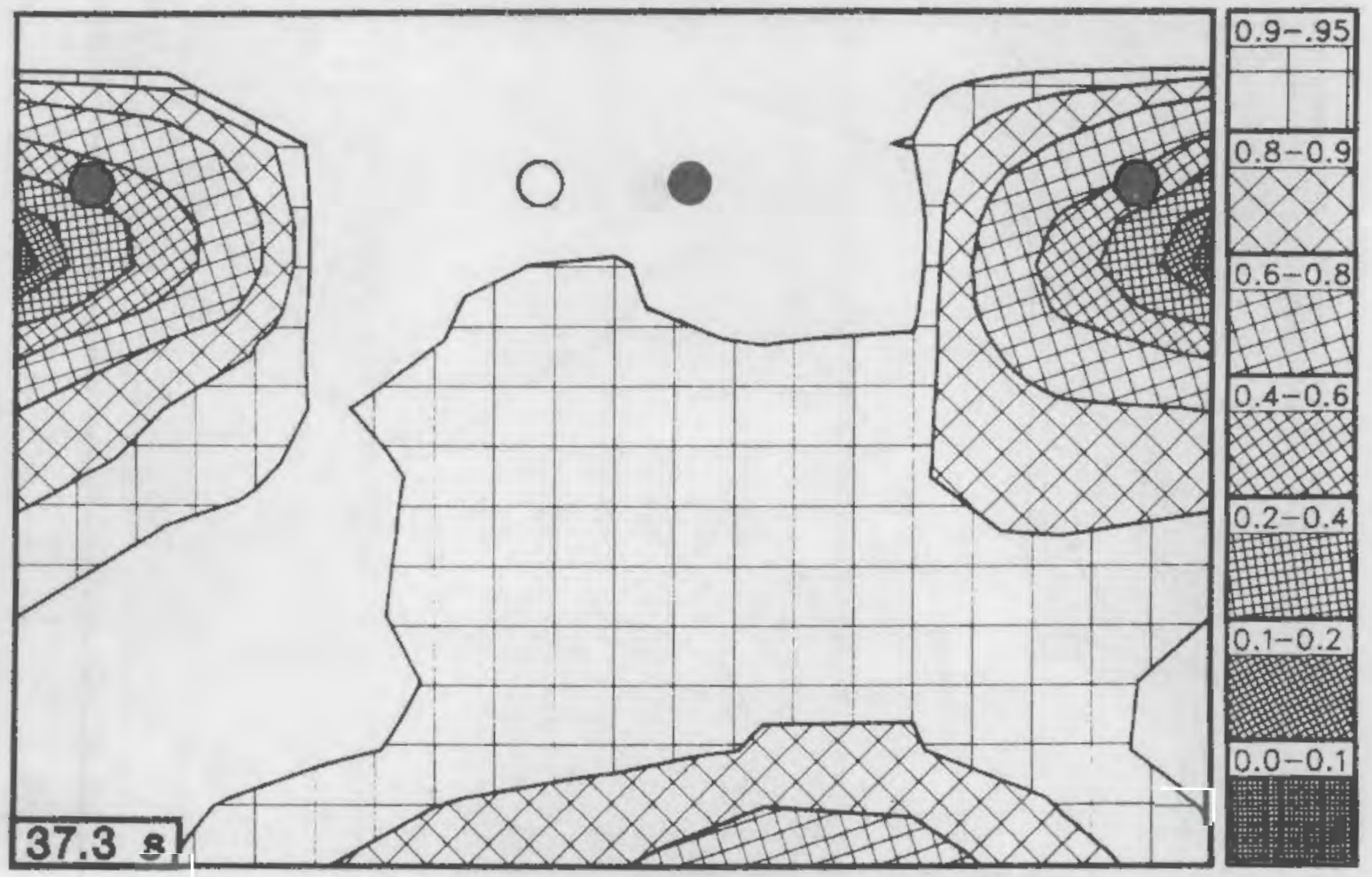

Figure B.75. Downcomer void fraction contour at $37.3 \mathrm{~s}$ 


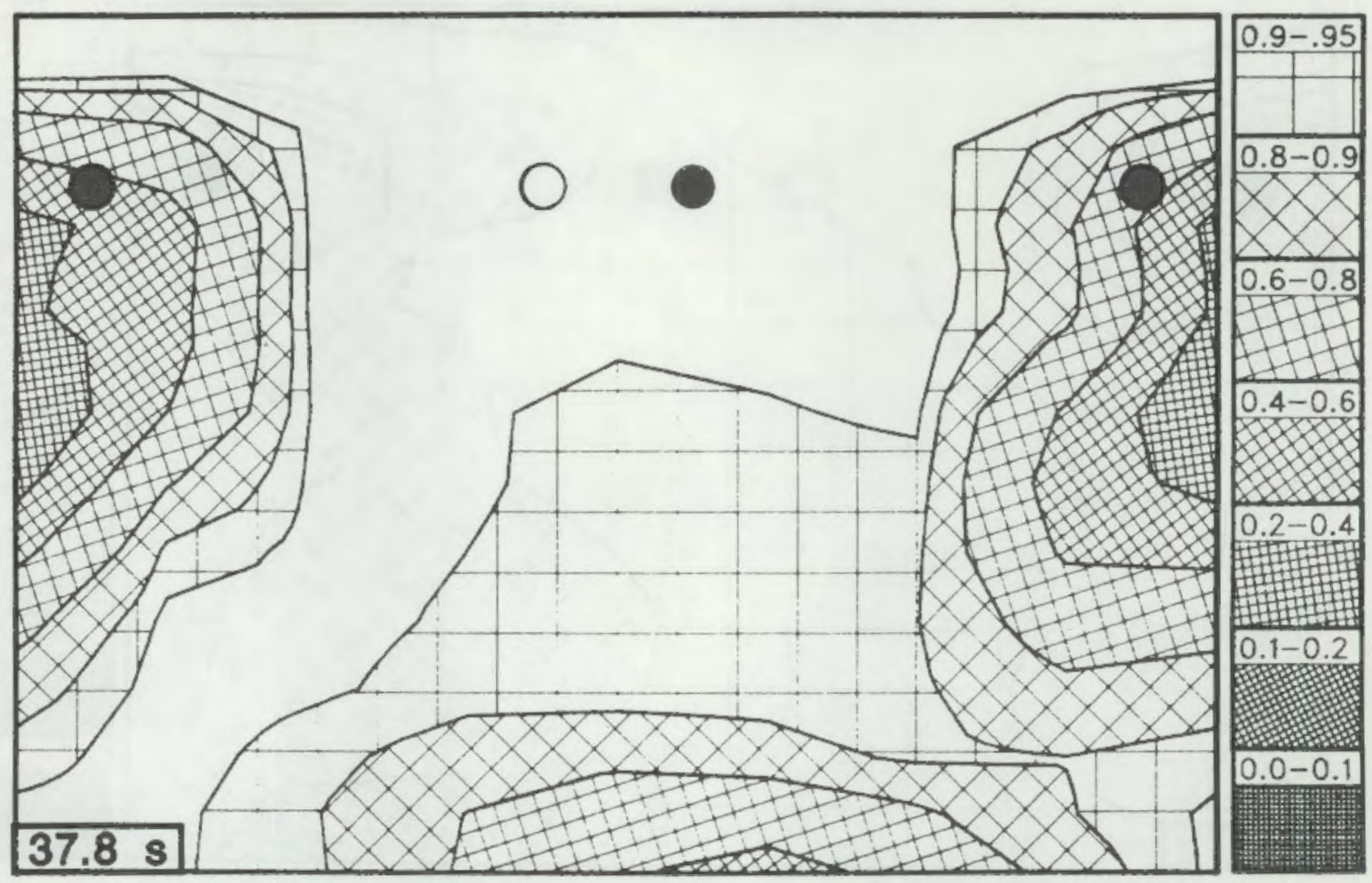

Figure B.76. Downcomer void fraction contour at $37.8 \mathrm{~s}$

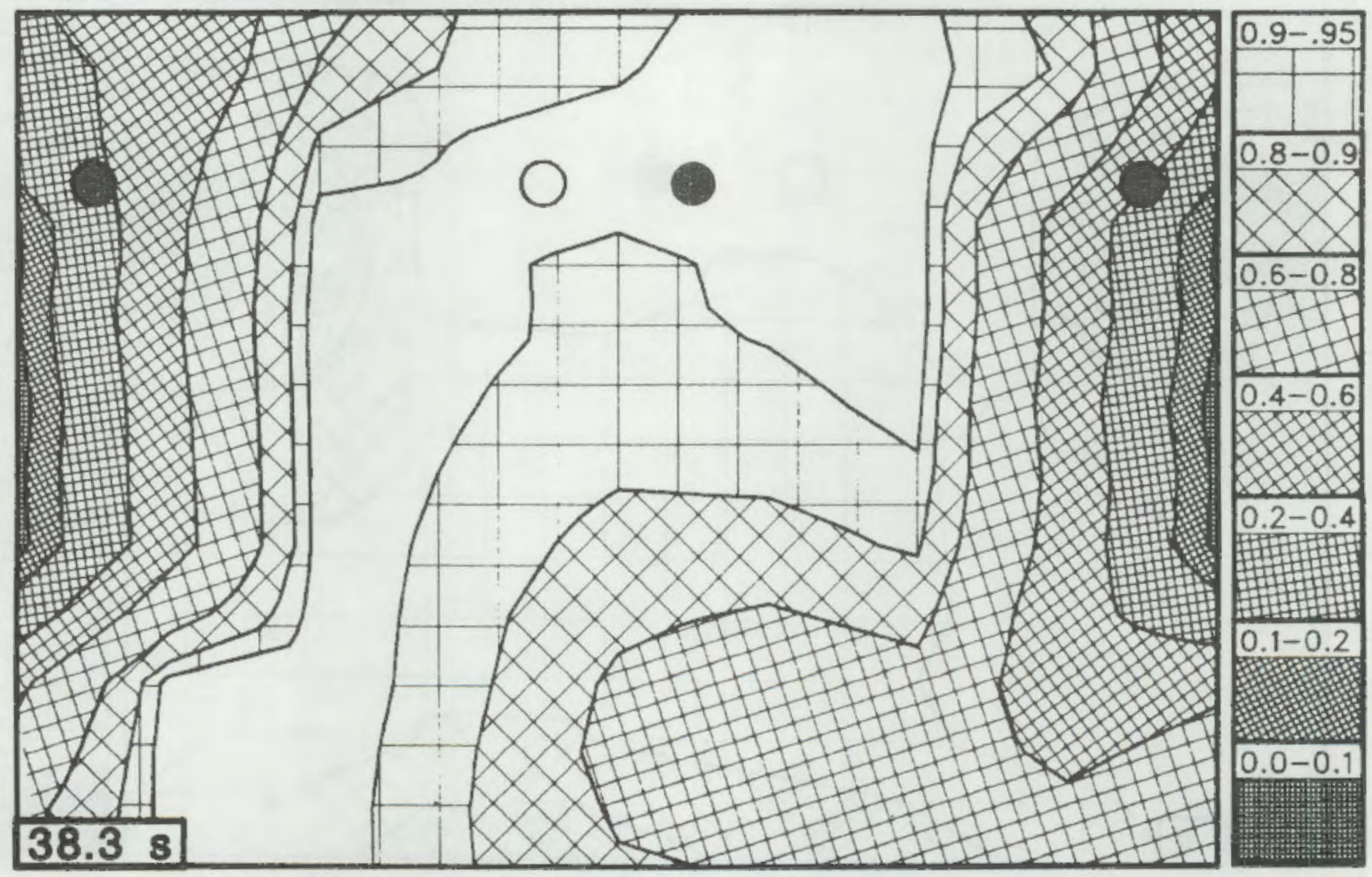

Figure B.77. Downcomer void fraction contour at $38.3 \mathrm{~s}$ 


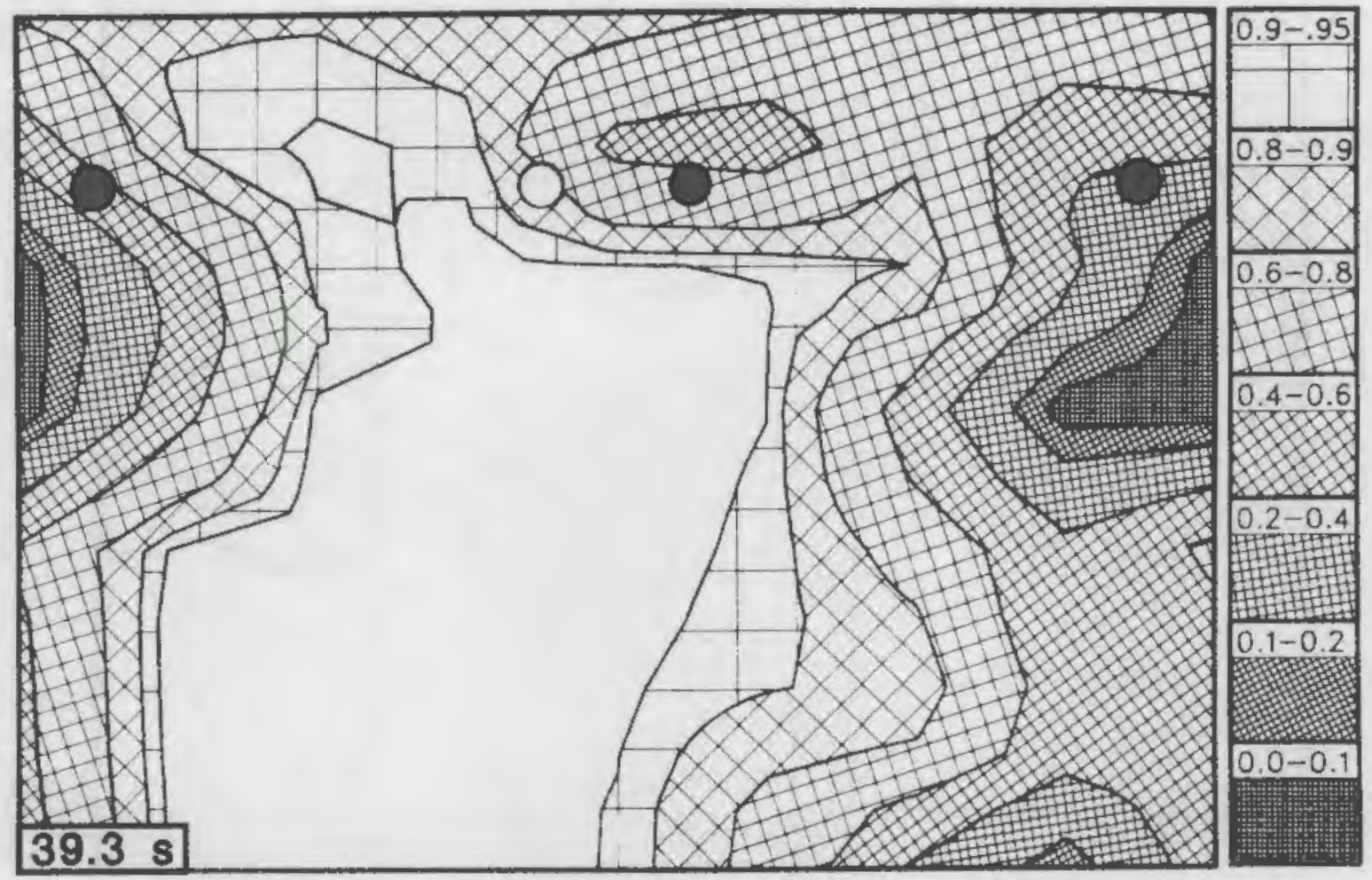

Figure B.78. Downcomer void fraction contour at $39.3 \mathrm{~s}$

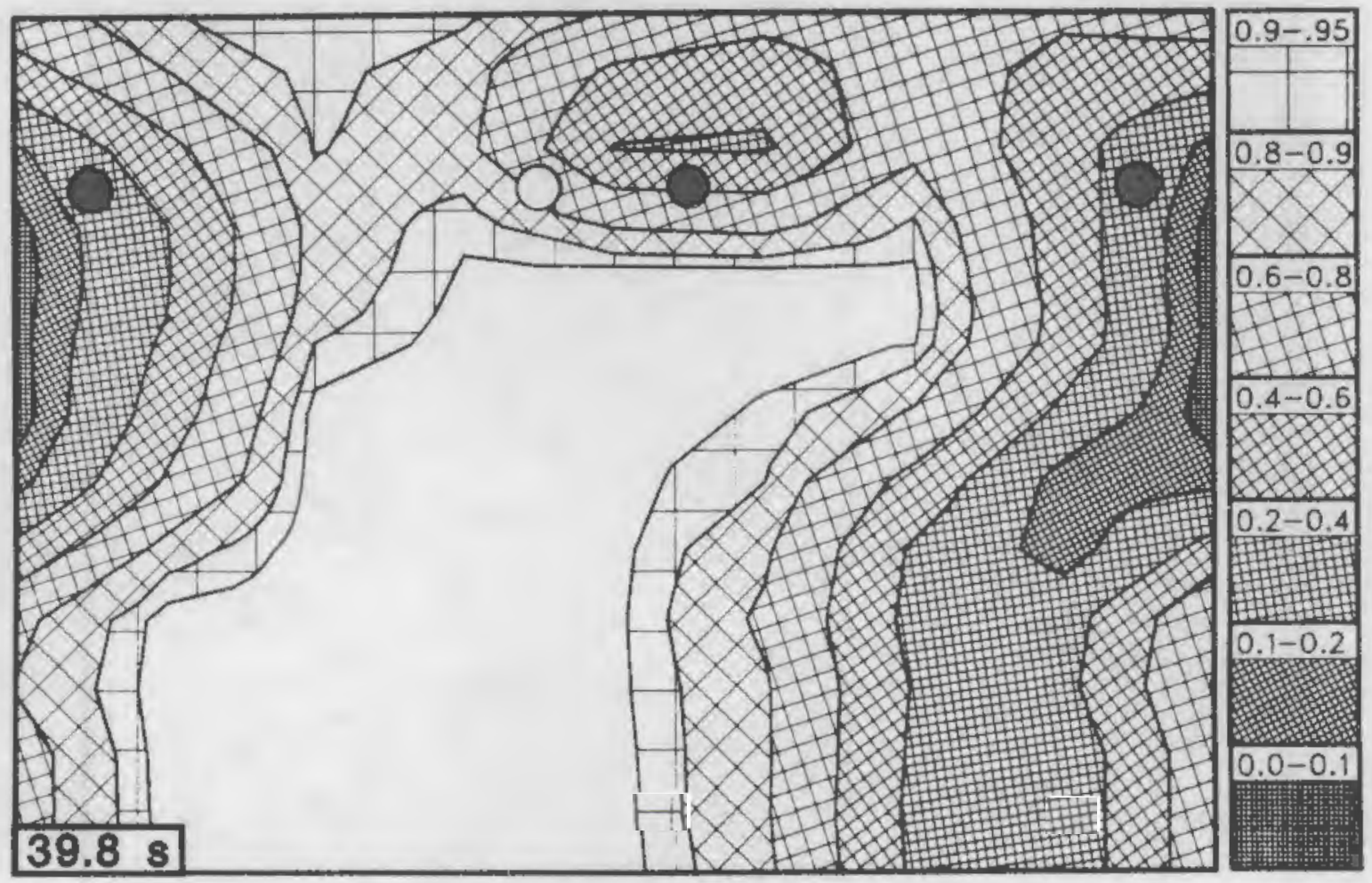

Figure B.79. Downcomer void fraction contour at $39.8 \mathrm{~s}$ 


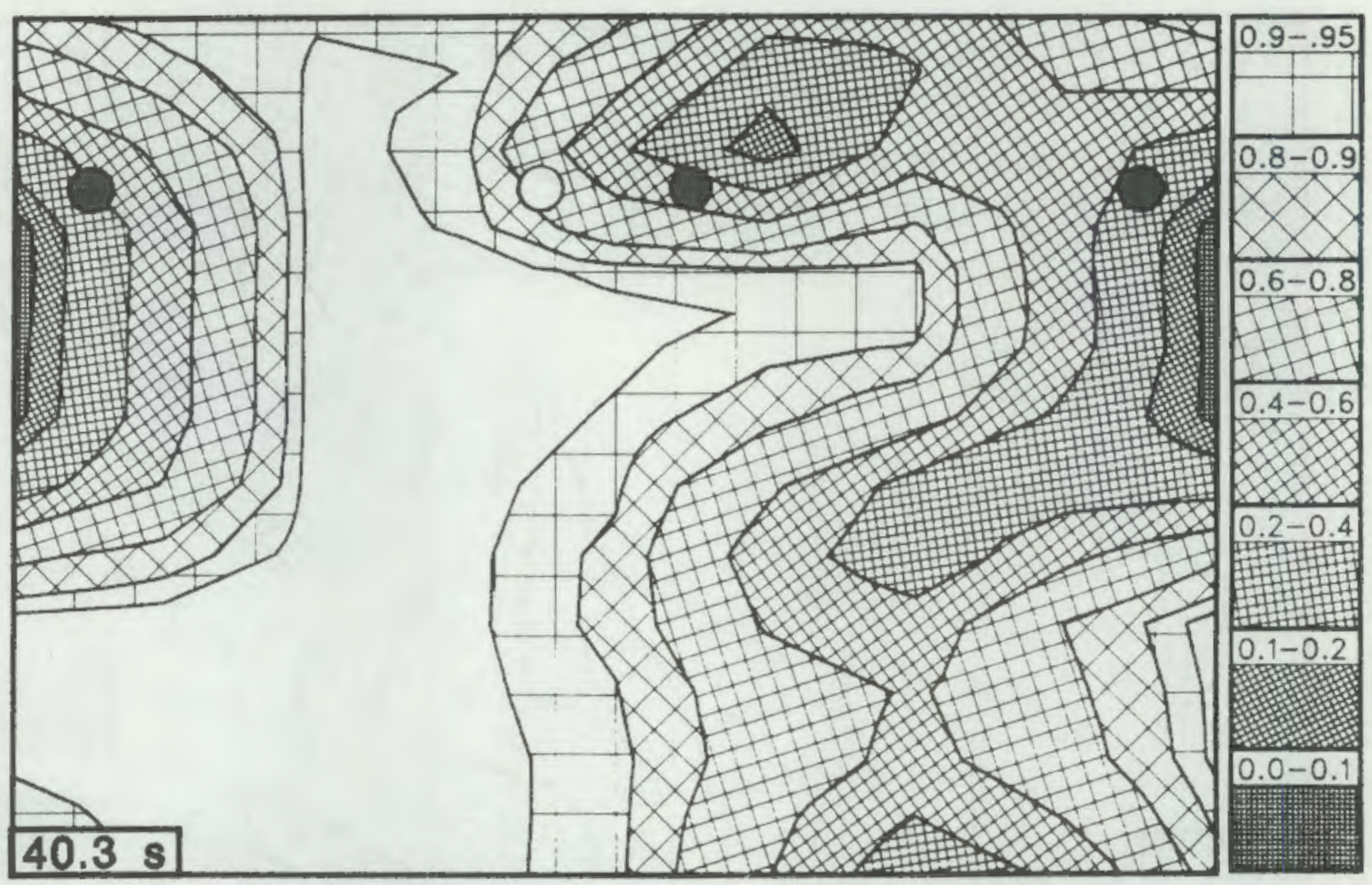

Figure B.80. Downcomer void fraction contour at $40.3 \mathrm{~s}$

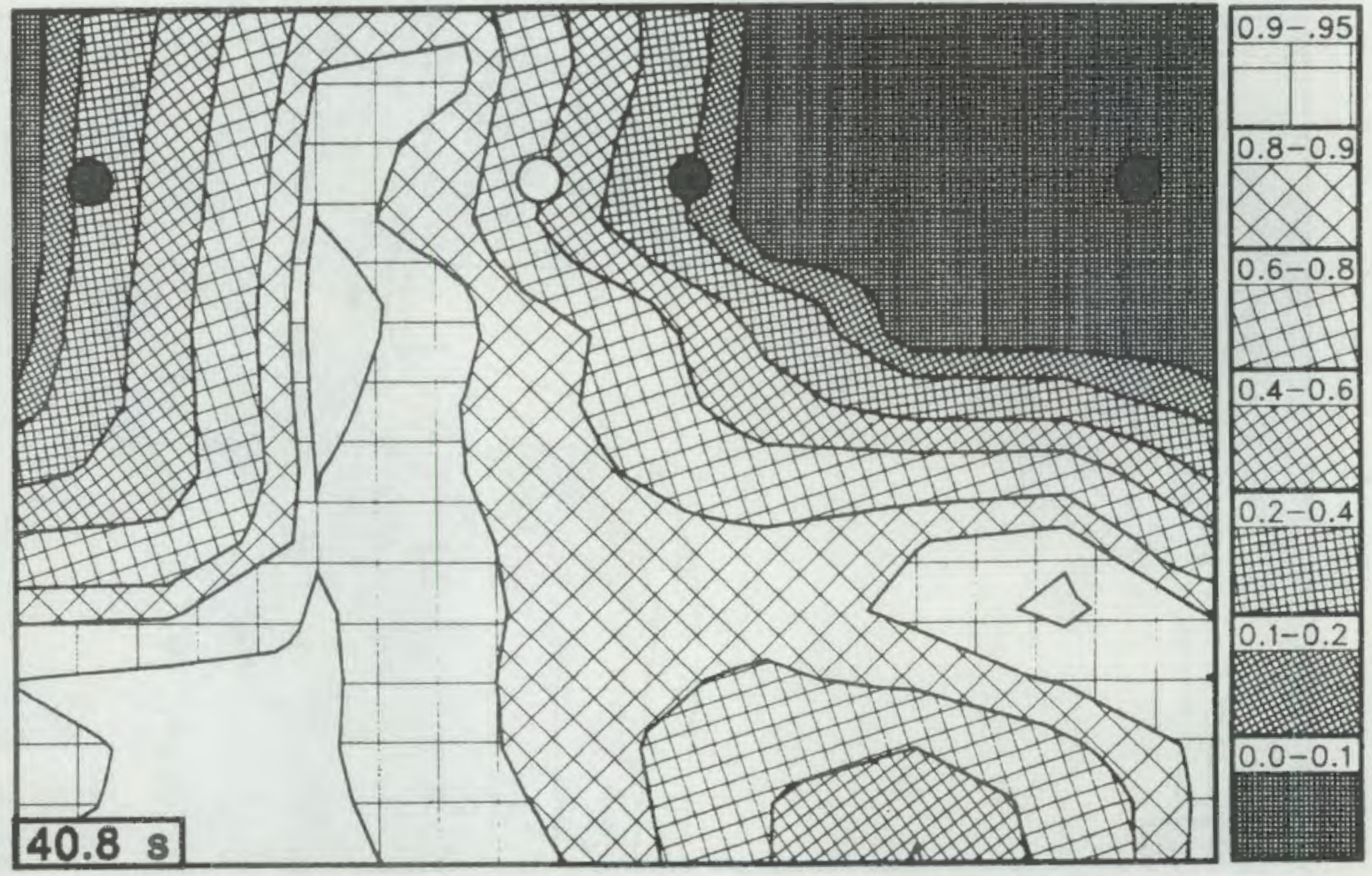

Figure B.81. Downcomer void fraction contour at $40.8 \mathrm{~s}$ 


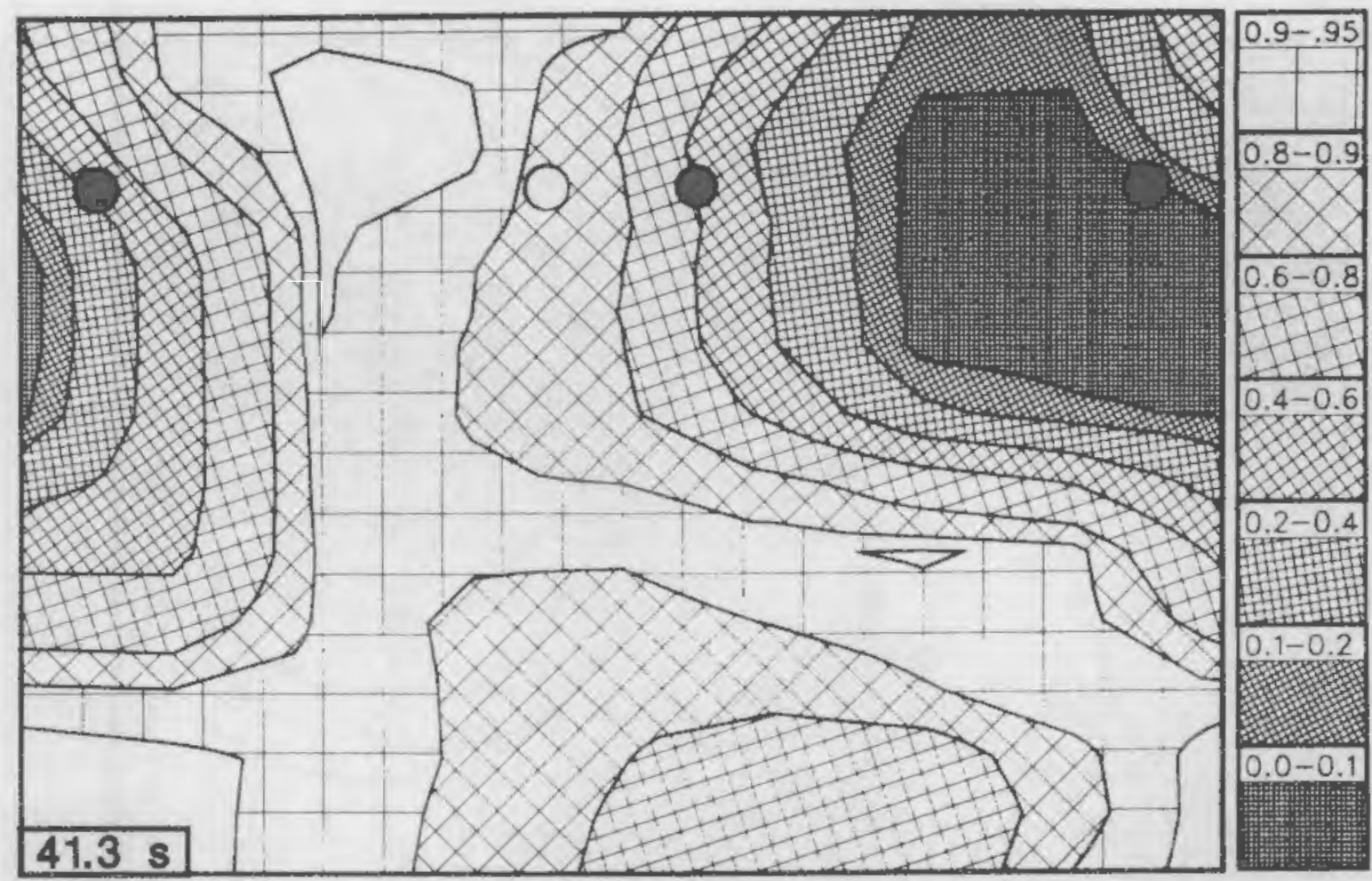

Figure B.82. Downcomer void fraction contour at $41.3 \mathrm{~s}$

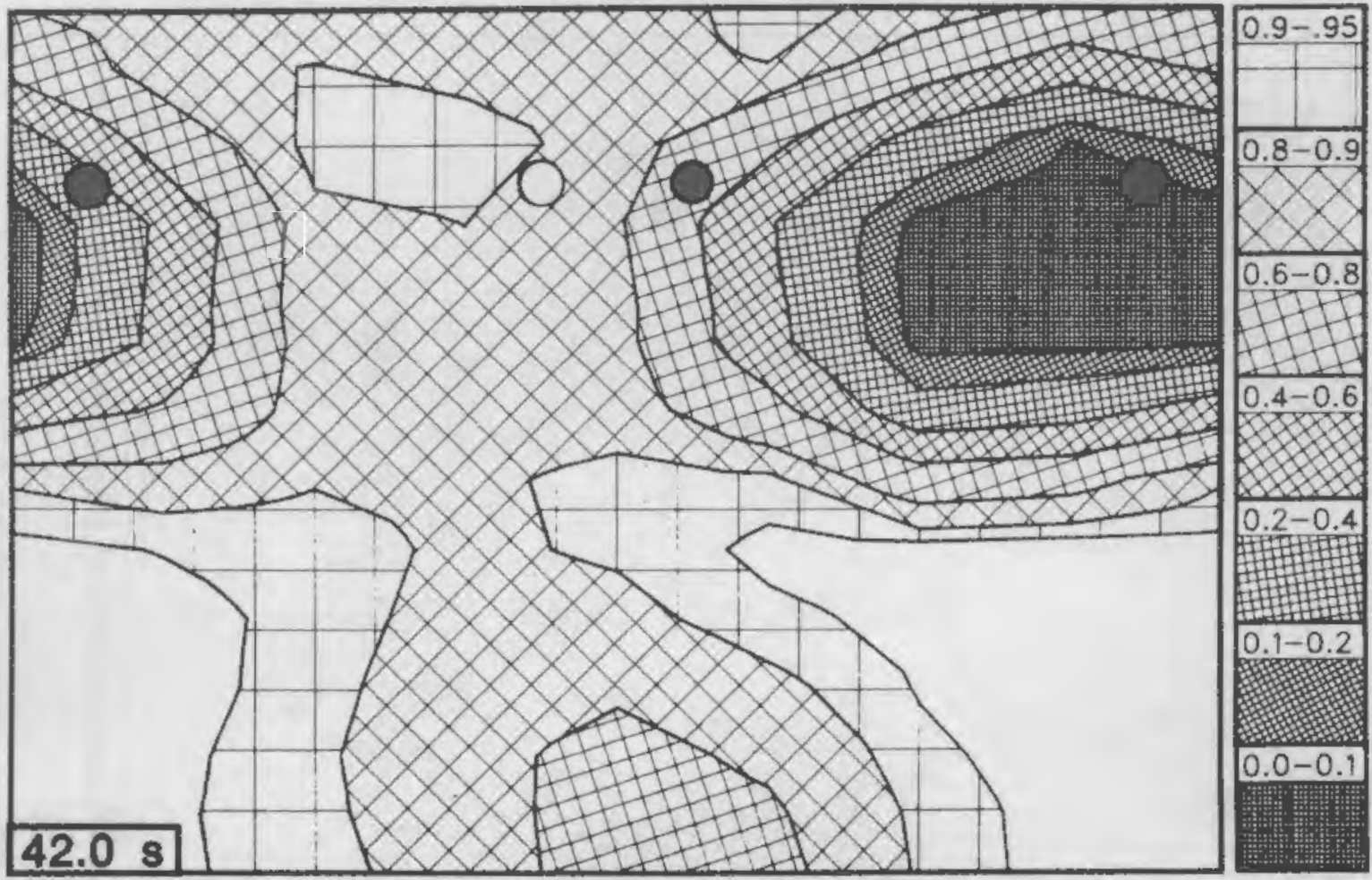

Figure B.83. Downcomer void fraction contour at $42.0 \mathrm{~s}$ 


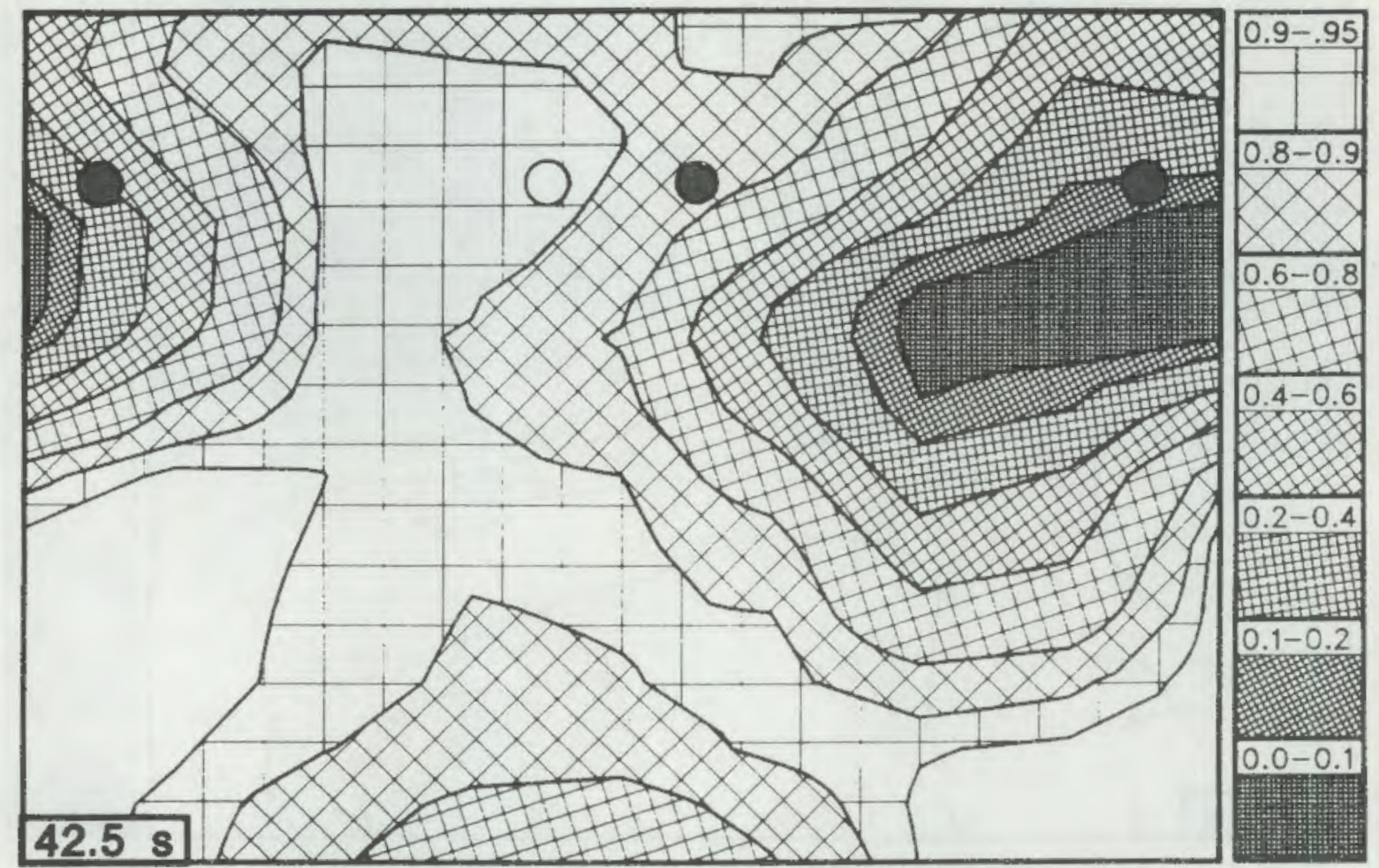

Figure B.84. Downcomer void fraction contour at $42.5 \mathrm{~s}$

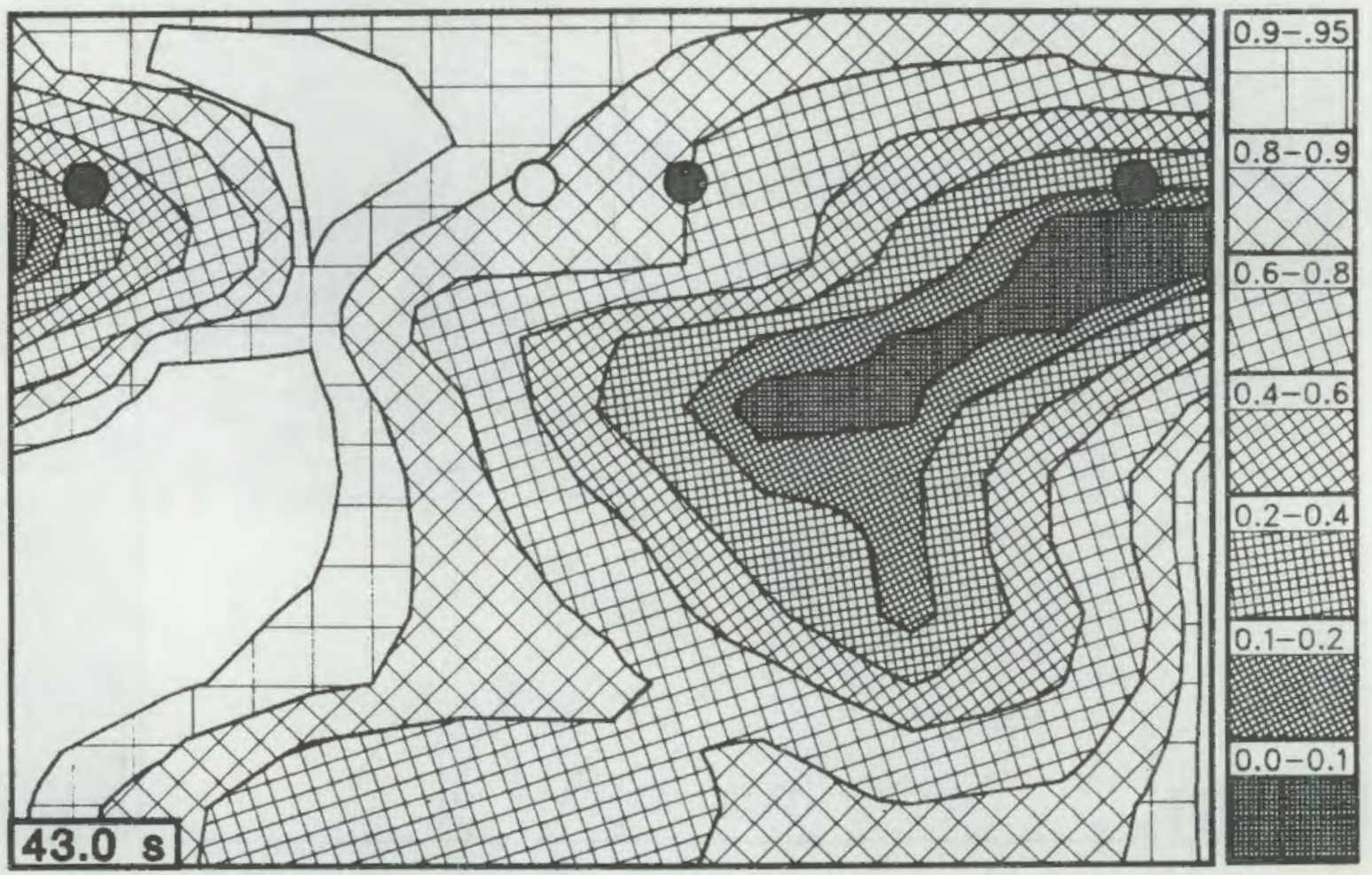

Figure B.85. Downcomer void fraction contour at $43.0 \mathrm{~s}$ 


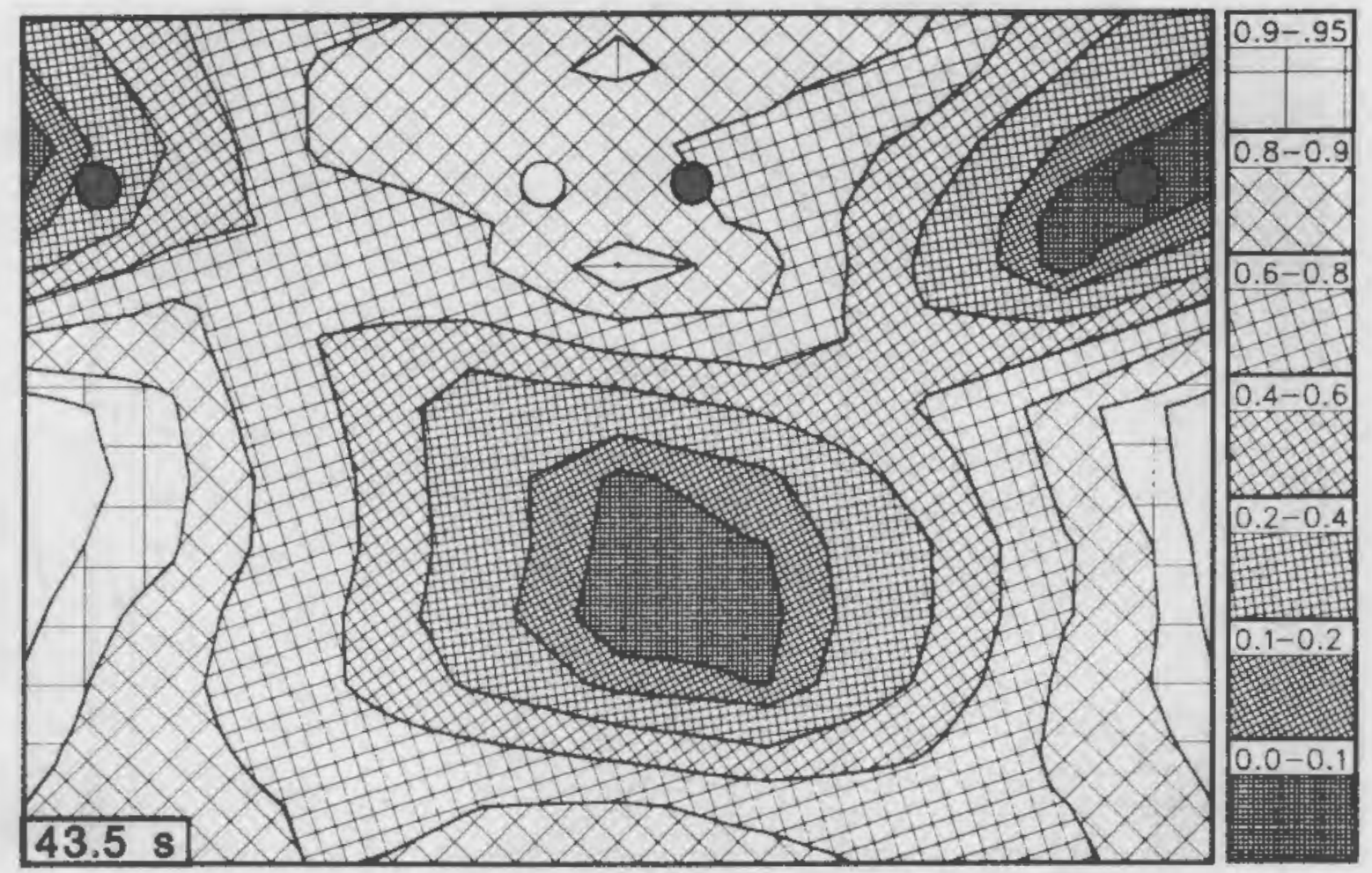

Figure B.86. Downcomer void fraction contour at $43.5 \mathrm{~s}$

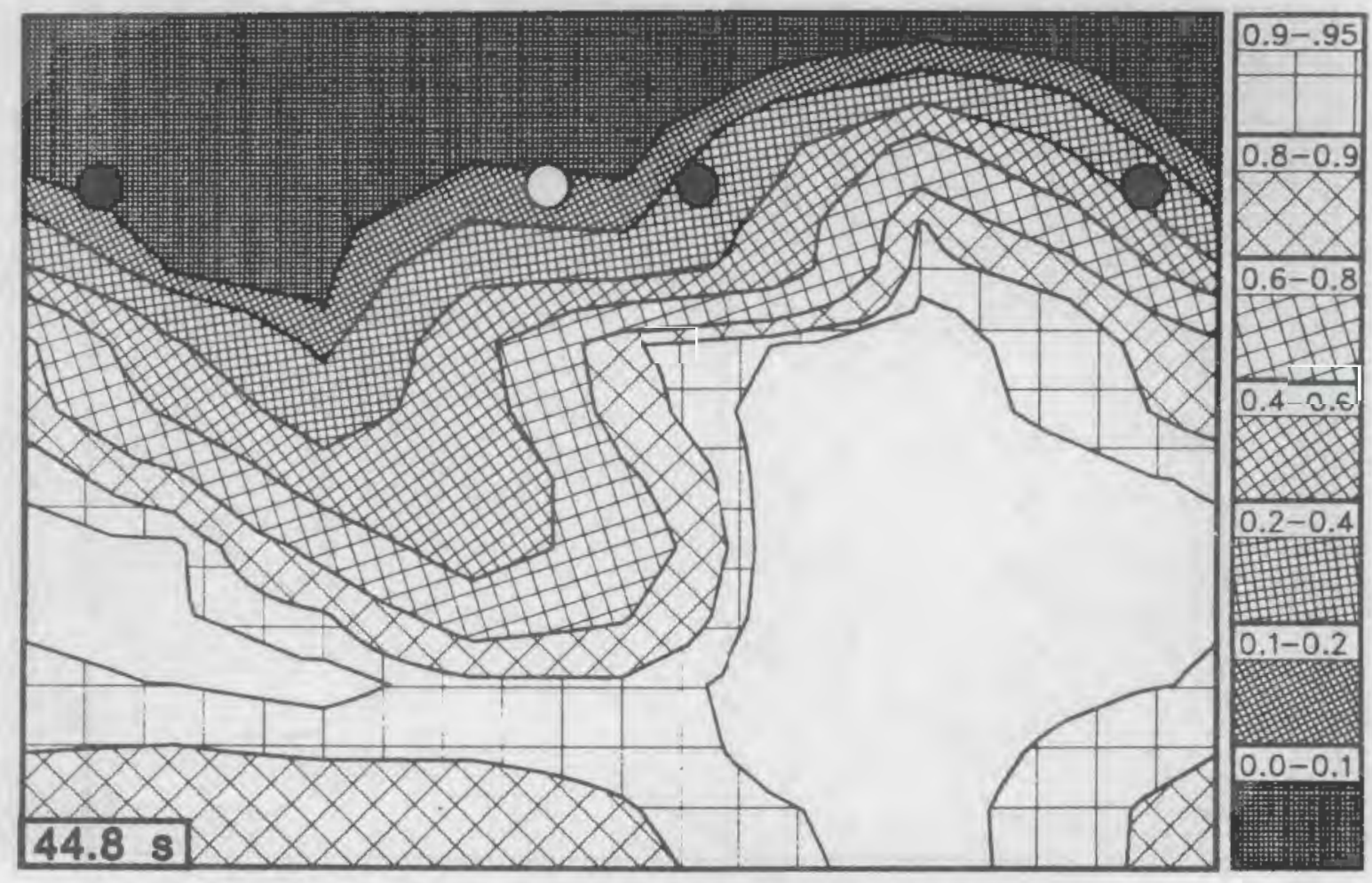

Figure B.87. Downcomer void fraction contour at $44.8 \mathrm{~s}$ 

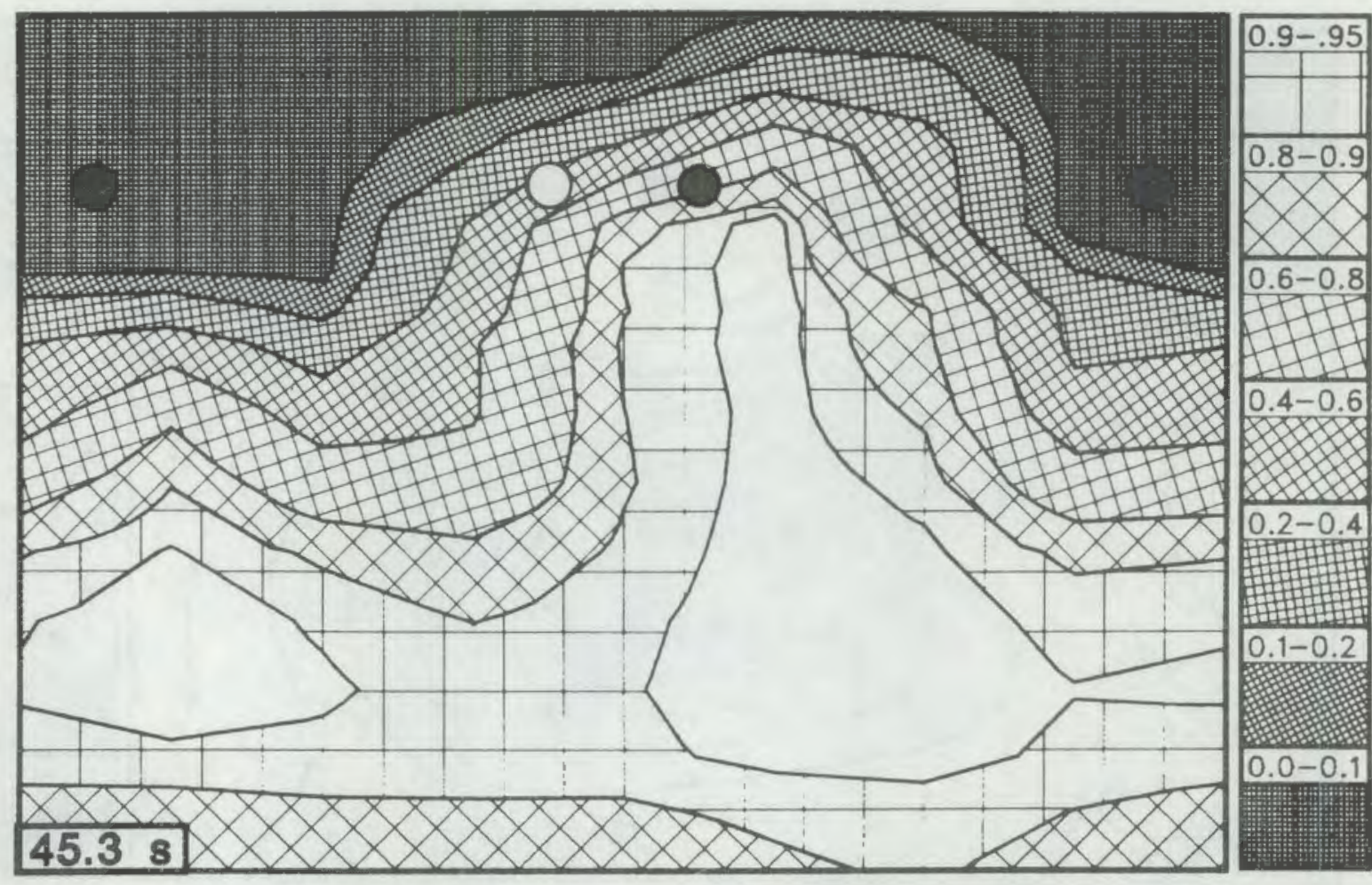

Figure B.88. Downcomer void fraction contour at $45.3 \mathrm{~s}$

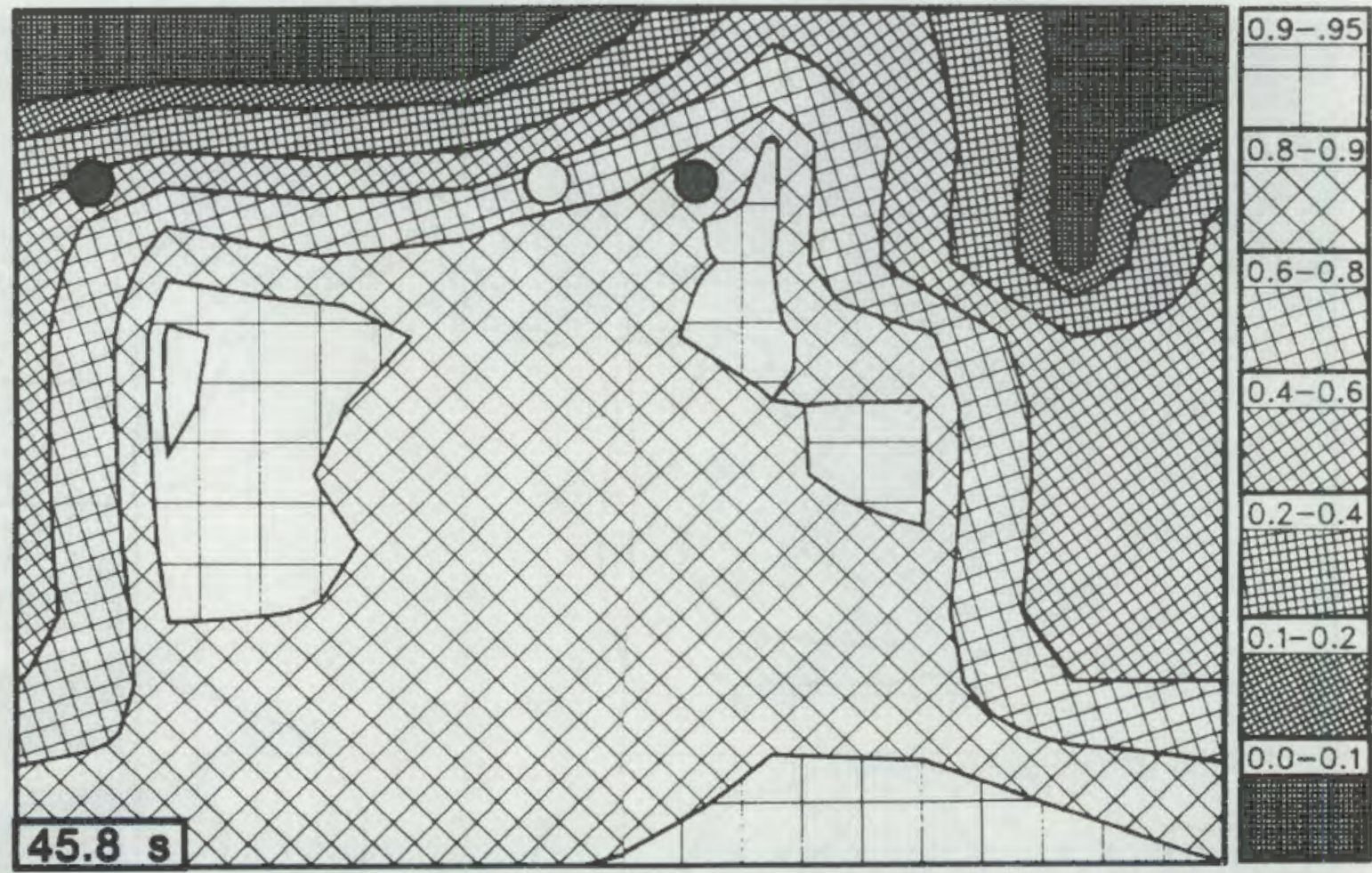

Figure B.89. Downcomer void fraction contour at $45.8 \mathrm{~s}$ 


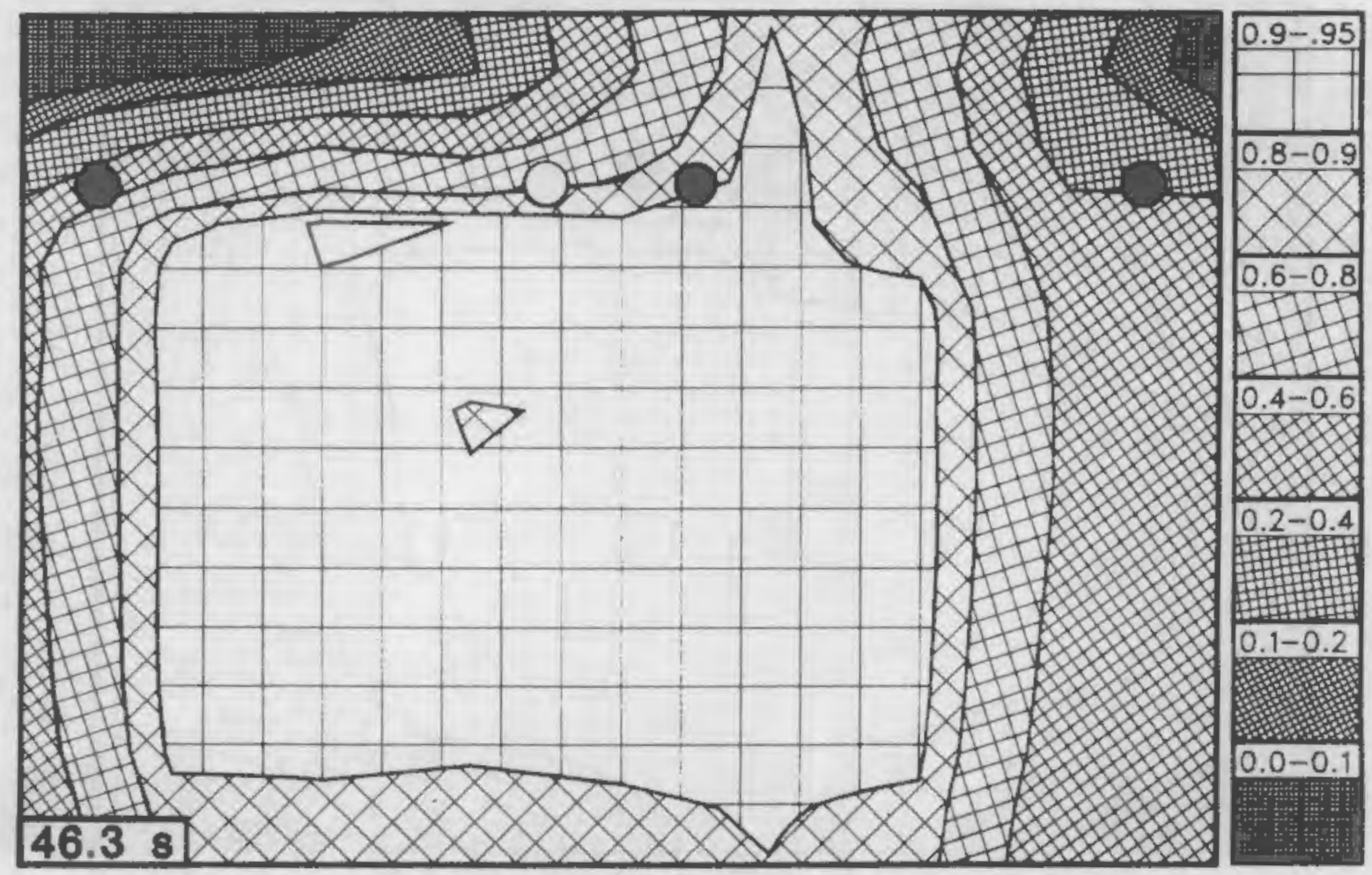

Figure B.90. Downcomer void fraction contour at $46.3 \mathrm{~s}$

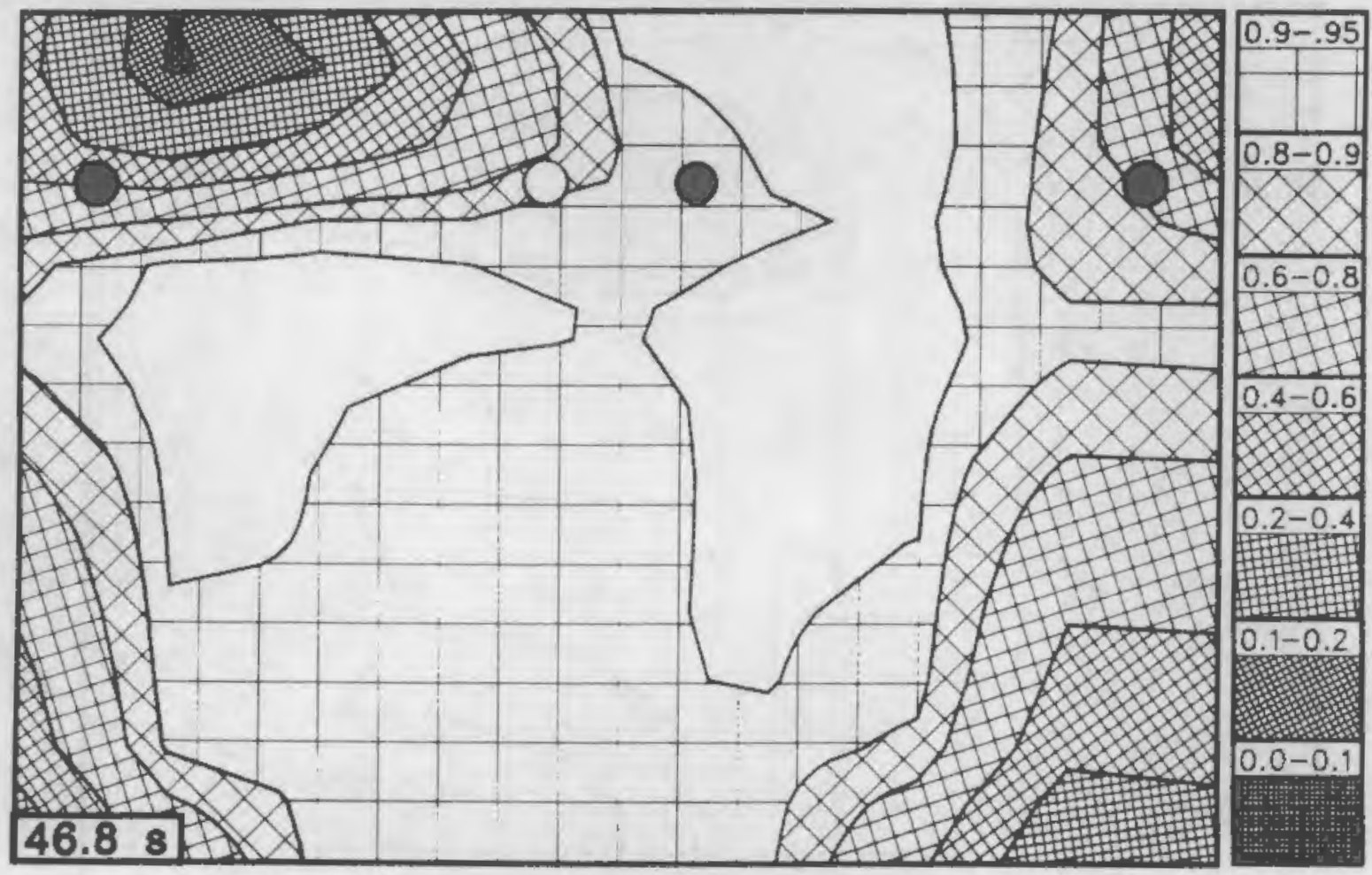

Figure B.91. Downcomer void fraction contour at $46.8 \mathrm{~s}$ 


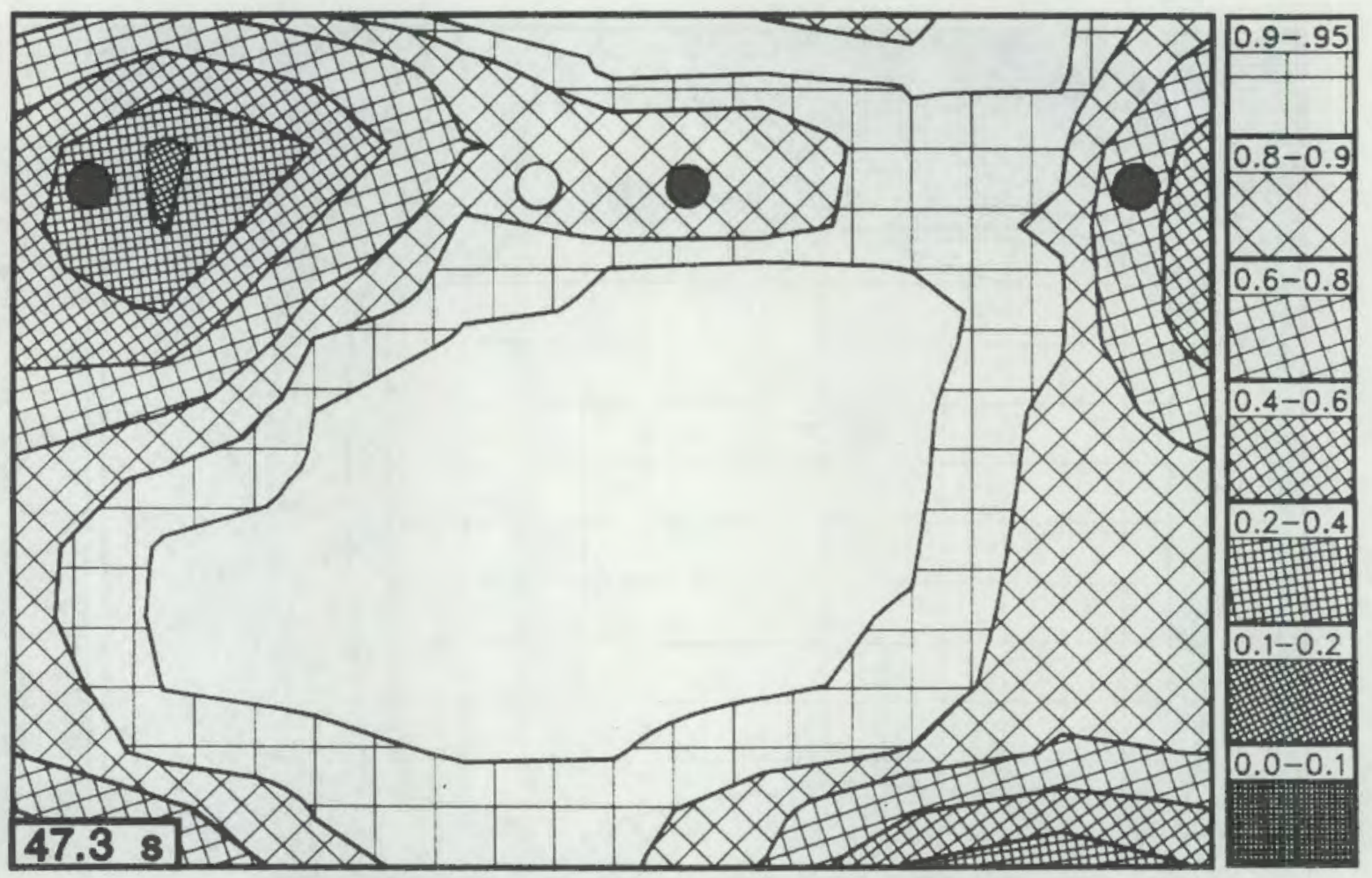

Figure B.92. Downcomer void fraction contour at $47.3 \mathrm{~s}$

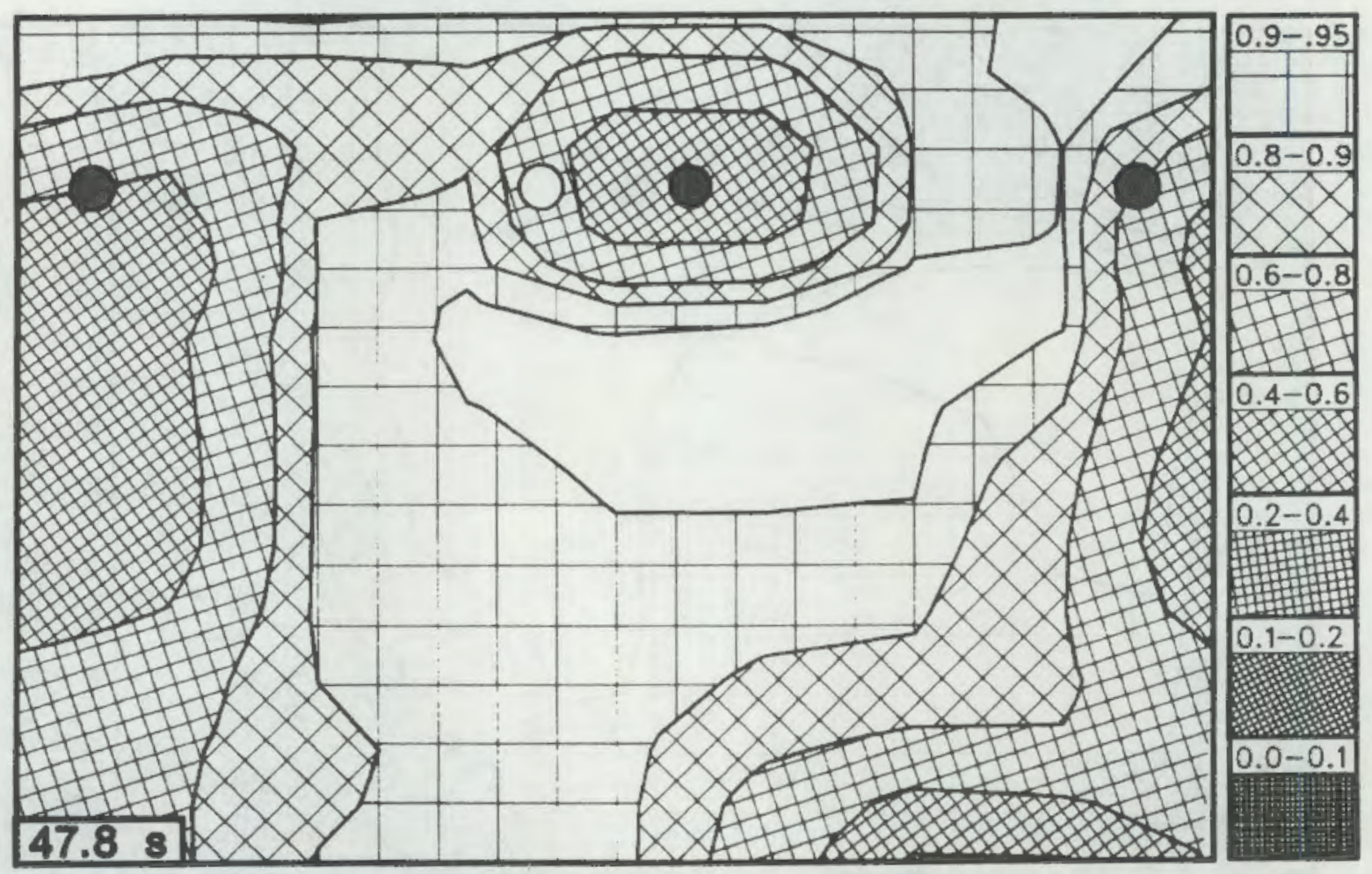

Figure B.93. Downcomer void fraction contour at $47.8 \mathrm{~s}$ 


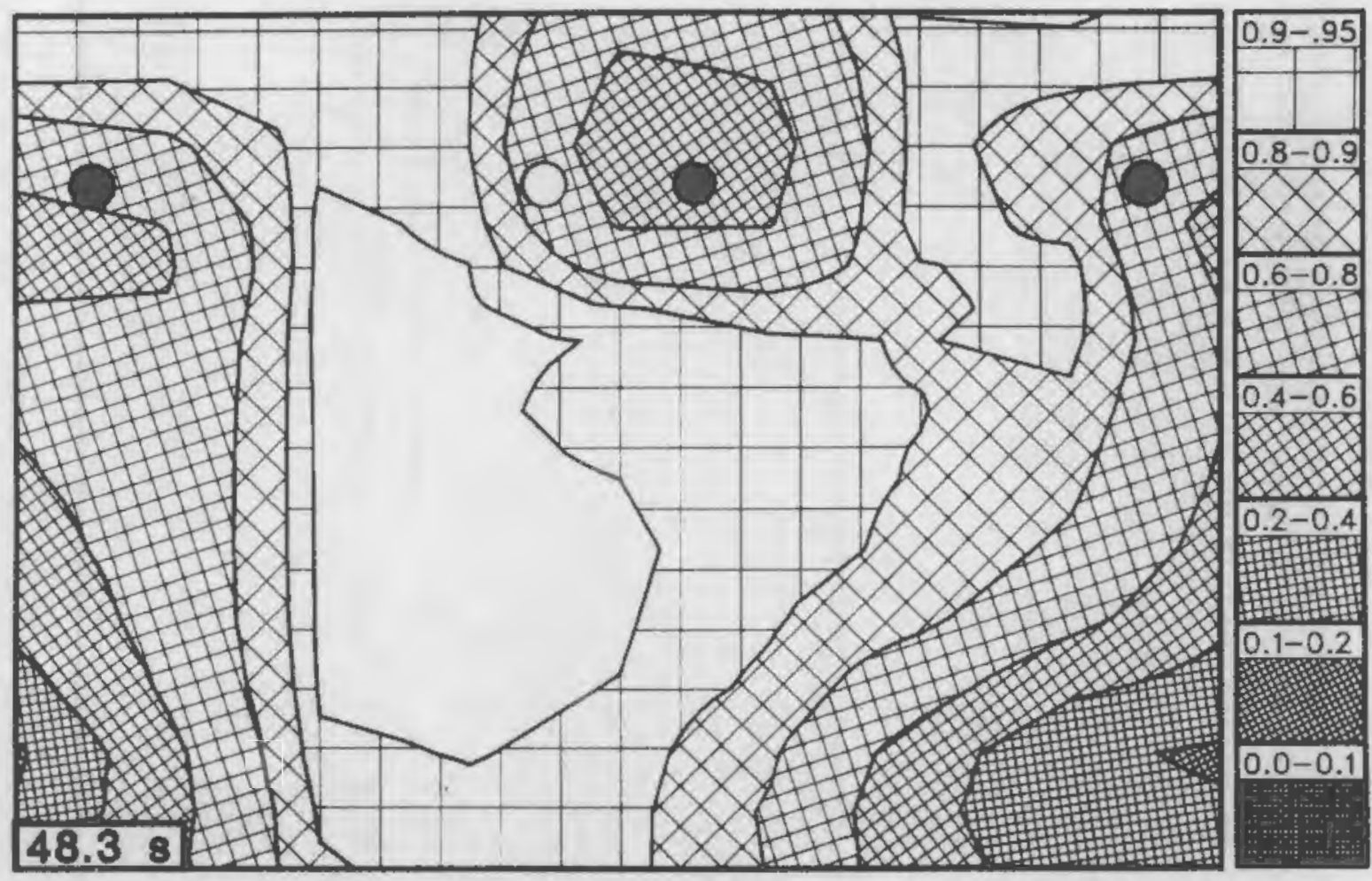

Figure B.94. Downcomer void fraction contour at $48.3 \mathrm{~s}$

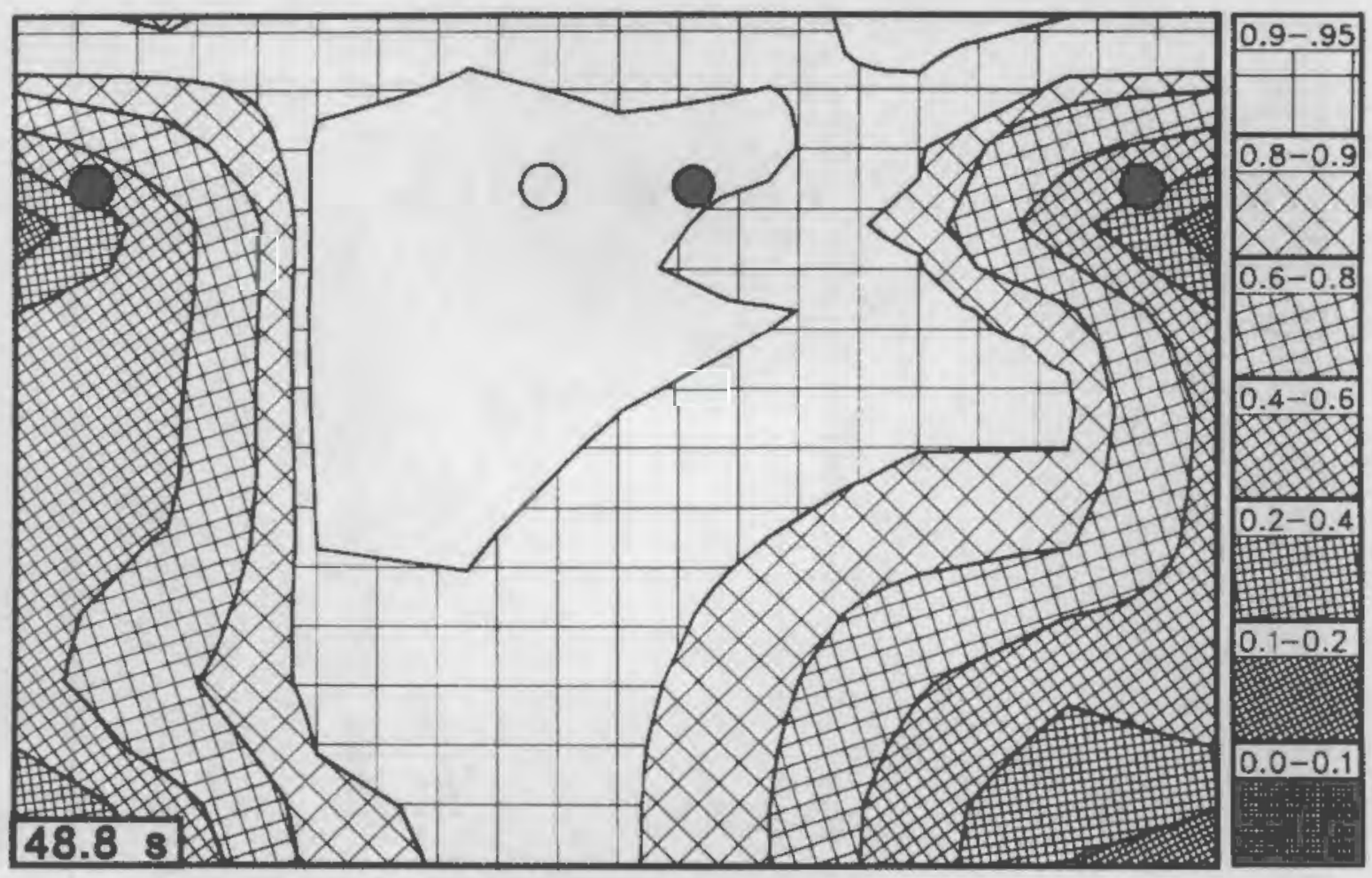

Figure B.95. Downcomer void fraction contour at $48.8 \mathrm{~s}$ 


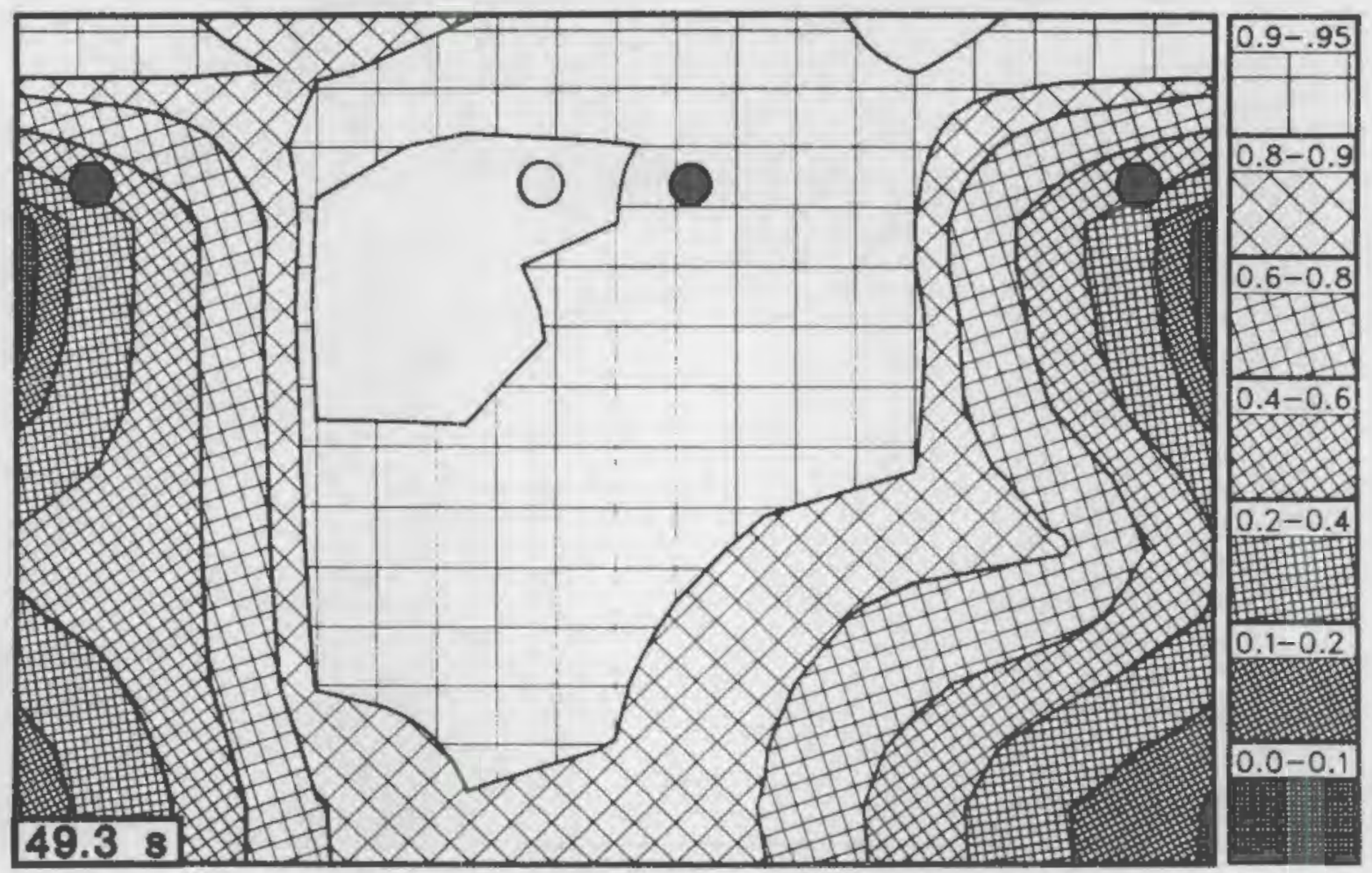

Figure B.96. Downcomer void fraction contour at $49.3 \mathrm{~s}$

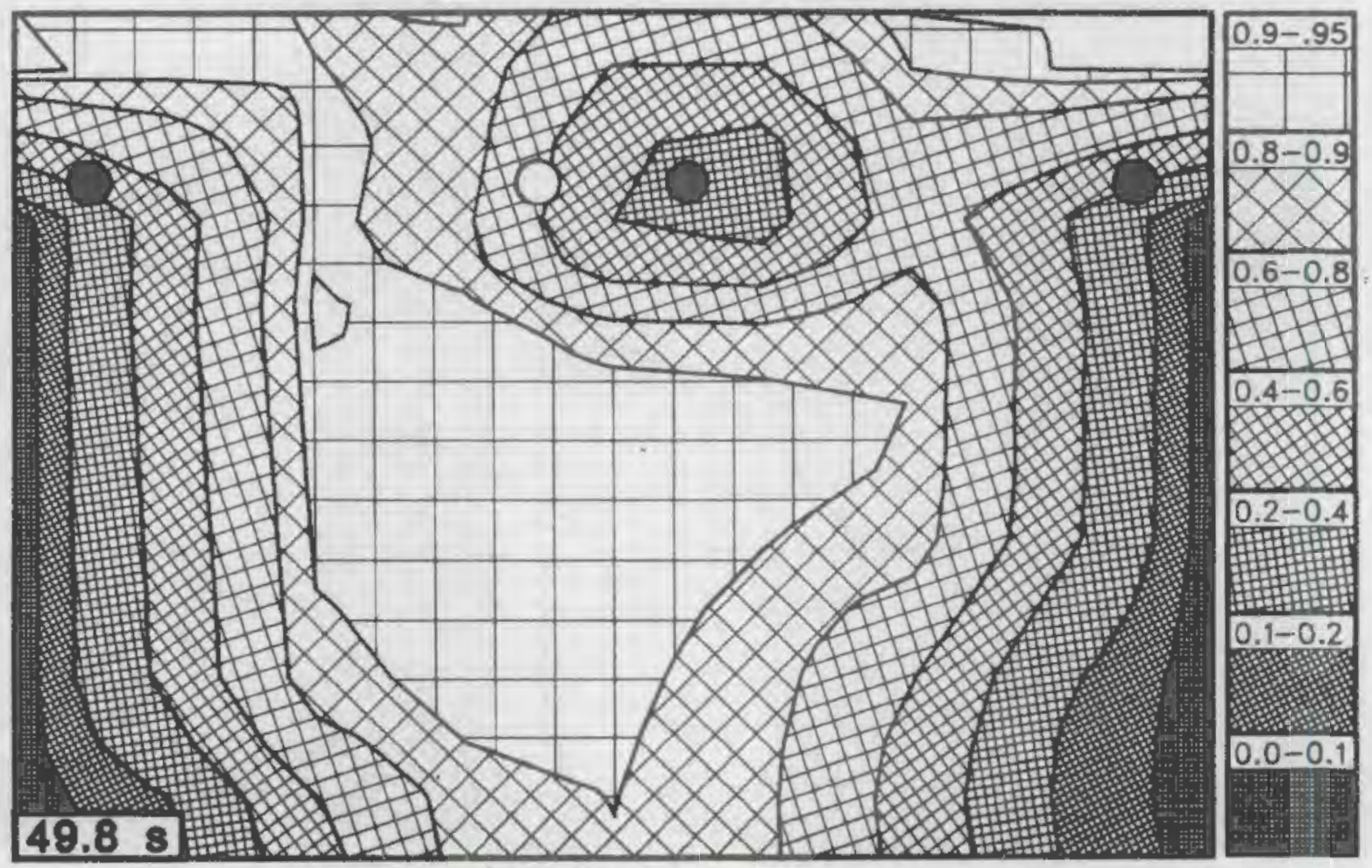

Figure B.97. Downcomer void fraction contour at $49.8 \mathrm{~s}$ 


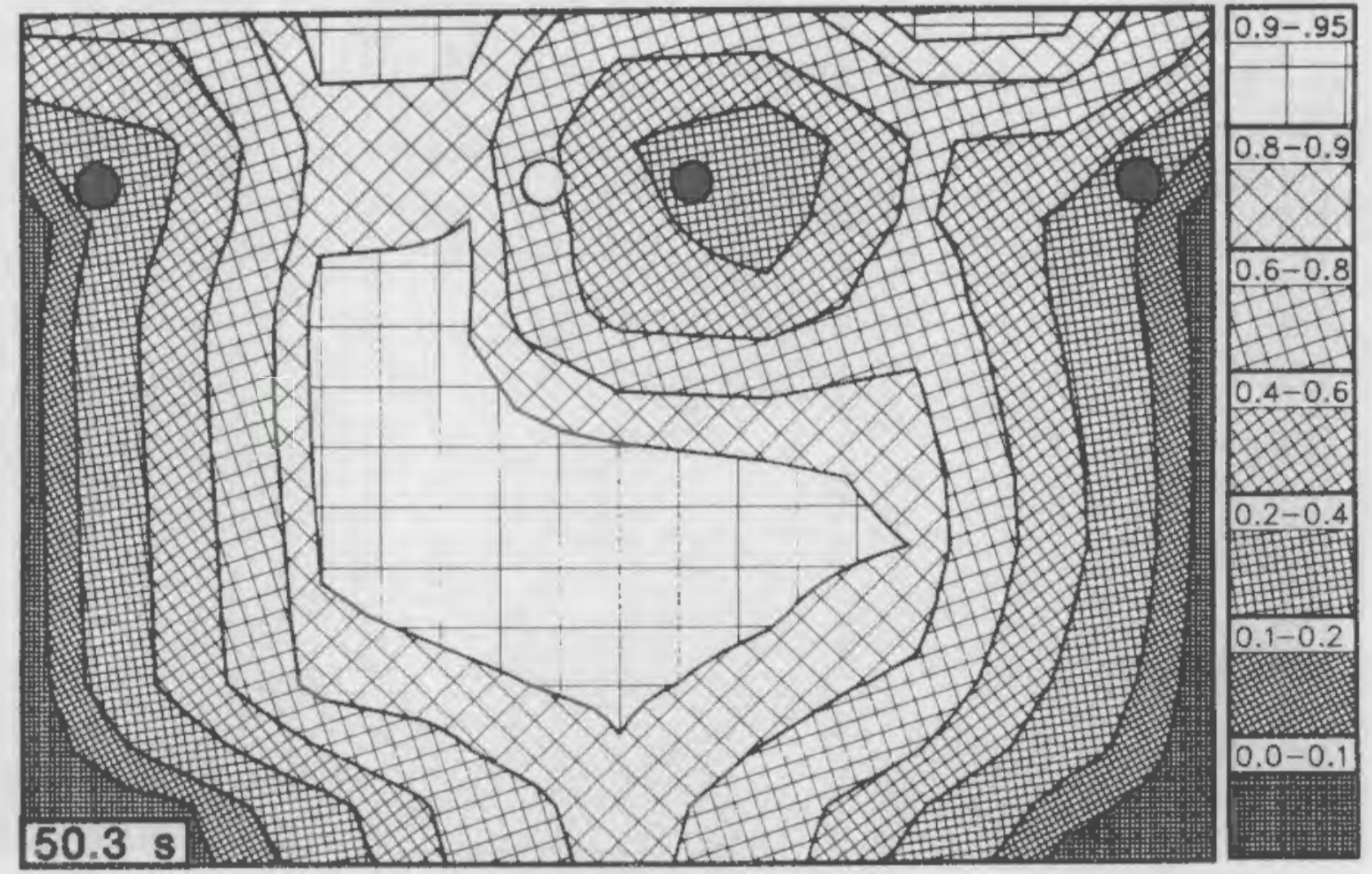

Figure B.98. Downcomer void fraction contour at $50.3 \mathrm{~s}$

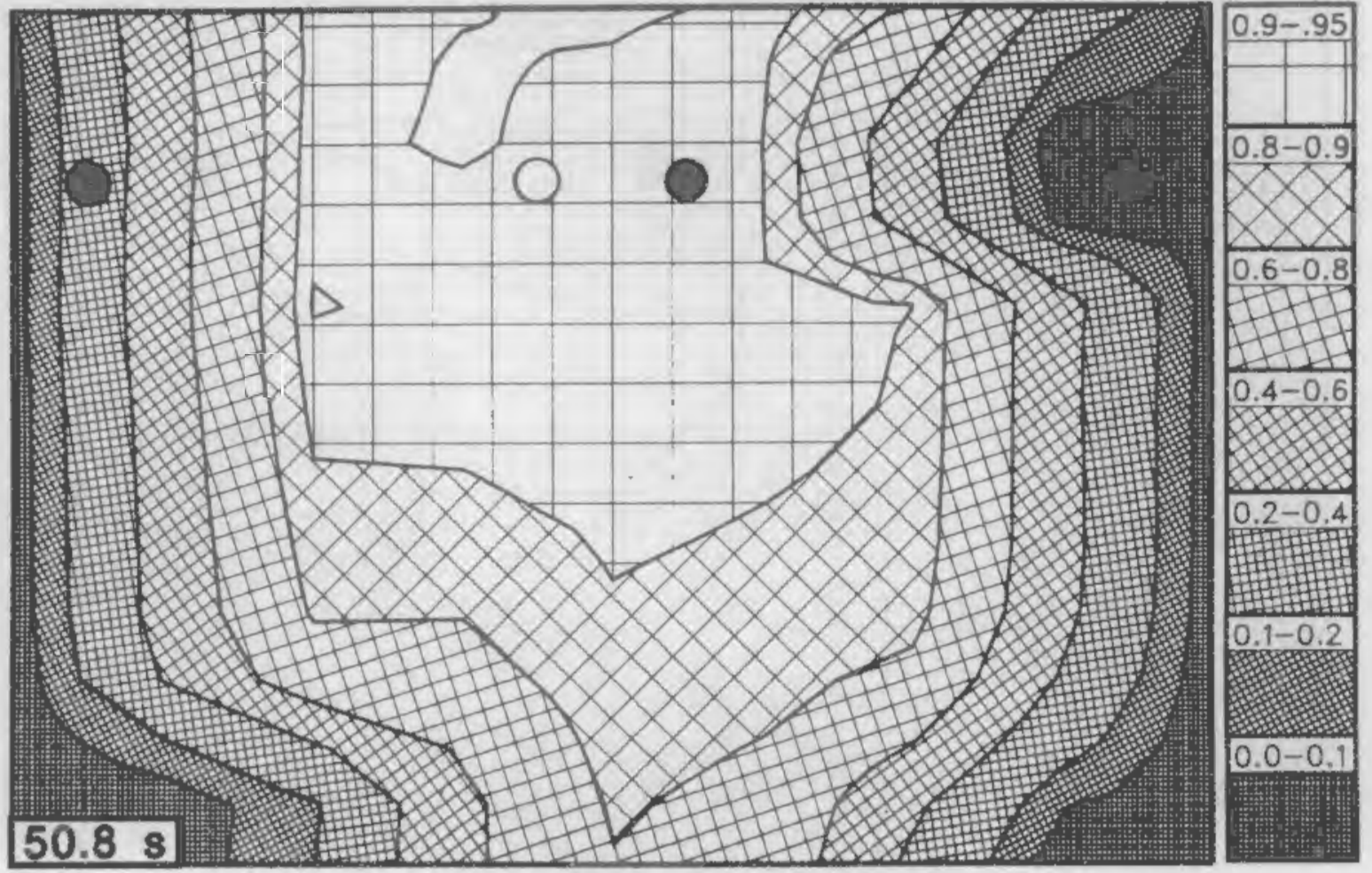

Figure B.99. Downcomer void fraction contour at $50.8 \mathrm{~s}$ 


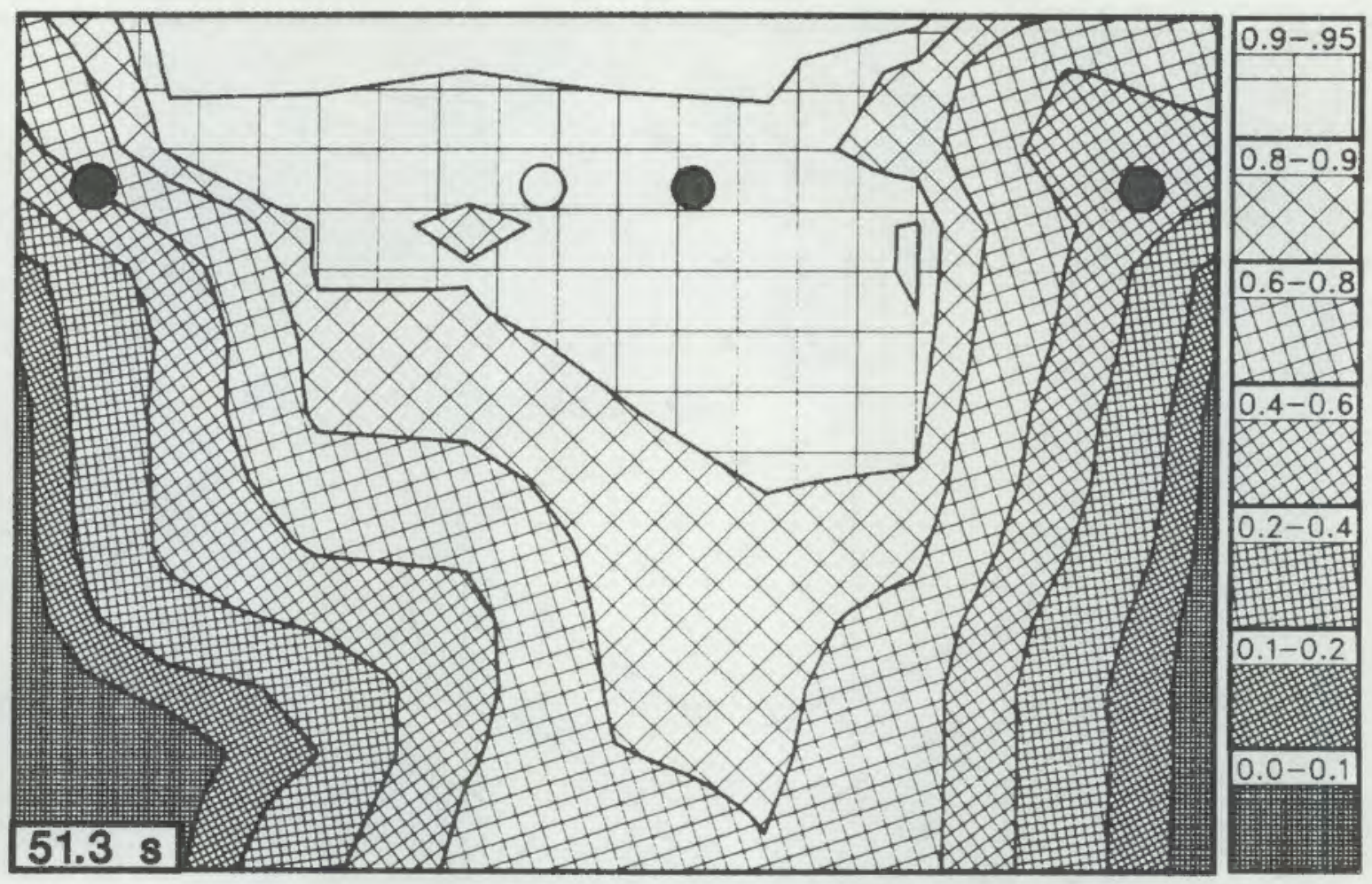

Figure B.100. Downcomer void fraction contour at $51.3 \mathrm{~s}$

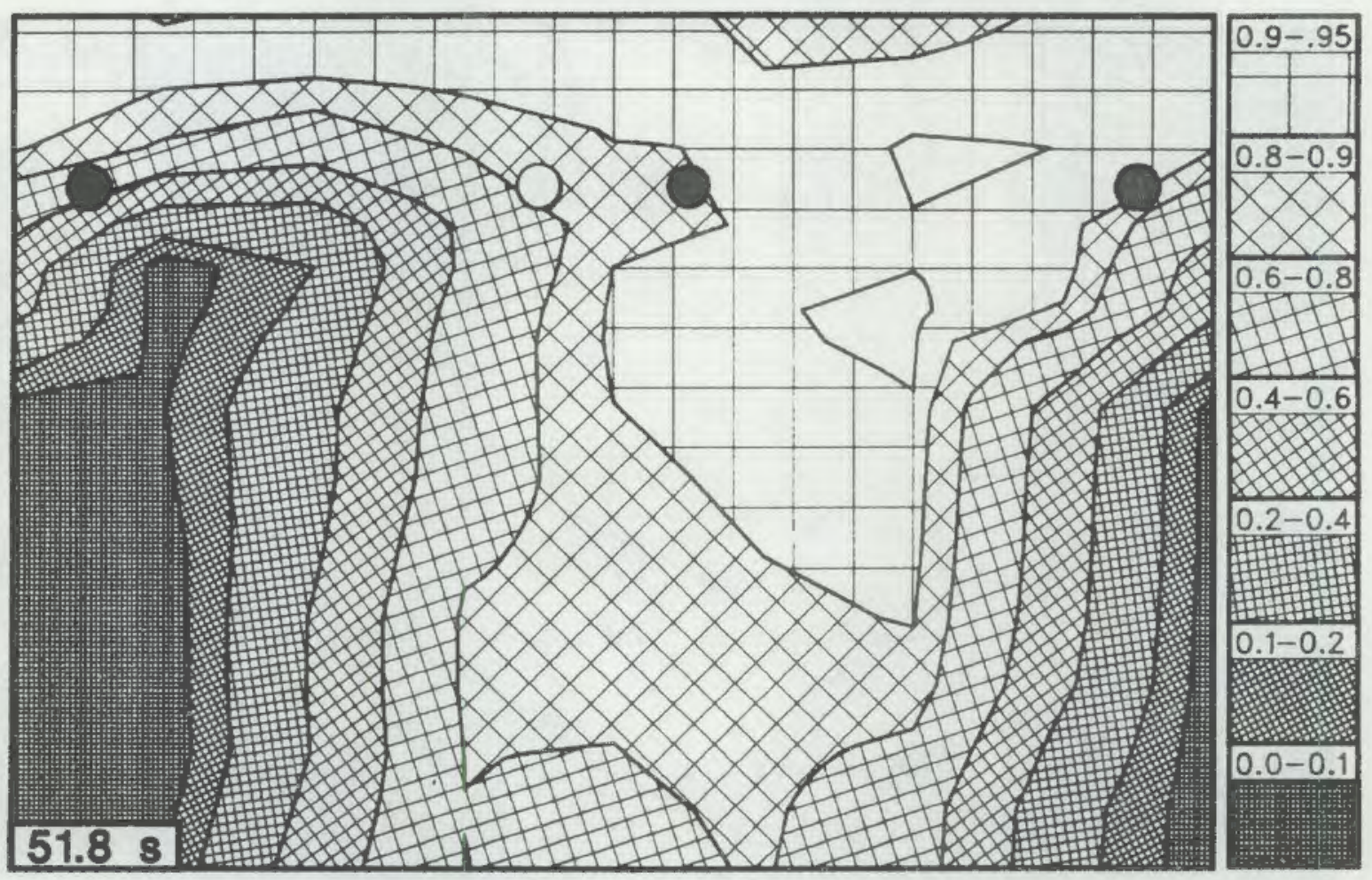

Figure B.101. Downcomer void fraction contour at $51.8 \mathrm{~s}$ 


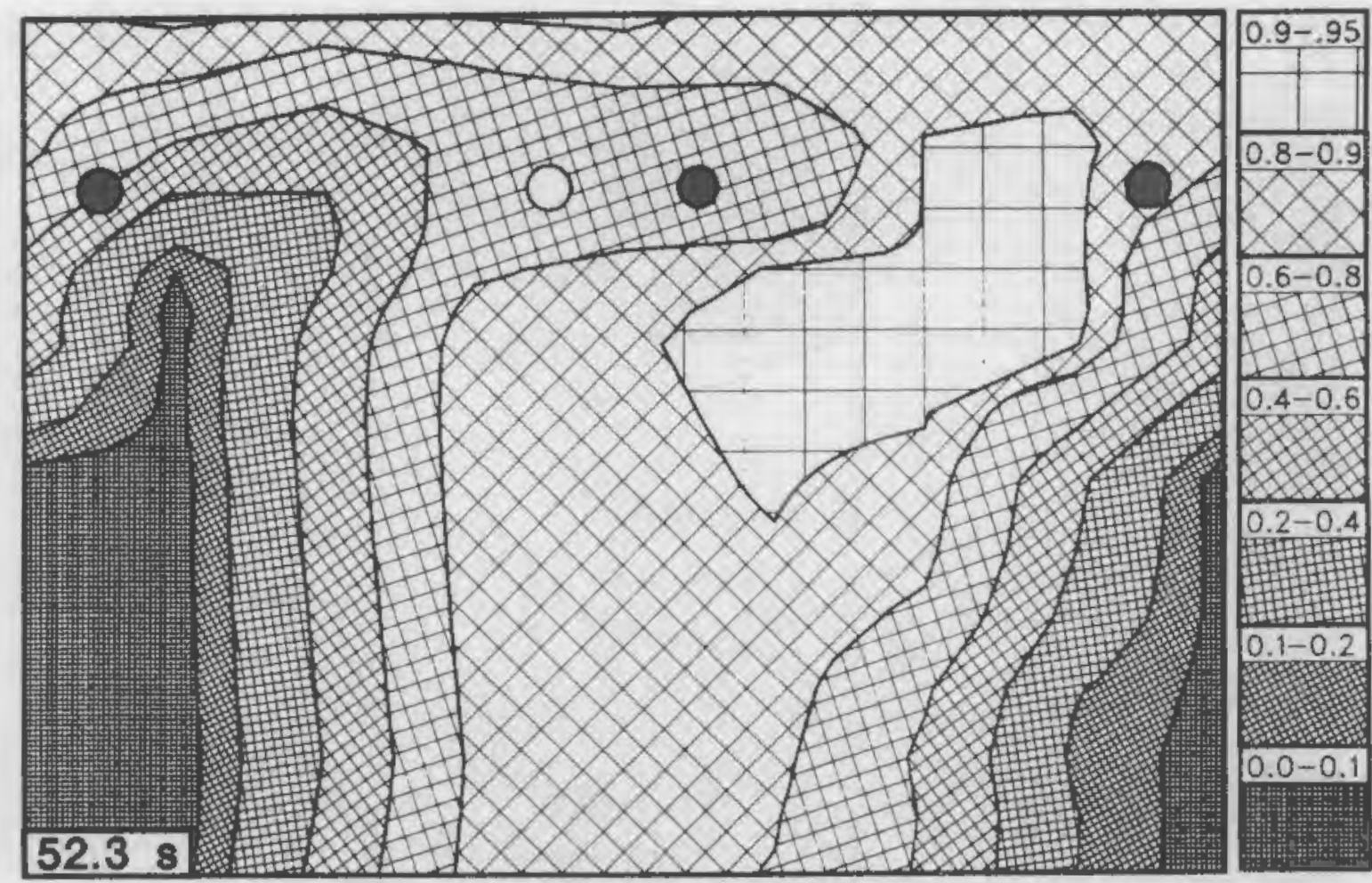

Figure B.102. Downcomer void fraction contour at $52.3 \mathrm{~s}$

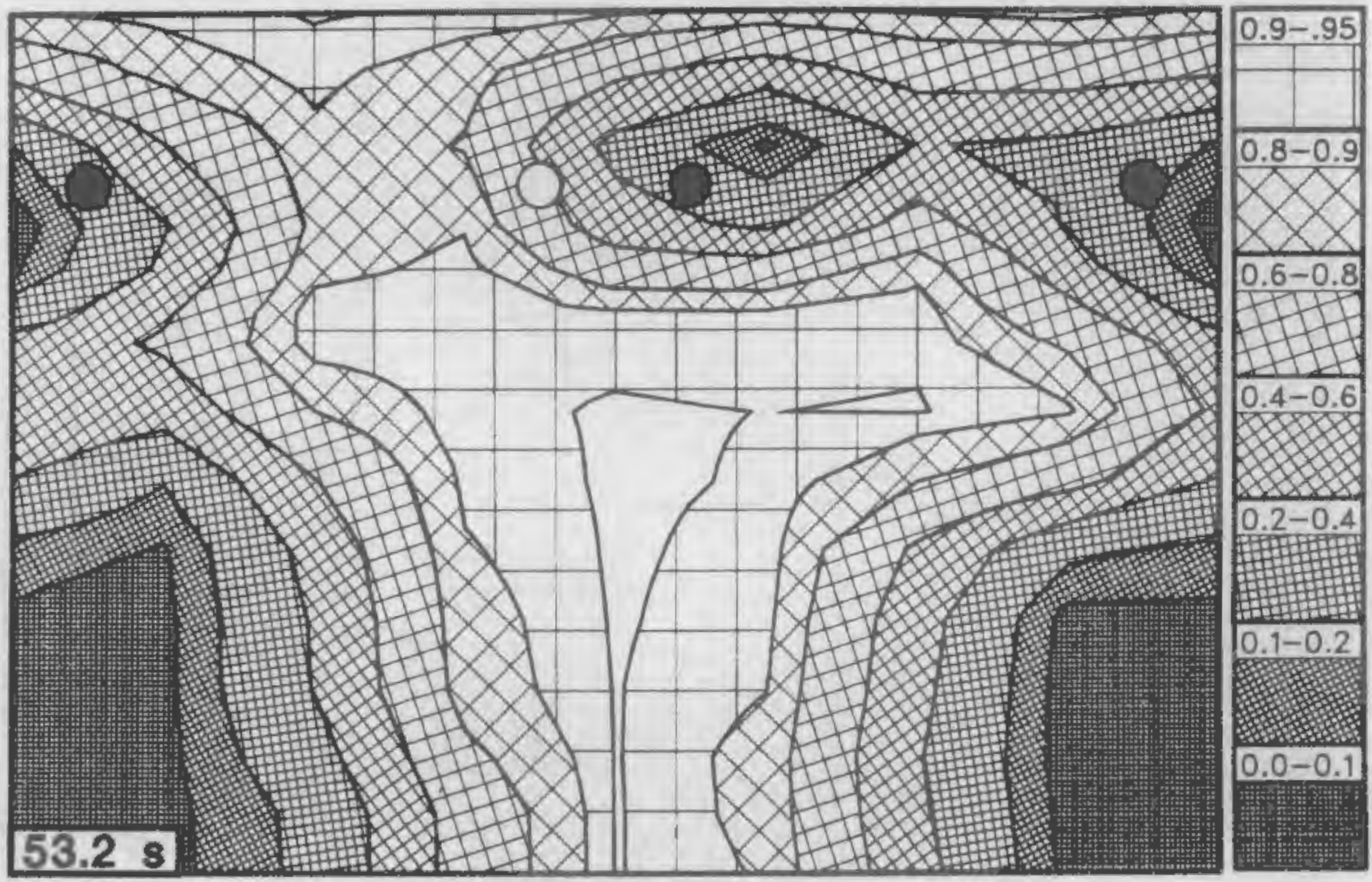

Figure B.103. Downcomer void fraction contour at $53.2 \mathrm{~s}$ 


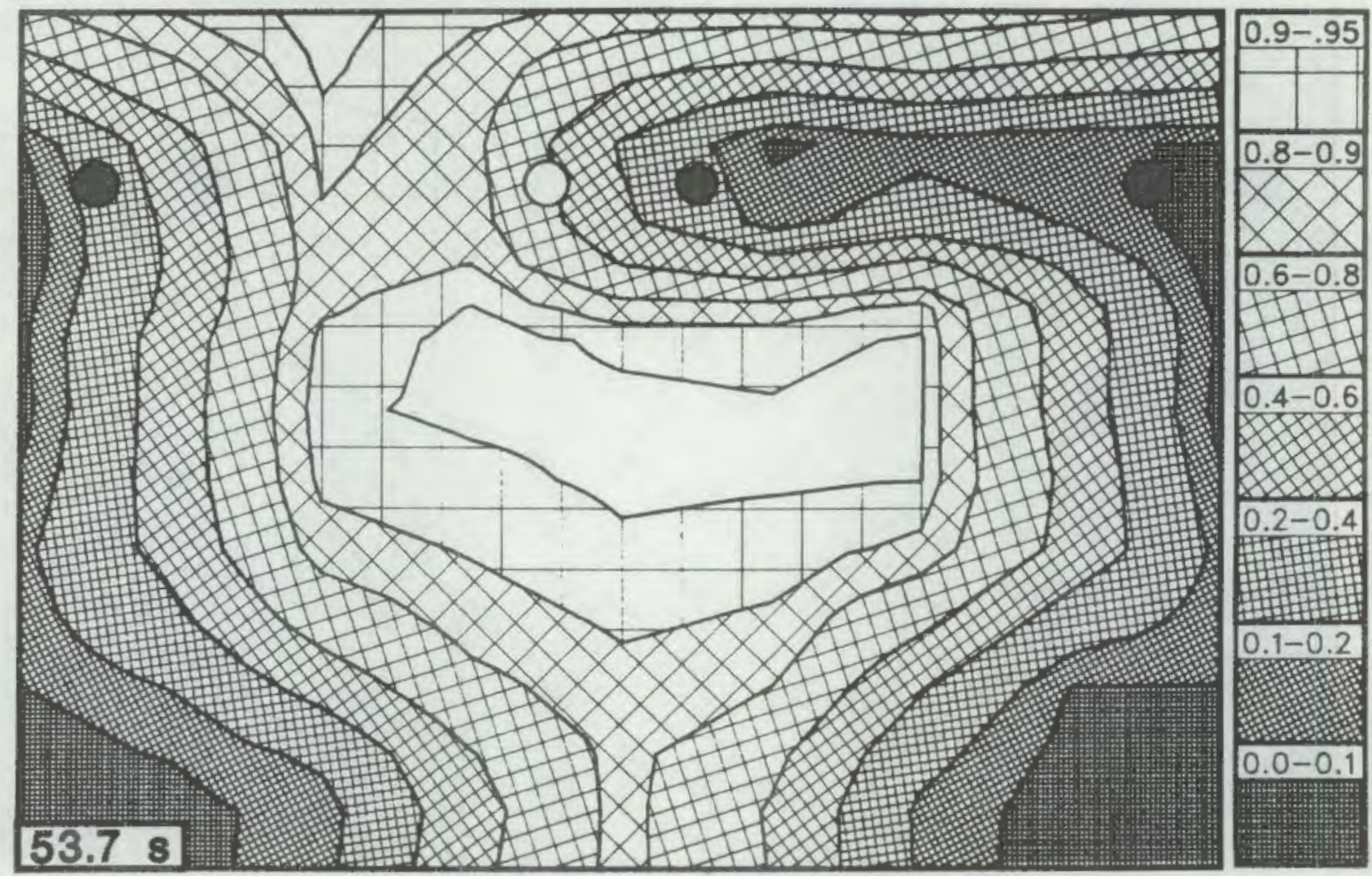

Figure B.104. Downcomer void fraction contour at $53.7 \mathrm{~s}$

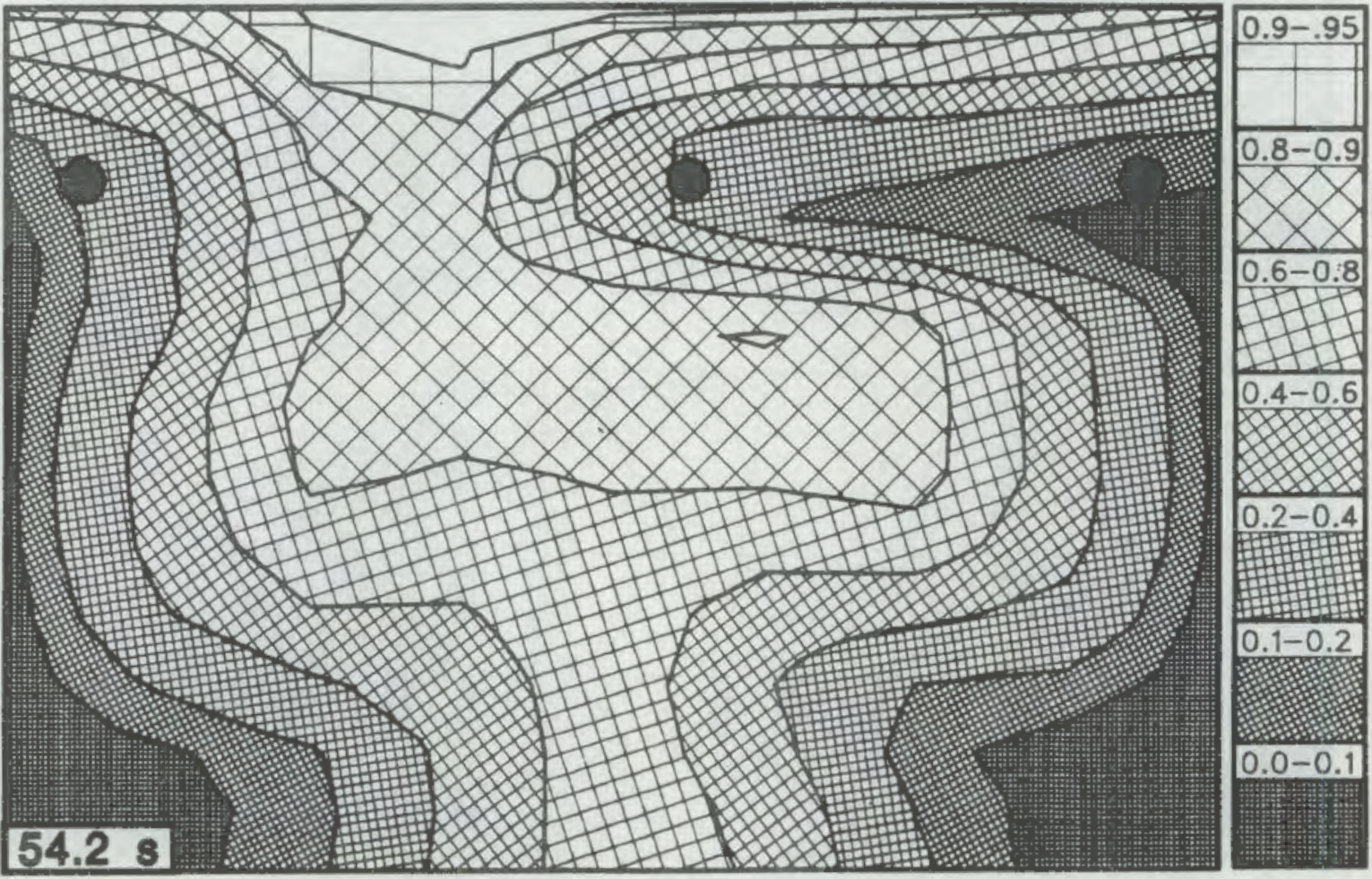

Figure B.105. Downcomer void fraction contour at $54.2 \mathrm{~s}$ 


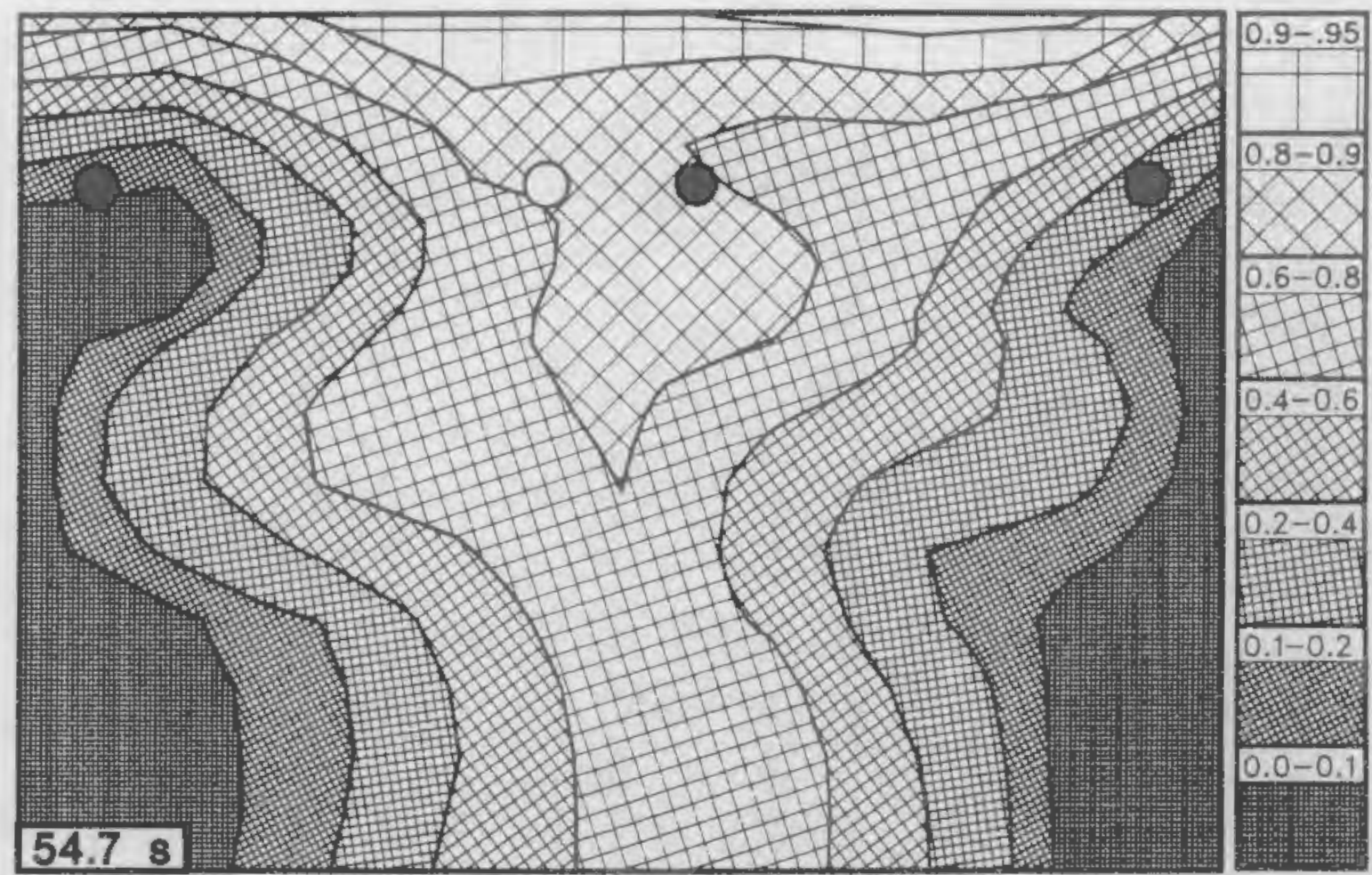

Figure B.106. Downcomer void fraction contour at $54.7 \mathrm{~s}$

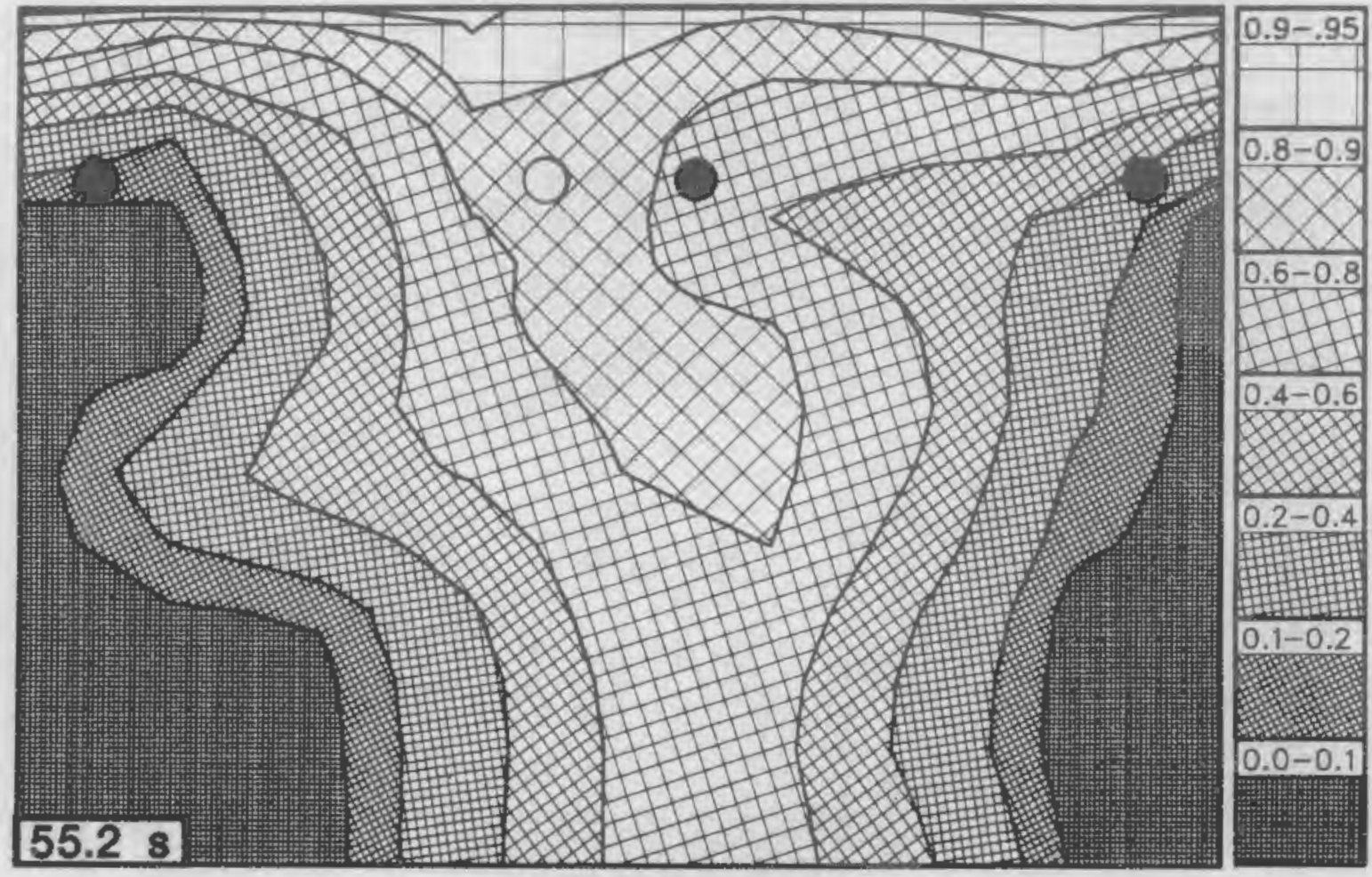

Figure B.107. Downcomer void fraction contour at $55.2 \mathrm{~s}$ 


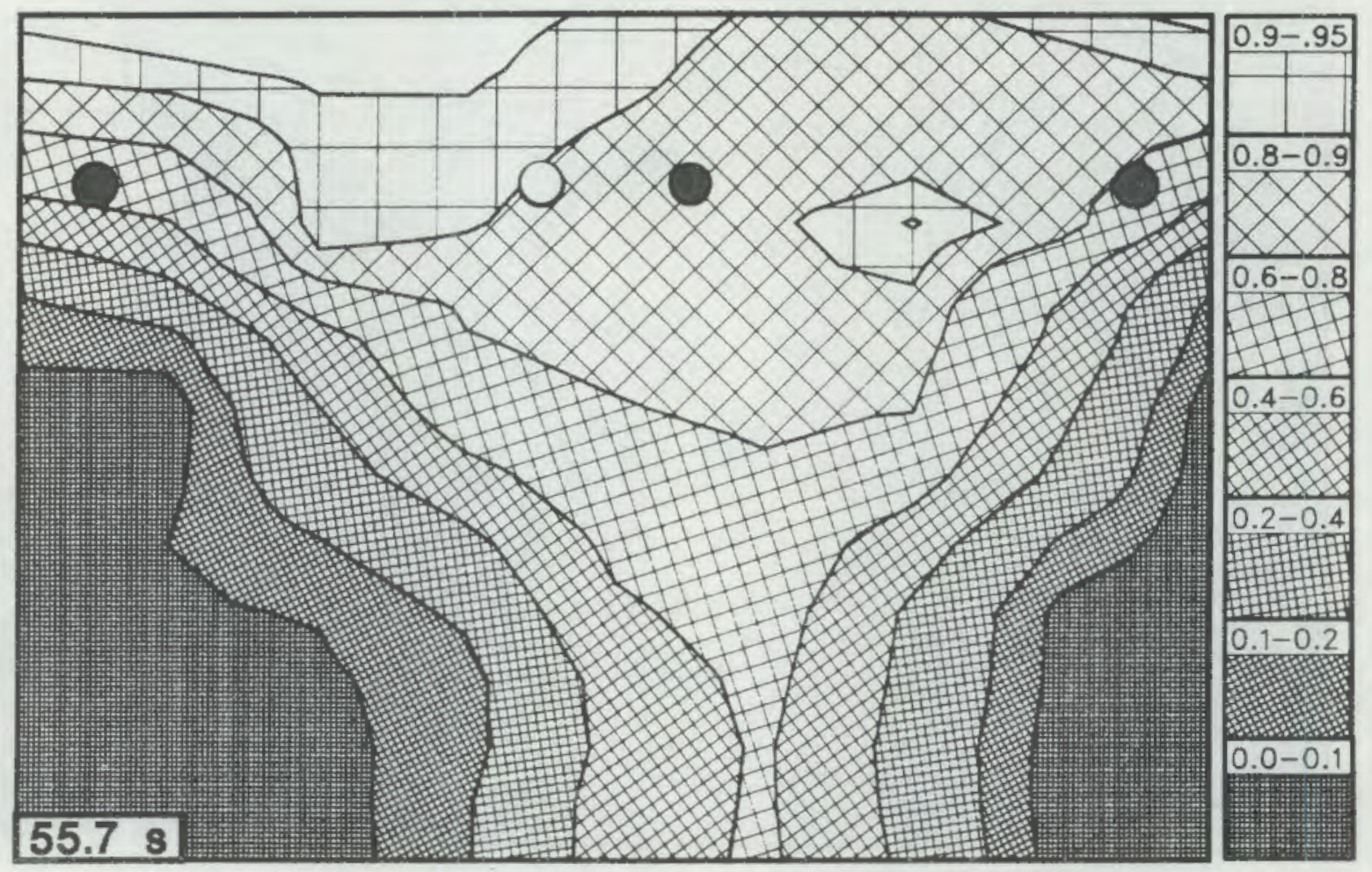

Figure B.108. Downcomer void fraction contour at $55.7 \mathrm{~s}$

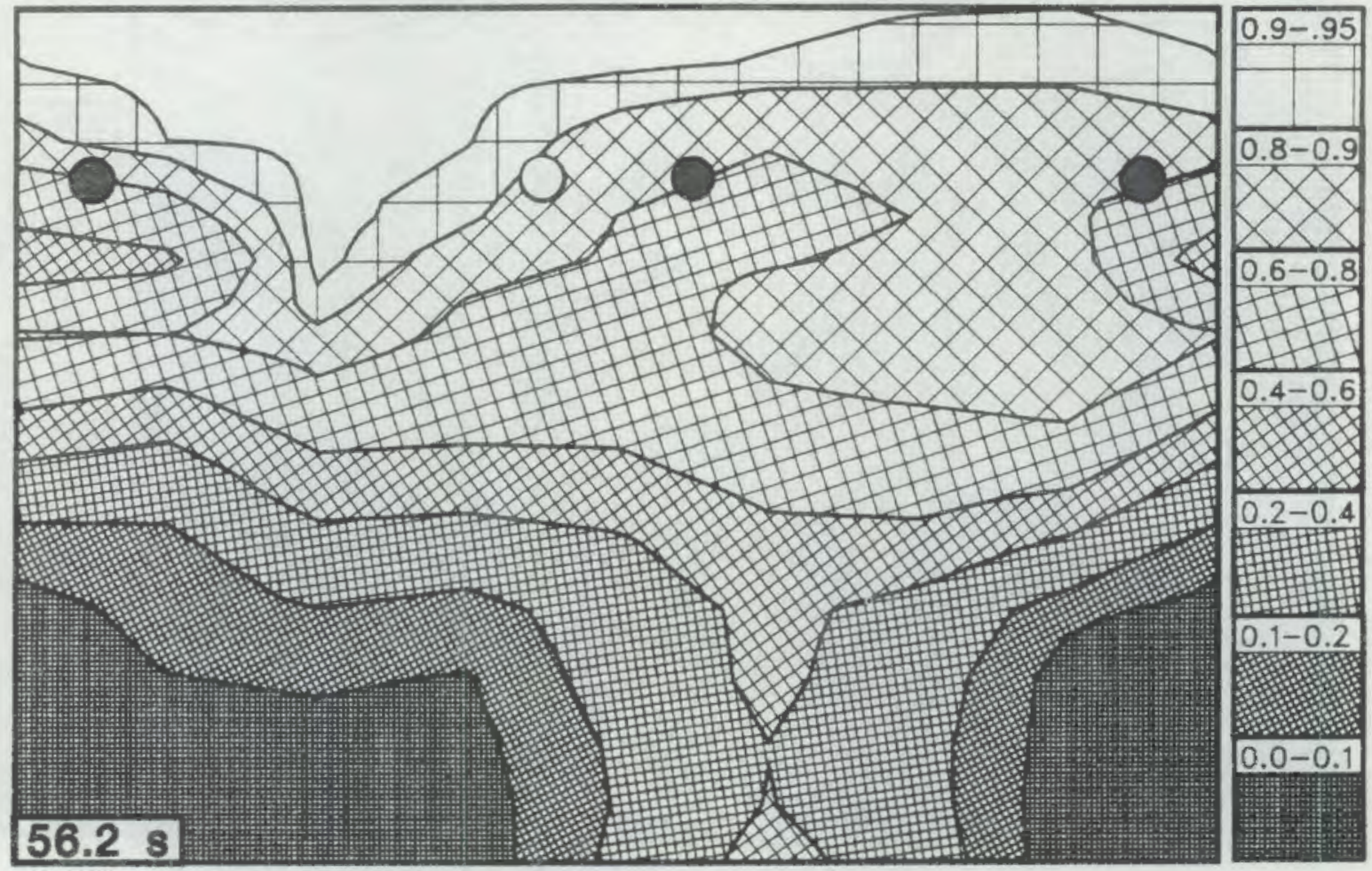

Figure B.109. Downcomer void fraction contour at $56.2 \mathrm{~s}$ 


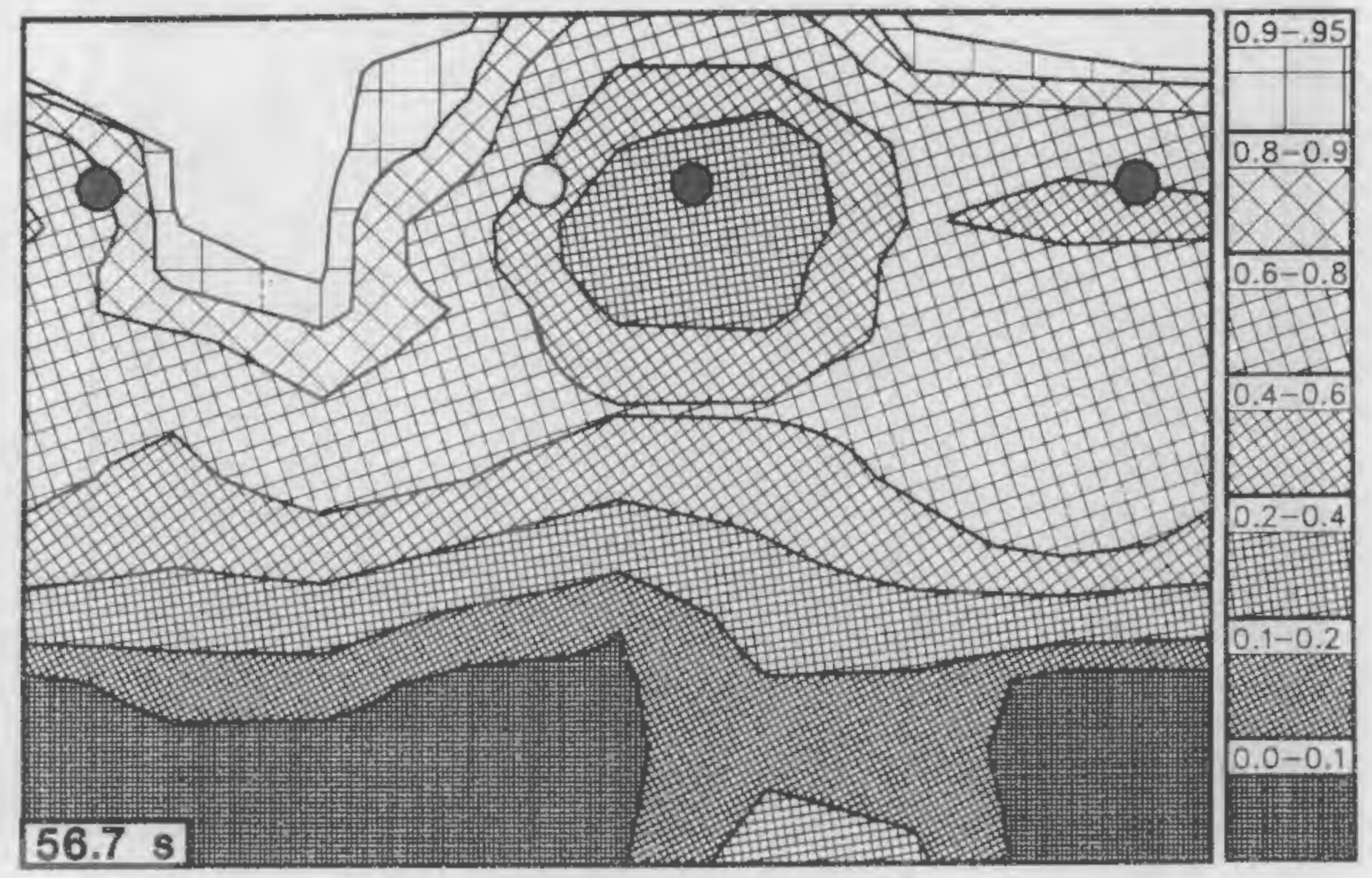

Figure B.110. Downcomer void fraction contour at $56.7 \mathrm{~s}$
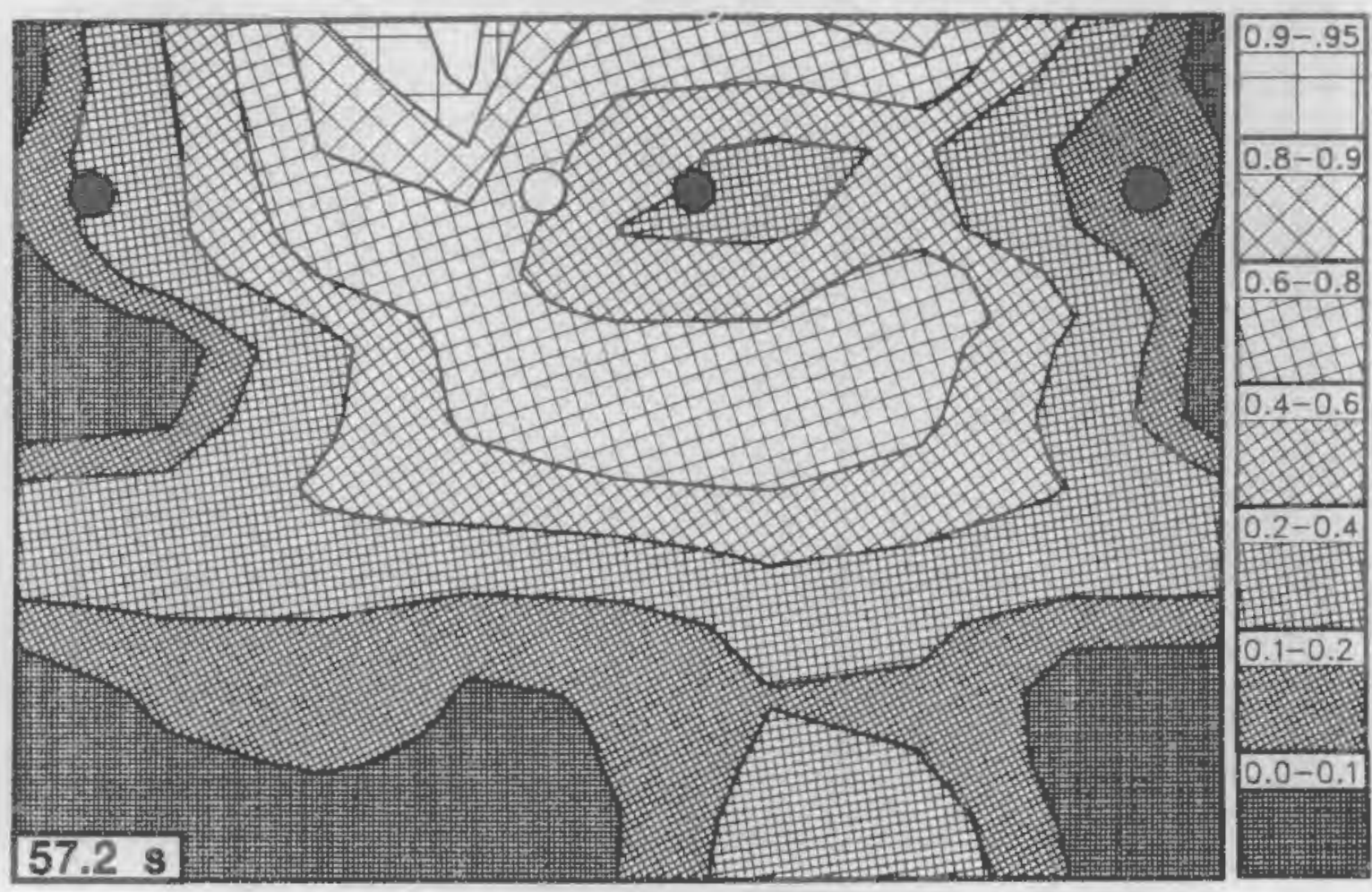

Figure B.111. Downcomer void fraction contour at $57.2 \mathrm{~s}$ 


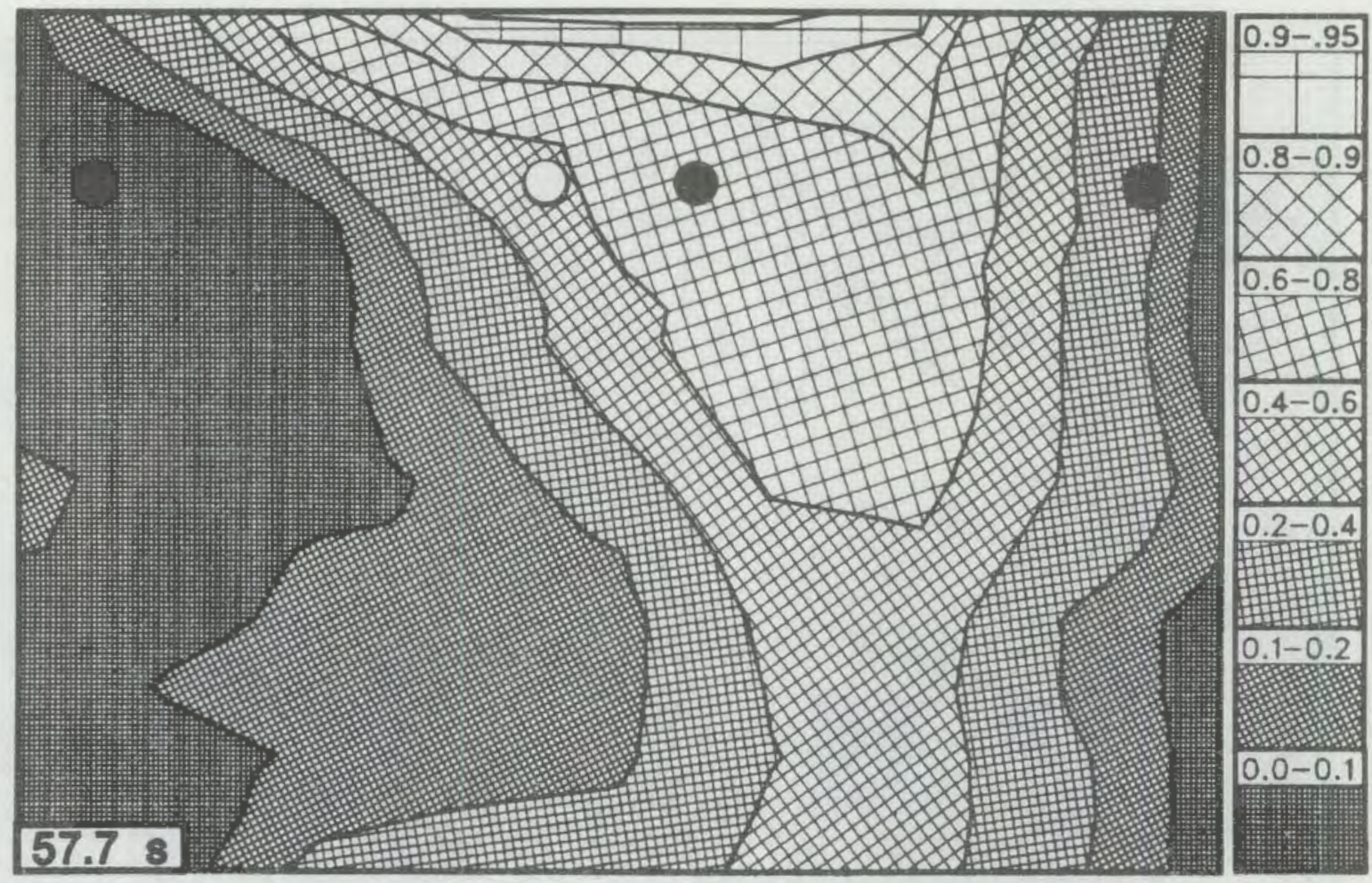

Figure B.112. Downcomer void fraction contour at $57.7 \mathrm{~s}$
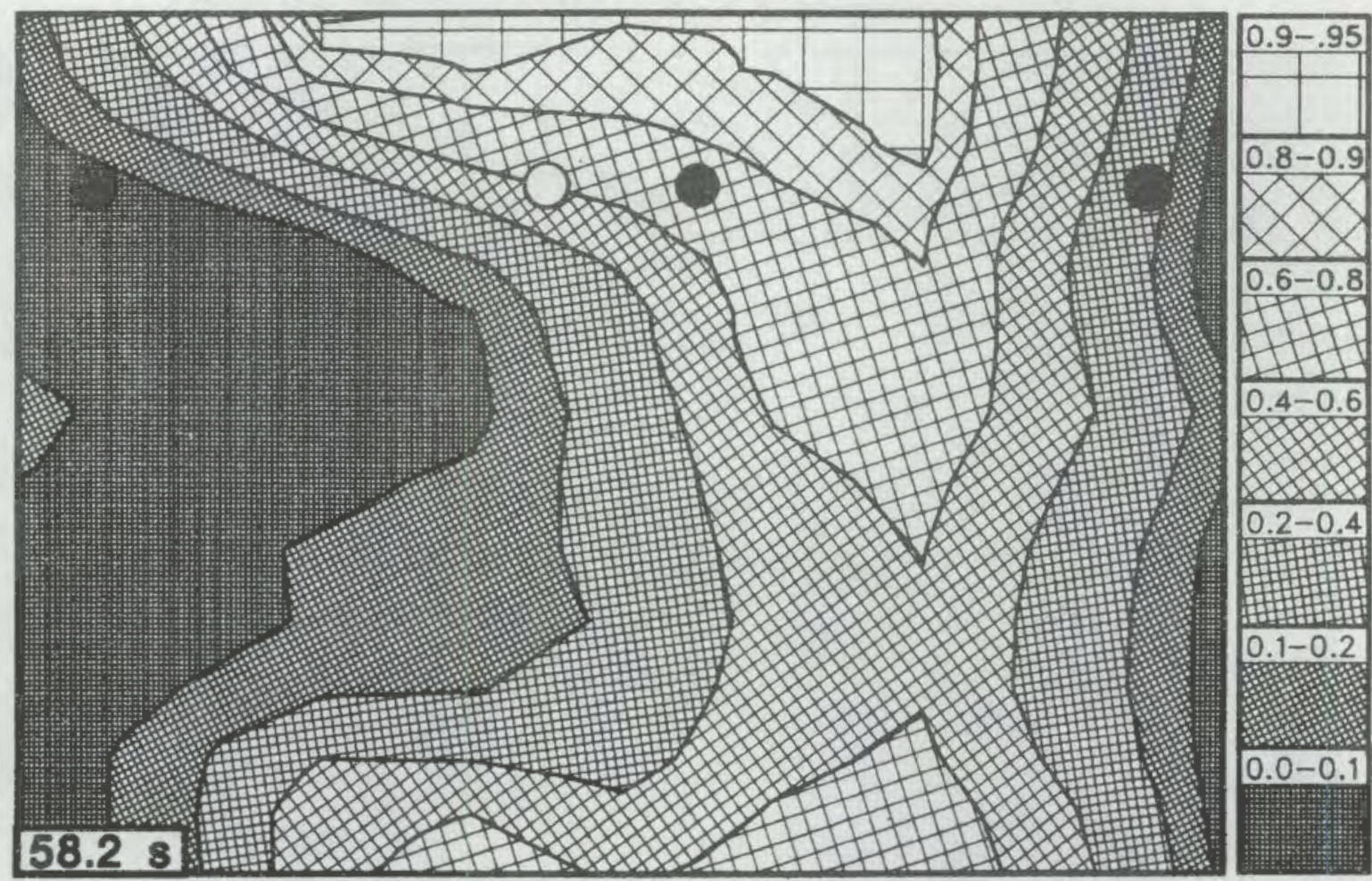

Figure B.113. Downcomer void fraction contour at $58.2 \mathrm{~s}$ 


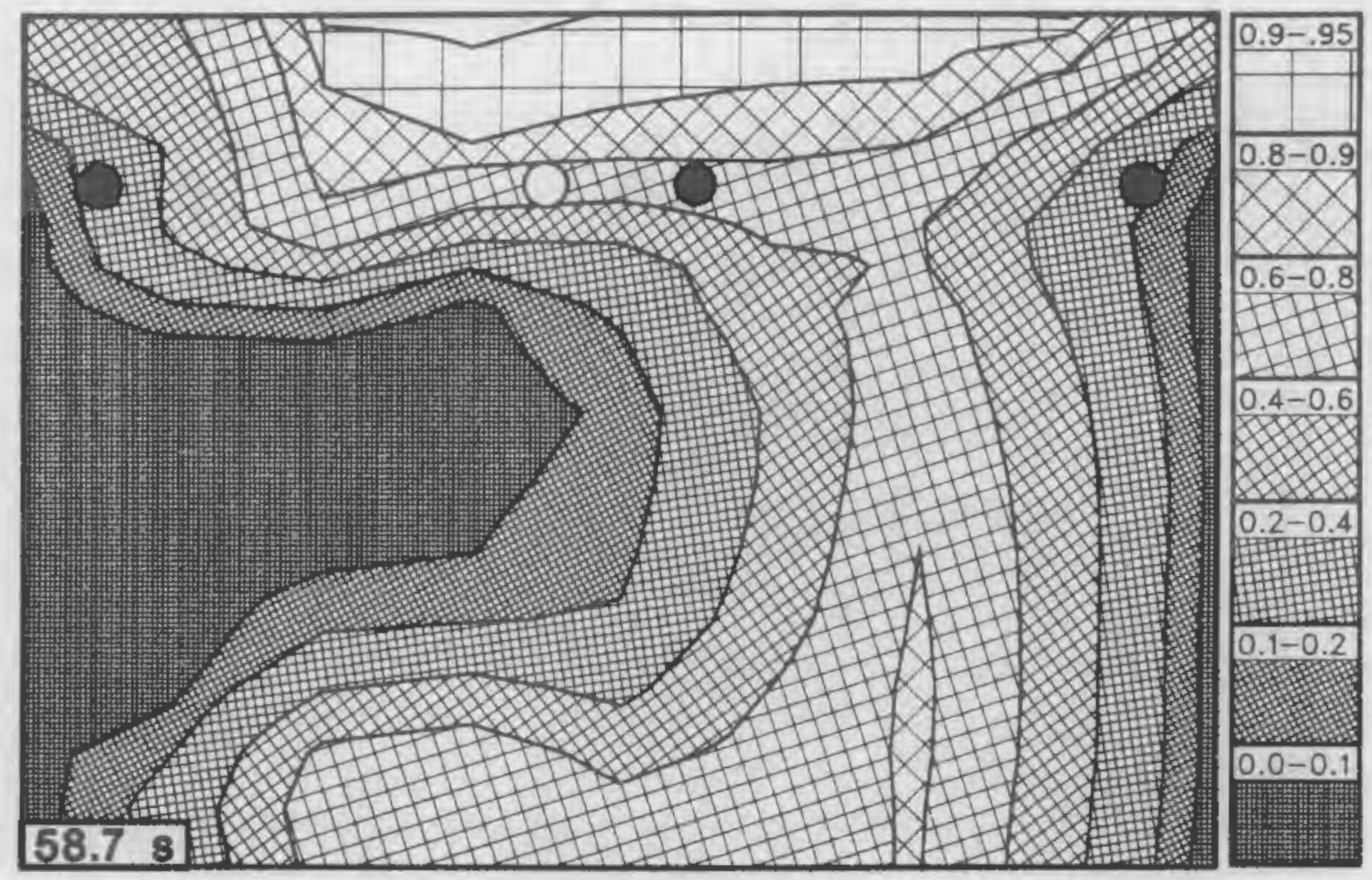

Figure B.114. Downcomer void fraction contour at $58.7 \mathrm{~s}$

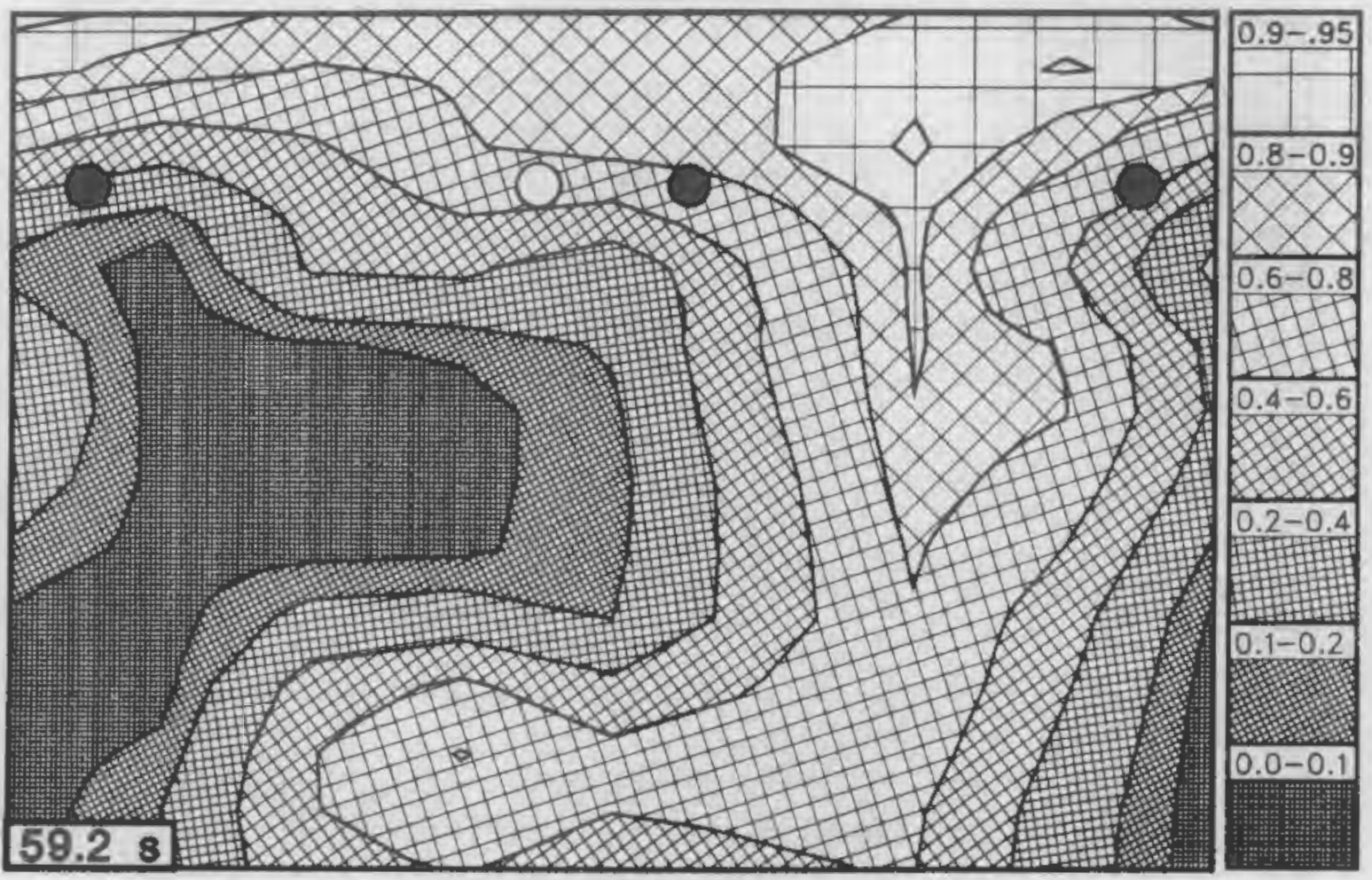

Figure B.115. Downcomer void fraction contour at $59.2 \mathrm{~s}$ 


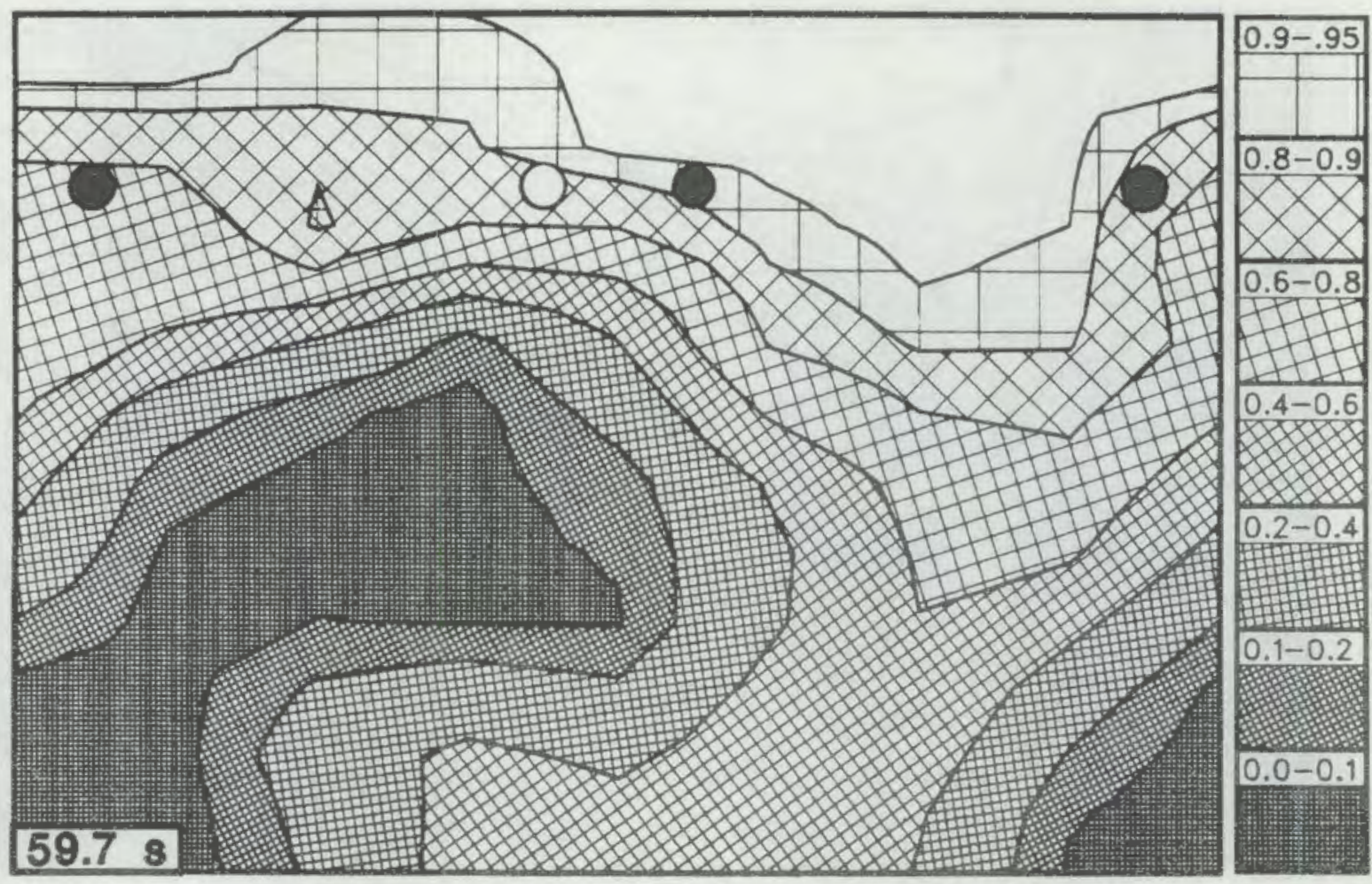

Figure B.116. Downcomer void fraction contour at $59.7 \mathrm{~s}$

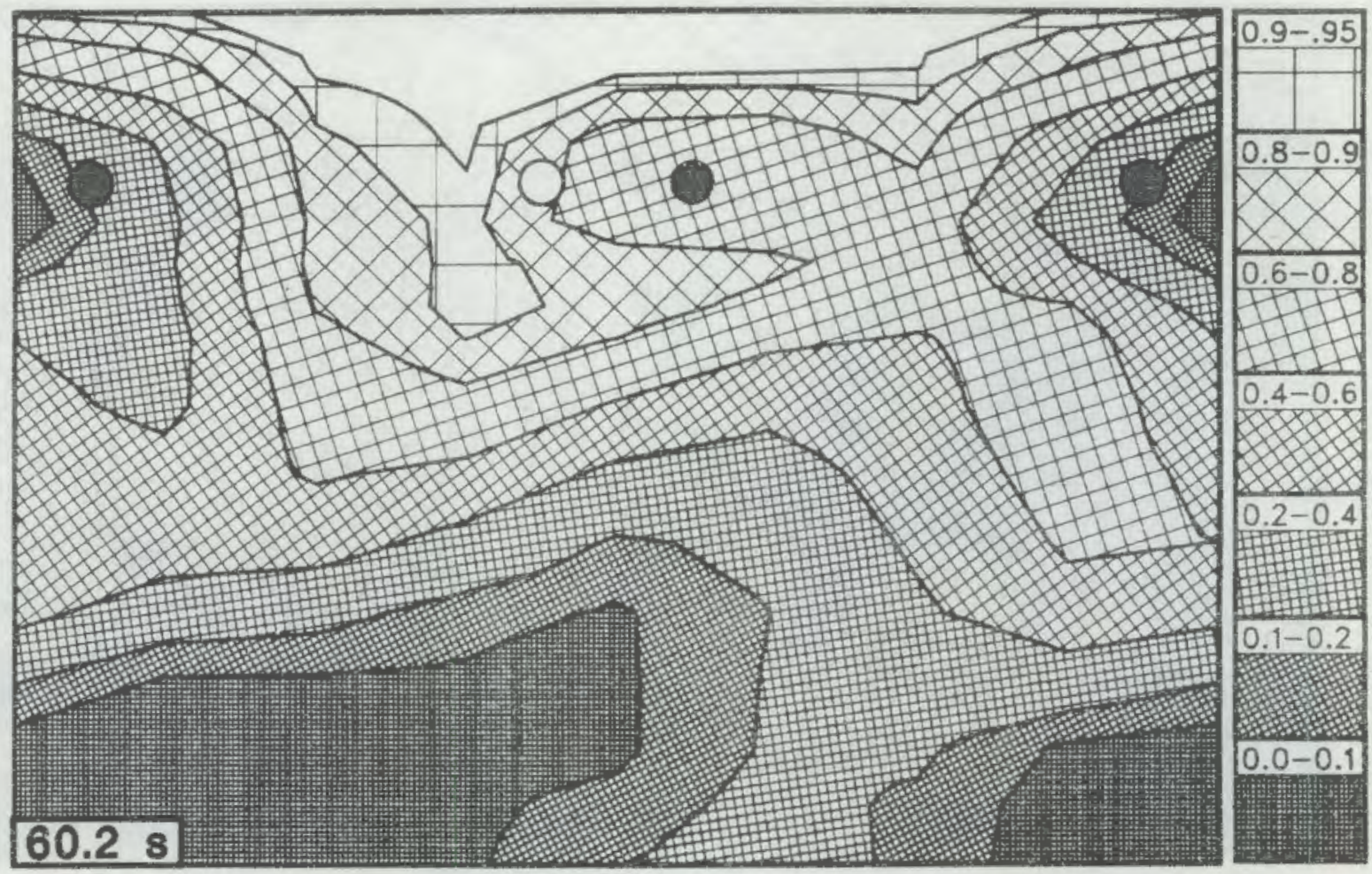

Figure B.117. Downcomer void fraction contour at $60.2 \mathrm{~s}$ 


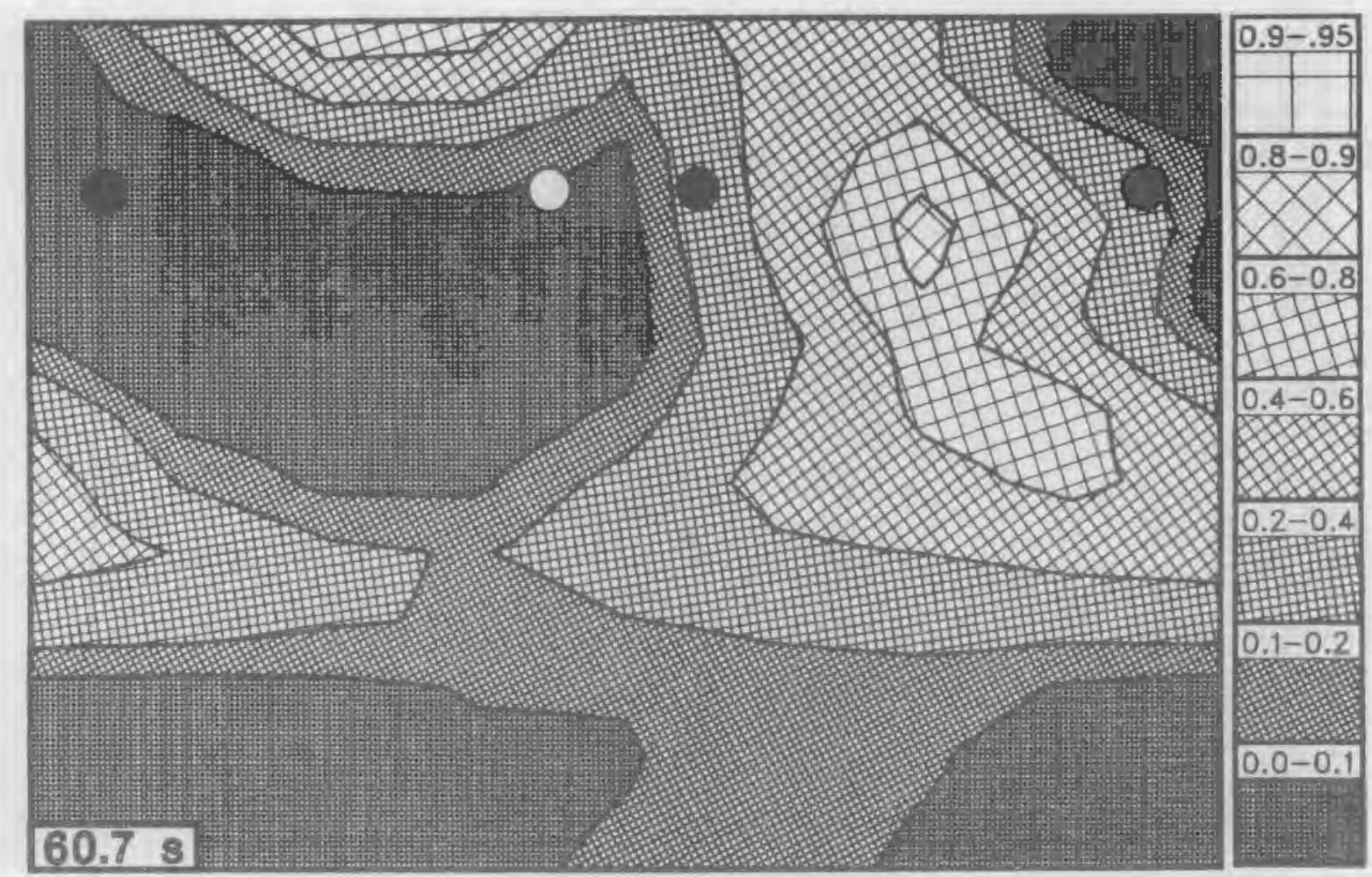

Figure B.118. Downcomer void fraction contour at $60.7 \mathrm{~s}$

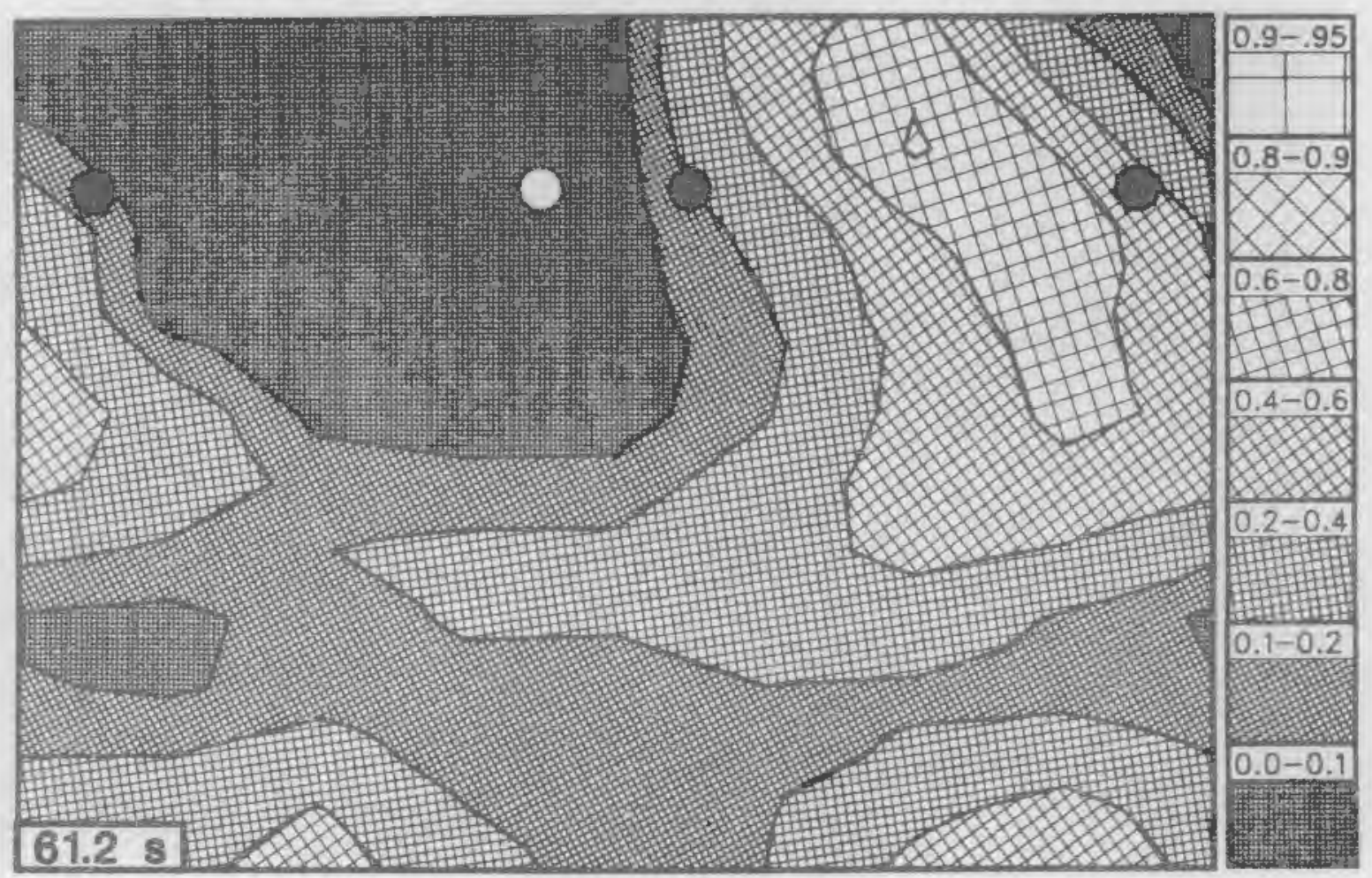

Figure B.119. Downcomer void fraction contour at $61.2 \mathrm{~s}$ 


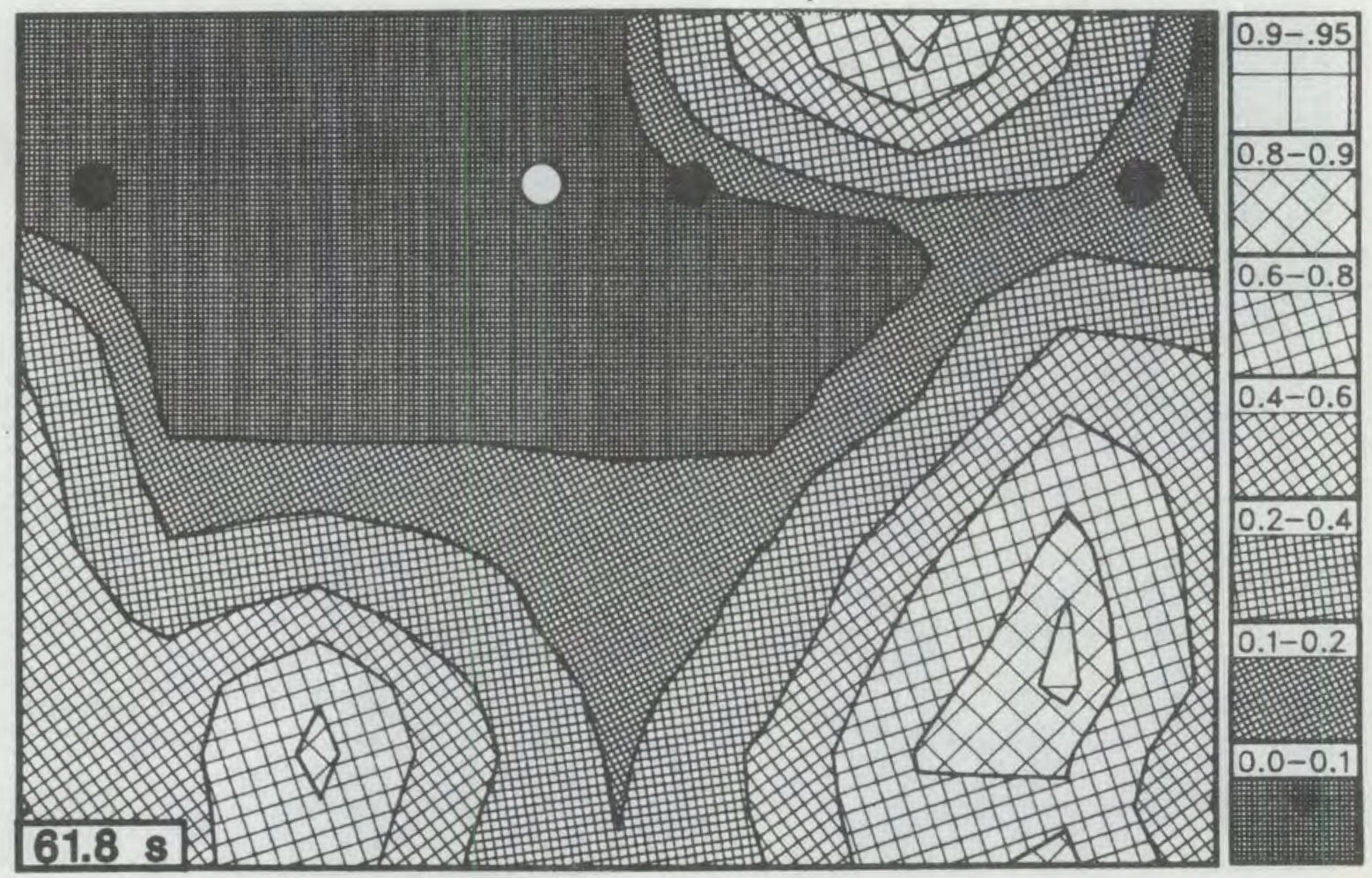

Figure B.120. Downcomer void fraction contour at $61.8 \mathrm{~s}$

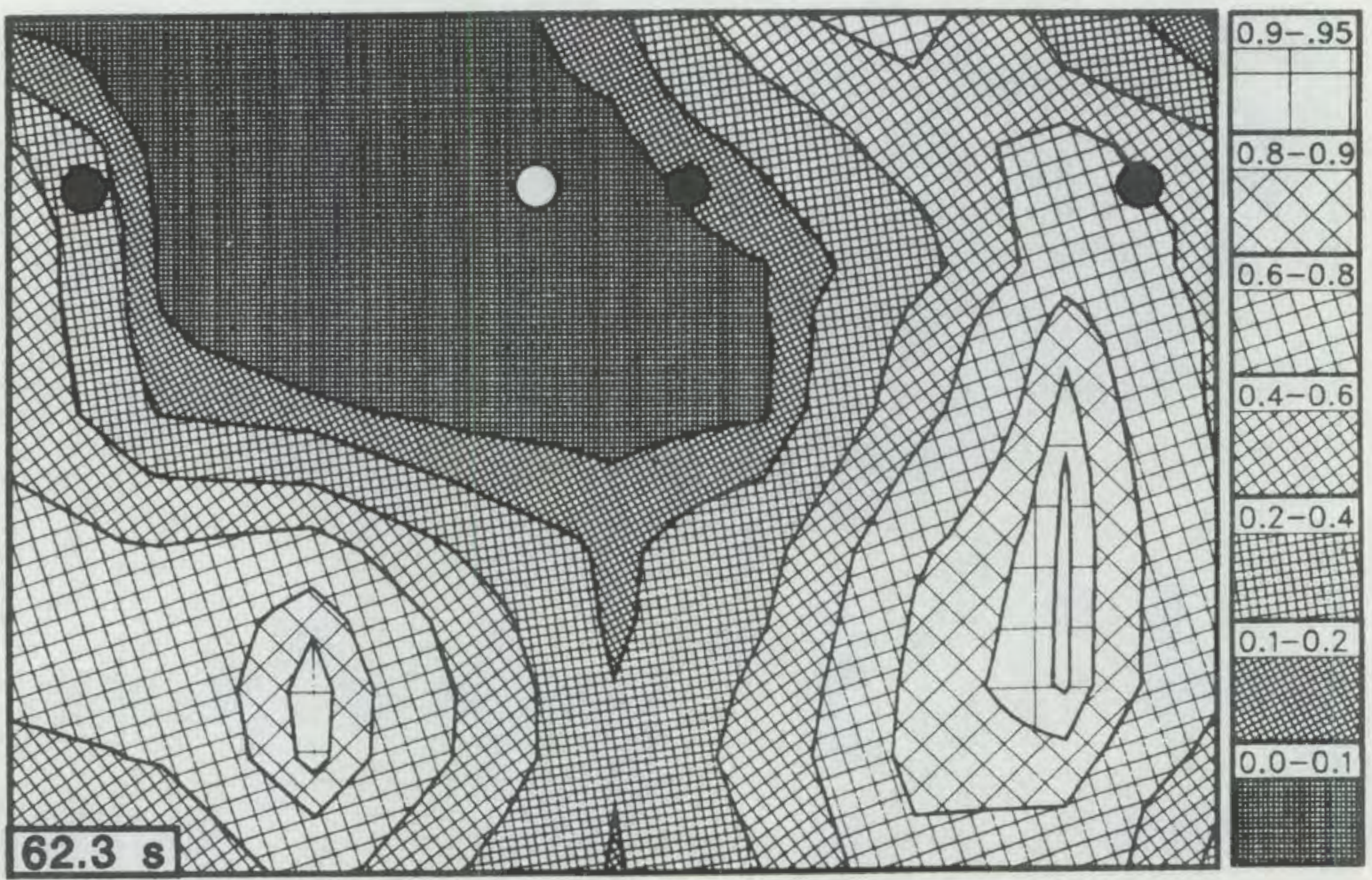

Figure B.121. Downcomer void fraction contour at $62.3 \mathrm{~s}$ 


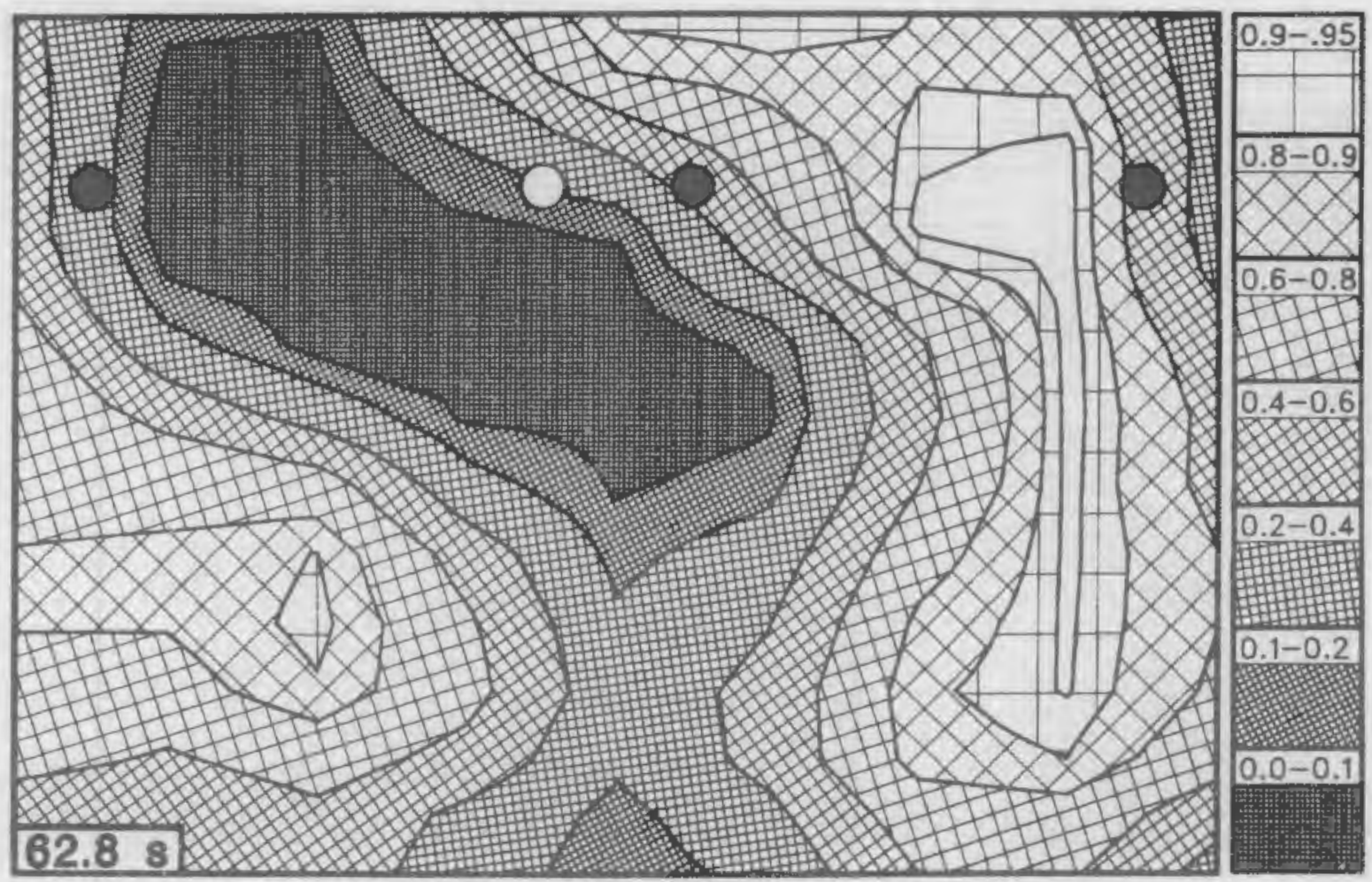

Figure B.122. Downcomer void fraction contour at $62.8 \mathrm{~s}$
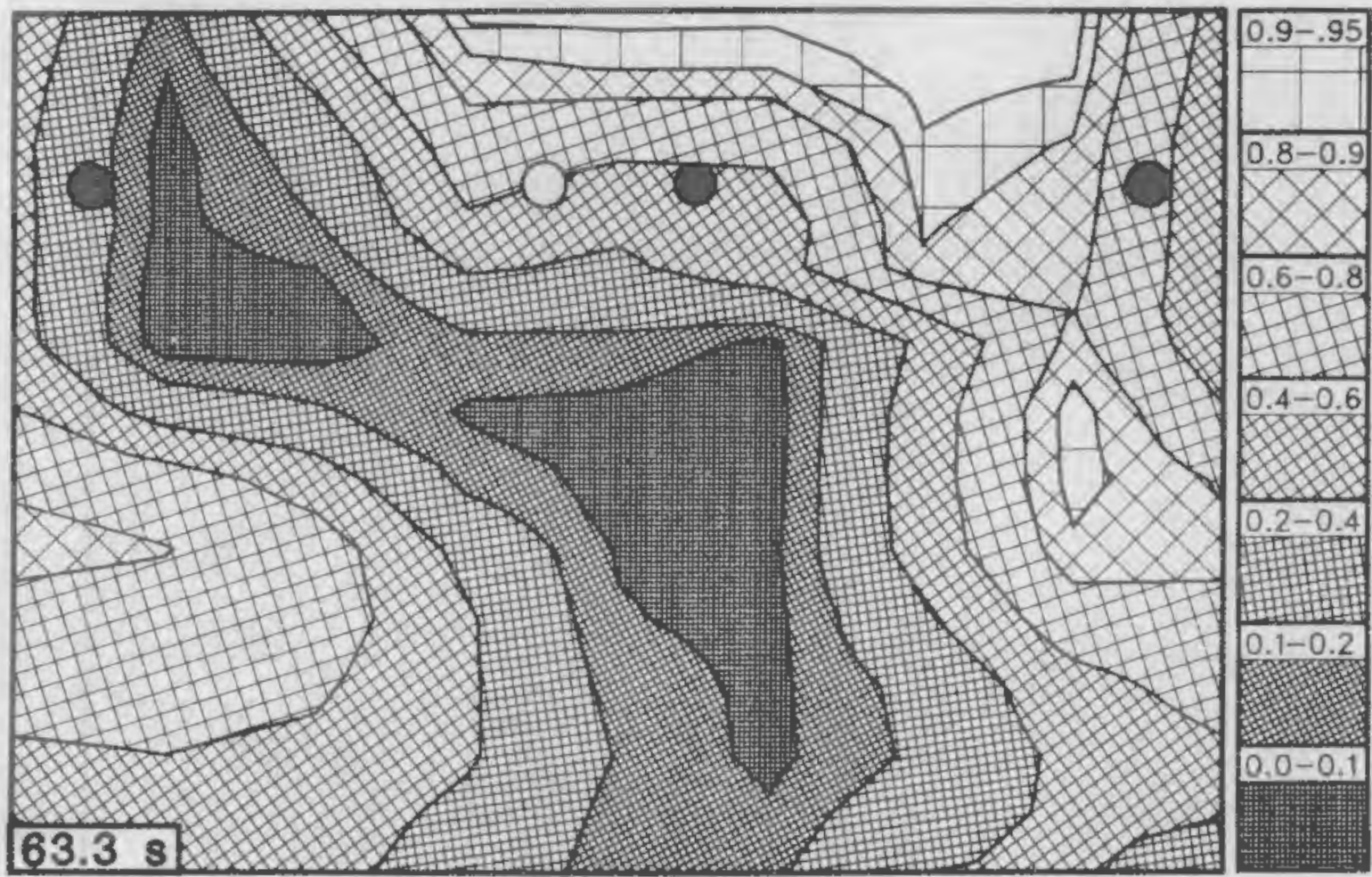

Figure B.123. Downcomer void fraction contour at $63.3 \mathrm{~s}$ 


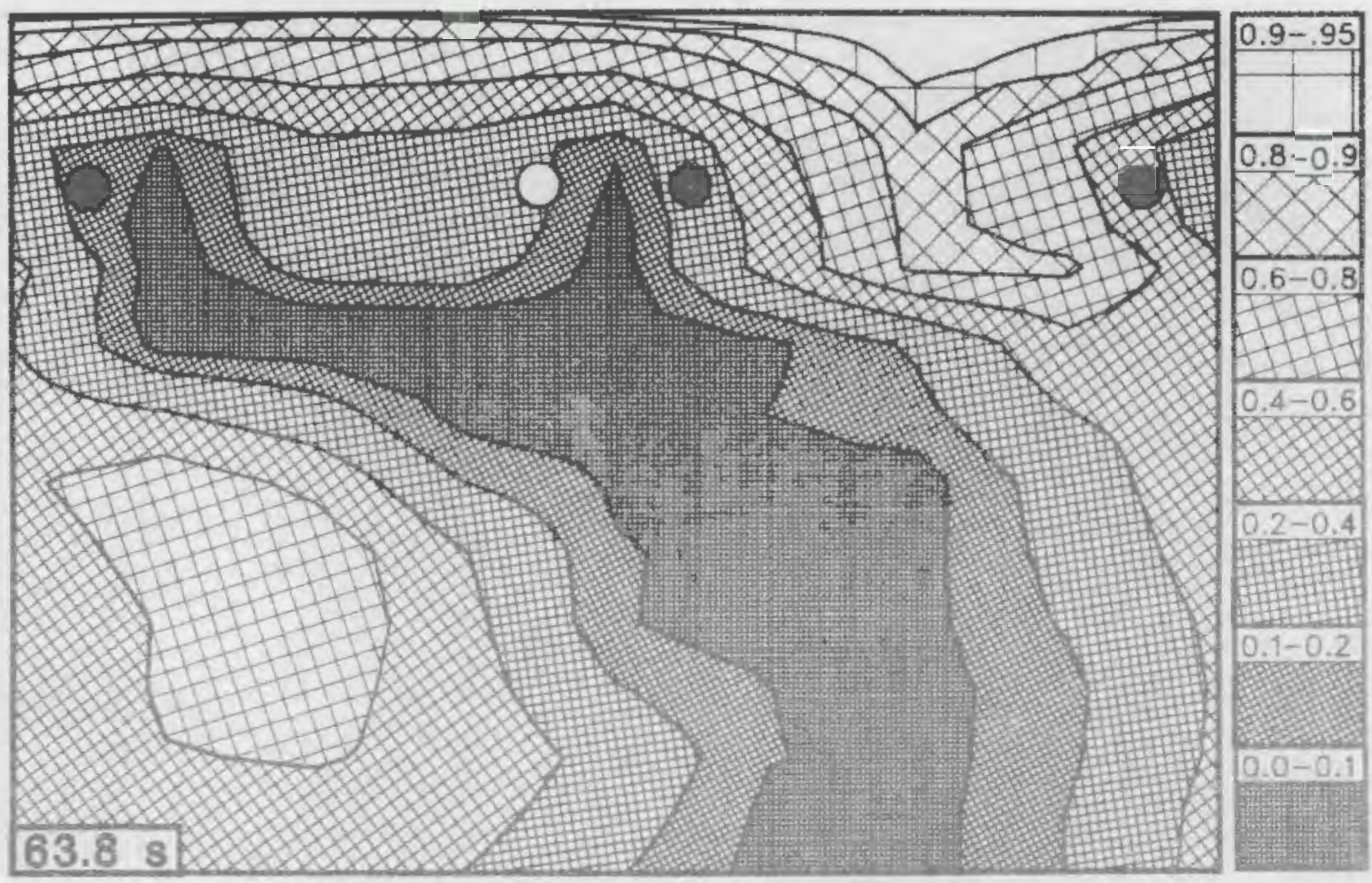

Figure B.124. Downcomer void fraction contour at $63.8 \mathrm{~s}$

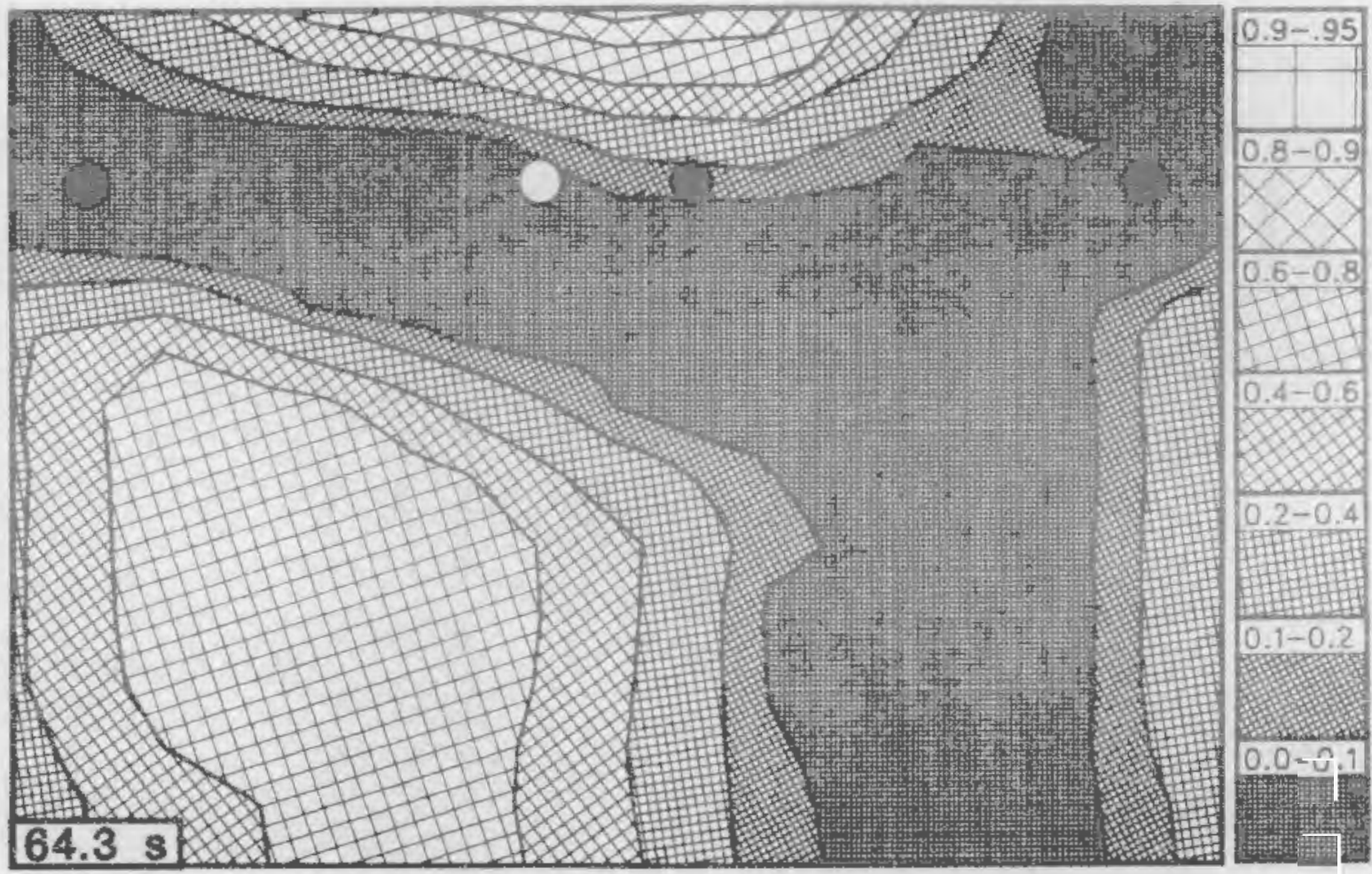

Figure B.125. Downcomer void fraction contour at $64.3 \mathrm{~s}$ 


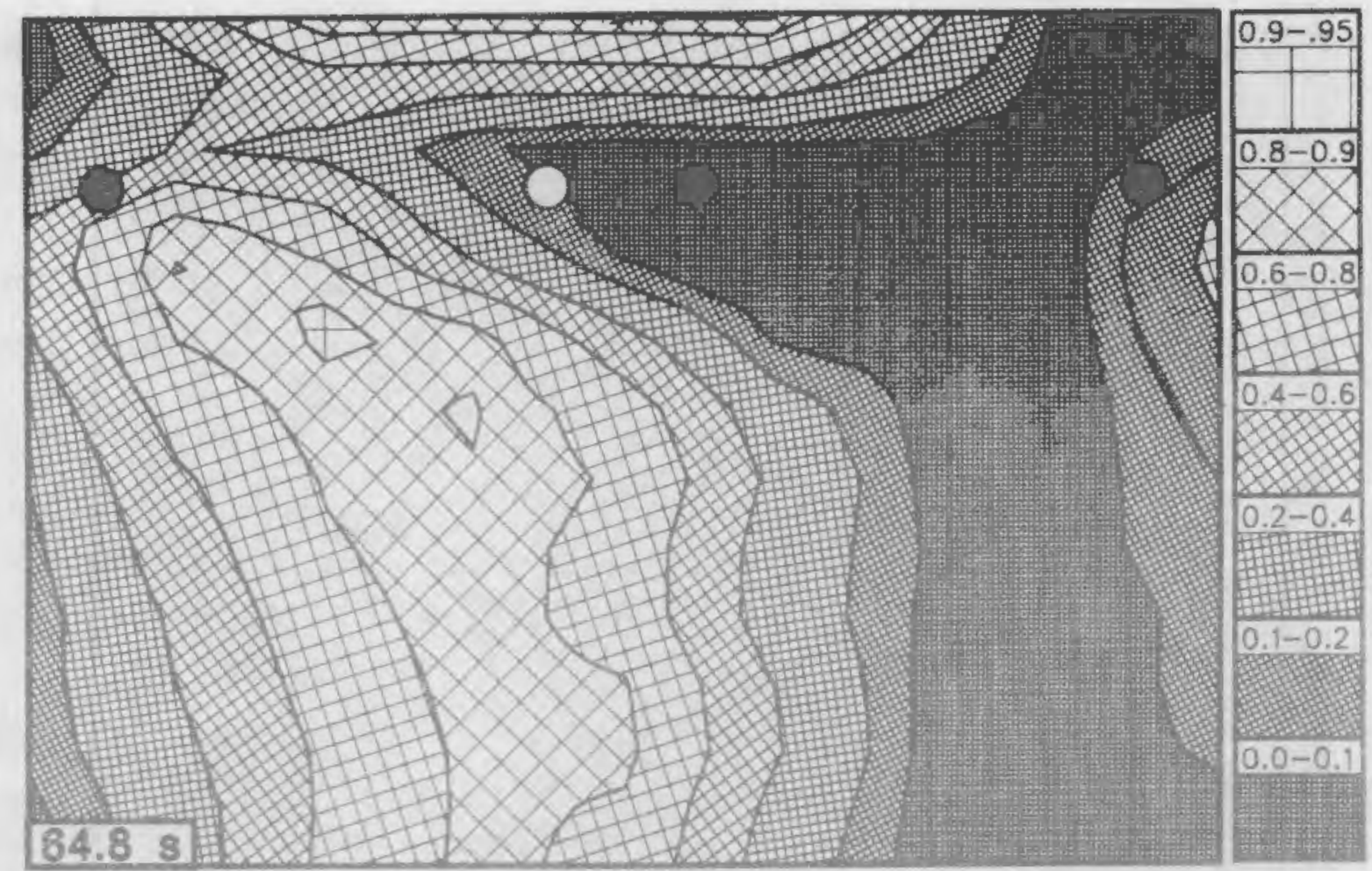

Figure B.126. Downcomer void fraction contour at $64.8 \mathrm{~s}$

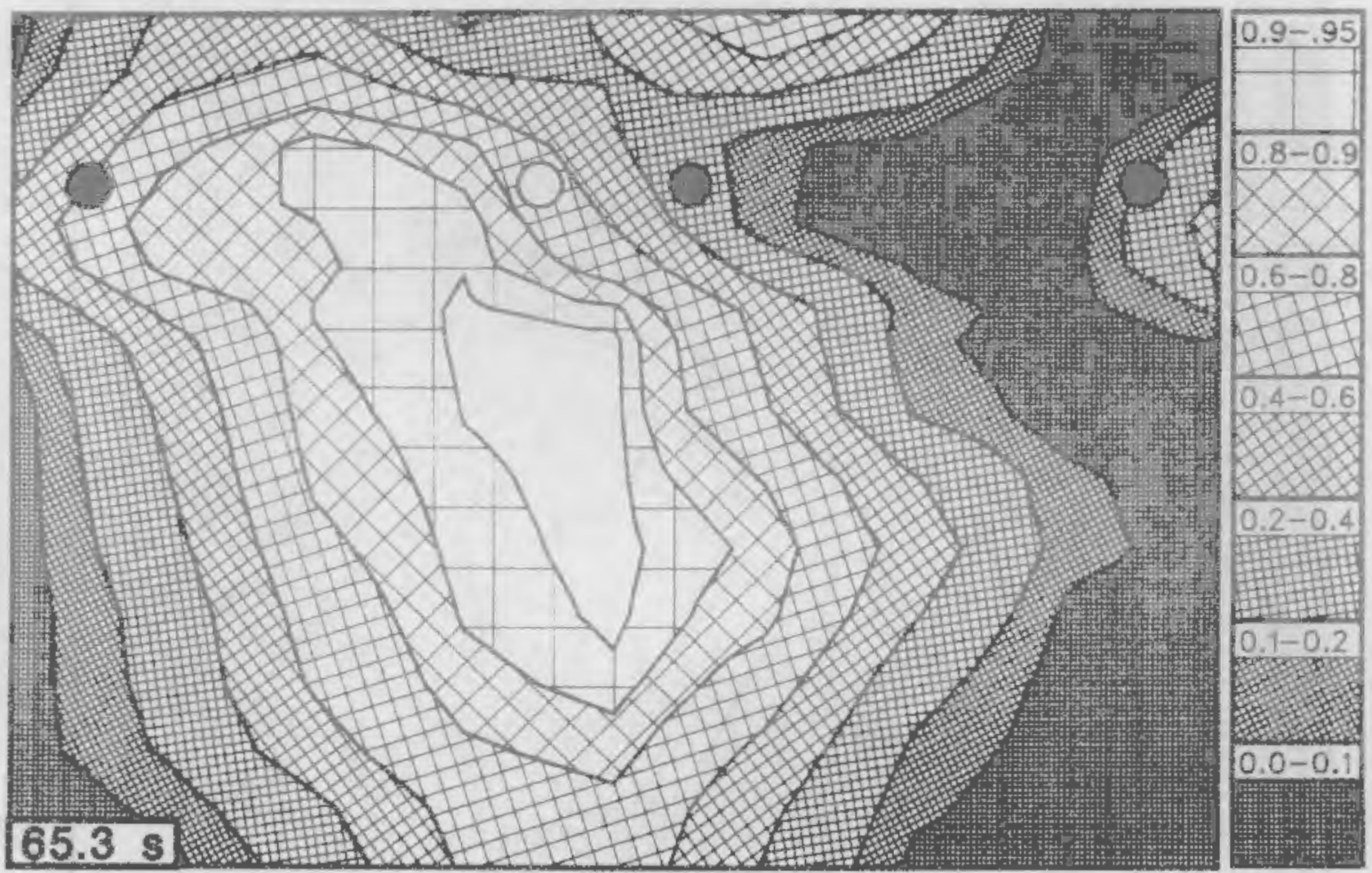

Figure B.127. Downcomer void fraction contour at $65.3 \mathrm{~s}$ 


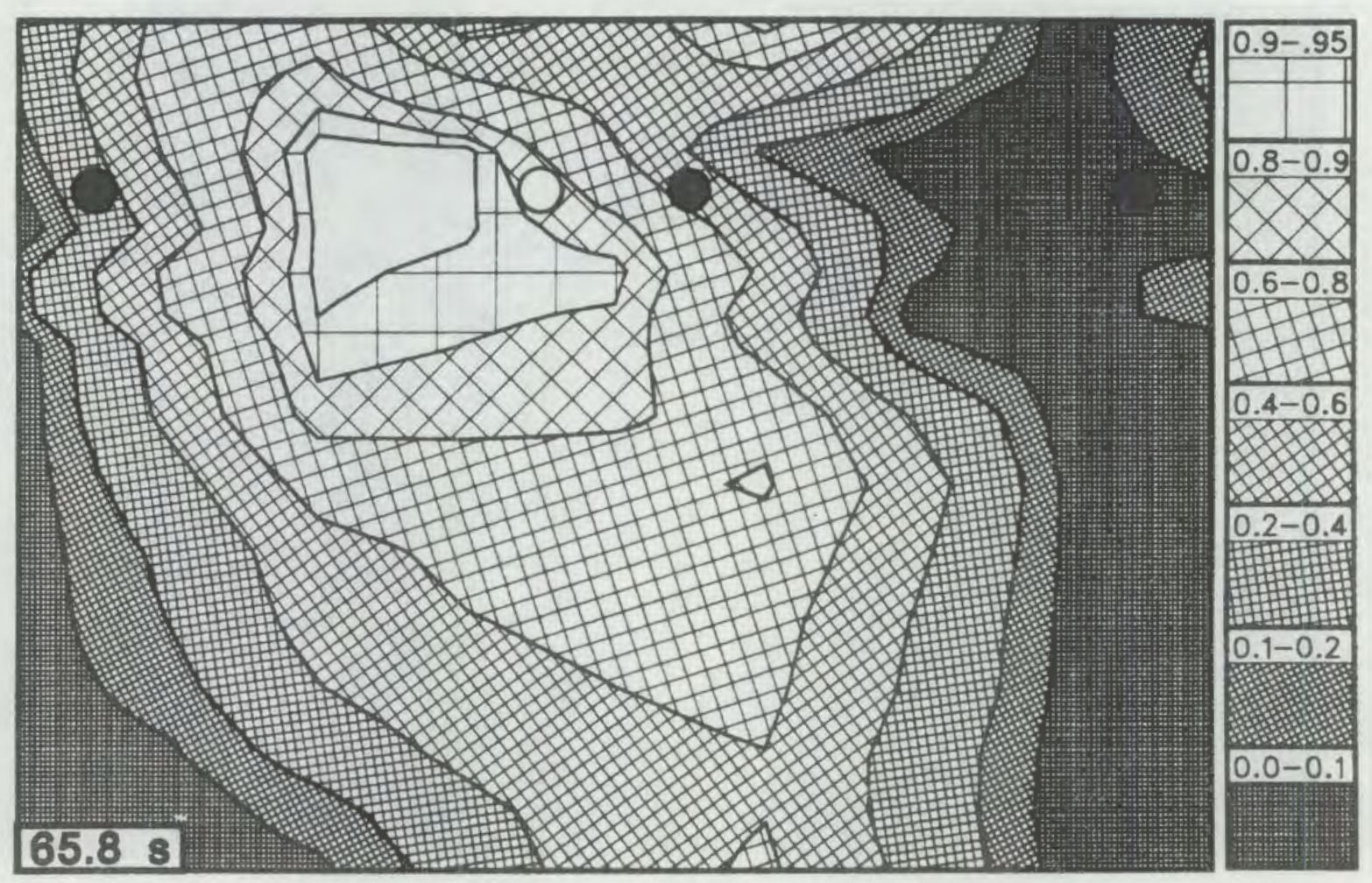

Figure B.128. Downcomer void fraction contour at $65.8 \mathrm{~s}$

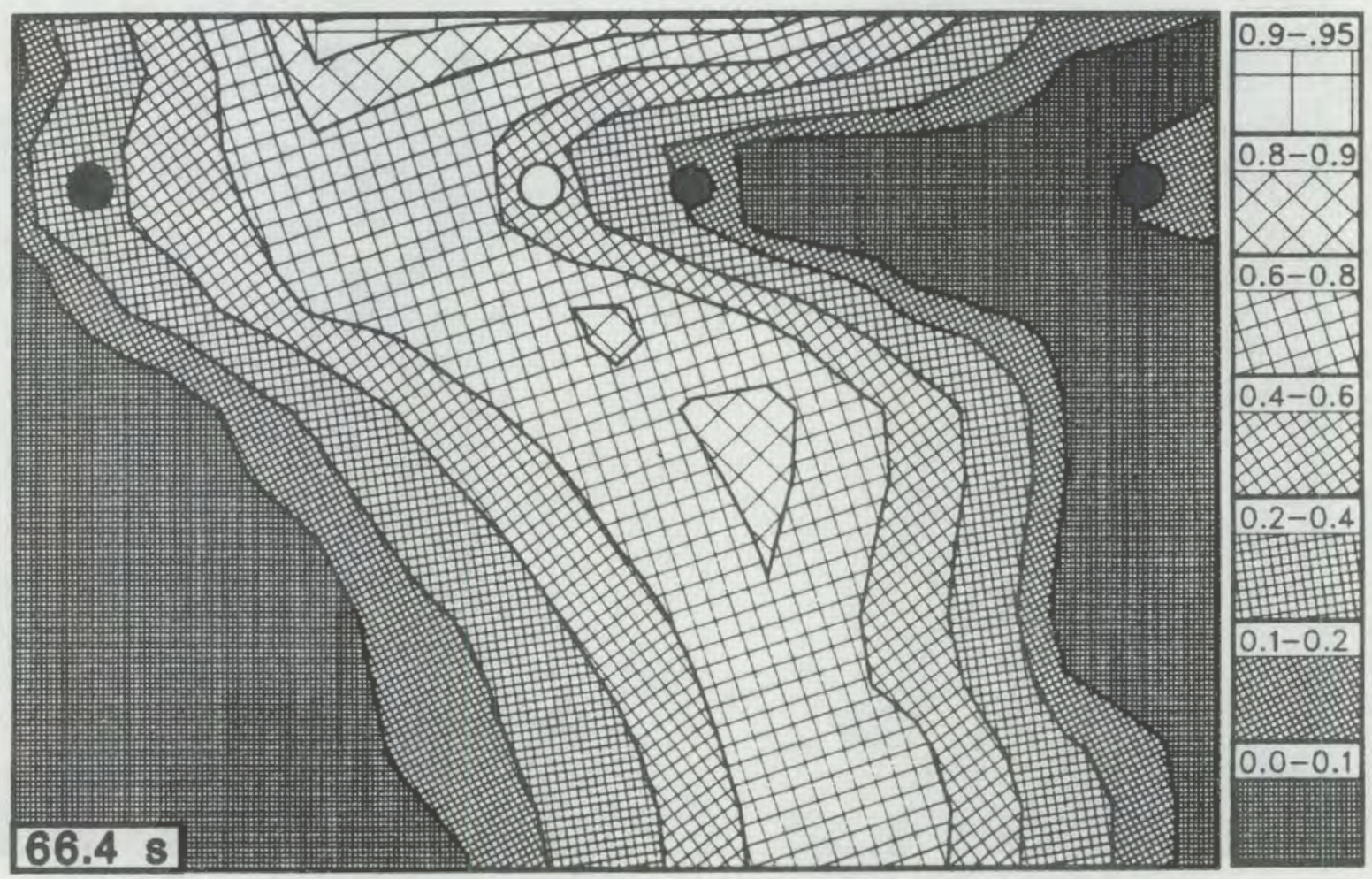

Figure B.129. Downcomer void fraction contour at $66.4 \mathrm{~s}$ 


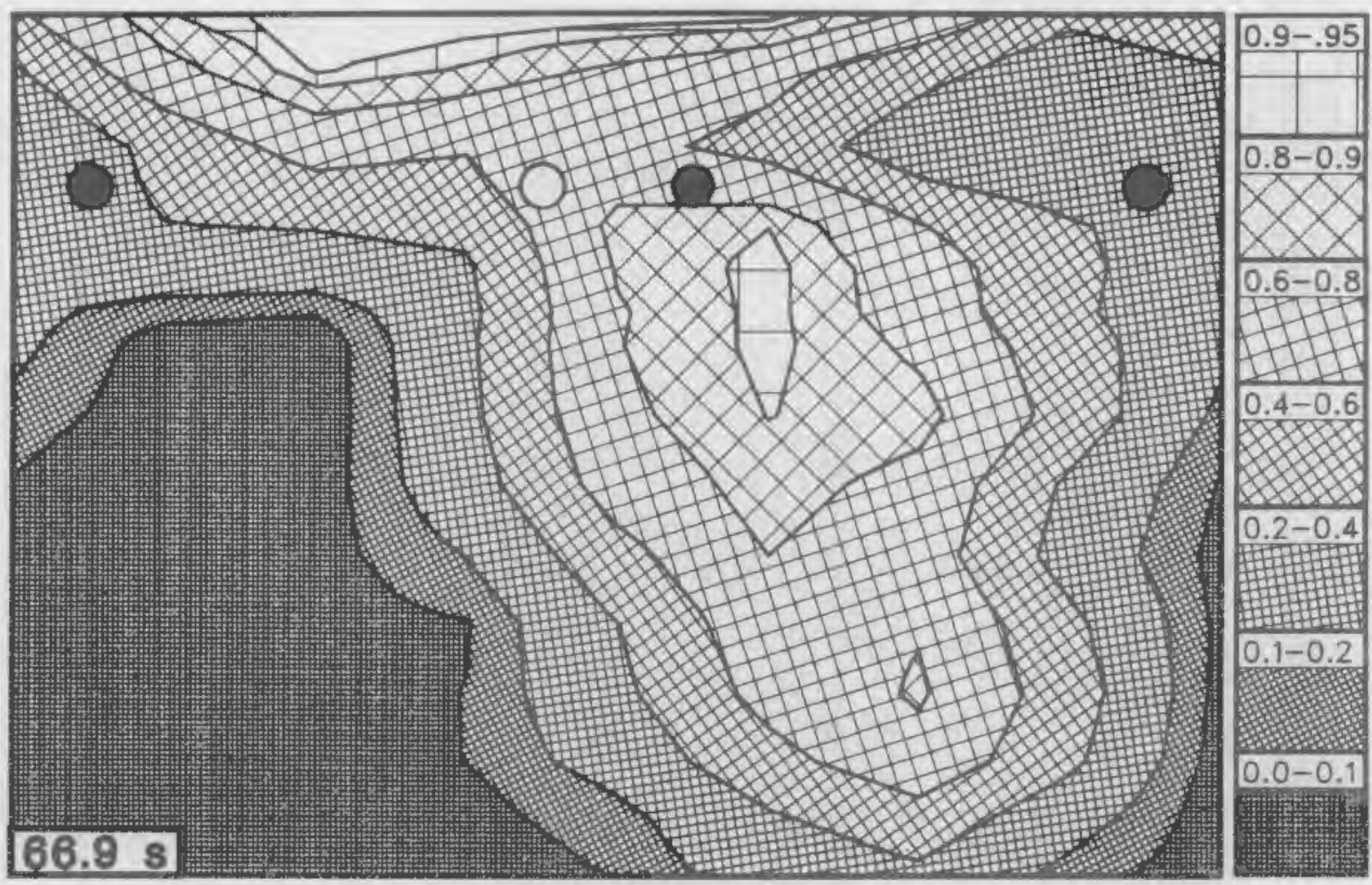

Figure B.130. Downcomer void fraction contour at $66.9 \mathrm{~s}$
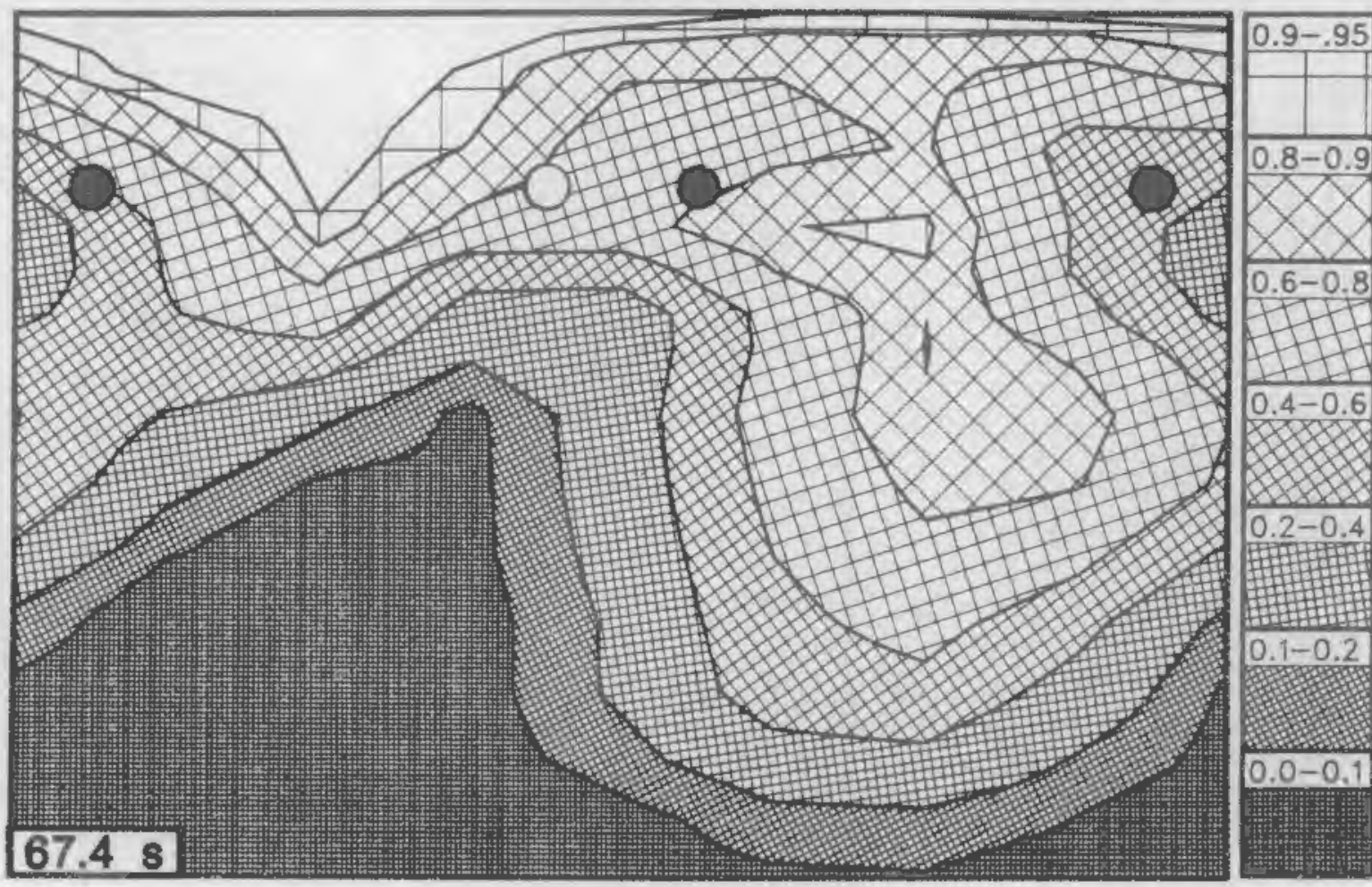

Figure B.131. Dọwncomer void fraction contour at $67.4 \mathrm{~s}$ 


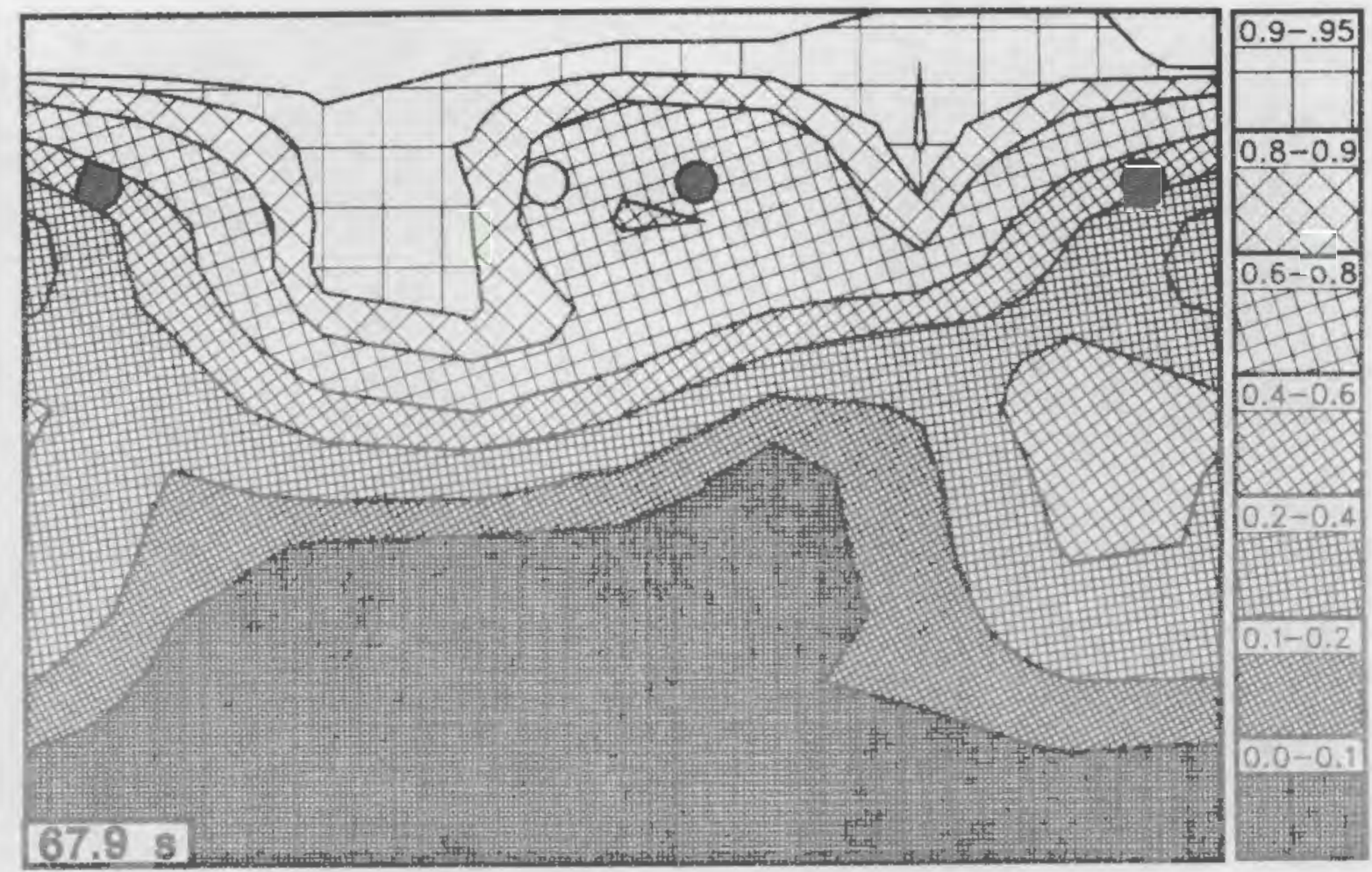

Figure B.132. Downcomer void fraction contour at $67.9 \mathrm{~s}$

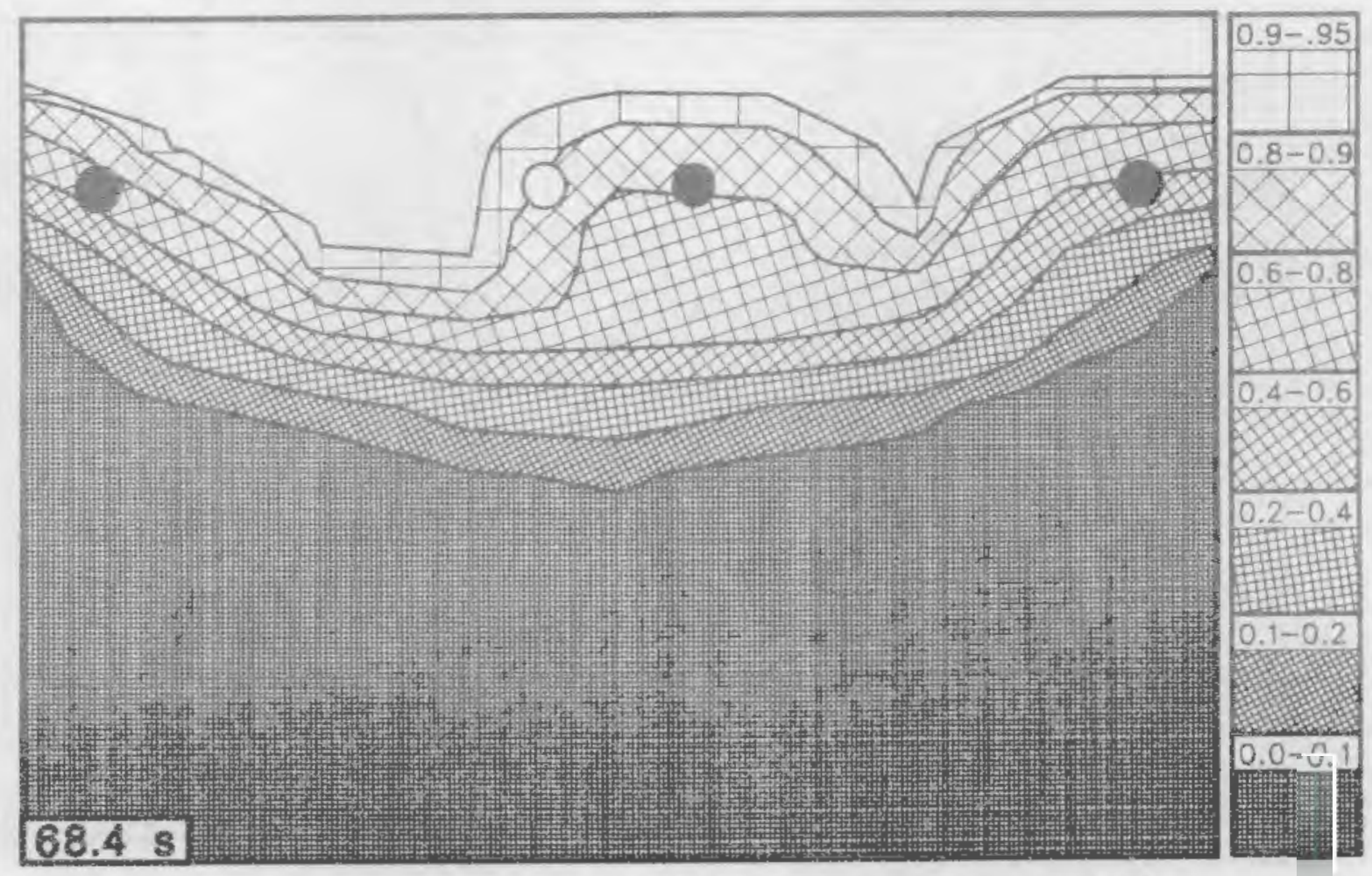

Figure B.133. Downcomer void fraction contour at $68.4 \mathrm{~s}$ 


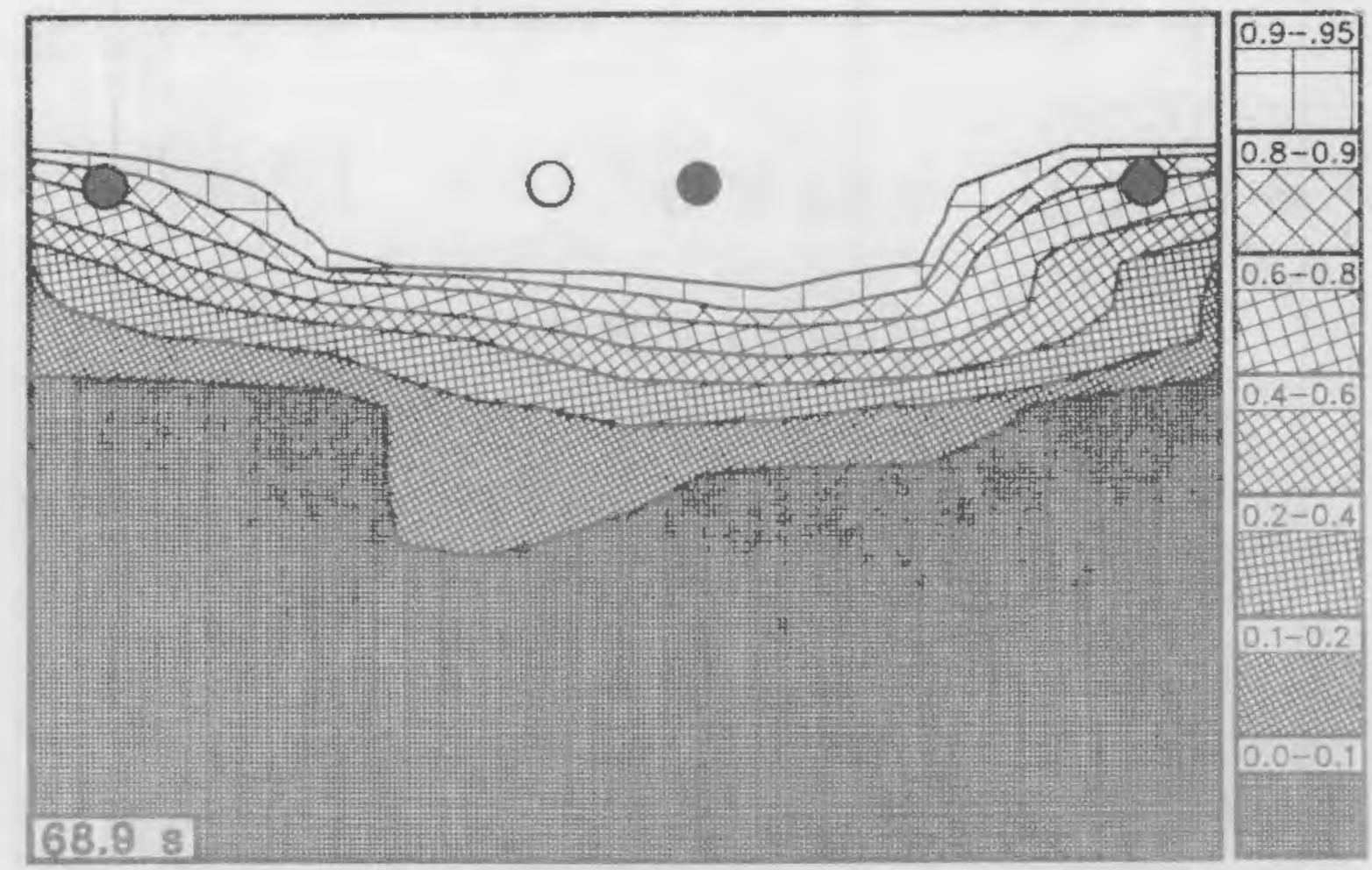

Figure B.134. Downcomer void fraction contour at $68.9 \mathrm{~s}$

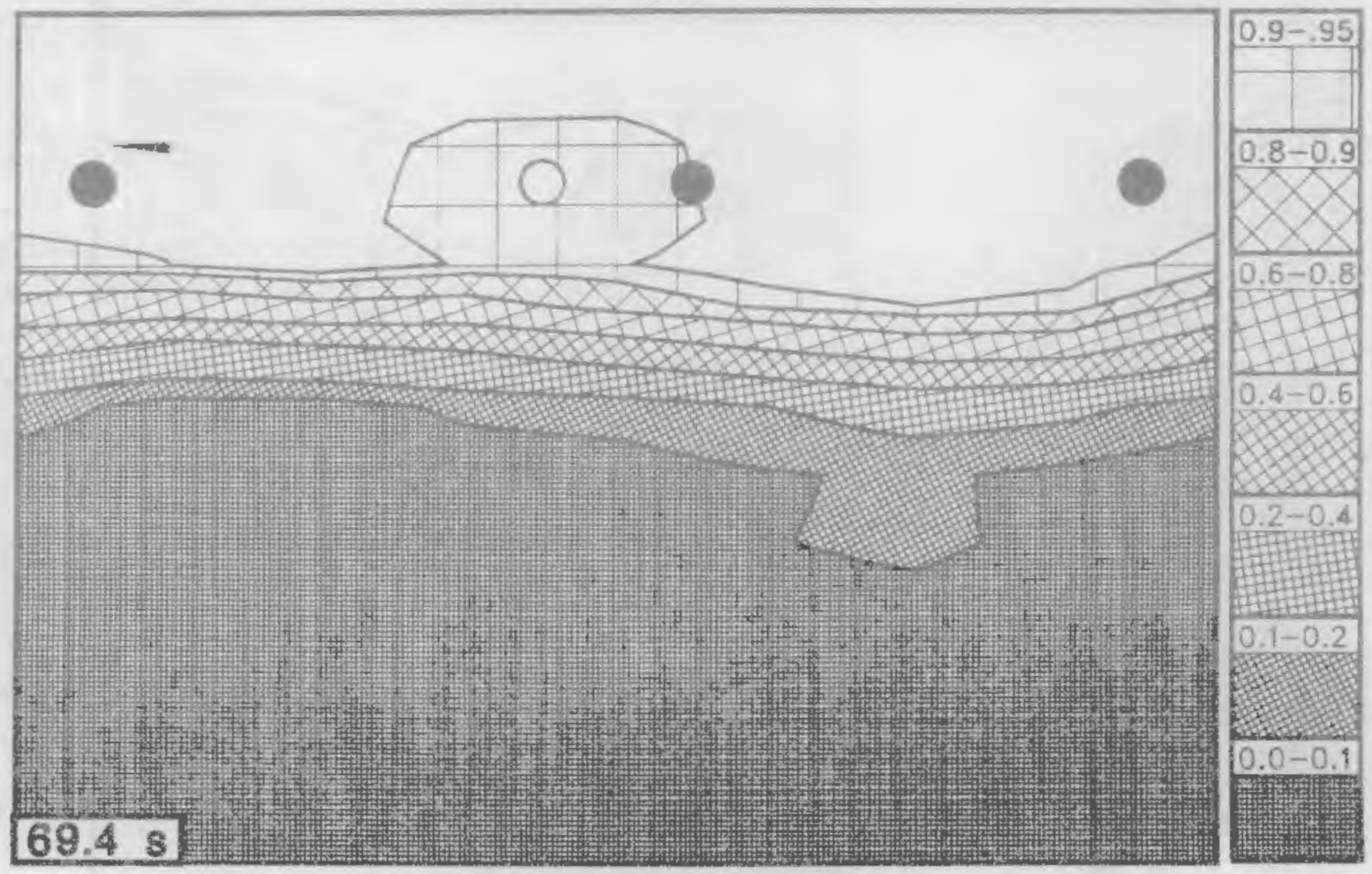

Figure B.135. Downcomer void fraction contour at $69.4 \mathrm{~s}$ 


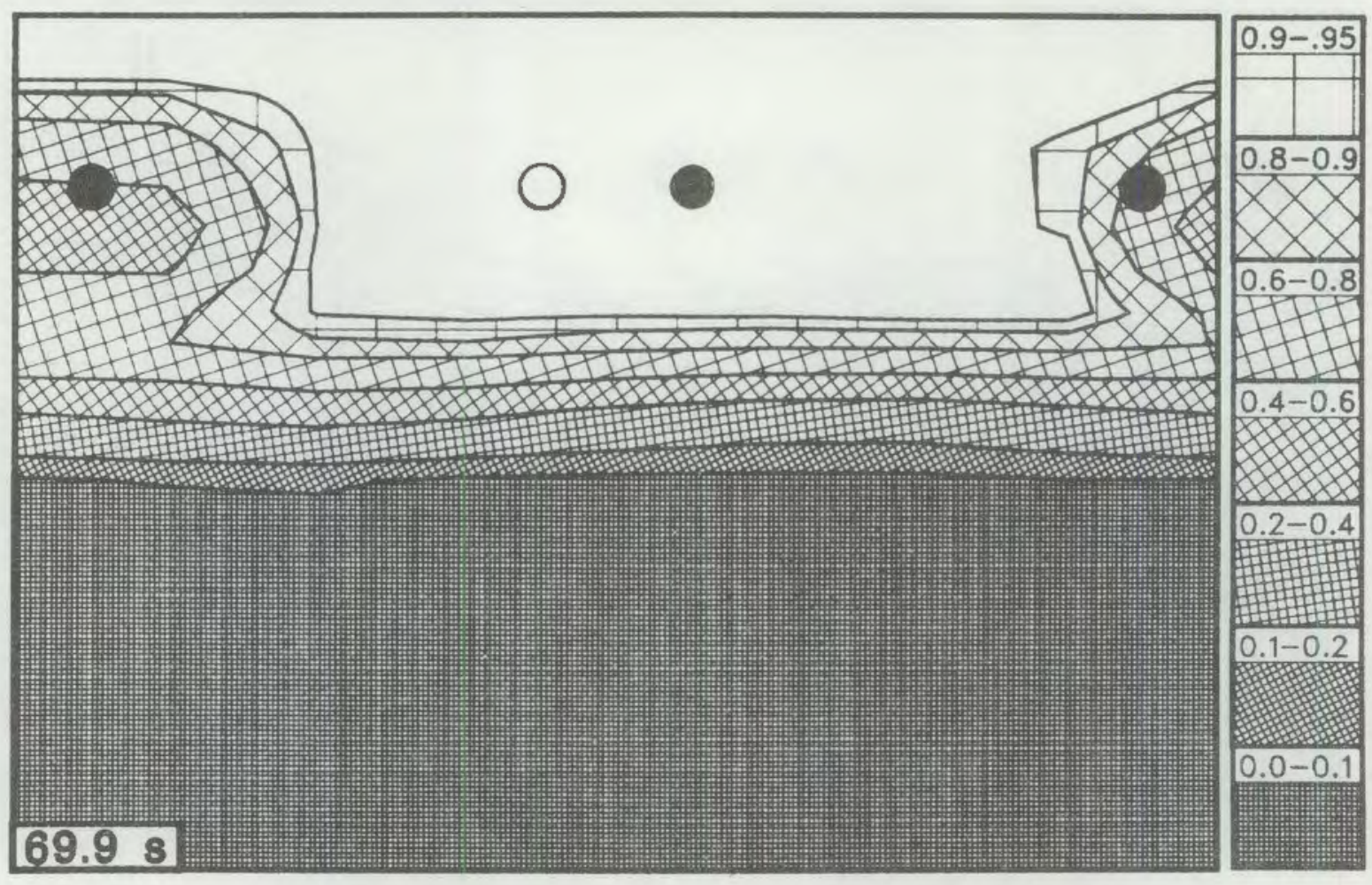

Figure B.136. Downcomer void fraction contour at $69.9 \mathrm{~s}$

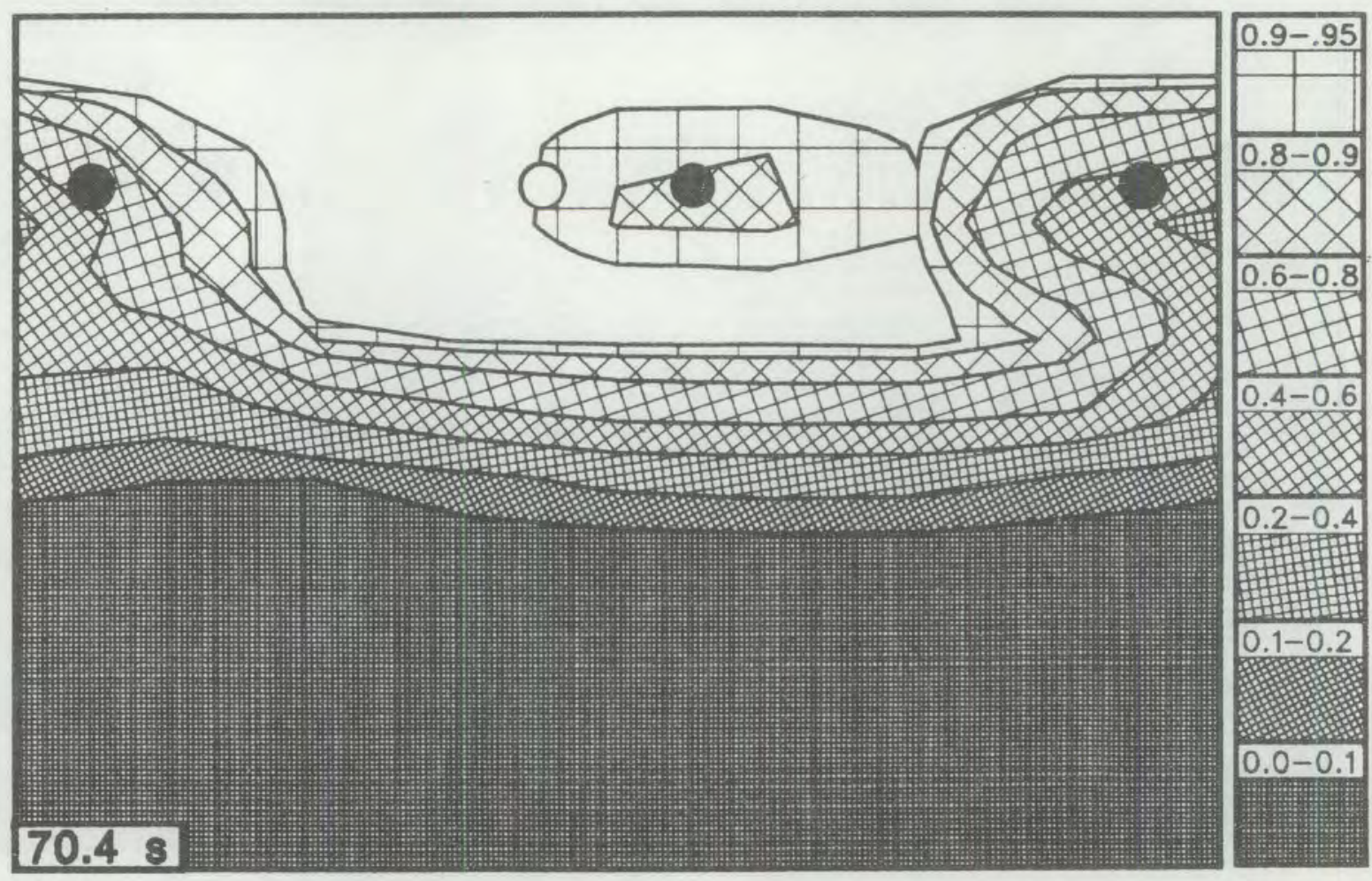

Figure B.137. Downcomer void fraction contour at $70.4 \mathrm{~s}$ 


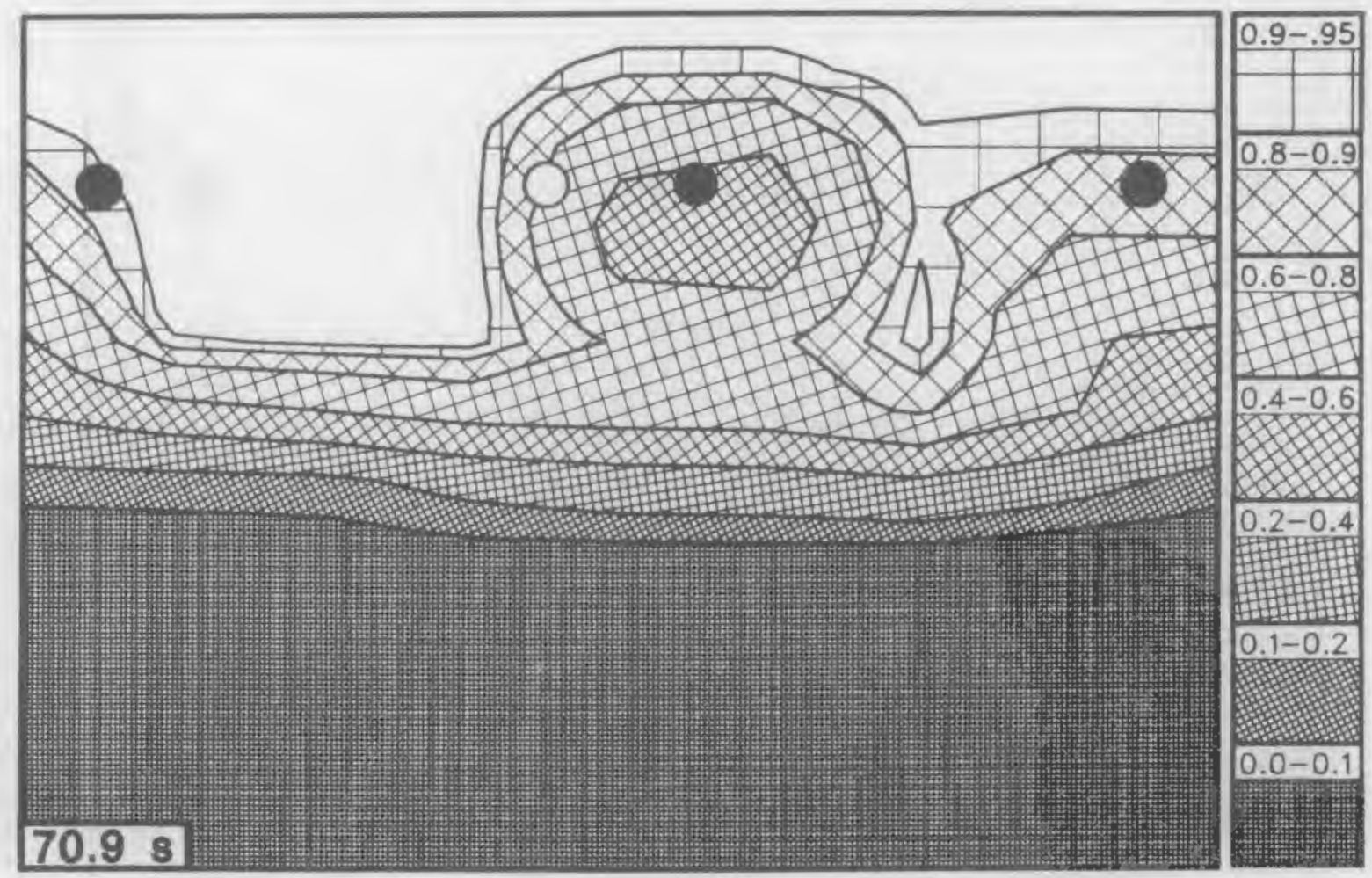

Figure B.138. Downcomer void fraction contour at $70.9 \mathrm{~s}$

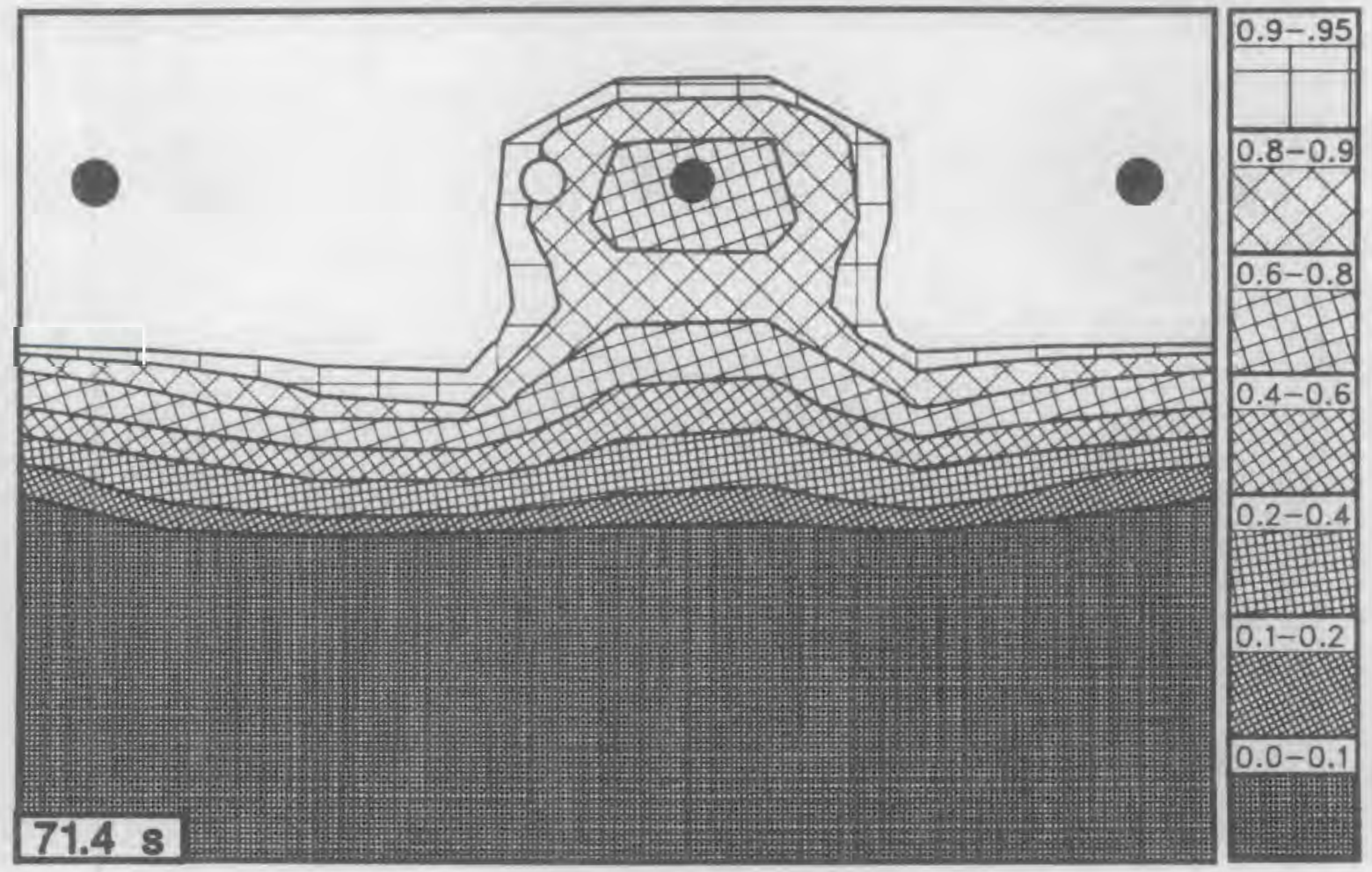

Figure B.139. Downcomer void fraction contour at $71.4 \mathrm{~s}$ 


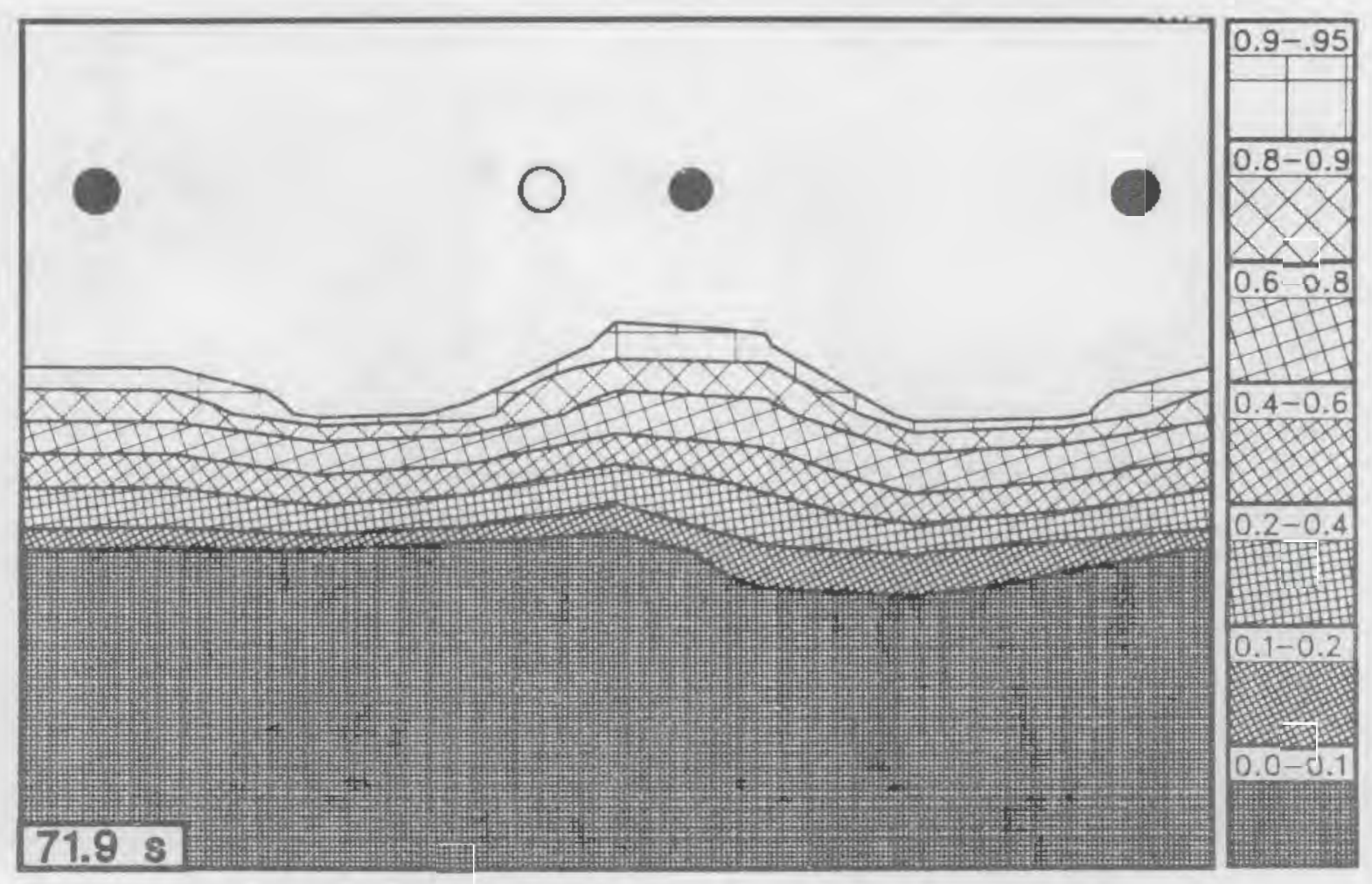

Figure B.140. Downcomer void fraction contour at $71.9 \mathrm{~s}$

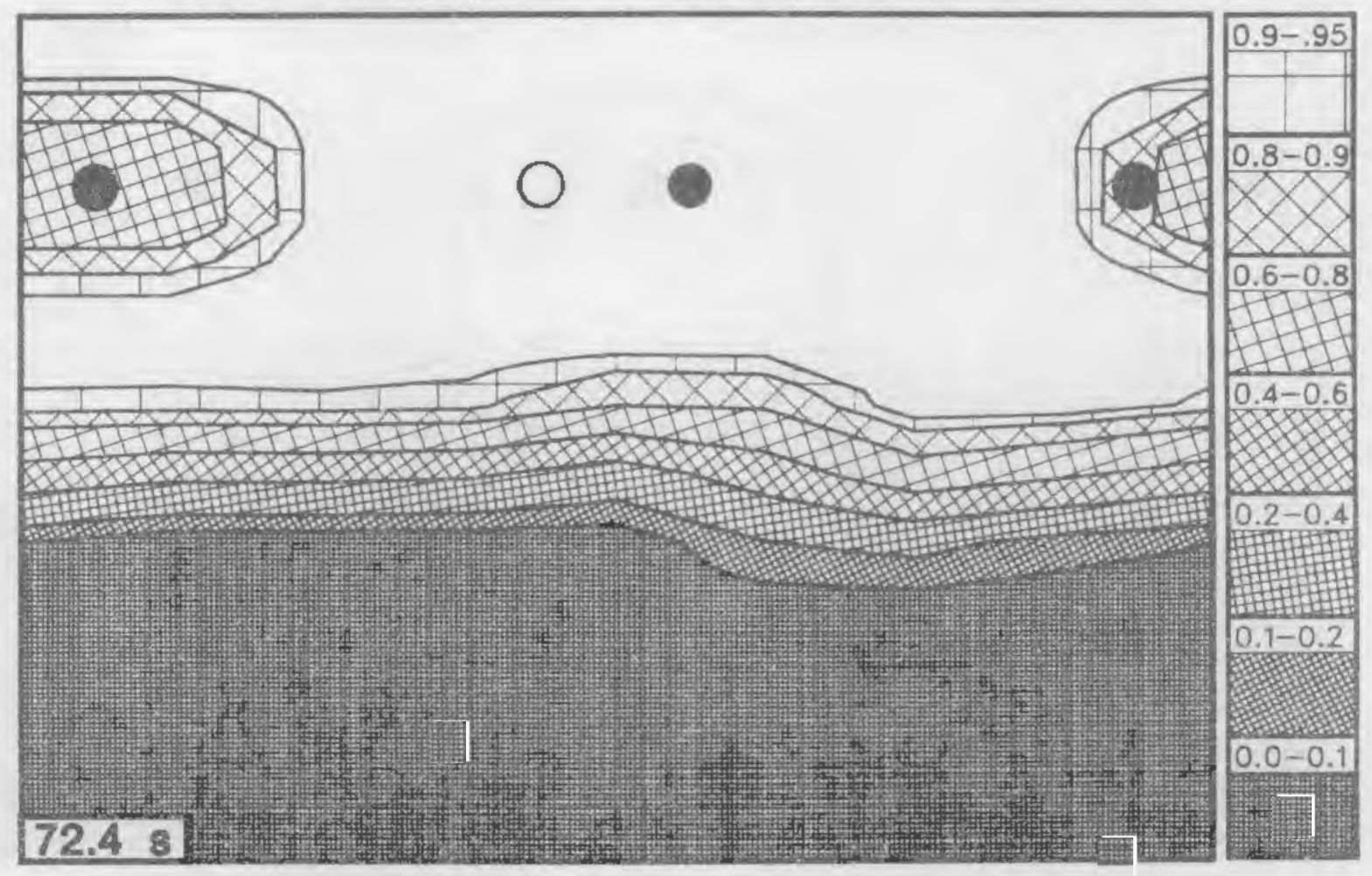

Figure B.141. Downcomer void fraction contour at $72.4 \mathrm{~s}$ 


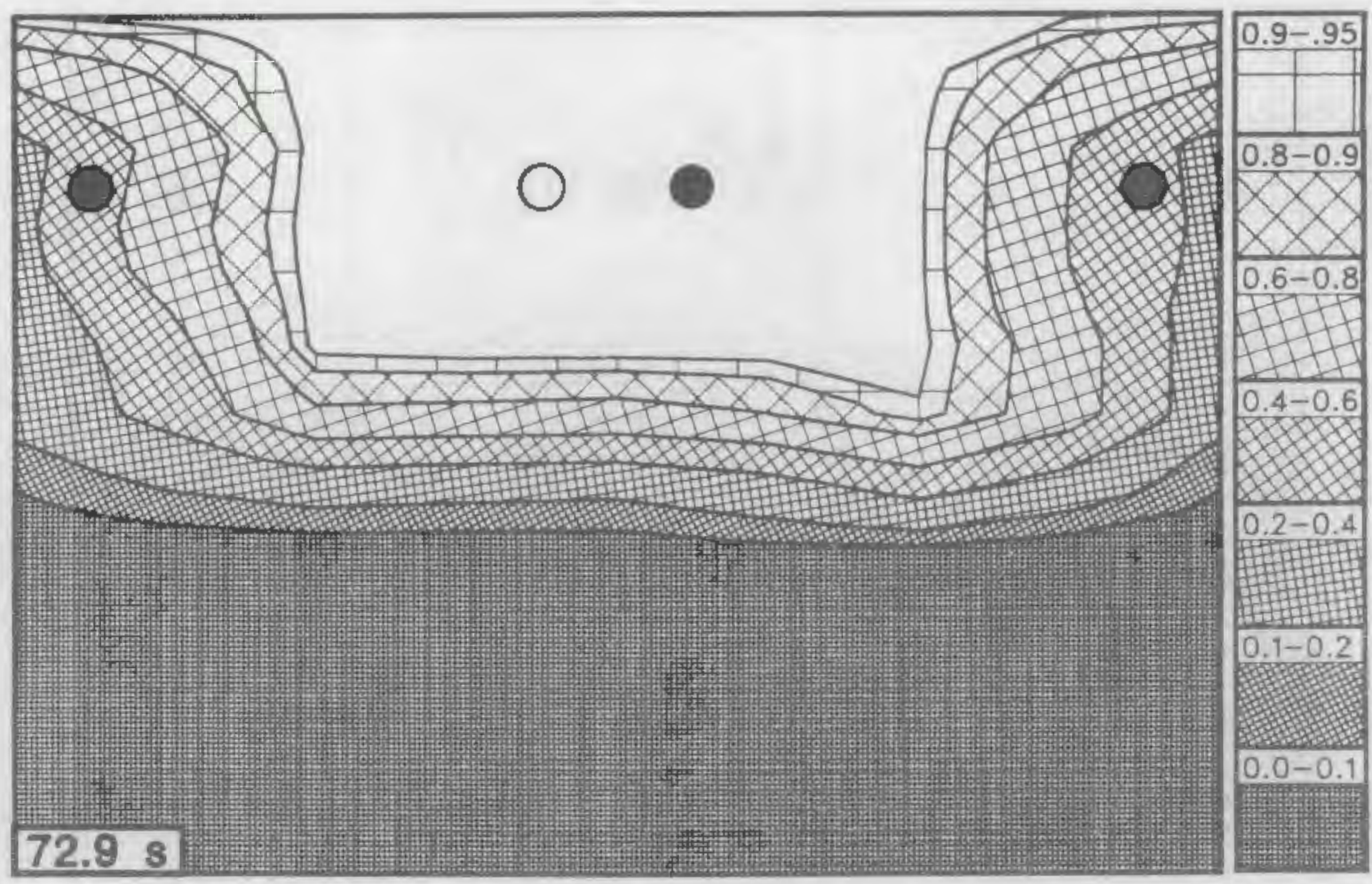

Figure B.142. Downcomer void fraction contour at $72.9 \mathrm{~s}$

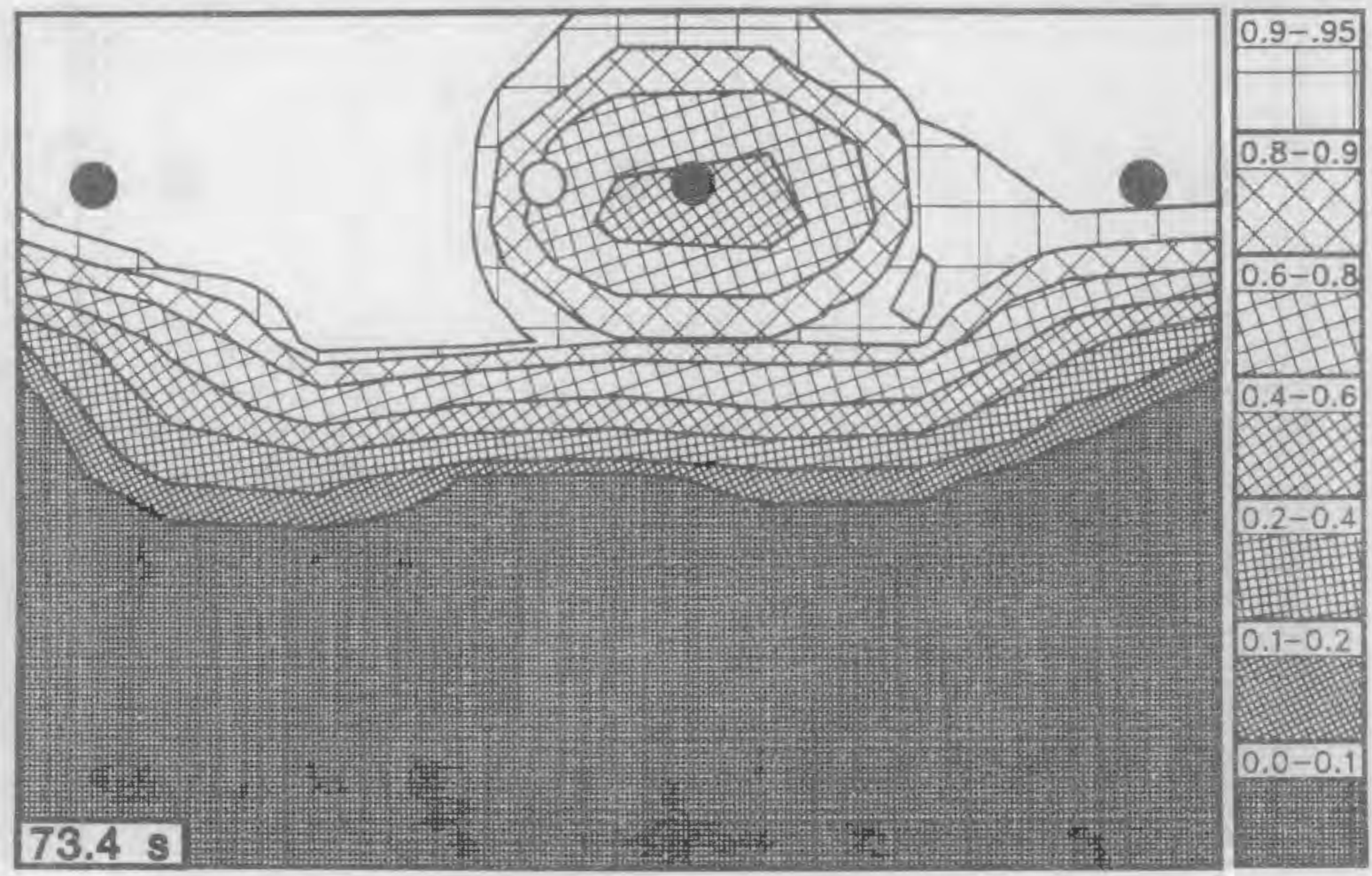

Figure B.143. Downcomer void fraction contour at $73.4 \mathrm{~s}$ 


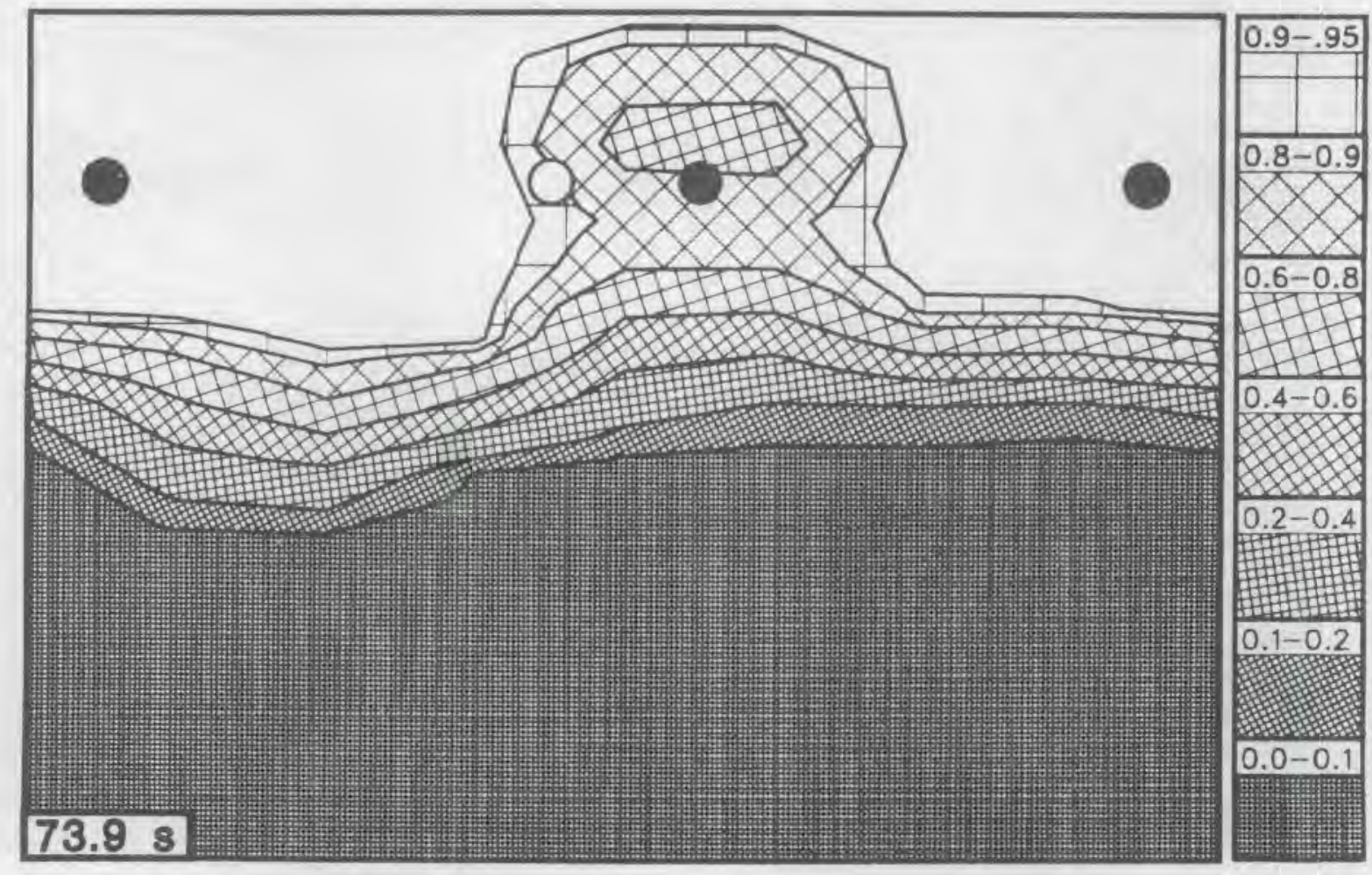

Figure B.144. Downcomer void fraction contour at $73.9 \mathrm{~s}$

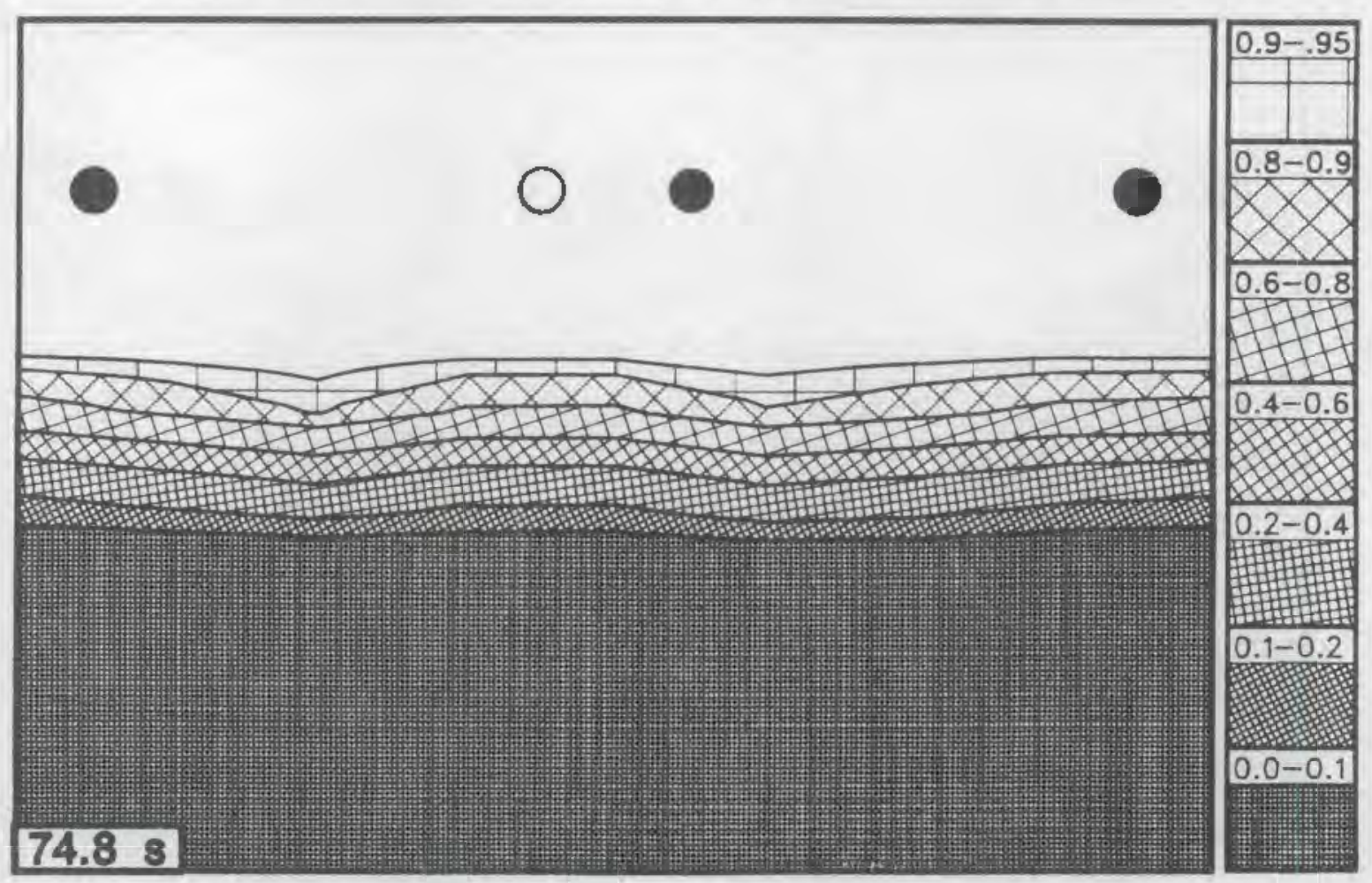

Figure B.145. Downcomer void fraction contour at $74.8 \mathrm{~s}$ 


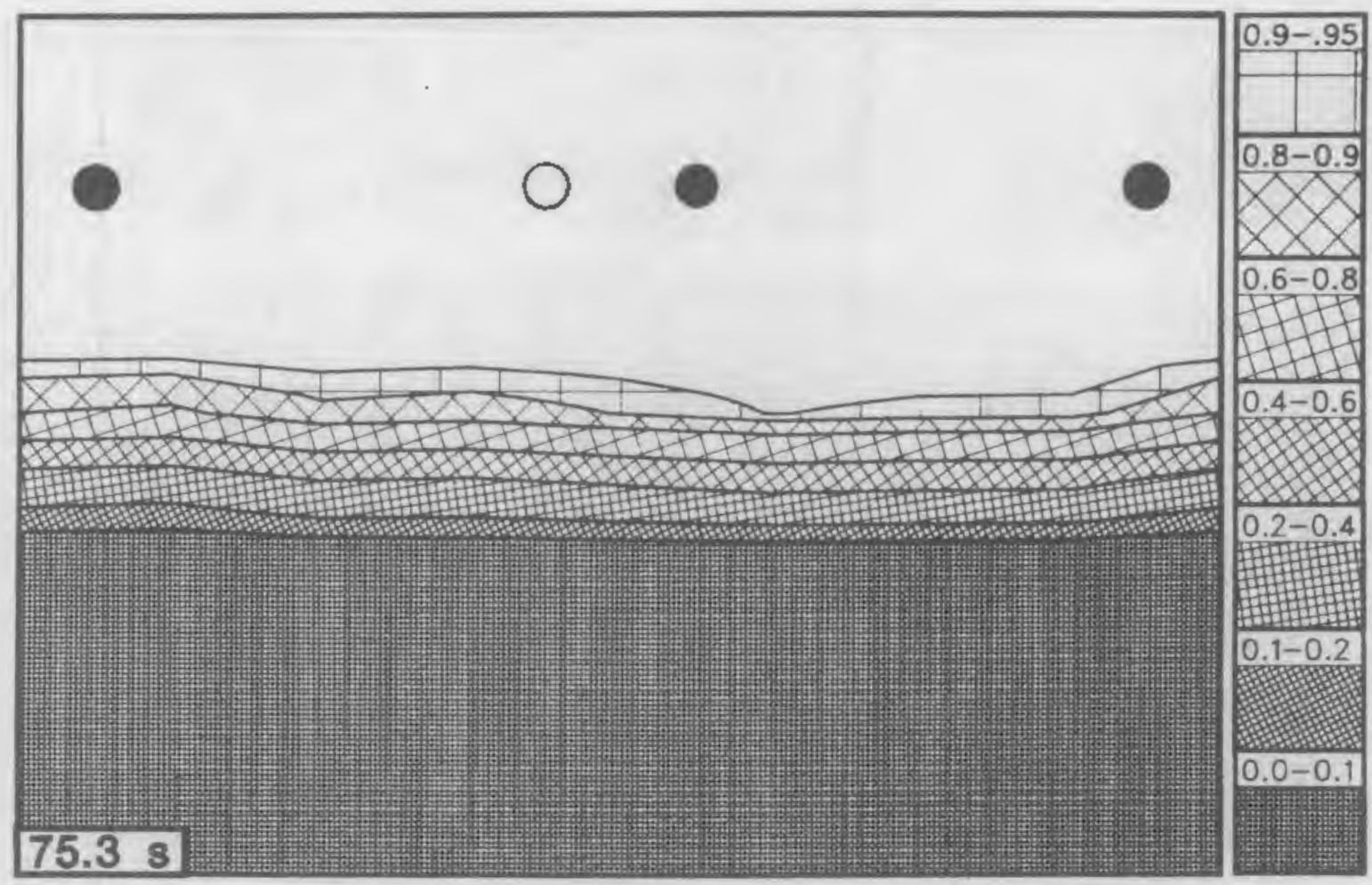

Figure B.146. Downcomer void fraction contour at $75.3 \mathrm{~s}$

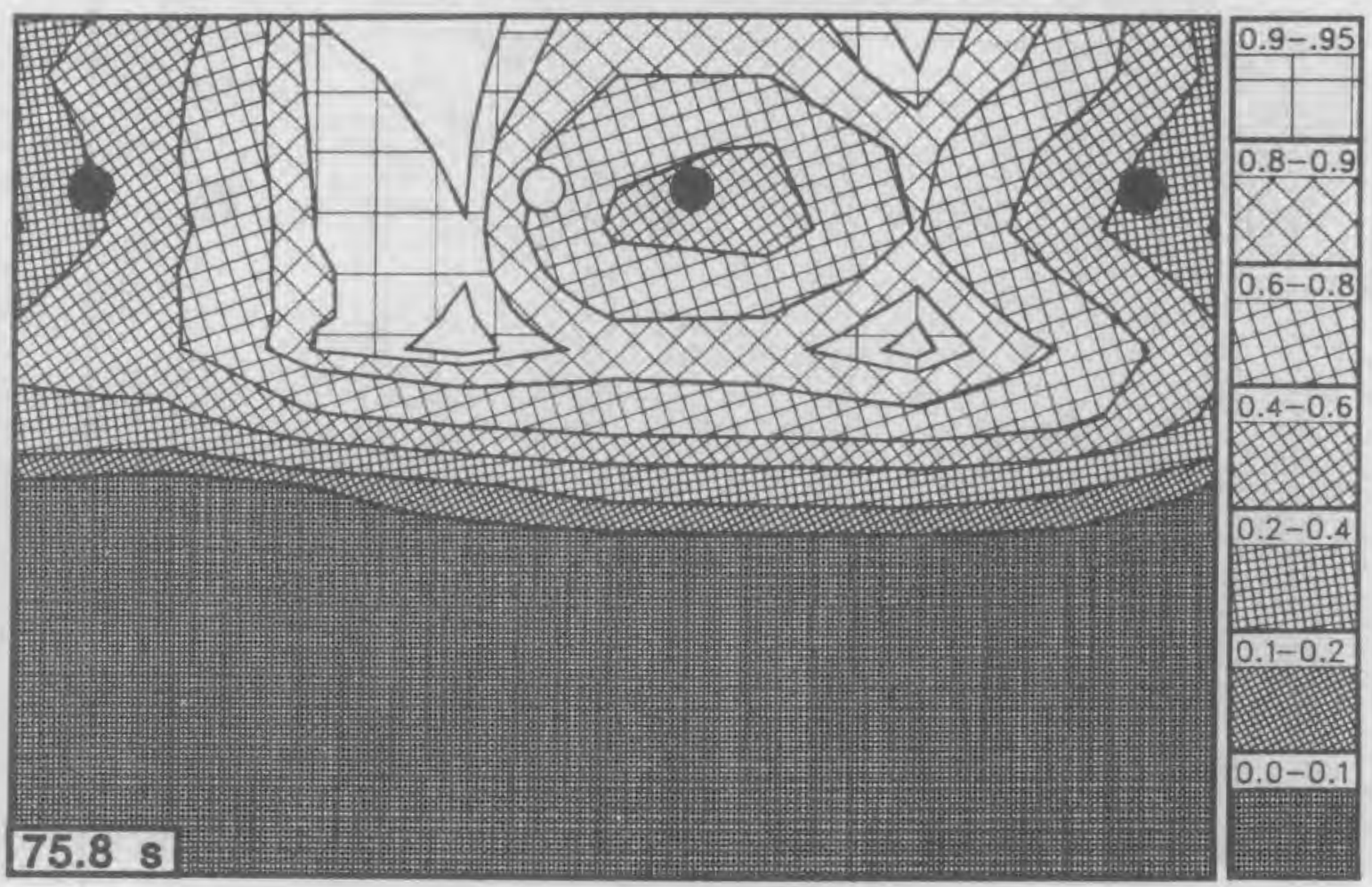

Figure B.147. Downcomer void fraction contour at $75.8 \mathrm{~s}$ 


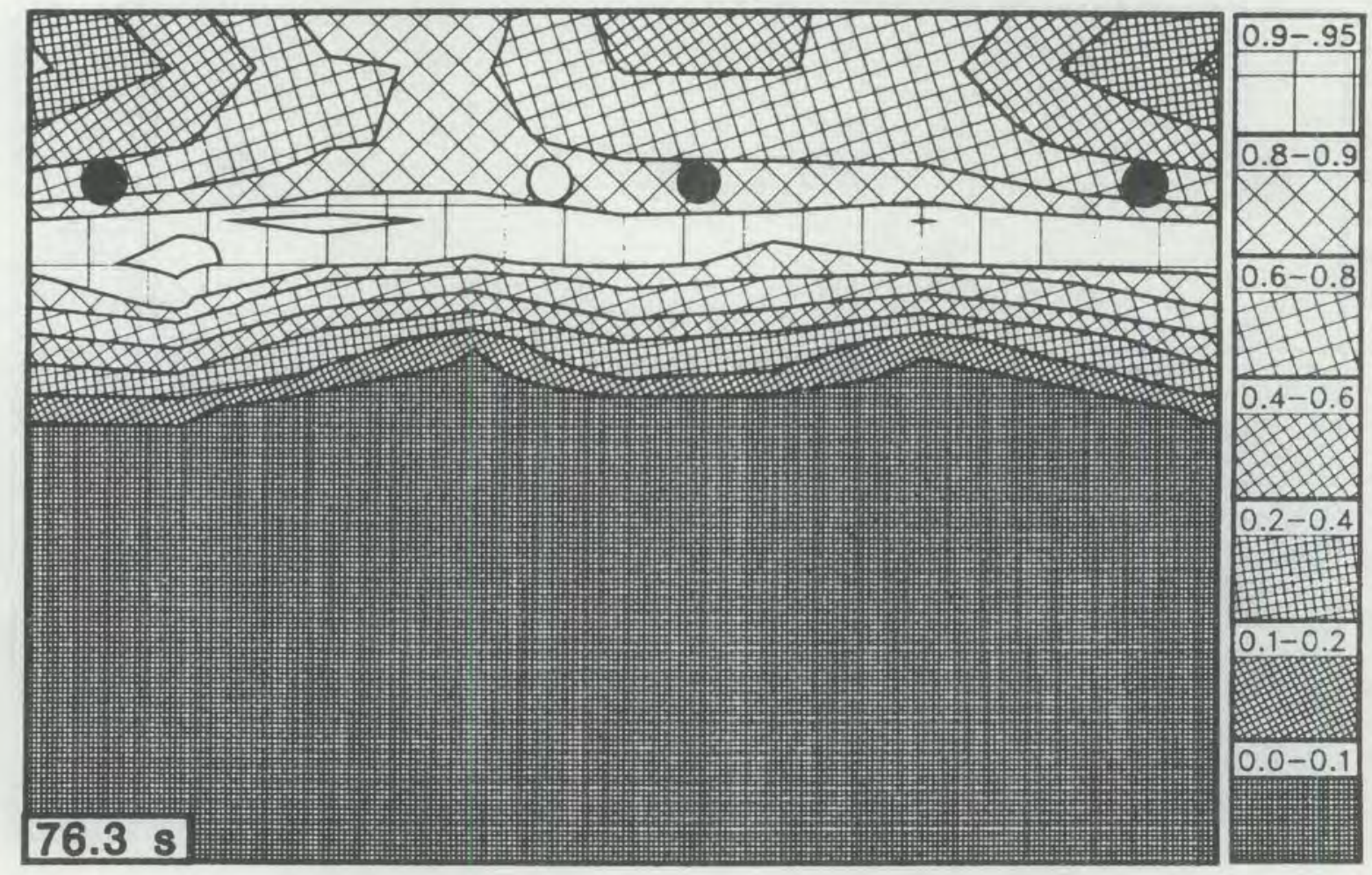

Figure B.148. Downcomer void fraction contour at $76.3 \mathrm{~s}$

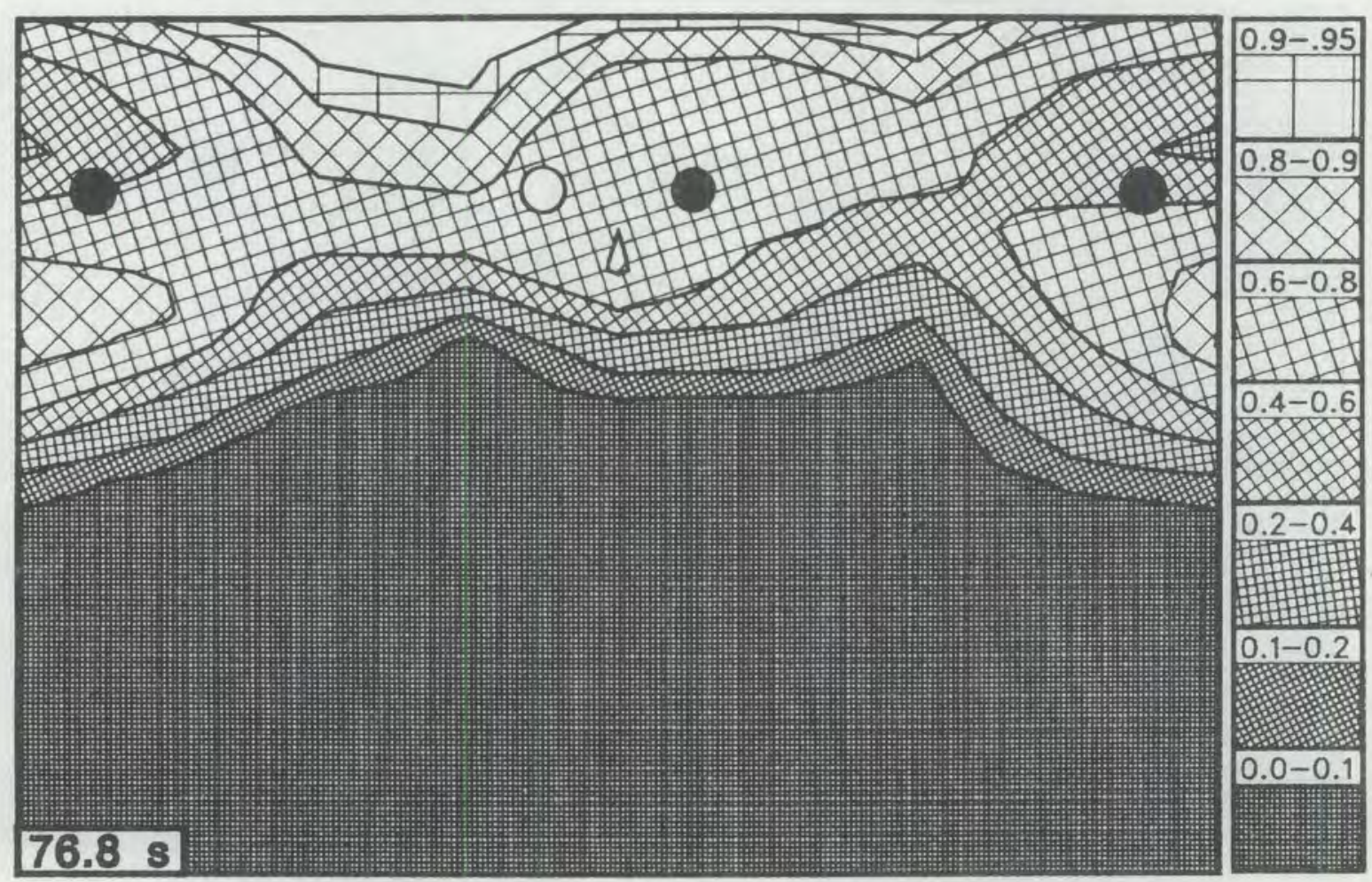

Figure B.149. Downcomer void fraction contour at $76.8 \mathrm{~s}$ 


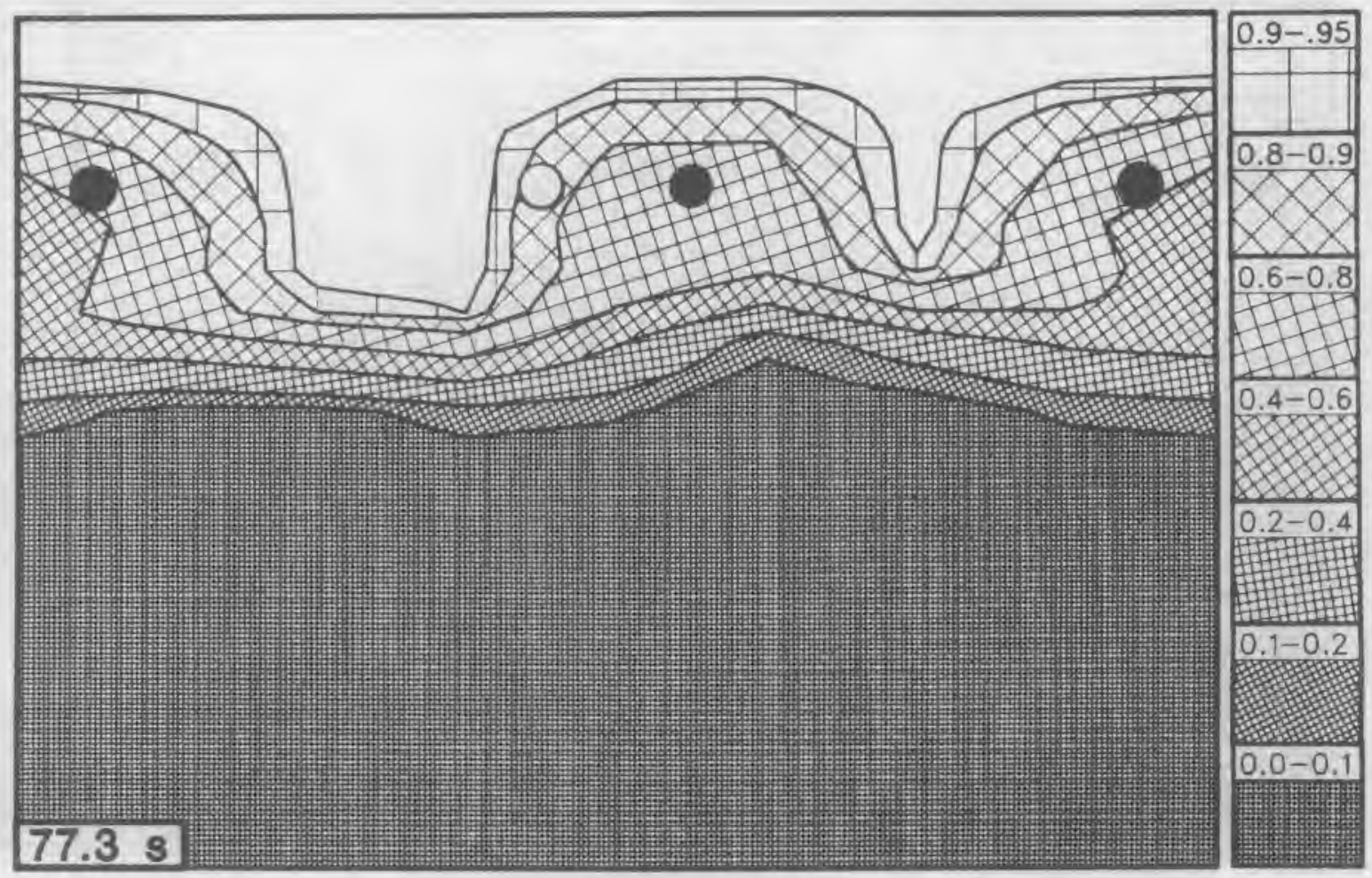

Figure B.150. Downcomer void fraction contour at $77.3 \mathrm{~s}$

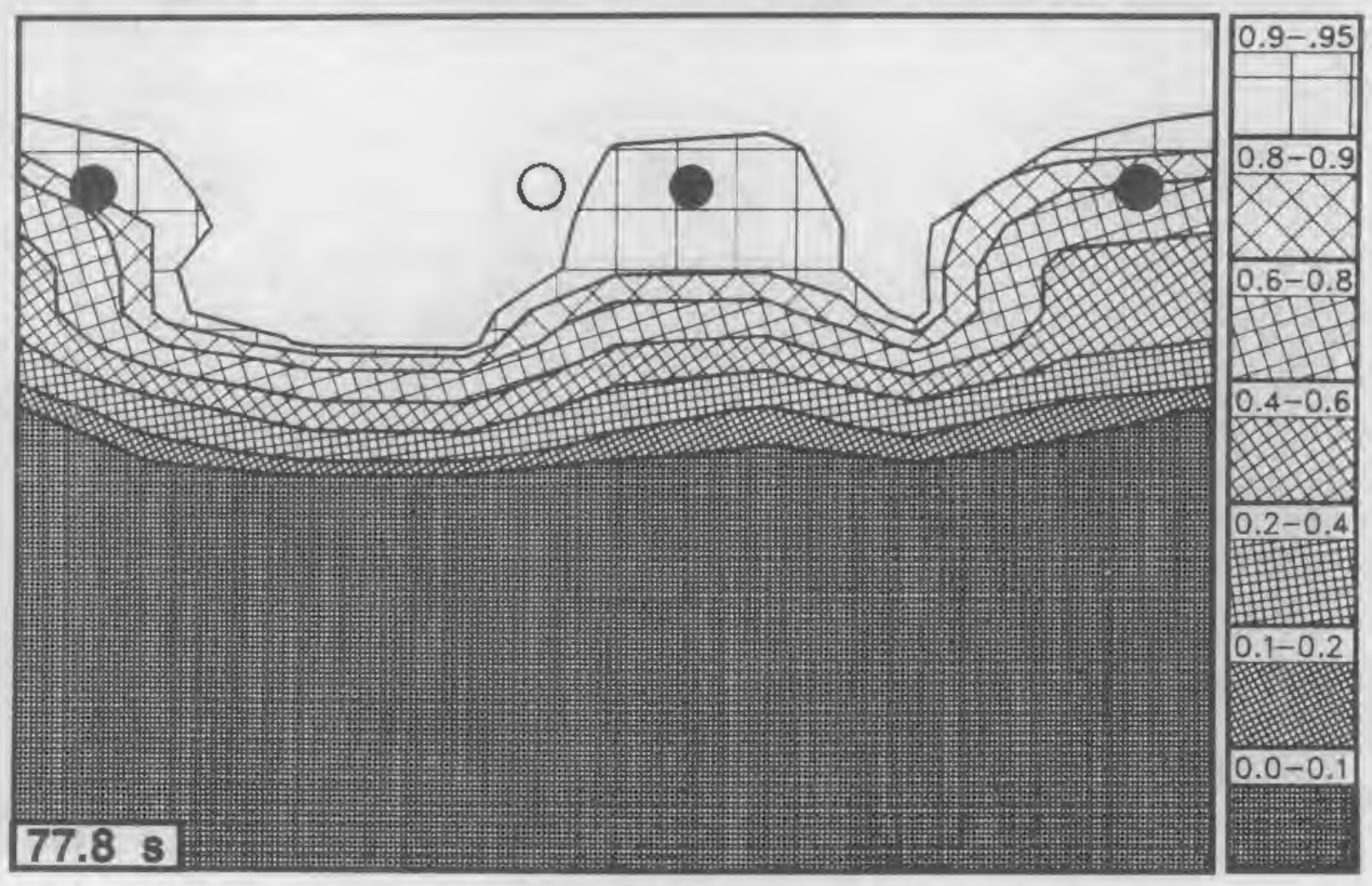

Figure B.151. Downcomer void fraction contour at $77.8 \mathrm{~s}$ 


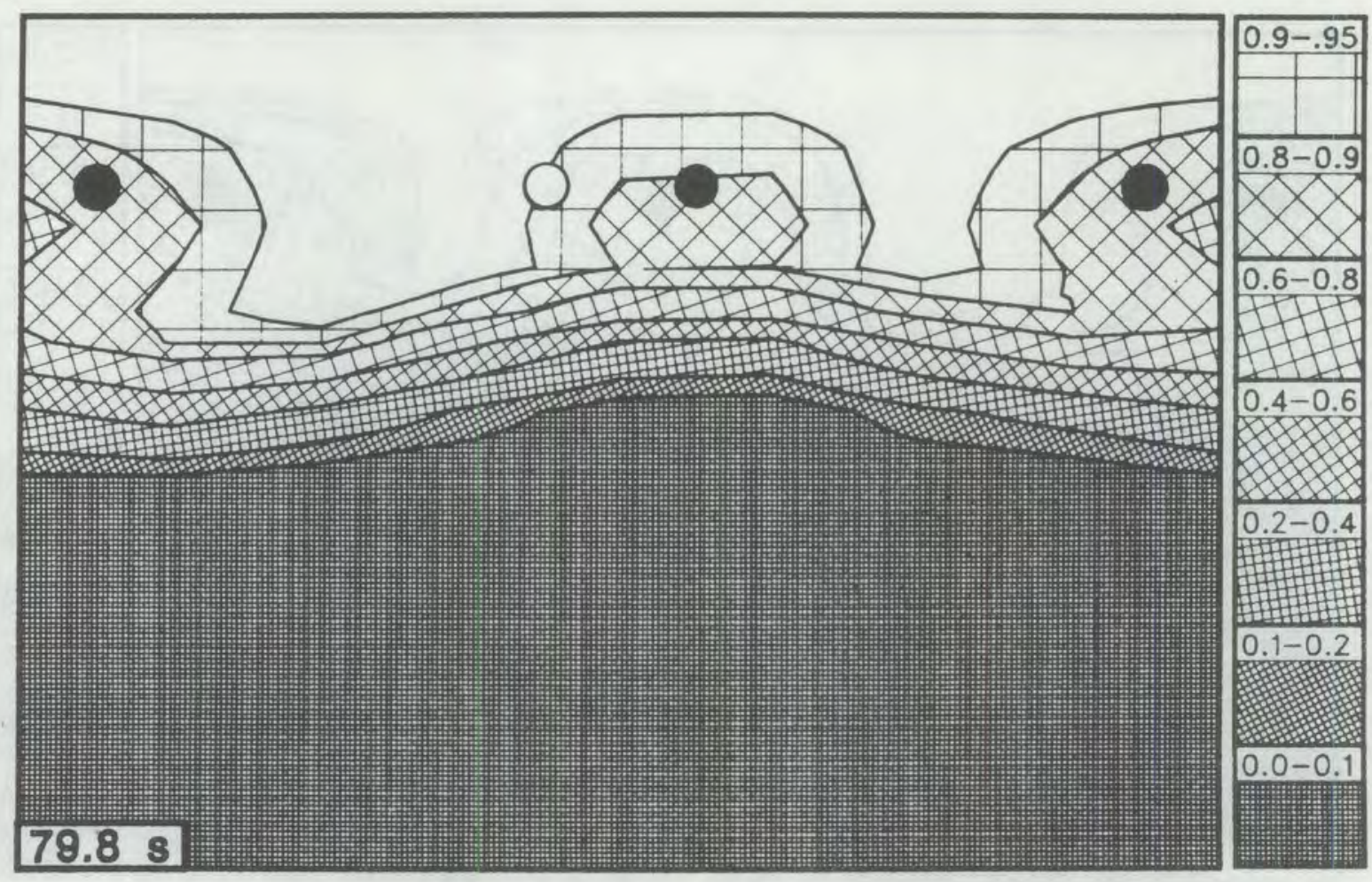

Figure B.152. Downcomer void fraction contour at $79.8 \mathrm{~s}$

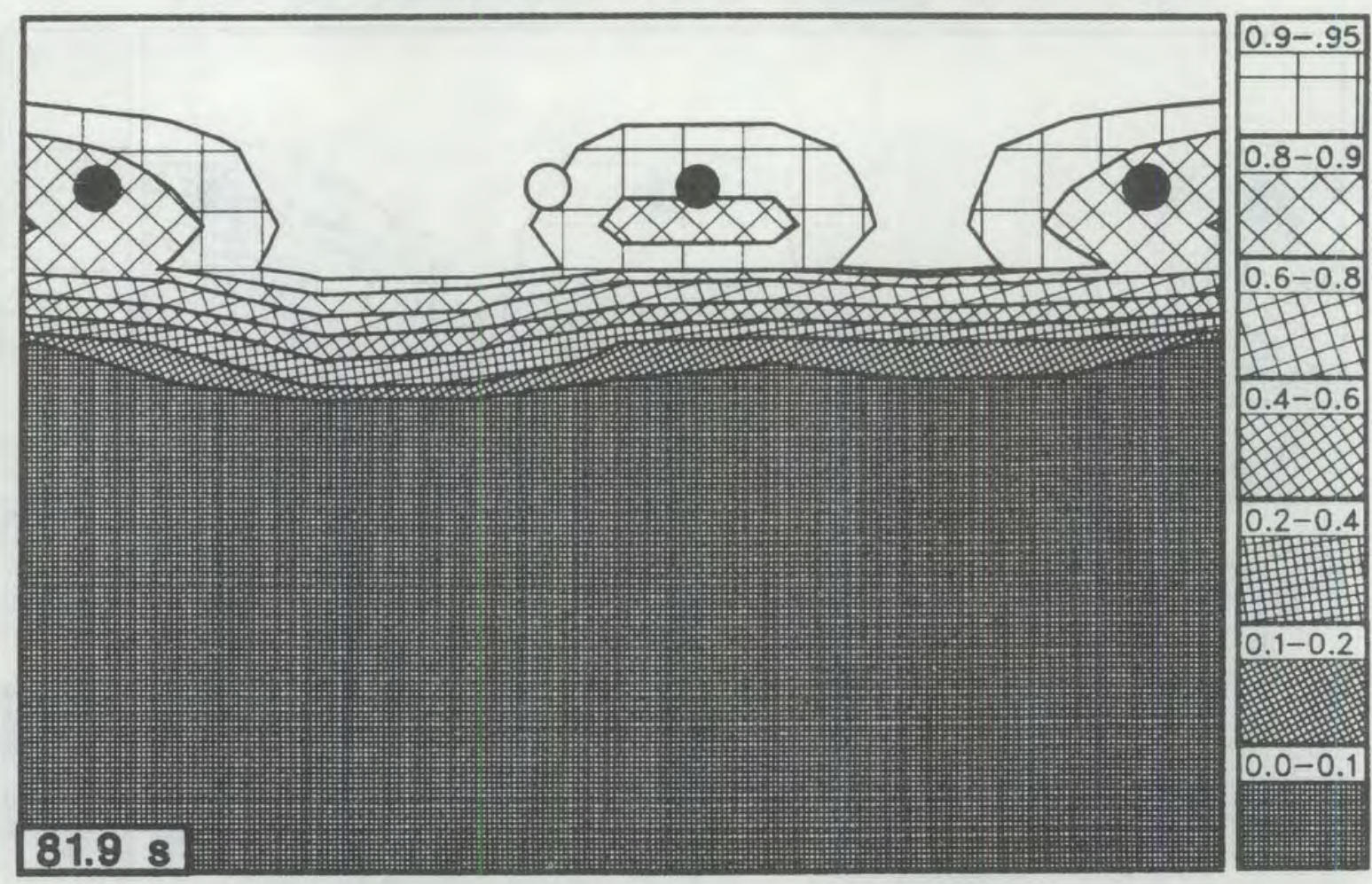

Figure B.153. Downcomer void fraction contour at $81.9 \mathrm{~s}$ 


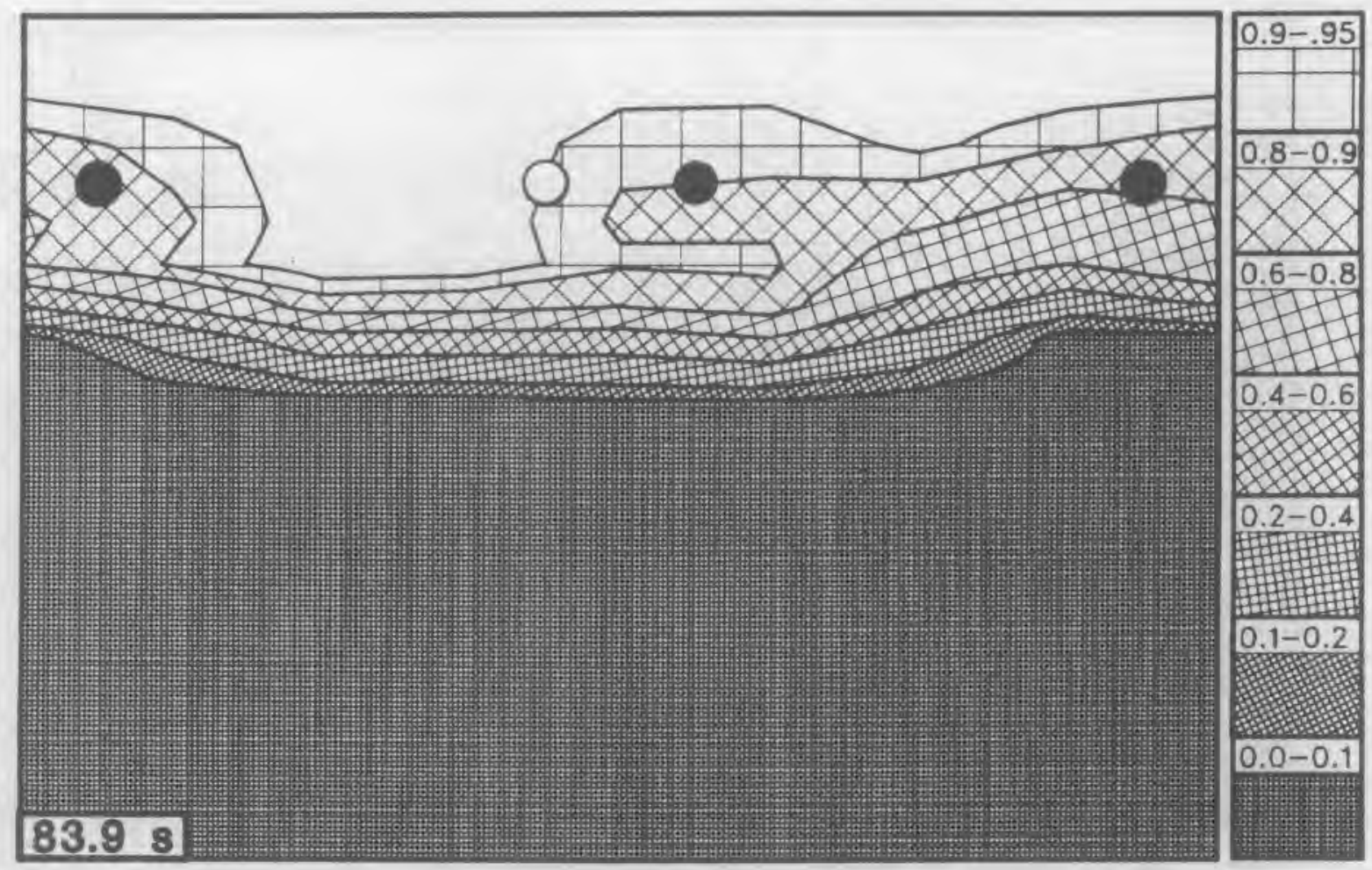

Figure B.154. Downcomer void fraction contour at $83.9 \mathrm{~s}$

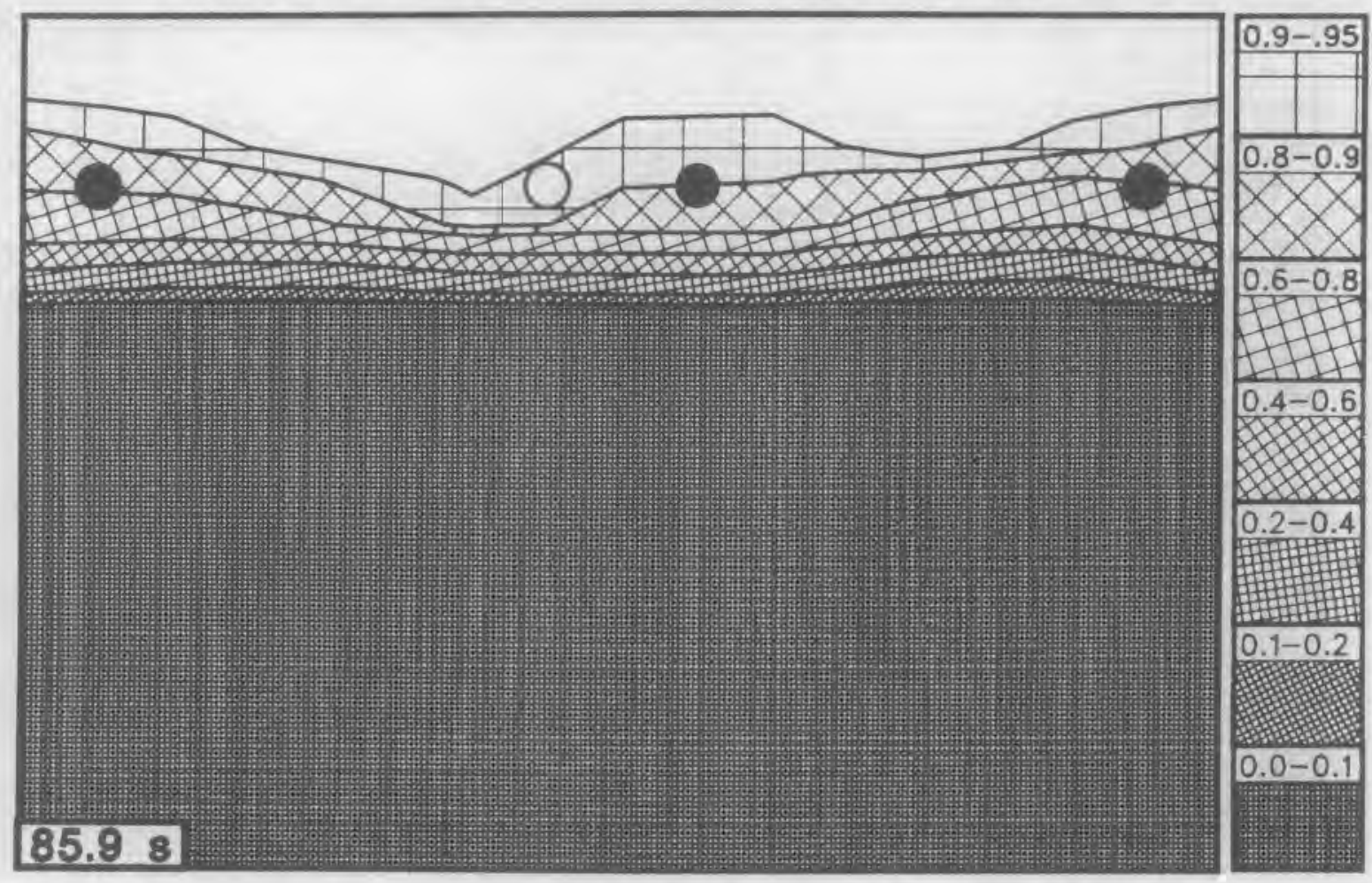

Figure B.155. Downcomer void fraction contour at $85.9 \mathrm{~s}$ 


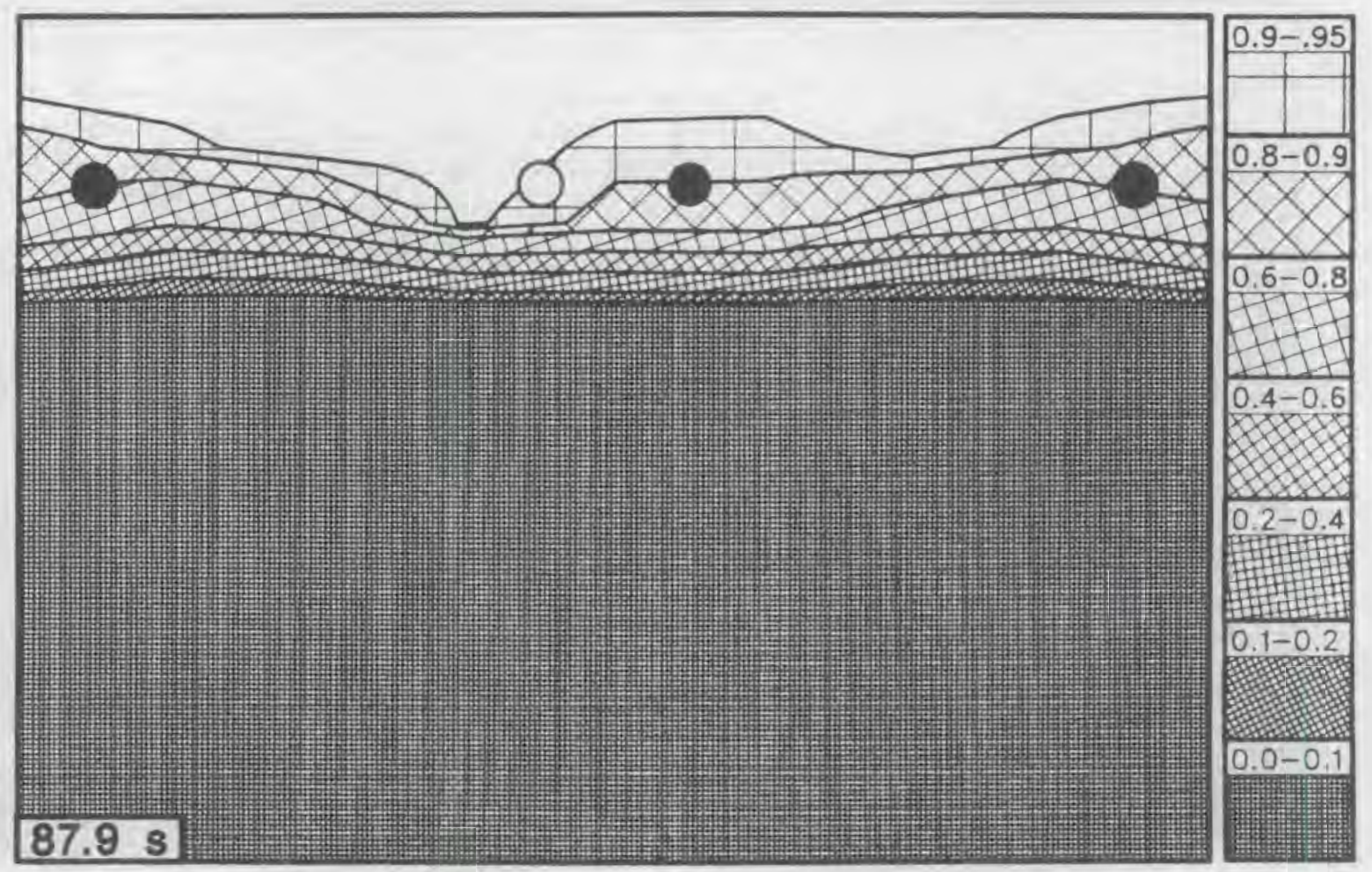

Figure B.156. Downcomer void fraction contour at $87.9 \mathrm{~s}$

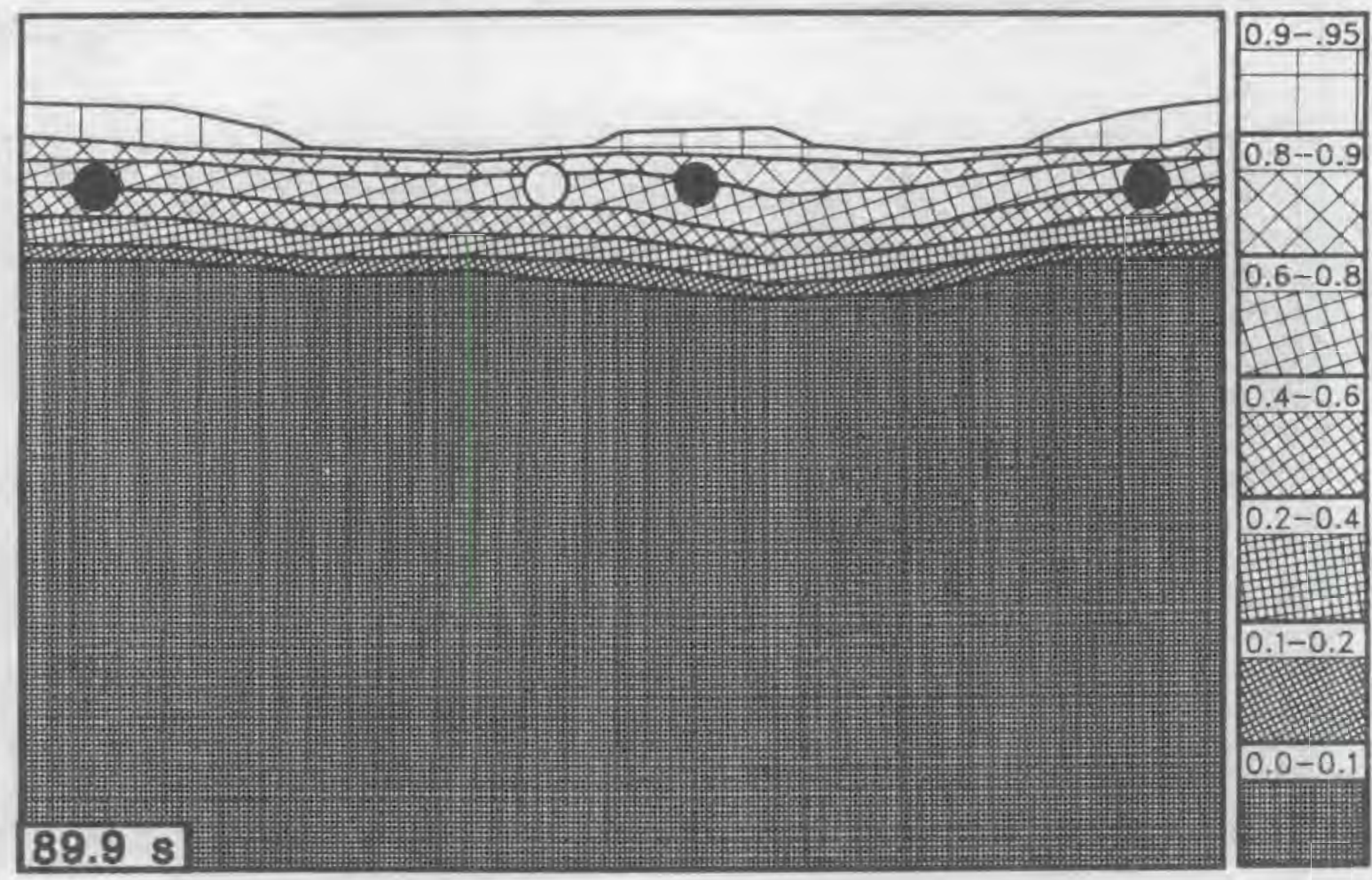

Figure B.157. Downcomer void fraction contour at $89.9 \mathrm{~s}$ 


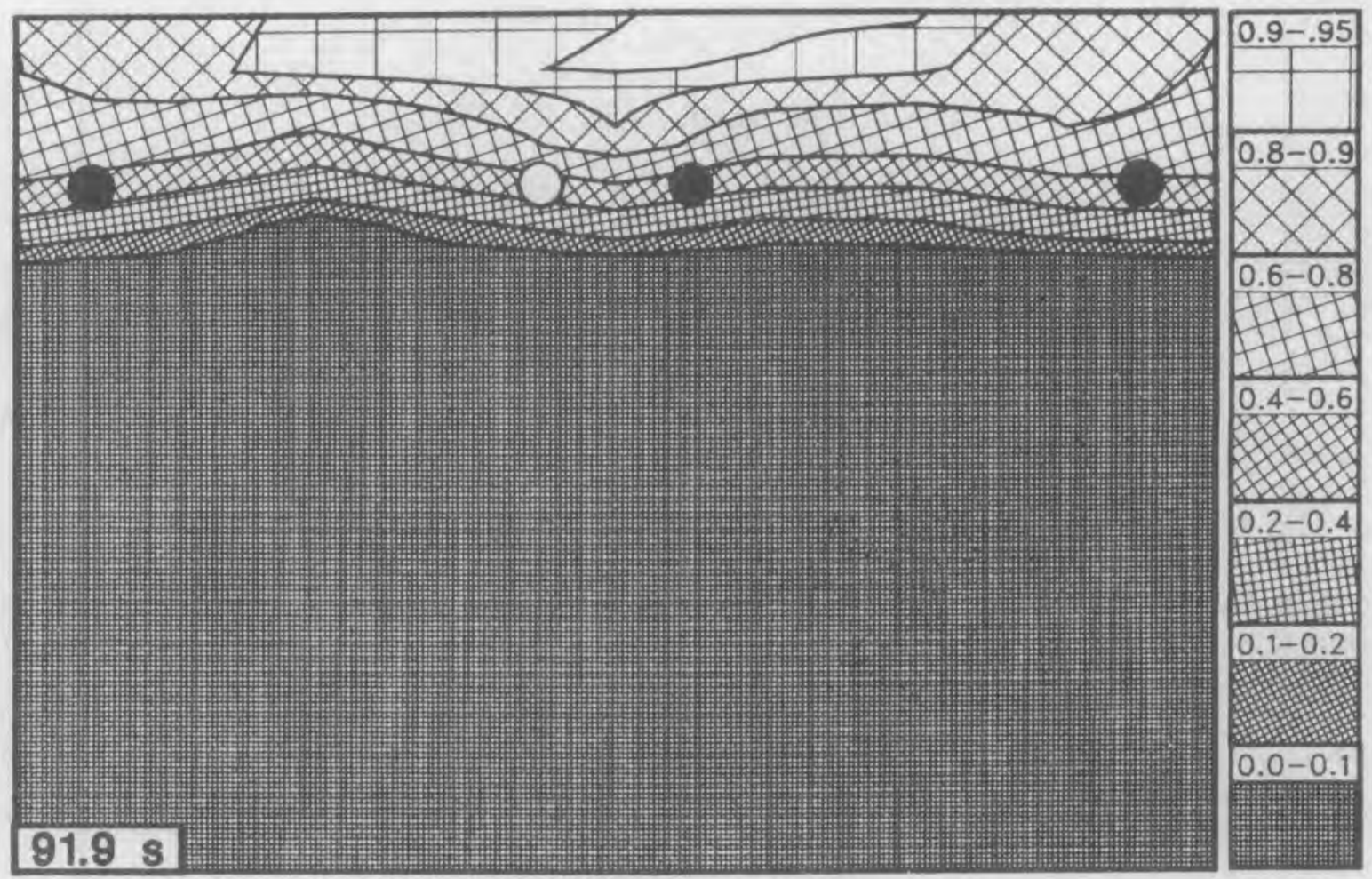

Figure B.158. Downcomer void fraction contour at $91.9 \mathrm{~s}$ 


\section{APPENDIX C \\ ADOITIONAL RESULTS IN THE VESSEL}

This appendix gives additional plots of the predicted response in the vessel. The first 29 figures show additional temperature predictions in the core. Figures C.1 to C.9 indicate the peak (maximum) clad surface temperature along the length of each rod. The temperature as a function of vertical height is shown in the quench envelopes plotted in Figures C.10 to C.19. Figures C.20 to C.25 give the temperature response of rods 2,8 , and 9 at six elevations in the core. They show that some asymmetric quenching occurred. The predicted amount of core vapor superheat is shown in Figures C.26 to C.29.

The distribution of liquid throughout the three-dimensional core mesh can be examined in Figures 30 to 79 . The void fractions of every cell in the core are plotted in Figures $C .30$ to C.47. Figures $C .48$ to $C .52$ show total flow rates (summed over channels) at the inlet and exit of the core. Counter-current flow limiting (CCFL) at the top of the core is indicated in Figures $C .53$ to $C .61$ which are plots of the liquid, drop, and vapor flow rates at the top of each core channels. The amount and distribution of liquid delivered from the upper head through the support columns and guide tubes is shown in Figures C.62 to C.79.

Pressure drops within the vessel are plotted in Figures C.80 to C.84 and additional liquid levels are plotted in Figures C.85 to C.88. 


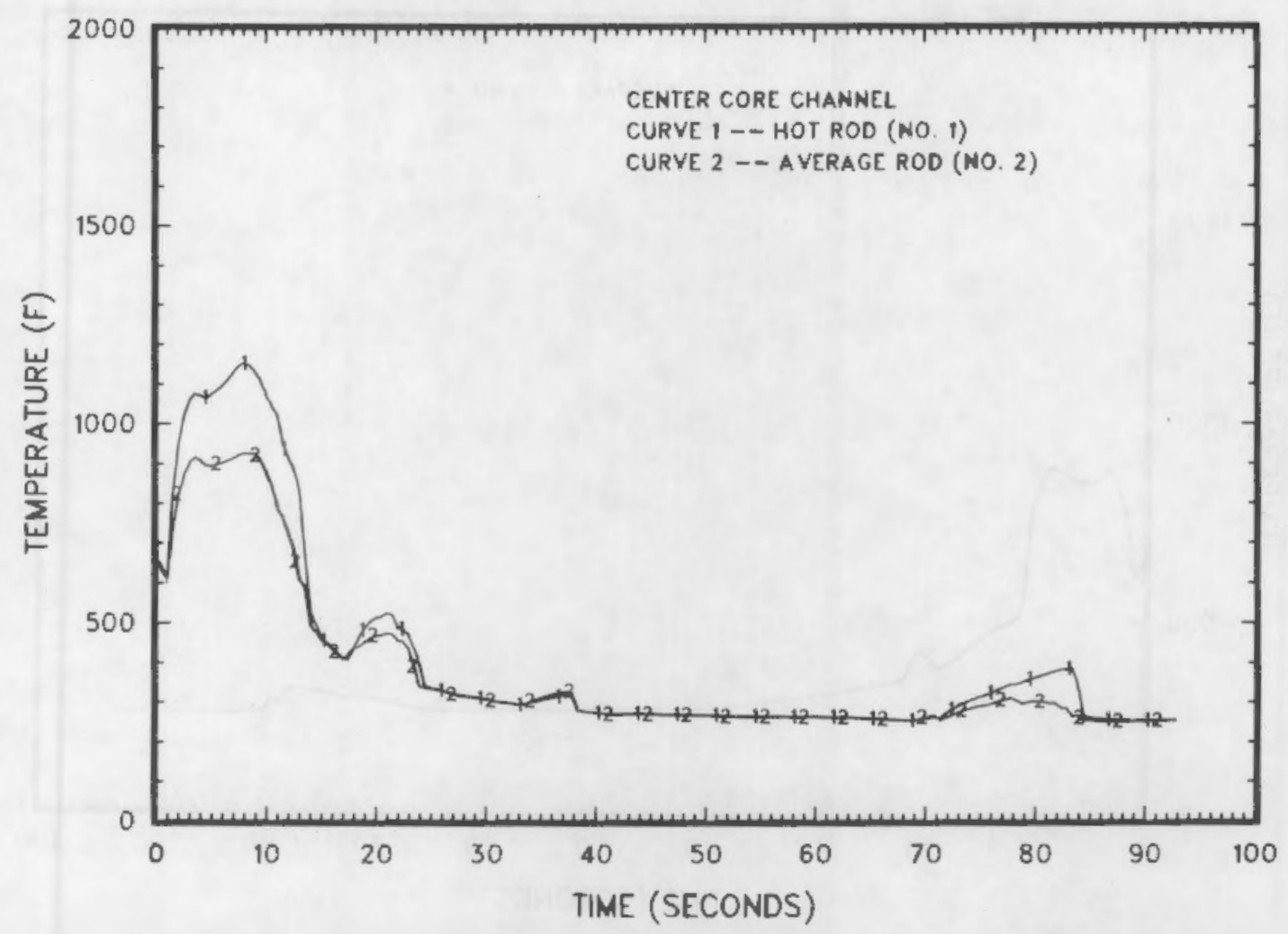

Figure C.1. Peak clad surface temperature of rods 1 and 2 vs. time

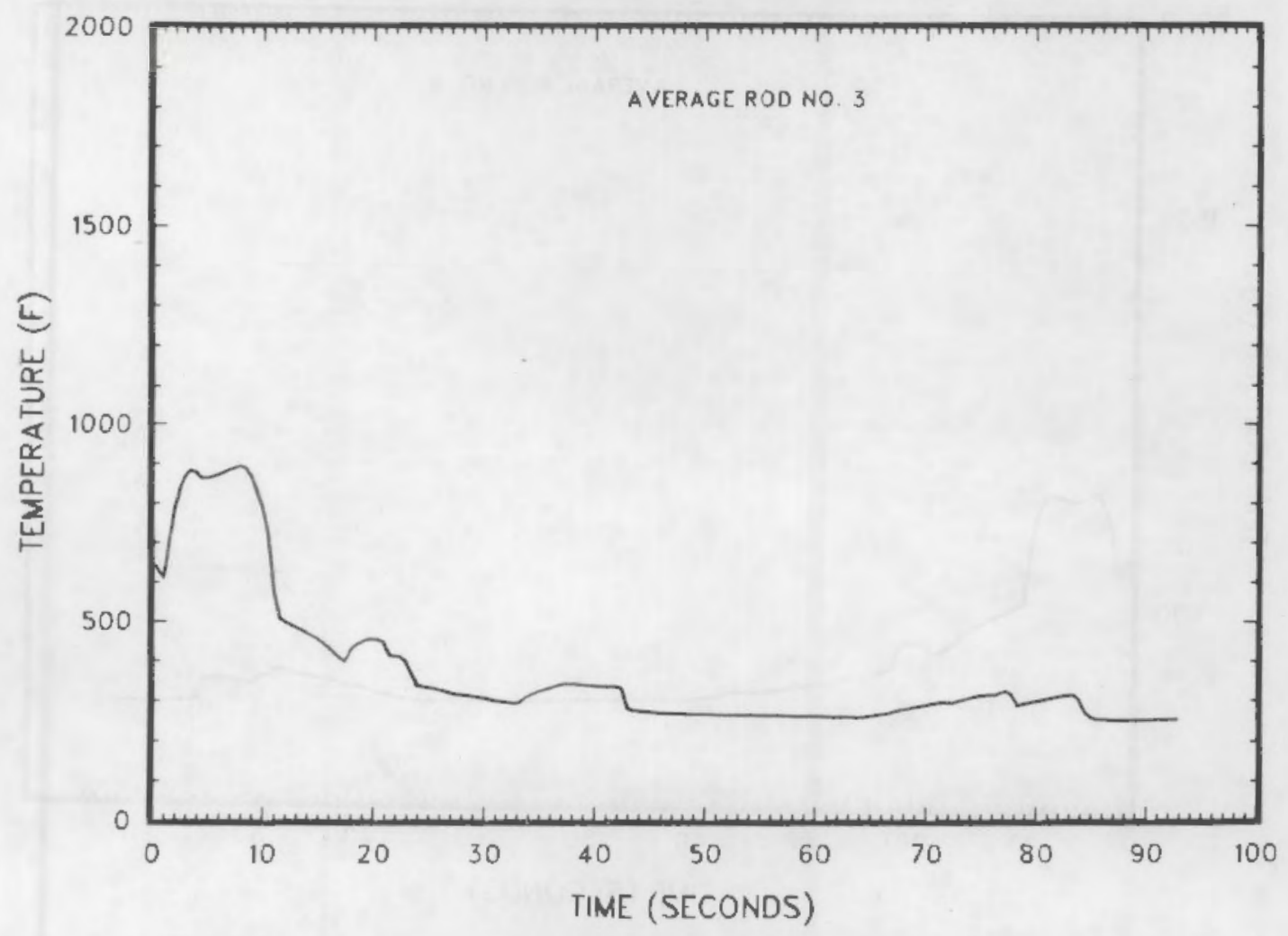

Figure C.2. Peak clad temperature of rod 3 vs. time 


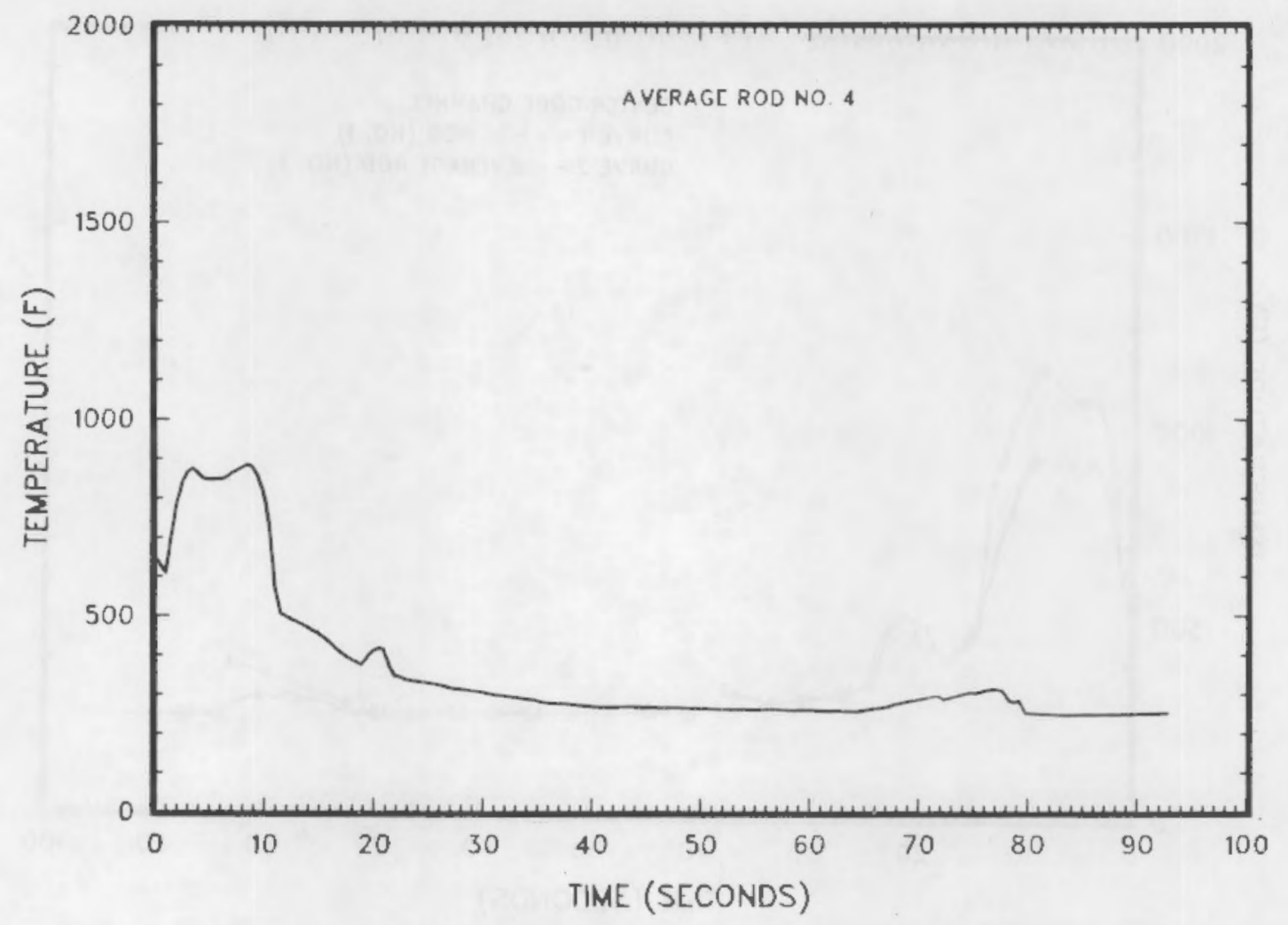

Figure C.3. Peak clad surface temperature of rod 4 vs. time

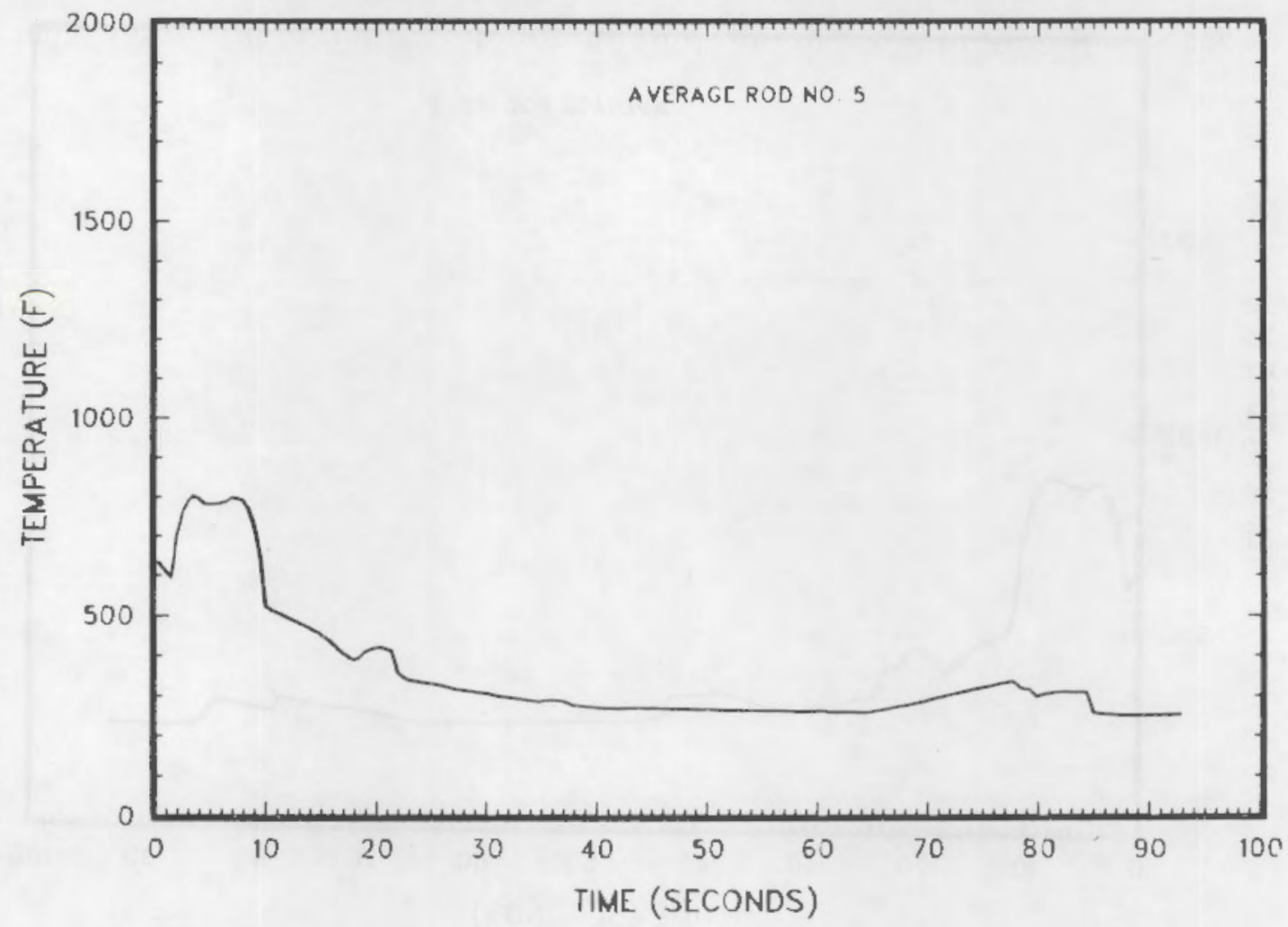

Figure C.4. Peak $\mathrm{clad}$ temperature of rod 5 vs. time 


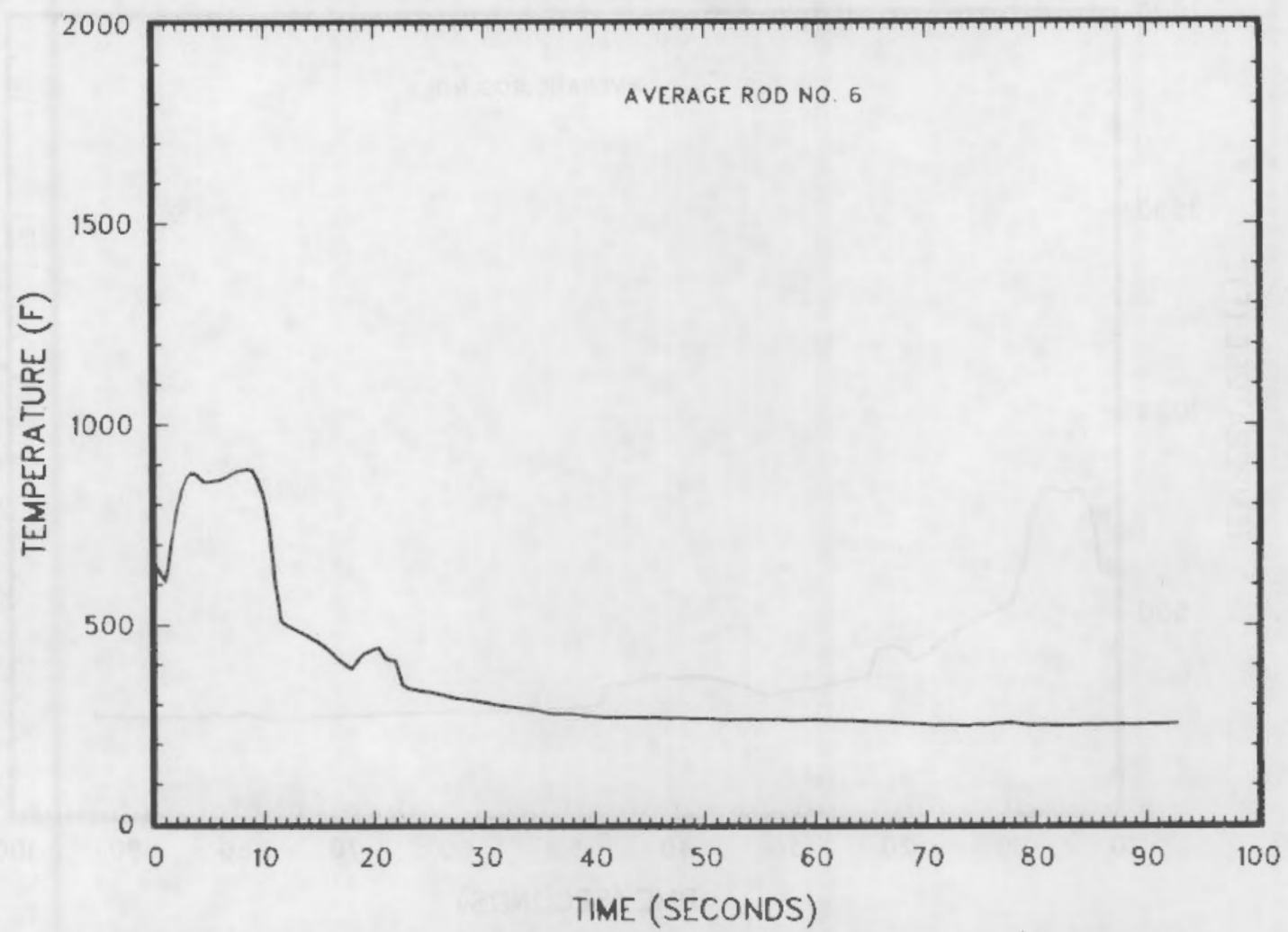

Figure C.5. Peak clad surface temperature of rod 6 vs. time

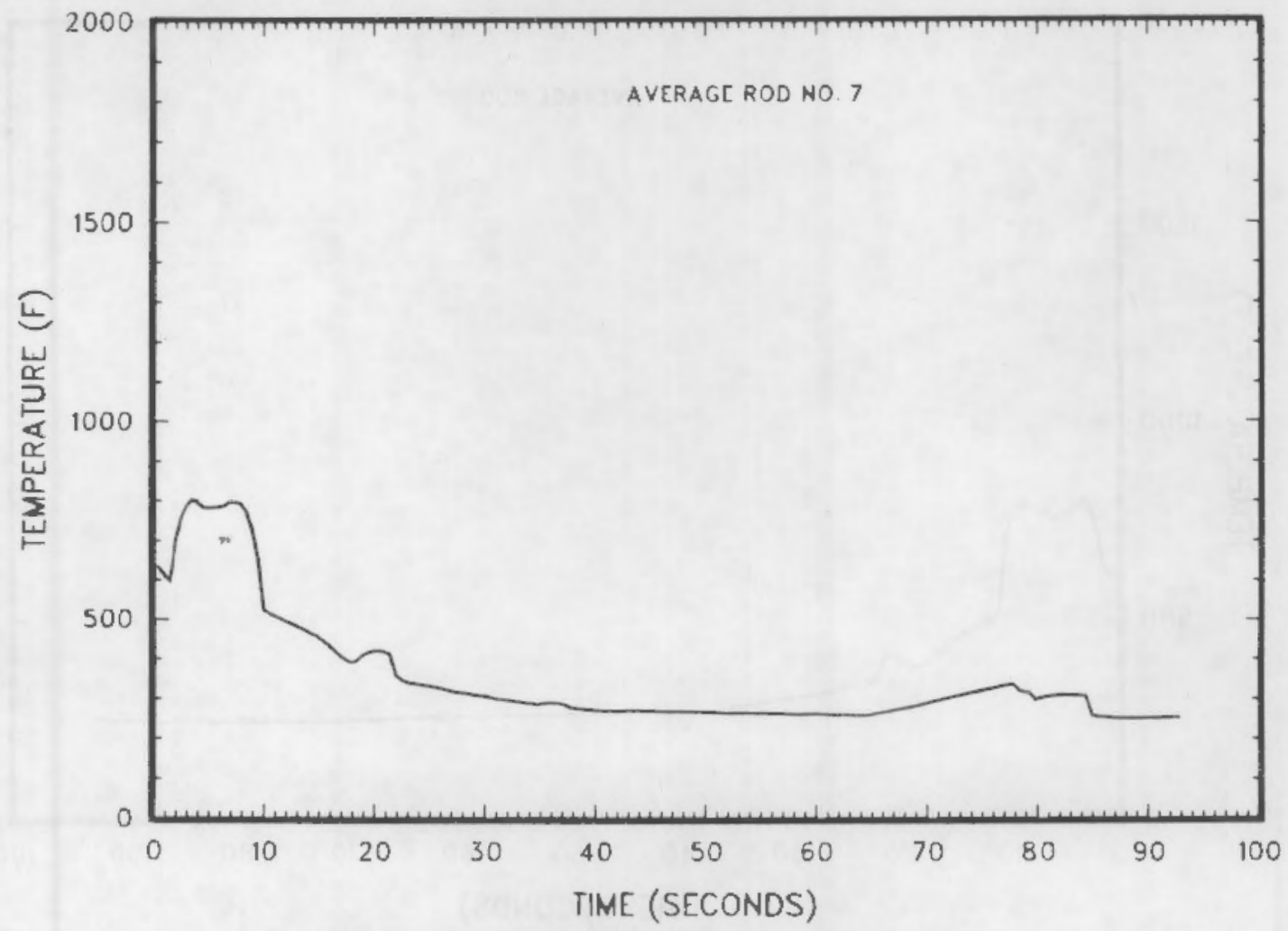

Figure C.6. Peak $\mathrm{clad}$ temperature of rod 7 vs. time 


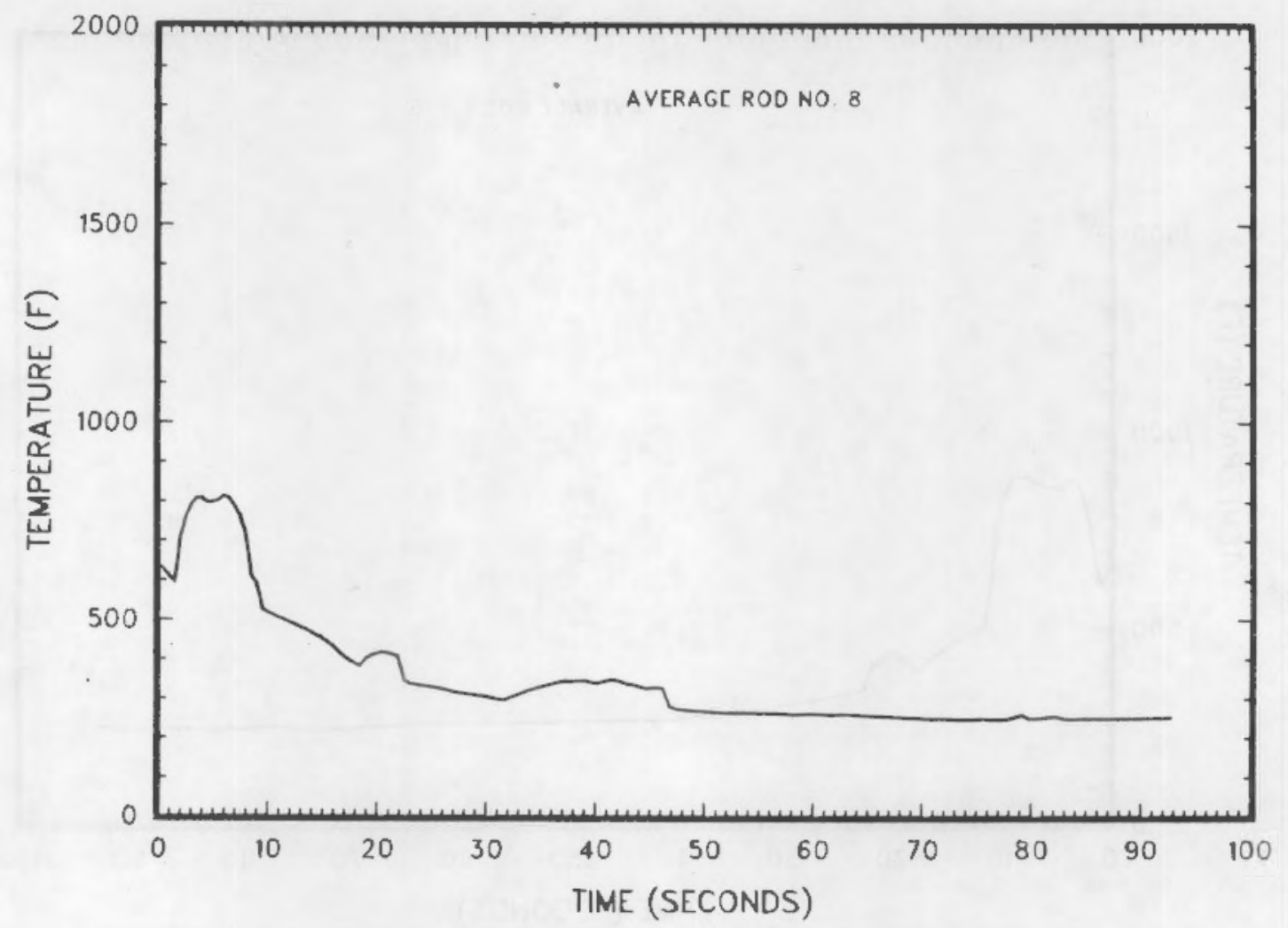

Figure C.7. Peak clad surface temperature of rod 8 vs. time

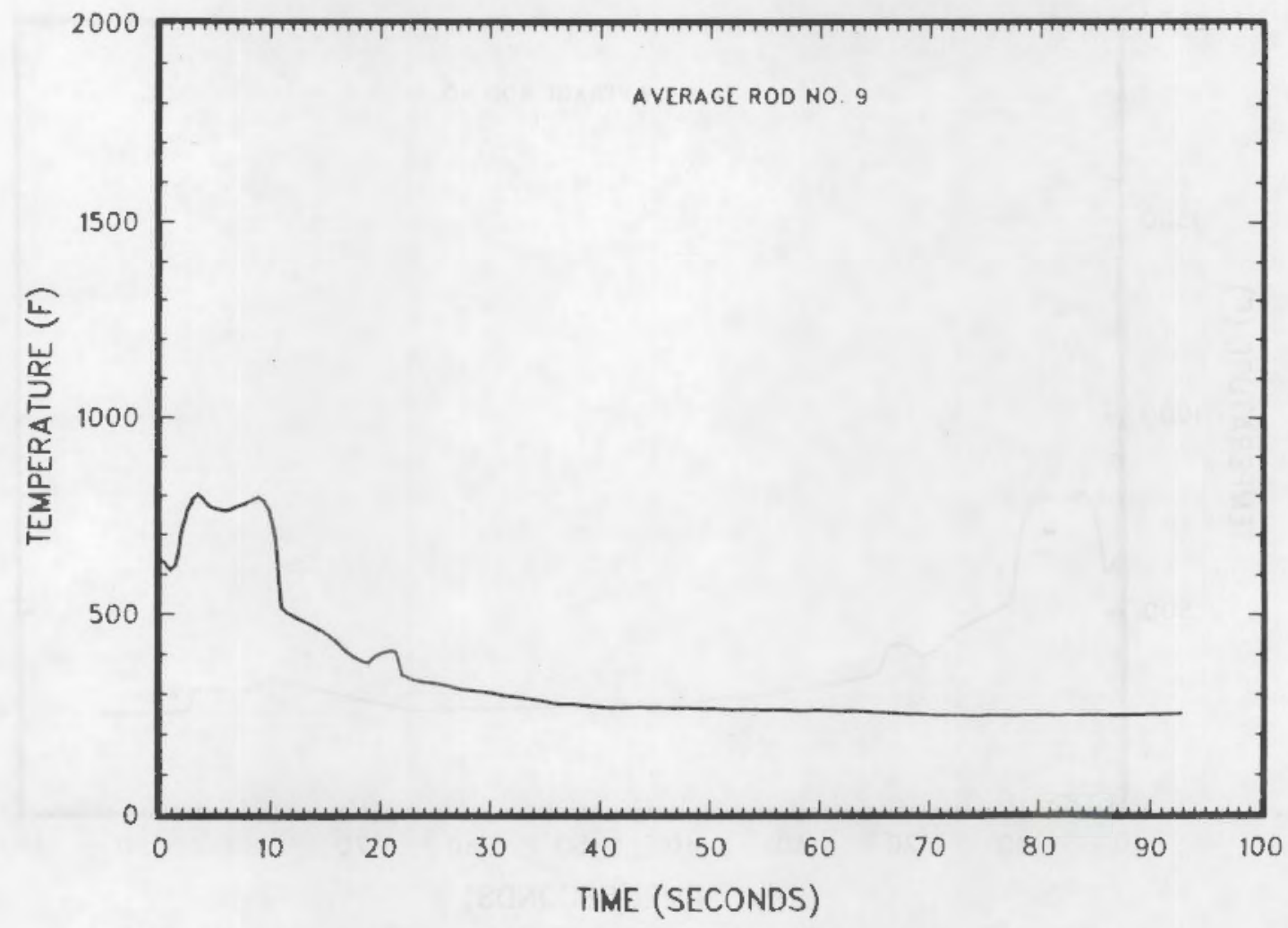

Figure C.8. Peak clad temperature of rod 9 vs. time 


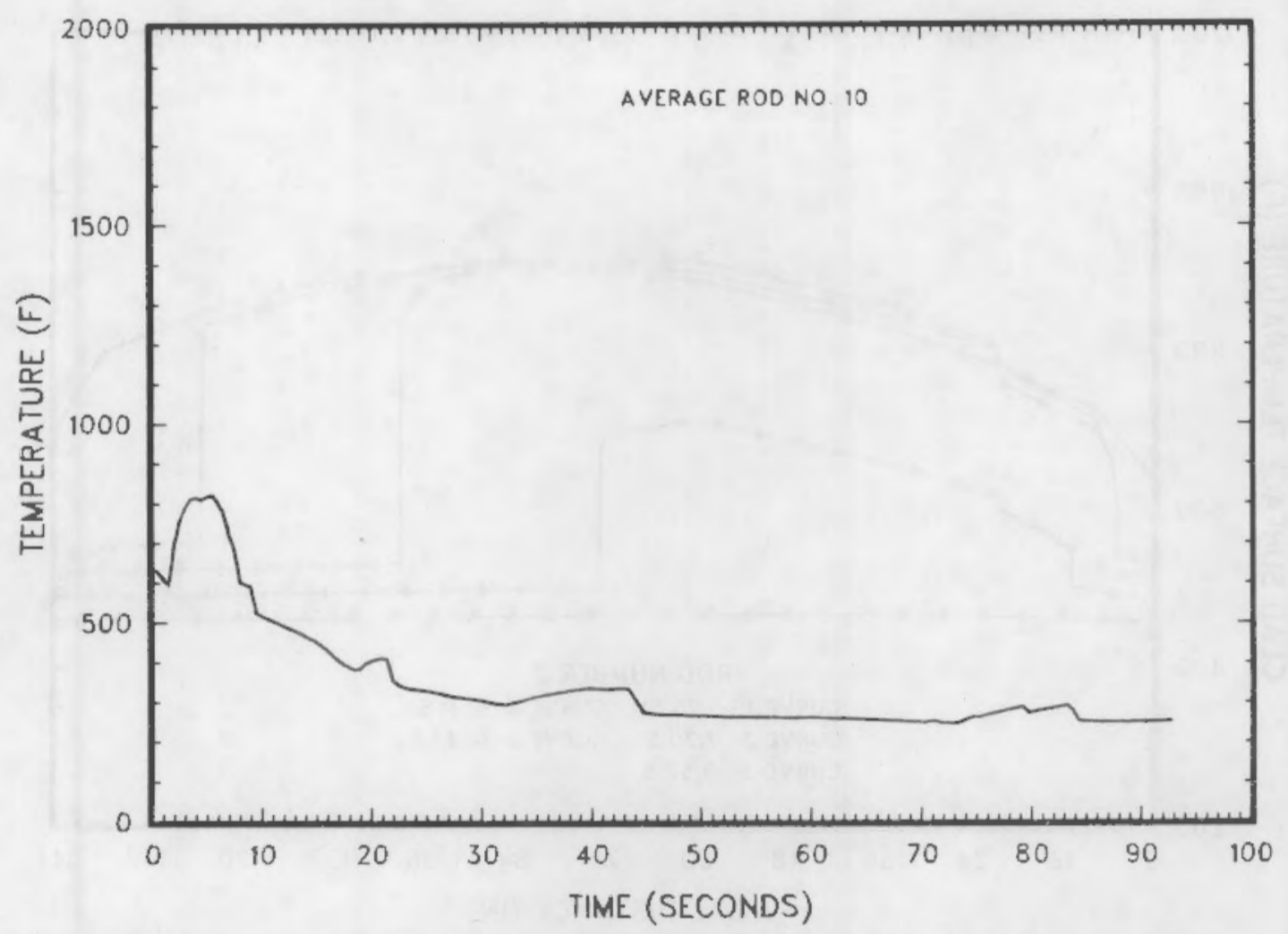

Figure C.9. Peak clad surface temperature of rod 10 vs. time

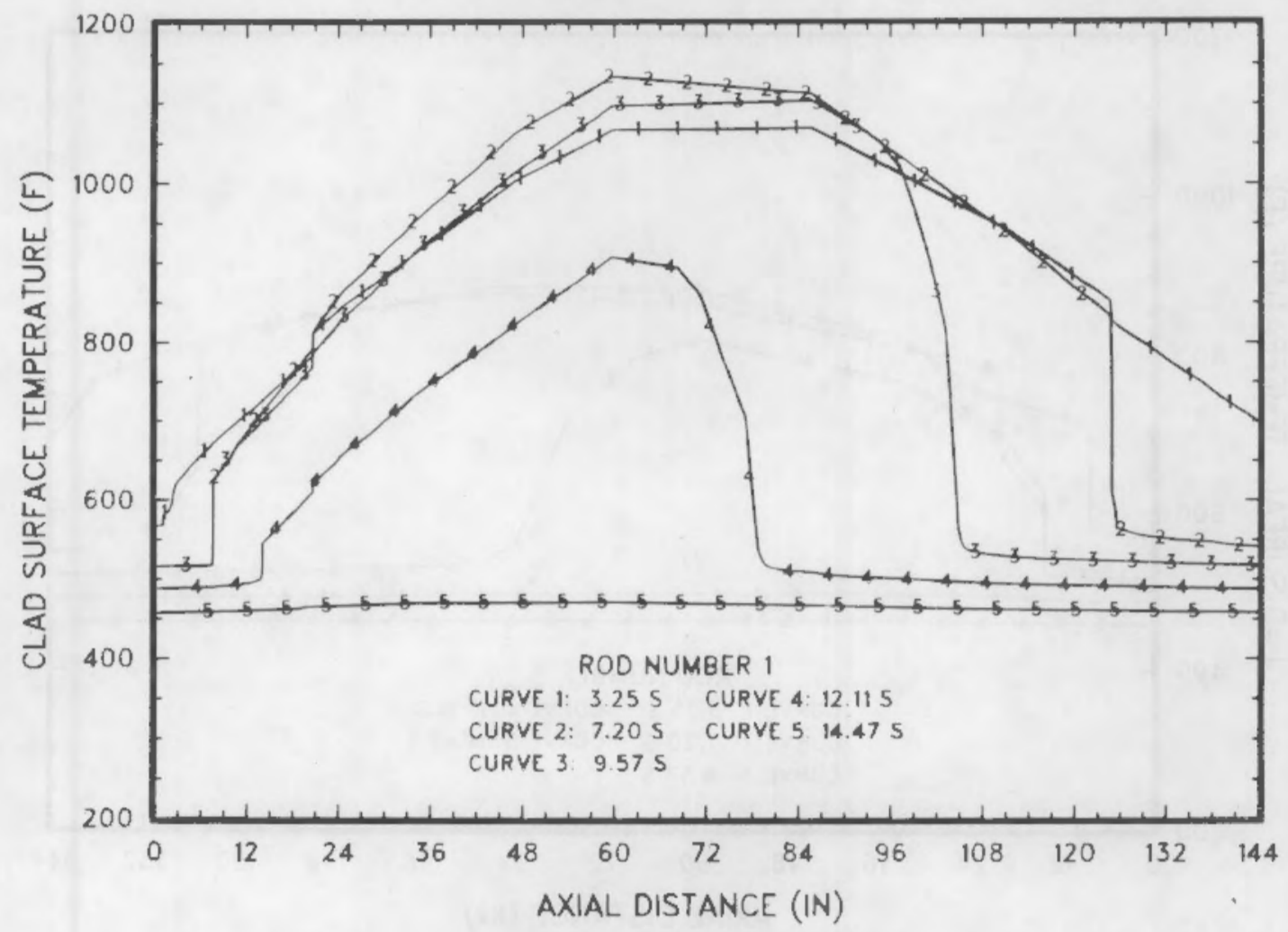

Figure C.10. Quench envelopes for rod 1 


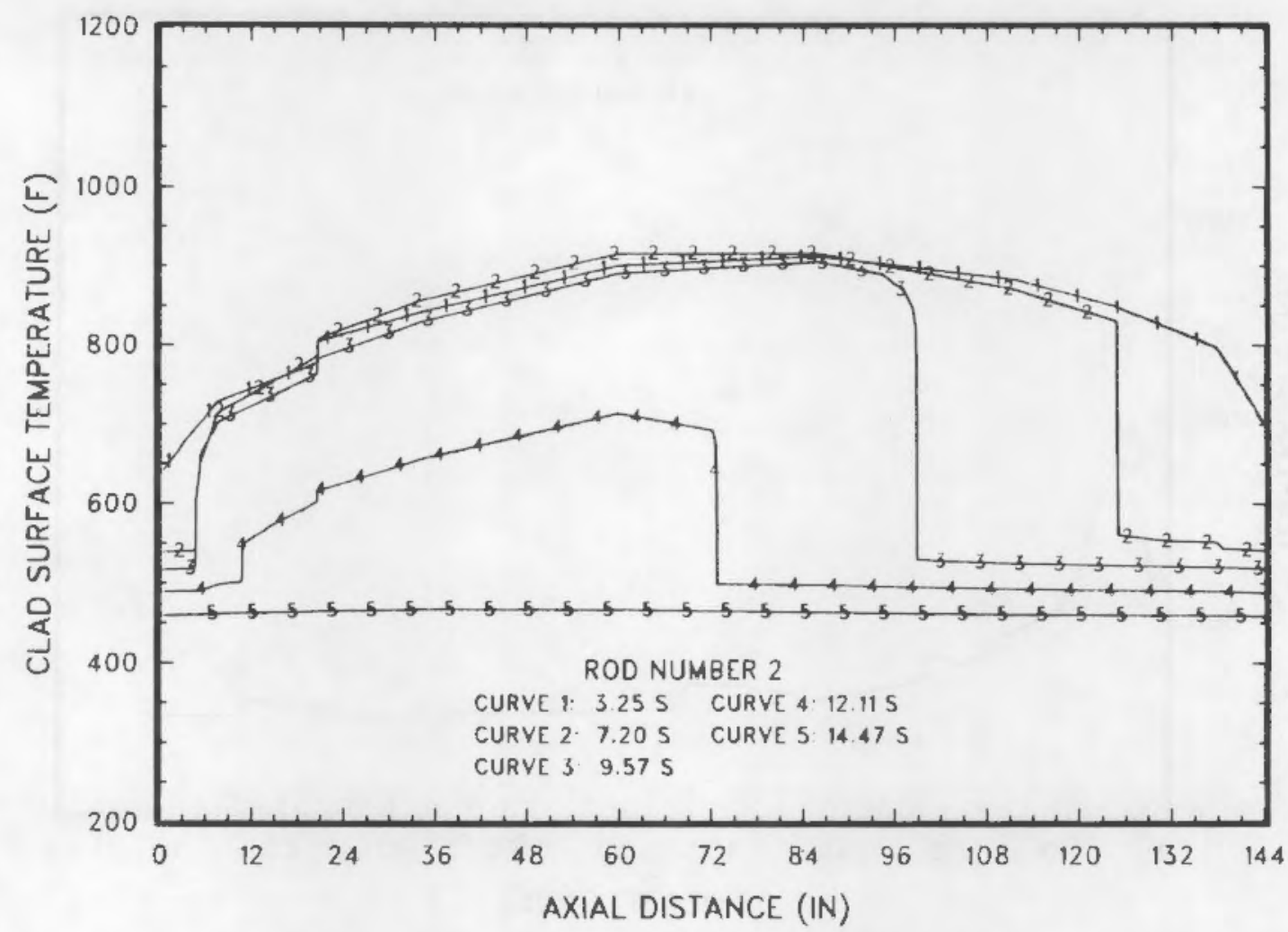

Figure C.11. Quench envelopes for rod 2

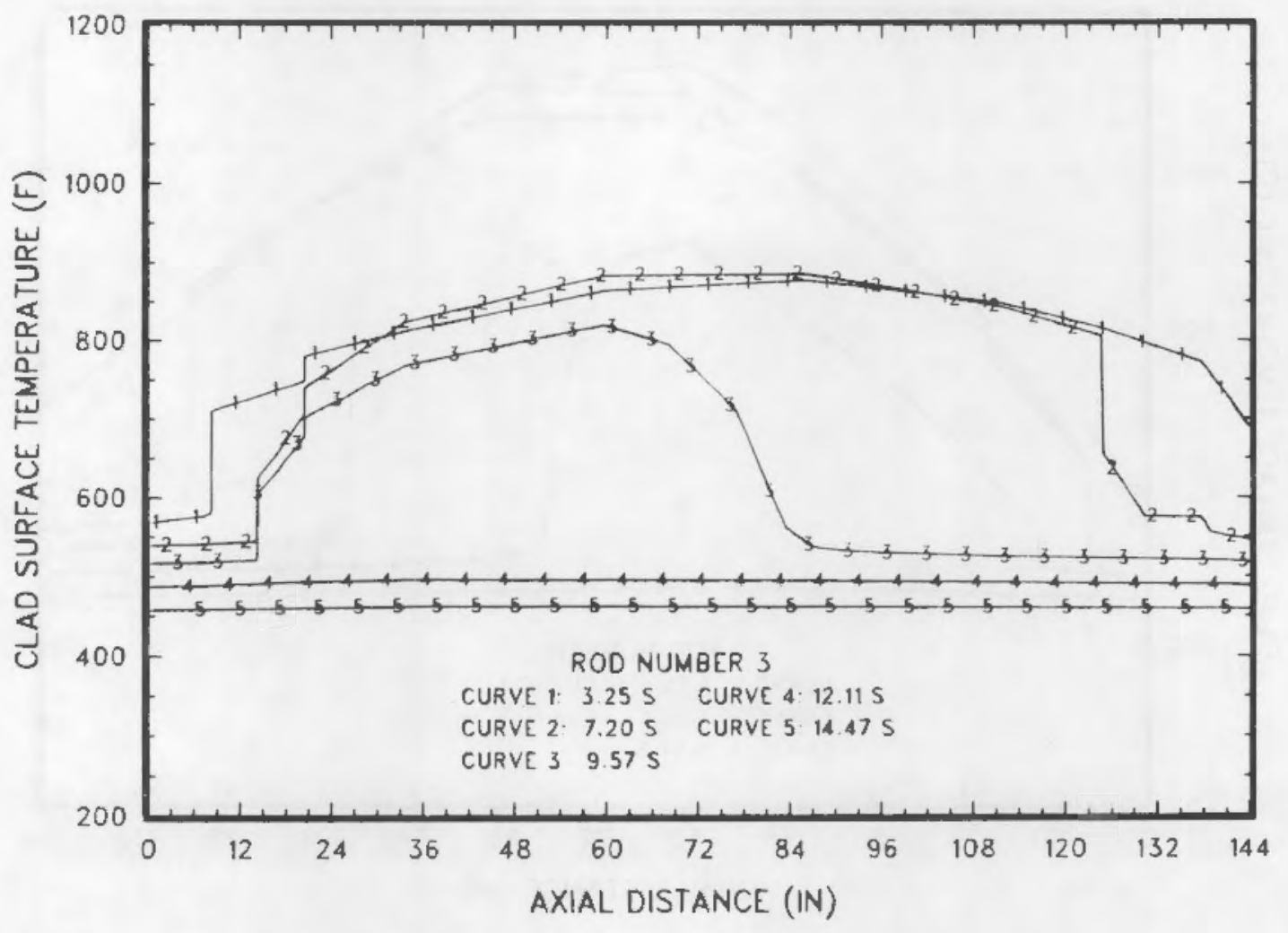

Figure C.12. Quench envelopes for rod 3 


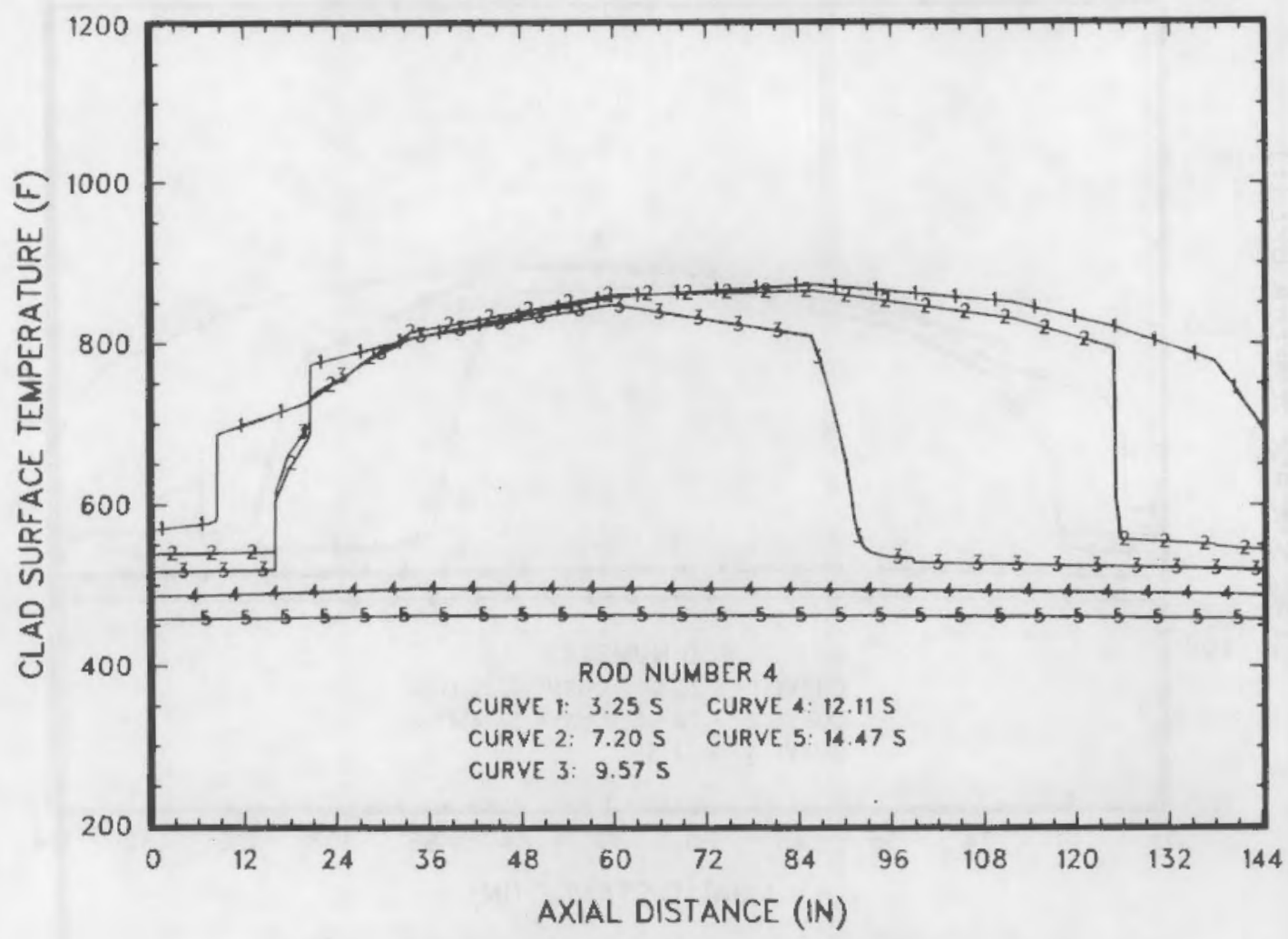

Figure C.13. Quench envelopes for rod 4

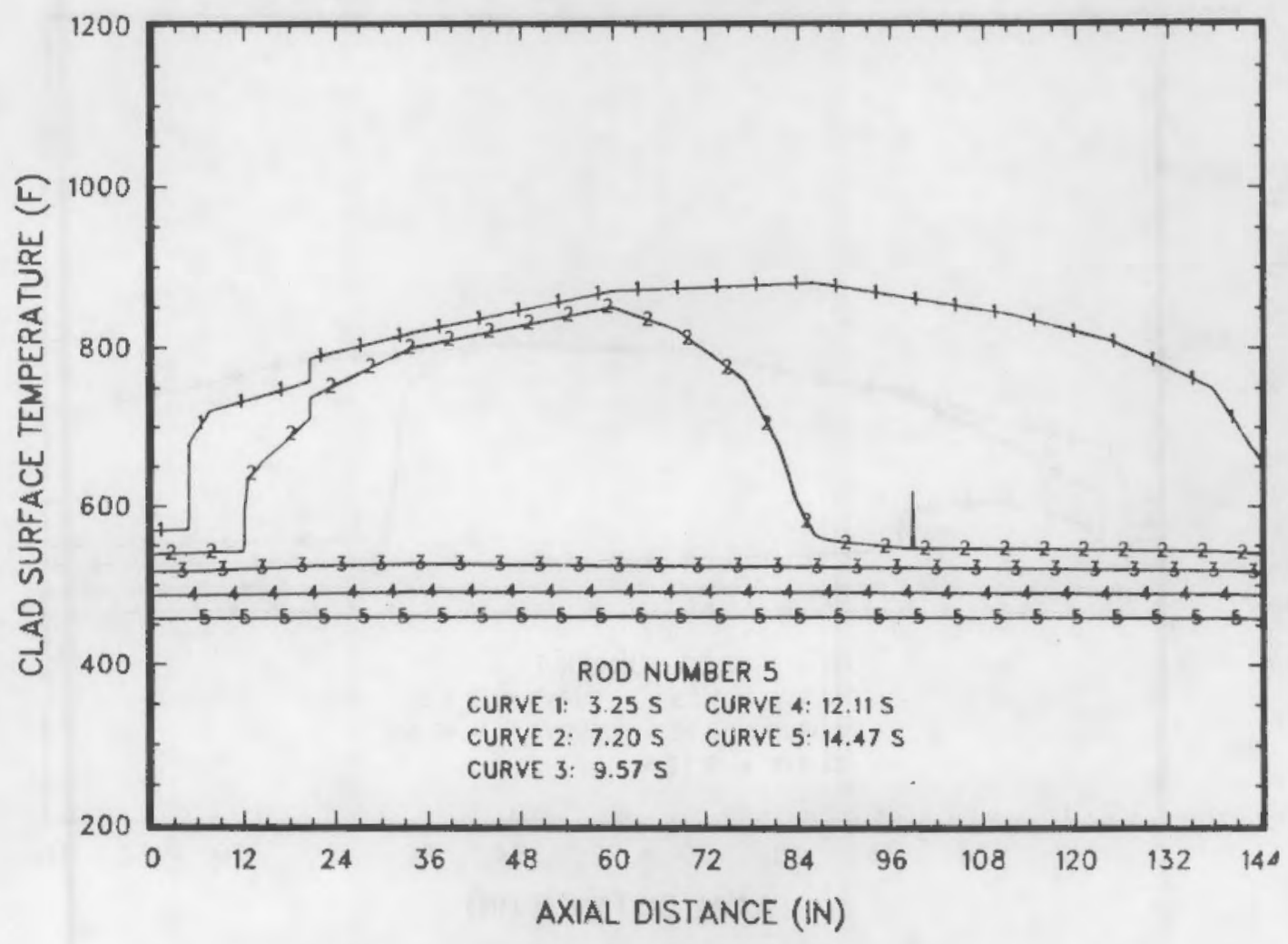

Figure C.14. Quench envelopes for rod 5 


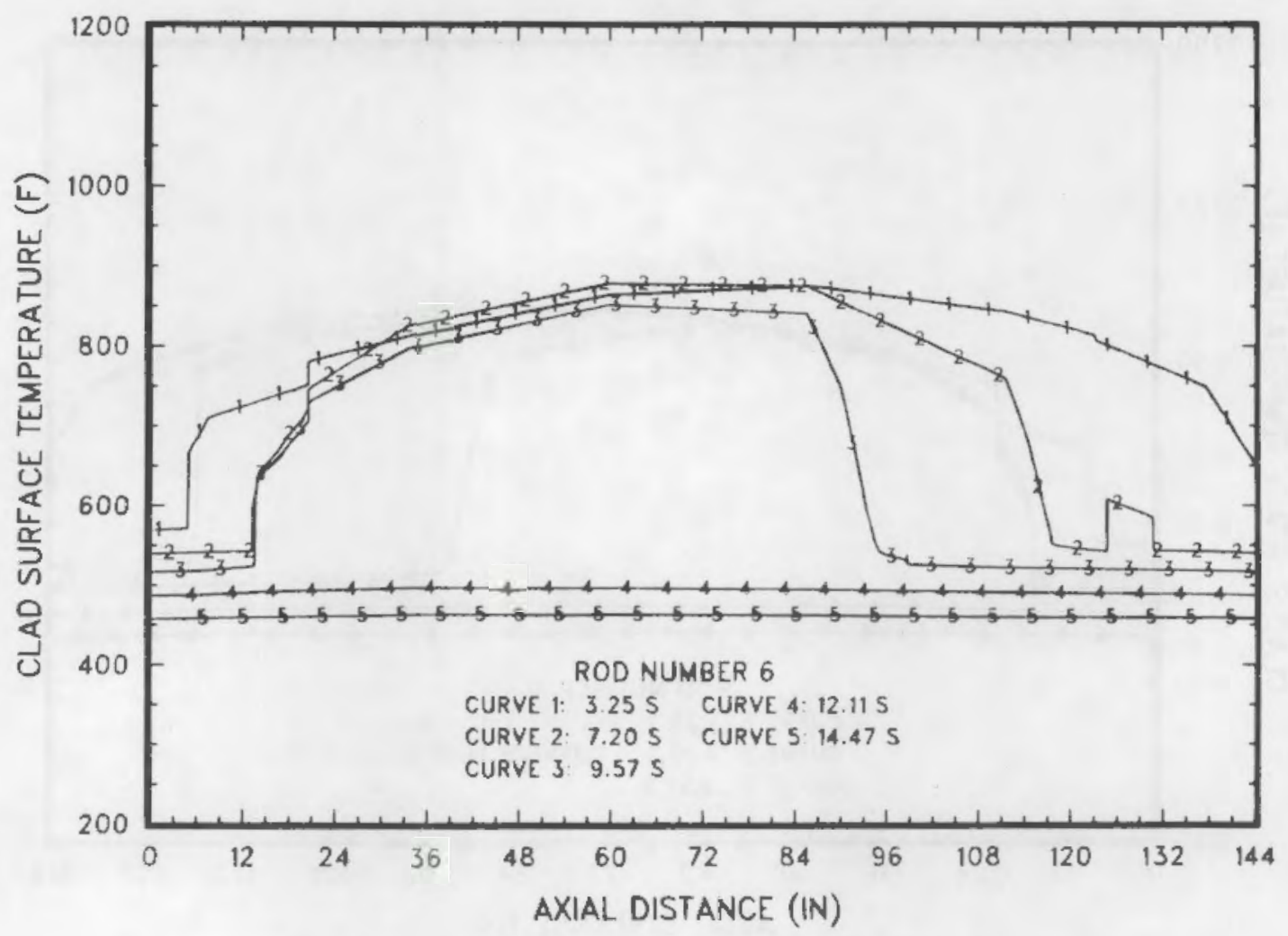

Figure C.15. Quench envelopes for rod 6

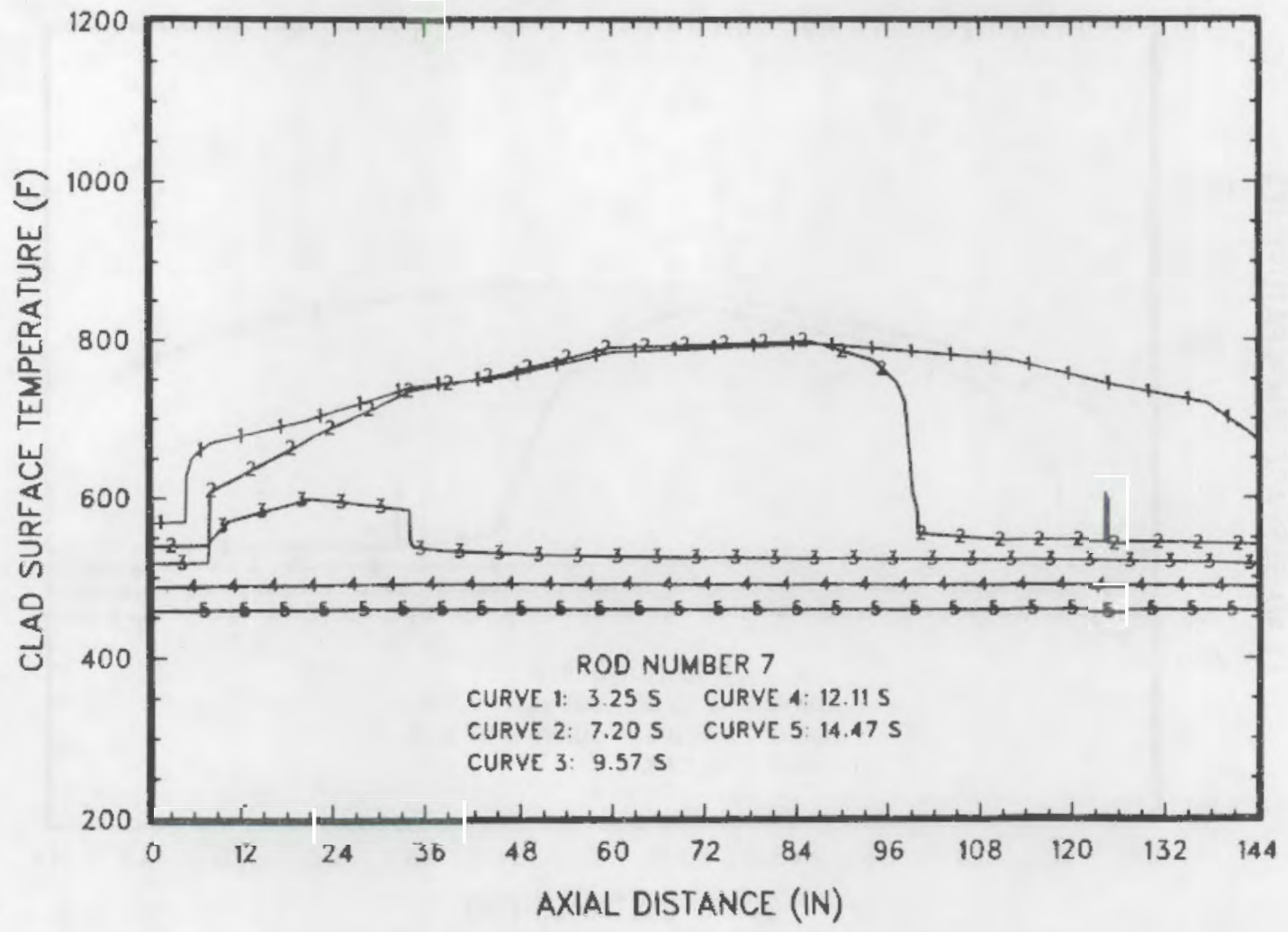

Figure C.16. Quench envelopes for $\operatorname{rod} 7$ 


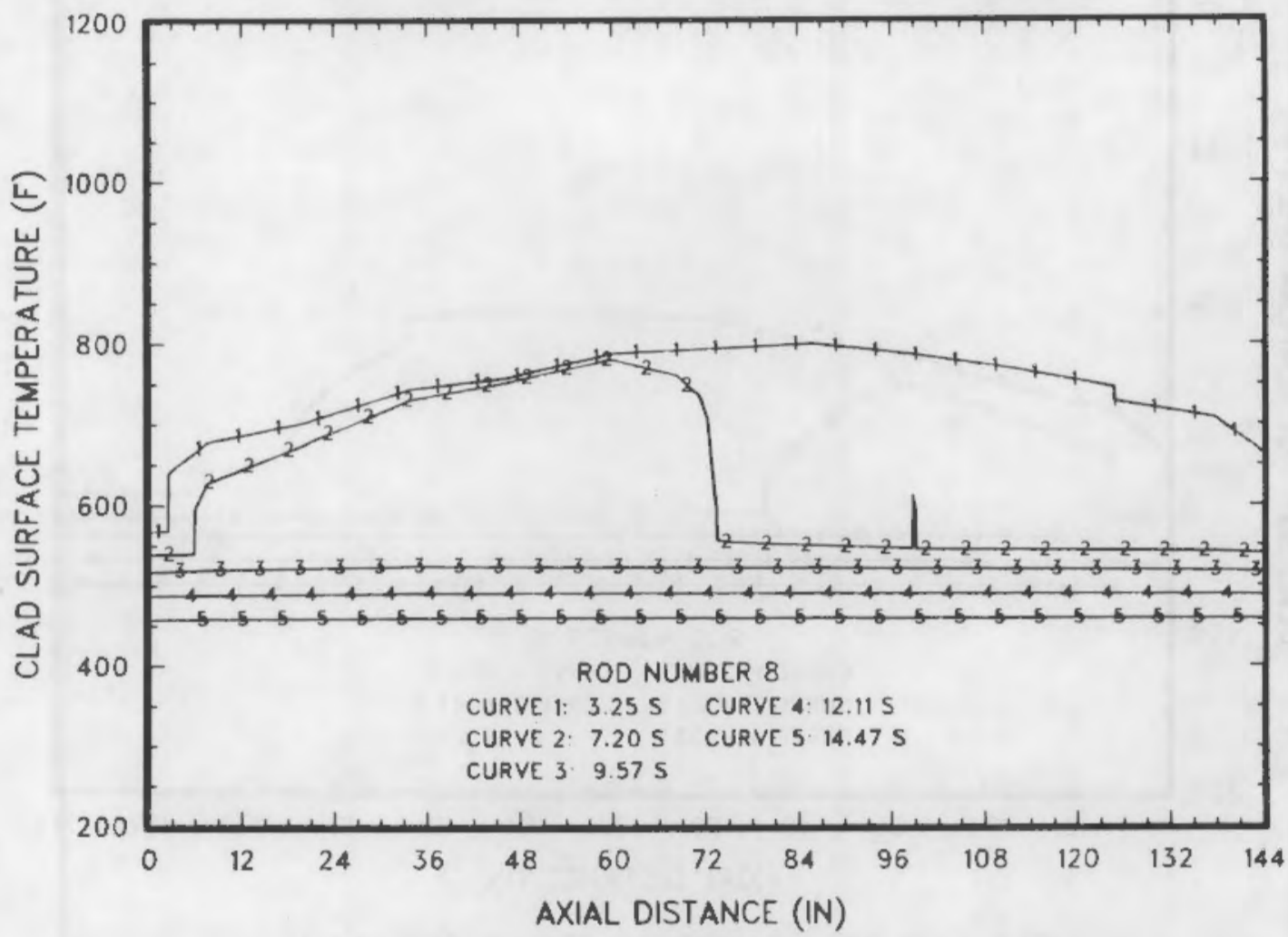

Figure C.17. Quench envelopes for rod 8

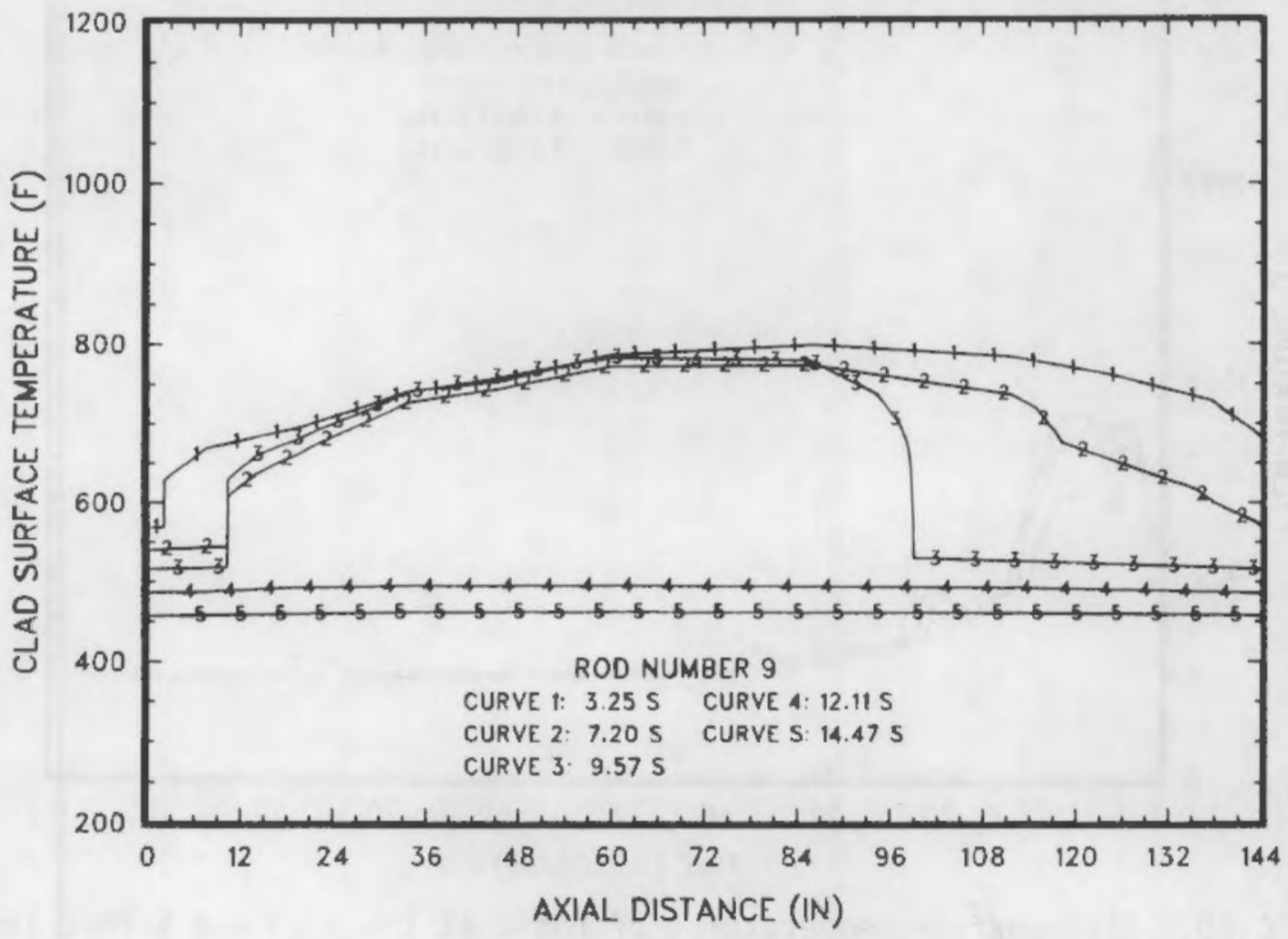

Figure C.18. Quench envelopes for rod 9 


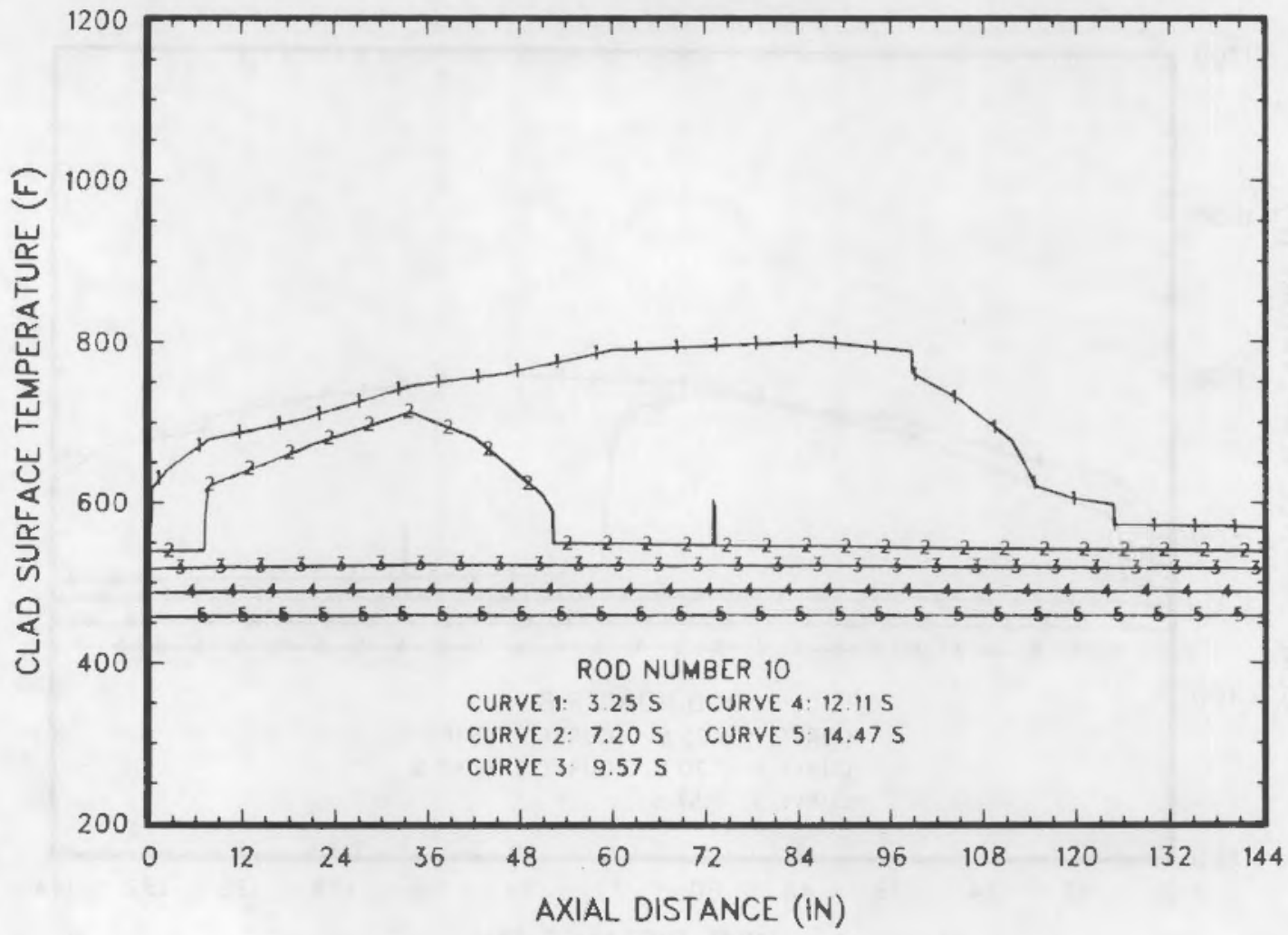

Figure C.19. Quench envelopes for rod 10

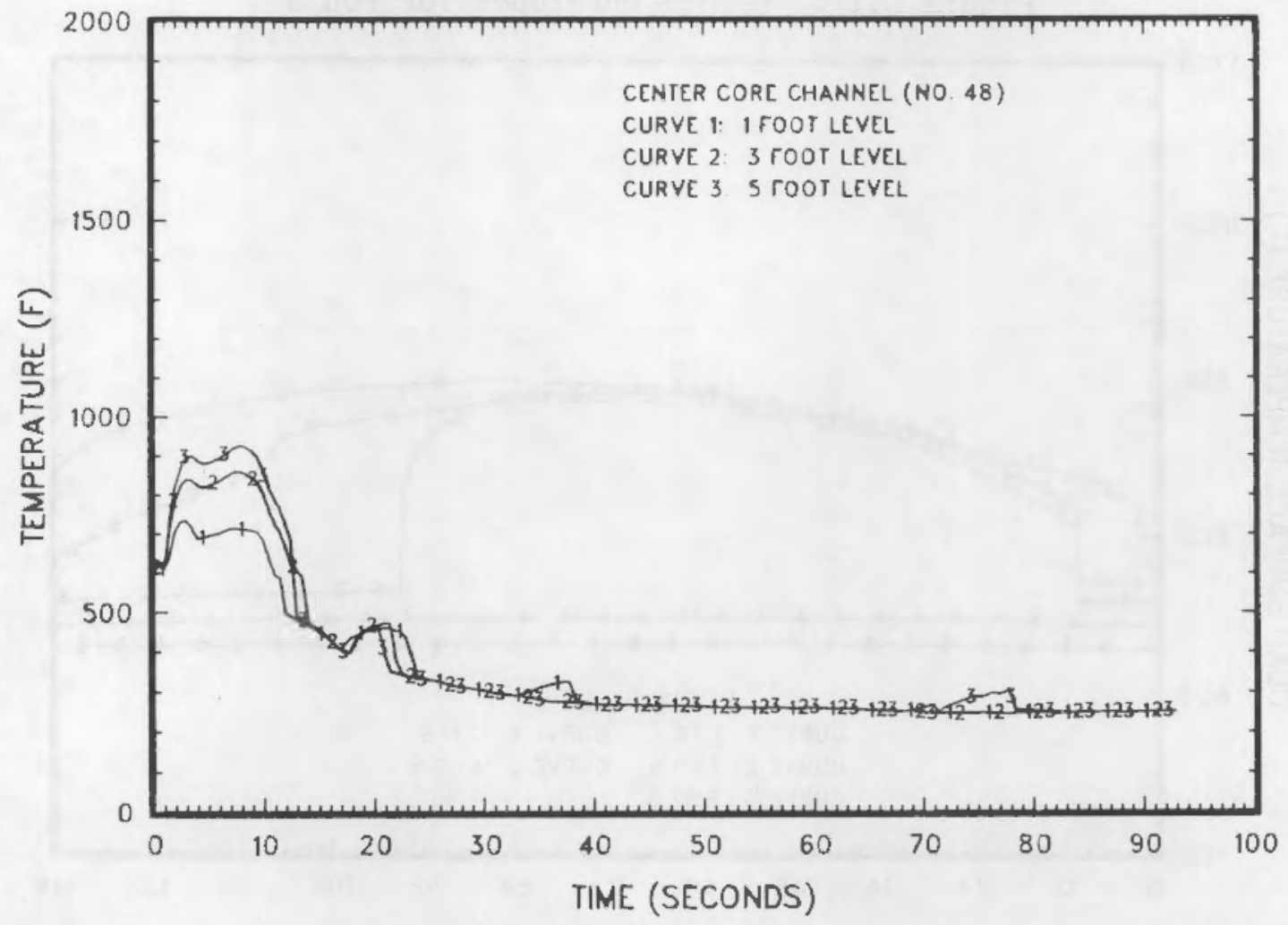

Figure C.20. Clad surface temperatures of rod 2 at the 1,3 and 5 foot levels vs. time 


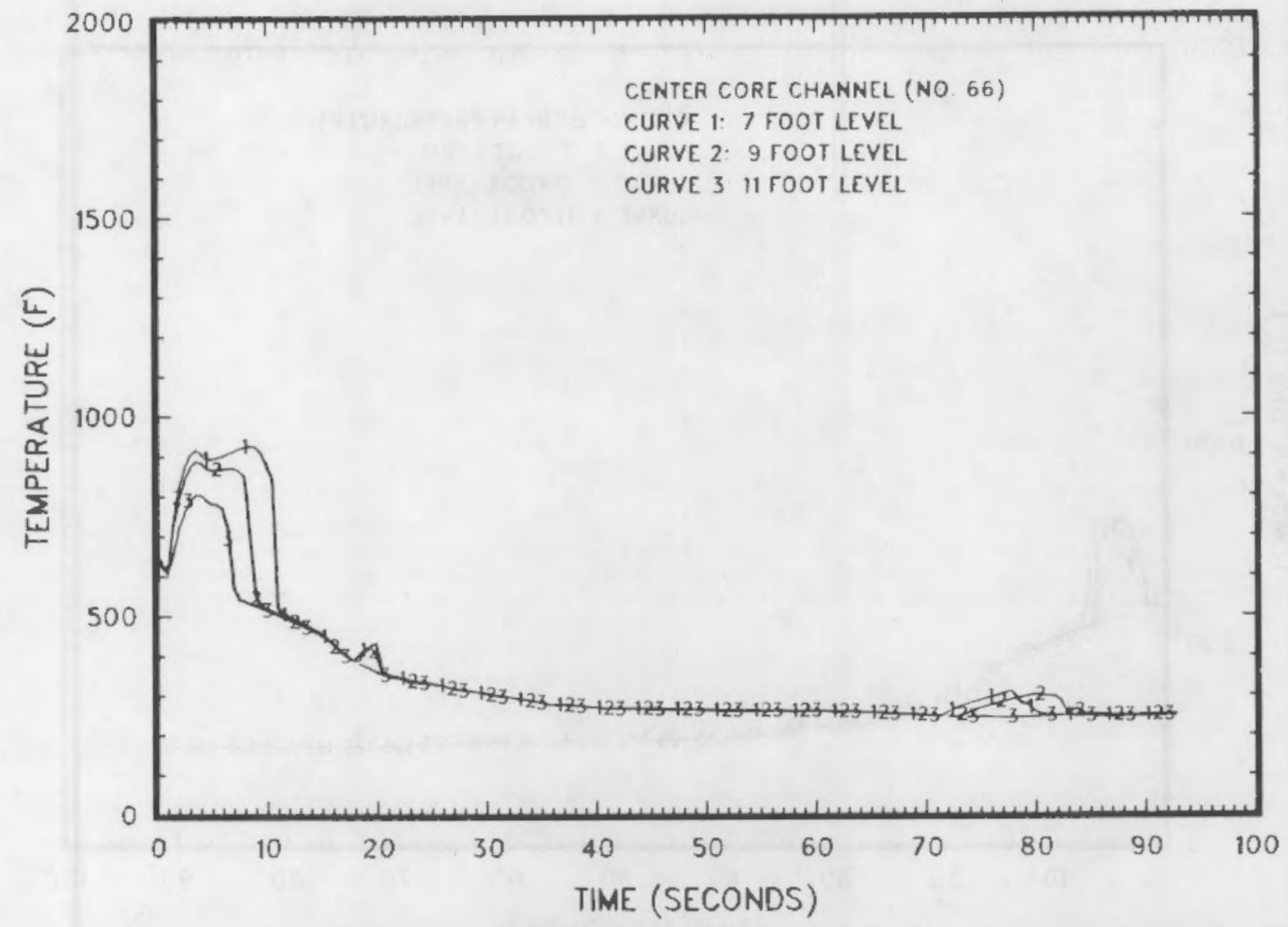

Figure C.21. Clad surface temperatures of rod 2 at the 7,9 , and 11 foot levels vs. time

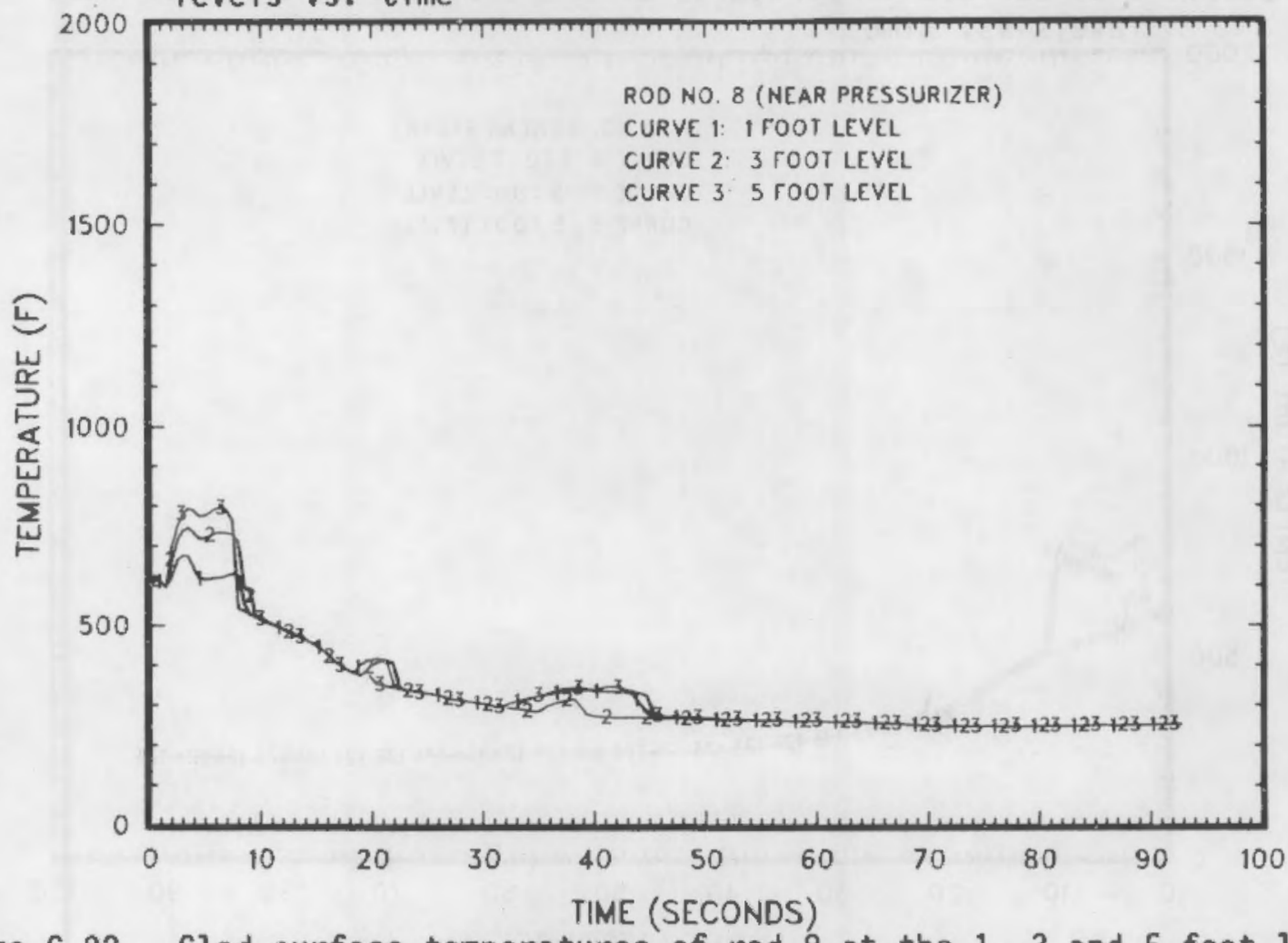

Figure C.22. Clad surface temperatures of $\operatorname{rod} 8$ at the 1,3 and 5 foot levels vs. time 


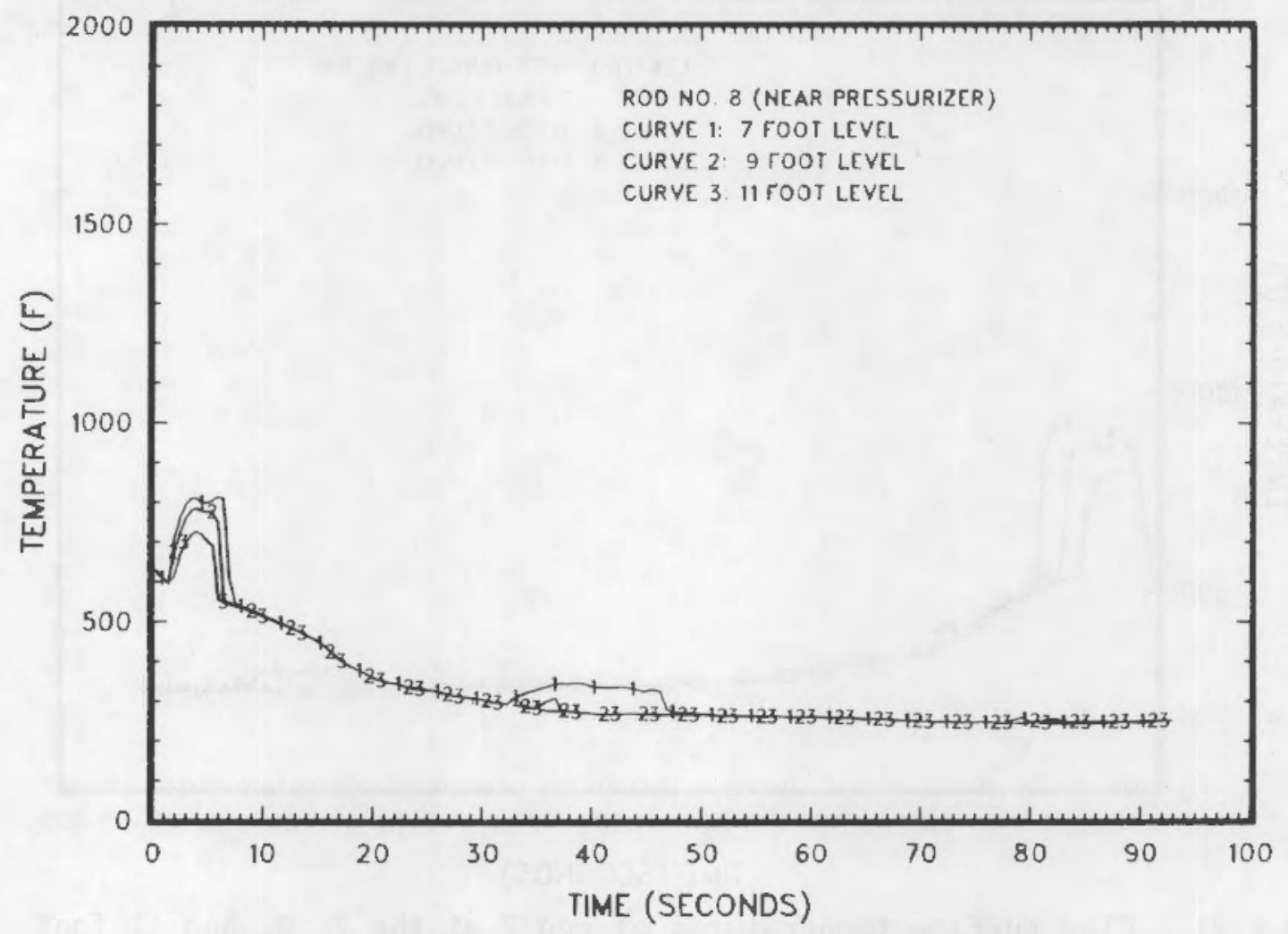

Figure C.23. Clad surface temperatures of $\operatorname{rod} 8$ at the 7,9 and 11 foot levels vs. time

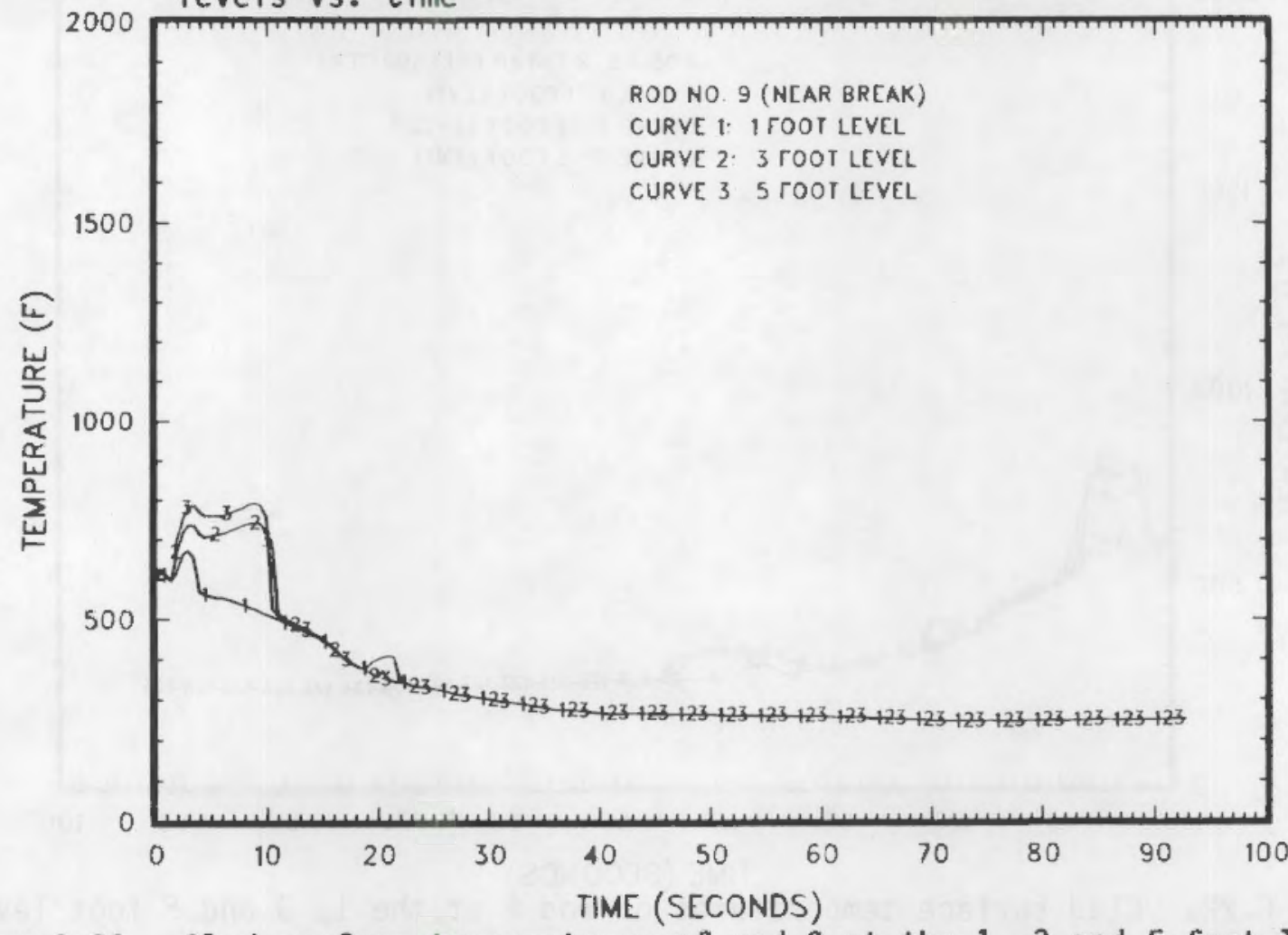

Figure C.24. Clad surface temperatures of $\operatorname{rod} 9$ at the 1,3 and 5 foot levels vs. time 


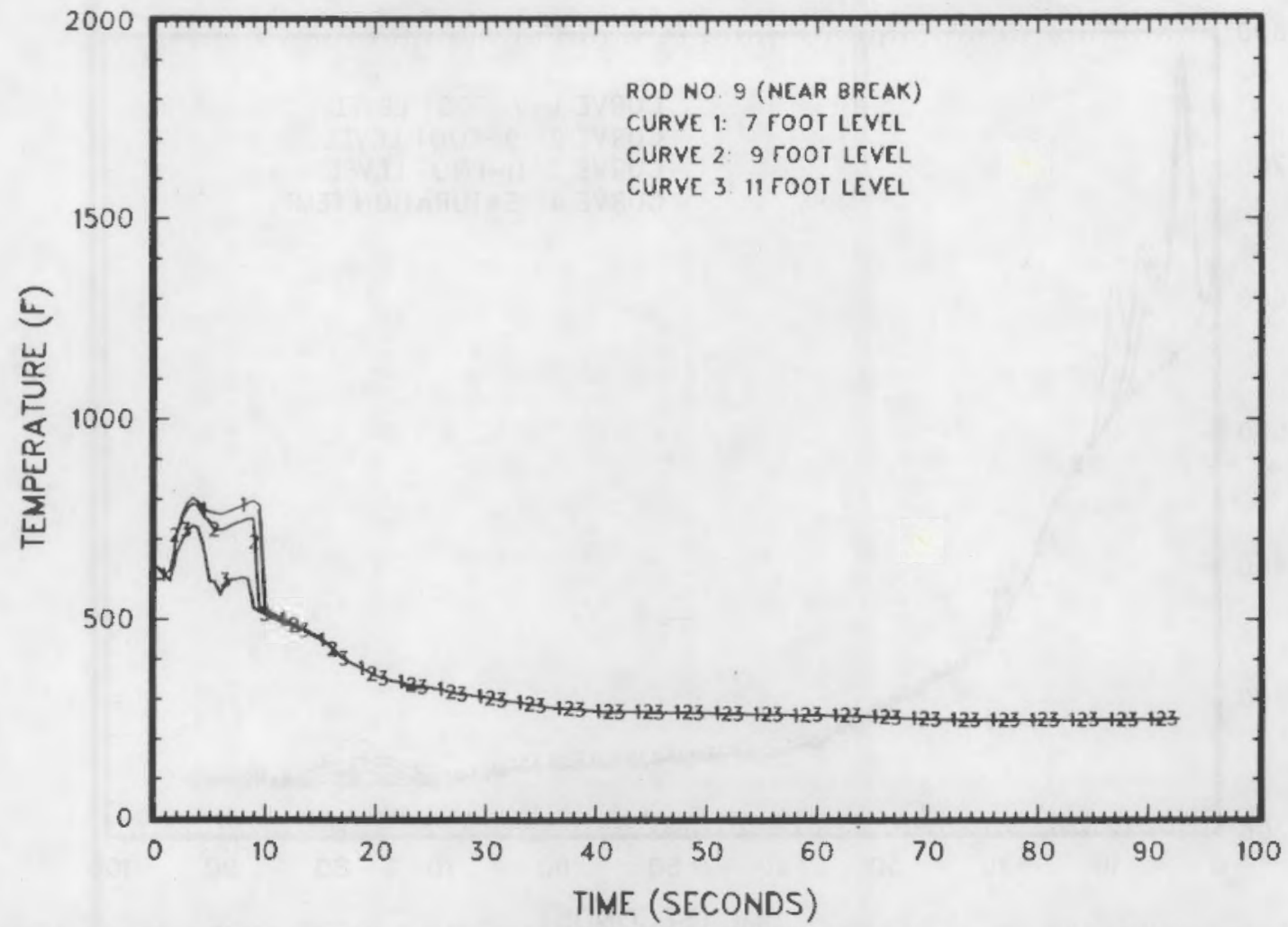

Figure C.25. Clad surface temperatures of $\operatorname{rod} 9$ at the 7,9 and 11 foot levels vs. time

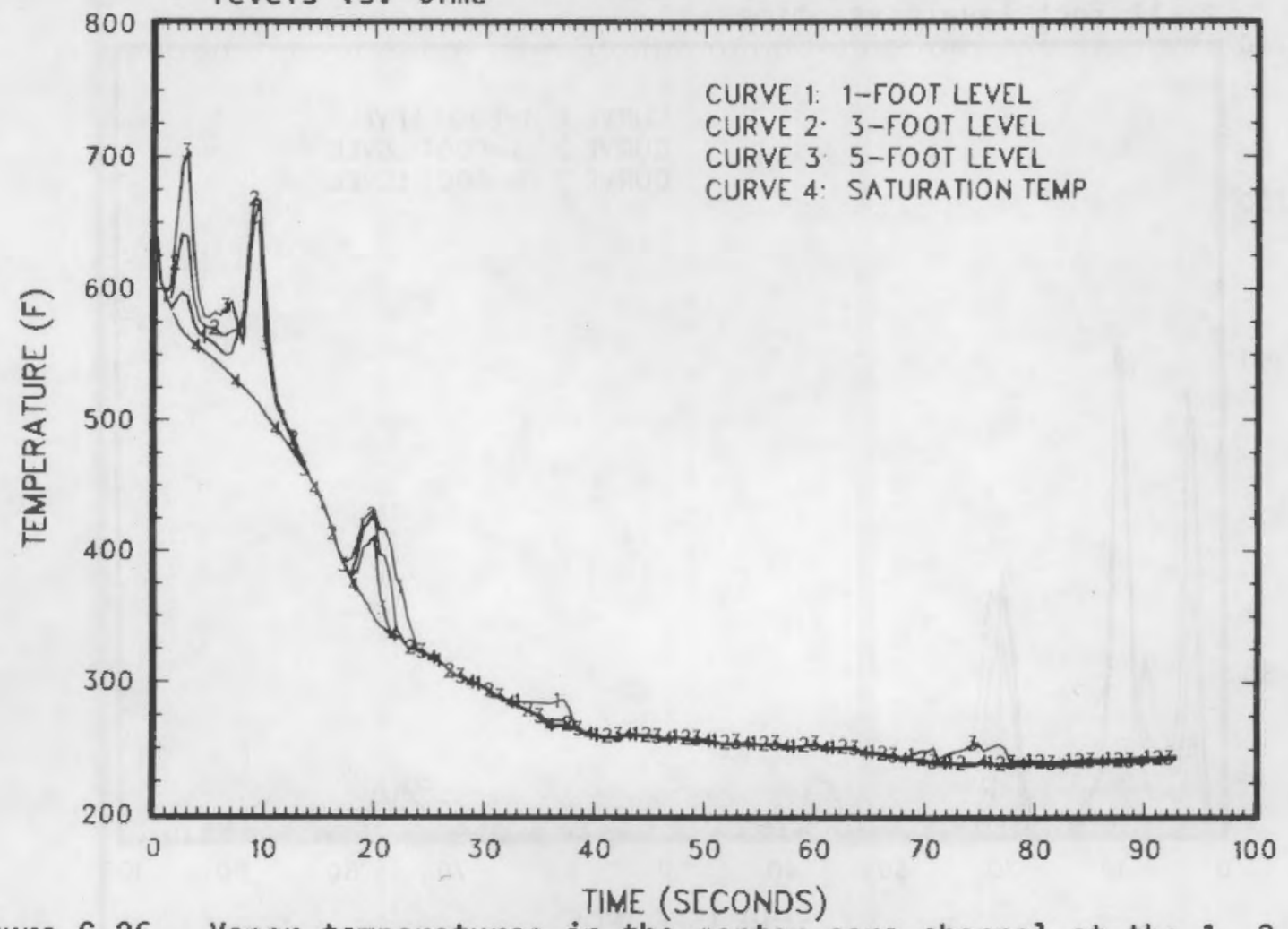

Figure C.26. Vapor temperatures in the center core channel at the 1,3 and 5 foot levels vs. time 


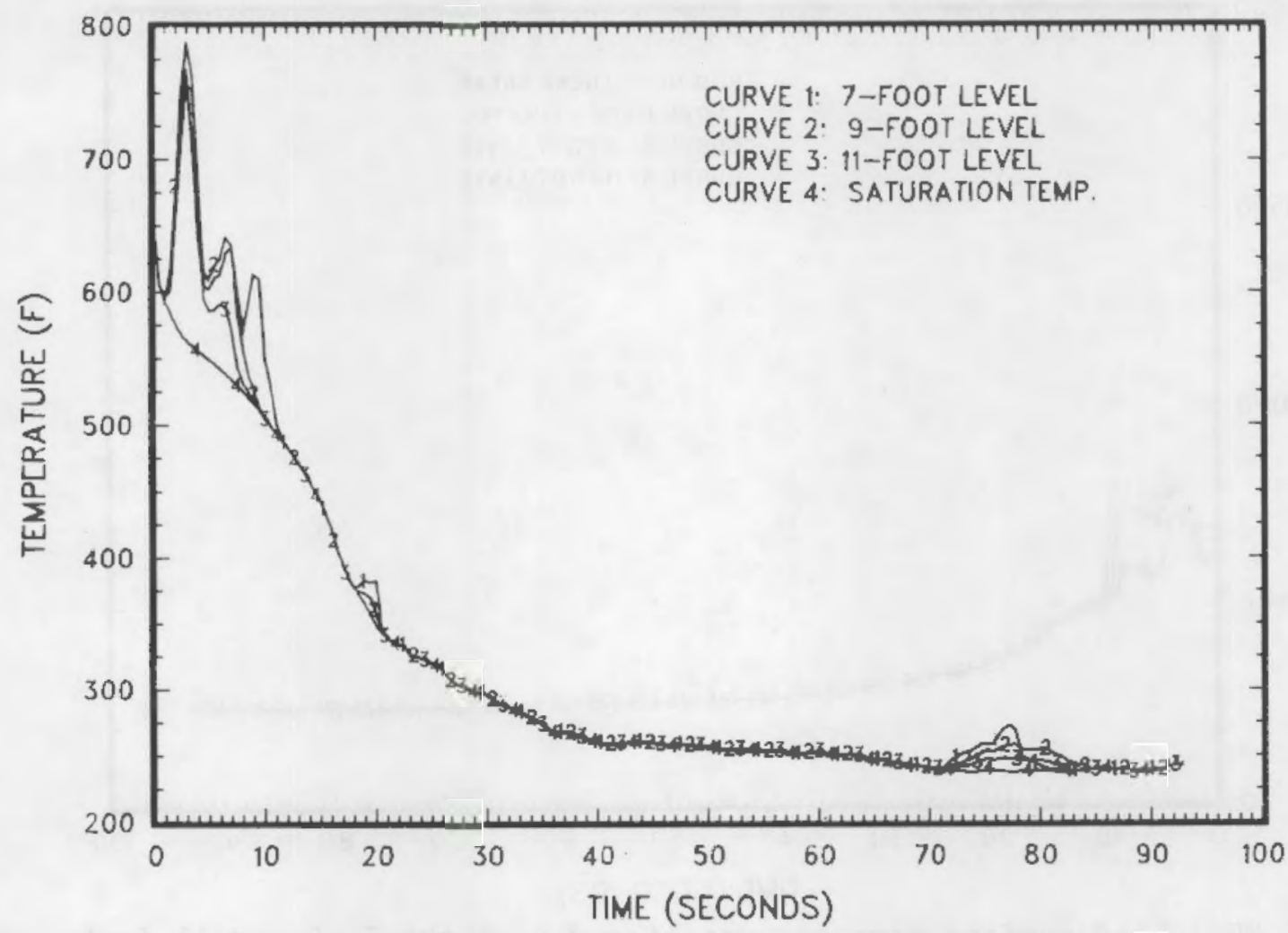

Figure C.27. Vapor temperatures in the center core channel at the 7, 9 and 11 foot levels vs. time

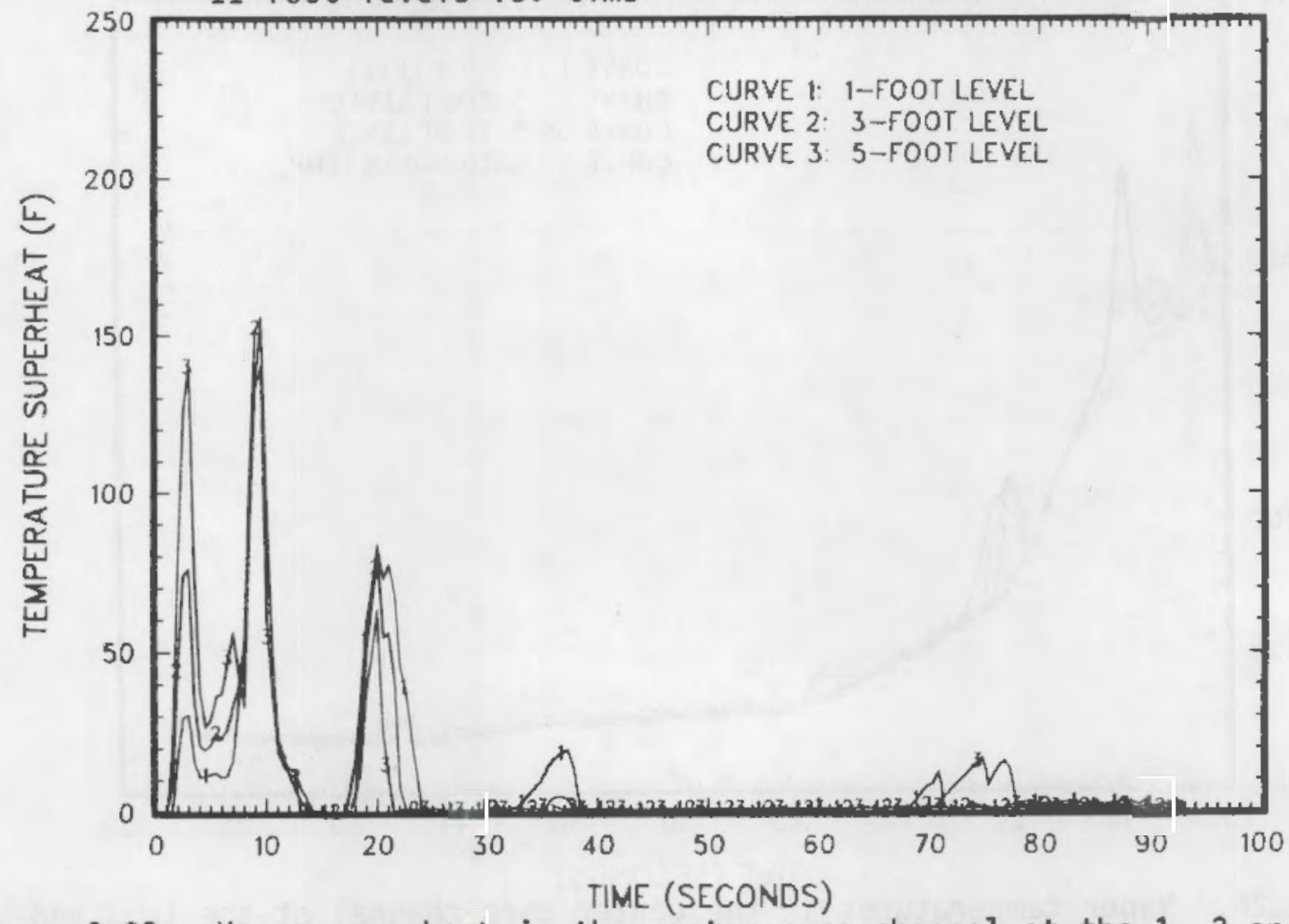

Figure C.28. Vapor superheat in the center core channel at the 1,3 and 5 foot levels vs. time 


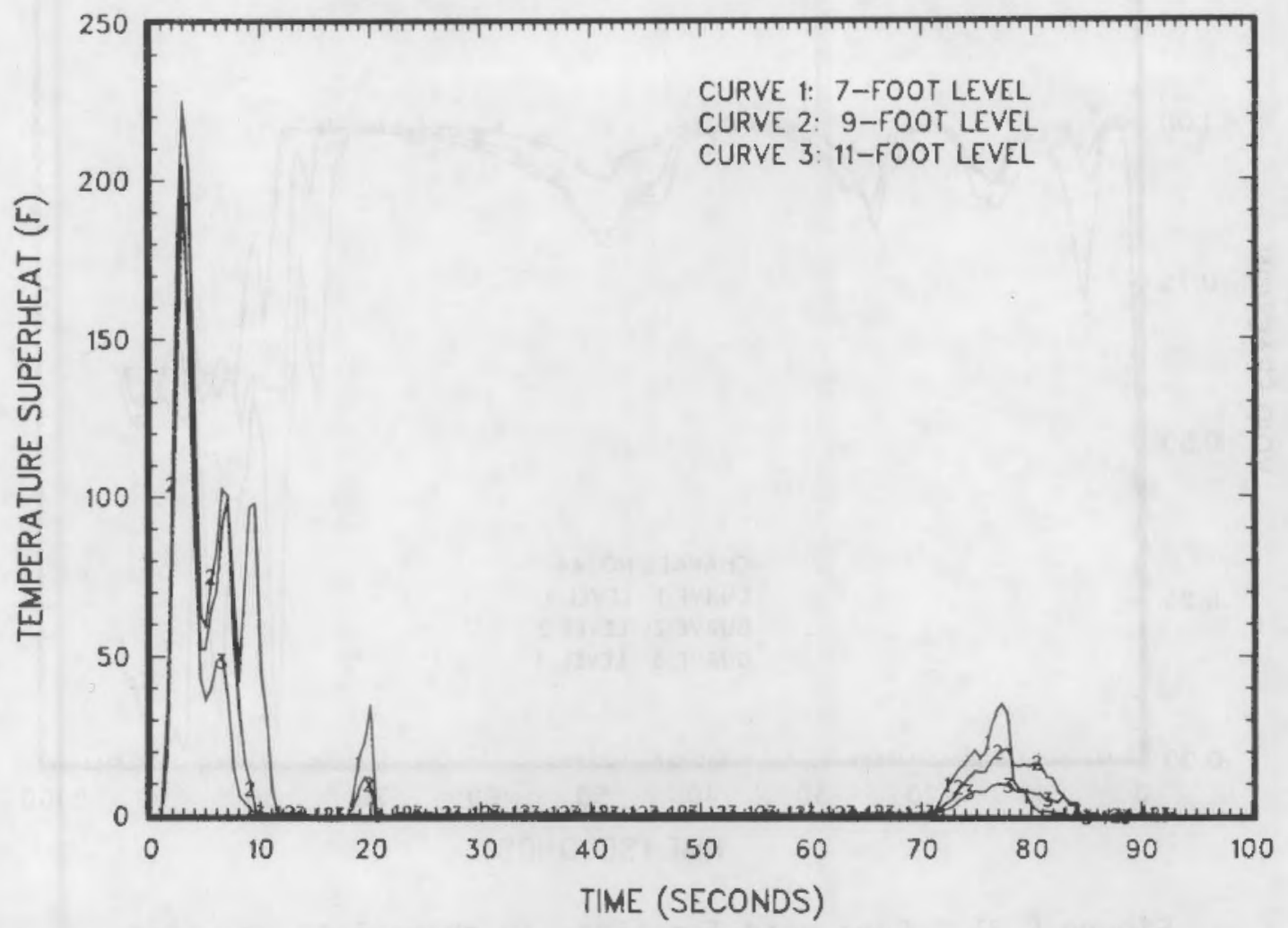

Figure C.29. Vapor superheat in the center core channel at the 7,9 and 11 foot levels vs. time

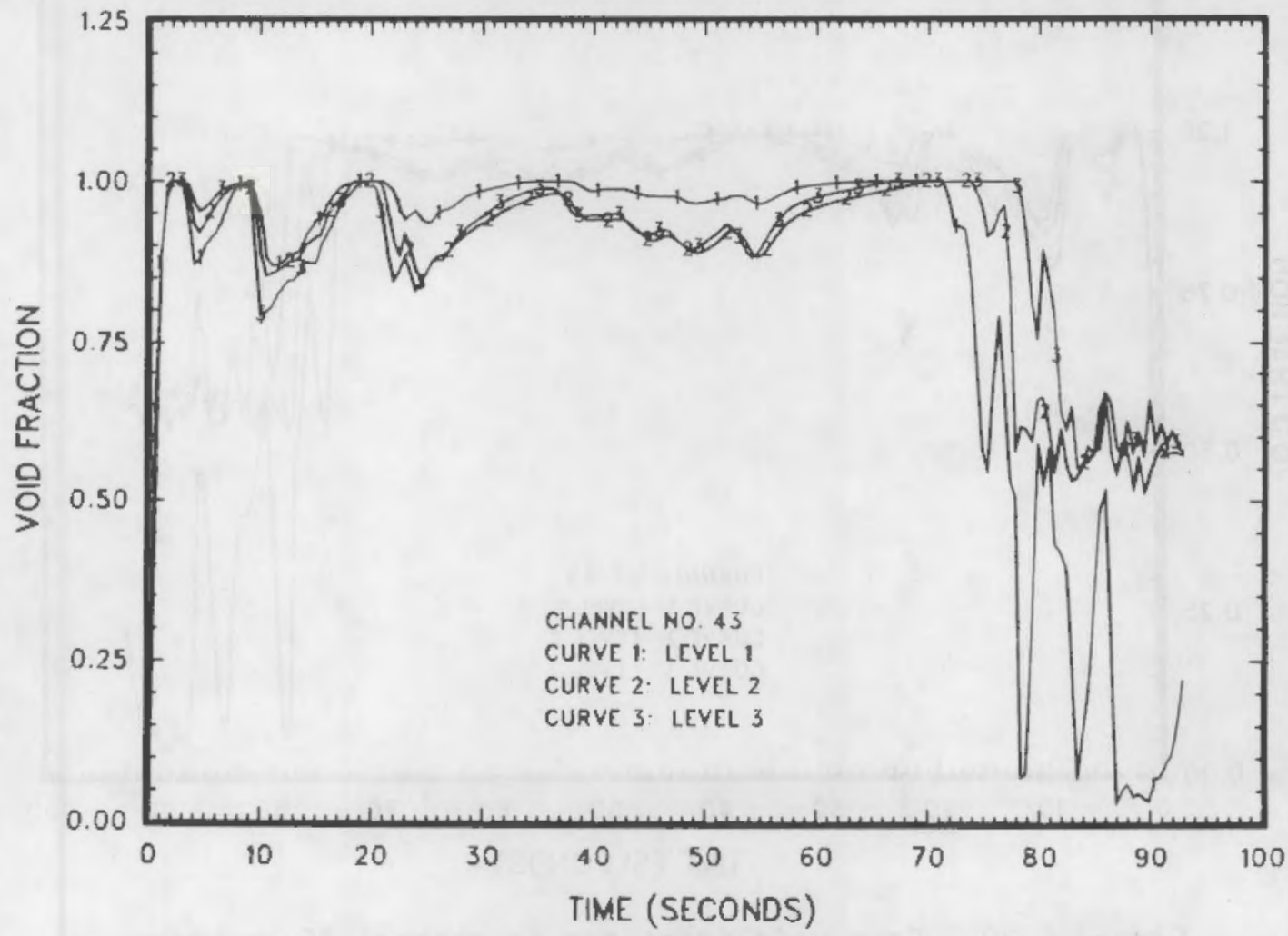

Figure C.30. Core void fractions in channel 43 vs. time 


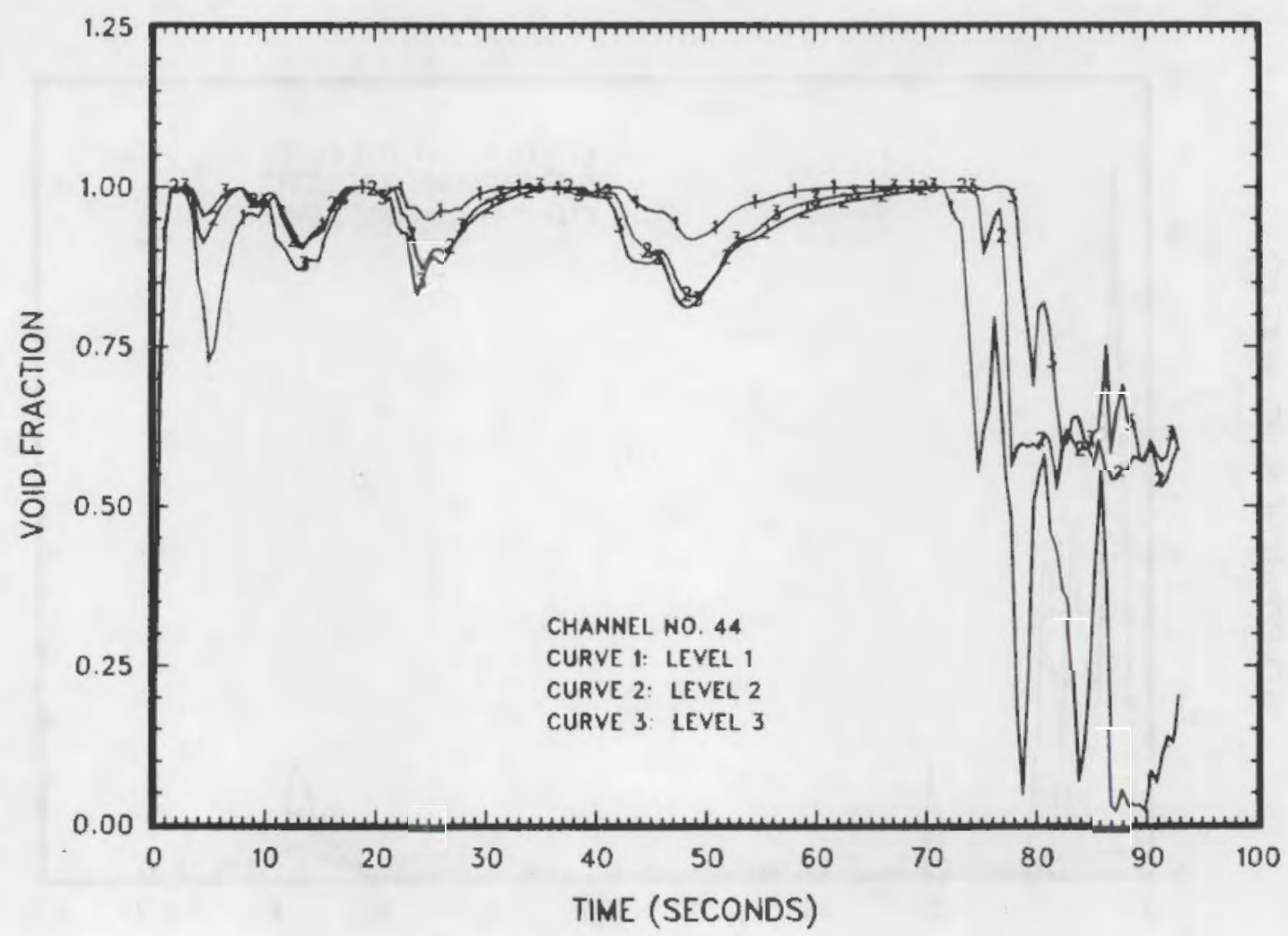

Figure C.31. Core void fractions in channel 44 vs. time

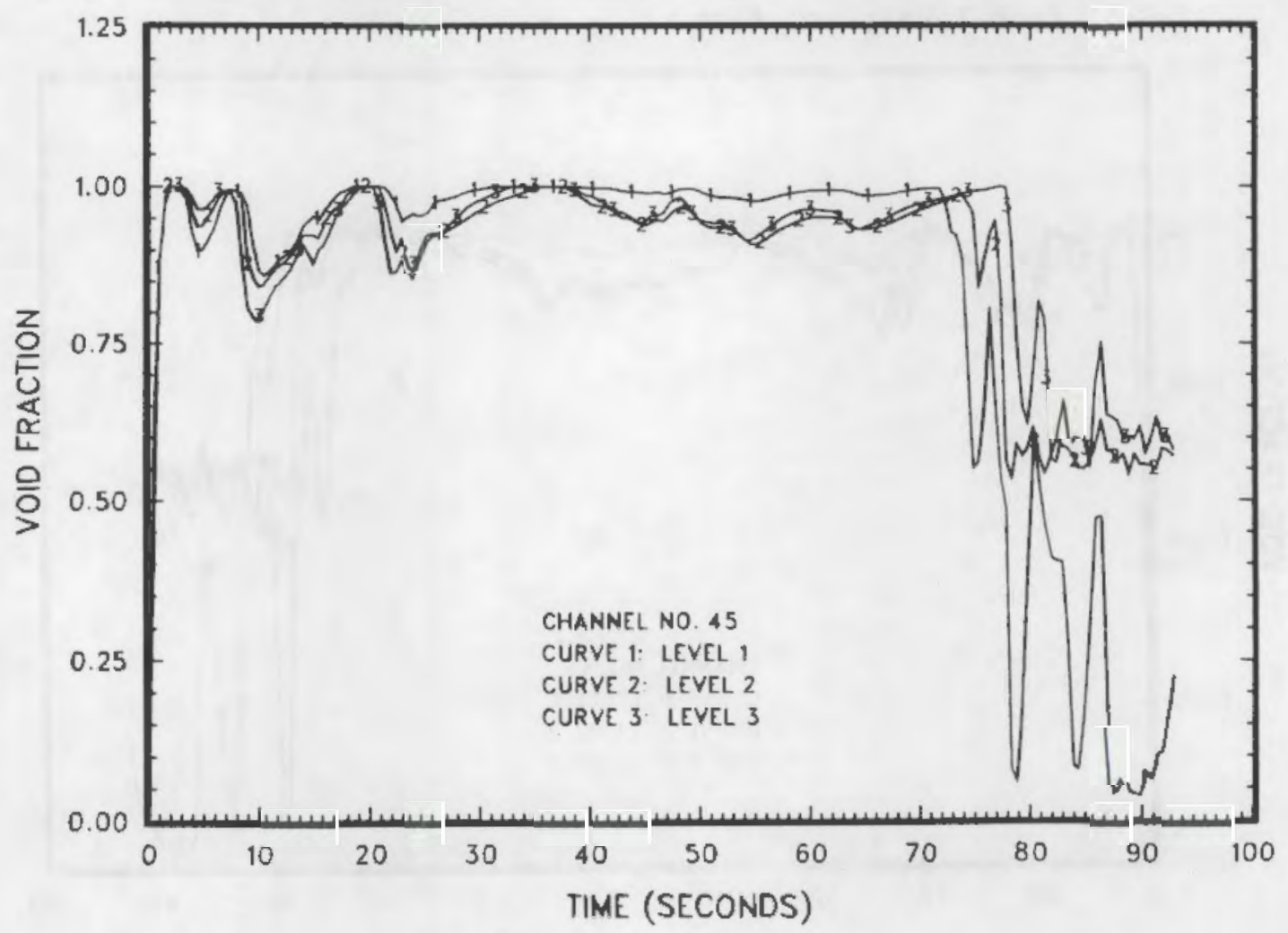

Figure C.32. Core void fractions in channel 45 vs. time 


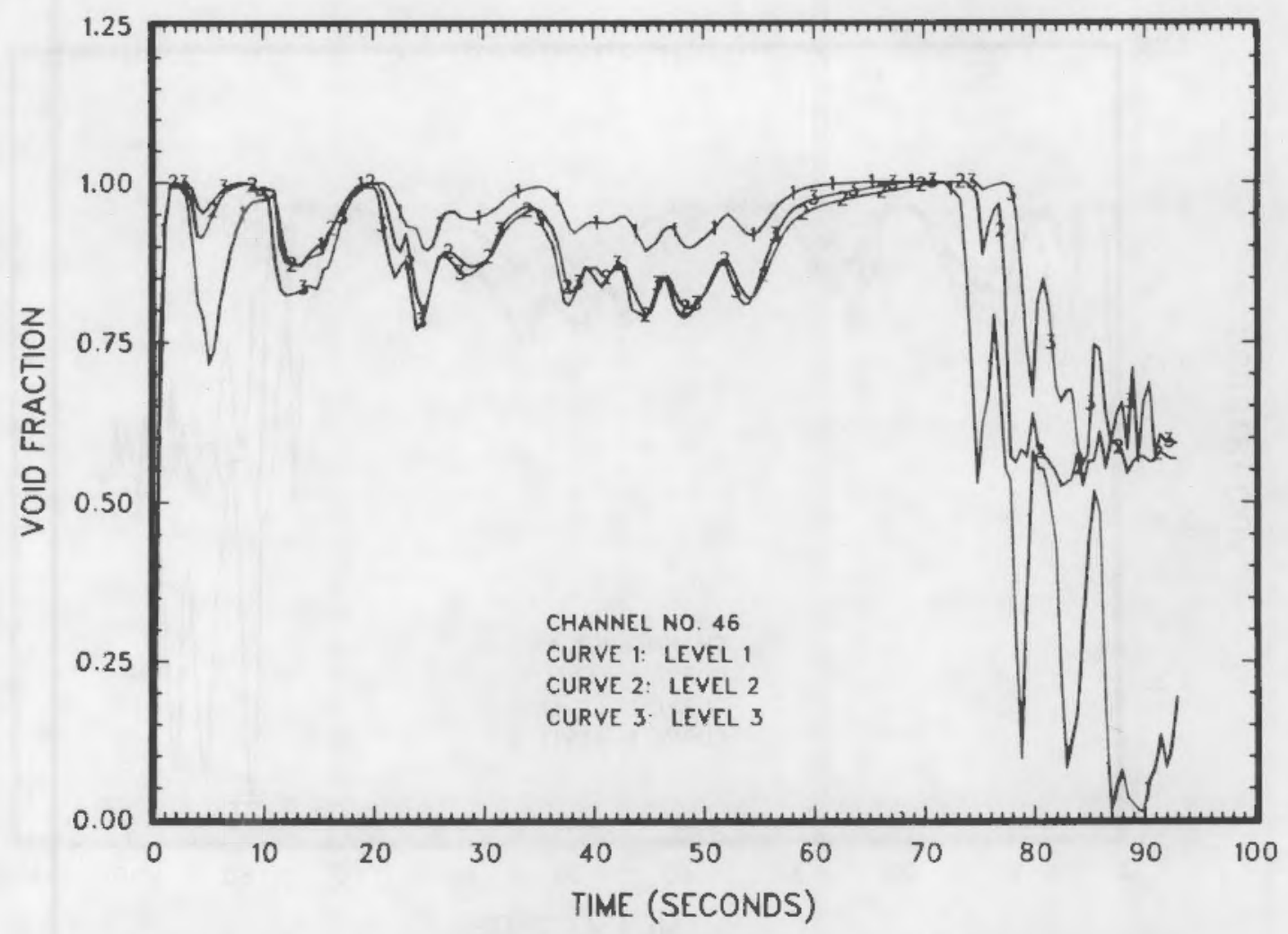

Figure C.33. Core void fractions in channel 46 vs. time

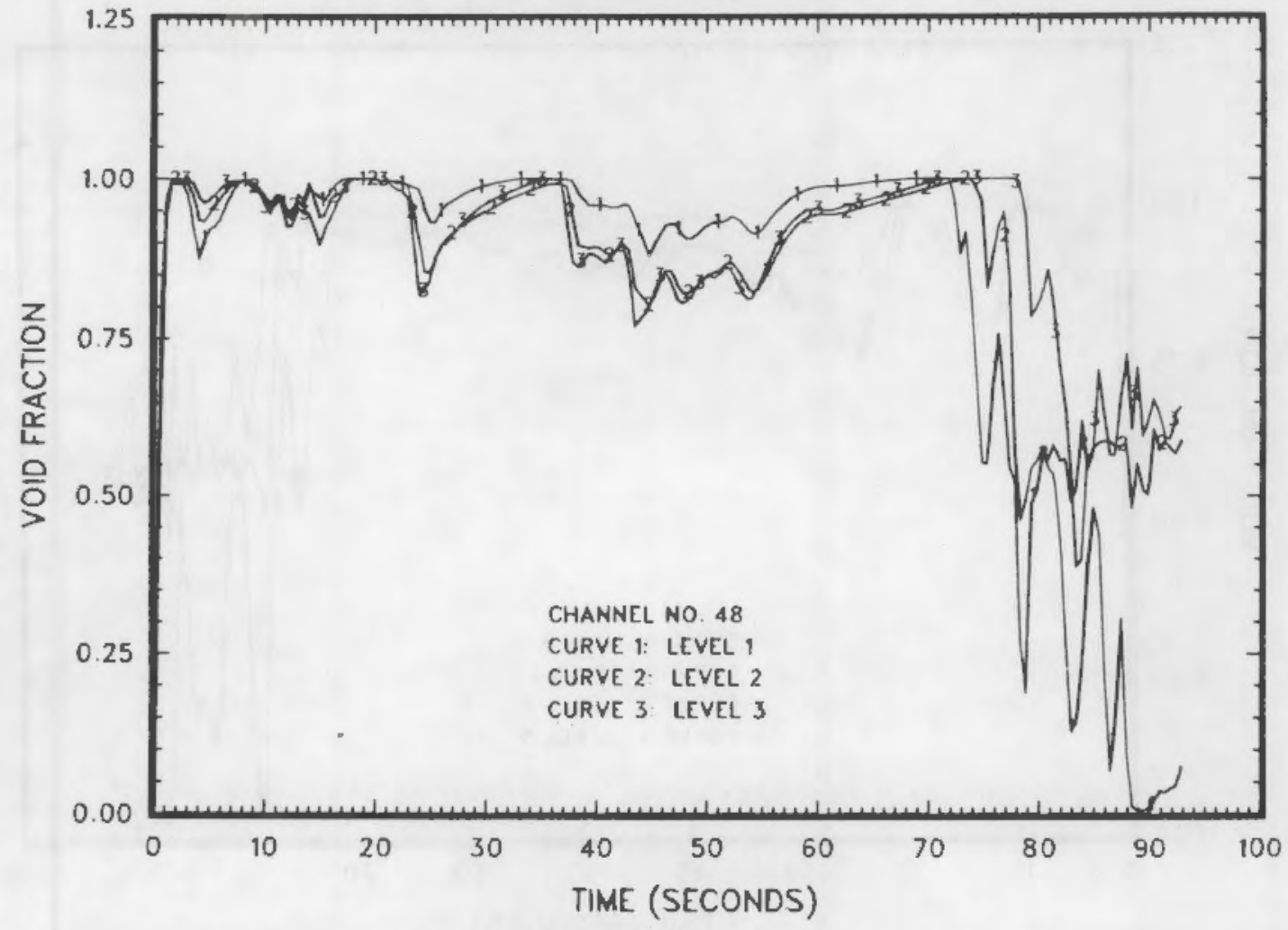

Figure C.34. Core void fractions in channel 48 vs. time 


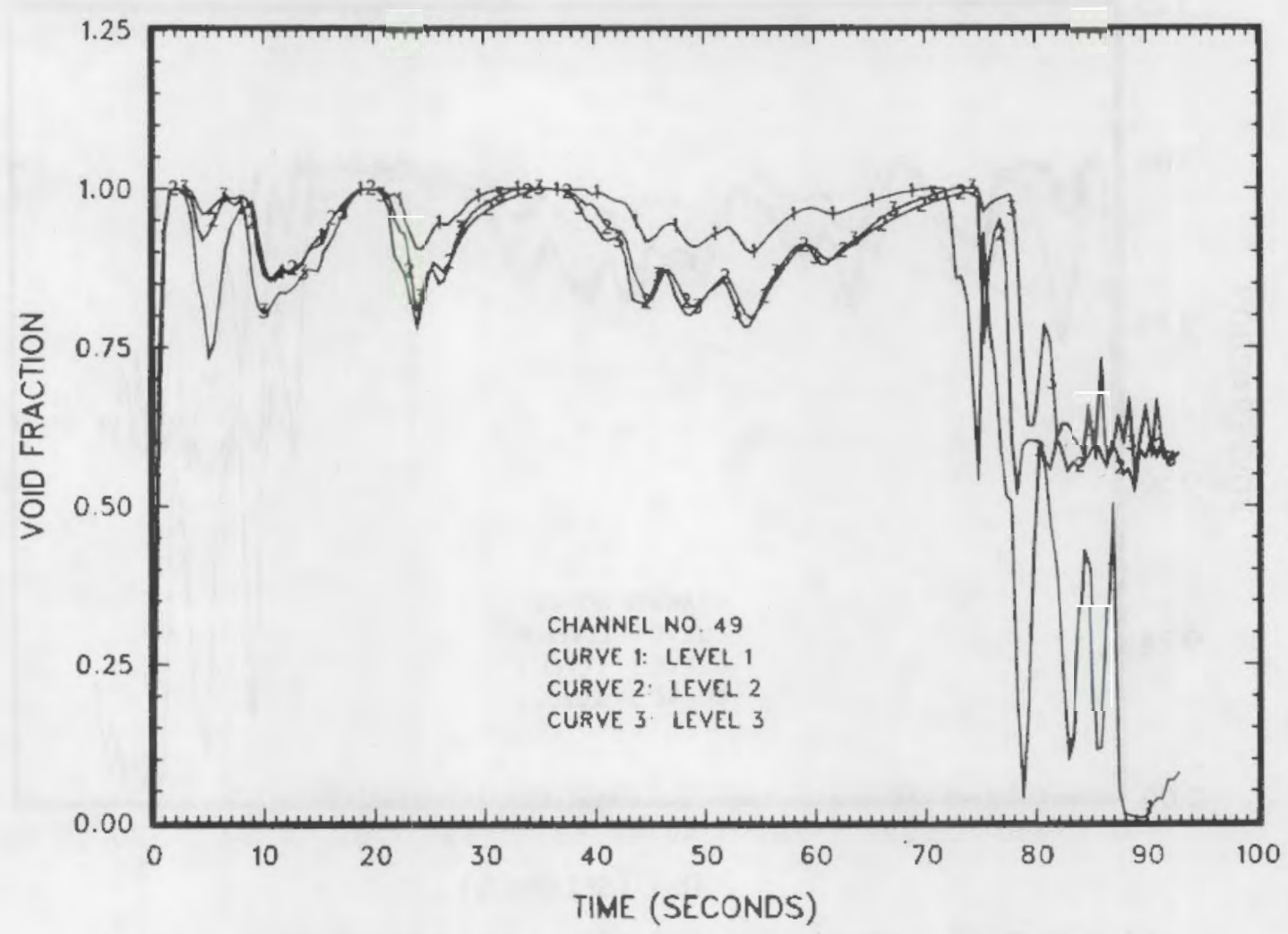

Figure C.35. Core void fractions in channel 49 vs. time

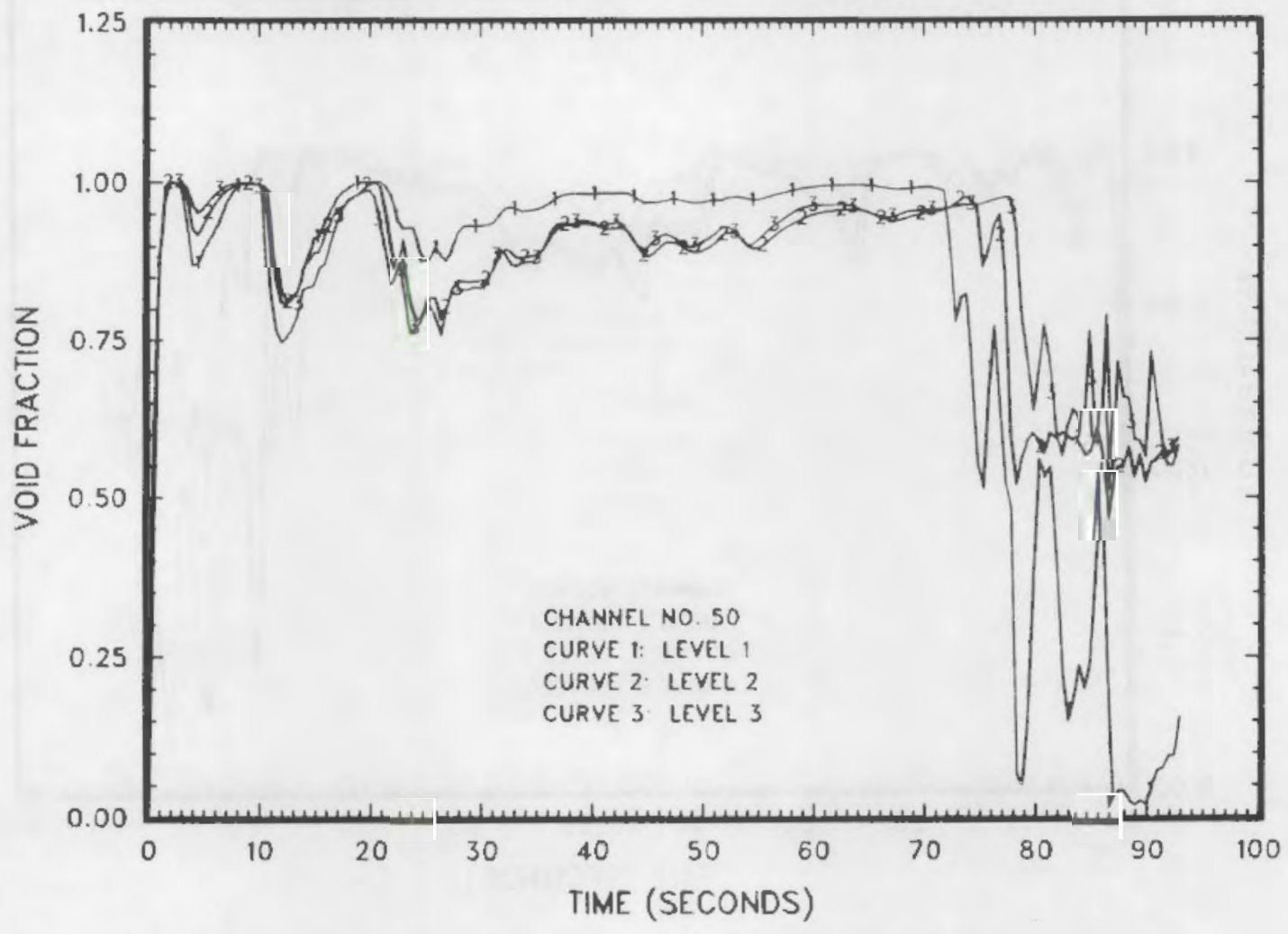

Figure C.36. Core void fractions in channel 50 vs. time 


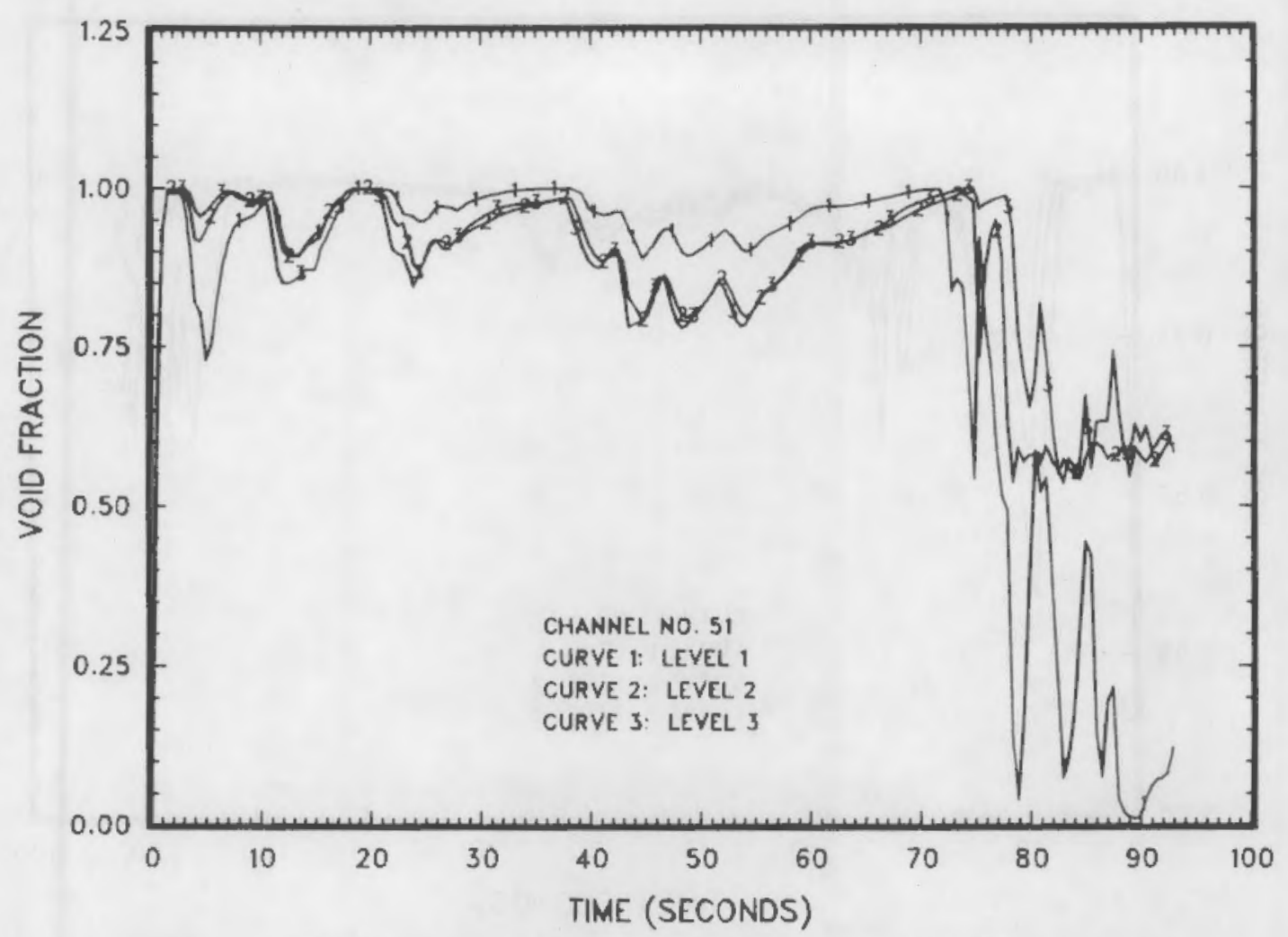

Figure C.37. Core void fractions in channel 51 vs. time

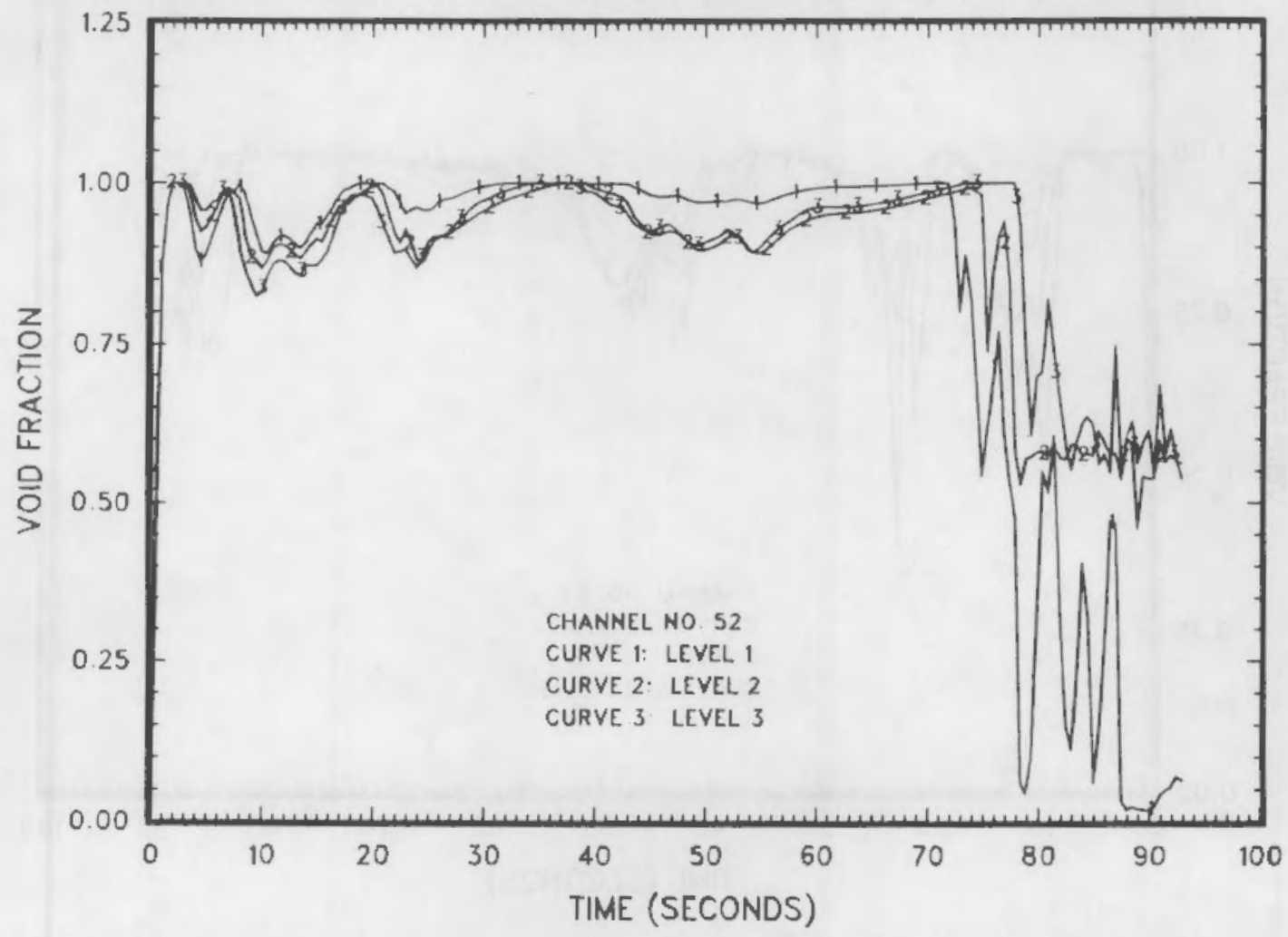

Figure C.38. Core void fractions in channel 52 vs. time 


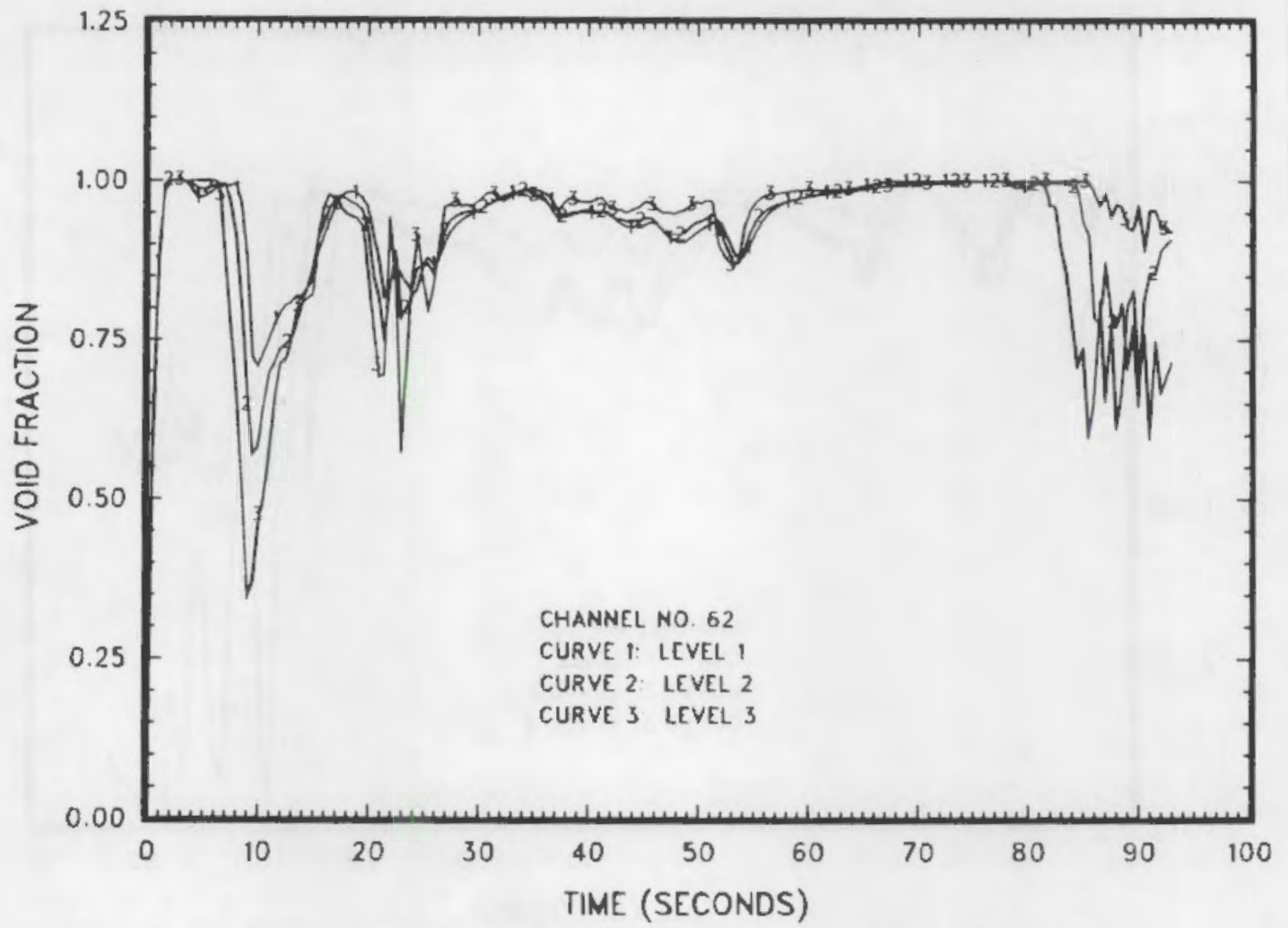

Figure C.39. Core void fractions in channel 62 vs. time

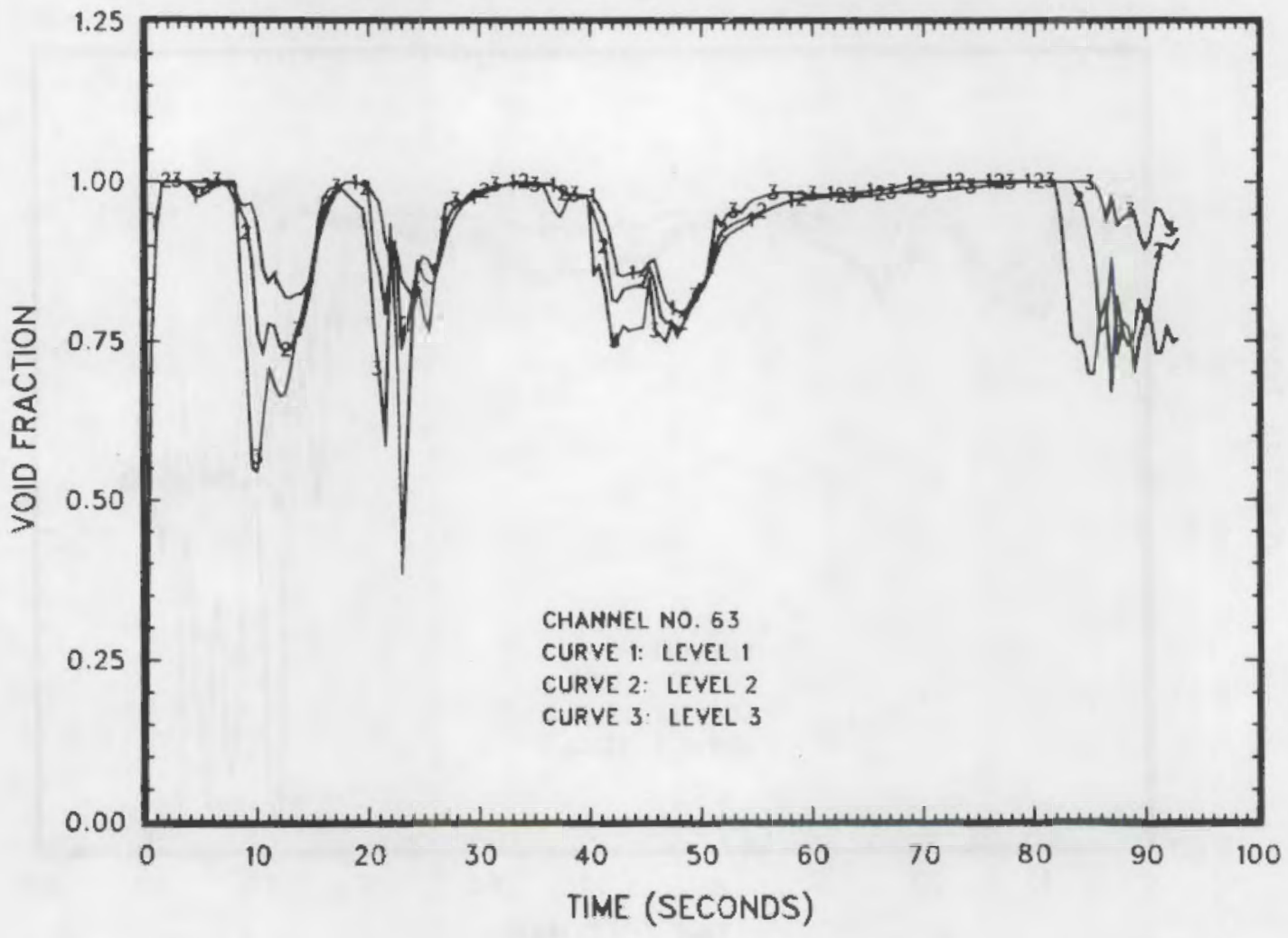

Figure C.40. Core void fractions in channel 63 vs. time 


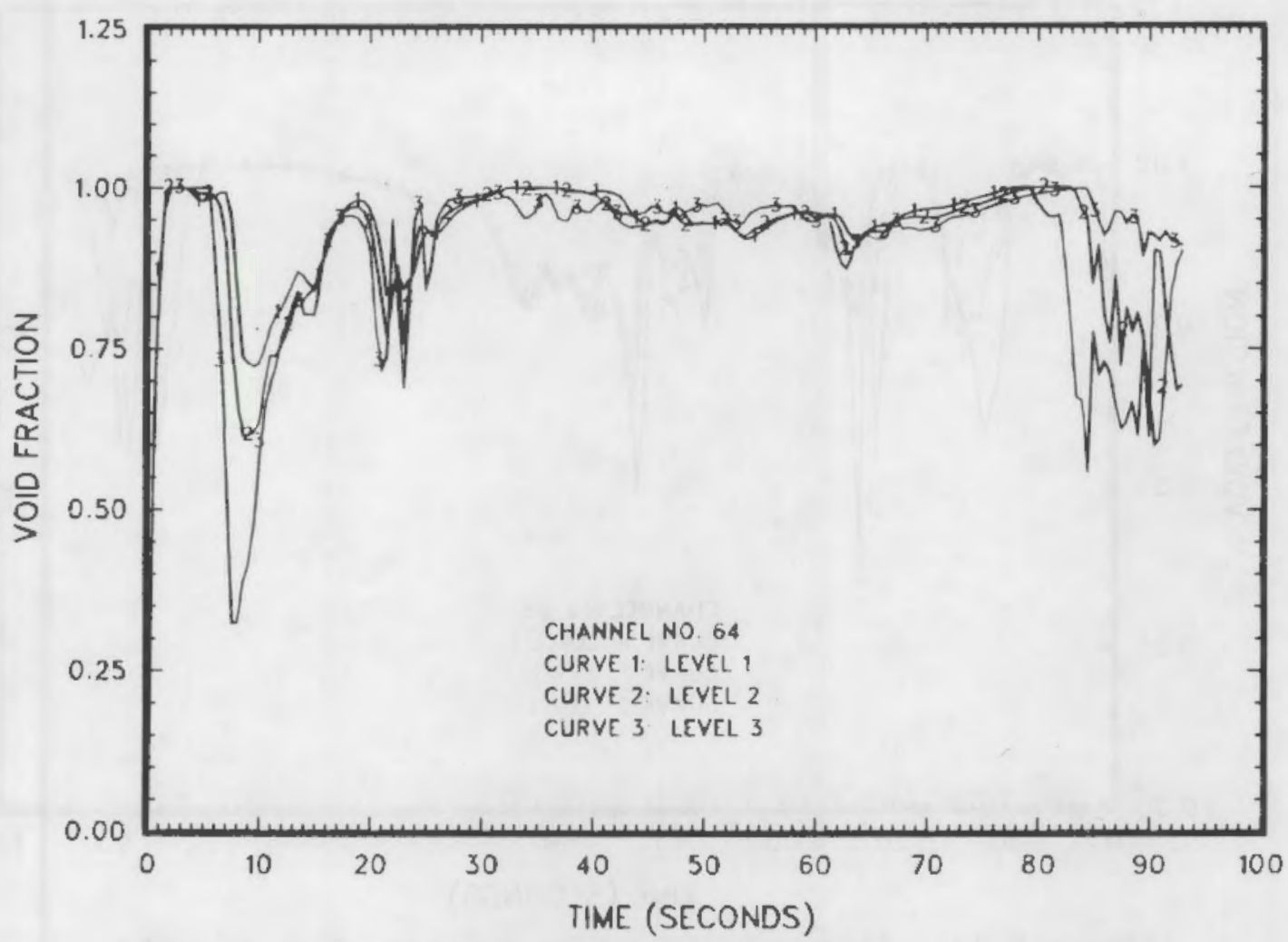

Figure C.41. Core void fractions in channel 64 vs. time

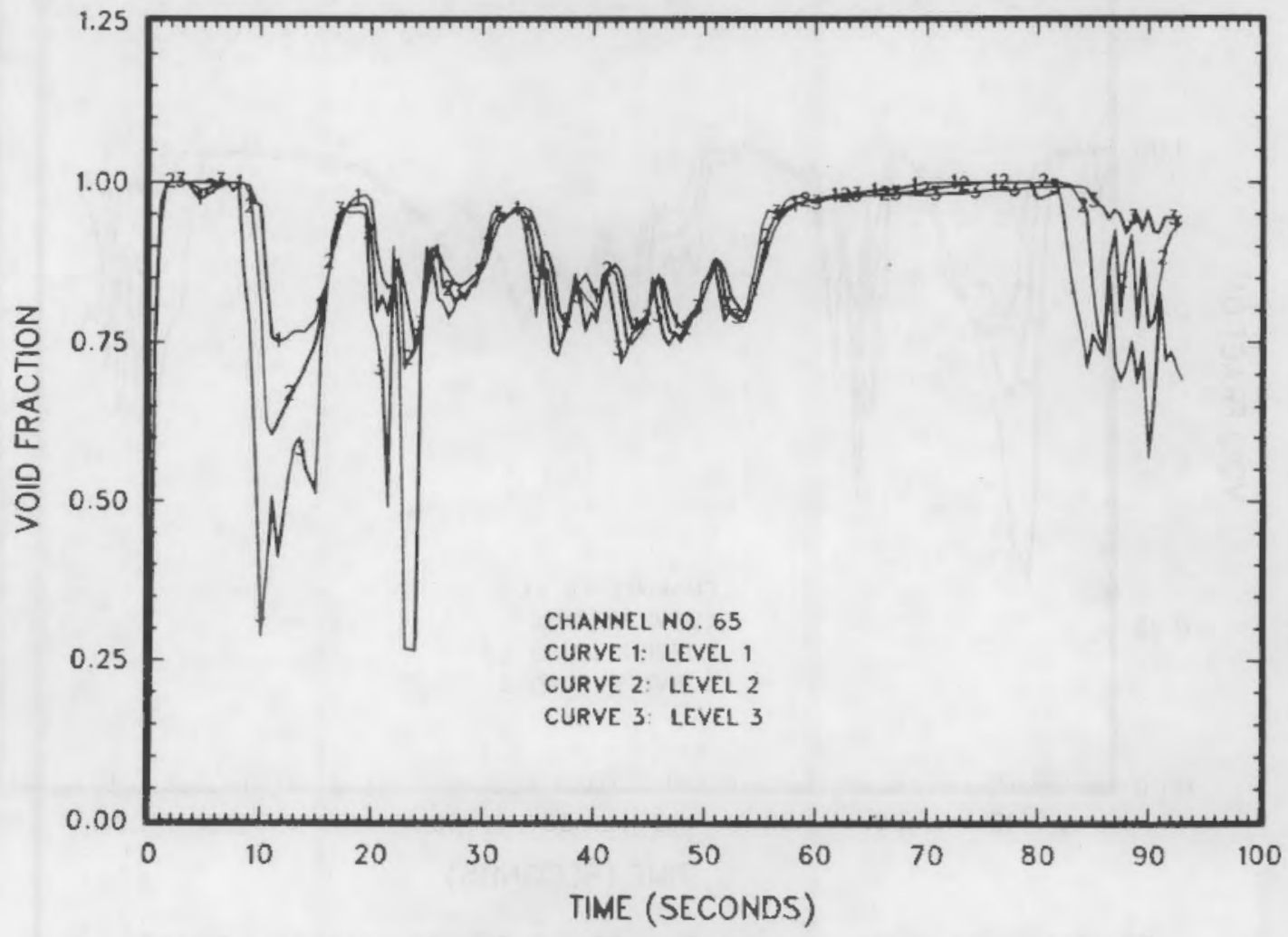

Figure C.42. Core void fractions in channel 65 vs. time 


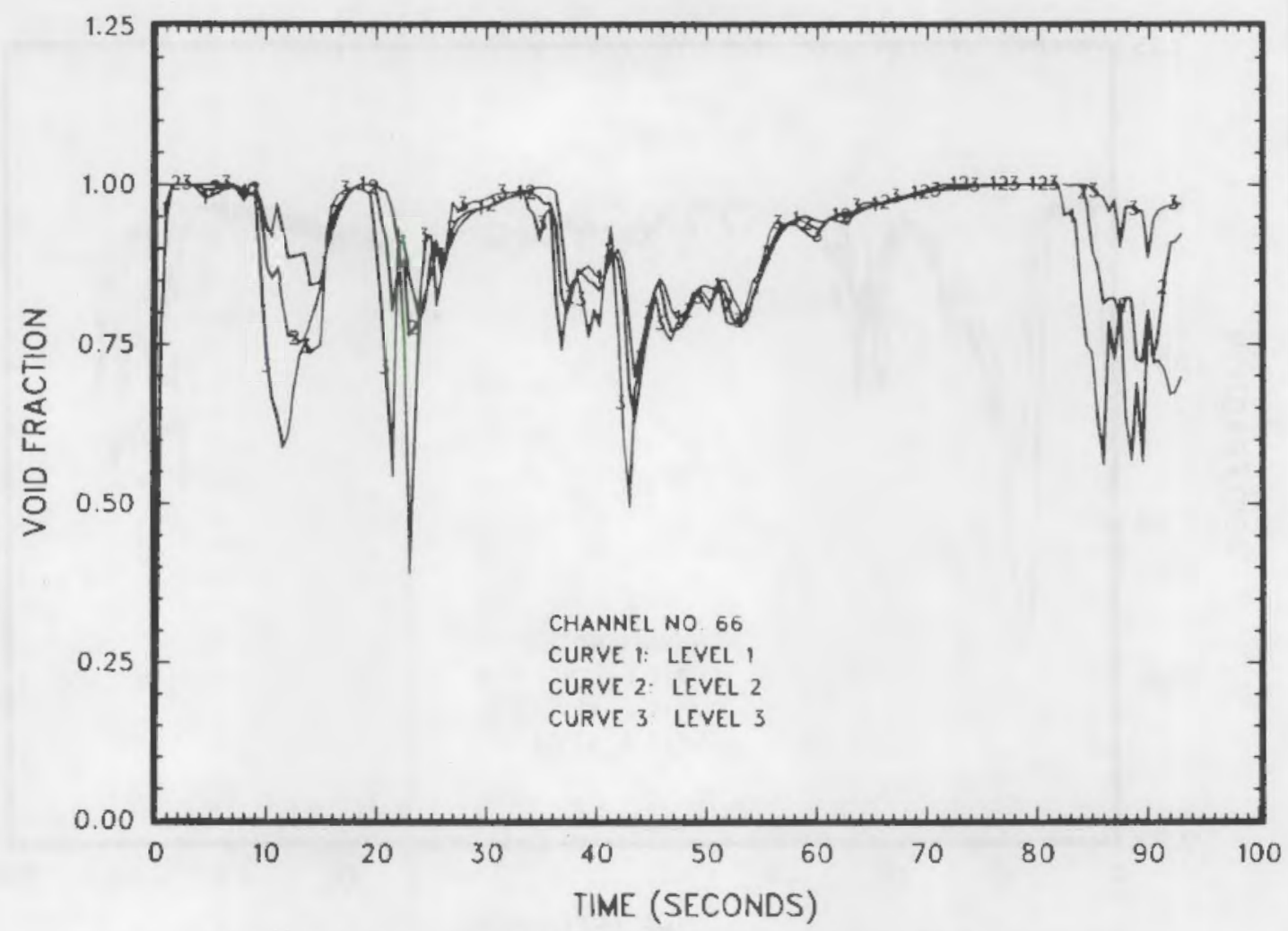

Figure C.43. Core void fractions in channel 66 vs. time

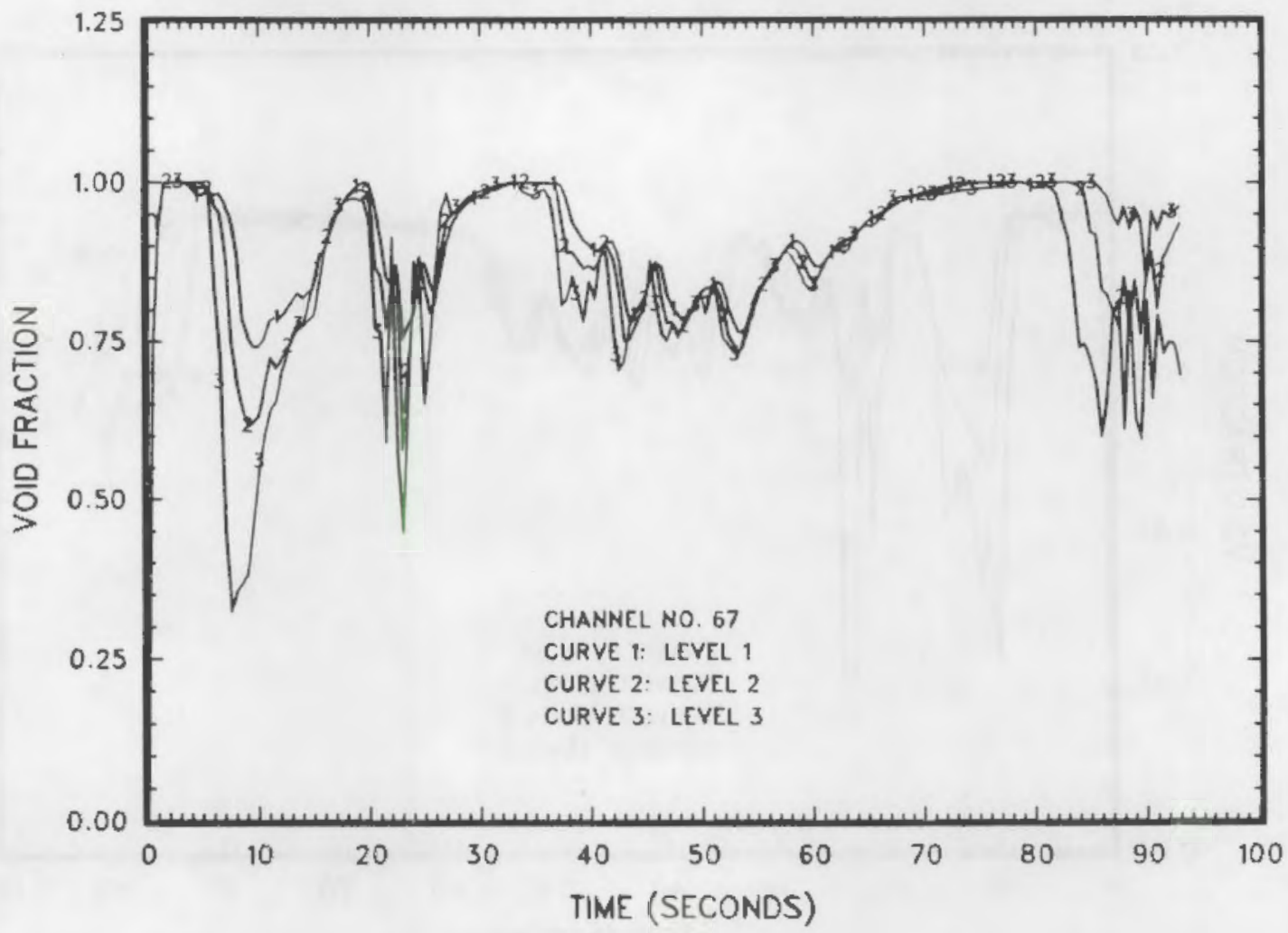

Figure C.44. Core void fractions in channel 67 vs. time 


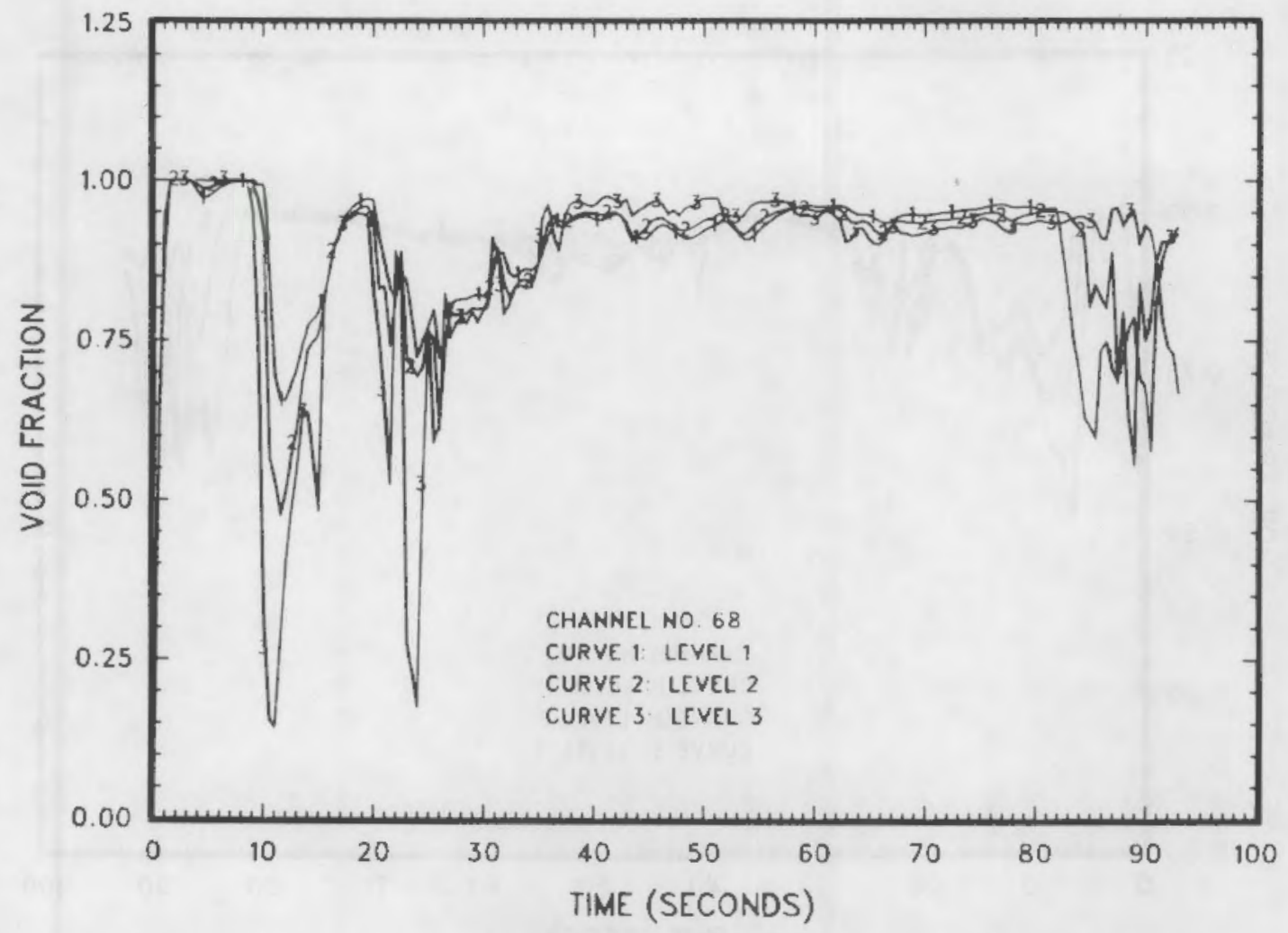

Figure C.45. Core void fractions in channel 68 vs. time

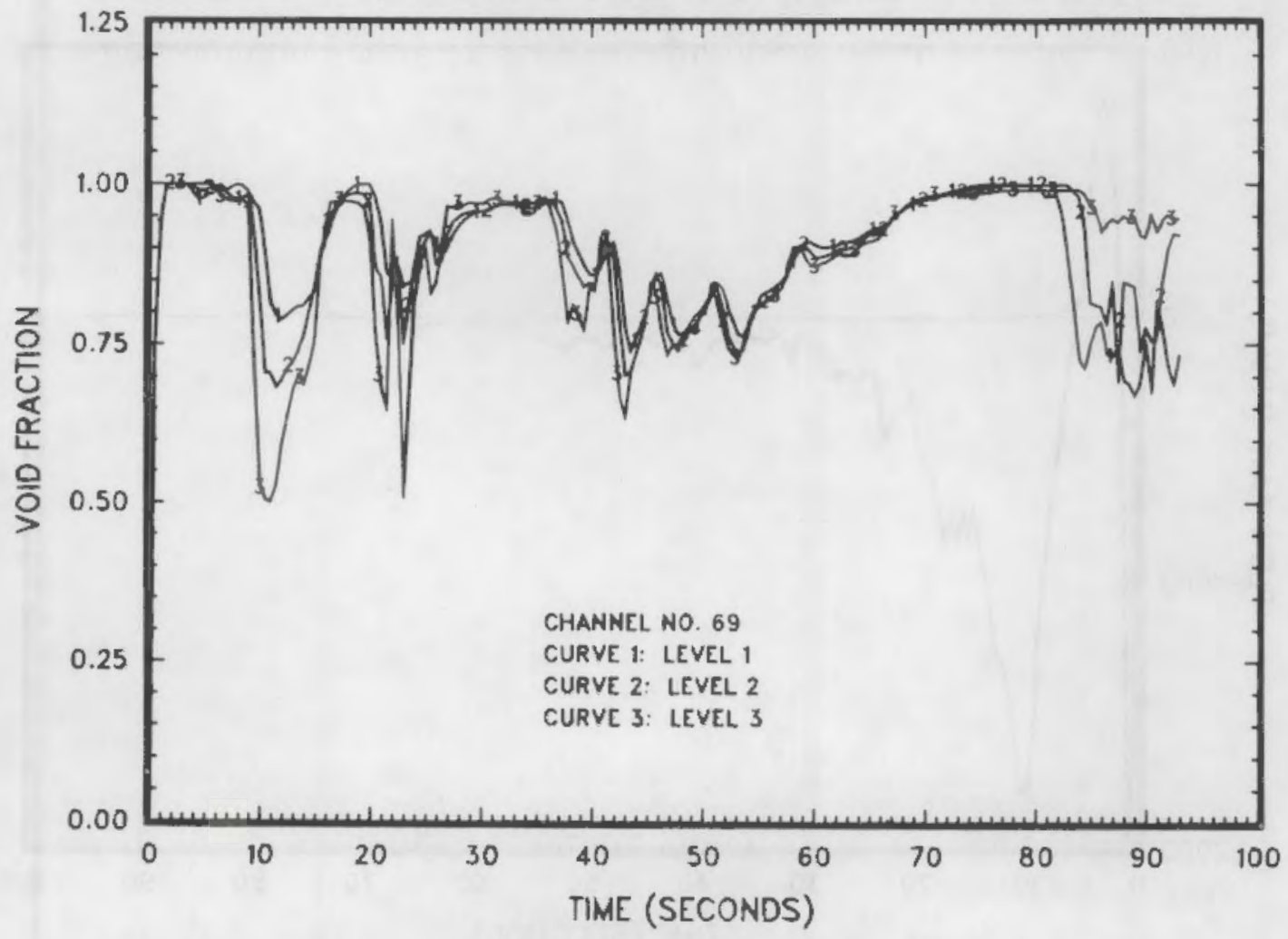

Figure C.46. Core void fractions in channel 69 vs. time 


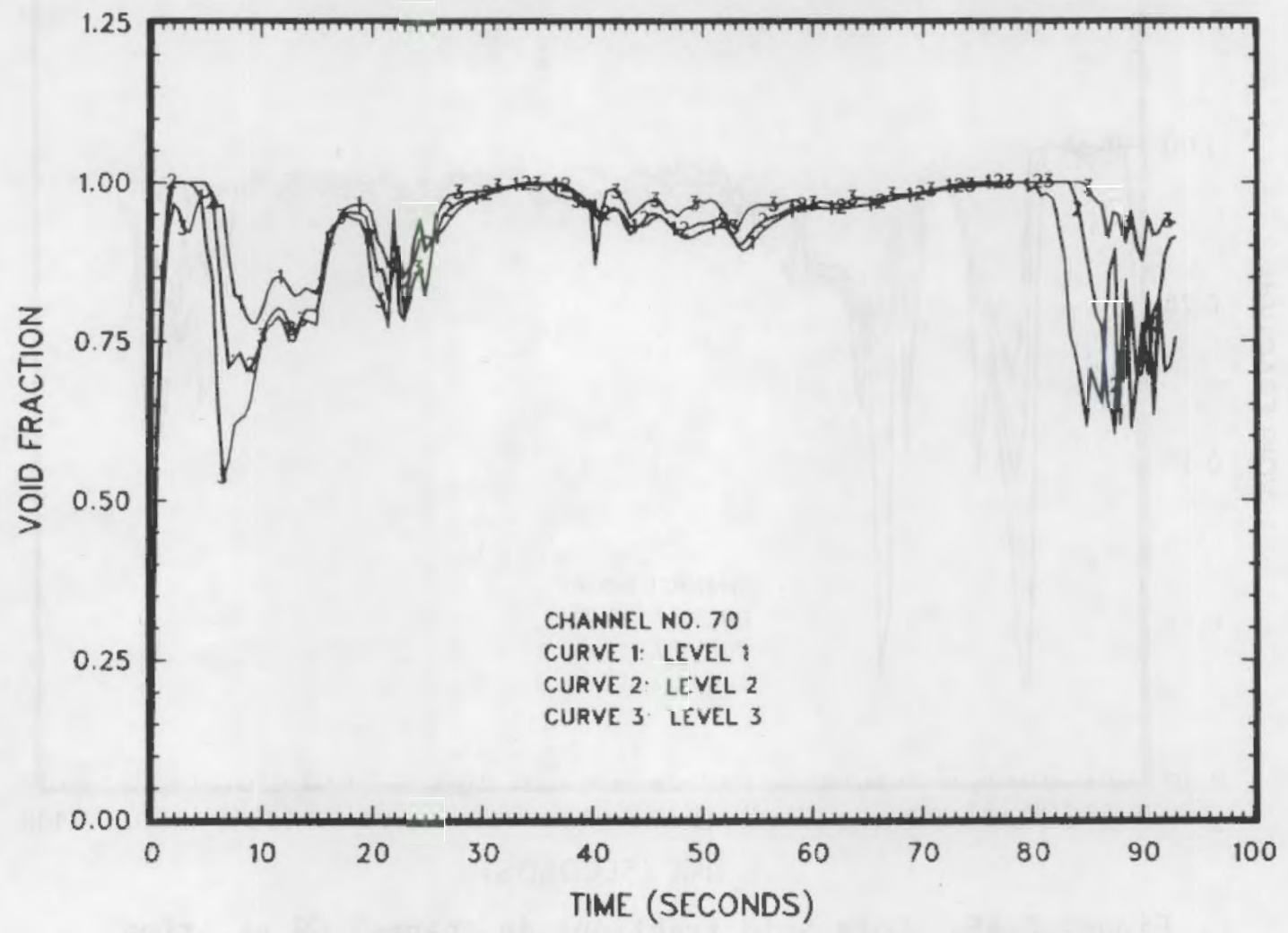

Figure C.47. Core void fractions in channel 70 vs. time

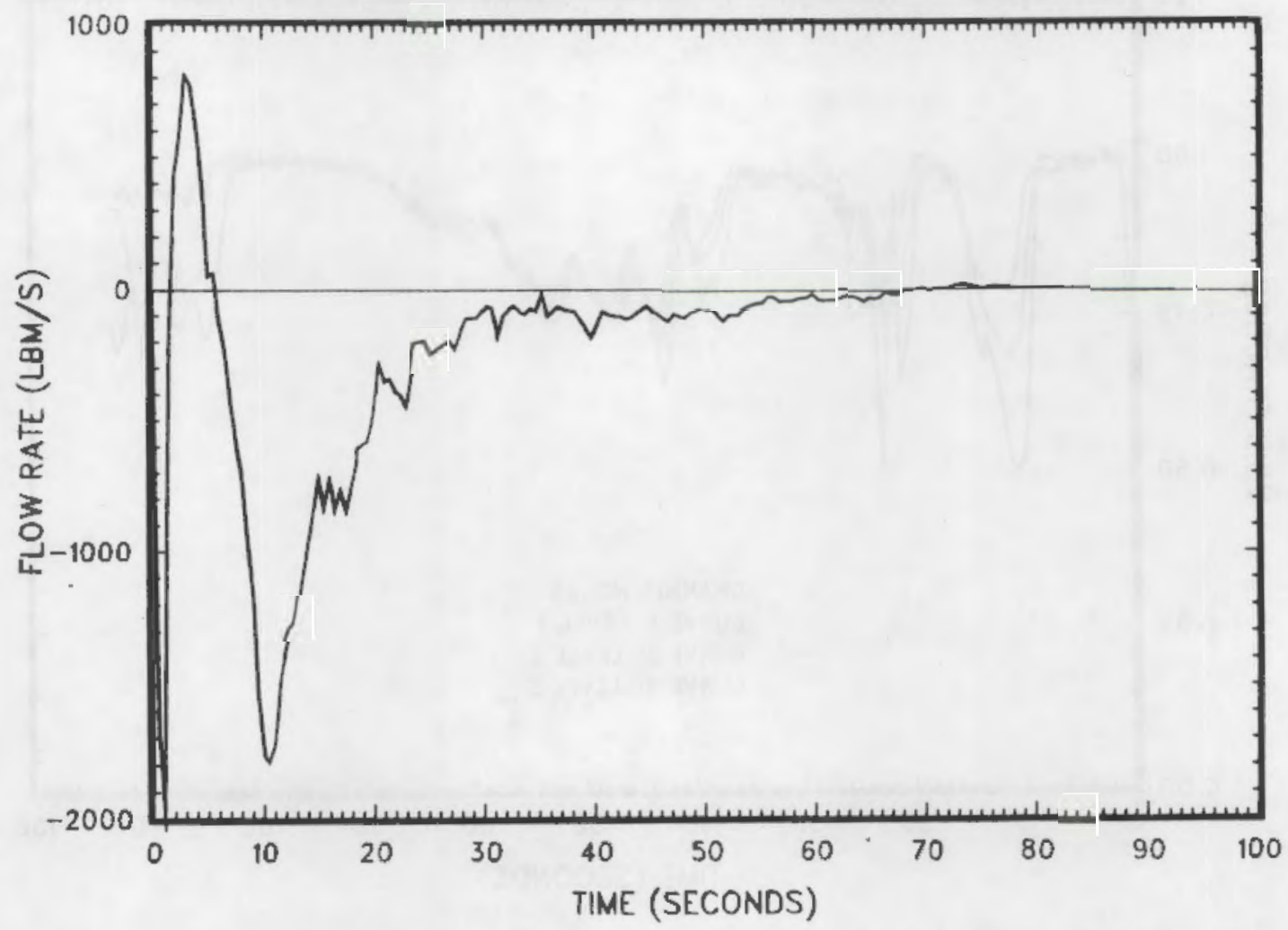

Figure C.48. Core inlet vapor flow rate vs. time 


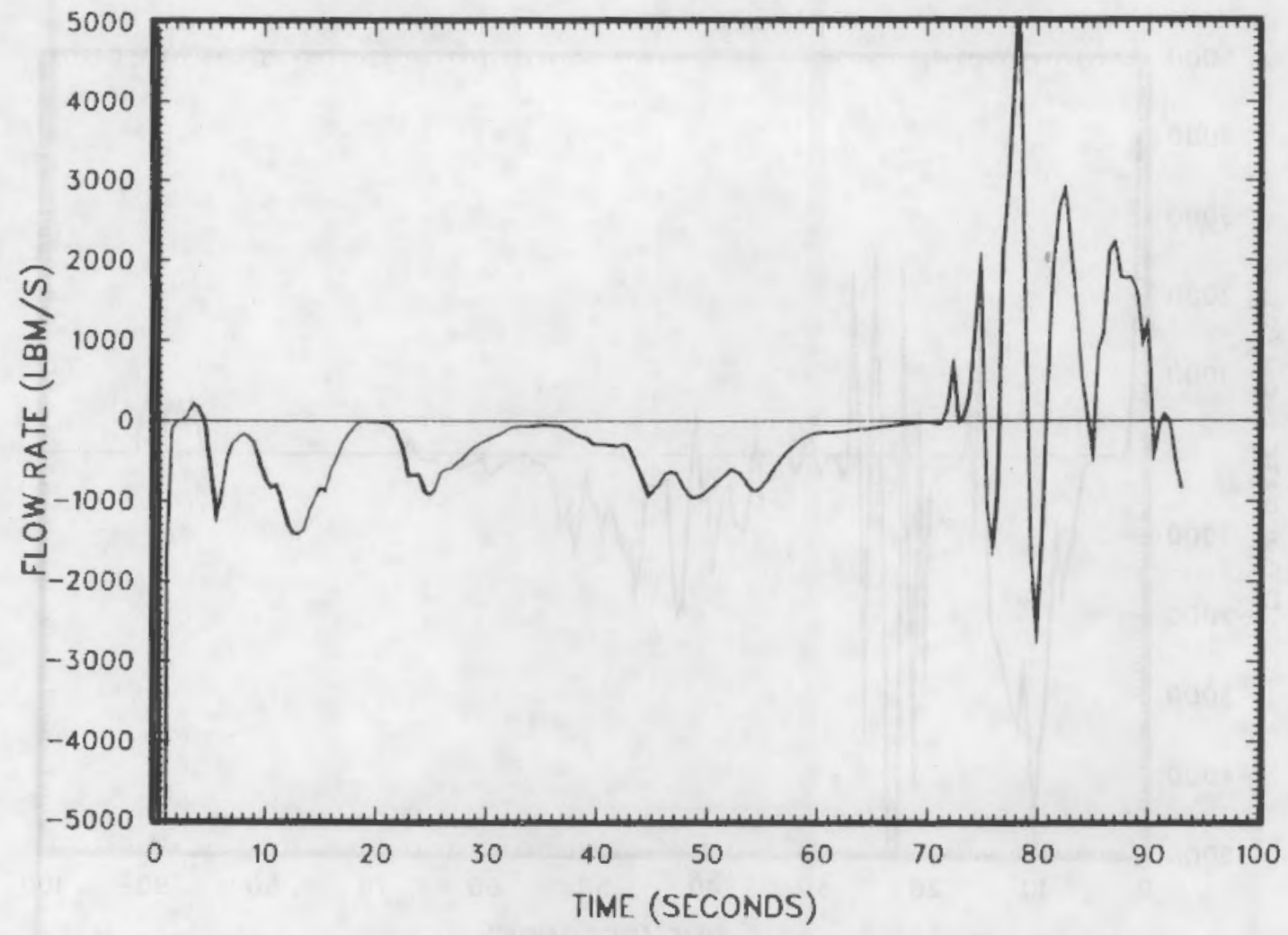

Figure C.49. Core inlet liquid flow rate vs. time

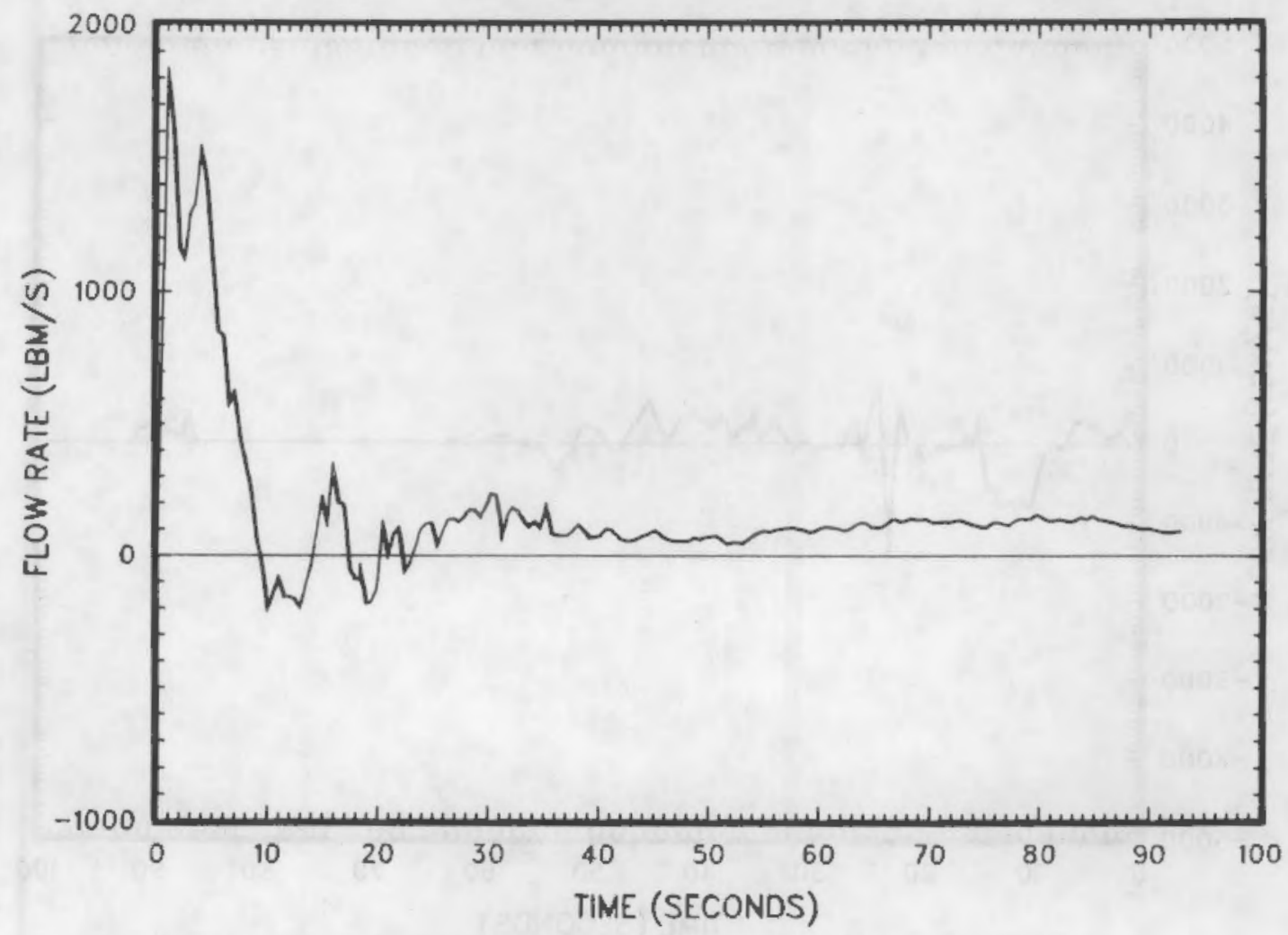

Figure C.50. Core exit vapor flow rate vs. time 


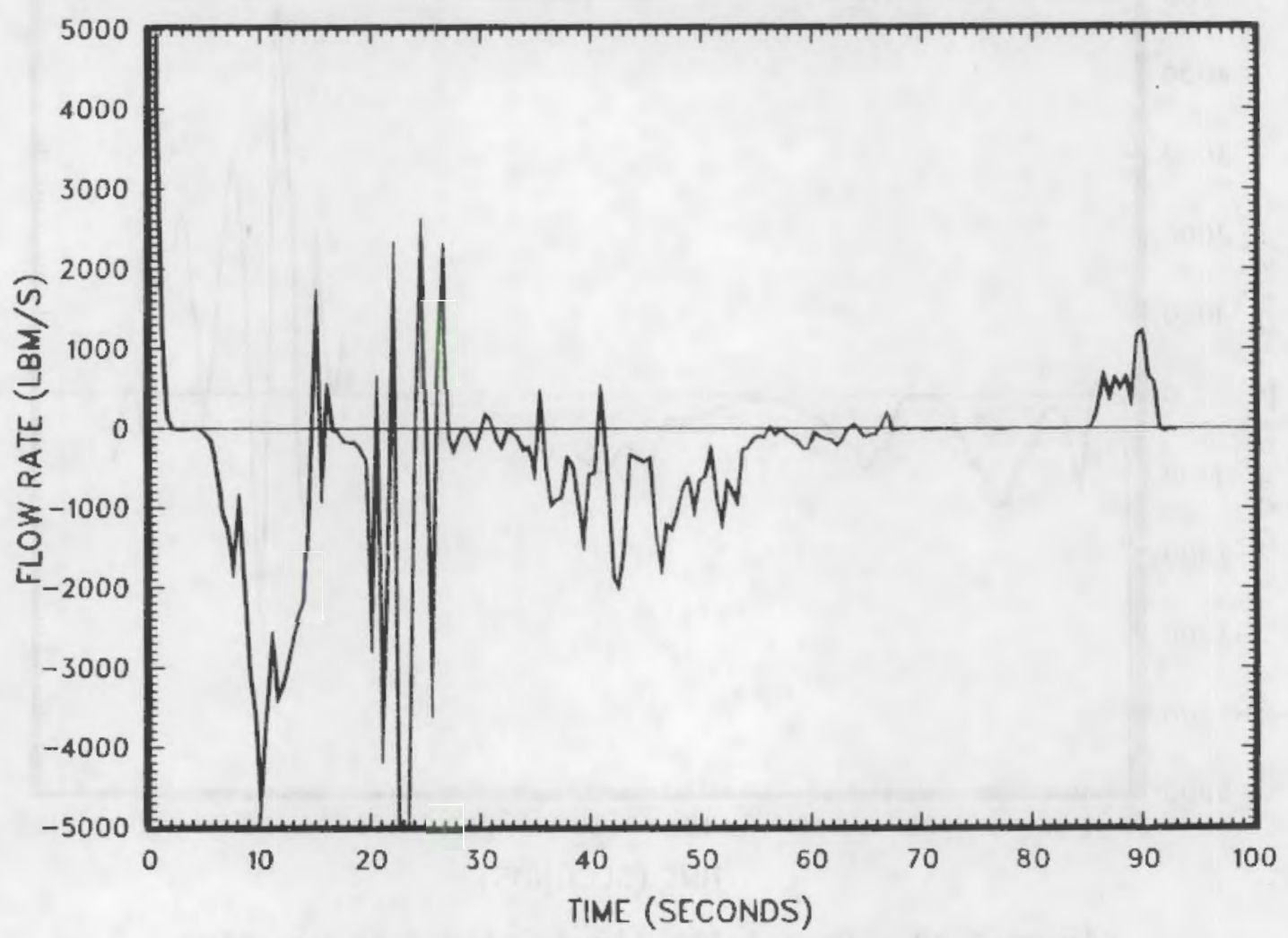

Figure C.51. Core exit liquid flow rate vs. time

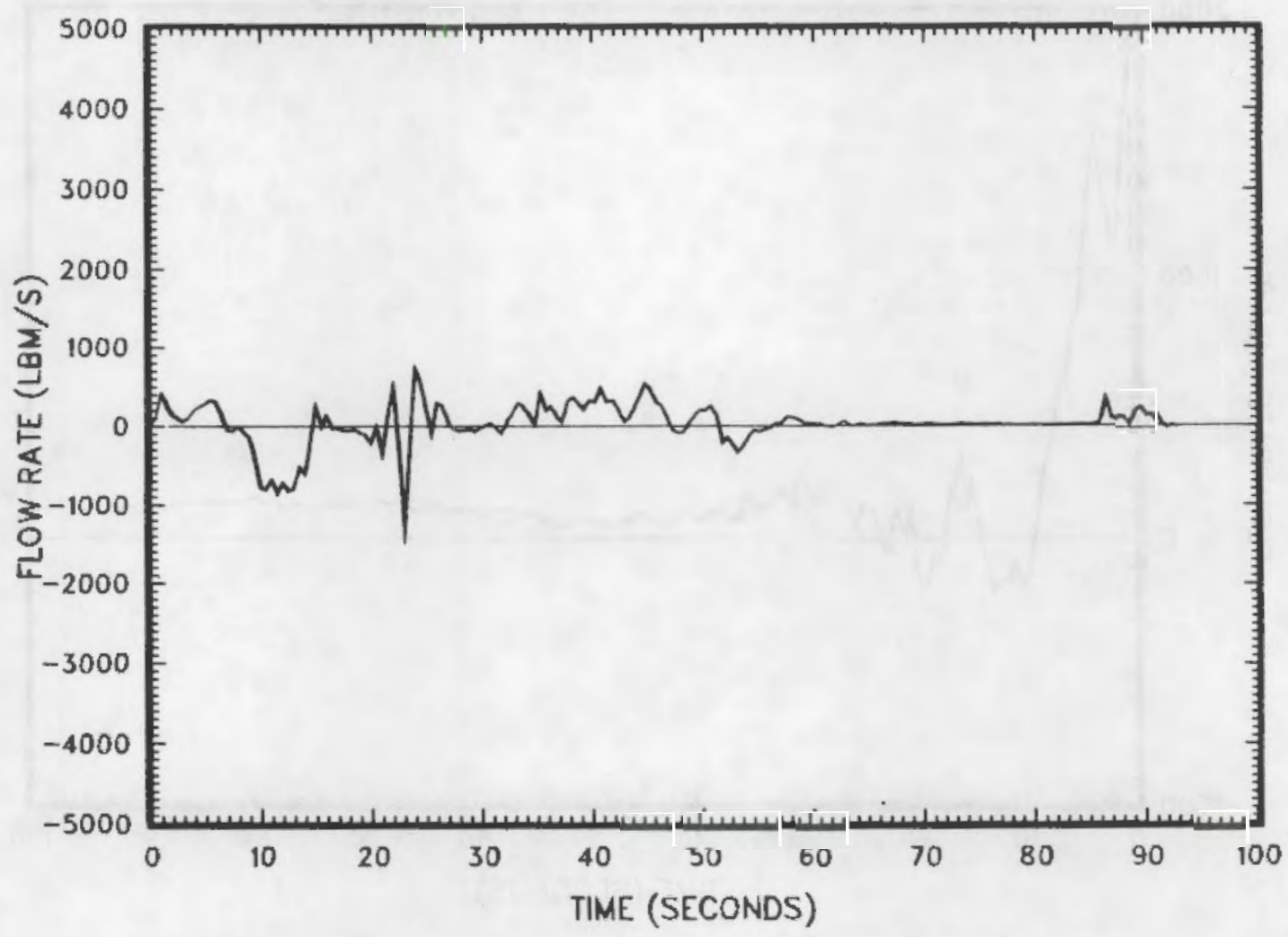

Figure C.52. Core exit drop flow rate vs. time 


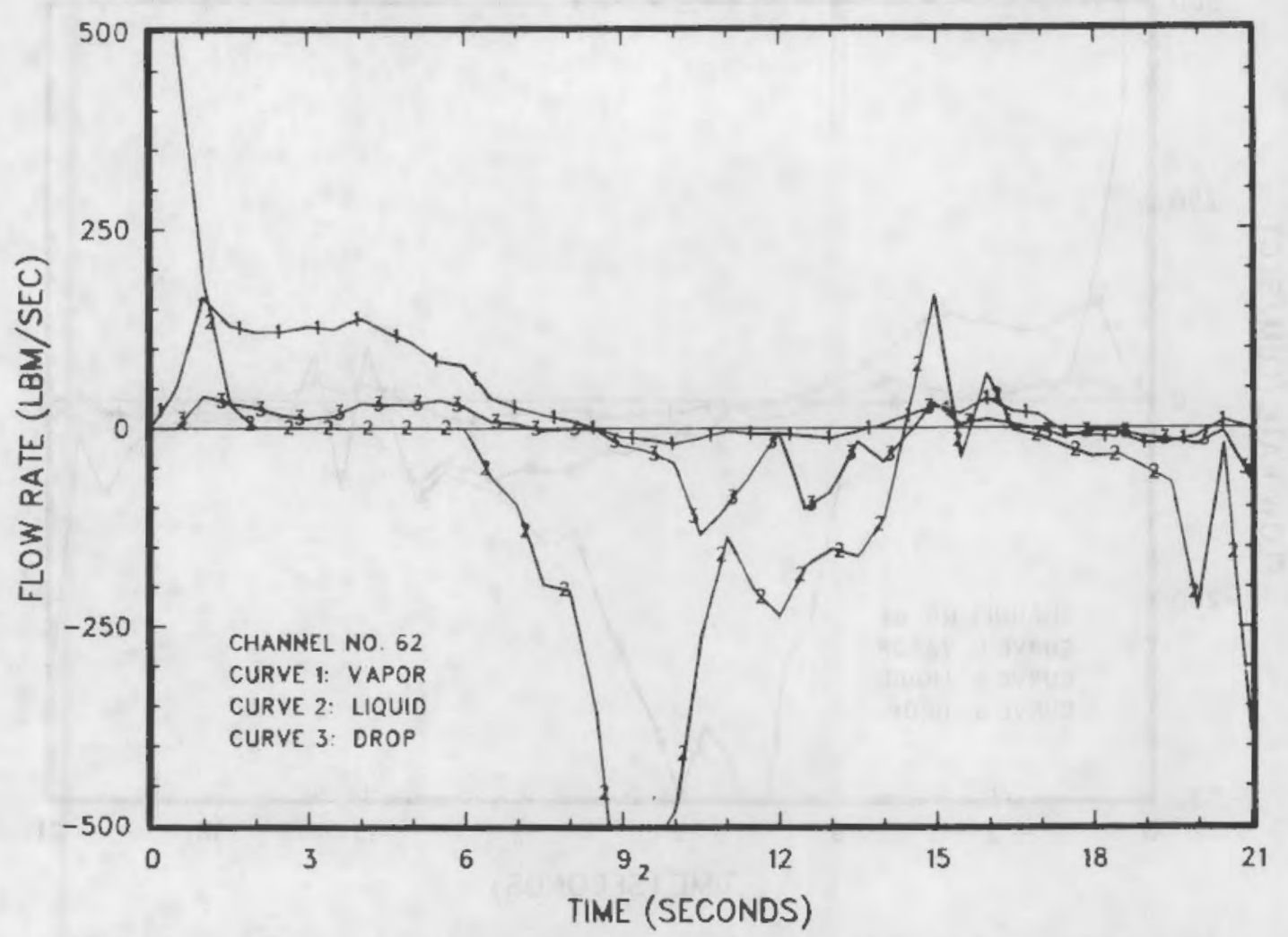

Figure C.53. Core exit flow rates in channel 62 vs. time (CCFL)

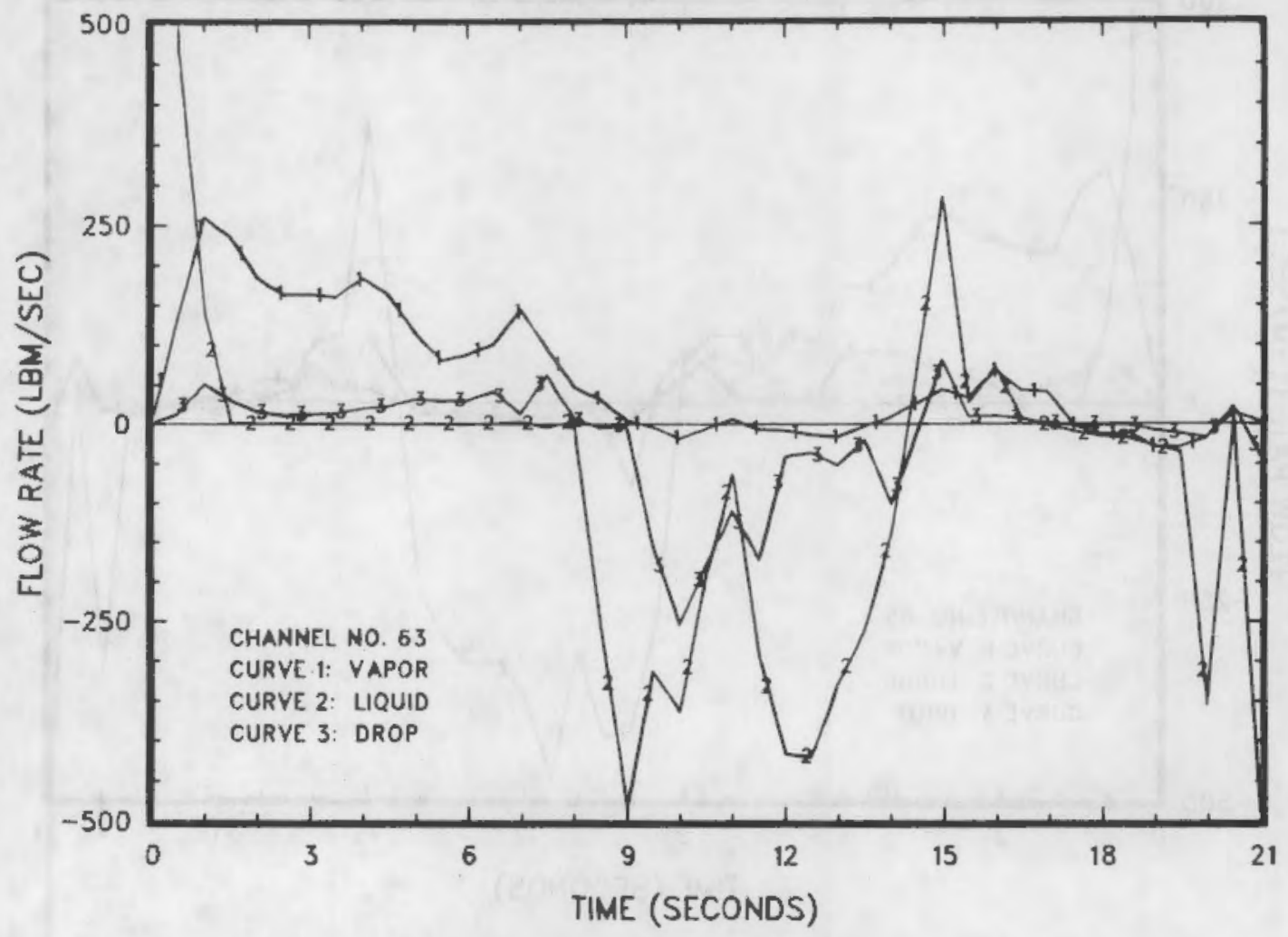

Figure C.54. Core exit flow rates in channel 63 vs. time (CCFL) 


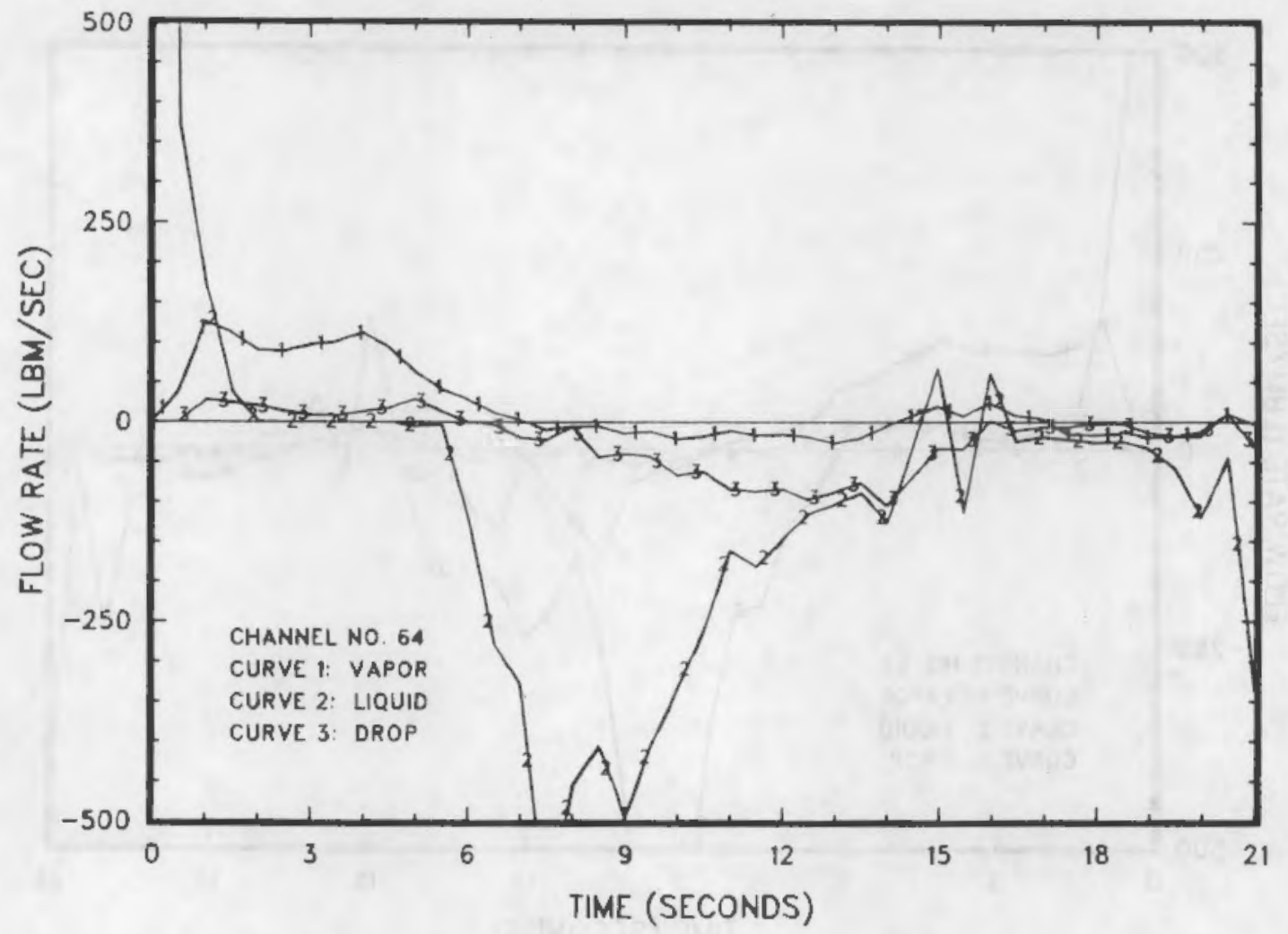

Figure C.55. Core exit flow rates in channel 64 vs. time (CCFL)

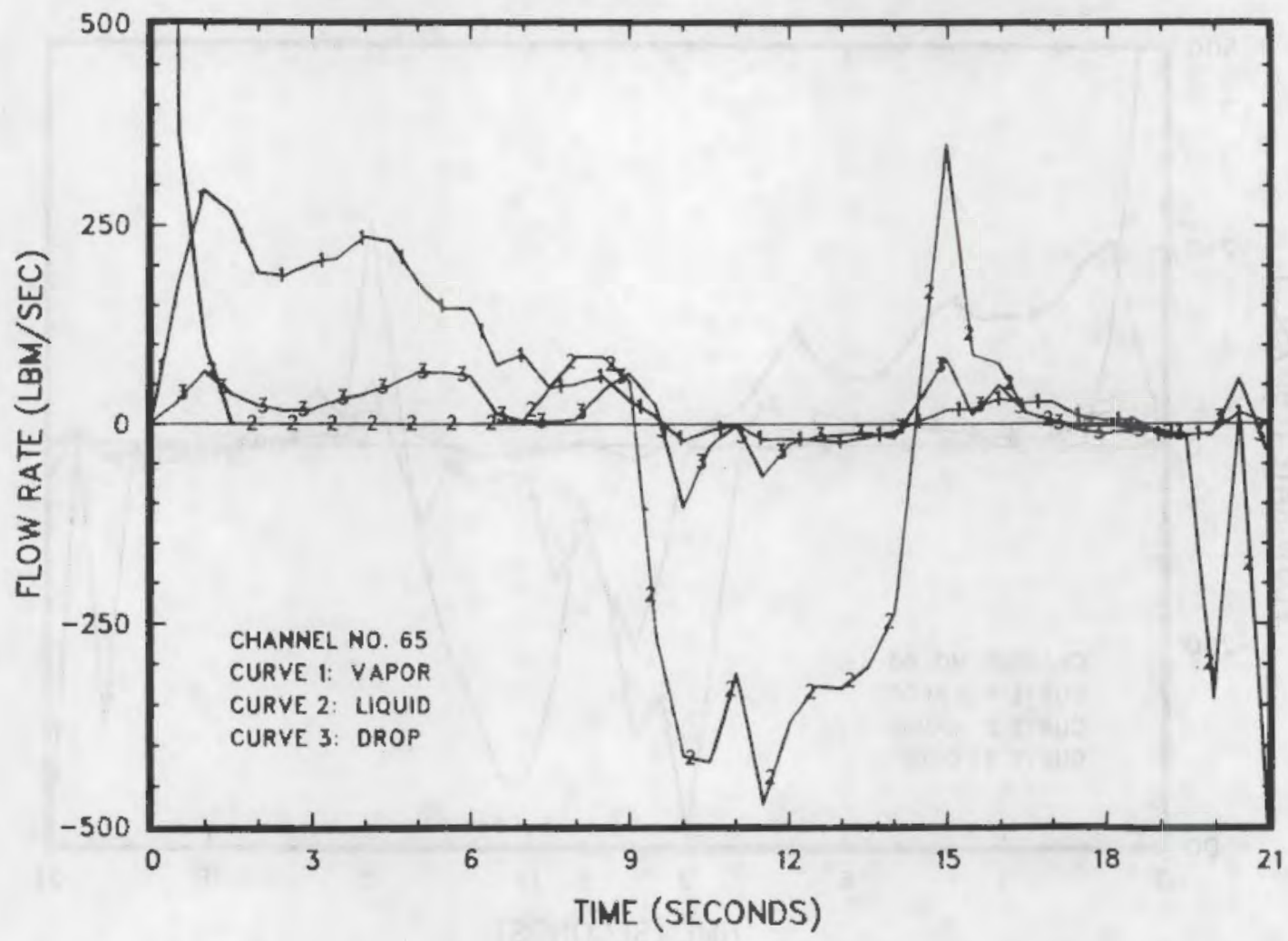

Figure C.56. Core exit flow rates in channel 65 vs. time (CCFL) 


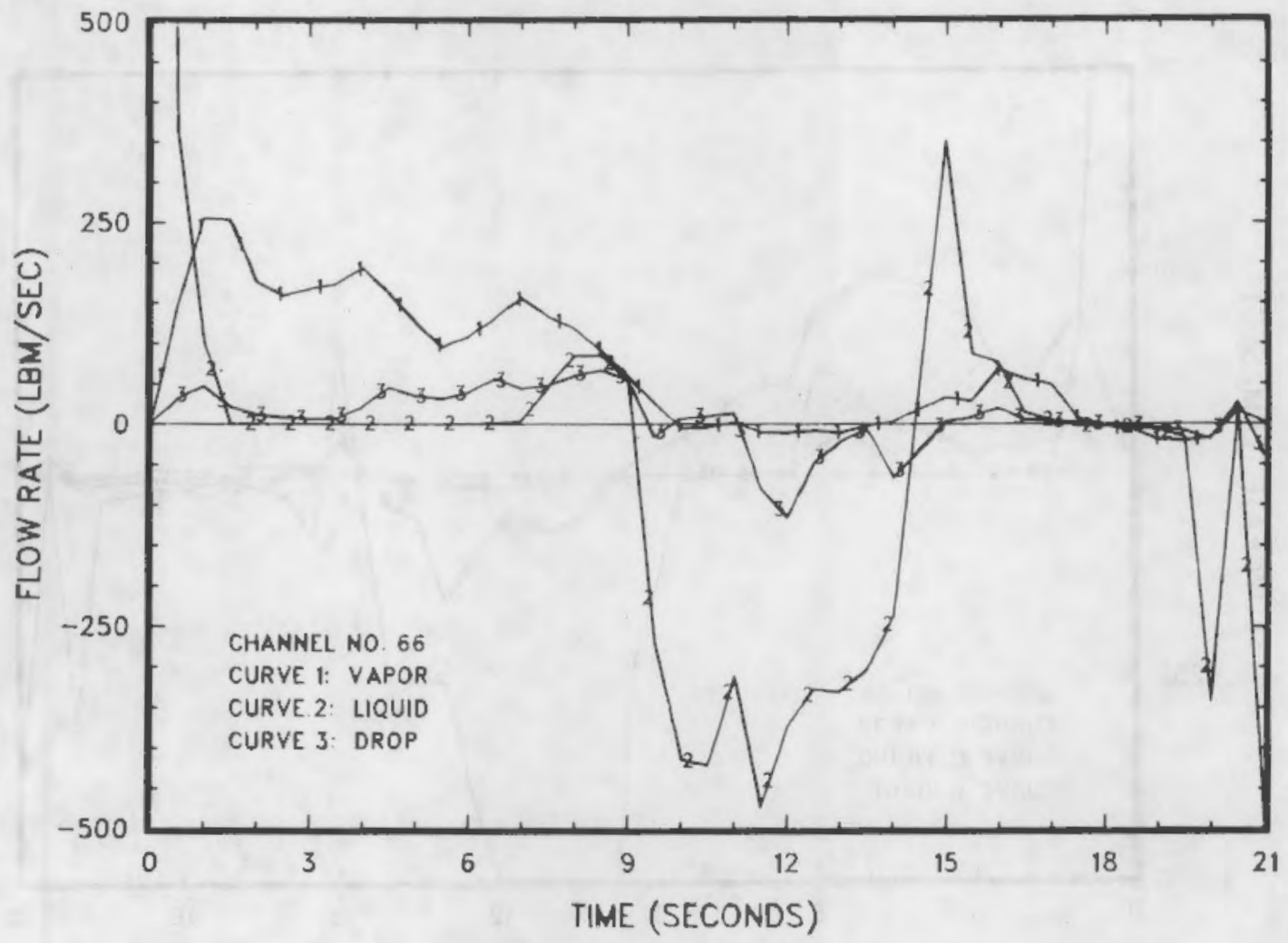

Figure C.57. Core exit flow rates in channel 66 vs. time (CCFL)

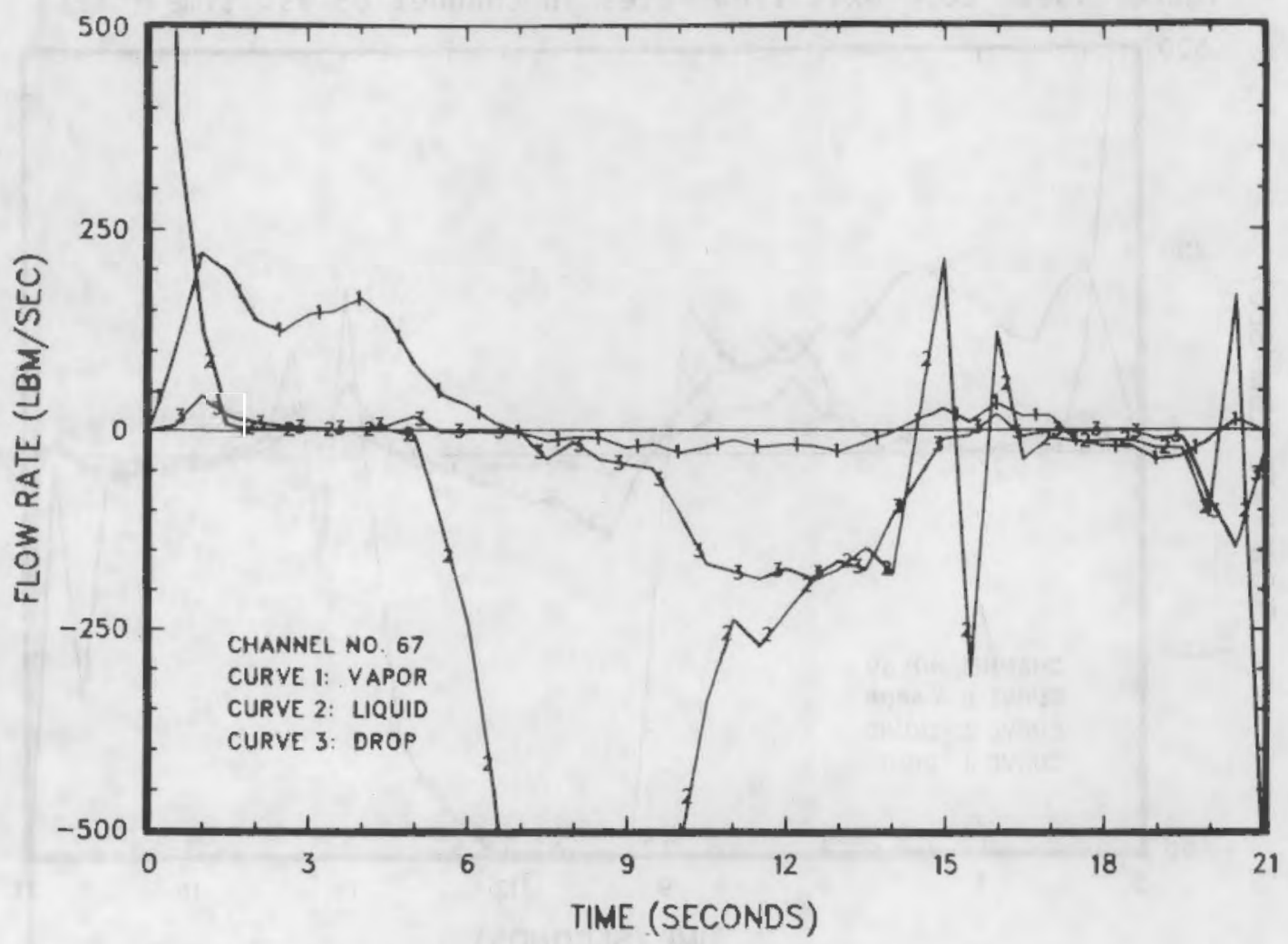

Figure C.58. Core exit flow rates in channel 67 vs. time (CCFL) 


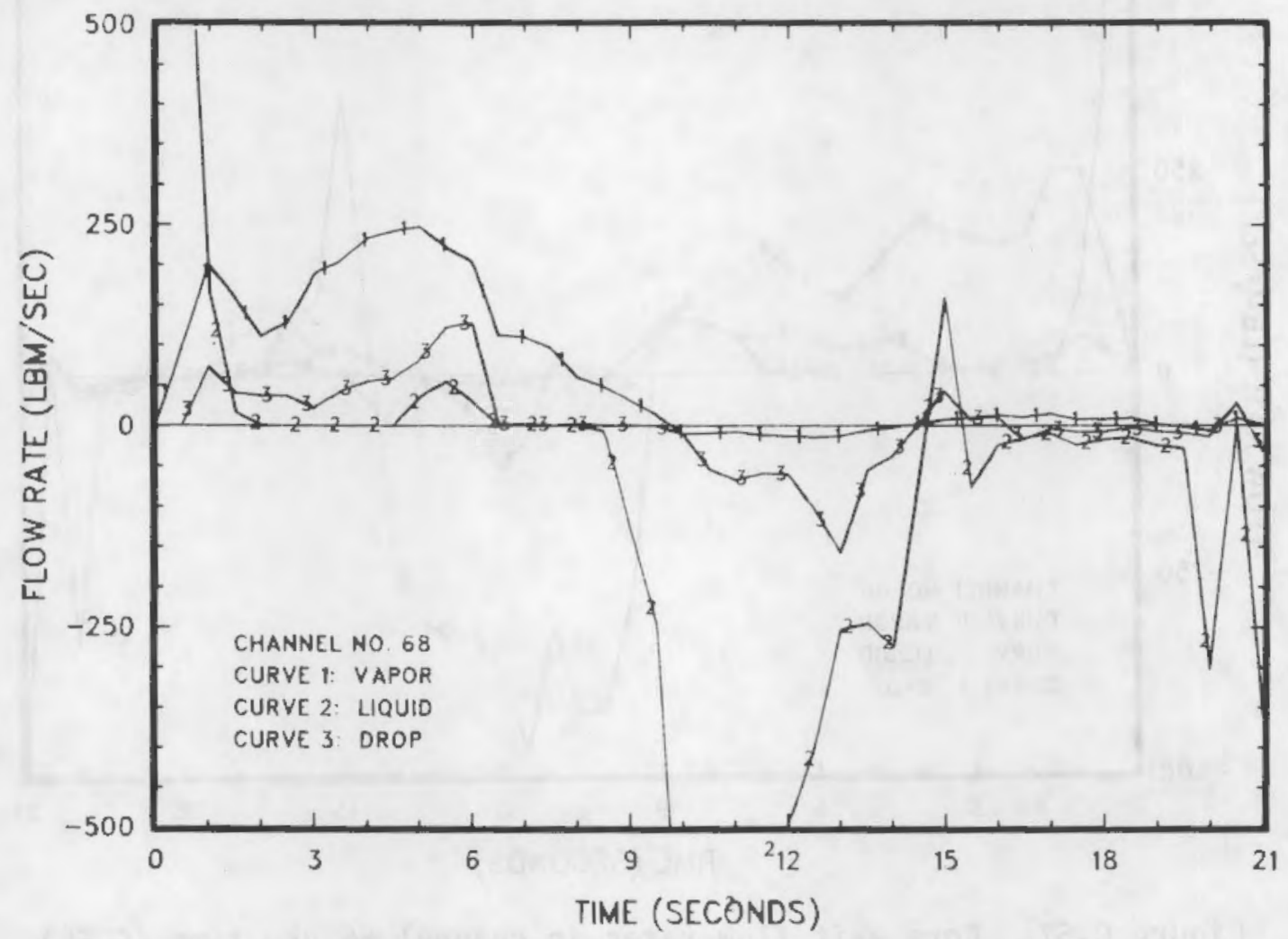

Figure C.59. Core exit flow rates in channel 68 vs. time (CCFL)

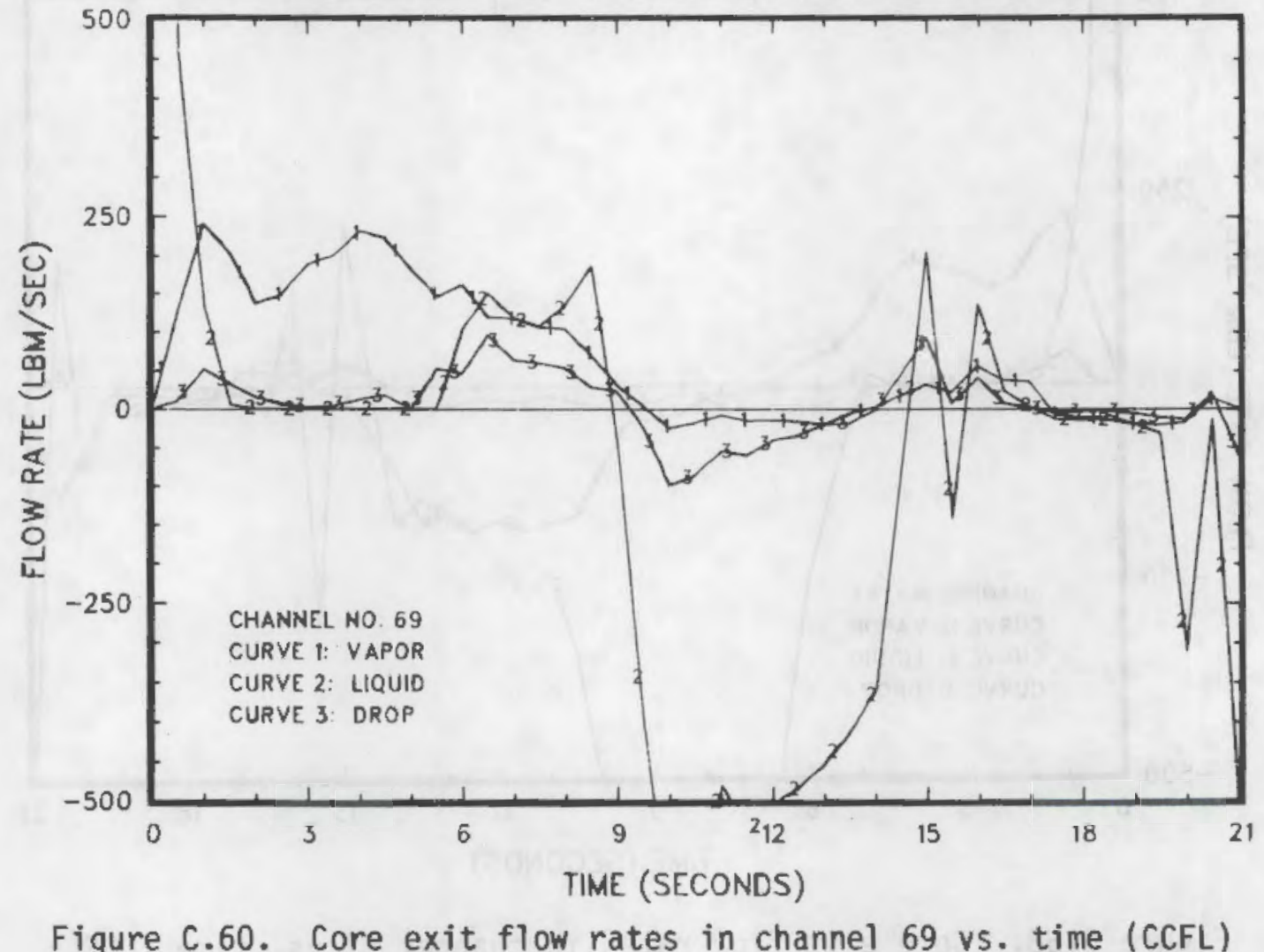

Figure C.60. Core exit flow rates in channel 69 vs. time (CCFL) 


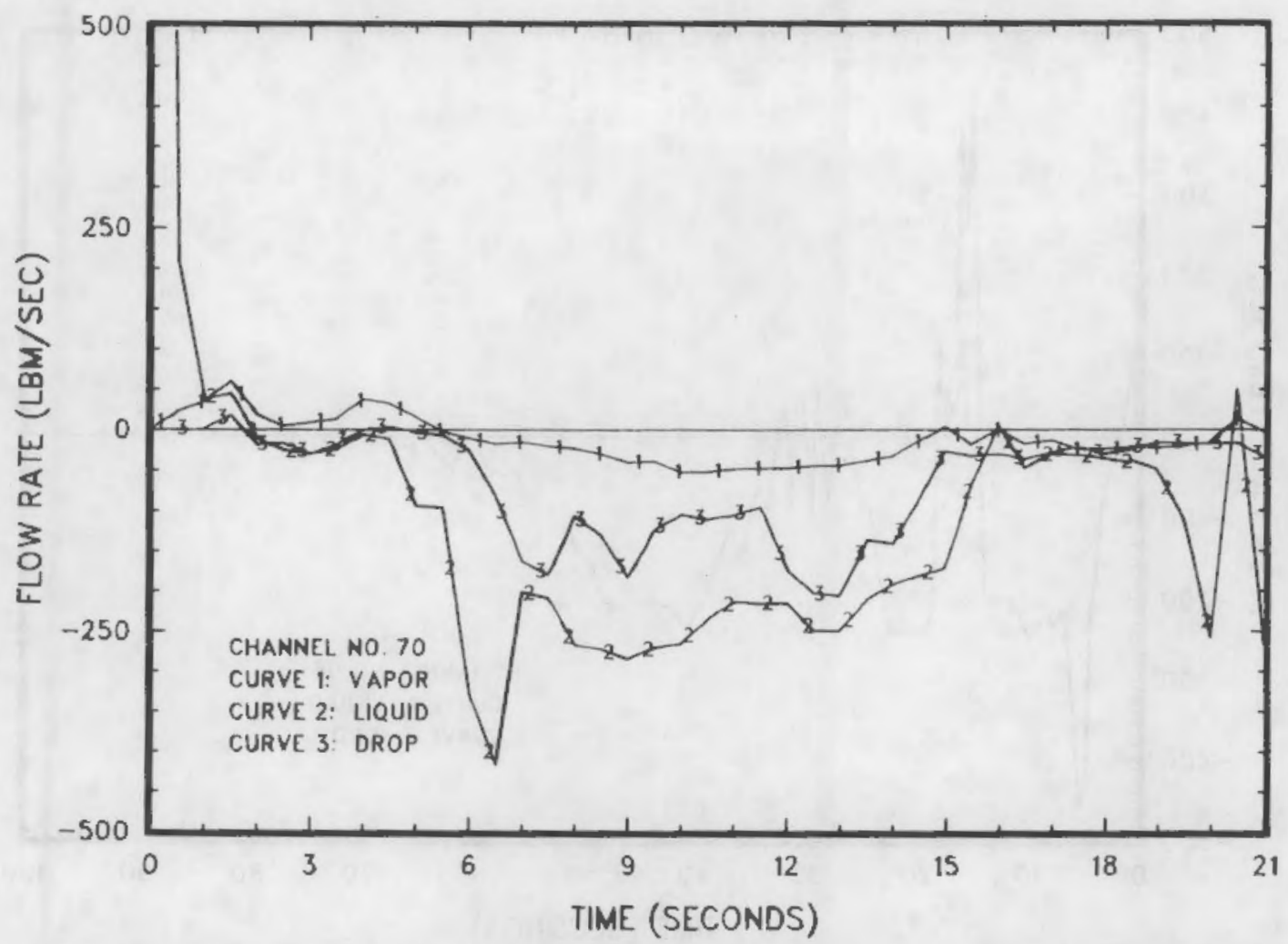

Figure C.61. Core exit flow rates in channel 70 vs. time (CCFL)

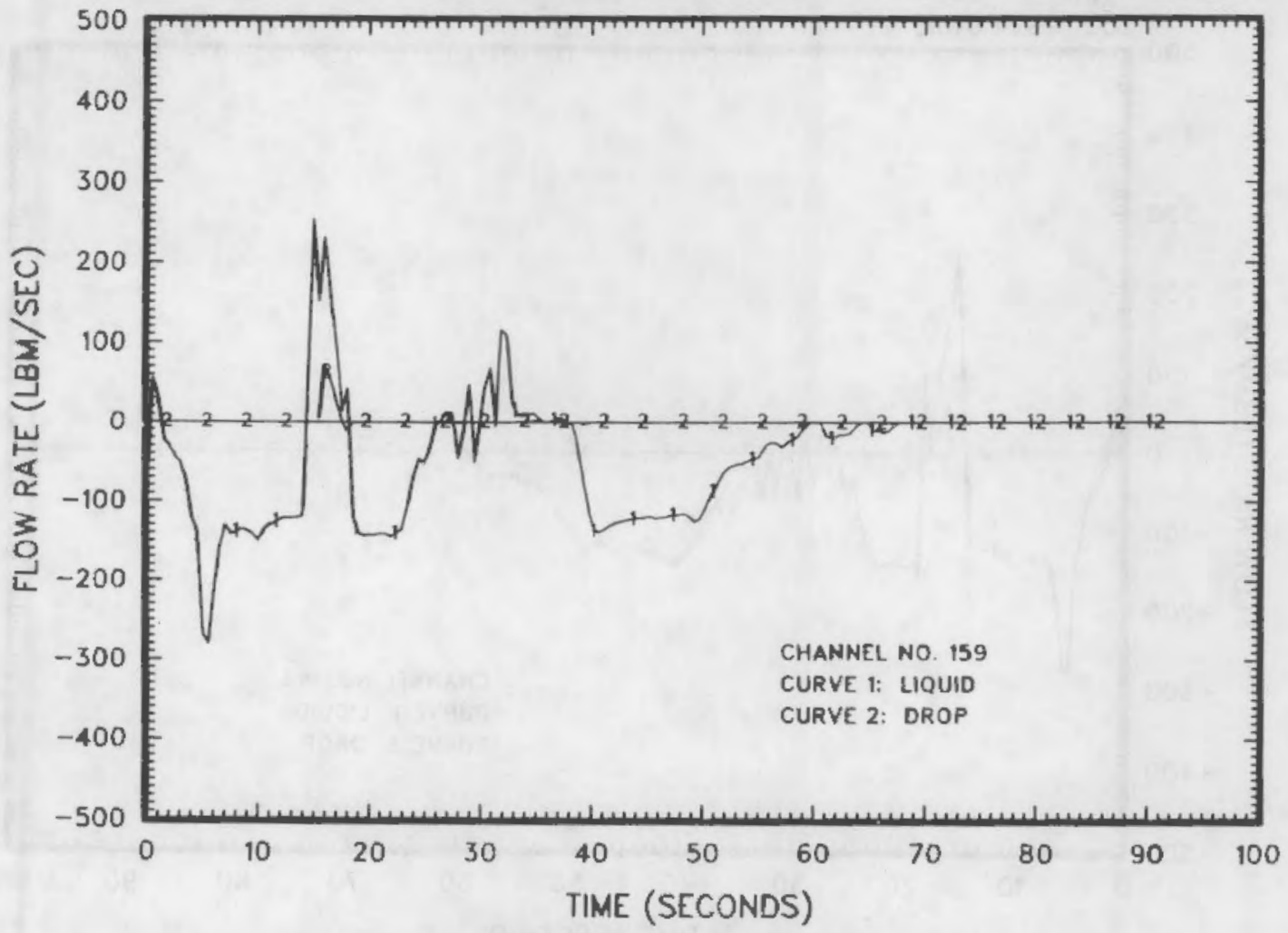

Figure C.62. Support column liquid and drop flow rates through channel 159 vs. time 


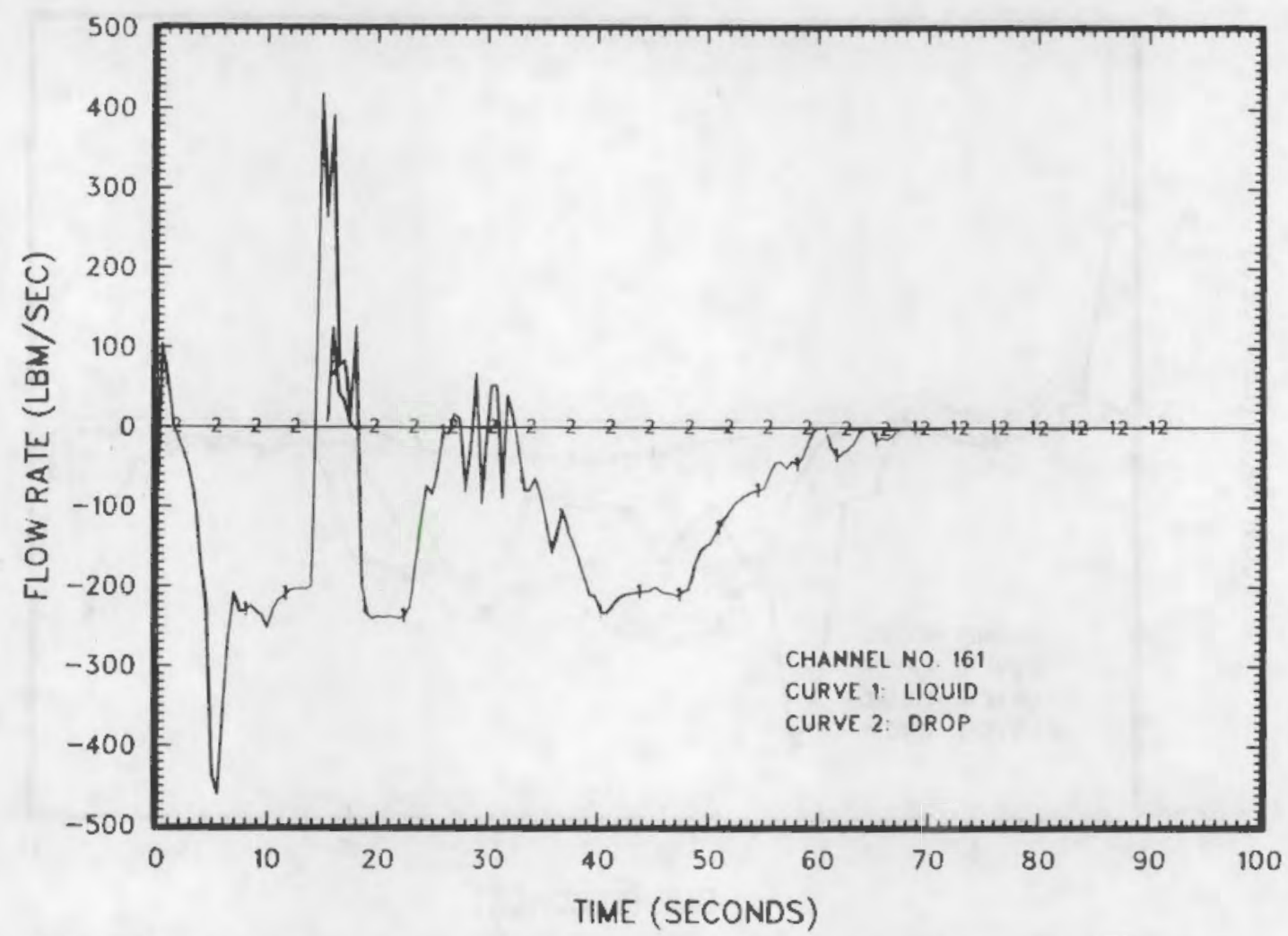

Figure C.63. Support column liquid and drop flow rates through channel

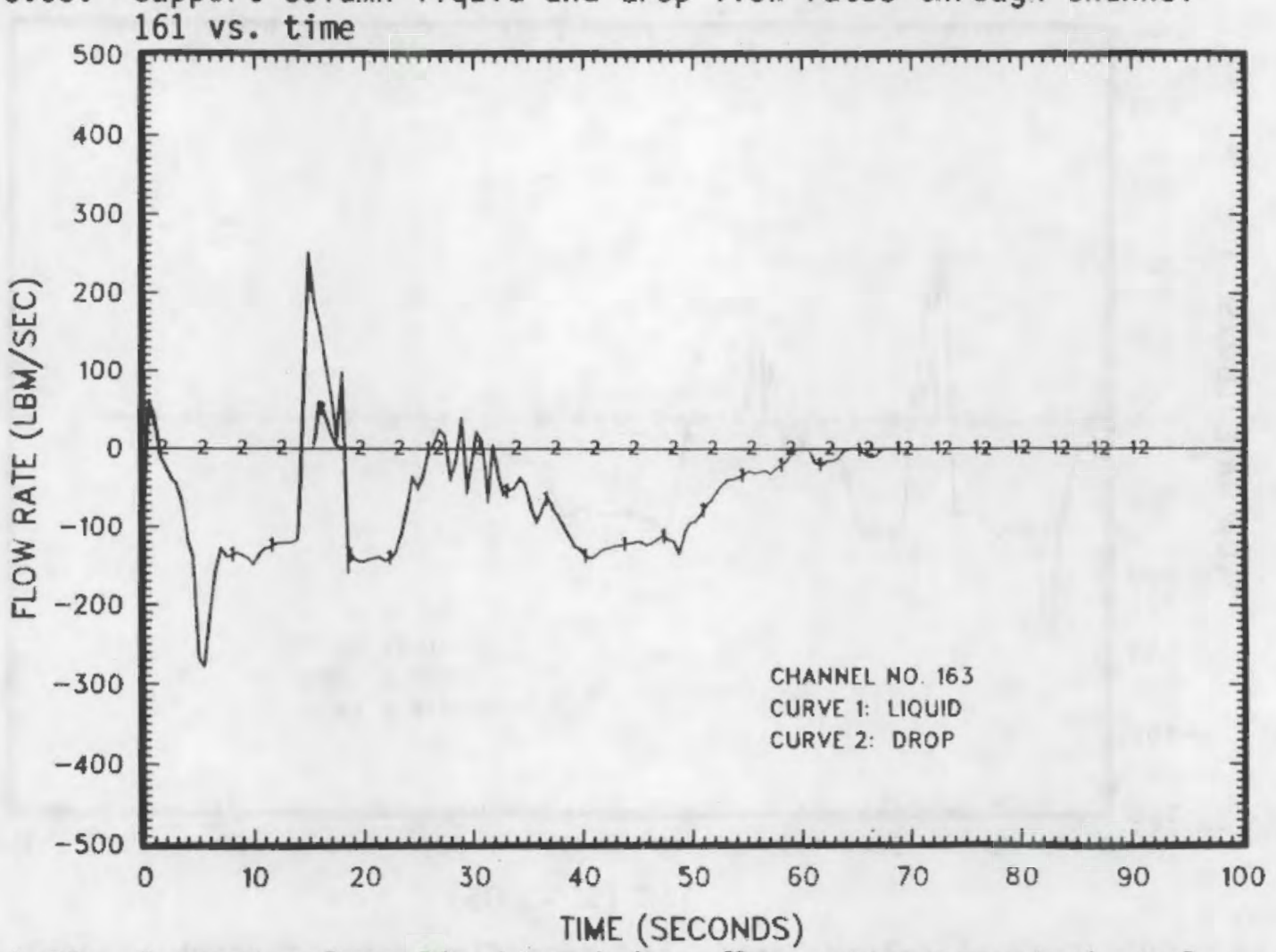

Figure C.64. Support column liquid and drop flow rates through channel 163 vs. time 


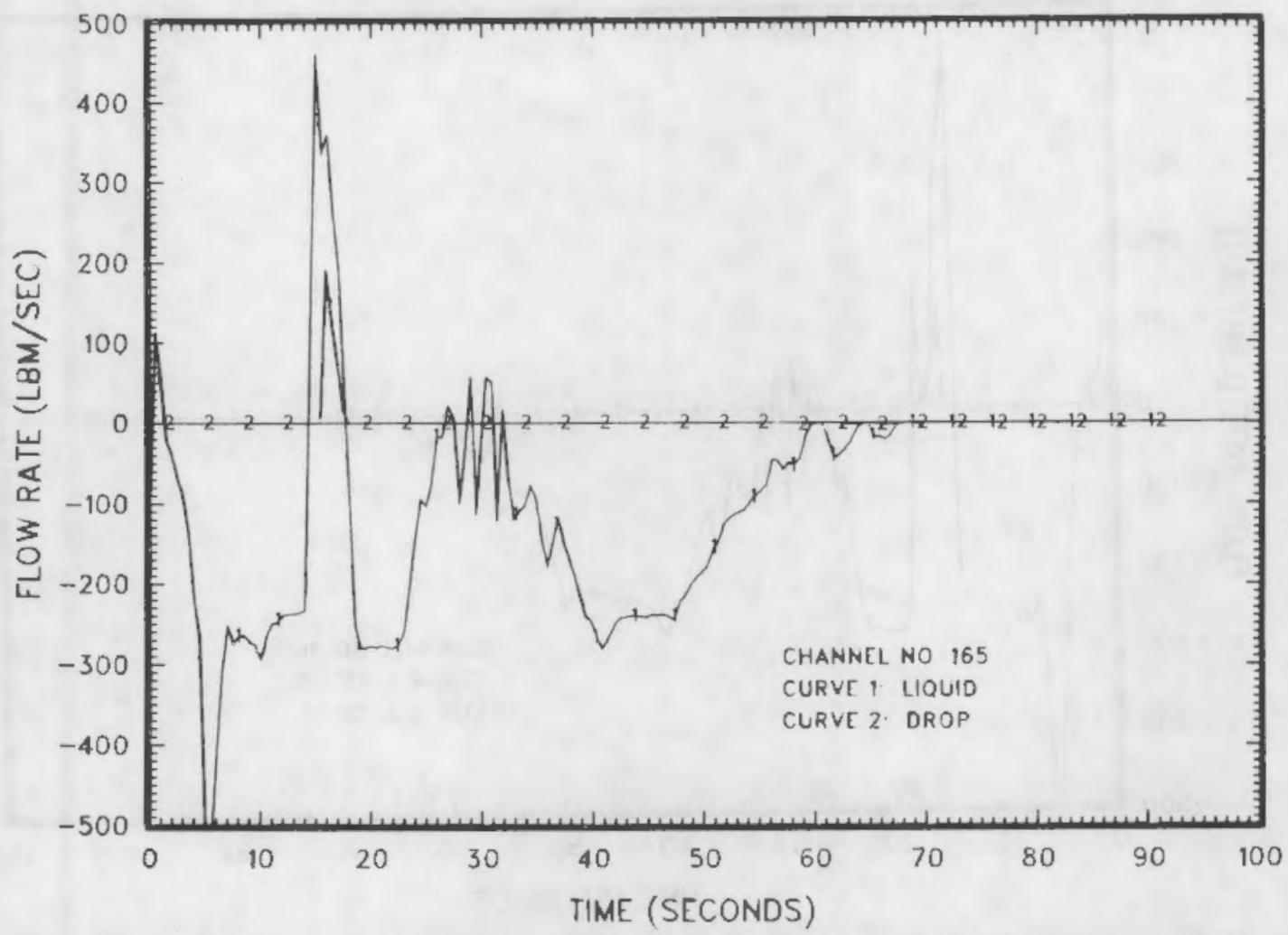

Figure C.65. Support column liquid and drop flow rates through channel

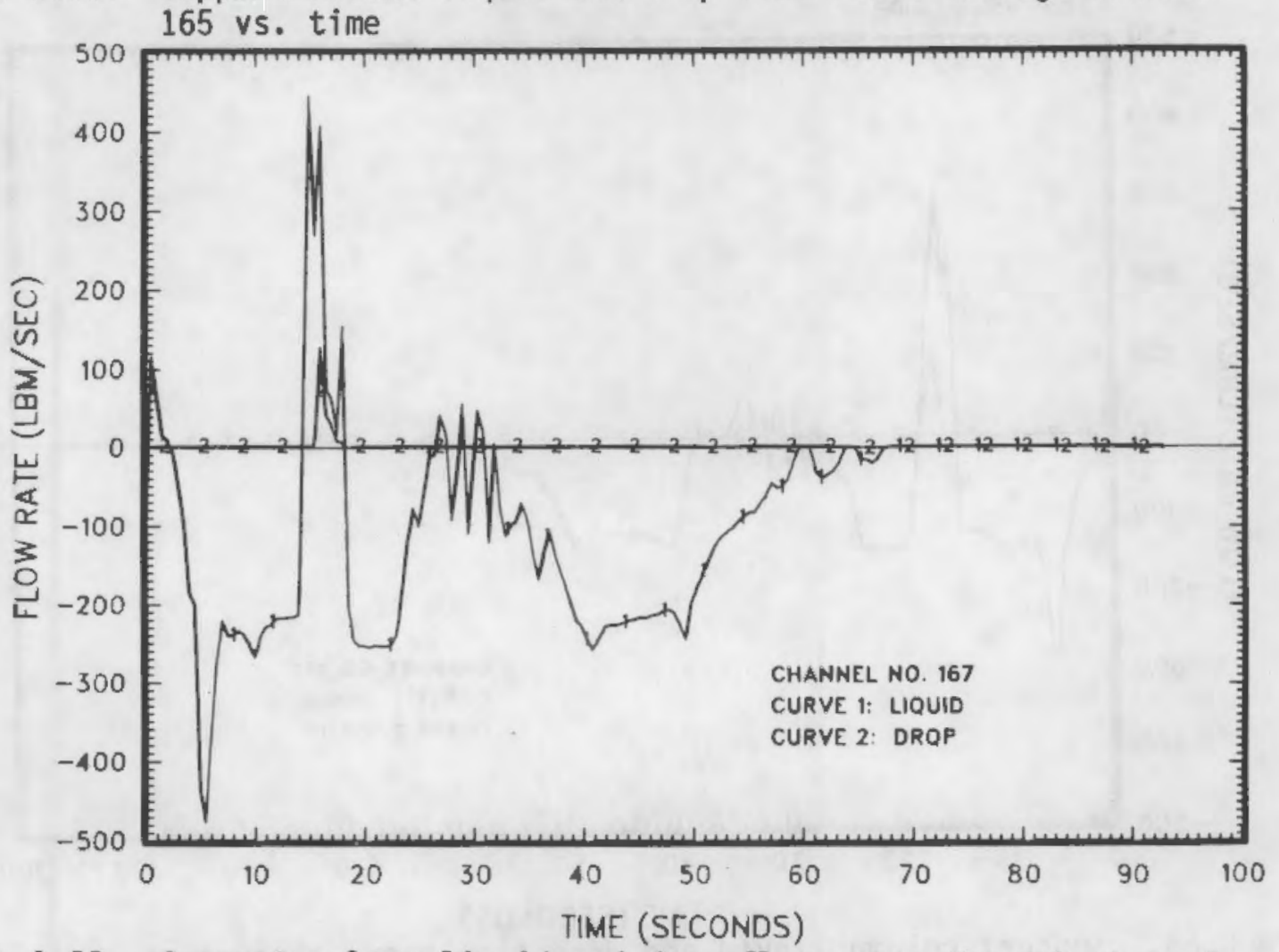

Figure C.66. Support column liquid and drop flow rates through channel 167 vs. time 


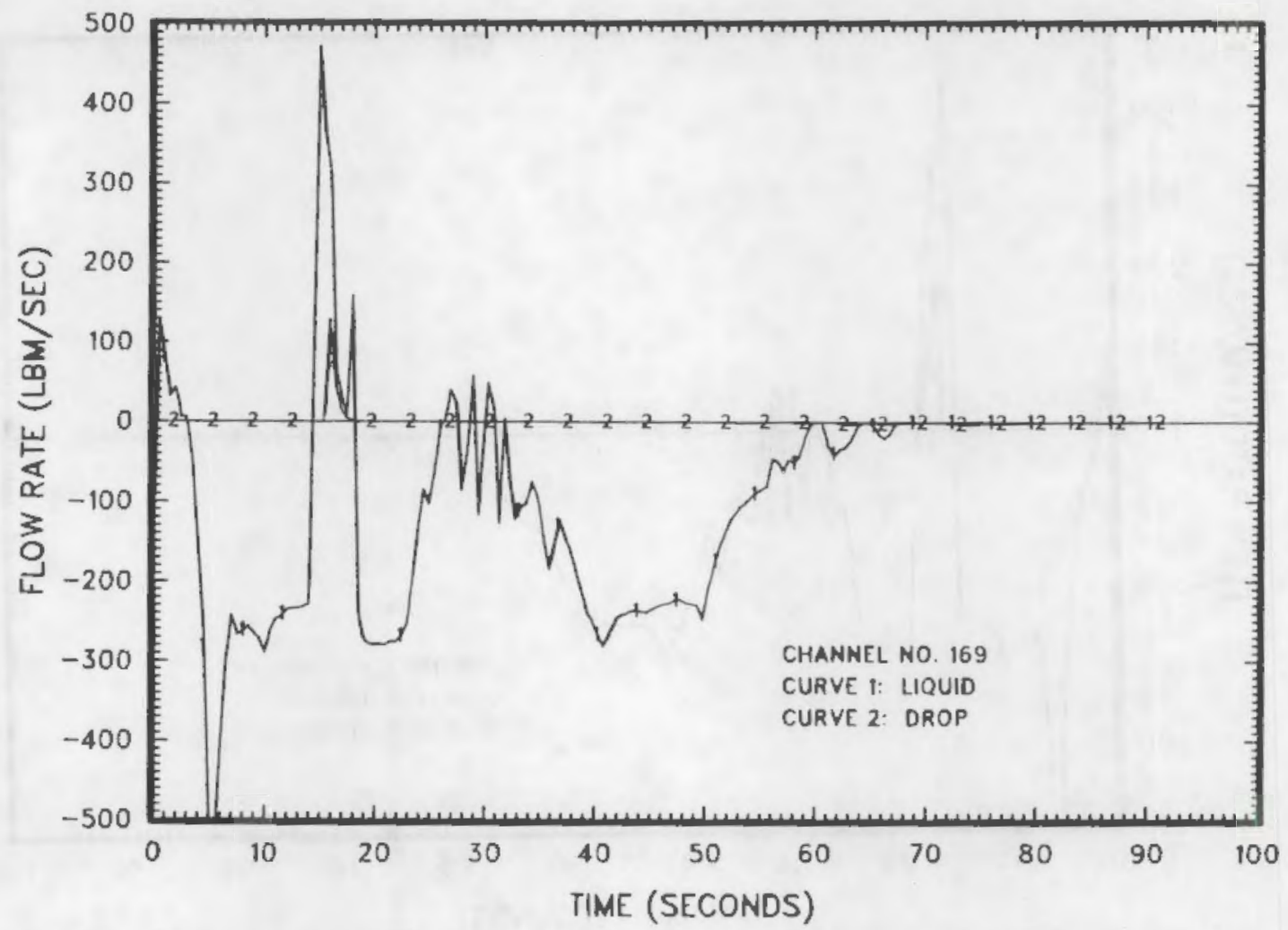

Figure C.67. Support column liquid and drop flow rates through channel 169 vs. time

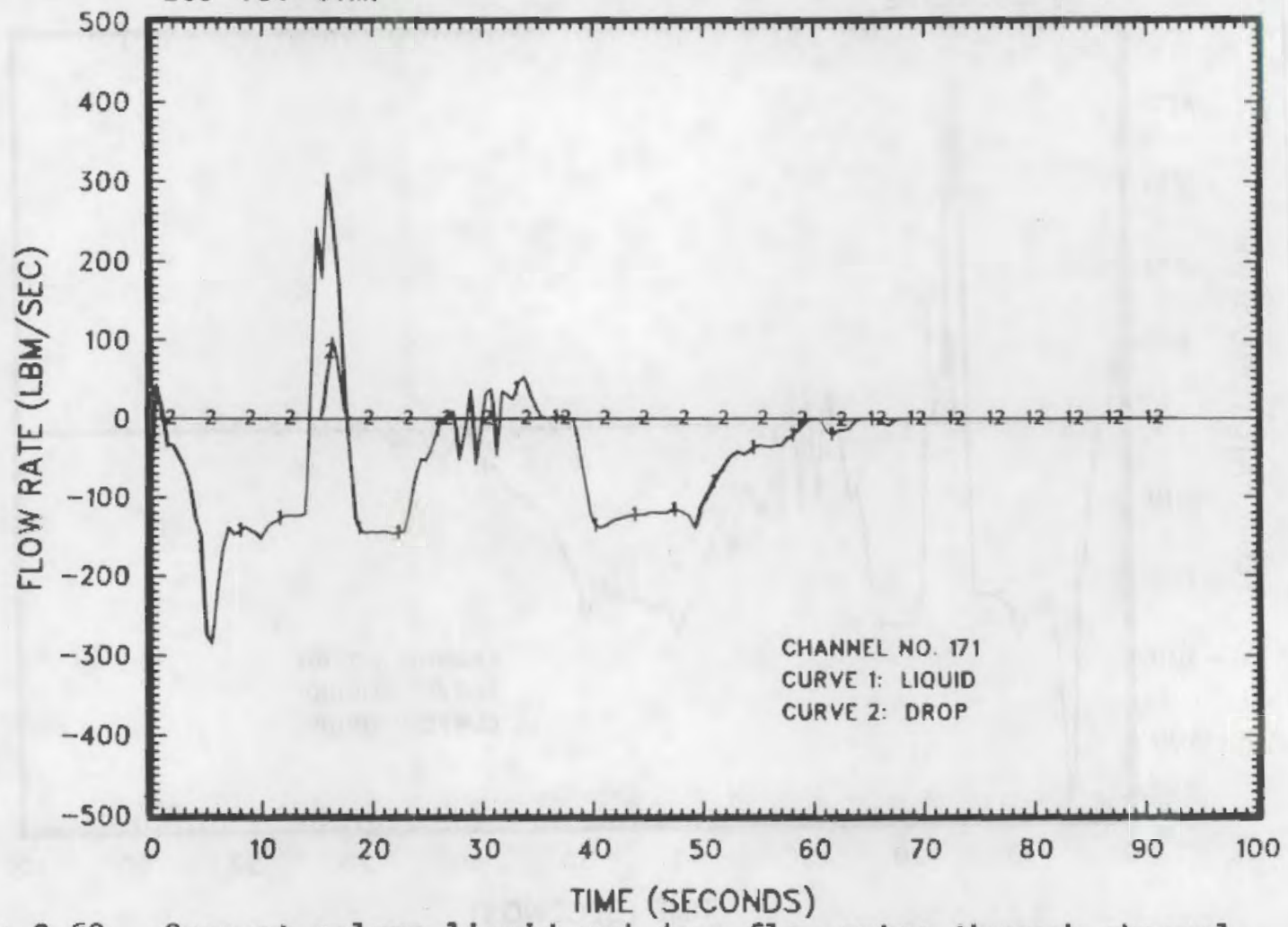

Figure C.68. Support column liquid and drop flow rates through channel 171 vs. time 


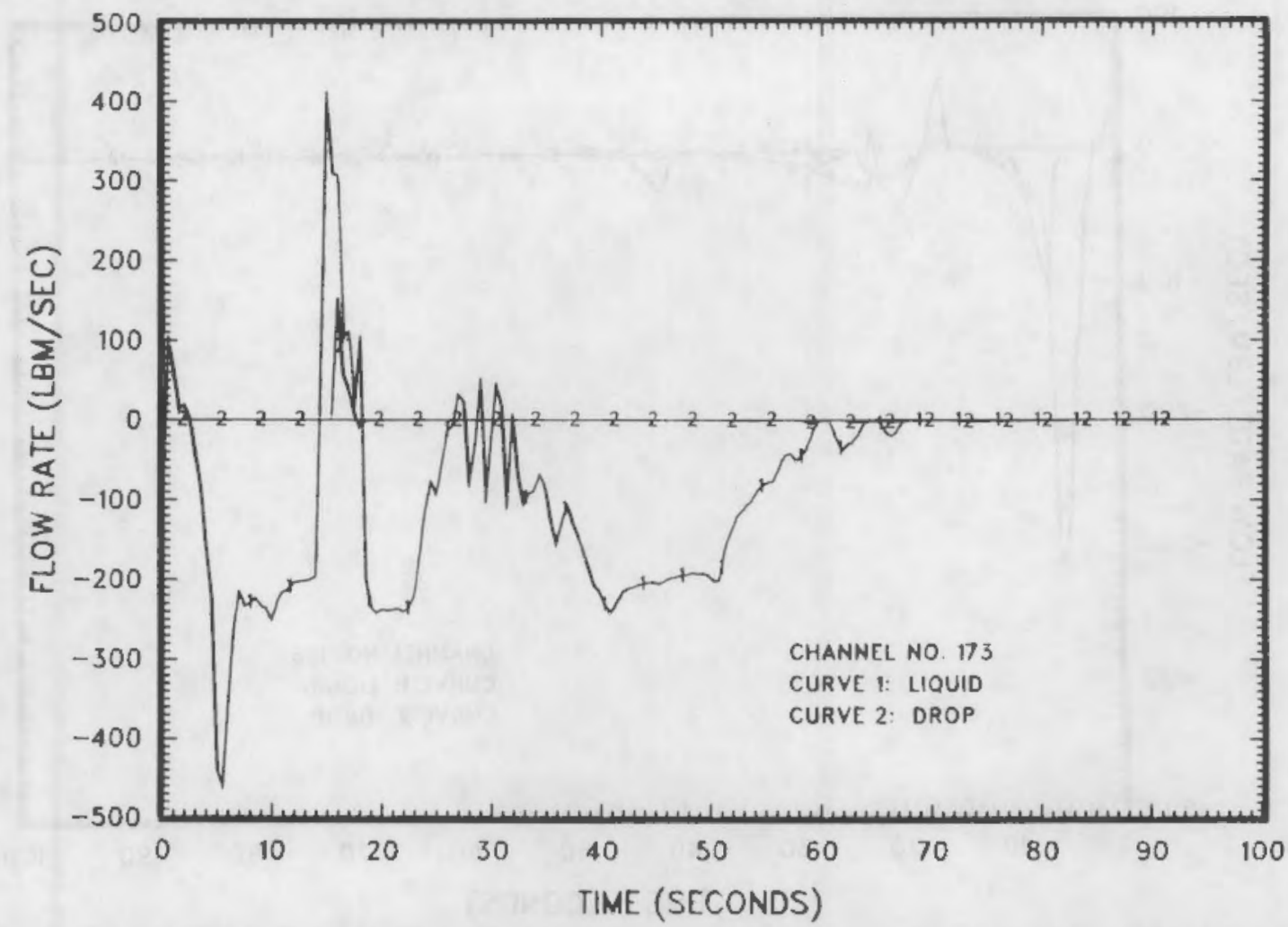

Figure C.69. Support column liquid and drop flow rates through channel

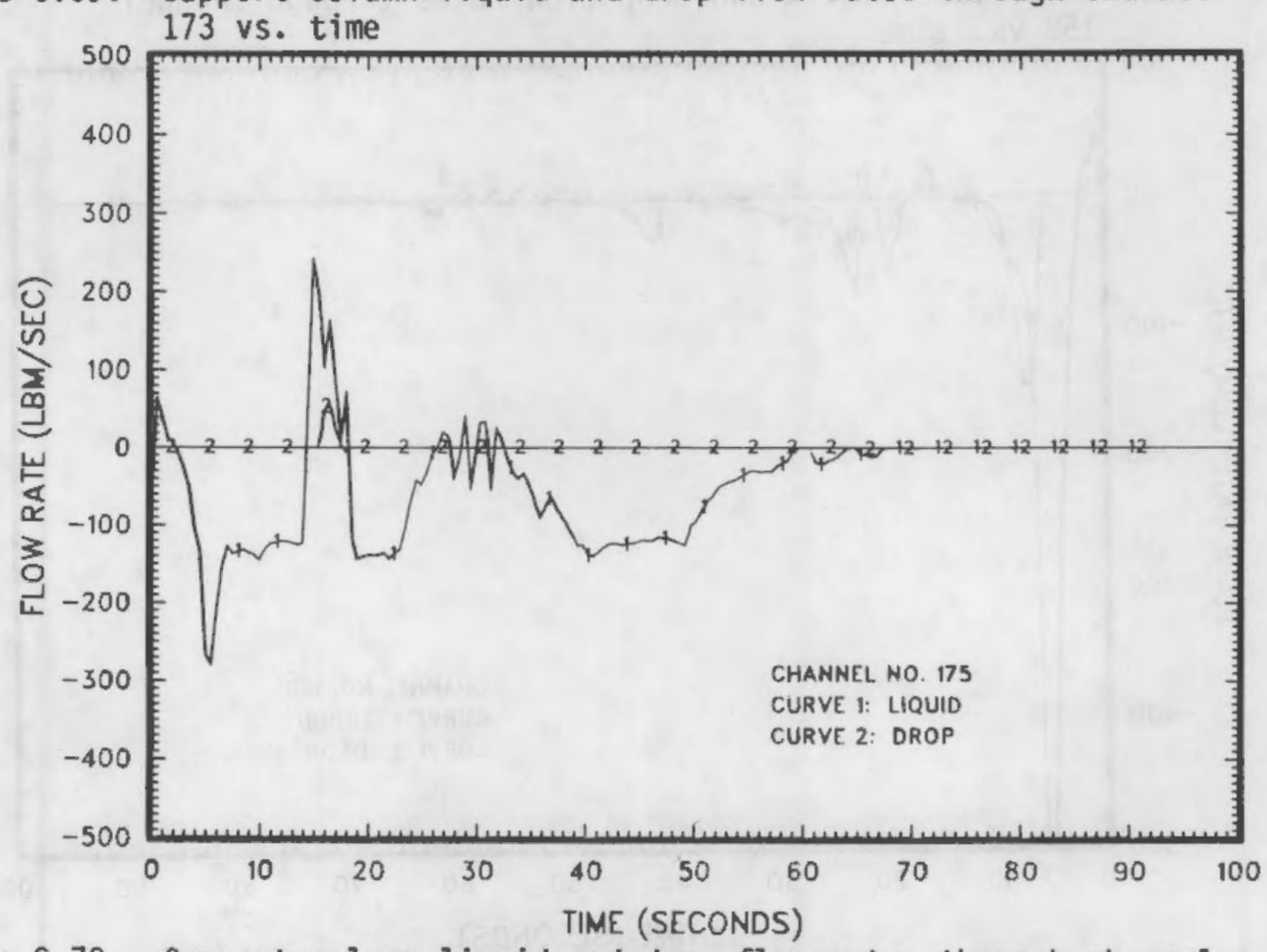

Figure C.70. Support column liquid and drop flow rates through channel 175 vs. time 


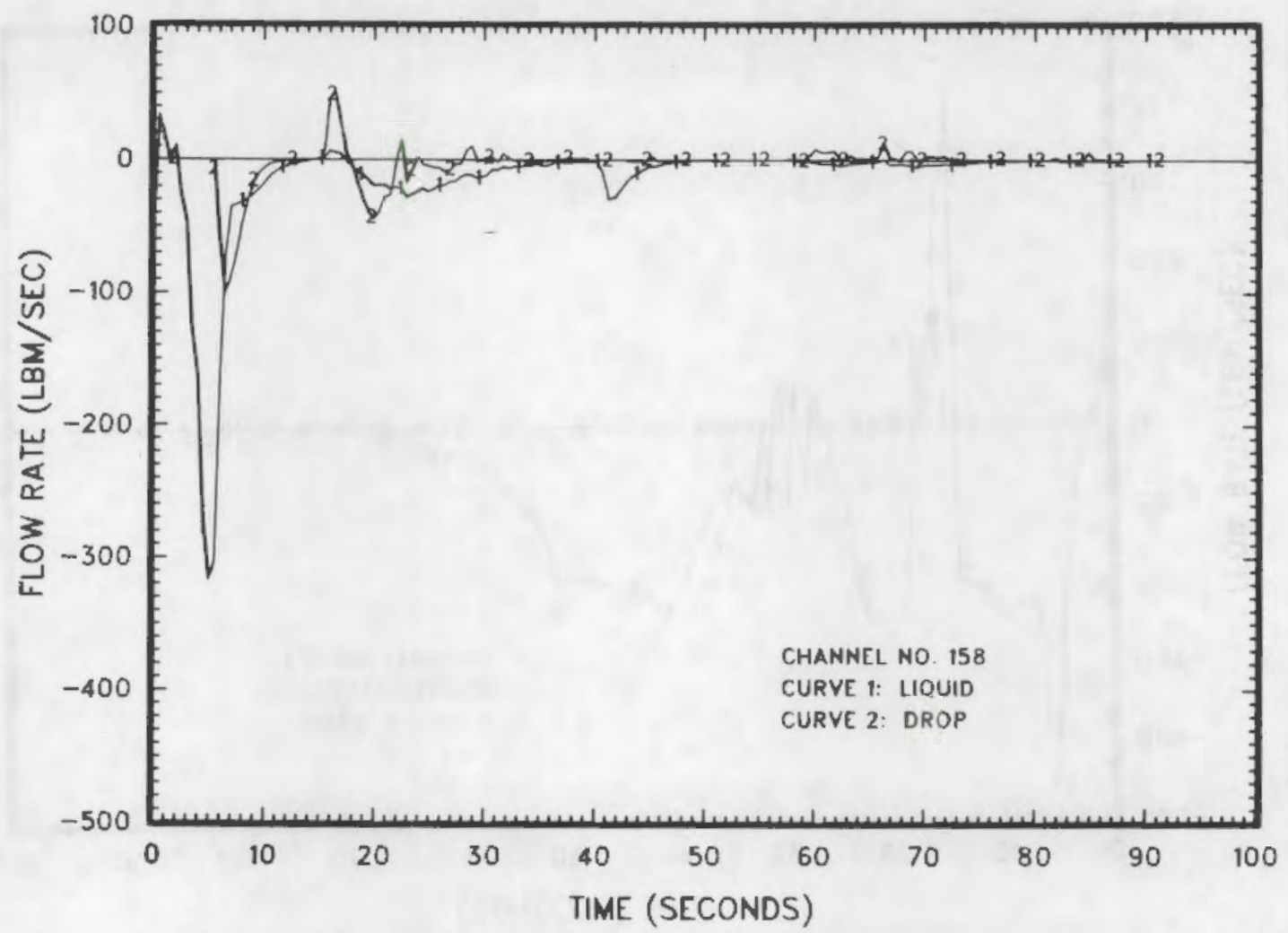

Figure C.71. Guide tube liquid and drop flow rates through channel 158 vs. time

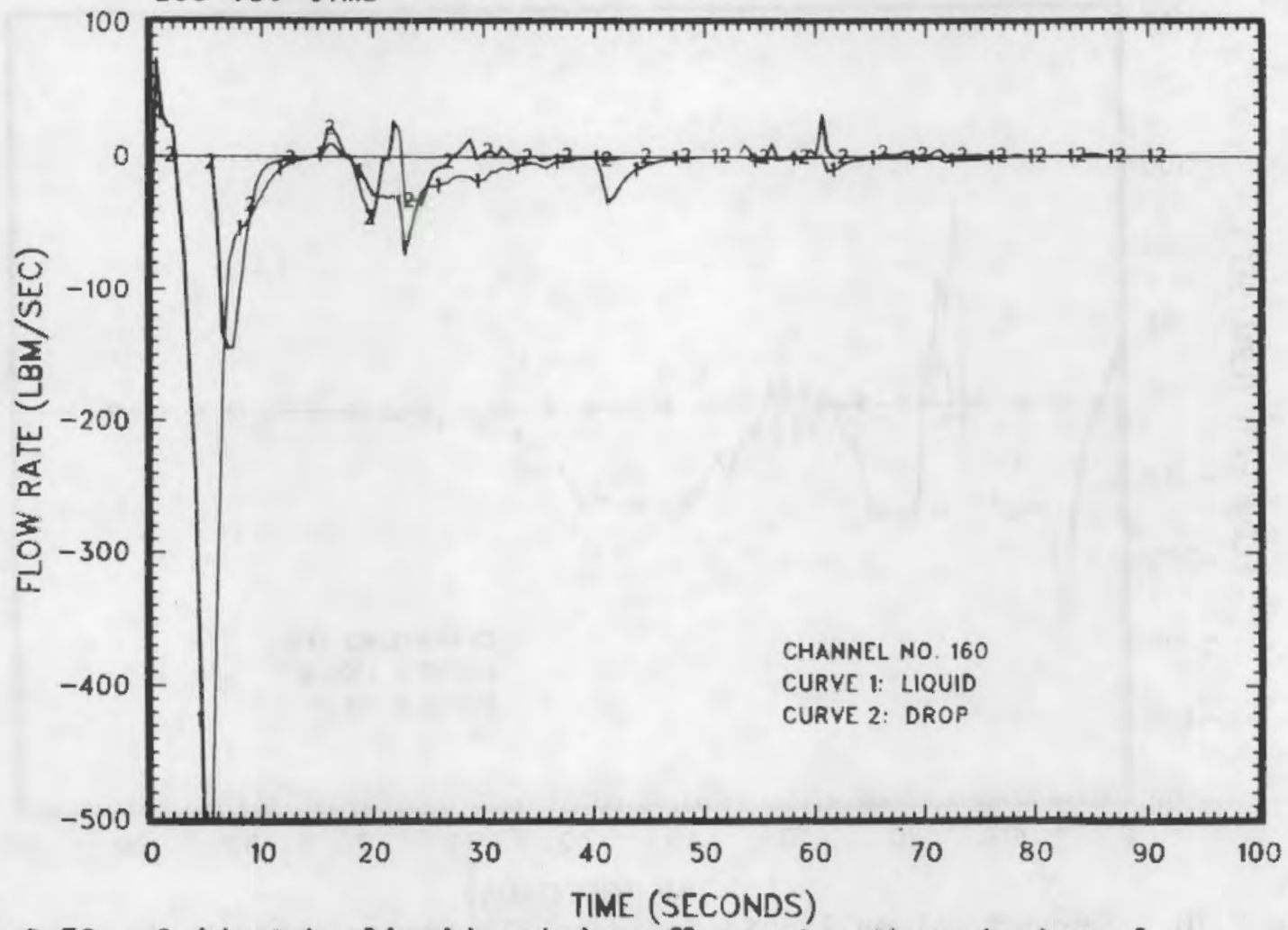

Figure C.72. Guide tube liquid and drop flow rates through channel 160 vs. time 


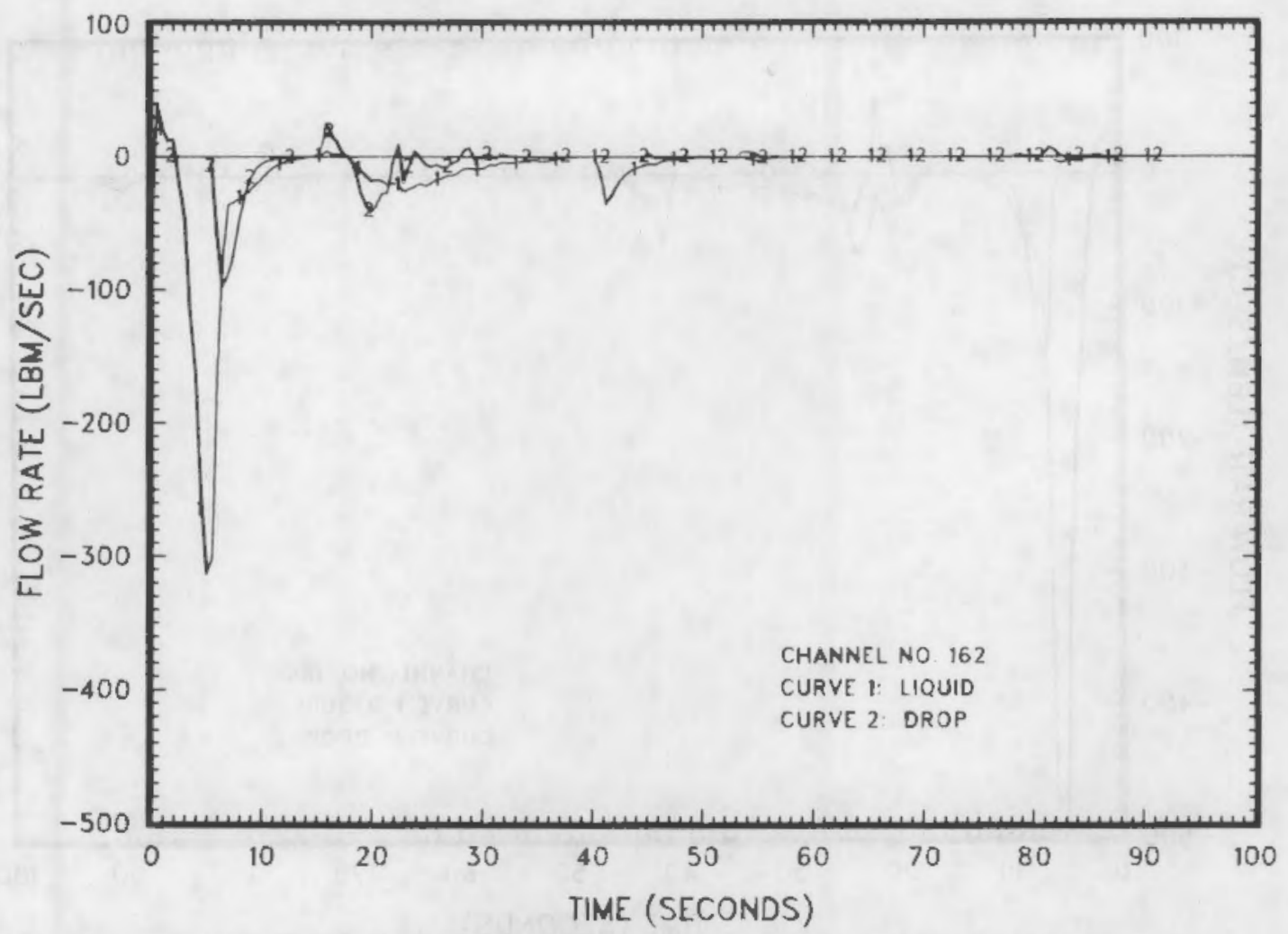

Figure C.73. Guide tube liquid and drop flow rates through channel 162 vs. time

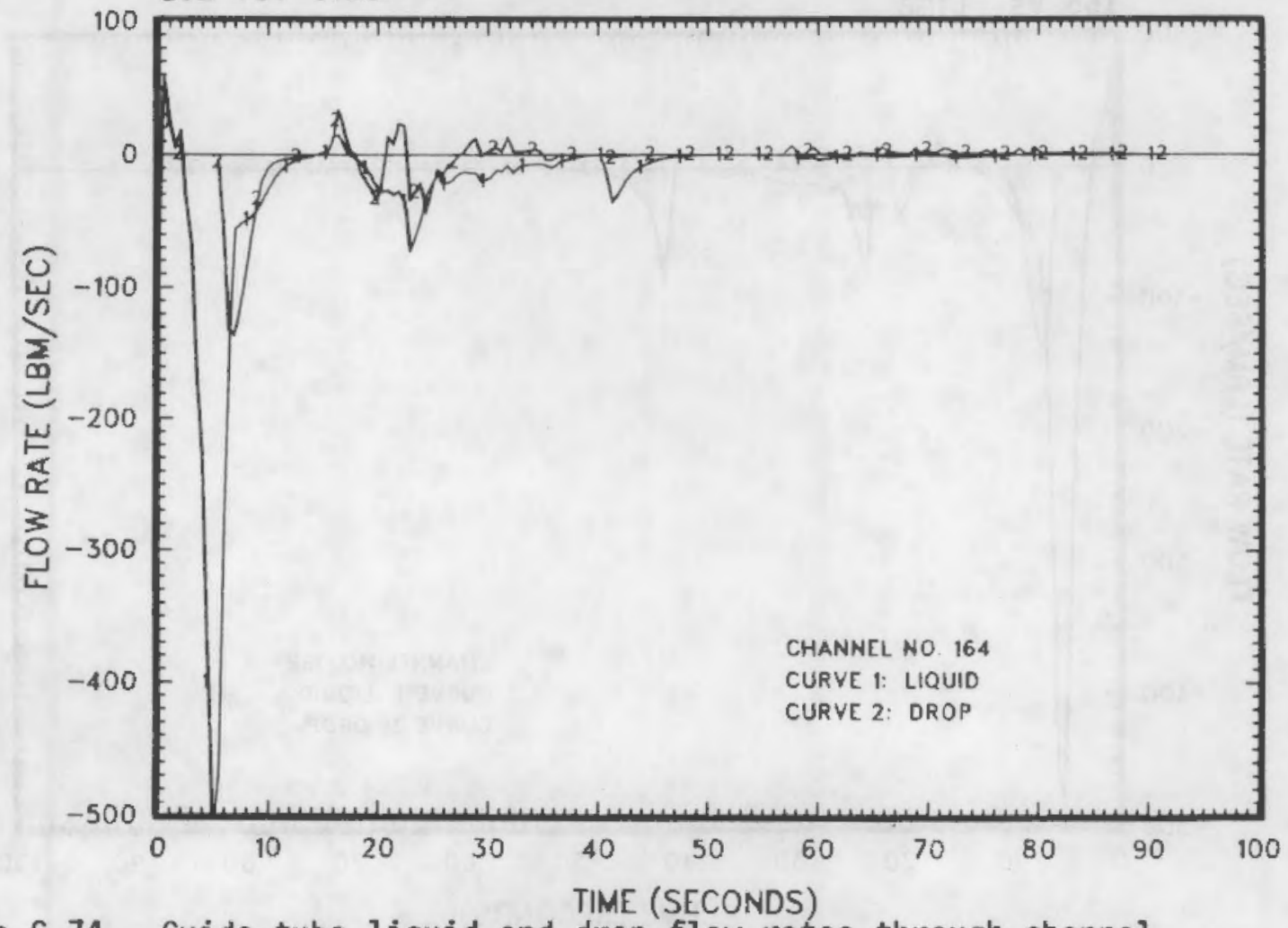

Figure C.74. Guide tube liquid and drop flow rates through channel 164 vs. time. 


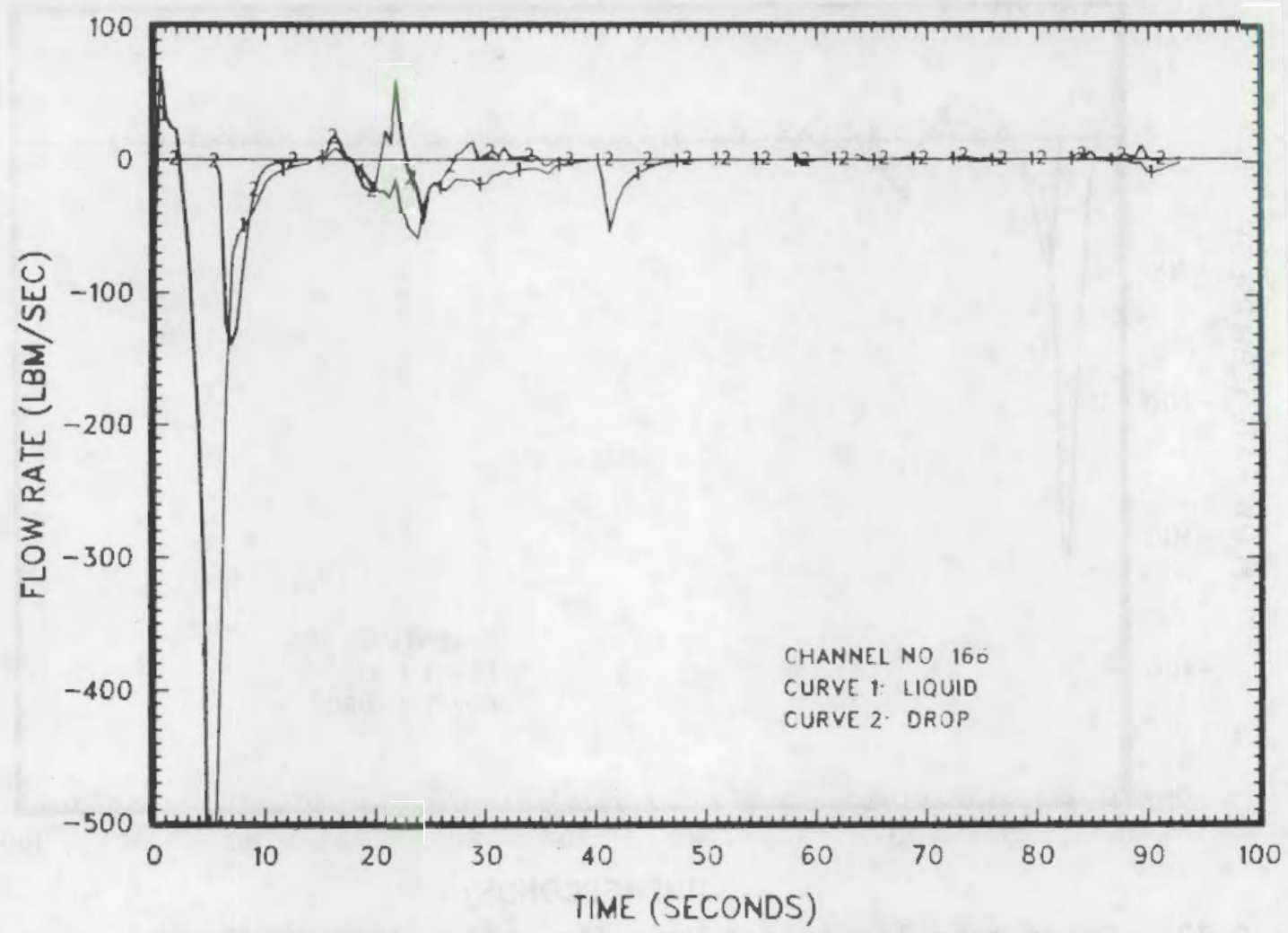

Figure C.75. Guide tube liquid and drop flow rates through channe1

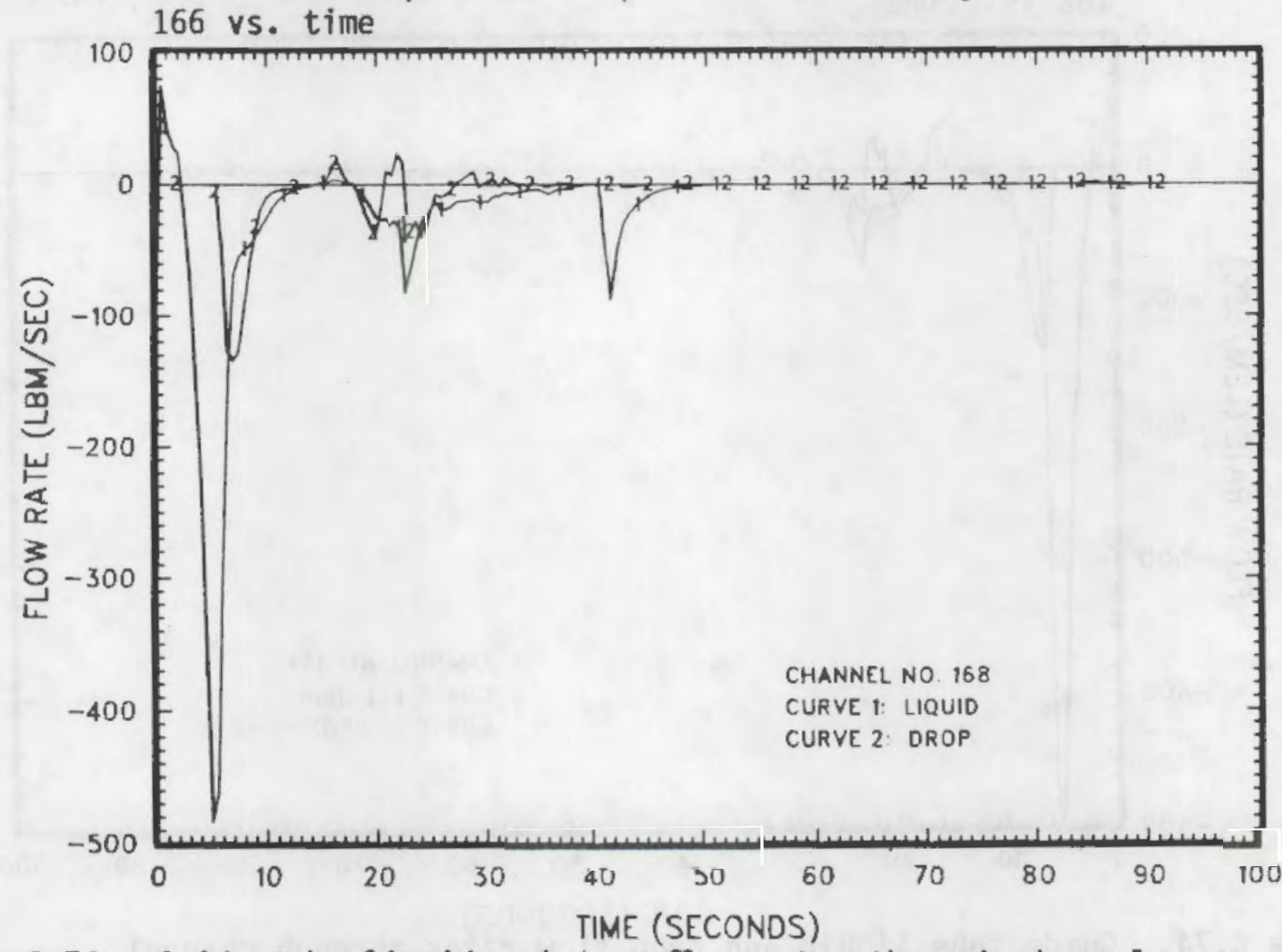

Figure C.76. Guide tube liquid and drop flow rates through channel 168 vs. time 


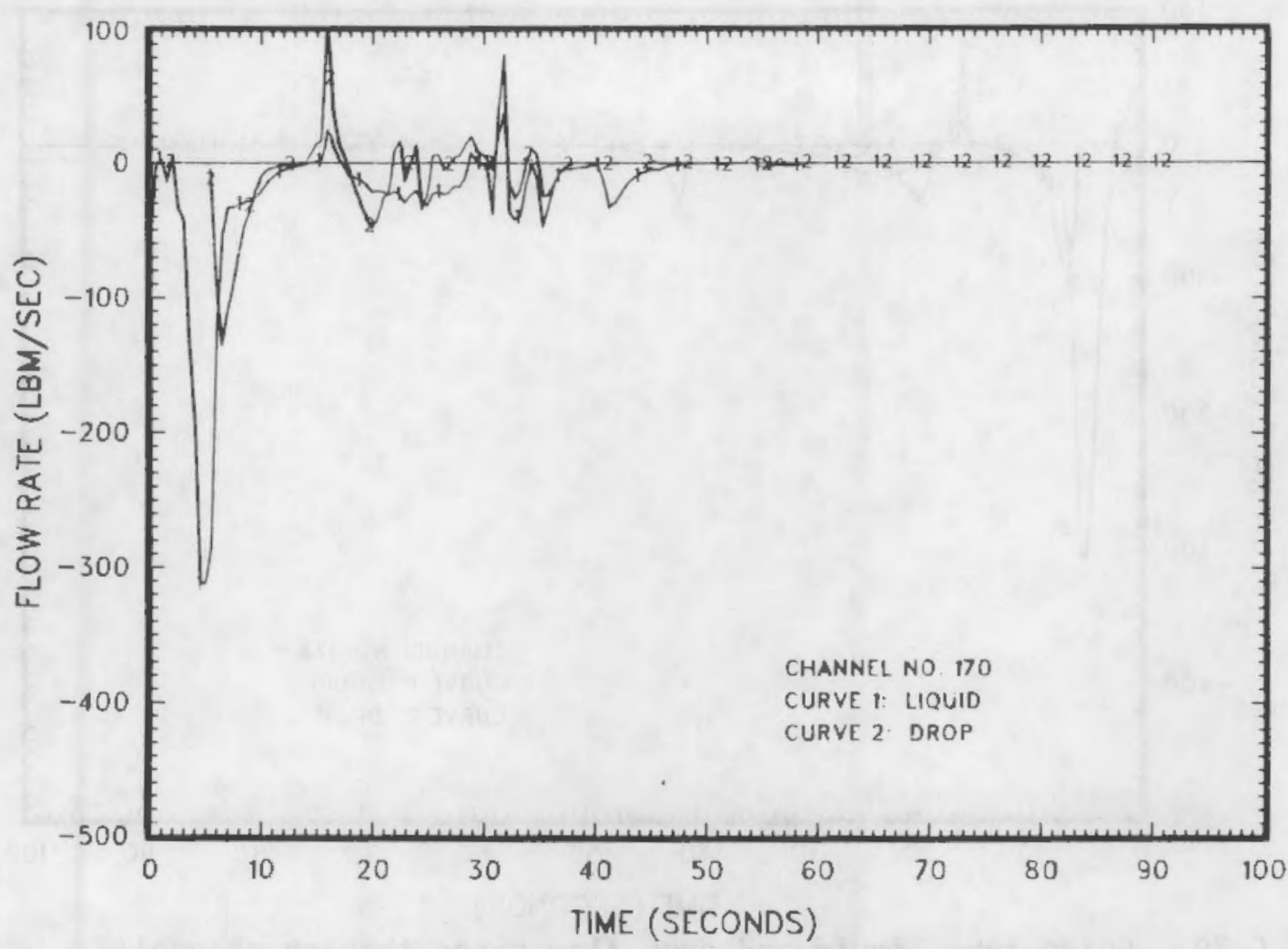

Figure C.77. Guide tube liquid and drop flow rates through channel 170 vs. time

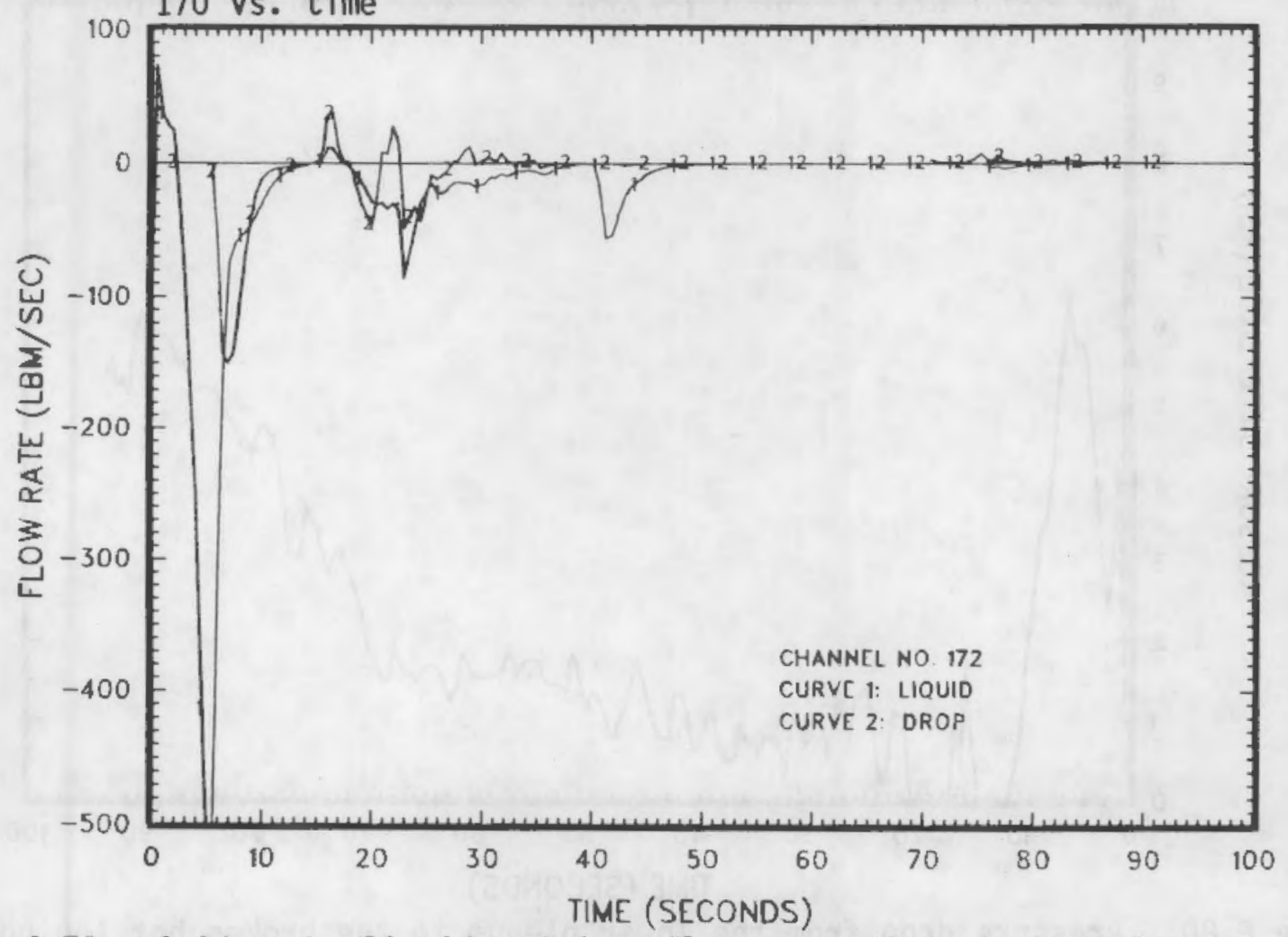

Figure C.78. Guide tube liquid and drop flow rates through channel 172 vs. time 


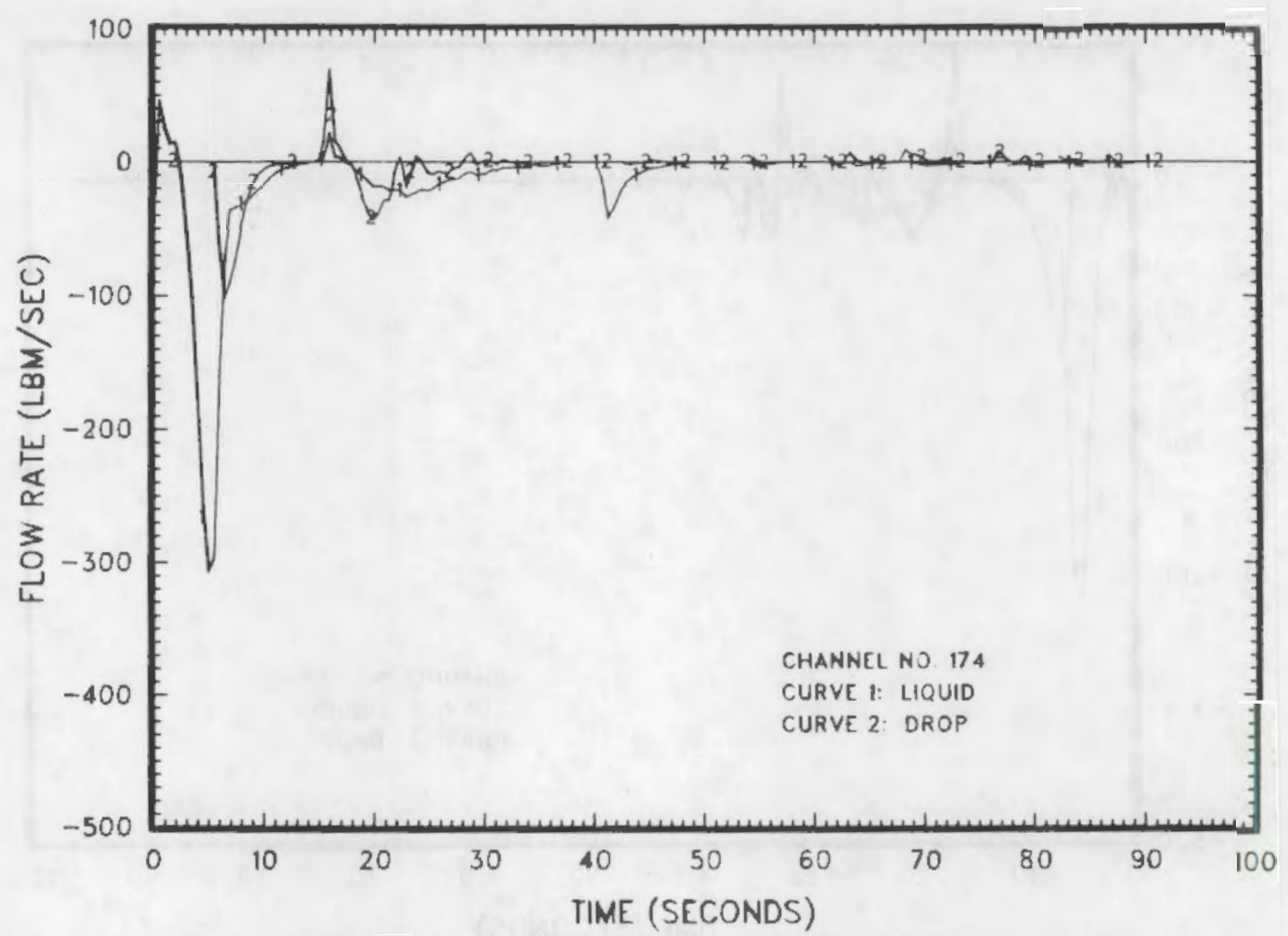

Figure C.79. Guide tube liquid and drop flow rates through channel

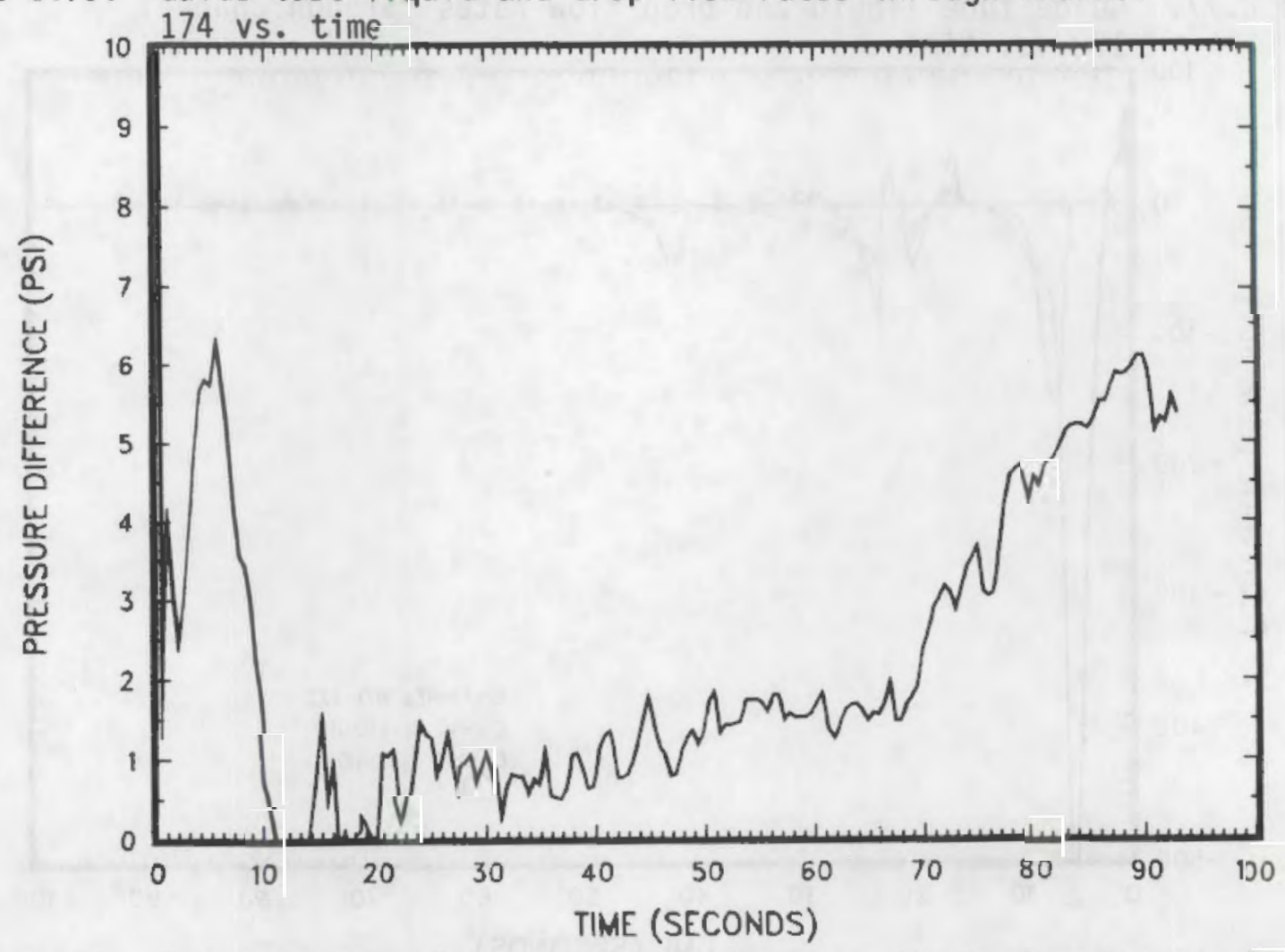

Figure C.80. Pressure drop from the lower plenum to the broken hot leg nozzle vs. time 


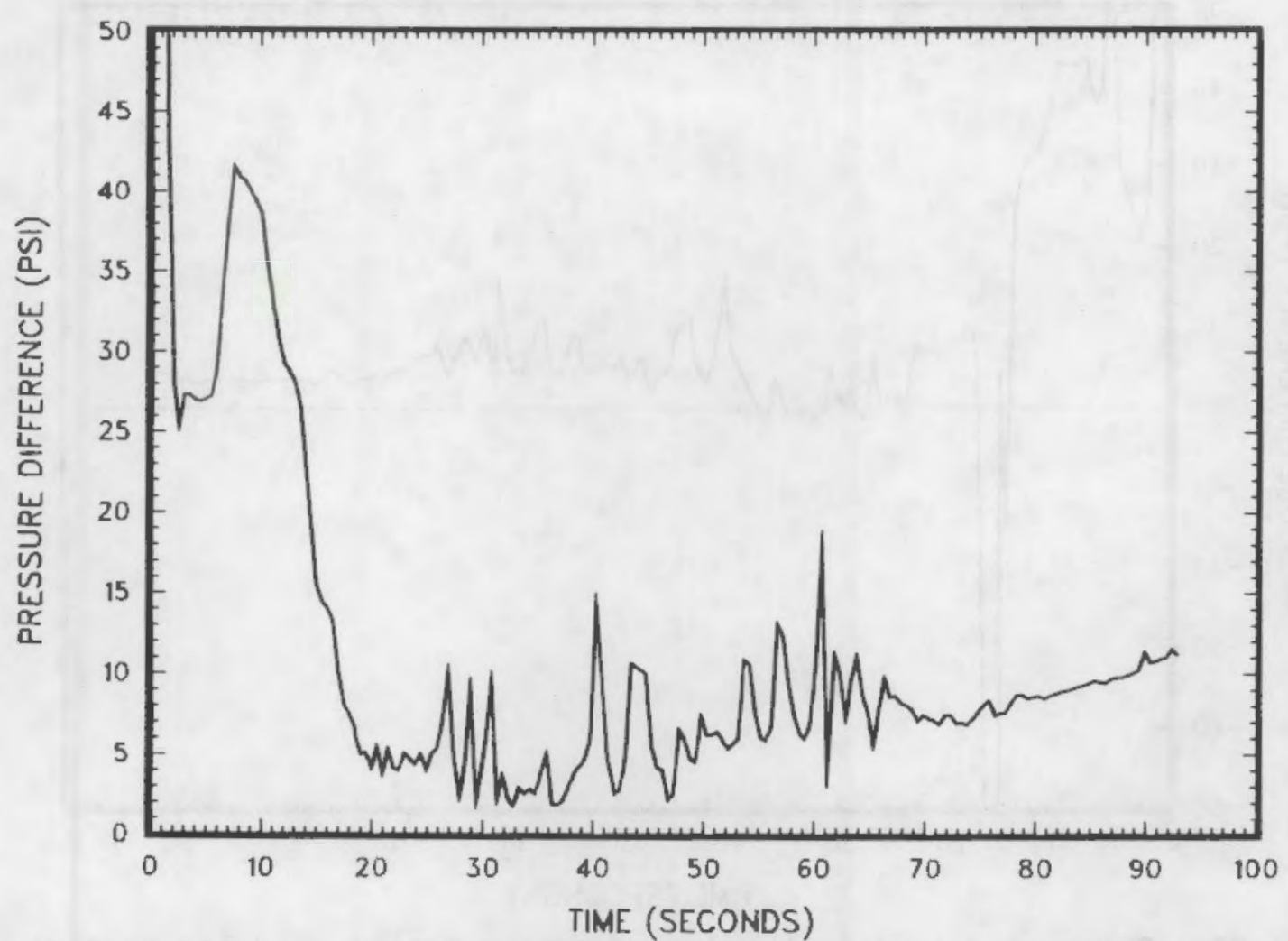

Figure C.81. Pressure drop from the lower plenum to the broken cold leg nozzle

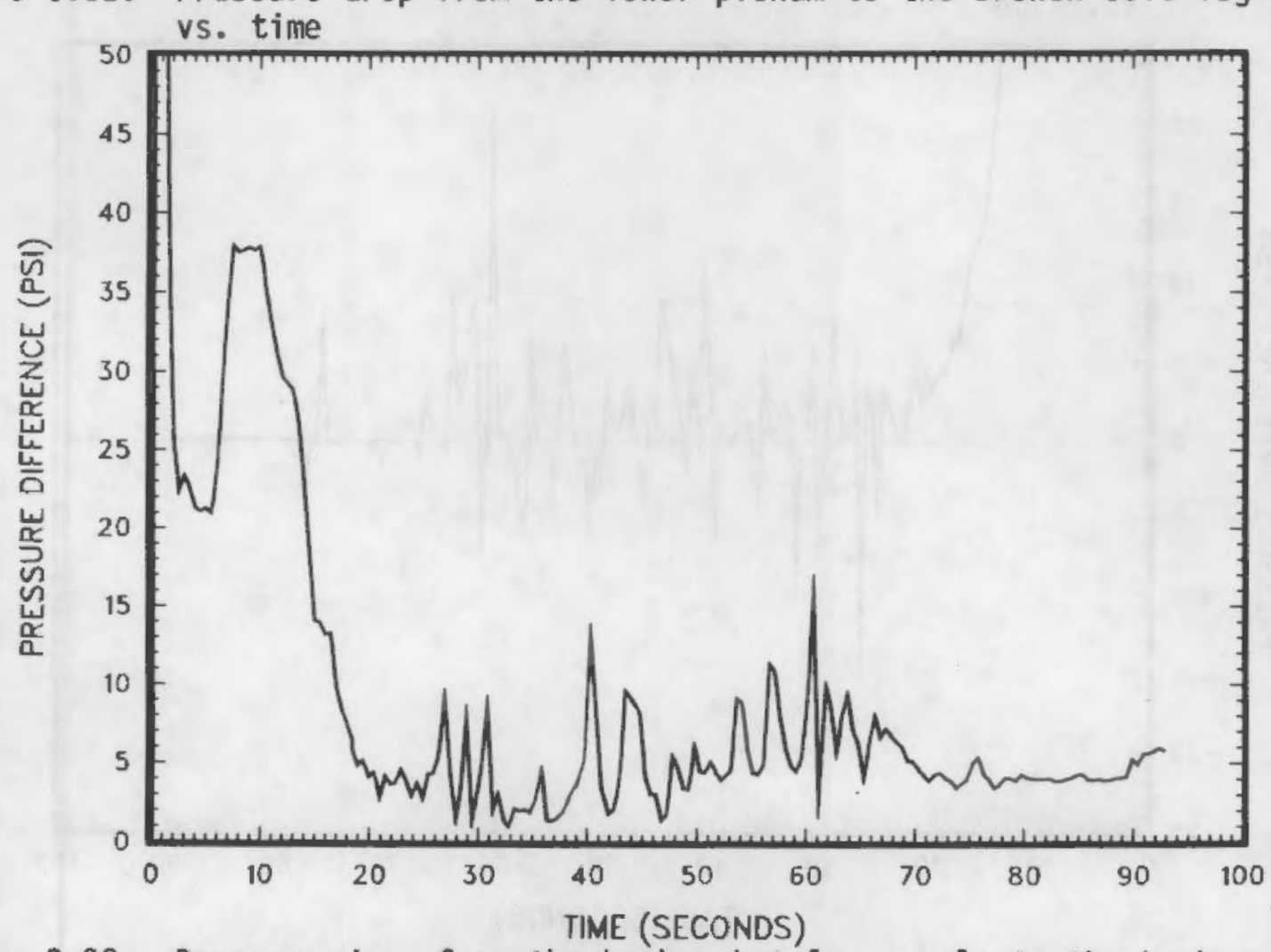

Figure C.82. Pressure drop from the broken hot leg nozzle to the broken cold leg nozzle vs. time 


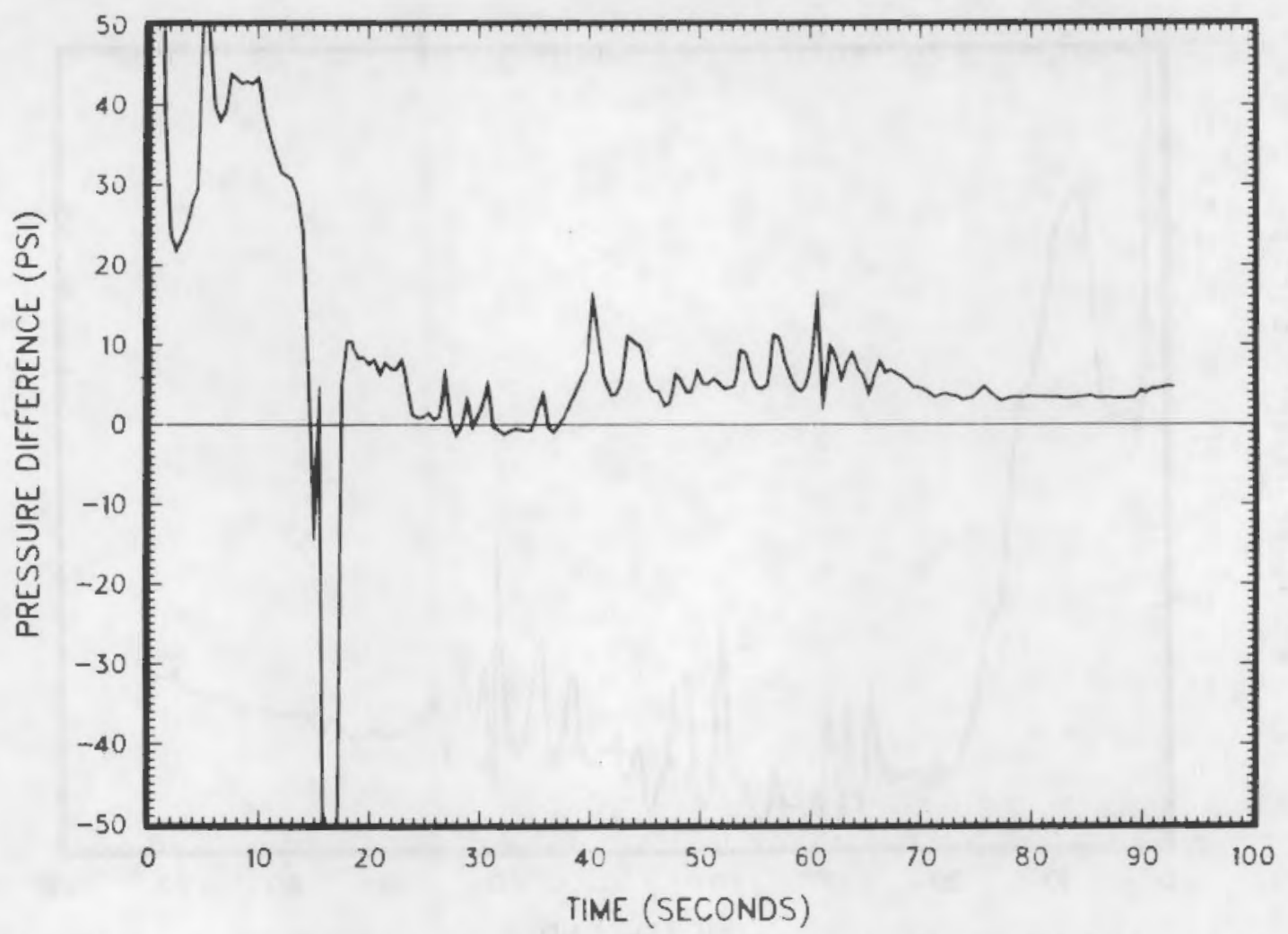

Figure C.83. Pressure drop from the intact to the broken cold leg nozzles vs. time

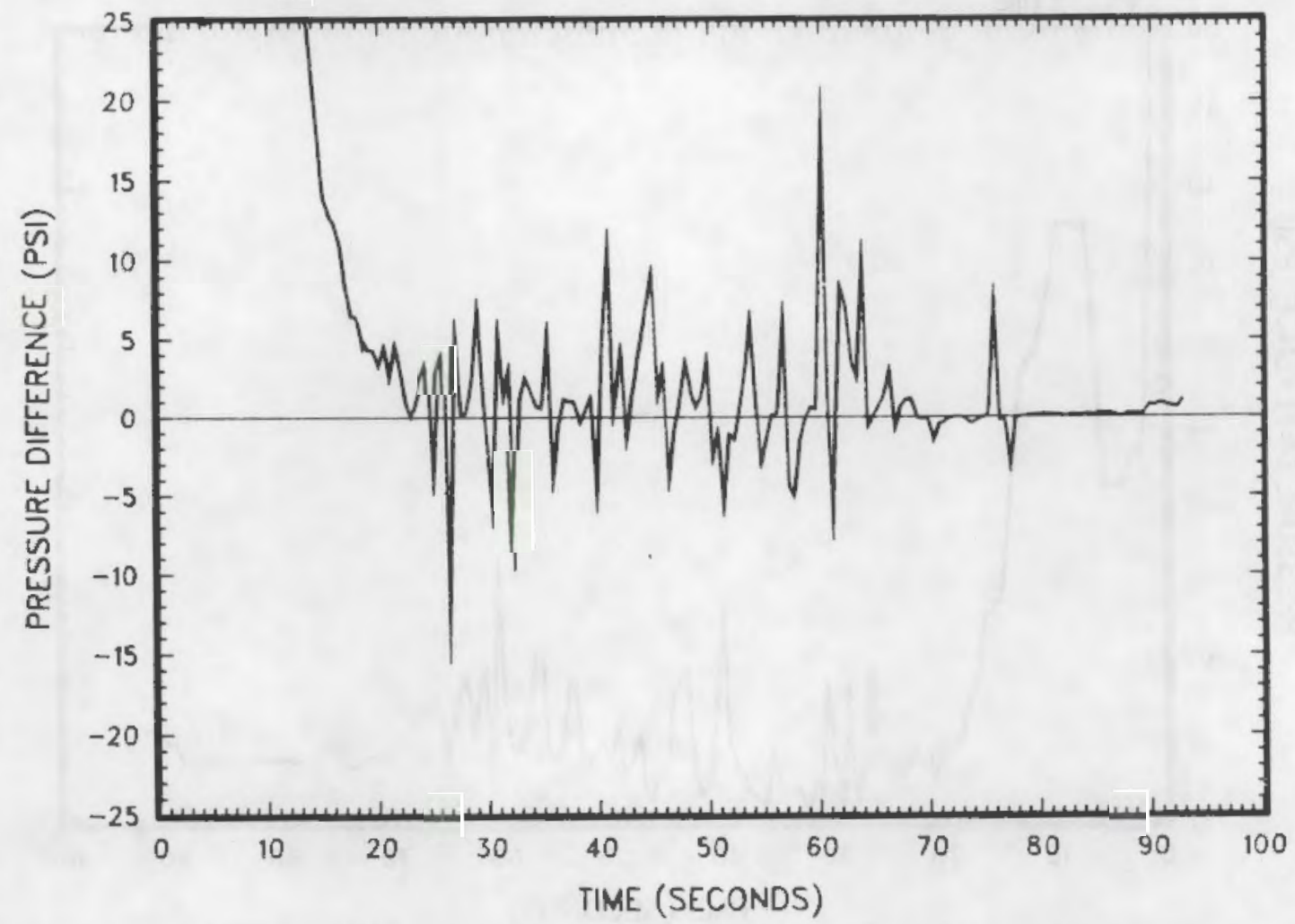

Figure C.84. Pressure drop from the upper head to the upper plenum vs. time 


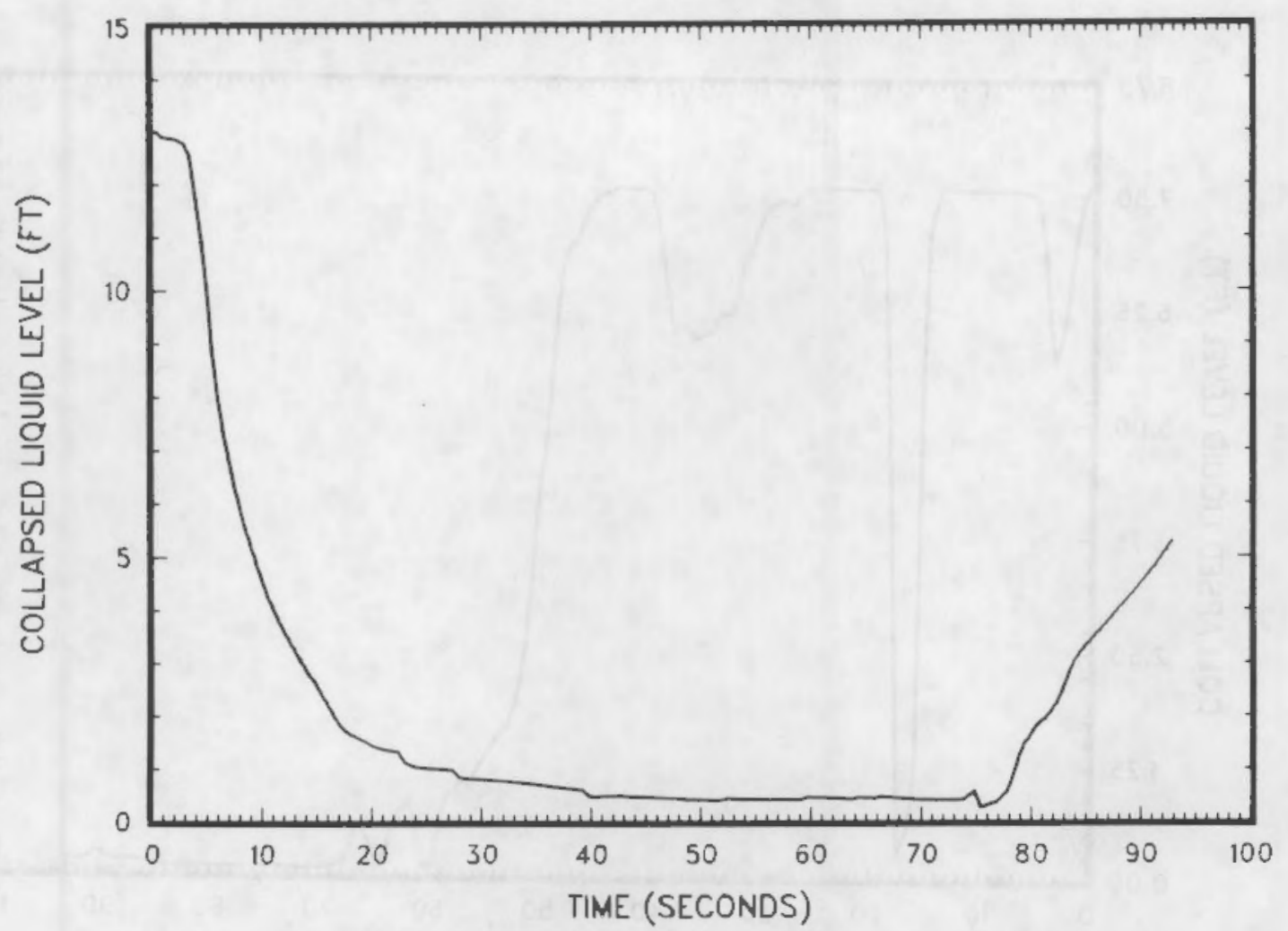

Figure C.85. Core bypass liquid level vs. time

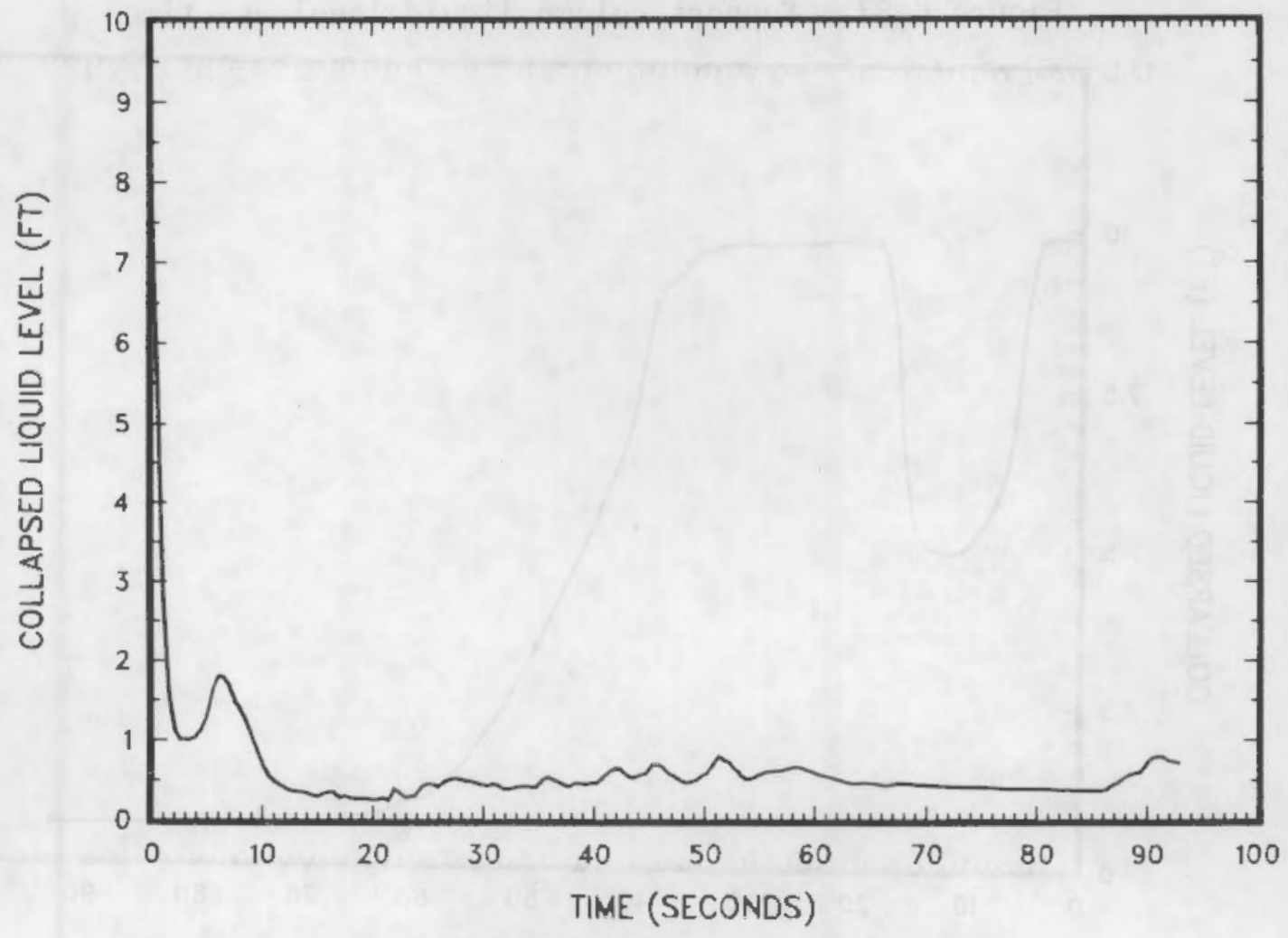

Figure C.86. Upper plenum liquid level vs. time 


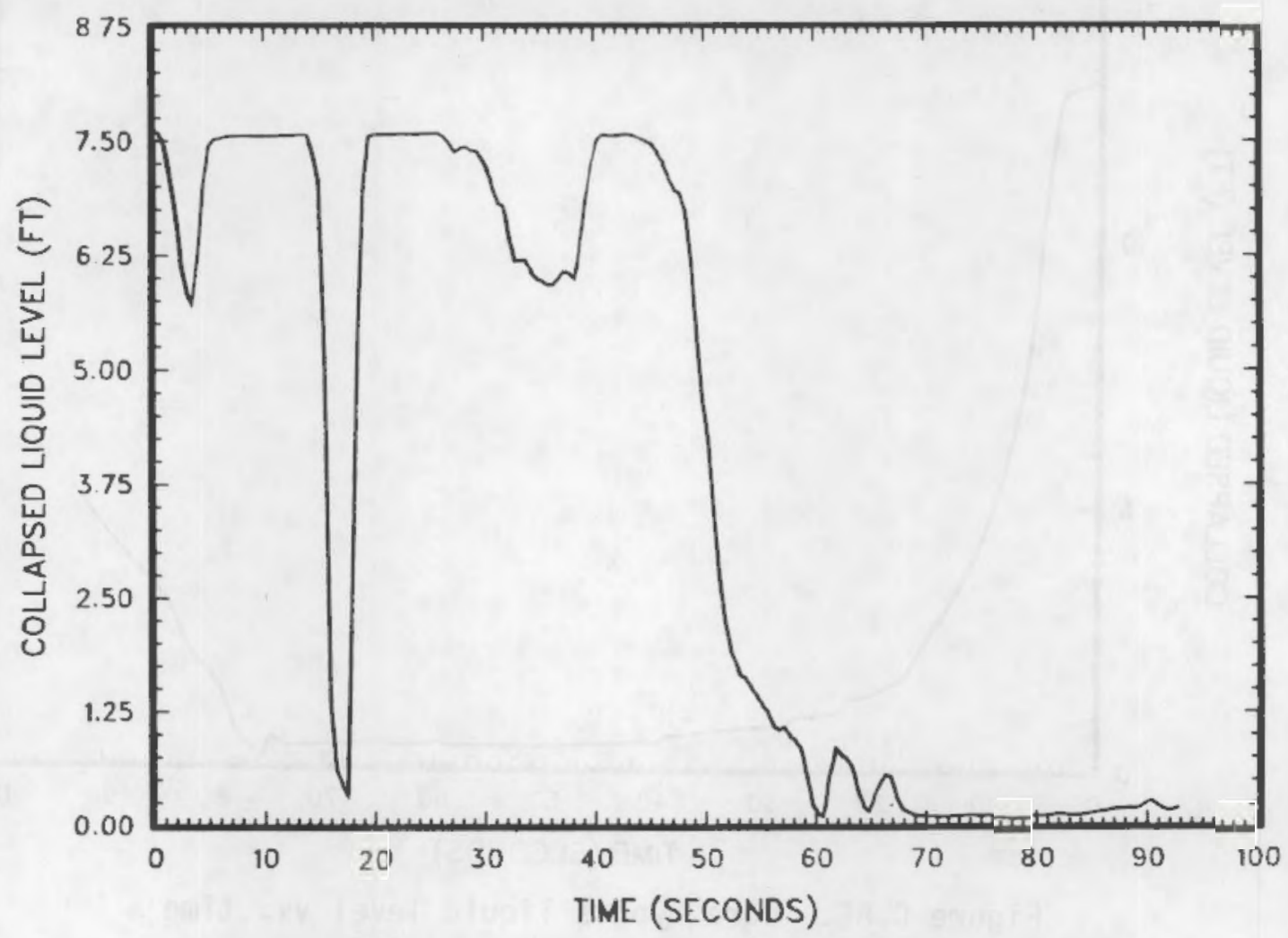

Figure C.87. Support column liquid level vs. time

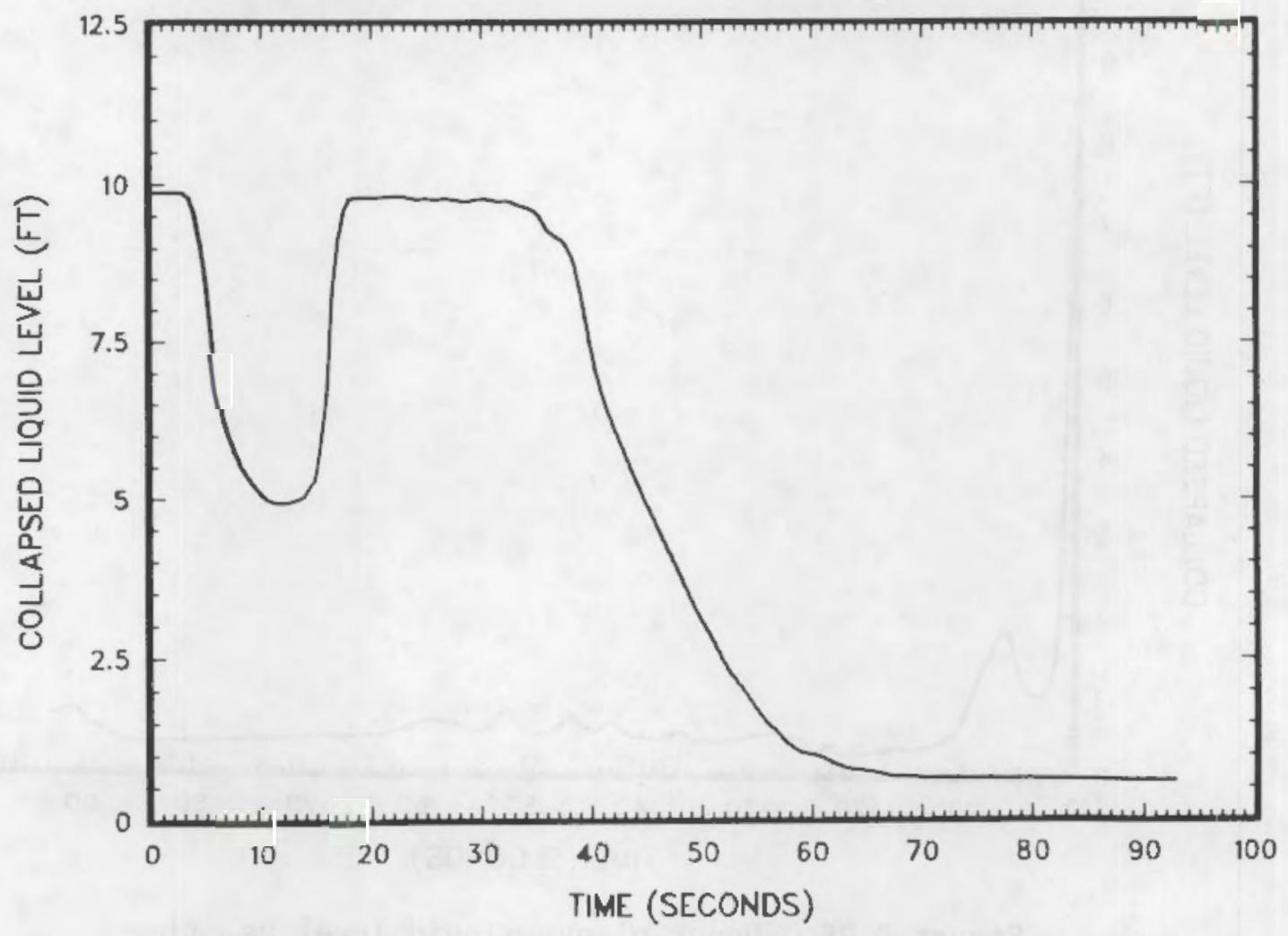

Figure C.88. Upper head liquid level vs. time 


\section{APPENDIX D \\ ADDITIONAL RESULTS IN THE LOOPS}

This appendix gives additional plots of loop variables not already given in this report. Figures D.1 to D.6 show the temperature and void fraction predictions in the broken and intact loop steam generators. The pump speed, head, pressure rise, and torque results for the intact and broken loop pumps are plotted in Figures 0.7 to D.14. The discontinuity in pump speed was caused by an error in restarting the calculation at $18 \mathrm{~s}$. The pump speed was mistakenly reset to the steady-state operating pump speed. This did not have a significant impact on the simulation since the core had already quenched and the loops were voided.

Figures 0.15 to 0.17 show additional results in the broken loop while Figures $\mathrm{D} .18$ to $\mathrm{D.23}$ show results in the loop containing the pressurizer. 


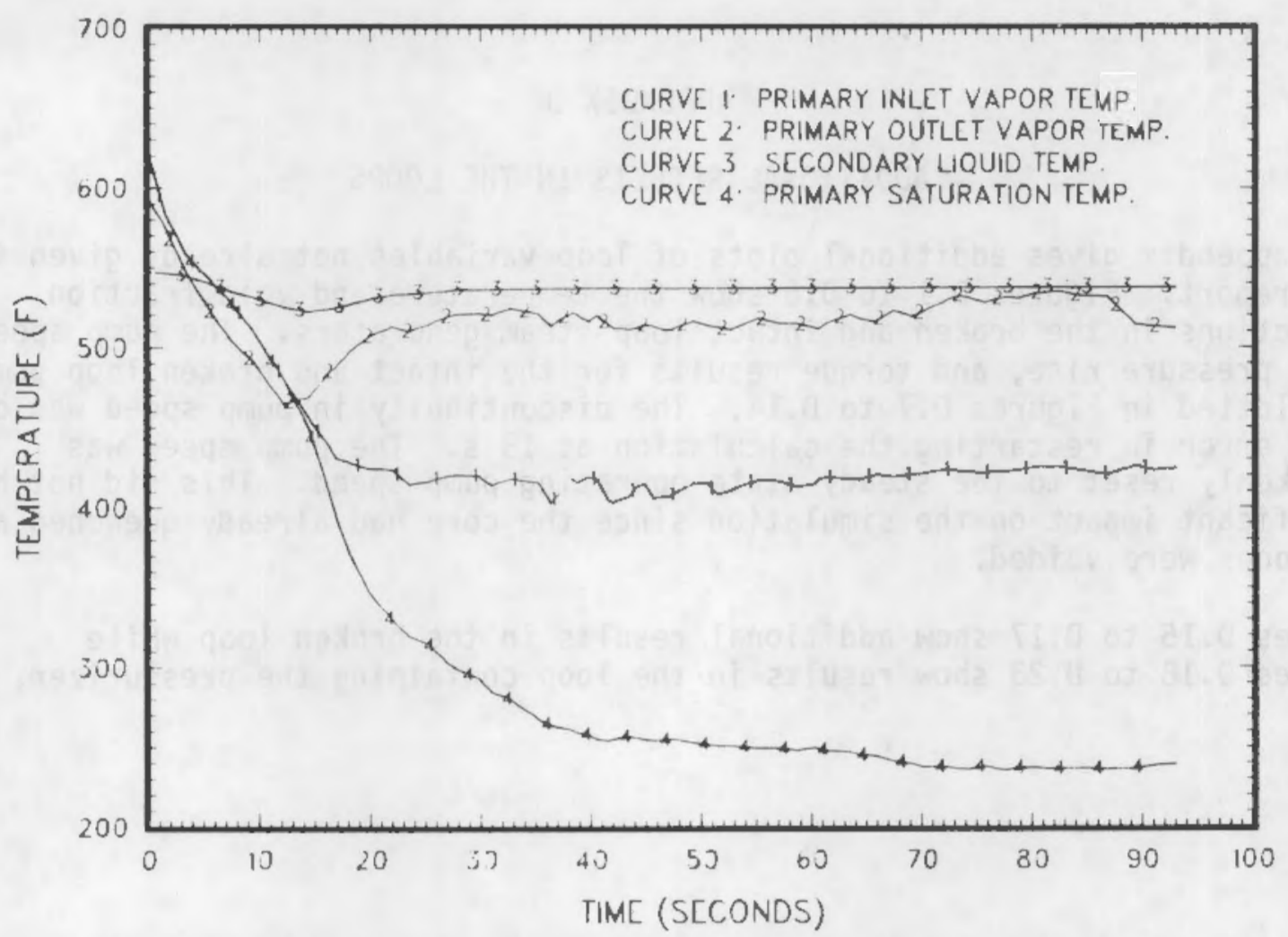

Figure D.1. Broken loop steam generator temperatures vs. time

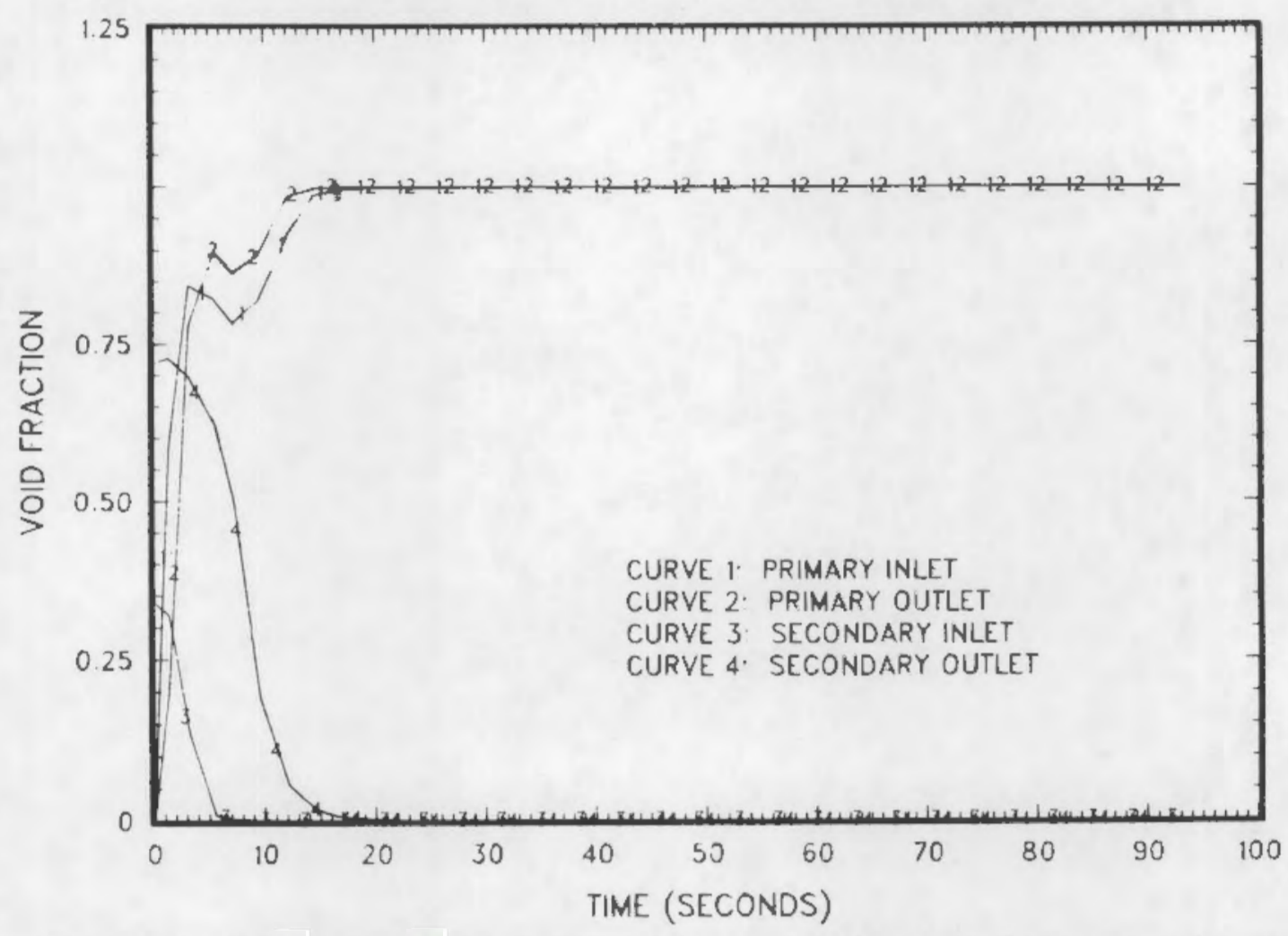

Figure 0.2. Broken loop steam generator void fractions vs. time 


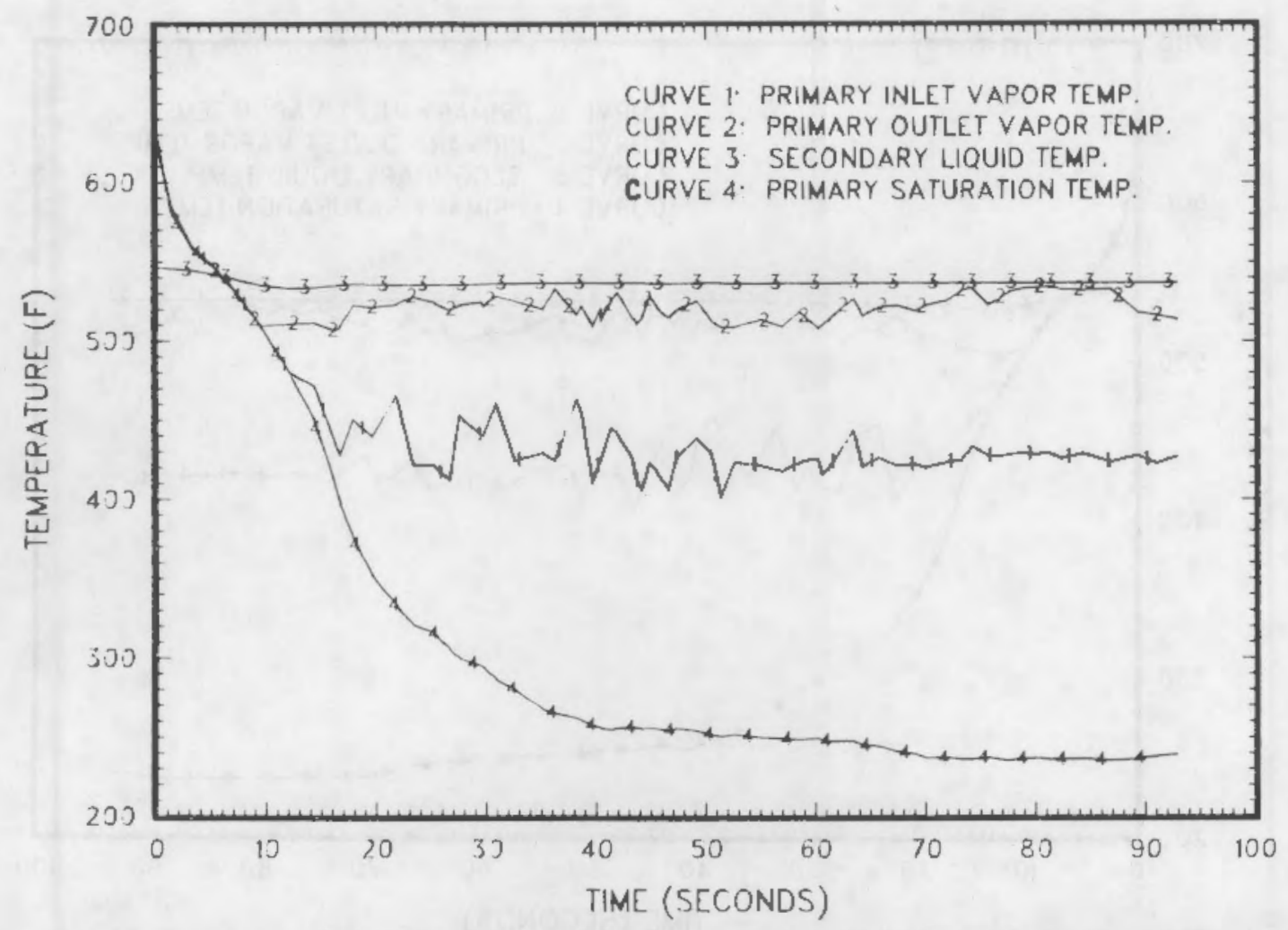

Figure D.3. Intact loop steam generator temperatures vs. time

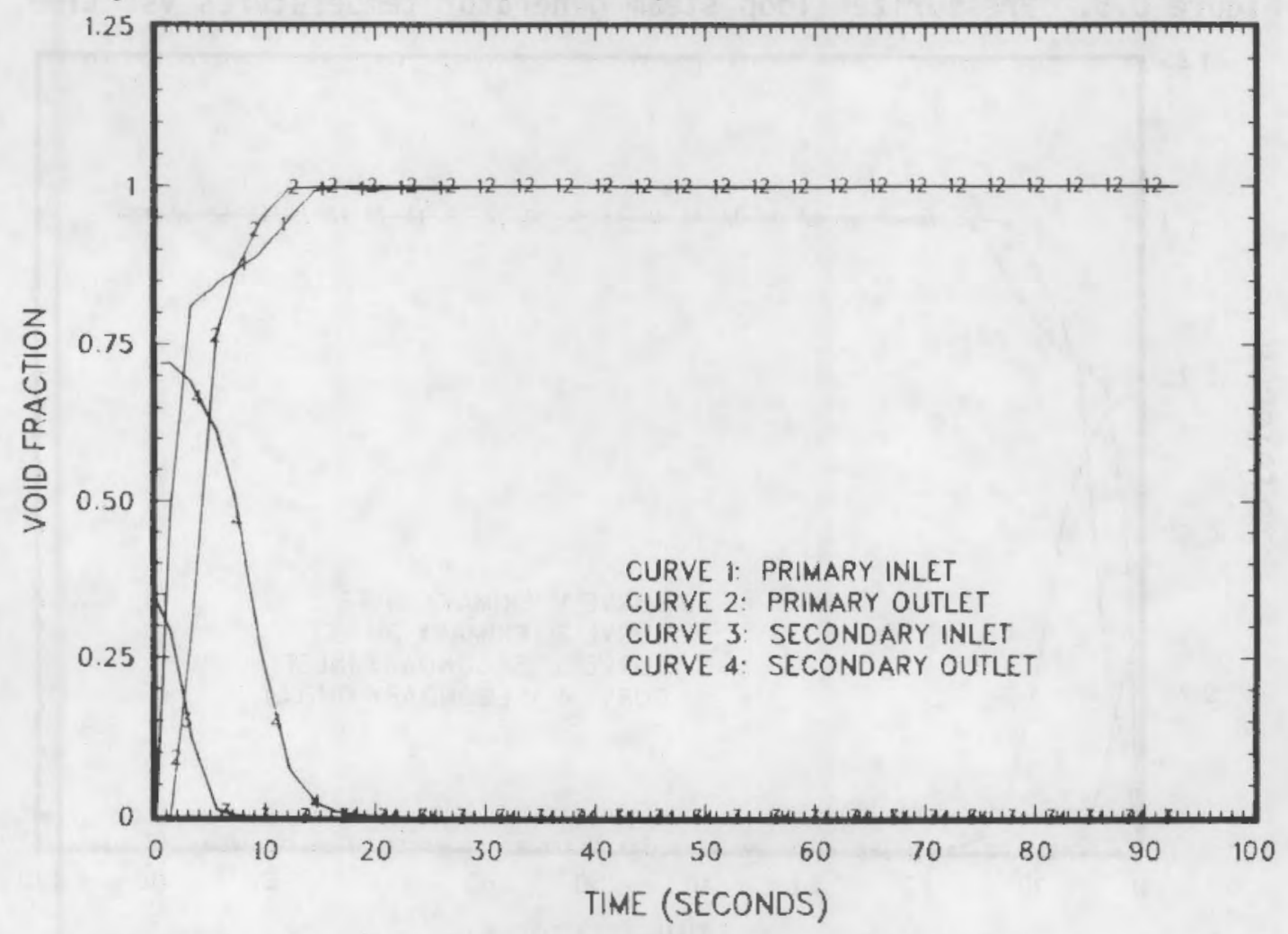

Figure D.4. Intact loop steam generator void fraction vs. time 


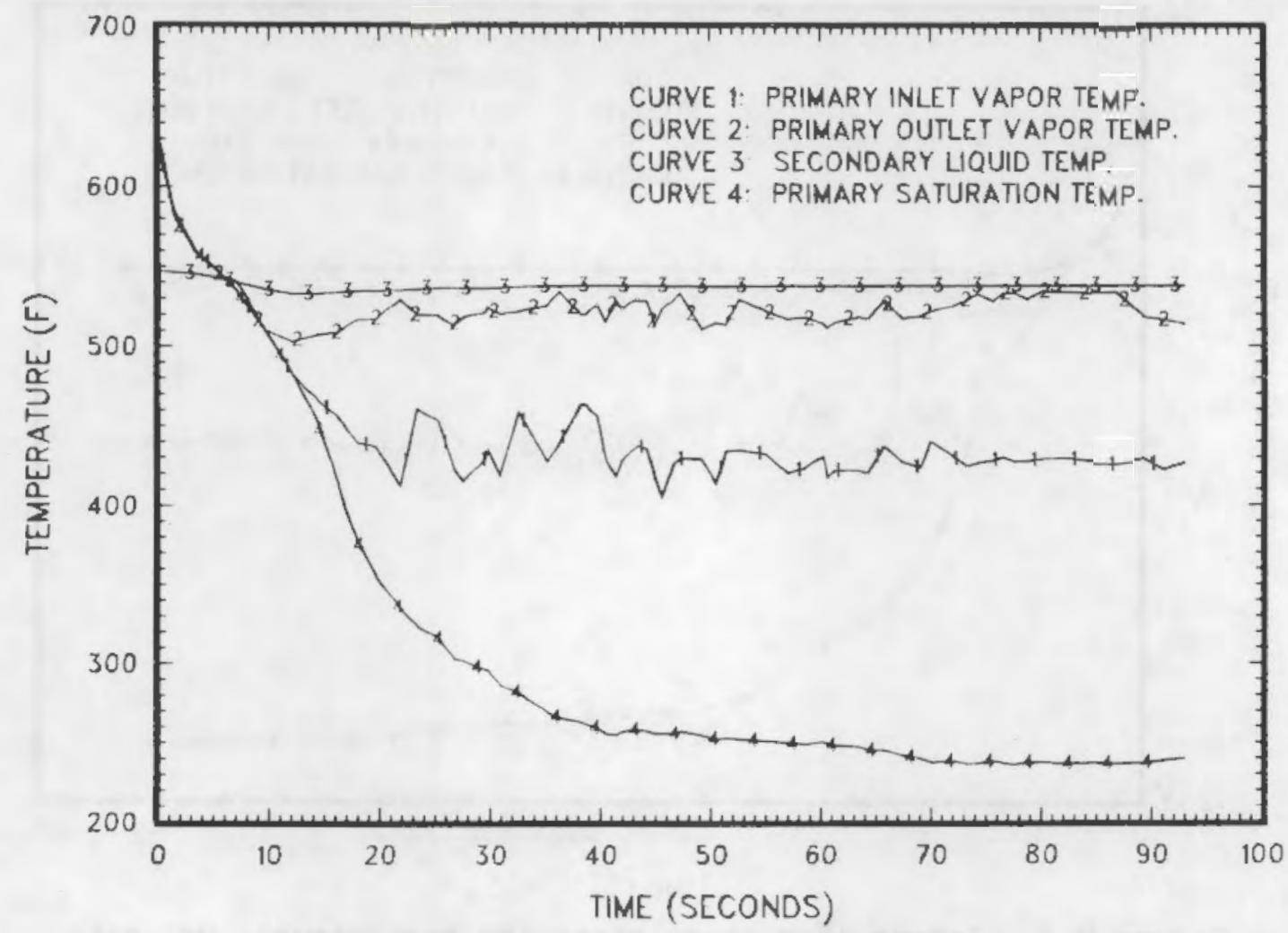

Figure D.5. Pressurizer loop steam generator temperatures vs. time

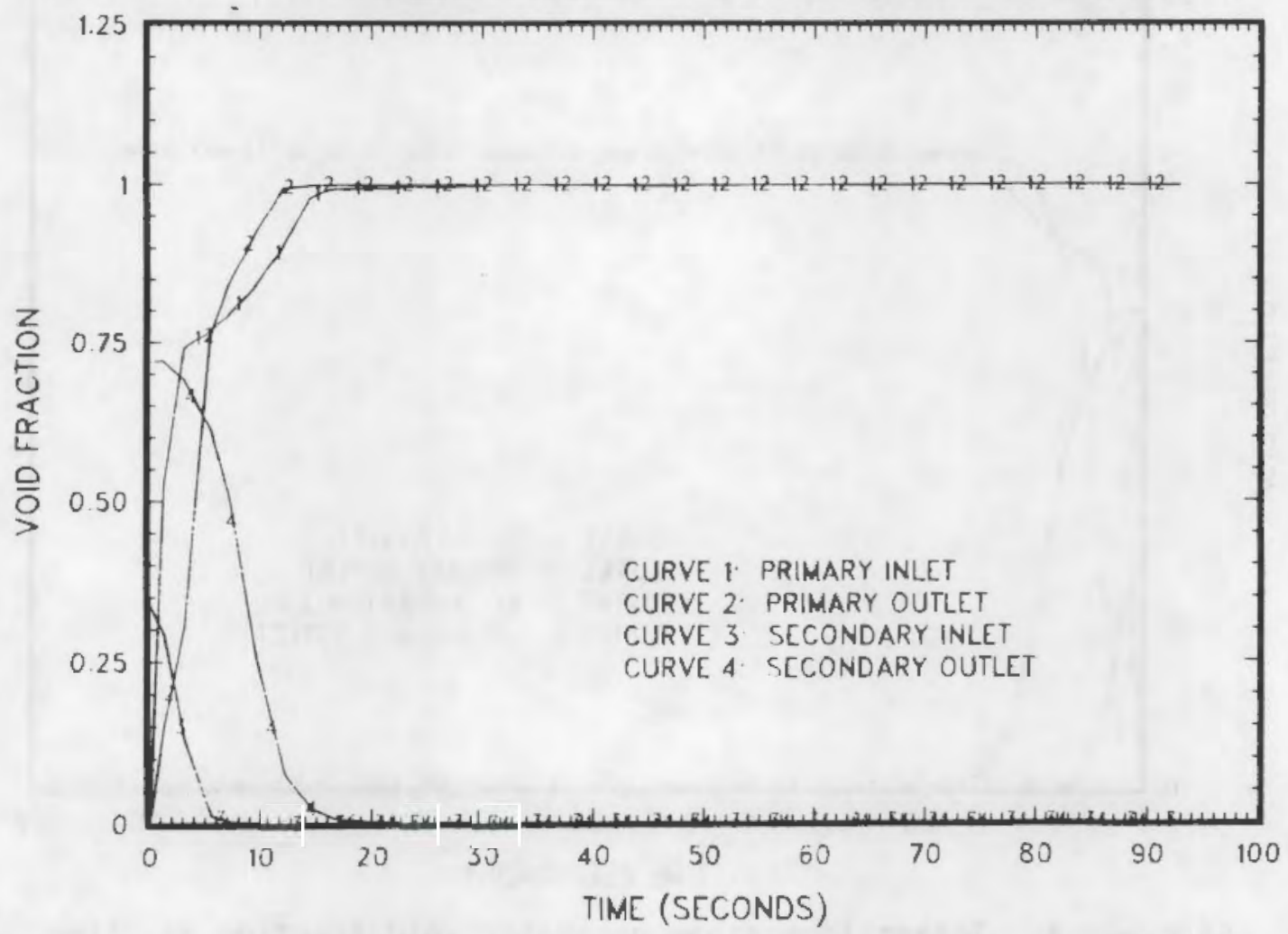

Figure D.6. Pressurizer loop steam generator void fractions vs. time 


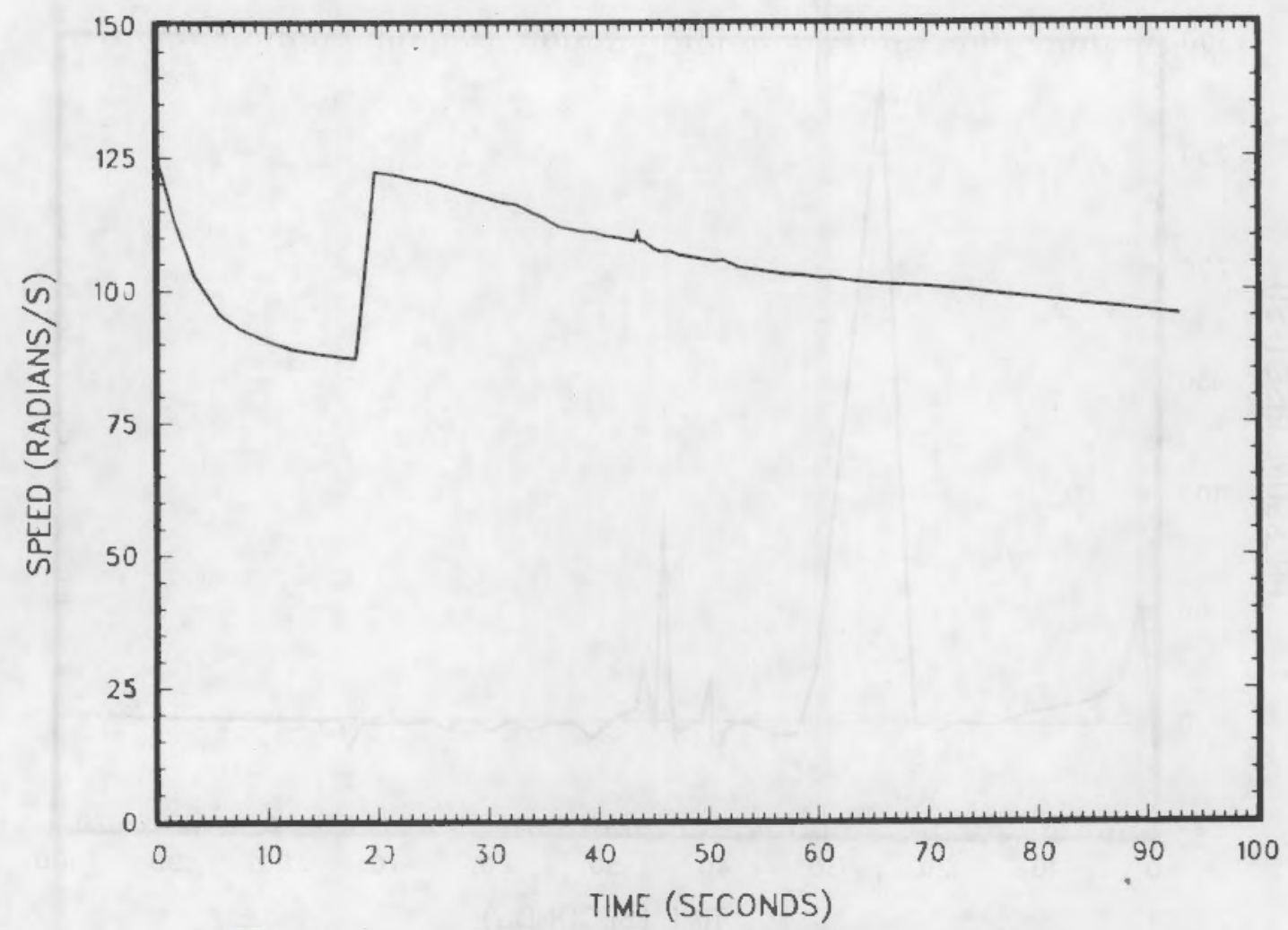

Figure D.7. Intact loop pump speed vs. time

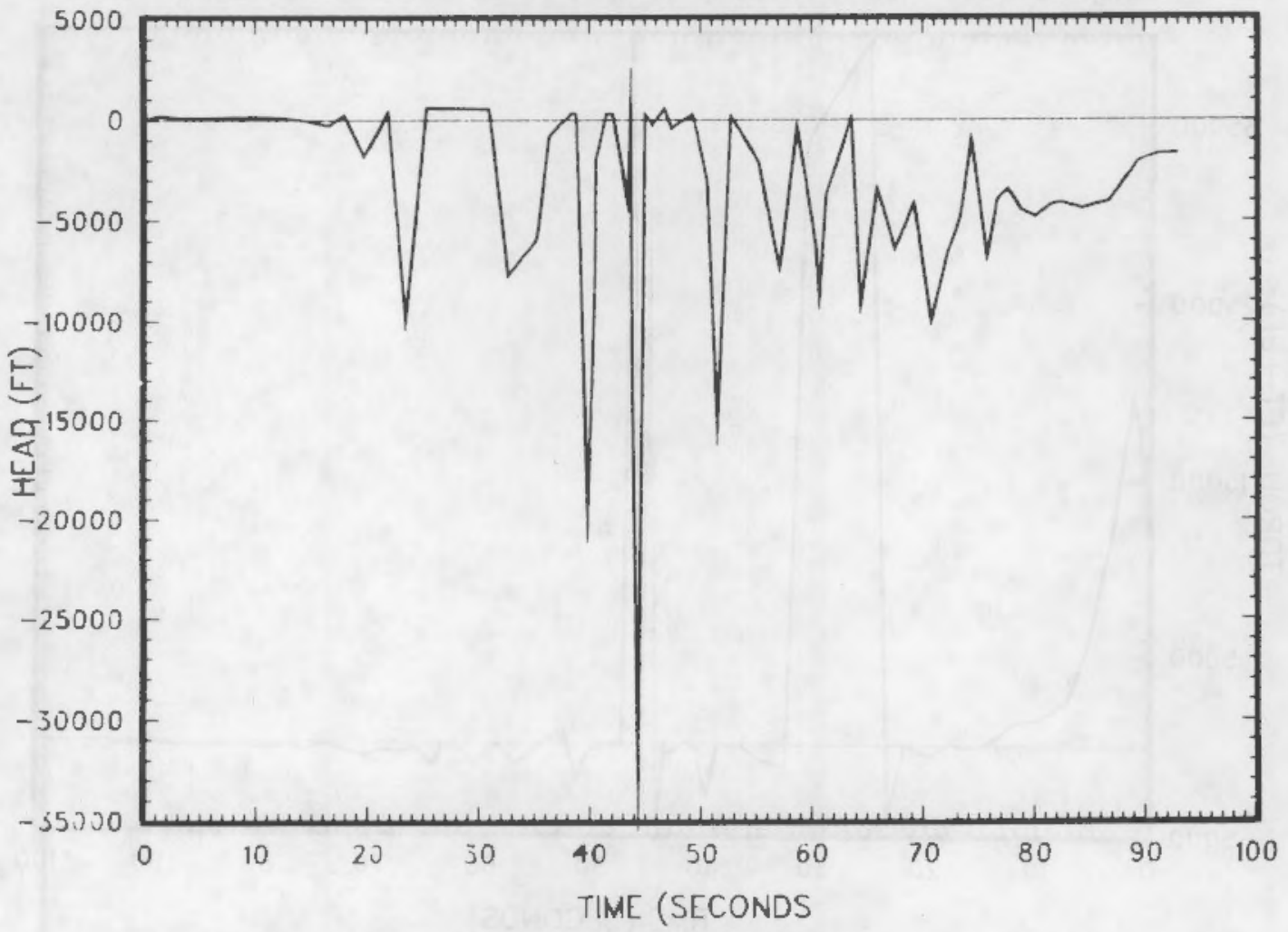

Figure D.8. Intact loop pump head vs. time 


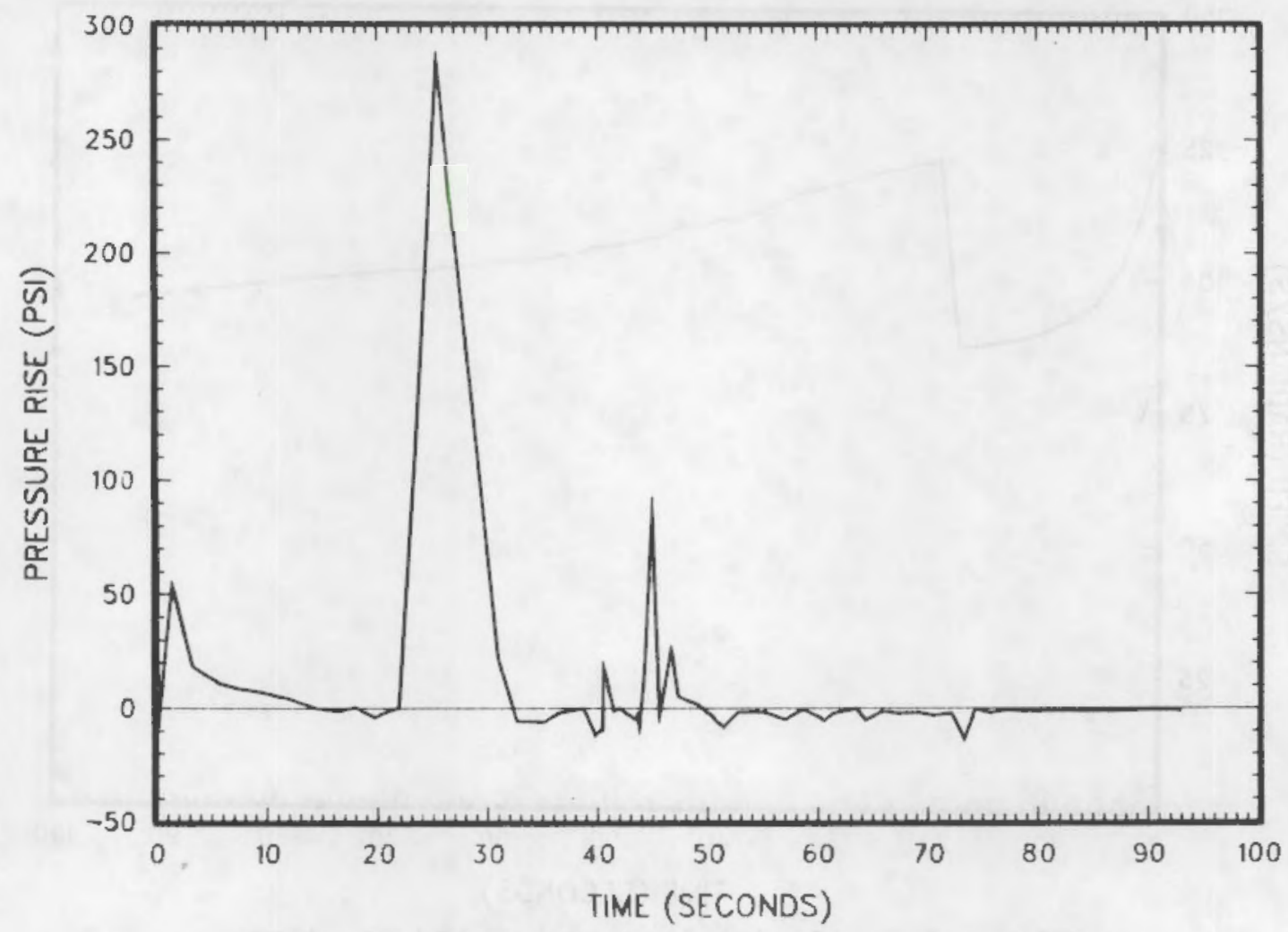

Figure D.9. Intact loop pump pressure rise vs. time

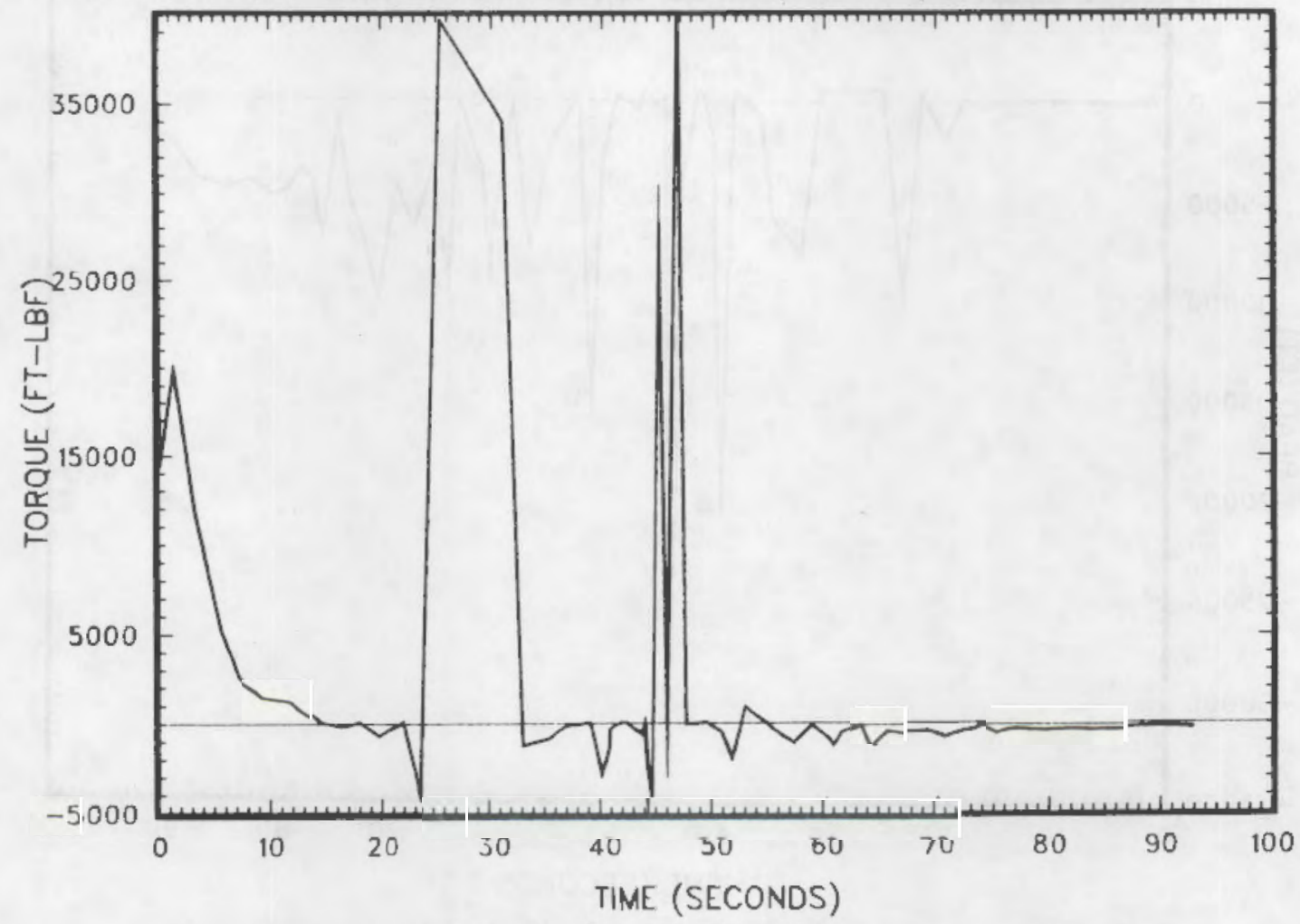

Figure 0.10 . Intact loop pump torque vs. time 


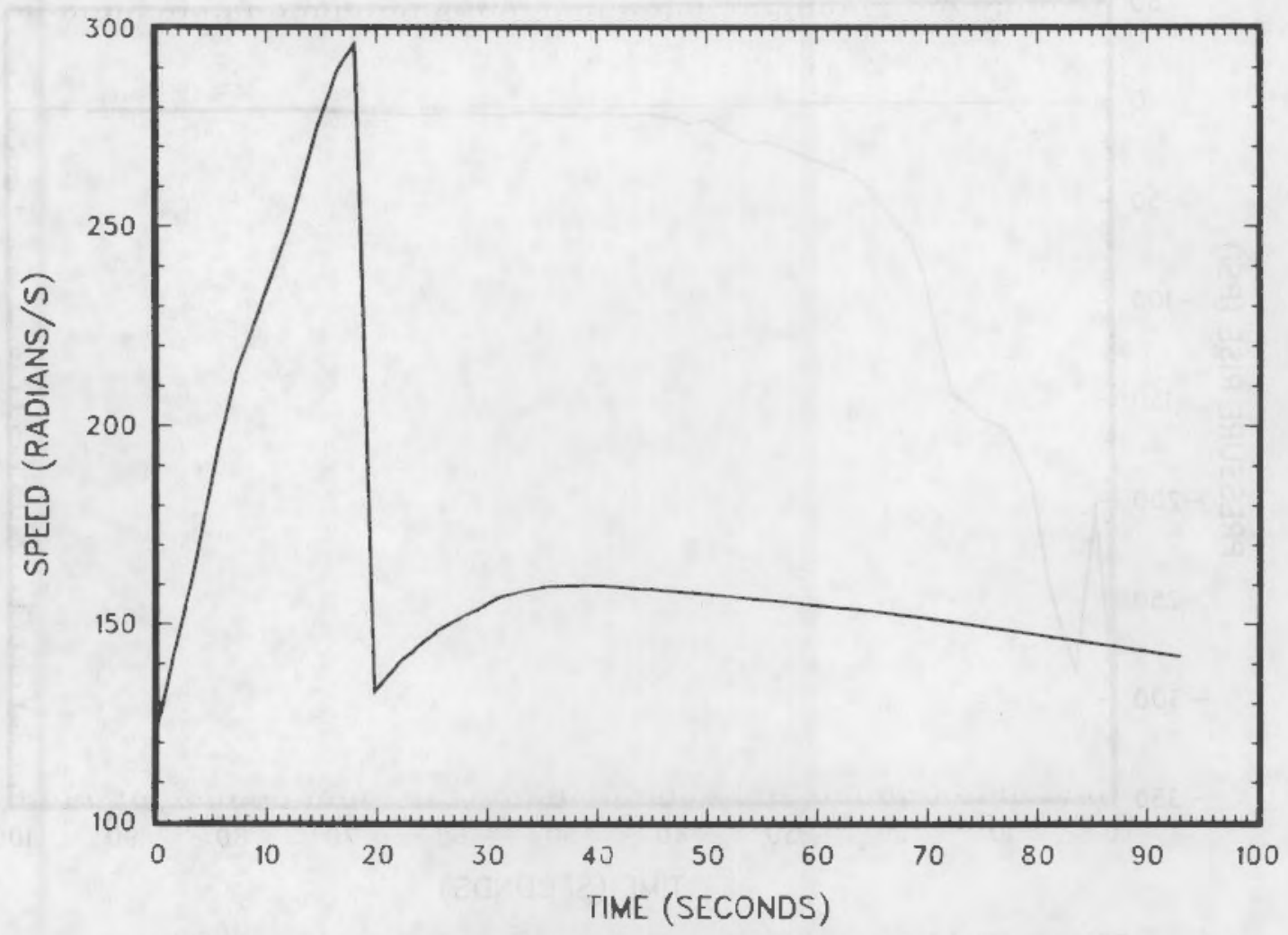

Figure D.11. Broken loop pump speed vs. time

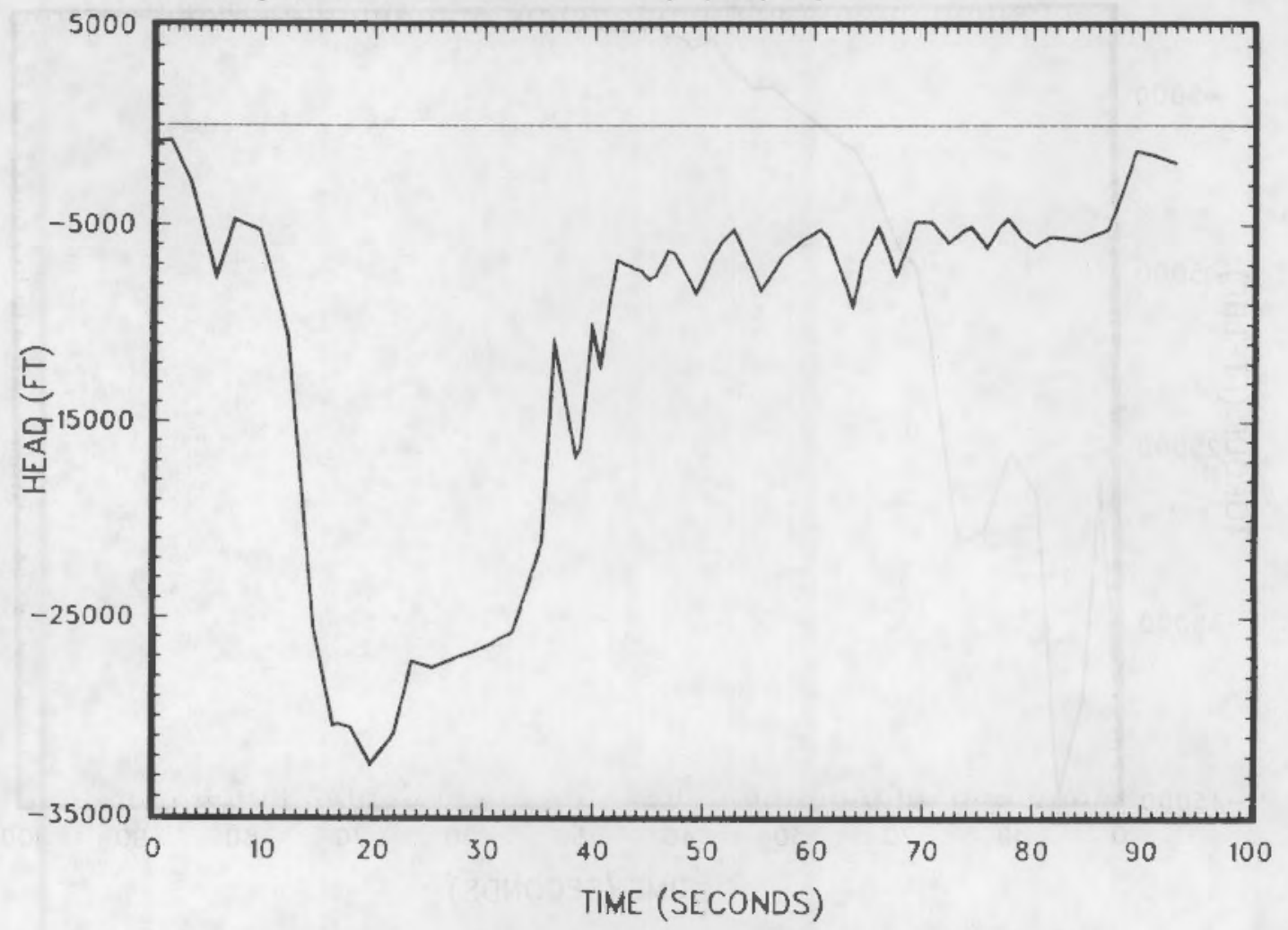

Figure D.12. Broken loop pump head vs. time 


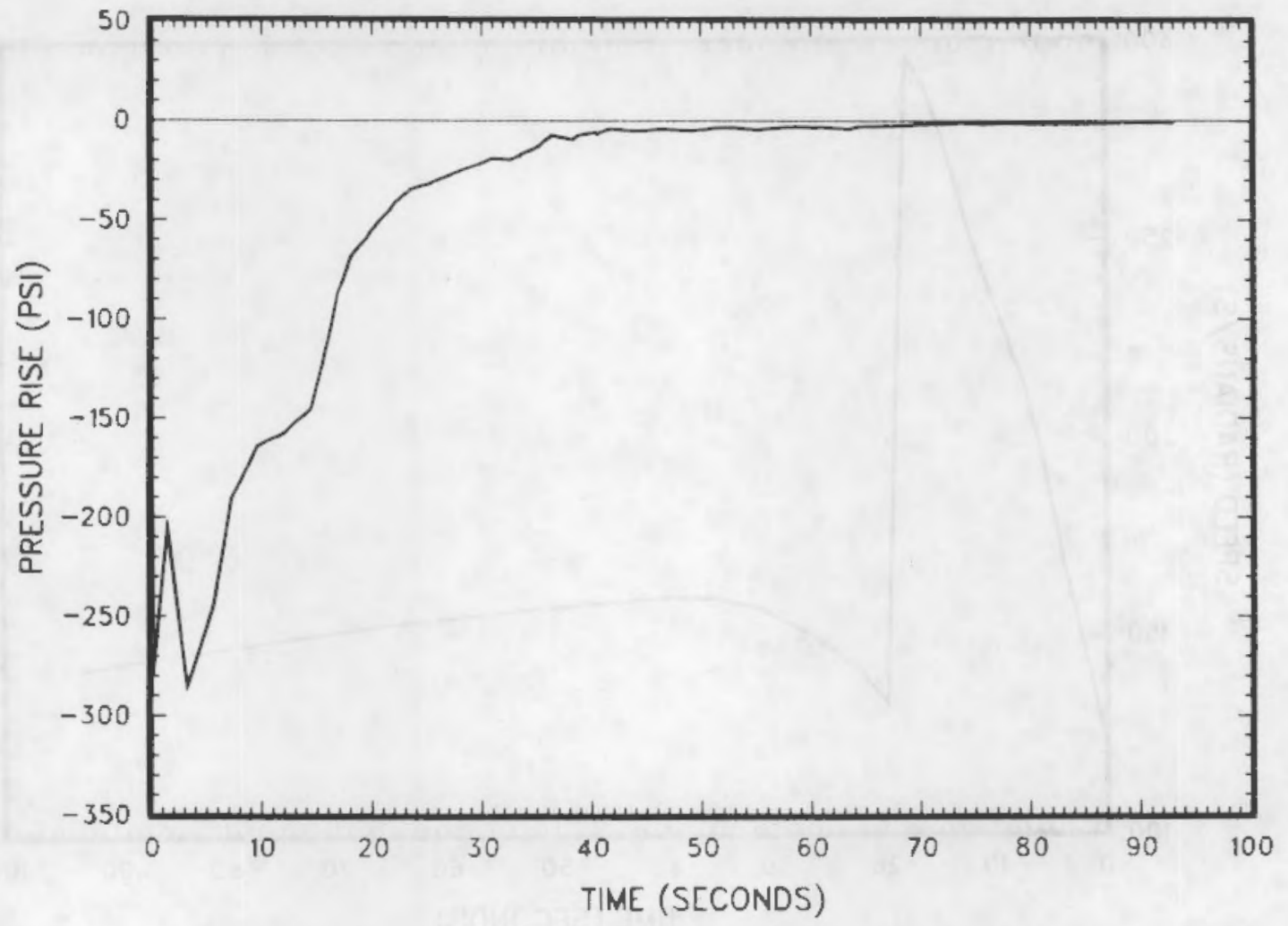

Figure 0.13. Broken loop pump pressure rise vs. time

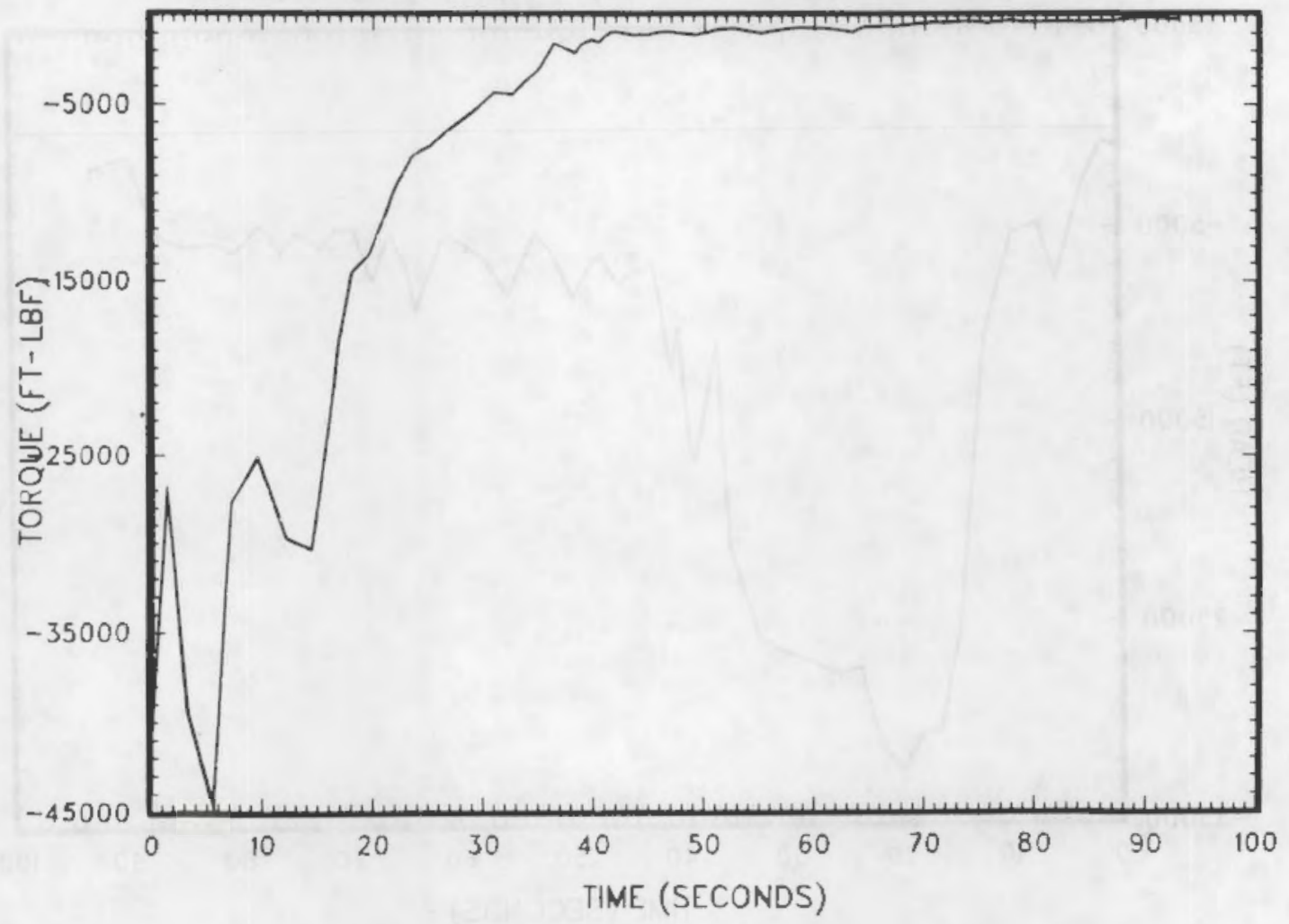

Figure D.14. Broken loop pump torque vs. time 


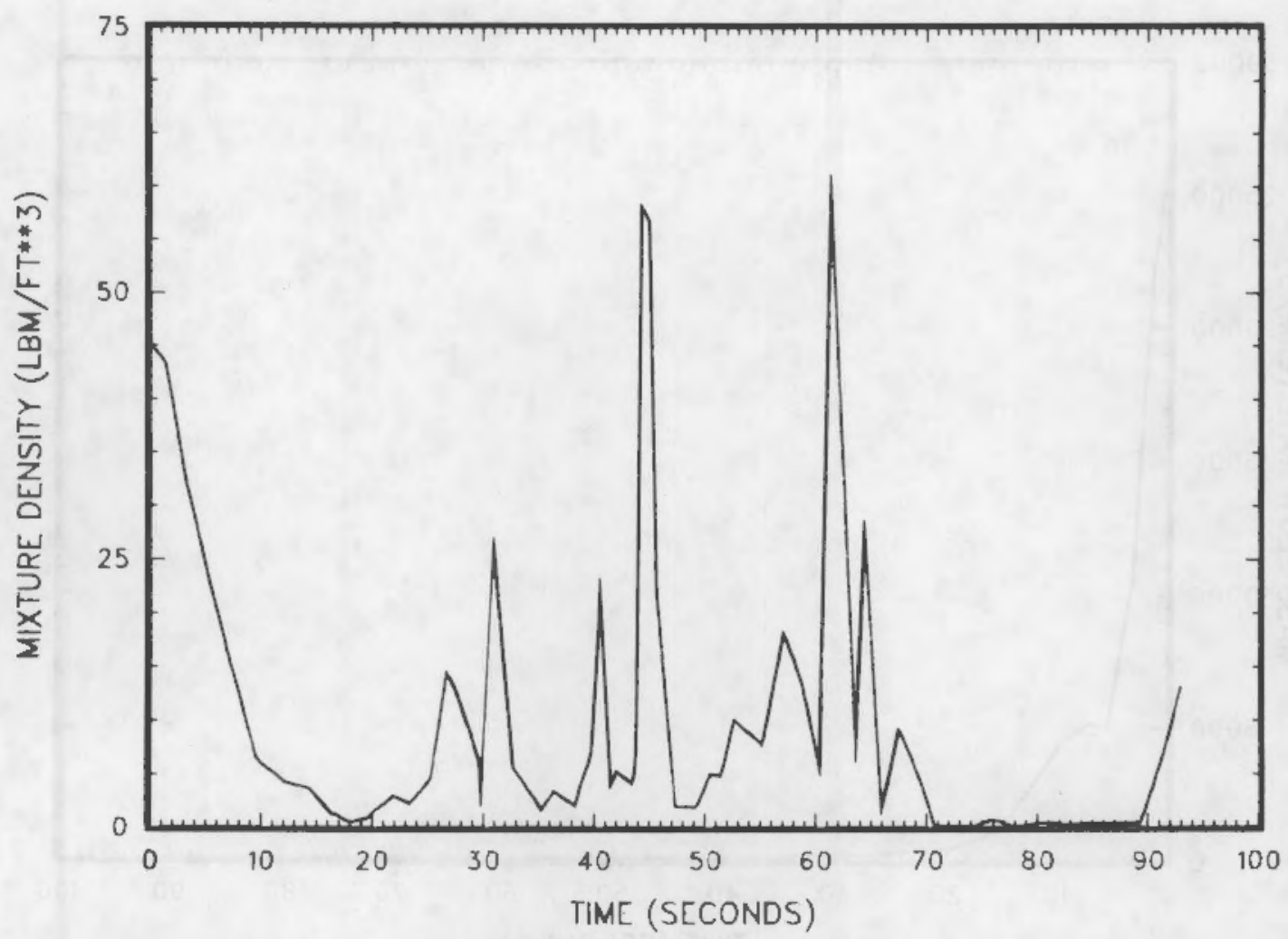

Figure D.15. Cold leg mixture density on the vessel side of the break vs. time

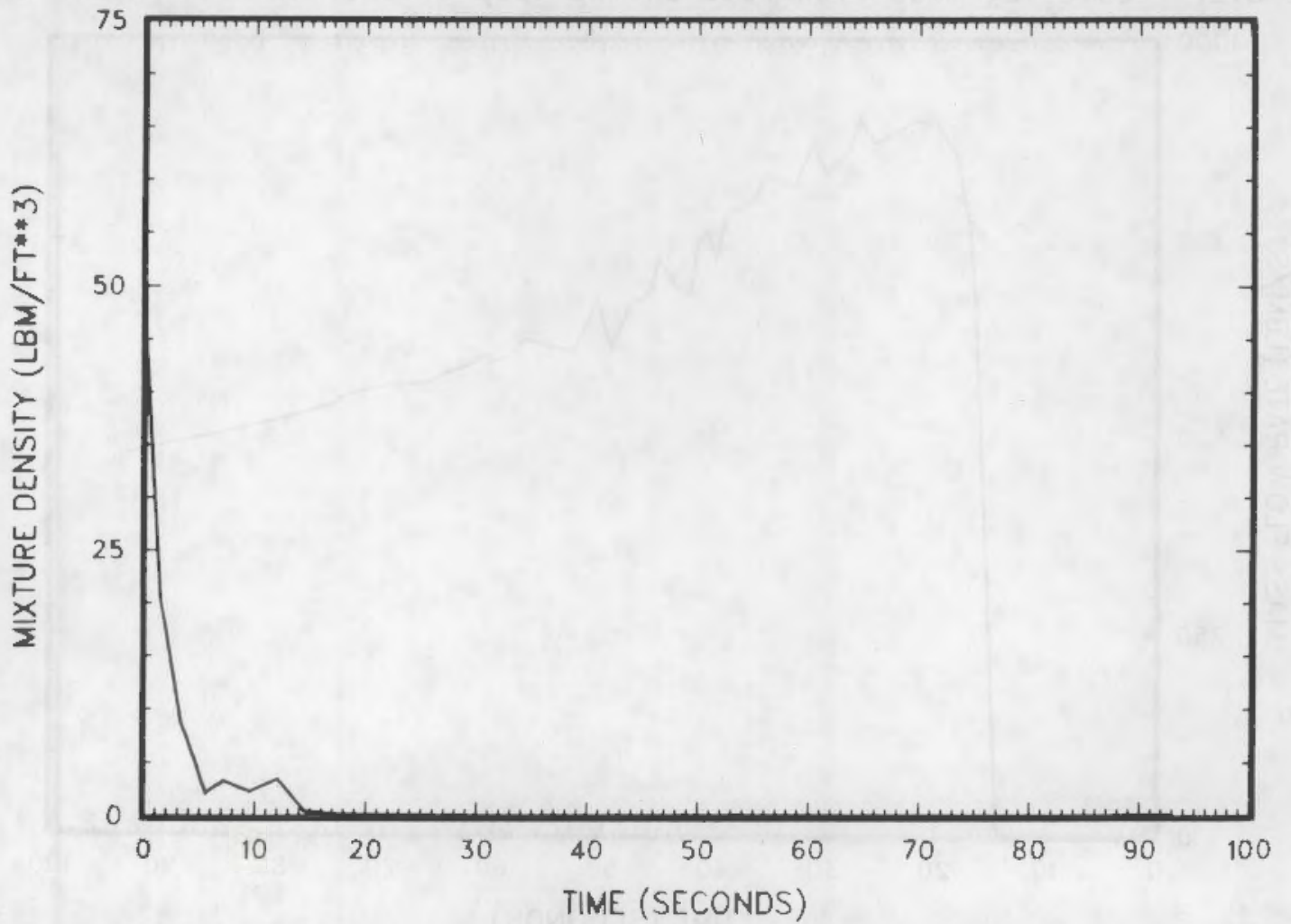

Figure D.16. Cold leg mixture density on the loop side of the break vs. time 


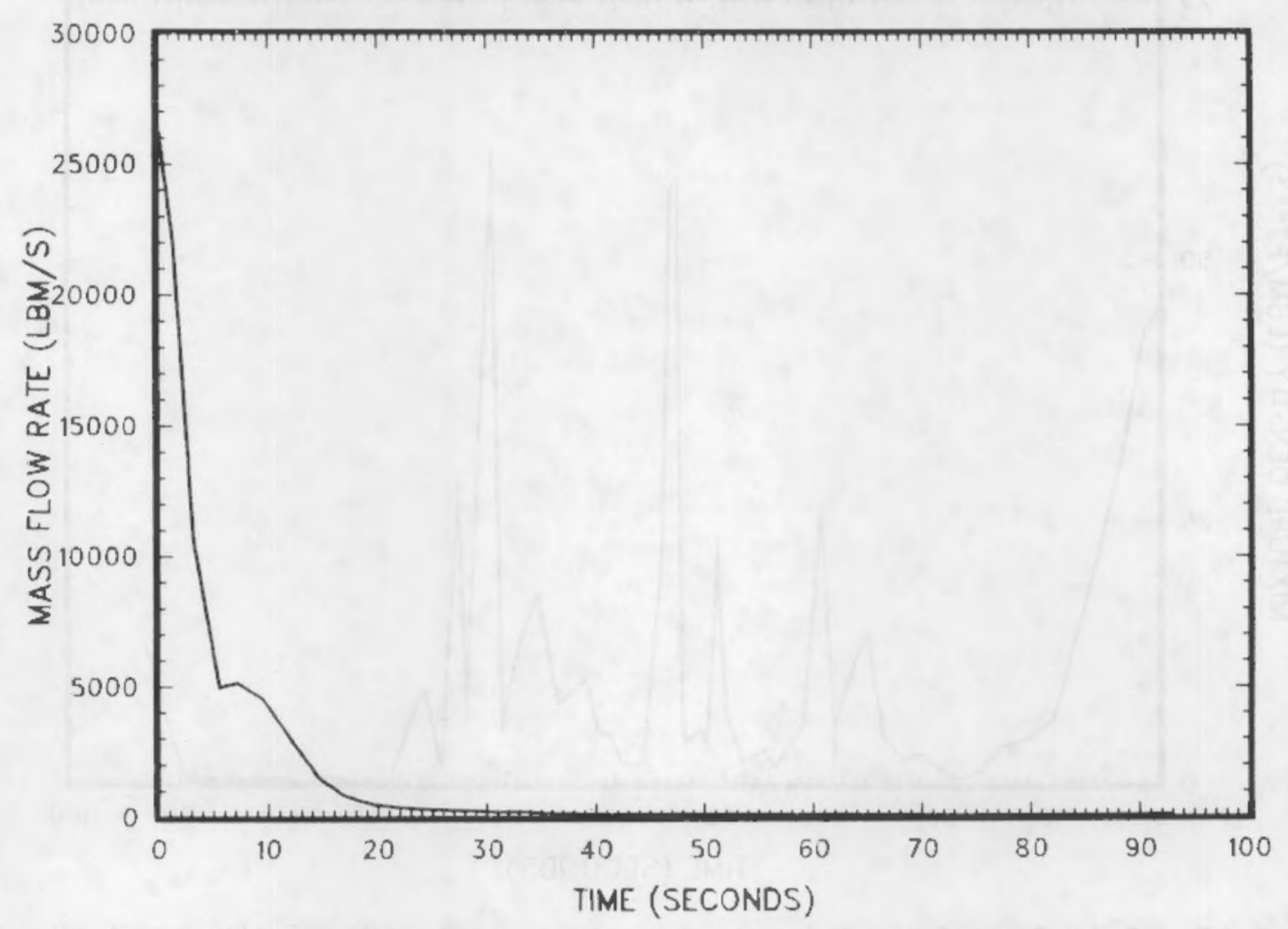

Figure D.17. Cold leg mass flow rate on the loop side of the break vs. time

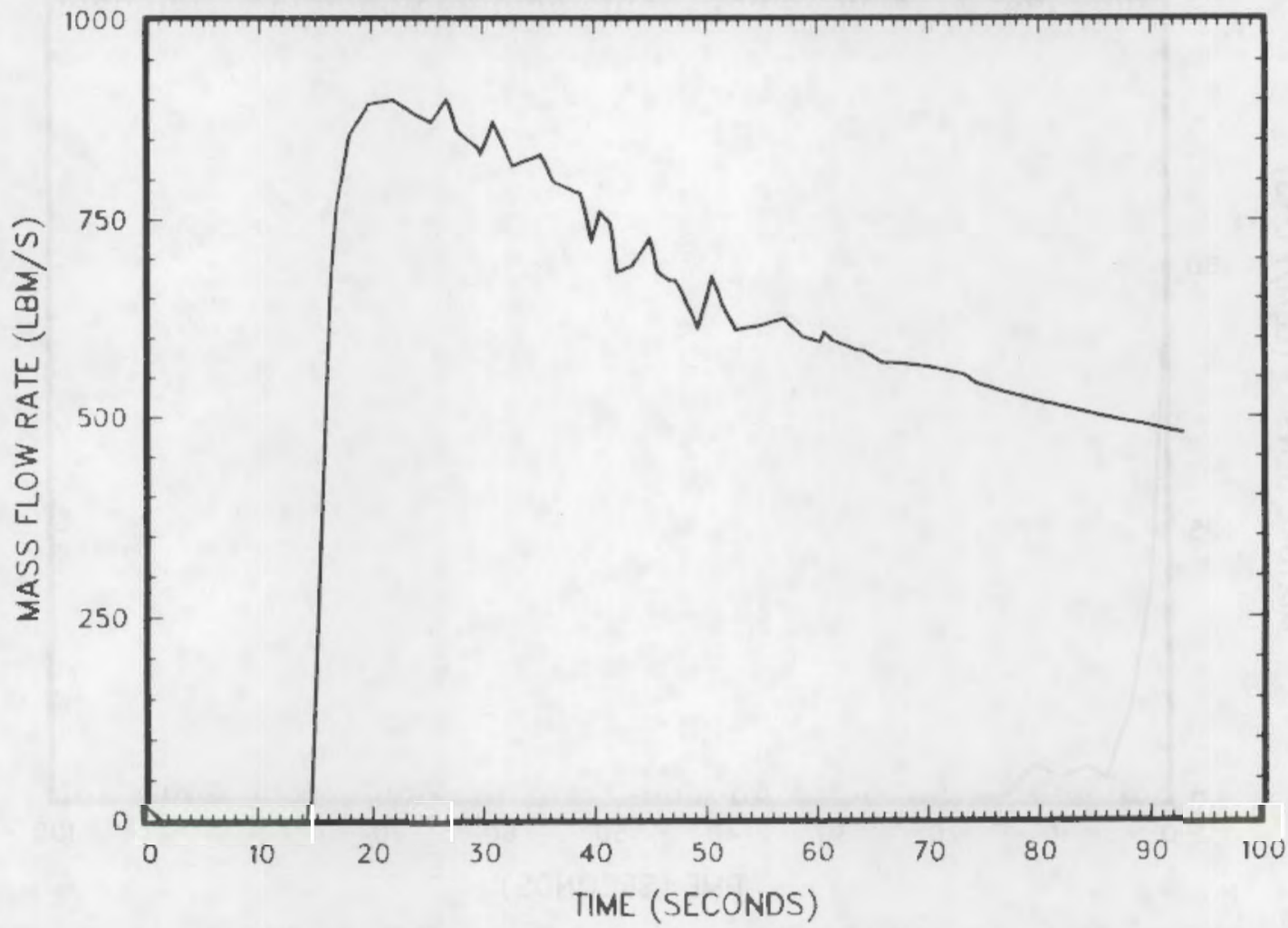

Figure D.18. Pressurizer loop cold leg accumulator mass flow rate vs. time 


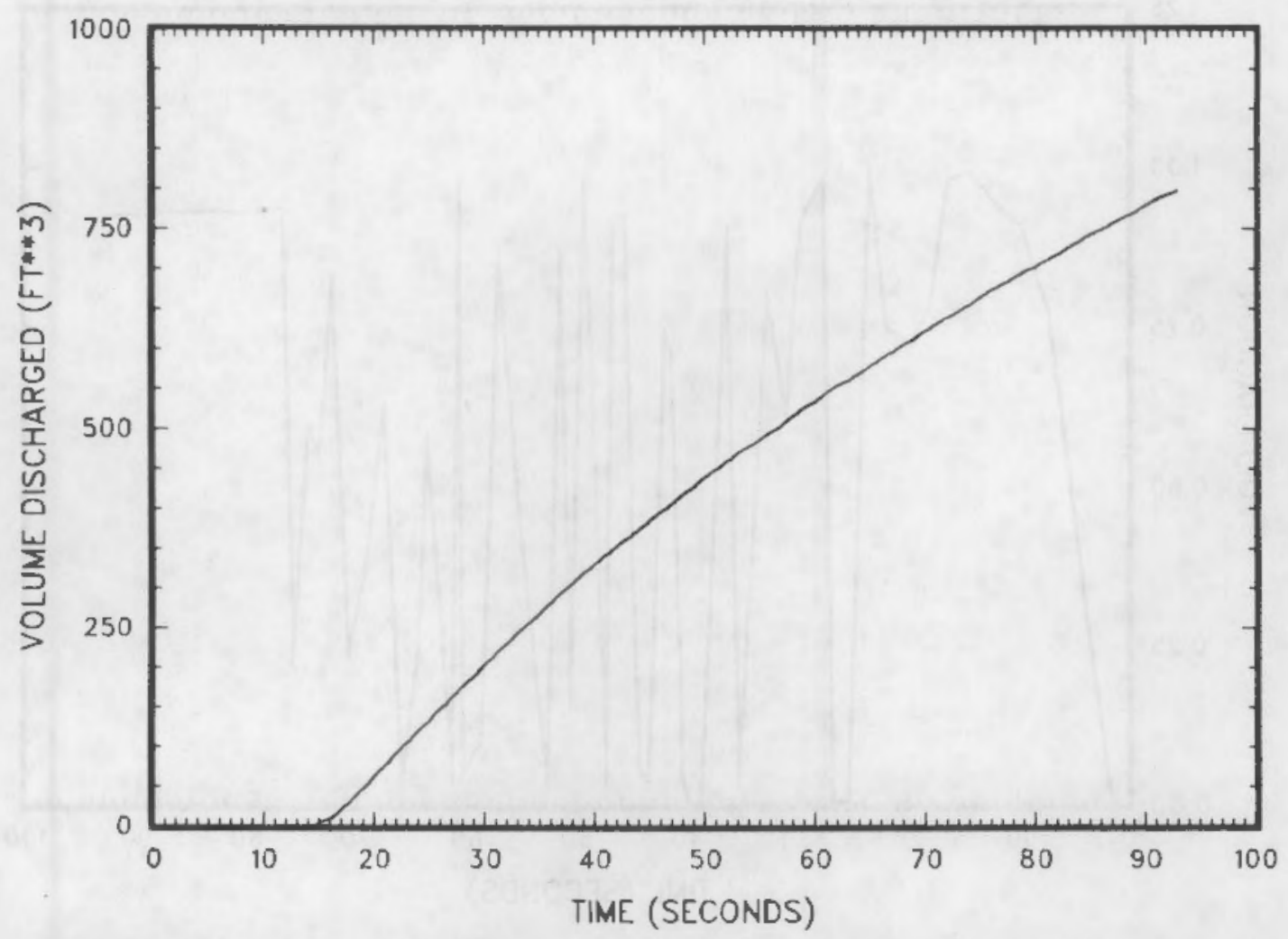

Figure D.19. Pressurizer loop cold leg accumulator discharge liquid volume

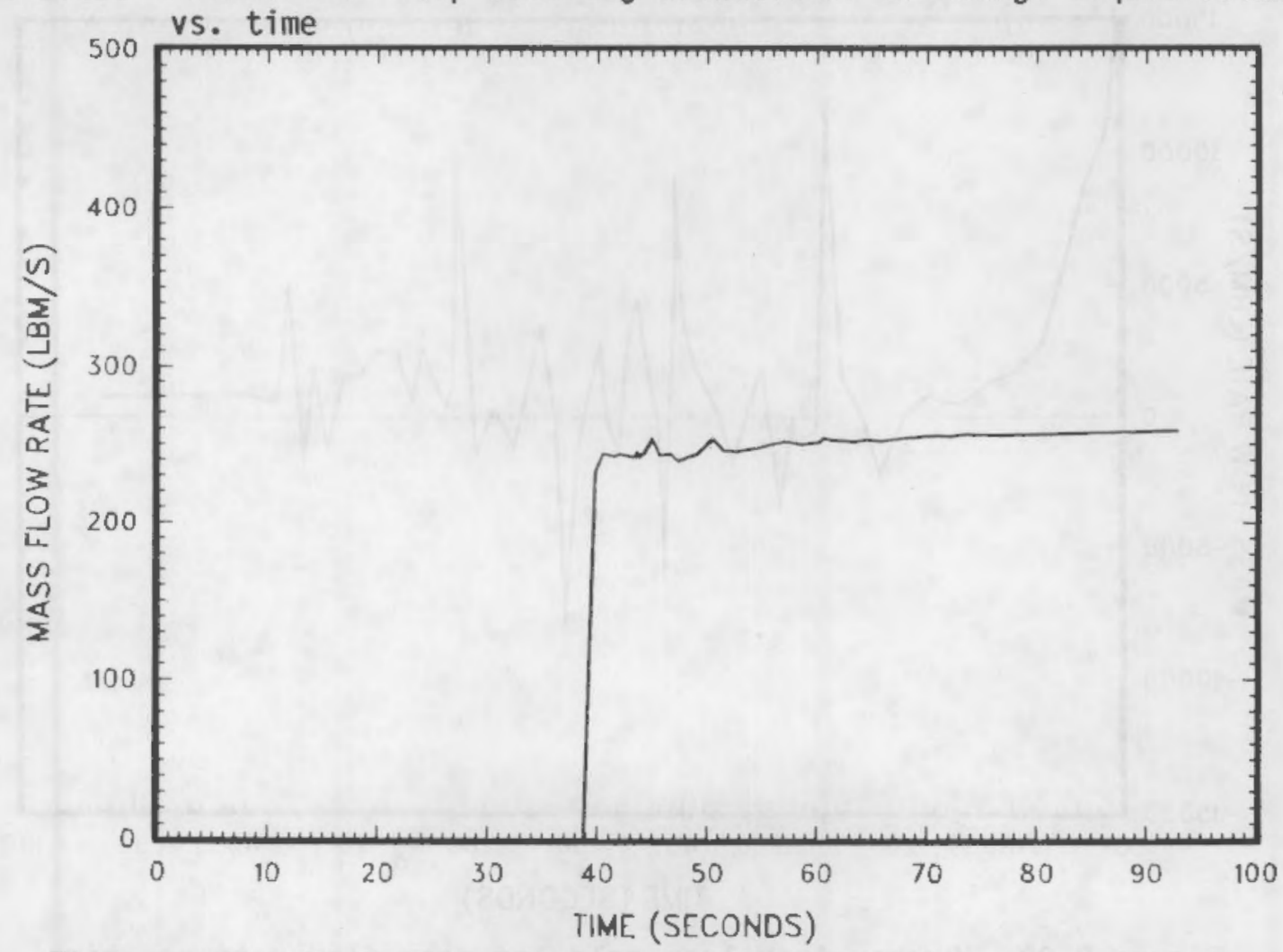

Figure 0.20. Pressurizer loop HPIS-LPIS mass flow rate vs. time 


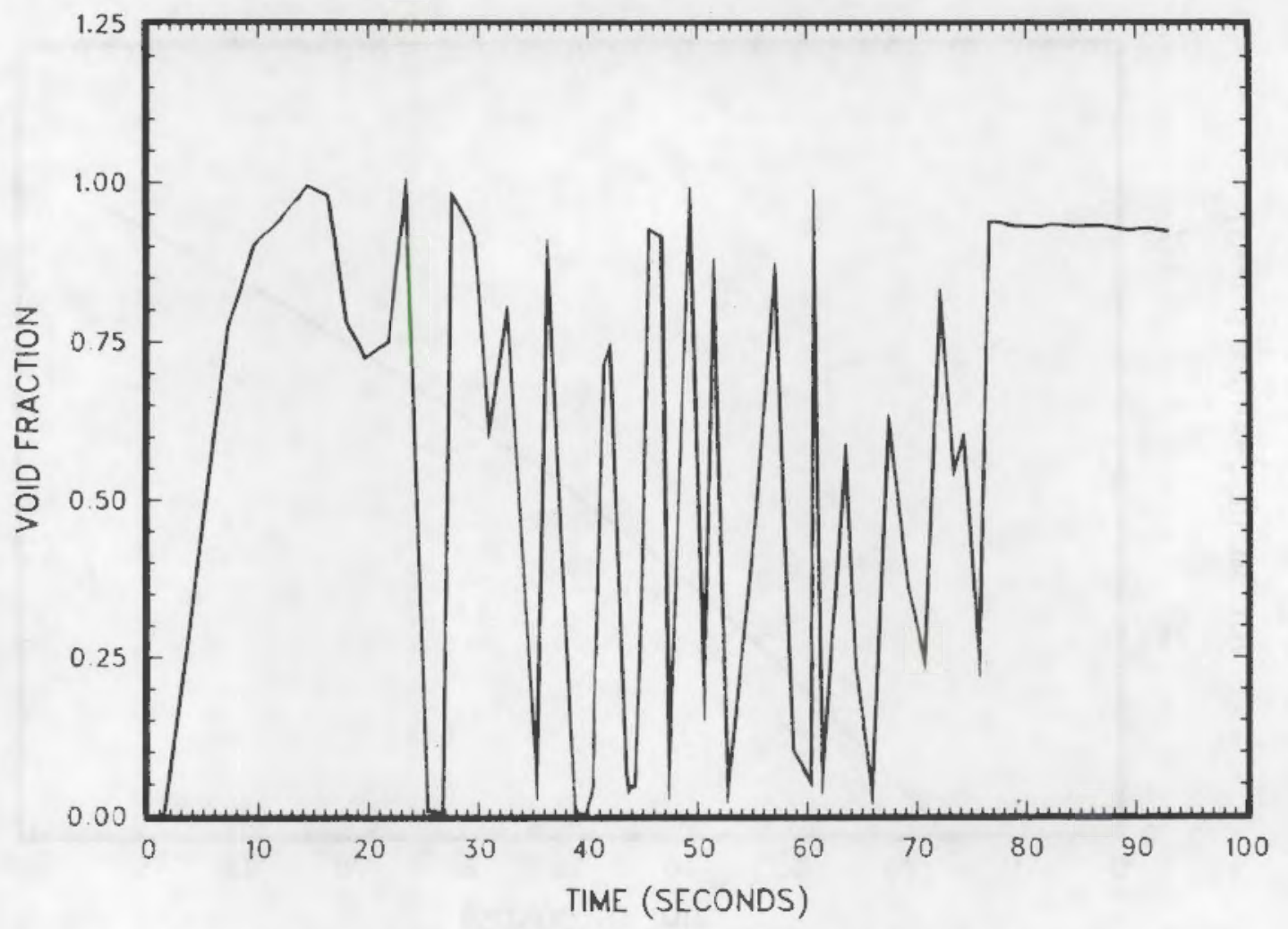

Figure D.21. Pressurizer loop cold leg void fraction vs. time

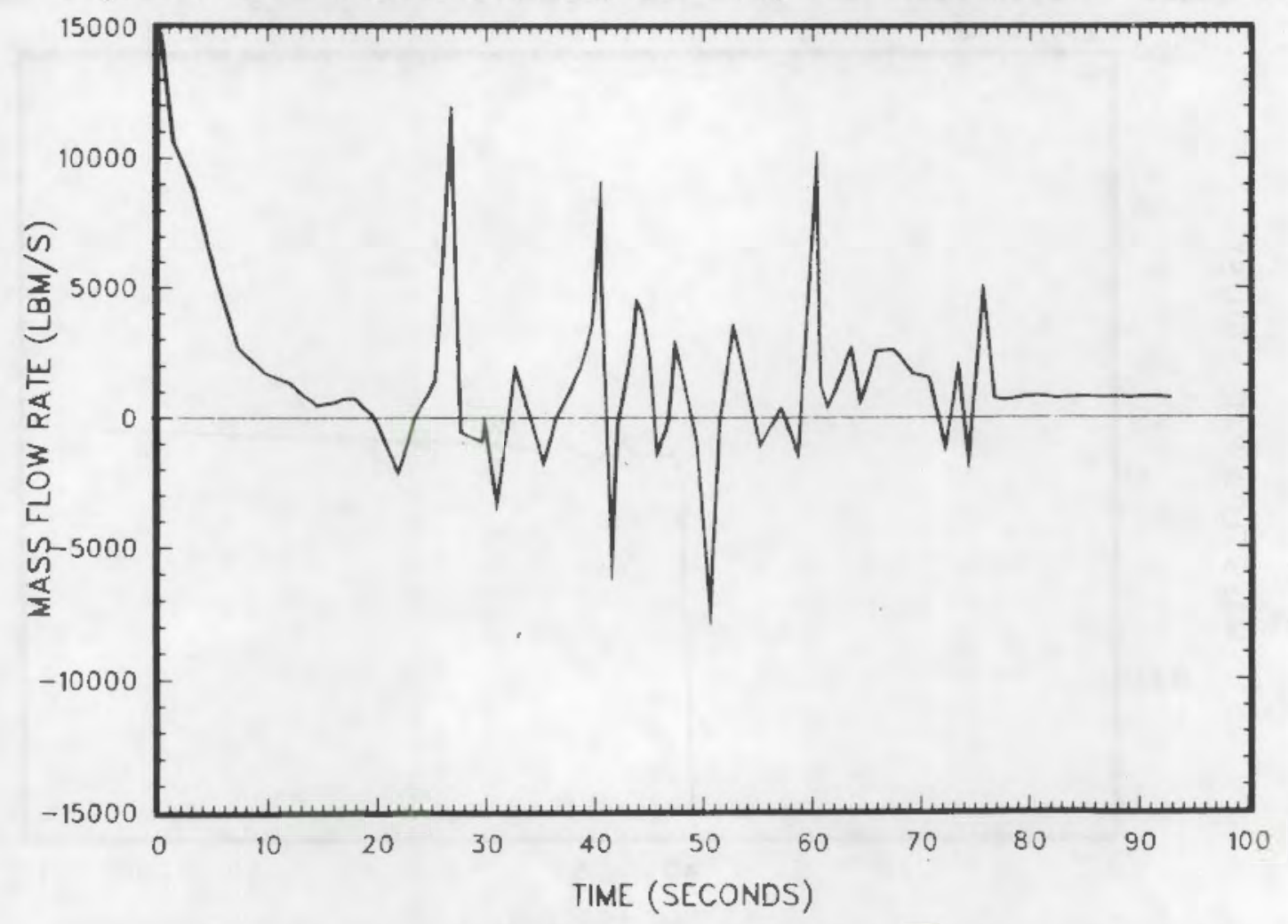

Figure 0.22 . Pressurizer loop cold leg mass flow rate vs. time 


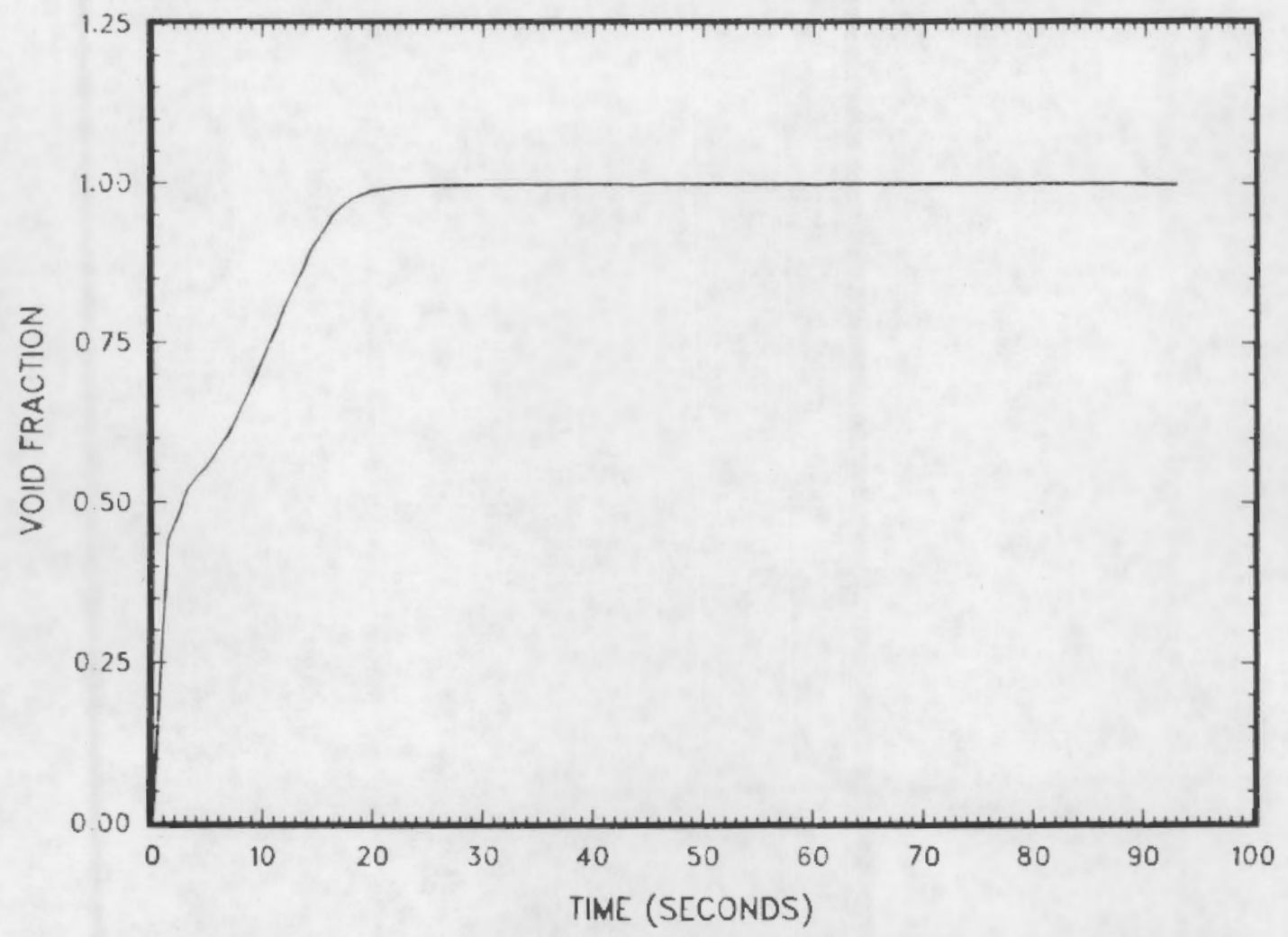

Figure D.23. Surge line average void fraction vs. time 

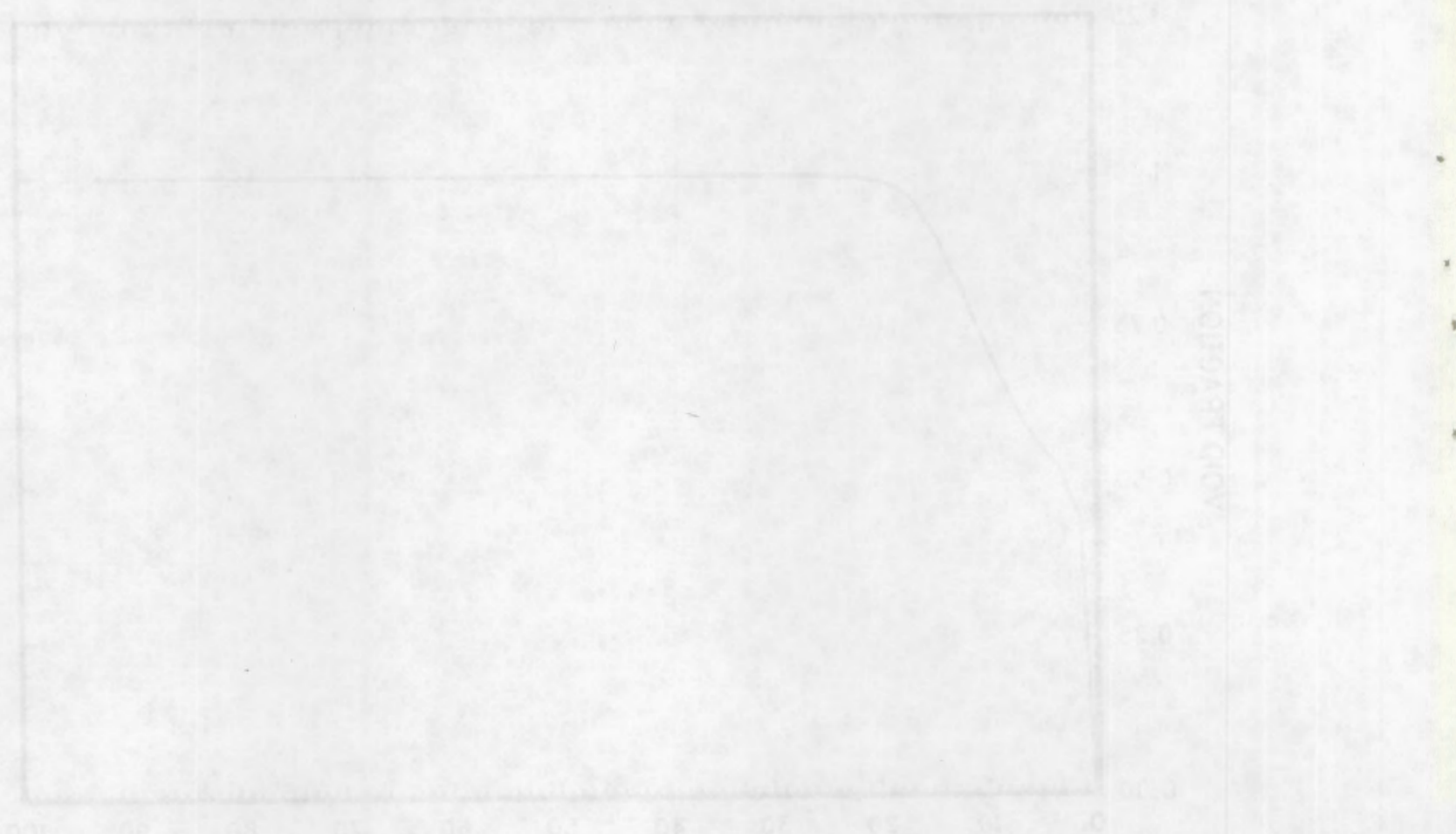

s

, 


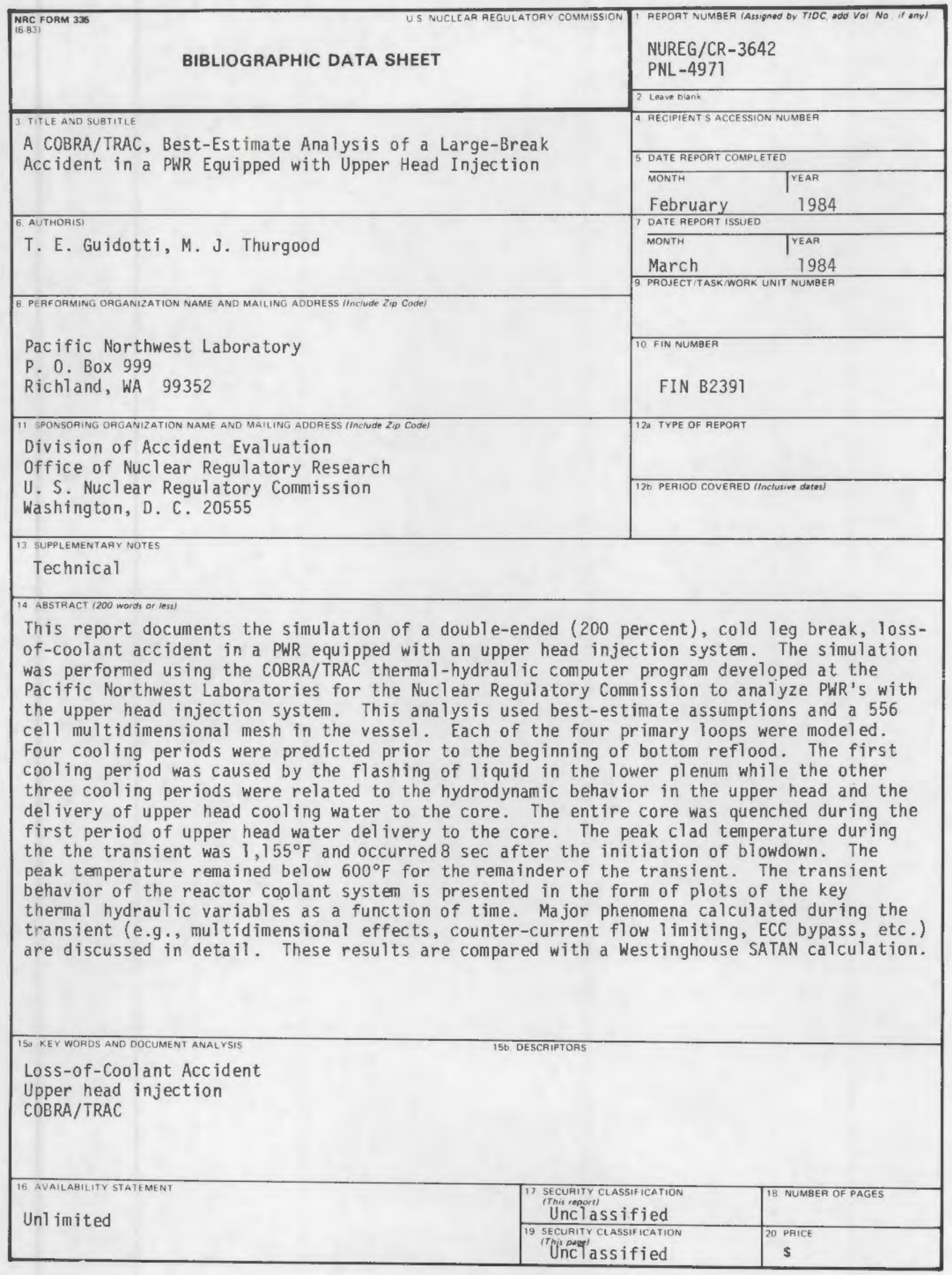


